\title{
Improvement and Validation of a Model for Photovoltaic Array Performance
}

By Widalys De Soto

A thesis submitted in partial fulfillment of the requirements for the degree of:

Master of Science

Mechanical Engineering

Solar Energy Laboratory

University of Wisconsin-Madison

2004 


\title{
$\underline{\text { Abstract }}$ \\ Improvement and Validation of a Model for Photovoltaic Array Performance
}

\author{
by Widalys De Soto \\ under the supervision of Dr. William Beckman and Dr. Sanford Klein
}

The use of photovoltaic cells has increased in the last few decades as their manufacturing cost has decreased and as people have become more concerned about energy use. Designers need a reliable tool to predict energy production resulting from building integrated photovoltaic panels in order to make a sound decision on whether or not to incorporate this technology into a building. A few models that predict energy production have been developed, but they require a large amount of input data that are normally not available during the design phase. The 5-Parameter model investigated in this research uses the data provided by the manufacturers and semi-empirical correlation equations to predict the energy production for specified cell parameters and operating conditions. Data were obtained from a building integrated photovoltaic facility at the National Institute of Standards and Technology (NIST), where four different cell technologies were tested. These data were used to verify the accuracy of the energy production predictions, therefore validating the model suggested in this study. The model was analyzed for these four different cell technologies and compared with different existing models, showing acceptable and sometimes even better results than the existing models that require more input information. Because the model only requires a 
small amount of input data available from the manufacturer, it provides a valuable tool for energy prediction. 


\section{Acknowledgements}

I would like to thank my family for their economical and emotional support, especially my parents who always encouraged me to pursue at least an MS Degree. Thanks to my mom for always studying with us and helping us develop good studying habits and to my dad for encouraging me to study engineering.

Thank you also to my beloved husband for his words of support when classes were getting though and I doubted I would get good grades. Thanks for always making me believe in myself and my potential.

A very big thank you to my advisors Professors Klein and Beckman for all they taught me, for their patience in starting from the beginning because before I came here I didn't know anything about solar energy and now, although I'm not an expert (like them), I can say that at least I understand how it works. It's amazing the amount of information I have learned in such a short period of time, mostly, thanks to them.

I would also like to thank Michaël Kummert for all his help in teaching me how to use and program in TRNSYS. Without his help I would still be staring angrily at the computer, trying to find my mistakes. Thank you also for arranging all the data I needed in one file rather than in the more than 4000 files that I originally had, which would have taken me a year to go through.

Thank you to Mark Davis from the National Institute of Standards and Technology (NIST) for providing all the data we used to validate our models and for answering all my questions. 
Thank you to the Graduate Engineering Research Students (GERS) for their financial and emotional support, especially to Kelly who has always been so nice to me. Thanks also to Tim Shedd for nominating me for the GERS fellowship, even when he didn't know me yet. A big hug and thanks to my office mates Gayathri, Kurt, Seth, Michael, and Mike and to all those at the SEL for all the fun times we spent together and making work a fun place to be. I'll miss you guys! 


\section{$\underline{\text { Table of Contents }}$}

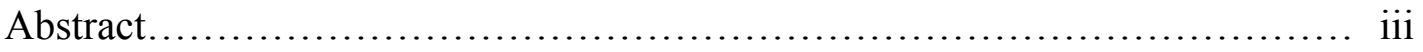

Acknowledgements................................................ v

List of Figures....................................................

List of Tables..................................................... xix

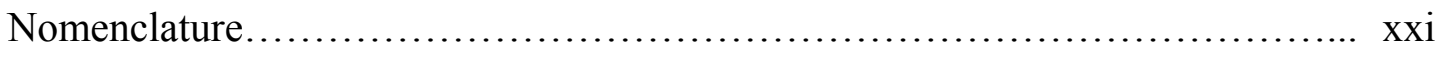

Chapter 1: Introduction.............................................. 1

1.1 Statement of problem 1

1.2 Objective 2

$\begin{array}{ll}1.3 & \text { Available information }\end{array}$

1.3.1 Data available from manufacturer 2

1.3.2 Different four cell technologies used 3

1.3.3 Data available from NIST 4

$\begin{array}{lll}1.4 & \text { Literature review } & 5\end{array}$

Chapter 2: Basic solar energy information.............................. 7

2.1 Incident Radiation and its components 7

2.1.1 Beam radiation $\quad 7$

2.1.2 Diffuse radiation 7

2.1.3 Ground reflected radiation 8

2.1.4 Effective radiation $\left(G_{\text {eff }}\right) \quad 8$

2.2 Air mass modifier $\left(M_{a m}\right) \quad 9$

$\begin{array}{lll}2.3 & \text { Incidence angle modifier }\left(K_{\tau \alpha}\right) & 10\end{array}$

2.3.1 Importance of the incidence angle modifier $\quad 10$

2.3.2 King et al.'s incidence angle modifier 11

2.3.3. Improved Incidence angle modifier $\left(K_{\tau \alpha}\right) \quad 12$

2.3.3.1 Using index of refraction $n=1.526 \quad 13$

2.3.3.2 Using index of refraction $n=1.256 \quad 14$

2.3.3.3 Using index of refraction $n=1.1 \quad 15$

2.3.3.4 Comparing the different $K_{\tau \alpha}$ values available 17

Chapter 3: PV Physical Models......................................... 20

$\begin{array}{ll}3.1 & \text { The 5-Parameter model } \\ 3.2 & 20\end{array}$

3.2 Suitability of the 5-Parameter model 22

3.3 Calculating the reference parameters at SRC 25

3.3.1 The 5-Parameter model for Solarex, Uni-Solar, and Astropower 27

3.3.2 The 4-Parameter model for Siemens $\left(R_{s h} \rightarrow \infty\right) \quad 27$ 
3.4 Calculating the reference parameters for winter and summer conditions

Chapter 4: Variation of PV model parameters with operating conditions........... 30

$\begin{array}{lll}4.1 & \text { Ideality factor, } a & 30\end{array}$

4.2 Diode reverse saturation current, $I_{o}$

4.3 Light current, $I_{L} \quad 33$

4.3.1 Using effective radiation $\left(G_{\text {eff }}\right)$ vs. radiation on a tilted surface $\left(G_{T}\right)$

4.3.2 Effect of air mass modifier $\left(M_{a m}\right) \quad 37$

$4.4 \quad$ Series resistance, $R_{s} \quad 40$

4.4.1 Derivation of equation to correct $R_{S} \quad 41$

4.4.2 Allowing negative values of $R_{s}$ versus forcing it to be zero 62

4.5 Shunt resistance $R_{\text {sh }} \quad 65$

4.5.1 Derivation of equation to correct $R_{s h} \quad 66$

Chapter 5: Comparing Predicted I-V curves with NIST data...................... 74

Chapter 6: Uncertainty Analysis.............................................. 83

Chapter 7: Advantage of manufacturers providing two sets of data instead of one (Two-curve optimization method) ........................... 88

Chapter 8: Comparing 5-Parameter Model with other Models..................... 98

8.1 Available models 98

8.1.1 5-Parameter model 98

8.1.2 King's model 101

8.1.3 Luft et al.'s equation 103

8.1.4 A. Hadj Arab et al.'s equations 104

8.2 Comparing the models 108

8.2.1 5-Parameter model vs. King's model and

Luft et al.'s equation 108

8.2.2 5-Parameter model vs. A. Hadj Arab's equations 121

Chapter 9: Implementation in TRNSYS.................................... 125

9.1 Simulation using the 5-Parameter model 126

9.2 Simulation using King's model 138

9.3 Conclusion and Suggestions 149

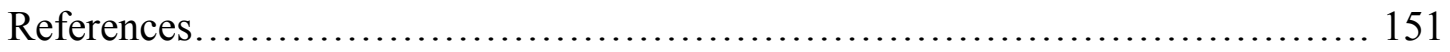

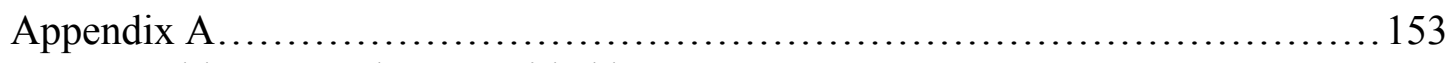

Table A.1: Values provided by NIST 153

Table A.2: Values used to calculate incidence angle modifier, using

King's correlation 
Table A.3: Incidence angle modifier $\left(K_{\tau \alpha}\right)$ values

Appendix B....................................................... 156

Part I: Calculating the effective irradiance $\left(G_{\text {eff }}\right) \quad 156$

Part II: Calculating the $K_{\tau \alpha}$ values: Using index of refraction $(n)$ equal to 1.526

Part III: Calculating the $K_{\tau \alpha}$ values: Finding index of refraction $(n)$ that minimizes difference between King et al.'s and SEL's incidence angle modifiers 157

Part IV: Calculating the $K_{\tau \alpha}$ values: Finding index of refraction $(n)$ that minimizes the error between the measured data and the predictions 158

Part V: Calculating the reference parameters $\left(a_{r e f}, I_{o, r e f}, I_{L, r e f}, R_{s, r e f}\right.$, and $\left.R_{s h, r e f}\right)$

Appendix C......................................................... 164

$\begin{array}{lll}\text { Part I: } & \text { Error calculation } & 164\end{array}$

a) Using fifteen (15) equidistant points 164

b) Using five (5) important points 165

c) Using the maximum power point (1 point) 166

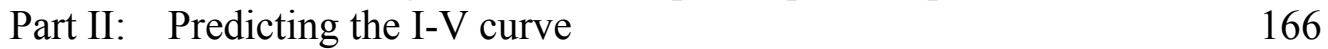

Part III: Two-curve optimization method (if manufacturers provided 2 $\begin{array}{ll}\text { sets of data) } & 168\end{array}$

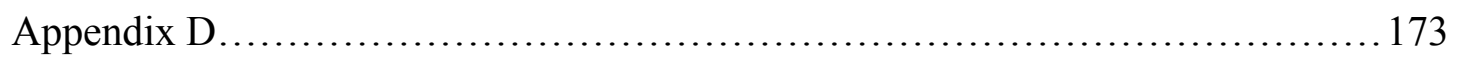

Part I: Comparing the 5-Parameter model with King's model and the TRW equation

Part II: Comparing the 5-Parameter model with A. Hadj Arab et al.'s model

Appendix E List of changes made to Type 94, TRANSYS code................ 206 


\section{List of Figures}

Figure 2.1: $\quad$ Air mass modifier $\left(M_{a m}\right)$ as a function of solar zenith angle $\left(\theta_{z}\right)$ for different cell types

Figure 2.2: $\quad$ King et al.'s incidence angle modifier $\left(M_{\theta}\right)$ versus incidence angle $(\theta)$

Figure 2.3: $\quad$ Incidence angle modifier $\left(K_{\tau \alpha}\right)$ versus Incidence angle $(\theta)$, using index of refraction $n=1.526$

Figure 2.4: Incidence angle modifier $\left(K_{\tau \alpha}\right)$ versus Incidence angle $(\theta)$, using index of refraction $n=1.256$ and comparing with King et al.'s correlation

Figure 2.5: $\quad$ Incidence angle modifier $\left(K_{\tau \alpha}\right)$ versus Incidence angle $(\theta)$, using different indexes of refraction and comparing with King et al.'s correlation

Figure 2.6: Predicted current-voltage (I-V) curves for Siemens cell type, June 20 at noon, using the different $K_{\tau \alpha}$ values available and $\mathrm{SRC}$ as reference conditions

Figure 2.7: Predicted current-voltage (I-V) curves for Siemens cell type, December 31 at noon, using the different $K_{\tau \alpha}$ values available and SRC as reference conditions

Figure 2.8: $\quad$ Incidence angle modifier $\left(K_{\tau \alpha}\right)$ versus Incidence angle $(\theta)$, using index of refraction $n=1.1$. The dots indicate the location of the incidence angles used for this study.

Figure 3.1: Equivalent circuit representing the 5-Parameters model

Figure 3.2: Different shapes of I-V curves as the weather conditions change

Figure 3.3: $\quad$ Measured vs. Predicted I-V curves for Siemens, summer and winter conditions

Figure 3.4: $\quad$ Measured vs. Predicted I-V curves for Solarex, summer and winter conditions

Figure 3.5: $\quad$ Measured vs. Predicted I-V curves for Astropower, summer and winter conditions 
Figure 3.6: Measured vs. Predicted I-V curves for Uni-solar, summer and winter conditions

Figure 3.7: Location of the points of interest for calculating the reference Parameters

Figure 4.1: Effect of ideality factor parameter $(a)$ on the I-V curve

Figure 4.2: Effect of diode reverse saturation current parameter $\left(I_{o}\right)$ on the I-V curve

Figure 4.3: Effect of light current $\left(I_{L}\right)$ on the I-V curve

Figure 4.4: Using $G_{\text {eff }}$ vs. $G_{T}$ for Siemens, using SRC as reference conditions to predict summer and winter operating conditions

Figure 4.5: Using $G_{\text {eff }}$ vs. $G_{T}$ for Solarex, using winter as reference conditions to predict summer and winter operating conditions

Figure 4.6: $\quad$ Using $G_{e f f}$ vs. $G_{T}$ for Astropower, using winter as reference conditions to predict summer and winter operating conditions

Figure 4.7: Using $G_{\text {eff }}$ vs. $G_{T}$ for Uni-Solar, using SRC as reference conditions to predict summer and winter operating conditions

Figure 4.8: With and without taking in consideration $M_{a m}$ 's effect for Siemens cell type, using SRC as reference conditions to predict summer and winter operating conditions

Figure 4.9: With and without taking in consideration $M_{a m}$ 's effect for Solarex cell type, using winter as reference conditions to predict summer and winter operating conditions

Figure 4.10: With and without taking in consideration $M_{a m}$ 's effect for Astropower cell type, using winter as reference conditions to predict summer and winter operating conditions

Figure 4.11: With and without taking in consideration $M_{a m}$ 's effect for Uni-Solar cell type, using SRC as reference conditions to predict summer and winter operating conditions

Figure 4.12: Effect of series resistance $\left(R_{S}\right)$ on the I-V curve

Figure 4.13: Derivative of current with respect to voltage at the max power point versus cell temperature, representative of all cell types 
Figure 4.14: Derivative of current with respect to voltage, evaluated at the max power point versus irradiance for the different cell types

Figure 4.15: Derivative of current with respect to voltage at the max power point versus effective irradiance, representative of all cell types

Figure 4.16: I-V curve for Siemens, October 13 at 11:00am, using different references (SRC, winter, and summer), without correcting series resistance, $R_{S}$

Figure 4.17: I-V curve for Siemens, October 13 at 11:00am, using different references (SRC, winter, and summer), correcting series resistance parameter, $R_{S}$

Figure 4.18: Series resistance, $R_{s}$, versus irradiance, $G$, for Siemens cell type, using SRC as reference

Figure 4.19: Series resistance, $R_{s}$, versus cell temperature, $T_{c}$, for Siemens cell type, using SRC as reference

Figure 4.20: Current at maximum power point $\left(I_{m p}\right)$ versus effective irradiance $\left(G_{\text {eff }}\right)$

Figure 4.21: Current at maximum power point $\left(I_{m p}\right)$ versus cell temperature $\left(T_{c}\right)$

Figure 4.22: Voltage at maximum power point $\left(V_{m p}\right)$ versus effective irradiance $\left(G_{\text {eff }}\right)$

Figure 4.23: Voltage at maximum power point $\left(V_{m p}\right)$ versus cell temperature $\left(T_{c}\right)$

Figure 4.24: Solarex cell type, December 31 at noon, $T_{c}=39.3{ }^{\circ} \mathrm{C}$, $G_{\text {eff }}=864.5 \mathrm{~W} / \mathrm{m}^{2}$, using SRC as reference

Figure 4.25: $\quad$ Siemens cell type, October 13 at noon, $T_{c}=37.2{ }^{\circ} \mathrm{C}$, $G_{\text {eff }}=520.6 \mathrm{~W} / \mathrm{m}^{2}, \mathrm{SRC}$ as reference

Figure 4.26: Astropower cell type, December 31 at noon, $T_{c}=39.9{ }^{\circ} \mathrm{C}$, $G_{e f f}=864.5 \mathrm{~W} / \mathrm{m}^{2}$, SRC as reference

Figure 4.27: Uni-Solar cell type, October 13 at 11:00am, $T_{c}=47.2{ }^{\circ} \mathrm{C}$, $G_{e f f}=733.8 \mathrm{~W} / \mathrm{m}^{2}$, SRC as reference

Figure 4.28: Solarex cell type, June 20 at noon, $T_{c}=47.4^{\circ} \mathrm{C}, G_{e f f}=297.7 \mathrm{~W} / \mathrm{m}^{2}$, using winter as reference 
Figure 4.29: Siemens cell type, June 20 at noon, $T_{c}=37.1^{\circ} \mathrm{C}, G_{\text {eff }}=297.7 \mathrm{~W} / \mathrm{m}^{2}$, winter as reference

Figure 4.30: Astropower cell type, October 13 at 9:00am, $T_{c}=37.7^{\circ} \mathrm{C}$, $G_{e f f}=520.6 \mathrm{~W} / \mathrm{m}^{2}$, winter as reference

Figure 4.31: Uni-Solar cell type, October 13 at 11:00am, $T_{c}=47.2^{\circ} \mathrm{C}$, $G_{e f f}=733.8 \mathrm{~W} / \mathrm{m}^{2}$, winter as reference

Figure 4.32: Location of the five important points on the I-V curve used to calculate the RMS error

Figure 4.33: Solarex cell type, October 13 at 9:00am, $T_{c}=47.3{ }^{\circ} \mathrm{C}$, $G_{e f f}=520.6 \mathrm{~W} / \mathrm{m}^{2}, \mathrm{SRC}$ as reference conditions

Figure 4.34: Siemens cell type, June 20 at noon, $T_{c}=47.6^{\circ} \mathrm{C}, G_{\text {eff }}=297.7 \mathrm{~W} / \mathrm{m}^{2}$, SRC as reference conditions

Figure 4.35: Astropower cell type, October 13 at 9:00am, $T_{c}=47.9^{\circ} \mathrm{C}$, $G_{e f f}=520.6 \mathrm{~W} / \mathrm{m}^{2}$, using SRC as reference conditions

Figure 4.36: Uni-Solar cell type, October 13 at 9:00am, $T_{c}=47.7^{\circ} \mathrm{C}$, $G_{\text {eff }}=520.7 \mathrm{~W} / \mathrm{m}^{2}, \mathrm{SRC}$ as reference conditions

Figure 4.37: Effect of shunt resistance $\left(R_{s h}\right)$ on the I-V curve

Figure 4.38: Siemens cell type, October 13 at 9:00am, $T_{c}=37.2^{\circ} \mathrm{C}$, $G_{\text {eff }}=520.6 \mathrm{~W} / \mathrm{m}^{2}, \mathrm{SRC}$ as reference conditions

Figure 4.39: Siemens cell type, December 31 at 12:00pm, $T_{c}=39.5^{\circ} \mathrm{C}$, $G_{e f f}=864.5 \mathrm{~W} / \mathrm{m}^{2}, \mathrm{SRC}$ as reference conditions

Figure 4.40: $\quad$ Solarex cell type, October 13 at 9:00am, $T_{c}=38.1^{\circ} \mathrm{C}$, $G_{\text {eff }}=520.6 \mathrm{~W} / \mathrm{m}^{2}, \mathrm{SRC}$ as reference conditions

Figure 4.41: Solarex cell type, December 31 at 12:00pm, $T_{c}=39.3{ }^{\circ} \mathrm{C}$, $G_{e f f}=864.5 \mathrm{~W} / \mathrm{m}^{2}, \mathrm{SRC}$ as reference conditions

Figure 4.42: Astropower cell type, October 13 at 11:00am, $T_{c}=47.3{ }^{\circ} \mathrm{C}$, $G_{e f f}=733.8 \mathrm{~W} / \mathrm{m}^{2}$, SRC as reference conditions

Figure 4.43: Astropower cell type, Dec. 31 at $12: 00 \mathrm{pm}, T_{c}=39.9^{\circ} \mathrm{C}$, $G_{e f f}=866.3 \mathrm{~W} / \mathrm{m}^{2}$, SRC as reference conditions

Figure 4.44: Uni-Solar cell type, October 13 at 9:00am, $T_{c}=37.8^{\circ} \mathrm{C}$, $G_{\text {eff }}=520.7 \mathrm{~W} / \mathrm{m}^{2}$, SRC as reference conditions 
Figure 4.45: Uni-Solar cell type, December 31 at 12:00pm, $T_{c}=36.2^{\circ} \mathrm{C}$, $G_{e f f}=864.5 \mathrm{~W} / \mathrm{m}^{2}$, SRC as reference conditions

Figure 5.1: $\quad \mathrm{I}-\mathrm{V}$ curve predictions for Siemens, October 13 at 9:00am, using as reference conditions SRC, winter, and summer conditions

Figure 5.2: $\quad \mathrm{I}-\mathrm{V}$ curve predictions for Siemens, June 20 at 12:00pm, using as reference conditions SRC, winter, and summer conditions

Figure 5.3: $\quad \mathrm{I}-\mathrm{V}$ curve predictions for Siemens, December 31at 12:00pm, using as reference conditions SRC, winter, and summer conditions $\quad 76$

Figure 5.4: $\quad \mathrm{I}-\mathrm{V}$ curve predictions for Solarex, October 13 at 9:00am, using as reference conditions SRC, winter, and summer conditions

Figure 5.5: $\quad \mathrm{I}-\mathrm{V}$ curve predictions for Solarex, June 20 at 12:00pm, using as reference conditions SRC, winter, and summer conditions

Figure 5.6: I-V curve predictions for Solarex, December 31at 12:00pm, using as reference conditions SRC, winter, and summer conditions

Figure 5.7: $\quad \mathrm{I}-\mathrm{V}$ curve predictions for Astropower, October 13 at 9:00am, using as reference conditions SRC, winter, and summer conditions

Figure 5.8: $\quad \mathrm{I}-\mathrm{V}$ curve predictions for Astropower, June 20 at 12:00pm, using as reference conditions SRC, winter, and summer conditions

Figure 5.9: I-V curve predictions for Astropower, December 31at 12:00pm, using as reference conditions SRC, winter, and summer conditions

Figure 5.10: I-V curve predictions for Uni-Solar, October 13 at 9:00am, using as reference conditions SRC, winter, and summer conditions

Figure 5.11: I-V curve predictions for Uni-Solar, June 20 at 12:00pm, using as reference conditions SRC, winter, and summer conditions

Figure 5.12: I-V curve predictions for Uni-Solar, December 31at 12:00pm, using as reference conditions SRC, winter, and summer conditions

Figure 6.1: $\quad \mathrm{I}-\mathrm{V}$ curve predicted for Siemens cell type, December 31 at noon with $G_{e f f}=864.5 \mathrm{~W} / \mathrm{m}^{2}$ and $T_{c}=39.5^{\circ} \mathrm{C}$, using SRC as reference conditions

Figure 6.2: $\quad \mathrm{I}-\mathrm{V}$ curve predicted for Solarex cell type, December 31 at noon 
with $G_{e f f}=864.5 \mathrm{~W} / \mathrm{m}^{2}$ and $T_{c}=39.3^{\circ} \mathrm{C}$, using SRC as reference conditions

Figure 6.3: $\quad \mathrm{I}-\mathrm{V}$ curve predicted for Astropower cell type, December 31 at noon with $G_{e f f}=864.5 \mathrm{~W} / \mathrm{m}^{2}$ and $T_{c}=39.9^{\circ} \mathrm{C}$, using SRC as reference conditions

Figure 6.4: $\quad$ I-V curve predicted for Uni-Solar cell type, October 13 at 9:00am with $G_{e f f}=520.7 \mathrm{~W} / \mathrm{m}^{2}$ and $T_{c}=37.8^{\circ} \mathrm{C}$, using SRC as reference conditions

Figure 7.1: $\quad$ I-V curve predicted for Solarex cell type, October 13 at 9:00am with $G_{e f f}=520.6 \mathrm{~W} / \mathrm{m}^{2}$ and $T_{c}=38.1^{\circ} \mathrm{C}$, using $\mathrm{SRC}$ as reference conditions

Figure 7.2: $\quad$ I-V curve predicted for Siemens cell type, October 13 at 9:00am with $G_{e f f}=520.6 \mathrm{~W} / \mathrm{m}^{2}$ and $T_{c}=47.7^{\circ} \mathrm{C}$, using SRC as reference conditions

Figure 7.3: $\quad \mathrm{I}-\mathrm{V}$ curve predicted for Astropower cell type, December 31 at $12: 00 \mathrm{pm}$ with $G_{e f f}=866 \mathrm{~W} / \mathrm{m}^{2}$ and $T_{c}=39.9^{\circ} \mathrm{C}$, using SRC as reference conditions

Figure 7.4: $\quad$ I-V curve predicted for Uni-Solar cell type, October 13 at 10:00am with $G_{e f f}=654.3 \mathrm{~W} / \mathrm{m}^{2}$ and $T_{c}=43.7^{\circ} \mathrm{C}$, using SRC as reference conditions

Figure 8.1: $\quad$ I-V curve predicted for Solarex cell type, June 20 at noon with $G_{e f f}=298 \mathrm{~W} / \mathrm{m}^{2}$ and $T_{c}=37.4^{\circ} \mathrm{C}$, using SRC as reference conditions 109

Figure 8.2: $\quad$ I-V curve predicted for Solarex cell type, October 13 at 10:00am with $G_{\text {eff }}=654 \mathrm{~W} / \mathrm{m}^{2}$ and $T_{c}=43.9^{\circ} \mathrm{C}$, using SRC as reference conditions

Figure 8.3: $\quad$ I-V curve predicted for Solarex cell type, December 31 at noon with $G_{\text {eff }}=865 \mathrm{~W} / \mathrm{m}^{2}$ and $T_{c}=39.3^{\circ} \mathrm{C}$, using SRC as reference conditions

Figure 8.4: $\quad \mathrm{I}-\mathrm{V}$ curve predicted for Siemens cell type, June 20 at noon with $G_{\text {eff }}=298 \mathrm{~W} / \mathrm{m}^{2}$ and $T_{c}=37.1^{\circ} \mathrm{C}$, using SRC as reference conditions 110

Figure 8.5: $\quad$ I-V curve predicted for Siemens cell type, October 13 at 9:00am with $G_{\text {eff }}=520 \mathrm{~W} / \mathrm{m}^{2}$ and $T_{c}=37.2^{\circ} \mathrm{C}$, using SRC as reference conditions

Figure 8.6: I-V curve predicted for Siemens cell type, December 31 at noon 
with $G_{\text {eff }}=865 \mathrm{~W} / \mathrm{m}^{2}$ and $T_{c}=39.5^{\circ} \mathrm{C}$, using SRC as reference conditions

Figure 8.7: $\quad$ I-V curve predicted for Astropower cell type, June 20 at noon with $G_{\text {eff }}=298 \mathrm{~W} / \mathrm{m}^{2}$ and $T_{c}=36.9^{\circ} \mathrm{C}$, using $\mathrm{SRC}$ as reference conditions

Figure 8.8: $\quad$ I-V curve predicted for Astropower cell type, October 13 at 9:00am with $G_{\text {eff }}=520 \mathrm{~W} / \mathrm{m}^{2}$ and $T_{c}=37.7^{\circ} \mathrm{C}$, using $\mathrm{SRC}$ as reference conditions

Figure 8.9: $\quad$ I-V curve predicted for Astropower cell type, December 31 at noon with $G_{e f f}=865 \mathrm{~W} / \mathrm{m}^{2}$ and $T_{c}=39.9^{\circ} \mathrm{C}$, using $\mathrm{SRC}$ as reference conditions

Figure 8.10: $\quad \mathrm{I}-\mathrm{V}$ curve predicted for Uni-Solar cell type, October 13 at 9:00am with $G_{\text {eff }}=520 \mathrm{~W} / \mathrm{m}^{2}$ and $T_{c}=37.8^{\circ} \mathrm{C}$, using $\mathrm{SRC}$ as reference conditions

Figure 8.11: I-V curve predicted for Uni-Solar cell type, October 13 at 10:00am with $G_{\text {eff }}=654 \mathrm{~W} / \mathrm{m}^{2}$ and $T_{c}=43.7^{\circ} \mathrm{C}$, using $\mathrm{SRC}$ as reference conditions

Figure 8.12: $\quad$ I-V curve predicted for Uni-Solar cell type, December 31 at noon with $G_{\text {eff }}=865 \mathrm{~W} / \mathrm{m}^{2}$ and $T_{c}=36.2^{\circ} \mathrm{C}$, using $\mathrm{SRC}$ as reference conditions

Figure 8.13: Siemens cell type, December 31 at noon with $G_{\text {eff }}=864.5 \mathrm{~W} / \mathrm{m}^{2}$ and $T_{c}=39.5^{\circ} \mathrm{C}$, using SRC reference conditions

Figure 8.14: Siemens cell type, October 13 at 9:00am with $G_{\text {eff }}=520.6 \mathrm{~W} / \mathrm{m}^{2}$ and $T_{c}=37.2^{\circ} \mathrm{C}$, using SRC as reference conditions

Figure 8.15: Siemens cell type, June 20 at noon with $G_{\text {eff }}=297.7 \mathrm{~W} / \mathrm{m}^{2}$ and $T_{c}=37.1^{\circ} \mathrm{C}$, using $\mathrm{SRC}$ as reference conditions

Figure 8.16: Siemens cell type, October 13 at 10:00am with $G_{\text {eff }}=654.3 \mathrm{~W} / \mathrm{m}^{2}$ and $T_{c}=43.1^{\circ} \mathrm{C}$, using SRC as reference conditions

Figure 9.1: $\quad$ Measured irradiance on tilted surface for the different days selected for the simulation in TRNSYS

Figure 9.2: $\quad$ I-V curve for Astropower cell type, December 31 at noon, using SRC as reference conditions, calculated using TRNSYS. Obtained values: $I_{s c}=4.544 \mathrm{Amp}, V_{o c}=27.33 \mathrm{~V}, I_{m p}=3.951 \mathrm{Amp}$, $V_{m p}=21.44 \mathrm{~V}, P_{m p}=84.71 \mathrm{~W}$. 
Figure 9.3: $\quad$ I-V curve for Astropower cell type, December 31 at noon, using SRC as reference conditions, calculated using EES. Obtained values: $I_{s c}=4.544 \mathrm{Amp}, V_{o c}=27.34 \mathrm{~V}, I_{m p}=3.959 \mathrm{Amp}$, $V_{m p}=21.4 \mathrm{~V}, P_{m p}=84.72 \mathrm{~W}$.

Figure 9.4: TRNYS model in schematic form using the TRNSYS Studio graphical input program for the 5-Parameter model

Figure 9.5: Values used in the "Parameter" tab, parameters number 1-7, using the 5-Parameter model

Figure 9.6: Values used in the "Parameter" tab, parameters number 8-16, using the 5-Parameter model

Figure 9.7: Values used in the "Parameter" tab, parameters number 17-24, using the 5-Parameter model

Figure 9.8: Values used in the "Input" tab for the 5-Parameter model

Figure 9.9: $\quad$ Maximum power points measured by NIST versus predicted with the 5-Parameter model using TRNSYS for the Siemens cell type

Figure 9.10: Maximum power points measured by NIST versus predicted with the 5-Parameter model using TRNSYS for the Solarex cell type

Figure 9.11: Maximum power points measured by NIST versus predicted with the 5-Parameter model using TRNSYS for the Astropower cell type

Figure 9.12: Maximum power points measured by NIST versus predicted with the 5-Parameter model using TRNSYS for the Uni-Solar cell type

Figure 9.13: Maximum power points predicted with the 5-Parameter model using TRNSYS versus measured by NIST for the Siemens cell type

Figure 9.14: Maximum power points predicted with the 5-Parameter model using TRNSYS versus measured by NIST for the Solarex cell type

Figure 9.15: Maximum power points predicted with the 5-Parameter model using TRNSYS versus measured by NIST for the Astropower cell type

Figure 9.16: Maximum power points predicted with the 5-Parameter model 
using TRNSYS versus measured by NIST for the Uni-Solar cell type

Figure 9.17: TRNYS model in schematic form using the TRNSYS Studio graphical input program for King's model

Figure 9.18: Values used in the "Parameter" tab, parameters number 1-9, using King's model

Figure 9.19: Values used in the "Parameter" tab, parameters number 10-18, using King's model

Figure 9.20: Values used in the "Parameter" tab, parameters number 19-27, using King's model

Figure 9.21: Values used in the "Parameter" tab, parameters number 28-36, using King's model

Figure 9.22: Values used in the "Parameter" tab, parameters number 36-43, using King's model

Figure 9.23: Values used in the "Input" tab for King's model

Figure 9.24: Maximum power points measured by NIST versus predicted with King's model using TRNSYS for the Siemens cell type

Figure 9.25: Maximum power points measured by NIST versus predicted with King's model using TRNSYS for the Solarex cell type

Figure 9.26: Maximum power points measured by NIST versus predicted with King's model using TRNSYS for the Astropower cell type

Figure 9.27: Maximum power points measured by NIST versus predicted with King's model using TRNSYS for the Uni-Solar cell type

Figure 9.28: Maximum power points predicted with King's model using TRNSYS versus measured by NIST for the Siemens cell type

Figure 9.29: Maximum power points predicted with King's model using TRNSYS versus measured by NIST for the Solarex cell type

Figure 9.30: Maximum power points predicted with King's model using TRNSYS versus measured by NIST for the Astropower cell type

Figure 9.31: Maximum power points predicted with King's model using TRNSYS versus measured by NIST for the Uni-Solar cell type 
Table 4.1: $\quad$ Values of constant $C$ for different cell technologies

Table 4.2: $\quad$ Errors obtained for the different curves, using SRC as reference $\quad 61$

Table 4.3: $\quad$ Errors obtained for the different curves, using winter conditions as reference

Table 4.4: $\quad$ Siemens RMS Percentage Error using 5 points

Table 4.5: $\quad$ Solarex RMS Percentage Error using 5 points

Table 4.6: $\quad$ Astropower RMS Percentage Error using 5 points

Table 4.7: Uni-Solar RMS Percentage Error using 5 points

Table 4.8: $\quad$ Siemens RMS Percentage Error using Maximum Power point 72

Table 4.9: $\quad$ Solarex RMS Percentage Error using Maximum Power point 72

Table 4.10: Astropower RMS Percentage Error using Maximum Power point 72

Table 4.11: $\quad$ Uni-Solar RMS Percentage Error using Maximum Power point 72

Table 5.1: $\quad$ Errors (in percentage) calculated using five important points $\quad 82$

Table 5.2: $\quad$ Errors (in percentage) calculated using the maximum power point 82

Table 7.1: $\quad$ RMS Percentage Errors using 5 Points 96

Table 7.2: $\quad$ RMS Percentage Errors at Maximum Power Point 97

Table 8.1: $\quad$ RMS errors for different cell technologies, using 5 important points

Table 8.2: $\quad$ RMS errors for different cell technologies, using maximum power point

Table 8.3: $\quad$ RMS errors for different cell technologies, using different parameters

Table 8.4: $\quad$ Errors using five important points

Table 8.5: $\quad$ Errors using maximum power point only 
Table 9.1: Total energy and RMS values obtained for measured and predicted $P_{m p}$ for different cell types

Table 9.2: Values measured and predicted for different cell types using 5-Parameter and King's models

Table A.1: Values provided by NIST

Table A.2: Values used to calculate incidence angle modifier, using King's correlation

Table A.3: $\quad$ Incidence angle modifier $\left(K_{\tau \alpha}\right)$ values 


\section{Nomenclature}

Commonly used and 5-Parameter model:

\begin{tabular}{|c|c|c|}
\hline Symbol & Description & Units \\
\hline$a$ & Ideality factor parameter & $\mathrm{eV}$ \\
\hline$A M_{a}$ & Absolute air mass & \\
\hline$a_{\text {ref }}$ & Ideality factor parameter at SRC & $\mathrm{eV}$ \\
\hline G & Total irradiance on horizontal surface & $\mathrm{W} / \mathrm{m}^{2}$ \\
\hline$G_{b}$ & $\begin{array}{l}\text { Beam component of total irradiance on horizontal surface, } \\
\text { also } G_{b}=G_{b, n} \cos \theta_{z}\end{array}$ & $\mathrm{~W} / \mathrm{m}^{2}$ \\
\hline$G_{b, n}$ & Beam irradiance normal to a horizontal surface & $\mathrm{W} / \mathrm{m}^{2}$ \\
\hline$G_{d}$ & Diffuse component of total irradiance on horizontal surface & $\mathrm{W} / \mathrm{m}^{2}$ \\
\hline$G_{\text {eff }}$ & Effective irradiance incident on the tilted surface & $\mathrm{W} / \mathrm{m}^{2}$ \\
\hline$G_{\text {effiref }}$ & Effective irradiance at SRC $\left(1000 \mathrm{~W} / \mathrm{m}^{2}\right)$ & $\mathrm{W} / \mathrm{m}^{2}$ \\
\hline$I$ & Predicted current & Amp \\
\hline$I_{L}$ & Light current & Amp \\
\hline$I_{L, \text { ref }}$ & Light current at SRC & Amp \\
\hline$I_{m p}$ & Current at maximum power point & Amp \\
\hline$I_{\mathrm{mp}, \mathrm{ref}}$ & Current at maximum power point at SRC & Amp \\
\hline$I_{o}$ & Diode reverse saturation current & Amp \\
\hline$I_{o, r e f}$ & Diode reverse saturation current at SRC & Amp \\
\hline$K_{\tau \alpha}$ & Incidence angle modifier at incidence angle $\theta$ & \\
\hline$K_{\tau \alpha, d}$ & Incidence angle modifier at $\theta=58^{\circ}$ & \\
\hline$M_{a m}$ & Air mass modifier & \\
\hline$M_{\text {am,ref }}$ & Air mass modifier at SRC (1.0) & \\
\hline NOCT & Nominal Operating Cell Temperature & Kelvin \\
\hline$N_{s}$ & Number of cells in series & \\
\hline$P$ & Predicted power & Watt \\
\hline$P_{m p}$ & Maximum power & Watt \\
\hline$R_{\text {beam }}$ & $\begin{array}{l}\text { Ratio of beam radiation on tilted surface to that on a } \\
\text { horizontal surface }\left(\cos \theta / \cos \theta_{z}\right)\end{array}$ & \\
\hline$R_{S}$ & Series resistance & Ohm \\
\hline$R_{s, r e f}$ & Series resistance at $\mathrm{SRC}$ & Ohm \\
\hline$R_{s h}$ & Shunt resistance & Ohm \\
\hline$R_{s h, r e f}$ & Shunt resistance at SRC & Ohm \\
\hline$T_{c}$ & Cell temperature & ${ }^{\circ} \mathrm{C}$ \\
\hline$T_{c, \text { ref }}$ & Cell temperature at SRC & ${ }^{\circ} \mathrm{C}$ \\
\hline$V$ & Assigned voltage & Volt \\
\hline$V_{m p}$ & Voltage at maximum power point & Volt \\
\hline$V_{m p, r e f}$ & Voltage at maximum power point at SRC & Volt \\
\hline$\alpha_{I s c}$ & Temperature coefficient for short circuit current & $\mathrm{A} /{ }^{\circ} \mathrm{C}$ \\
\hline$\beta$ & Slope of the panel & Degree \\
\hline$\beta_{V o c}$ & Open voltage temperature coefficient & $\mathrm{V} /{ }^{\circ} \mathrm{C}$ \\
\hline$\varepsilon$ & Material band gap energy & $\mathrm{eV}$ \\
\hline
\end{tabular}


Incidence angle, angle between the beam of light and the normal to the panel surface

Degree

$\theta_{z} \quad$ Zenith angle, angle between the vertical and the line to the sun (beam)

$\rho_{g} \quad$ Ground reflectance factor

Degree

Only used for King's model:

Symbol

Description

Units

$a_{0}, a_{1}, a_{2}, a_{3}, a_{4} \quad$ Coefficients for air mass modifier calculation

AOI, $\theta \quad$ Solar angle of incidence

$b_{0}, b_{1}, b_{2}, b_{3}, b_{4}, b_{5} \quad$ Coefficients for incidence angle modifier calculation

Degree

$C_{0}, C_{1}$

Coefficients relating $\mathrm{I}_{\mathrm{mp}}$ to irradiance $\left(\mathrm{C}_{0}+\mathrm{C}_{1}=1\right)$

$C_{2}, C_{3}$

Coefficients relating $\mathrm{V}_{\mathrm{mp}}$ to irradiance

$C_{4}, C_{5}$

Coefficients relating $\mathrm{I}_{\mathrm{x}}$ to irradiance $\left(\mathrm{C}_{4}+\mathrm{C}_{5}=1\right)$

$C_{6}, C_{7}$

Coefficients relating $\mathrm{I}_{\mathrm{xx}}$ to irradiance $\left(\mathrm{C}_{6}+\mathrm{C}_{7}=1\right)$

$E_{b}$

Beam component of irradiance on module, also

$E_{\text {diff }}$

$E_{e}$

$E_{o}$

$\mathrm{E}_{\mathrm{b}}=\mathrm{E}_{\mathrm{bn}} \cos (\mathrm{AOI})$

$\mathrm{W} / \mathrm{m}^{2}$

Diffuse component of irradiance on module

$\mathrm{W} / \mathrm{m}^{2}$

Dimensionless effective irradiance

fl $\left(A M_{a}\right), M_{a m}$

Irradiance at SRC $\left(1000 \mathrm{~W} / \mathrm{m}^{2}\right)$

$\mathrm{W} / \mathrm{m}^{2}$

$\mathrm{f} 2(A O I), M_{\theta}$

Polynomial relating spectral influence on $\mathrm{I}_{\mathrm{sc}}$ to $\mathrm{AM}_{\mathrm{a}}$

$f_{d}$

$I_{m p 0}$

Polynomial describing AOI influence on $\mathrm{I}_{\mathrm{sc}}$

Fraction of diffuse irradiance used by module (1.0)

$I_{s c 0}$

Current at maximum power point at SRC

Short circuit current

Amp

Short circuit current at SRC

Amp

Current predicted using TRW Inc.'s equation

Amp

$I_{T R W}$

$I_{x}$

Current at $\mathrm{V}=0.5 \mathrm{~V}_{\text {oc }}$

Amp

$I_{x 0}$

Current at $\mathrm{V}=0.5 \mathrm{~V}_{\text {oc }}$, at $\mathrm{SRC}$

Amp

$I_{x x}$

Current at $\mathrm{V}=0.5\left(\mathrm{~V}_{\mathrm{mp}}+\mathrm{V}_{\mathrm{oc}}\right)$

Amp

Current at $\mathrm{V}=0.5\left(\mathrm{~V}_{\mathrm{oc}}+\mathrm{V}_{\mathrm{mp}}\right)$, at $\mathrm{SRC}$

Amp

$I_{x x 0}$

Boltzmann's constant (1.38066E-23 J/K)

Amp

$k$

Diode factor for each cell in module

$n$

Elementary charge (1.60218E-19 Coulomb)

$\mathrm{J} / \mathrm{K}$

$q$

Cell temperature at SRC $\left(25^{\circ} \mathrm{C}\right)$

C

Voltage at maximum power point at $\mathrm{SRC}$

Degree

$V_{m p 0}$

$V_{o c}$

Open circuit voltage

Volt

Open circuit voltage at SRC

Volt

Normalized temperature coefficient for Imp

$\alpha_{\text {Imp }}$

Normalized temperature coefficient for $\mathrm{I}_{\mathrm{sc}}$

$1 /{ }^{\circ} \mathrm{C}$

$\alpha_{I s c}$

$\beta_{V m p}$

$\beta_{V o c}$

Temperature coefficient for $\mathrm{V}_{\mathrm{mp}}$

$1 /{ }^{\circ} \mathrm{C}$

Temperature coefficient for $V_{o c}$

$\mathrm{V} /{ }^{\circ} \mathrm{C}$

"Thermal voltage" per cell with cell temperature 


\section{Chapter 1}

INTRODUCTION

\subsection{Statement of problem}

The use of photovoltaic (PV) cells to produce energy has increased in the last few decades and keeps growing as their manufacturing cost decreases and as the world becomes more concerned about energy use. Awareness requires than an environmentally-sound source be used for safe and clean energy production. Facilities in remote locations have always been the principal targets for this type of technology because they do not have access to electrical utility grids. Still, because it is known that buildings account for a large percent of the U.S. energy consumption, awareness is growing and building integrated technology is spreading. One of the applications for solar cells is building integrated photovoltaic (BIPV), where solar panels are used as walls or roof. This application provides a dual purpose because it decreases the amount of construction materials required while producing electricity. One of the greatest advantages is that the maximum power production occurs when the building is having its peak loads, therefore increasing the energy savings. The main disadvantage of placing the panels on the building surface results in the panels being oriented in non-optimal directions (high slope angle, $90^{\circ}$ ). In this case, the solar radiation's incidence angle will be very large for summer months (usually above $65^{\circ}$ ), decreasing the amount of solar energy that can be absorbed. Designers need a reliable tool to predict energy production resulting from BIPV in order to make a sound decision on whether or not to incorporate this technology into a building. Accurate, reliable, and easy to apply methods for 
predicting the energy production of photovoltaic panels are needed to identify optimum building integrated photovoltaic (BIPV) systems.

The power output from the photovoltaic cell depends on the light intensity, the cell temperature, the panel's orientation, and its size, among others. The light intensity affects primarily the amount of current produced, making it proportional, while the cell temperature controls the voltage produced. As the cell temperature increases, the current produced remains the same but the voltage is reduced, reducing the output power. All of these factors need been taken in consideration to accurately predict the energy production.

\subsection{Objective}

The objective of this research is to present the 5-Parameter model, an accurate, reliable, and easy to apply method for predicting the energy production of photovoltaic panels. The physics behind the model will be demonstrated and the model will be compared with other existing models, showing its advantages and disadvantages, as well as results typically obtained. It will be shown that the 5-Parameter model is a great tool for energy production prediction.

\subsection{Available information}

\subsubsection{Data available from manufacturer}

Manufacturers provide limited characteristic data for different photovoltaic cell technologies. Most of these data are obtained from measurements made at Standard Rated Conditions (SRC), where the irradiance is $1000 \mathrm{~W} / \mathrm{m}^{2}$ and the cell temperature $\left(T_{c}\right)$ 
is $25^{\circ} \mathrm{C}$. These conditions produce very high power output, but are rarely the conditions encountered in reality. Some of the parameters typically provided by the manufacturers are the maximum power $\left(P_{m p 0}\right)$, short circuit current $\left(I_{s c}\right)$, open circuit voltage $\left(V_{o c}\right)$, current and voltage at the maximum power point ( $I_{m p}$ and $V_{m p 0}$, respectively), nominal operating cell temperature (NOCT) and the coefficients of temperature for short circuit current and open circuit voltage ( $\alpha_{I s c}$ and $\beta_{V o c}$, respectively), where the subscript " 0 " implies that the value was obtained for SRC.

\subsubsection{Different four cell technologies used}

The data used for this study were obtained from a building integrated photovoltaic facility at the National Institute of Standards and Technology (NIST). It includes a one year (January 1, 2000-December 31, 2000) meteorological data, together with readings of measured current and voltage values for four different array types, installed on a vertical surface, in a facility at NIST, Gaithersburg, Maryland. These four different cell technologies have been tested to verify the accuracy of the energy production predictions. Among the different types of cell technologies currently available in the market are single crystalline, poly-crystalline, silicon thin film, and amorphous. Single crystal cells have very high purity and near perfect crystal structure and offer the highest efficiency. Due to the high temperatures needed for its manufacture, they are very expensive. Poly-crystalline wafers are made by a casting process in which molten silicon is poured into a mould and allowed to set. The casting process lowers the manufacturing costs considerably, but at the cost of increasing the imperfections in the crystal structure and therefore lowering their efficiency. Amorphous 
and thin film cells have many advantages, such as their easier deposition and assembly, the ability to be deposited on inexpensive substrates or building materials, the ease of mass production, and the high suitability to large applications. The main disadvantage of these types of cells consists in their lower efficiency, when compared to the crystalline technologies. These four cell technologies were the ones used by NIST and for which data were provided. The brands used are as follow:

Siemens: Single-crystalline

Solarex: Poly-crystalline

Astropower: Silicon thin film

Uni-Solar: 3-Junction amorphous

\subsubsection{Data available from NIST}

NIST provided a much larger set of data than manufacturers normally do, among which we can find the maximum power $\left(P_{m p 0}\right)$, short circuit current $\left(I_{s c 0}\right)$, open circuit voltage $\left(V_{o c 0}\right)$, current and voltage at the maximum power point $\left(I_{m p 0}\right.$ and $V_{m p 0}$, respectively), nominal operating cell temperature (NOCT), the coefficients of temperature for short circuit current and open circuit voltage ( $\alpha_{I s c}$ and $\beta_{V o c}$, respectively $)$, the coefficients of temperature for current and voltage at the maximum power point $\left(\alpha_{\operatorname{Imp}}\right.$ and $\beta_{V m p}$, respectively ), the number of cells in series $\left(N_{s}\right)$, the band gap energy $(\varepsilon)$, and the current-voltage (I-V) slope at short circuit current, as well as the Sandia National Labs Parameters used to determine incidence angle and air mass modifiers $\left(a_{0}, a_{1}, a_{2}, a_{3}\right.$, $\left.a_{4}, b_{0}, b_{1}, b_{2}, b_{3}, b_{4}, b_{5}\right)$ and the constants used to determine power production using 
King's model $\left(C_{0}, C_{1}, C_{2}, C_{3}, n\right)(2000)$. Once again the subscript " 0 " implies that the value was obtained for SRC. All of these values can be seen in Appendix A, Table A.1.

\subsection{Literature review}

A few models that predict energy production (discussed in greater depth in Chapter 8) have been developed, but they require a large amount of input data that are normally not available during the design phase. King $(1998,2000,2003)$ has developed a model to predict the energy production from a PV array. His model calculates the current at five strategically located points through out the current-voltage (I-V) curve. Although the results of the errors obtained for this model are considered to be small, making this its greatest advantage, its disadvantage consists in the large amount of input data that it requires (Fanney et al., 2002). Luft et al. (1967), in work done for TRW Inc. proposed an equation to predict the current produced. This equation is designed to calculate the entire I-V curve, in contrast to King's model, which focuses on only five points. A. Hadj Arab et al. (2004) use a modification of the 5-Parameter model, but they developed different equations from the ones presented in this research for the calculation of the five parameters. As will be shown in Chapter 8, neither Luft et al.'s nor A. Hadj Arab's equations yield small enough errors to be considered reliable.

Any practical model needs to use input data that are readily available. A model that uses these data to predict energy production has been investigated in this research and is explained with details through out this document. It will be referred to as the 5Parameter model. This model uses semi-empirical correlation equations to predict the energy production for specified cell parameters and operating conditions. The model was 
analyzed for four different cell technologies (single crystalline, poly-crystalline, silicon thin film, and 3-Junction amorphous), showing acceptable results and using only the data provided by NIST. It was compared in Chapter 8 with King's model (2000), Luft et al.'s equation (1967), and A. Hadj Arab et al.'s equations (2004). Because the 5-Parameter model only requires a small amount of input data available from the manufacturer, it provides a valuable tool for energy prediction. 


\section{Chapter 2}

\section{BASIC SOLAR ENERGY INFORMATION}

\subsection{Incident radiation and its components}

Irradiance is the rate at which radiant energy is incident on a surface per unit area of surface. The total irradiance incident on a surface has three components, beam, diffuse, and ground reflected.

\subsubsection{Beam radiation}

The beam radiation $\left(G_{b}\right)$, also known as direct solar radiation, is the solar radiation received from the sun without having been scattered by the atmosphere. It can be calculated from Equation (2.1),

$$
G_{b}=G_{b n} \operatorname{Cos}\left(\theta_{z}\right)
$$

where $G_{b n}$ is the beam component of the solar radiation, measured on a surface normal to the beam and $\theta_{z}$ is the zenith angle.

\subsubsection{Diffuse radiation}

The diffuse radiation $\left(G_{d}\right)$ is the radiation after the scattering by the atmosphere has changed its direction. Diffuse radiation can also be known as sky radiation or solar sky radiation. It can be measured using a pyranometer with a tracking device that shields the beam irradiance or if the total irradiance is known, from Equation (2.2),

$$
G_{d}=G-G_{b}
$$

where $G$ is the total irradiance. 


\subsubsection{Ground reflected radiation}

The ground reflected component is dependent on the ground reflectance factor $\left(\rho_{g}\right)$ of the surroundings where the object of interest is located. The value of the ground reflectance factor usually varies from near zero (dark, non-reflective ground) to 0.7 (fresh snow on the ground). For this study, the ground reflectance factor was calculated using the total irradiance on the tilted surface $\left(G_{T}\right)$, the total horizontal irradiance $(G)$, and the normal beam irradiance $\left(G_{b n}\right)$, together with Equations (2.1) through (2.3).

$$
\mathrm{G}_{\mathrm{T}}=\mathrm{G}_{\mathrm{b}} \mathrm{R}_{\text {beam }}+\mathrm{G}_{\mathrm{d}} \frac{1+\operatorname{Cos}(\beta)}{2}+\rho_{\mathrm{g}} \mathrm{G} \frac{1-\operatorname{Cos}(\beta)}{2}
$$

where $R_{\text {beam }}$ is the ratio of beam radiation on the tilted surface to that on a horizontal surface (also $\operatorname{Cos} \theta / \operatorname{Cos} \theta_{z}$ ), and $\beta$ is the slope of the panel.

In the case that the total irradiance on the tilted surface is not known, the ground reflectance factor can be estimated, according to experience.

\subsubsection{Effective radiation $\left(G_{e f f}\right)$}

The effective irradiance $\left(G_{e f f}\right)$ incident on a surface has the three components previously described (beam, diffuse, and ground reflected) and is dependent on the slope $(\beta)$ of the surface with respect to the horizontal. It can be calculated from Equation (2.4),

$$
G_{\text {eff }}=G_{b} R_{\text {beam }} K_{\tau \alpha}+G_{d} K_{\tau \alpha, d} \frac{1+\operatorname{Cos}(\beta)}{2}+\rho_{g} G K_{\tau \alpha, g} \frac{1-\operatorname{Cos}(\beta)}{2}
$$

where $K_{\tau \alpha}, K_{\tau \alpha, d}$ and $K_{\tau \alpha, g}$ are the incidence angle modifiers at any angle (for $K_{\tau \alpha}$ ) and at $58^{\circ}$ (for $K_{\tau \alpha, d}$ and $K_{\tau \alpha, g}$ ). Appendix B, Part I shows an example program on how to calculate it. 


\subsection{Air mass modifier $\left(M_{a m}\right)$}

Absolute air mass $\left(A M_{a}\right)$ is the ratio of the mass of atmosphere through which beam radiation passes to the mass it would pass through if the sun were located at the zenith (directly overhead). At sea level and when the sun is at the zenith, $A M_{a}=1$. As the air mass increases, the spectral content of irradiance changes and in many cases, affects the efficiency of the PV panel. King et al. $(1996,1998)$ have characterized this dependence in the form of a polynomial, function of the absolute air mass. Equation (2.5) shows the polynomial.

$$
M_{a m}=a_{0}+a_{1} A M_{a}+a_{2} A M_{a}^{2}+a_{3} A M_{a}^{3}+a_{4} A M_{a}^{4}
$$

The air mass modifier affects the beam as well as the diffuse components of the irradiance. Figure 2.1 shows the shape of $M_{a m}$ as a function of solar zenith angle $\left(\theta_{z}\right)$ for the different PV modules used in this study. From Figure 2.1 it can be seen that when the zenith angle is small (approximately under $60^{\circ}$ ), the air mass modifier is very close to 1.0 and therefore will have no effect on the predicted curve. From Figure 2.1 it can also be noted that the Uni-Solar cell type seems to be more sensitive to spectral changes in solar radiation than the other cell types. The values of the constants $a_{0}, a_{1}, a_{2}, a_{3}$, and $a_{4}$ for the different cell types can be found in Appendix A, Table A.1. Although this study was conducted using the different constants for their respective cell types, if one set of constants is chosen and used for all cell types, the difference in the results obtained is insignificant. Consequently, the five values of $a$ for the Solarex (poly-crystalline) cell is recommended. 


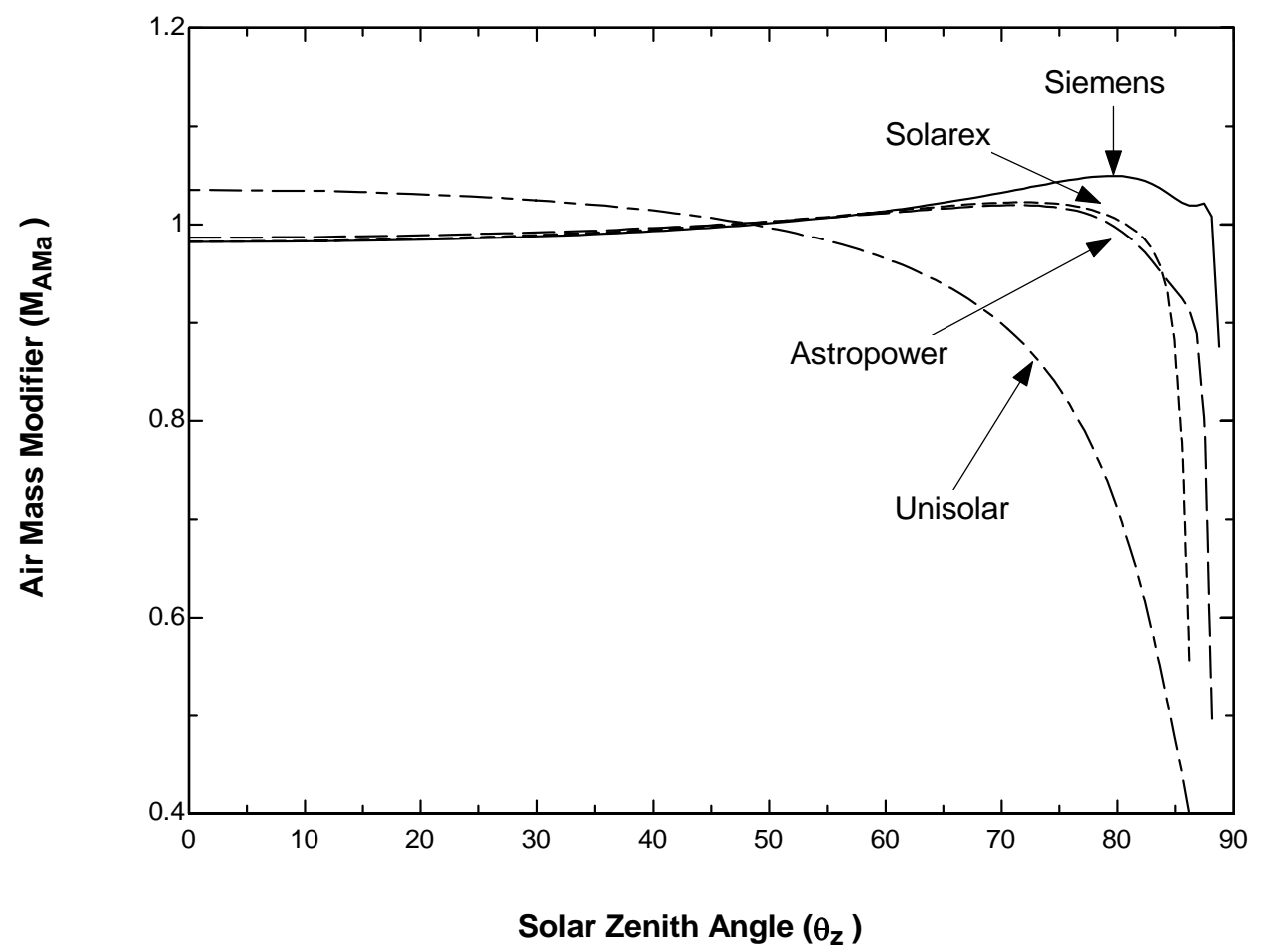

Figure 2.1 Air mass modifier $\left(M_{a m}\right)$ as a function of solar zenith angle $\left(\theta_{z}\right)$ for different cell types

\subsection{Incidence angle modifier $\left(K_{\tau \alpha}\right)$}

\subsubsection{Importance of the incidence angle modifier}

The incidence angle $(\theta)$ is the angle between the beam of light and the normal to the panel surface. It directly affects the amount of solar radiation absorbed because as the incidence angle increases, the amount of beam radiation reflected increases. The most noticeable effects occur at incidence angles $65^{\circ}$ and higher. Among many other parameters, the incidence angle is dependent on the slope $(\beta)$ of the panel. A vertical position results in large incidence angles during some parts of the year and thereby limits the amount of solar irradiance that can be absorbed by the panel. For the northern hemisphere and a panel having a slope of $90^{\circ}$, the incidence angles during most hours of the summer exceed $65^{\circ}$. The incidence angle modifier $\left(K_{\tau \alpha}\right.$ or $\left.M_{\theta}\right)$ takes this effect in 
consideration and corrects the irradiance parameter in the effective irradiance equation, Equation (2.4).

\subsubsection{King et al.'s incidence angle modifier $\left(M_{\theta}\right)$}

The incidence angle modifier $\left(K_{\tau \alpha}\right.$ or $\left.M_{\theta}\right)$ depends only on the incidence angle and strongly controls the amount of radiation absorbed by the panel. King et al. $(1996,1998)$ have developed this dependence in the form of a polynomial, function of the incidence angle $(\theta)$, and shown in Equation (2.6).

$$
\mathrm{M}_{\theta}=\mathrm{b}_{0}+\mathrm{b}_{1} \theta+\mathrm{b}_{2} \theta^{2}+\mathrm{b}_{3} \theta^{3}+b_{4} \theta^{4}+b_{5} \theta^{5}
$$

Figure 2.2 shows that at some incidence angles $(\theta)$ the value of the incidence angle modifier $\left(M_{\theta}\right)$ exceeds 1.0 , which is not physically possible without the use of a concentrator.

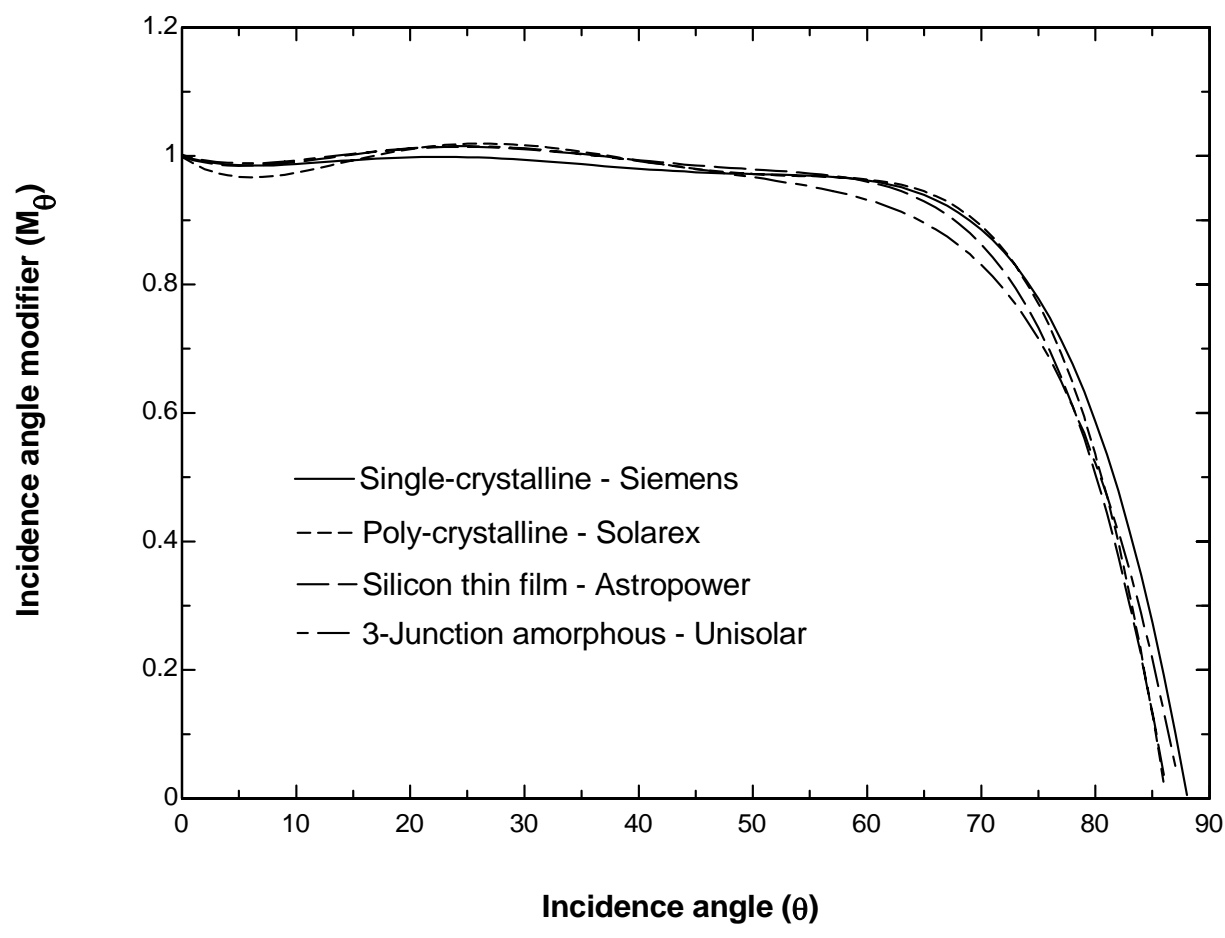

Figure 2.2: King et al.'s incidence angle modifier $\left(M_{\theta}\right)$ versus incidence angle $(\theta)$ 
King et al.'s Equation (2.6) was obtained from curve fits, where the coefficients $b_{0}, b_{1}, b_{2}, b_{3}, b_{4}$, and $b_{5}$ were empirically determined, based on results of experimental data. Because these results were not satisfying, especially the fact that values greater than 1.0 were obtained, a study was made in order to find a better and more reasonable way to calculate the incidence angle modifier. The values of the coefficients $b_{0}, b_{1}, b_{2}$, $b_{3}, b_{4}$, and $b_{5}$ suggested by the SNL's database and presented by Barker and Norton (Barker and Norton, 2001) for a Smooth Glass/Anti-Reflective cell were used in the calculations. These values are shown in Appendix A, Table A.2.

\subsubsection{Improved Incidence angle modifier $\left(K_{\tau \alpha}\right)$}

To calculate the transmittance through a single cover, Equations (2.7) through (2.10) were used. Snell's law, seen in Equation (2.7), can be used to calculate the angle of refraction $\left(\theta_{2}\right)$,

$$
\frac{n_{1}}{n_{2}}=\frac{\sin \theta_{2}}{\sin \theta_{1}}
$$

where $\theta_{1}$ is the angle of incidence, and $n_{1}$ and $n_{2}$ are the indexes of refraction of the air (1.0) and the panel surface, respectively.

Equation (2.8) shows Fresnel's equation for non-reflected unpolarized radiation as an average of its two components (perpendicular and parallel).

$$
\tau_{r}=1-\frac{1}{2}\left(\frac{\sin ^{2}\left(\theta_{2}-\theta_{1}\right)}{\sin ^{2}\left(\theta_{2}+\theta_{1}\right)}+\frac{\tan ^{2}\left(\theta_{2}-\theta_{1}\right)}{\tan ^{2}\left(\theta_{2}+\theta_{1}\right)}\right)
$$

Equation (2.9), derived from Bouguer's law, shows the absorbed radiation, 


$$
\tau_{a}=e^{-\left(\frac{K L}{\cos \theta_{2}}\right)}
$$

where $K$ is the proportionality constant and $L$ is the thickness of the panel. The value for the proportionality constant $(K)$ was assumed to be $4 \mathrm{~m}^{-1}$, the value for "water white" glass and the thickness was set as $2 \mathrm{~mm}$, a reasonable value for most PV cell panels. If the results of Equations (2.8) and (2.9) are multiplied in Equation (2.10), the transmittance through a single cover, $(\tau)$ is obtained.

$$
\tau=\tau_{r} \tau_{a}
$$

The value obtained in Equation (2.10) corresponds to an incidence angle $\theta$. To obtain the incidence angle modifier $\left(K_{\tau \alpha}\right)$, Equations (2.7) through (2.10) need be evaluated for an incidence angle of $0^{\circ}$, therefore yielding the transmittance through a single cover at an incidence angle normal to the surface $\left(\tau_{n}\right)$. The ratio of these two transmittances yields the incidence angle modifier $\left(K_{\tau \alpha}\right)$, seen in Equation (2.11).

$$
K_{\tau \alpha}=\frac{\tau}{\tau_{n}}
$$

More details on these derivations can be found in Duffie, J. and Beckman, W., Chapter 5 (1991). The values for the incidence angles $\left(\theta_{l}\right)$ were varied from $0^{\circ}$ to $90^{\circ}$ and the results obtained are shown in the following sub-sections. An example program can be found in Appendix B, Part II.

2.3.3.1 Using index of refraction $n=1.526$ 
The results obtained for the incidence angle modifier, evaluated on an interval of incidence angles of $0^{\circ}$ through $90^{\circ}$ and using an index of refraction $\left(n_{2}\right)$ of 1.526 (the index of refraction of glass) are shown in Figure 2.3.

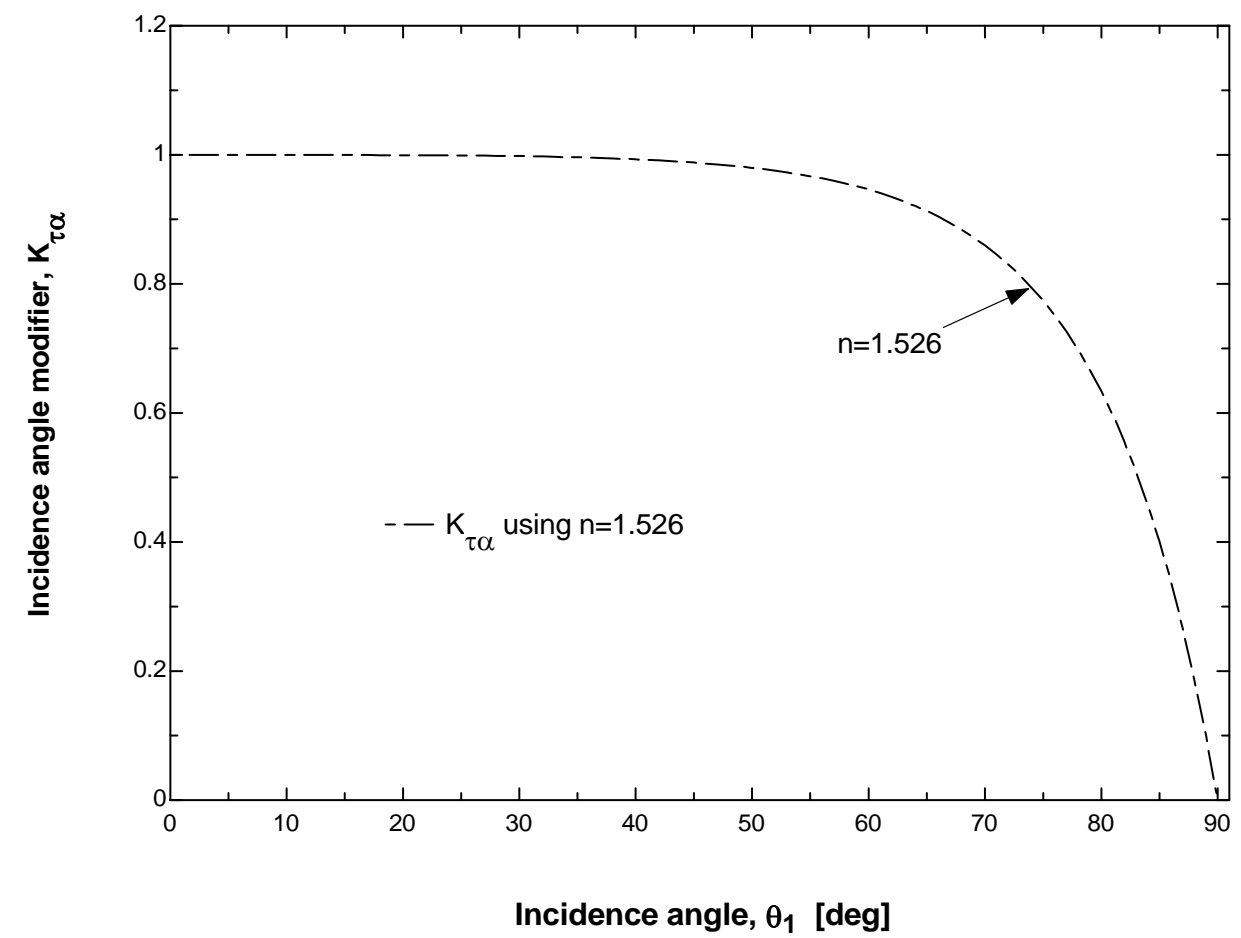

Figure 2.3: Incidence angle modifier $\left(K_{\tau \alpha}\right)$ versus incidence angle $(\theta)$, using index of refraction $n=1.526$

\subsubsection{Using index of refraction $n=1.256$}

The values for the incidence angle modifier obtained by both methods (using King's Equation (2.6), as well as using the previously discussed method in Section 2.3.3 for the $K_{\tau \alpha}$ calculation with $n=1.526$ ) were compared and predictions of the currentvoltage (I-V) curves were made. The predictions using King's Equation (2.6) yielded smaller errors than those obtained using the $K_{\tau \alpha}$ values. It was of interest finding a value for the index of refraction $(n)$ that would yield values for the incidence angle modifier $\left(K_{\tau \alpha}\right)$ as close as possible to those predicted by King, but without exceeding the physical 
limit of 1.0. The value obtained for the index of refraction was $n=1.256$ and the results can be seen in Figure 2.4. An example of the program used for this calculation can be found in Appendix B, Part III.

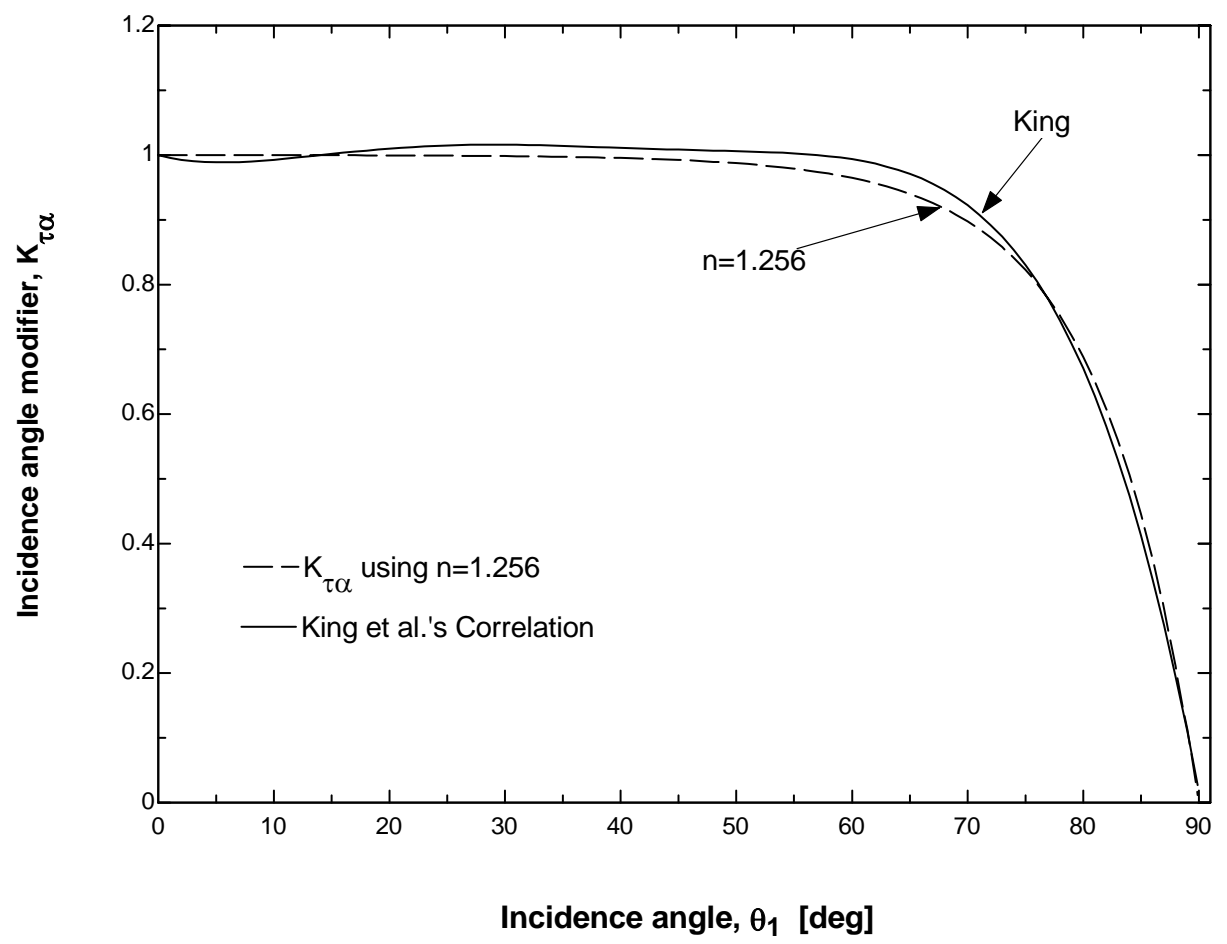

Figure 2.4: Incidence angle modifier $\left(K_{\tau \alpha}\right)$ versus Incidence angle $(\theta)$, using index of refraction $n=1.256$ and comparing with King et al.'s correlation

\subsubsection{Using index of refraction $n=1.1$}

It was observed that for high angles of incidence (above $65^{\circ}$ ) the values of $K_{\tau \alpha}$. under-predicted the current produced. The value of the index of refraction $\left(n_{2}\right)$ was varied and the error obtained between the current measured by NIST and that predicted was calculated for each of the different curves analyzed. Fifteen points were used for the error calculation, together with ten different curves for the Siemens cell type (covering a wide range of incidence angles). Equation (2.12) was used for this calculation. 


$$
\% R M S_{N=15}=\frac{\sqrt{\frac{\sum_{i=1}^{15}\left(I_{\text {Data }}-I_{\text {Model }}\right)^{2}}{15}}}{I_{\text {Data }, \text { sc }}} 100 \%
$$

$I_{\text {Data }}$ is the current measured by NIST, $I_{\text {Model }}$ is the current predicted, $I_{\text {Data,sc }}$ is the current measured at the short circuit point, and \%RMS is the percentage error.

It was found that substituting the value of 1.1 in Equations (2.7) through (2.11) minimized the errors between the measured data and that predicted. Although this was calculated only for the Siemens cell type, the results (shown in Chapters 5-6) show that acceptable results are obtained for the other cell types as well. The program used for this calculation can be seen in Appendix B, Part IV. Figure 2.5 shows a graph with the different curves calculated.

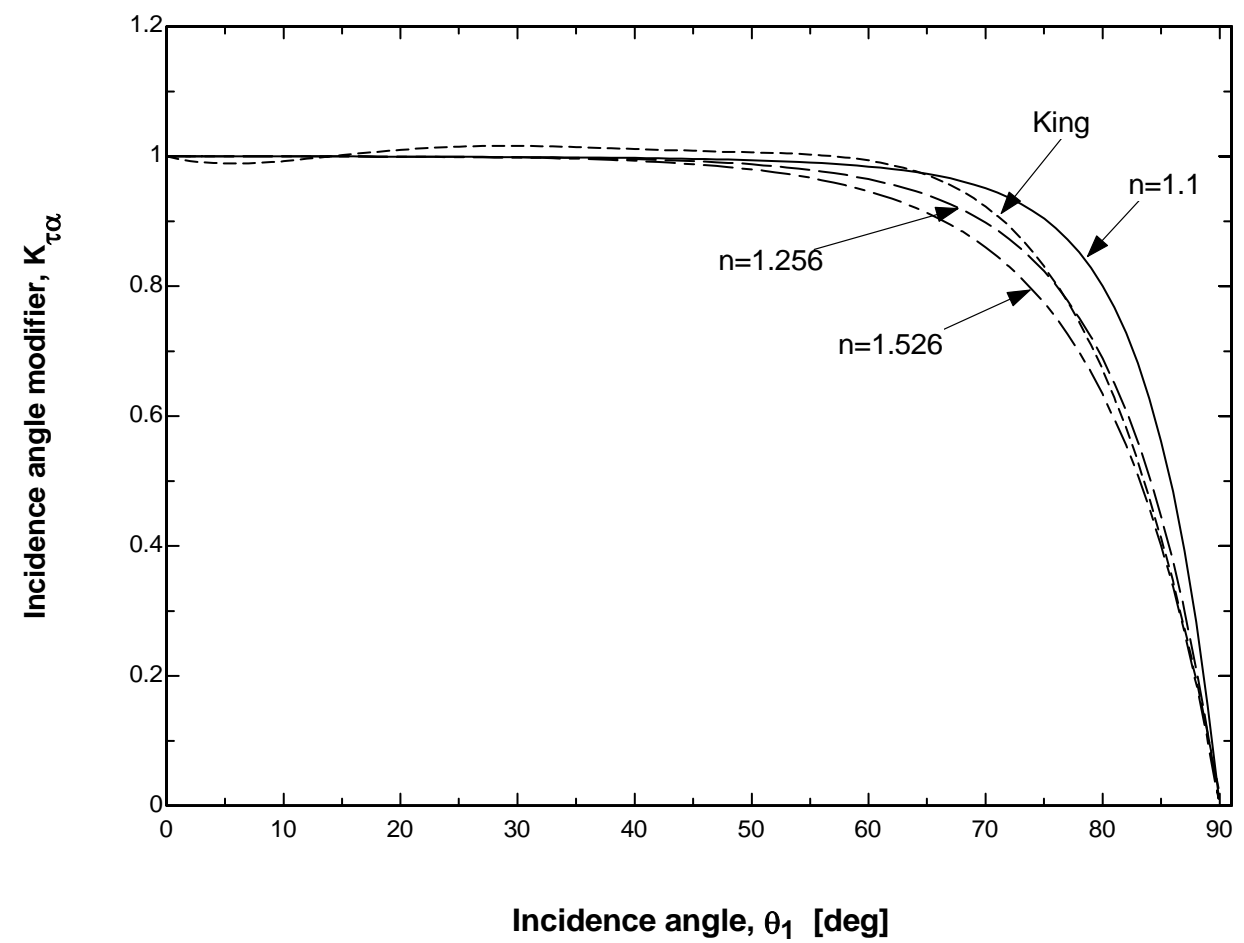

Figure 2.5: Incidence angle modifier $\left(K_{\tau \alpha}\right)$ versus Incidence angle $(\theta)$, using different indexes of refraction and comparing with King et al.'s correlation 


\subsubsection{Comparing the different $K_{\tau \alpha}$ values available}

I-V curve predictions were made using the different $K_{\tau \alpha}$ values and the results, shown in Figures 2.6 and 2.7 for two completely different operating conditions (summer and winter), demonstrate that smaller errors are obtained when using the incidence angle modifier $\left(K_{\tau \alpha}\right)$ obtained by using an index of refraction of $n=1.1$. Although the results shown in Figures 2.6 and 2.7 are for the Siemens (single-crystalline) cell type, they are characteristic for all the cell types and therefore the results for the other cell types are not shown. Figure 2.6 shows that for high incidence angles $(\theta)$ the best prediction is obtained using $K_{\tau \alpha}$ with an index of refraction of near 1.1. Figure 2.7 shows that for small incidence angles, the value of the index of refraction used does not significantly affect the outcome of the prediction, as expected from Figure 2.5, where the values of $K_{\tau \alpha}$ for the different indexes of refraction are almost the same at low $\theta$ values. The King et al., values that are greater than 1.0, end up slightly over-predicting the I-V curve. The details on how to predict the I-V curves at different operating conditions will be explained in Chapter 4. 


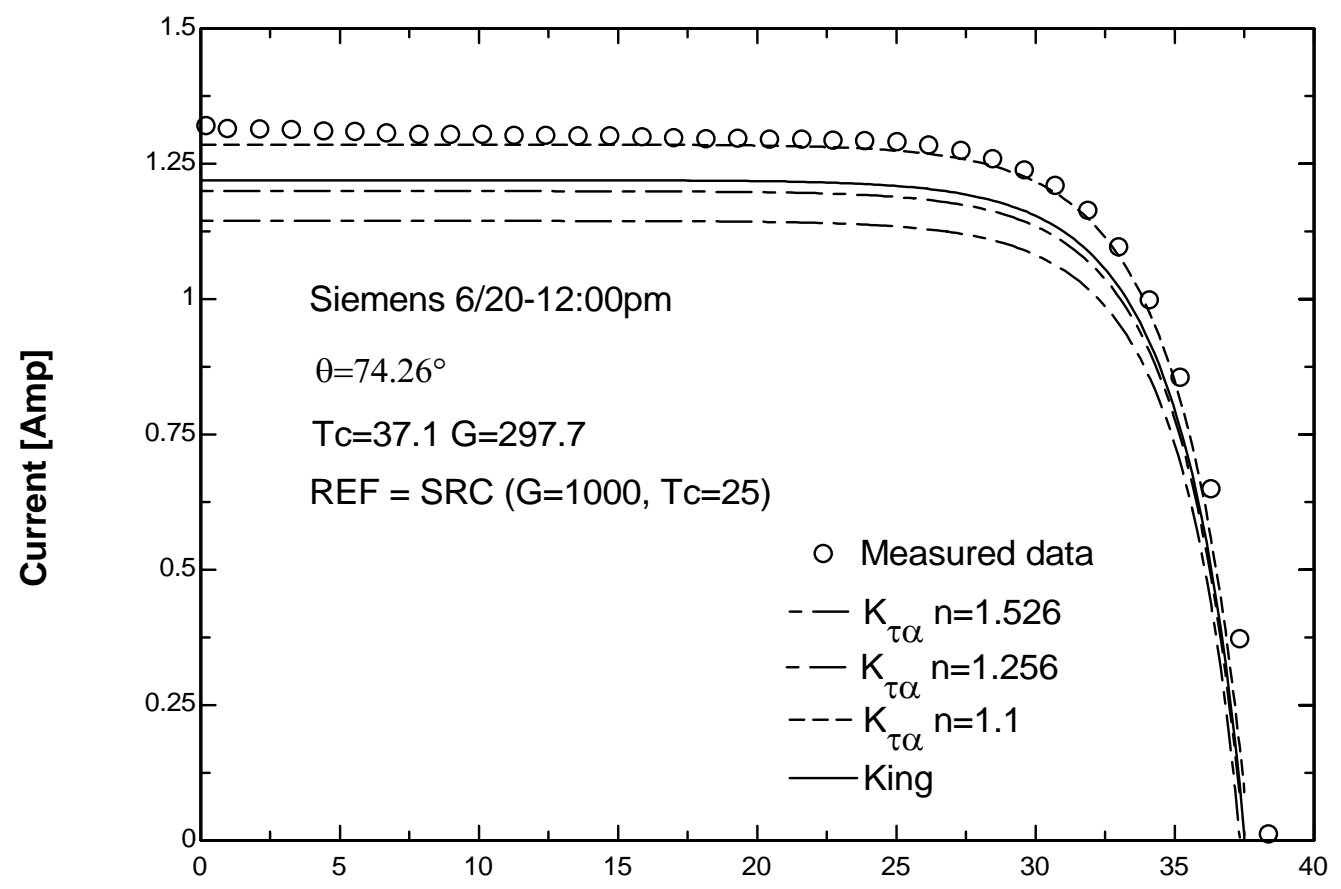

Voltage [V]

Figure 2.6: Predicted current-voltage (I-V) curves for Siemens cell type, June 20 at noon, using the different $K_{\tau \alpha}$ values available and SRC as reference conditions

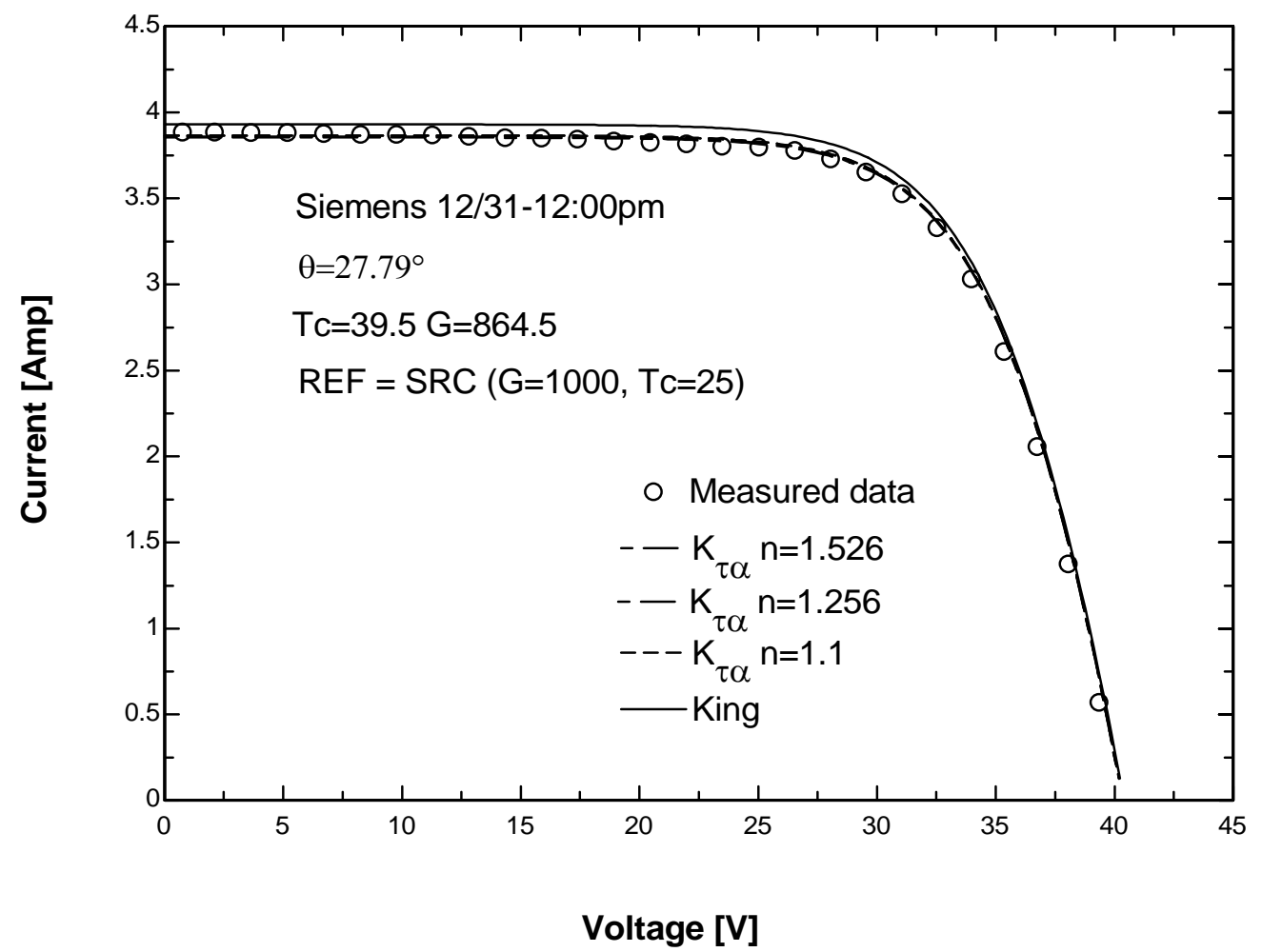

Figure 2.7: Predicted current-voltage (I-V) curves for Siemens cell type, December 31at noon, using the different $K_{\tau \alpha}$ values available and SRC as reference conditions 
Figure 2.8 shows the values of $K_{\tau \alpha}$ that will be used from now on. These values can be found tabulated in Appendix A, Table A.3.

An advantage of the proposed incidence angle modifier with $n=1.1$ is that it can be used for all cell types. The improvement in accuracy compared to King's method [1996, 1998] in Equation (2.6) is modest, but it eliminates the need to calculate six different coefficients for each cell type.

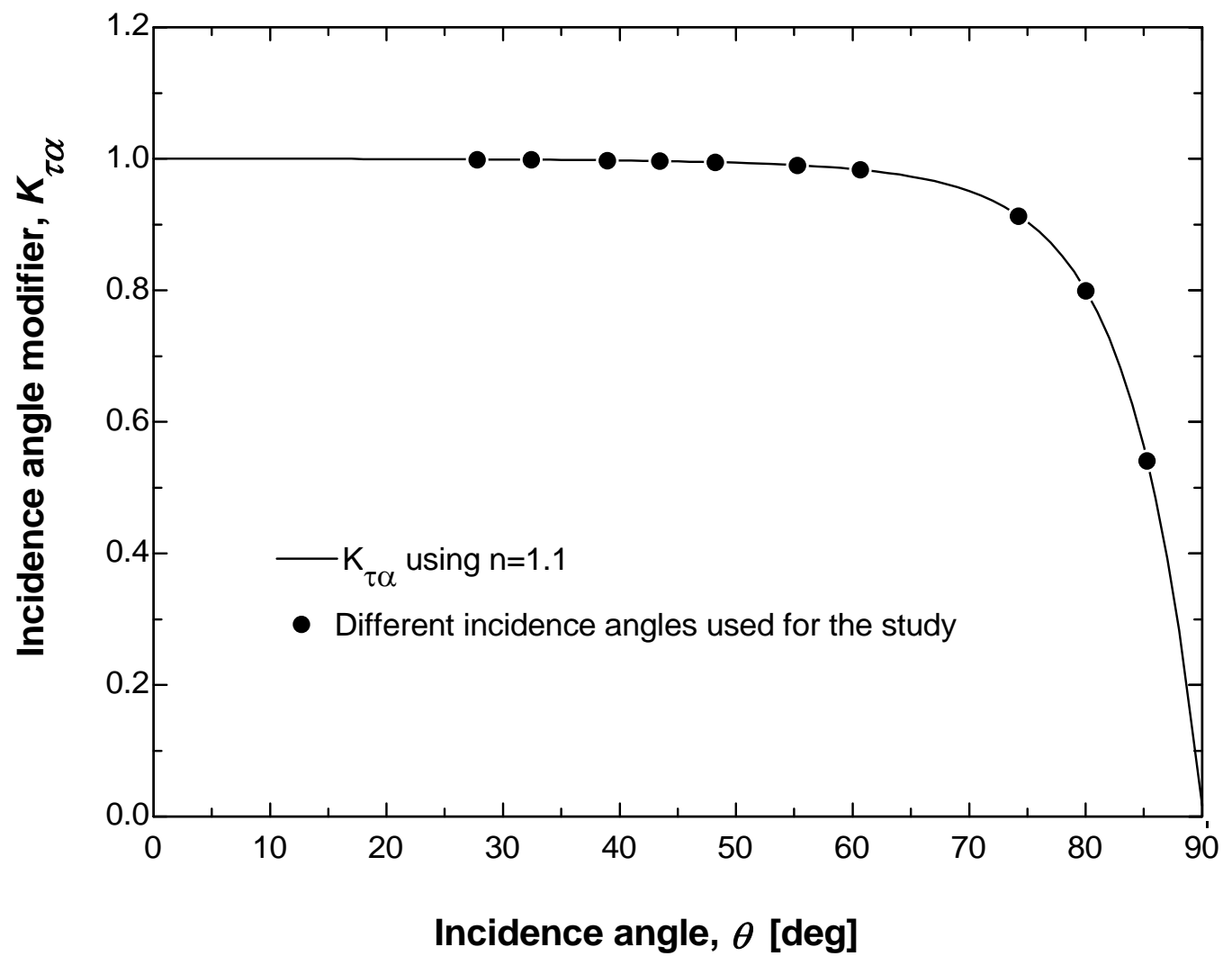

Figure 2.8: Incidence angle modifier $\left(K_{\tau \alpha}\right)$ versus Incidence angle $(\theta)$, using index of refraction $n=1.1$. The dots indicate the location of the incidence angles used for this study. 


\section{Chapter 3}

PV Physical Models

\subsection{The 5-Parameter Model}

The behavior of photovoltaic (PV) cells can be modeled with an equivalent circuit shown in Figure 3.1 (Duffie and Beckman, 1991). This circuit includes a series resistance and a diode in parallel with a shunt resistance. The letter "V" represents the voltage at the load. This circuit can be used for an individual cell, for a module consisting of several cells, or for an array consisting of several modules.

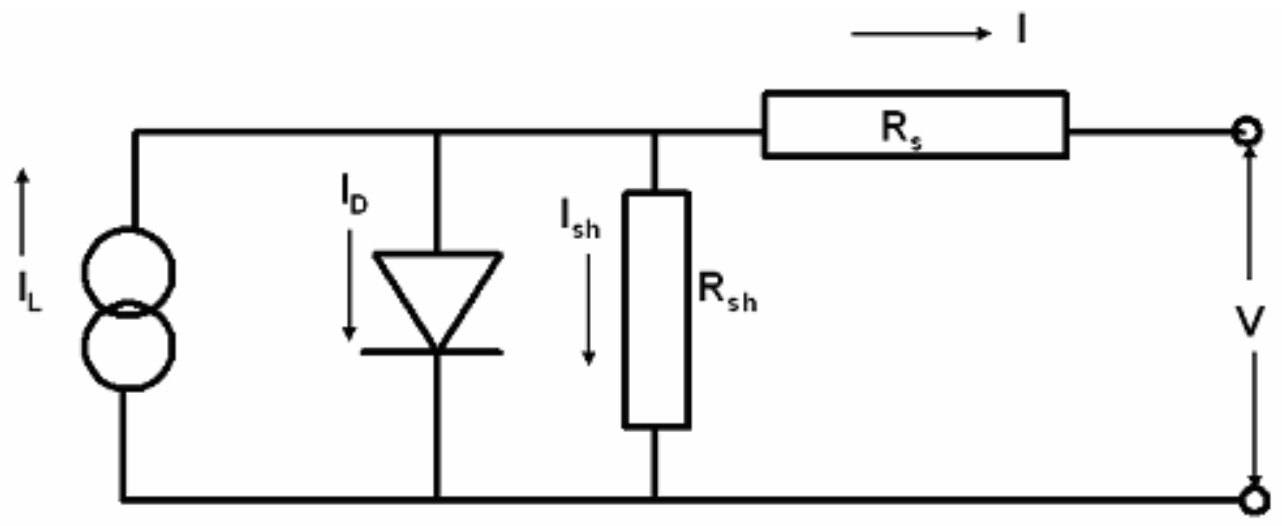

Figure 3.1: Equivalent circuit representing the 5-Parameter model

Application of Kirchoff's Current Law (Equation (3.1)) on the equivalent circuit results in the current flowing to the load

$$
I=I_{L}-I_{D}-I_{s h}
$$


If the diode current and the current through the shunt resistance ( $I_{D}$ and $I_{s h}$, respectively) are expanded, Equation (3.2) is obtained. Equation (3.3) is used to calculate the power $(P)$.

$$
\begin{gathered}
I=I_{L}-I_{o}\left[e^{\frac{V+I R_{s}}{a}}-1\right]-\frac{V+I R_{s}}{R_{s h}} \\
P=I V
\end{gathered}
$$

The five parameters (from which the 5-Parameter model obtains its name) are $a$, $I_{L}, I_{o}, R_{s}$, and $R_{s h}$, where

$a$ : ideality factor

$I_{L}$ : light current

$I_{o}$ : diode reverse saturation current

$R_{s}$ : series resistance

$R_{\text {sh }}$ : shunt resistance

The shape of the current-voltage (I-V) curve changes as the operating conditions (cell temperature, $T_{c}$, effective irradiance, $G_{\text {eff }}$, and incidence angle, $\theta$ ) change, therefore it is expected that the value of the parameters describing the curve will change as well. Figure 3.2 shows how the shape of the I-V curve changes by changes in the operating conditions during one clear, summer day. 


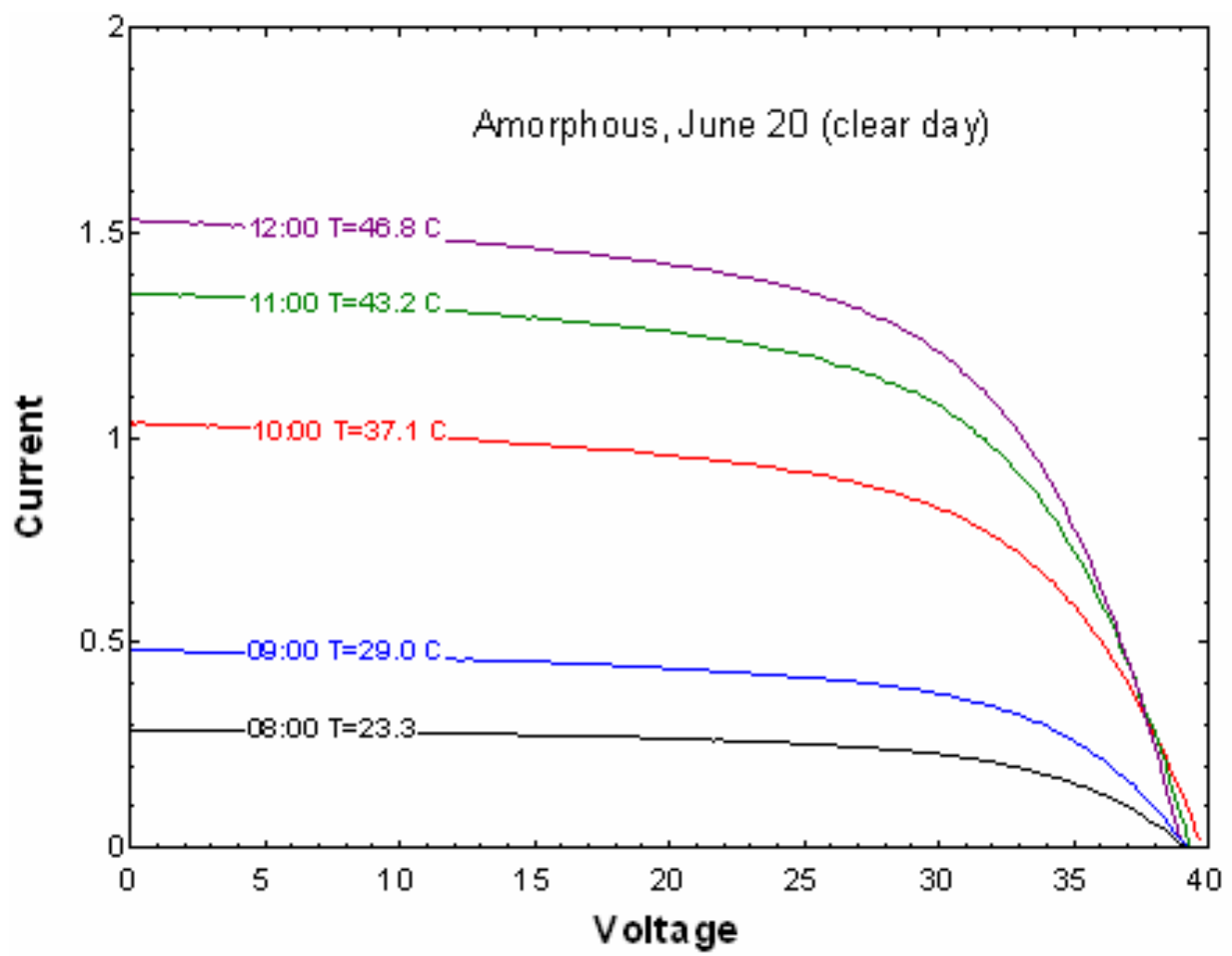

Figure 3.2: Different shapes of I-V curves as the operating conditions change

\subsection{Suitability of the 5-Parameter model}

I-V curves data provided by NIST were compared to the I-V curves predicted by using the 5-Parameter model for the four different cell types (single-crystalline, polycrystalline, silicon thin film, and 3-junction amorphous) as shown in Figures 3.3-3.6. The figures show I-V curves at two completely different operating conditions (summer and winter). From the curves it can be clearly seen that if the five parameters $\left(a, I_{o}, I_{L}, R_{s}\right.$, and $R_{s h}$ ) that correspond to a specific cell temperature and irradiance are known, the 5Parameter model is excellent at predicting the shape of the I-V curve. 


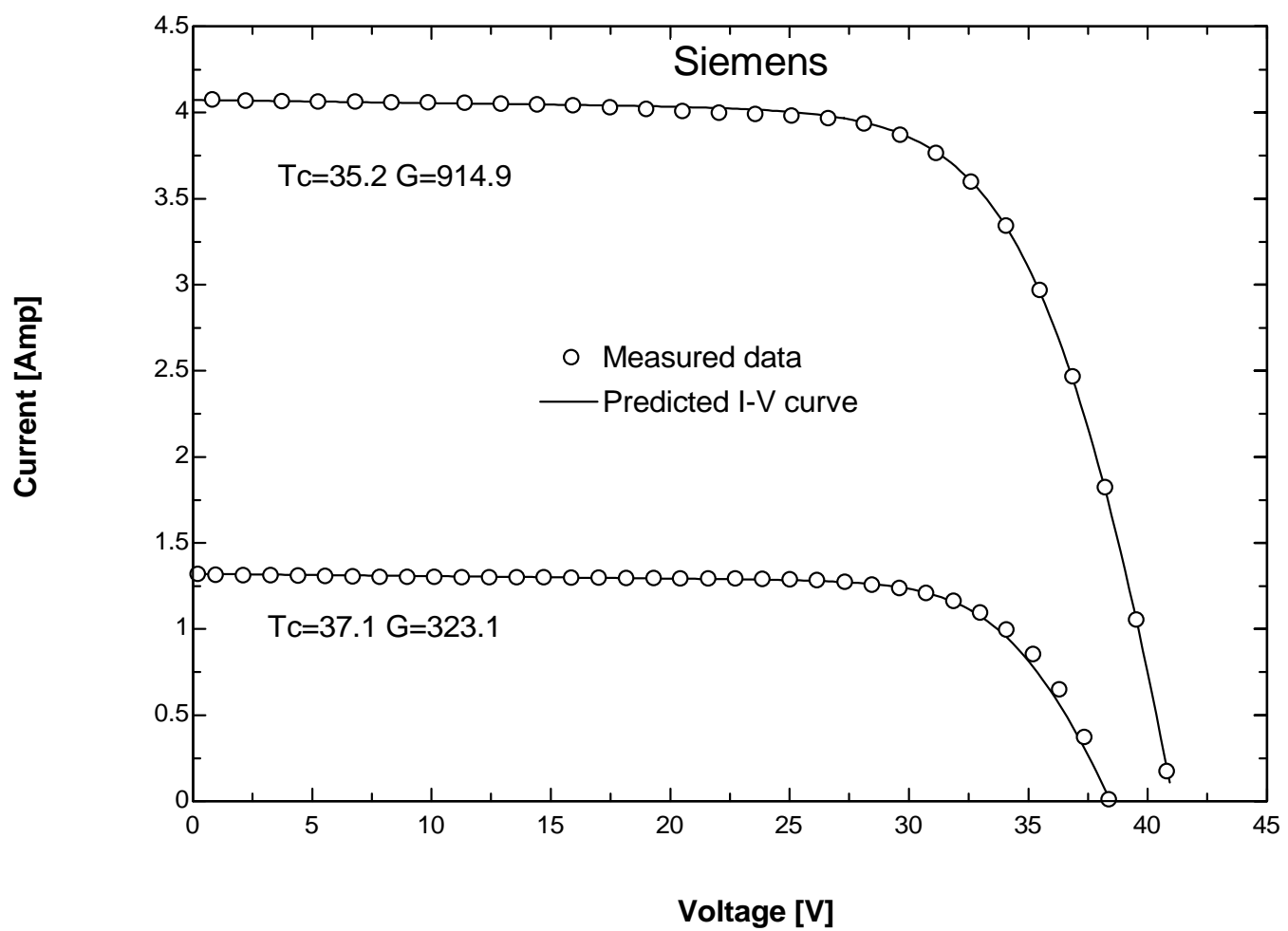

Figure 3.3: Measured vs. Predicted I-V curves for Siemens, summer and winter conditions

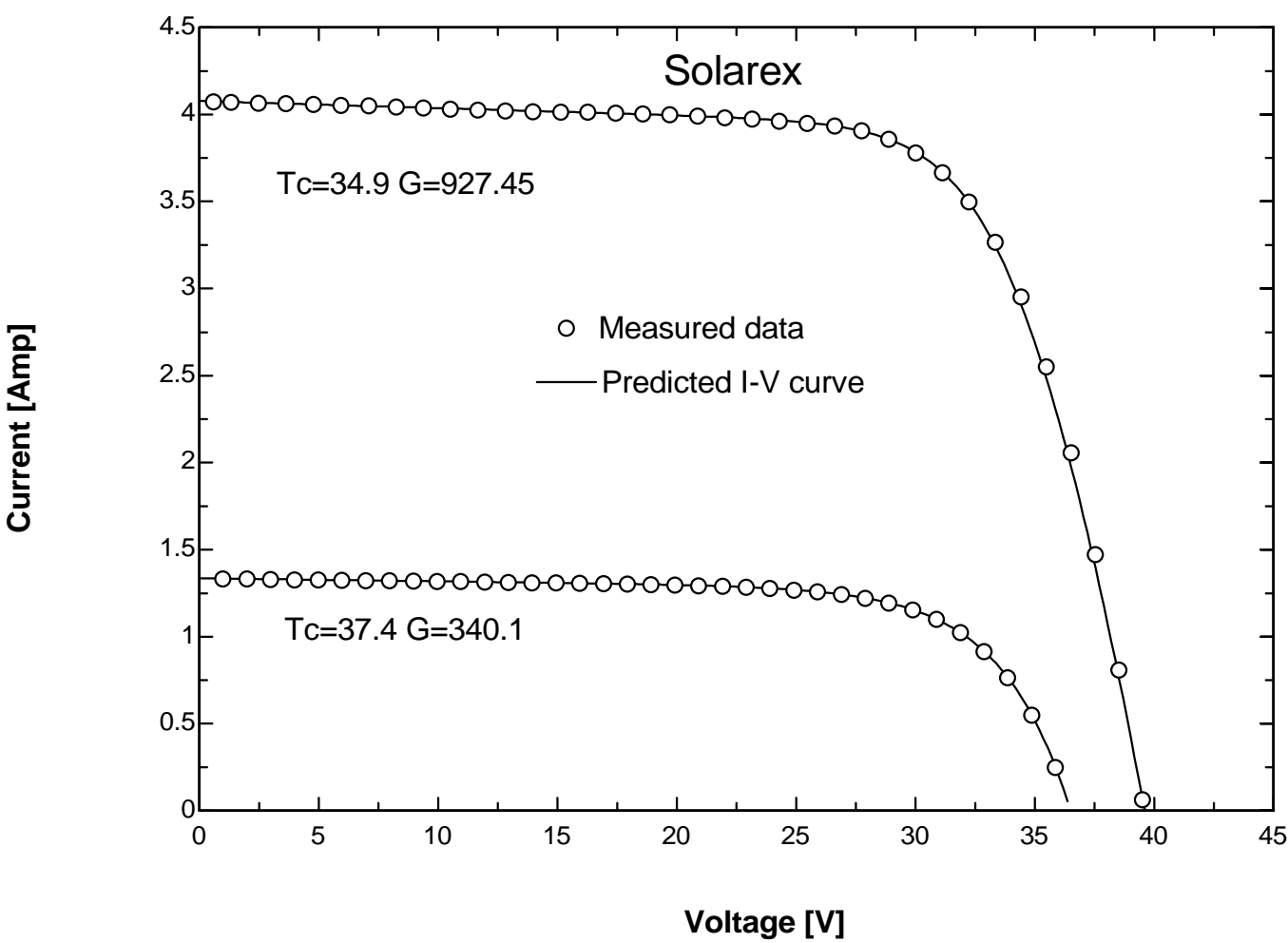

Figure 3.4: Measured vs. Predicted I-V curves for Solarex, summer and winter conditions 


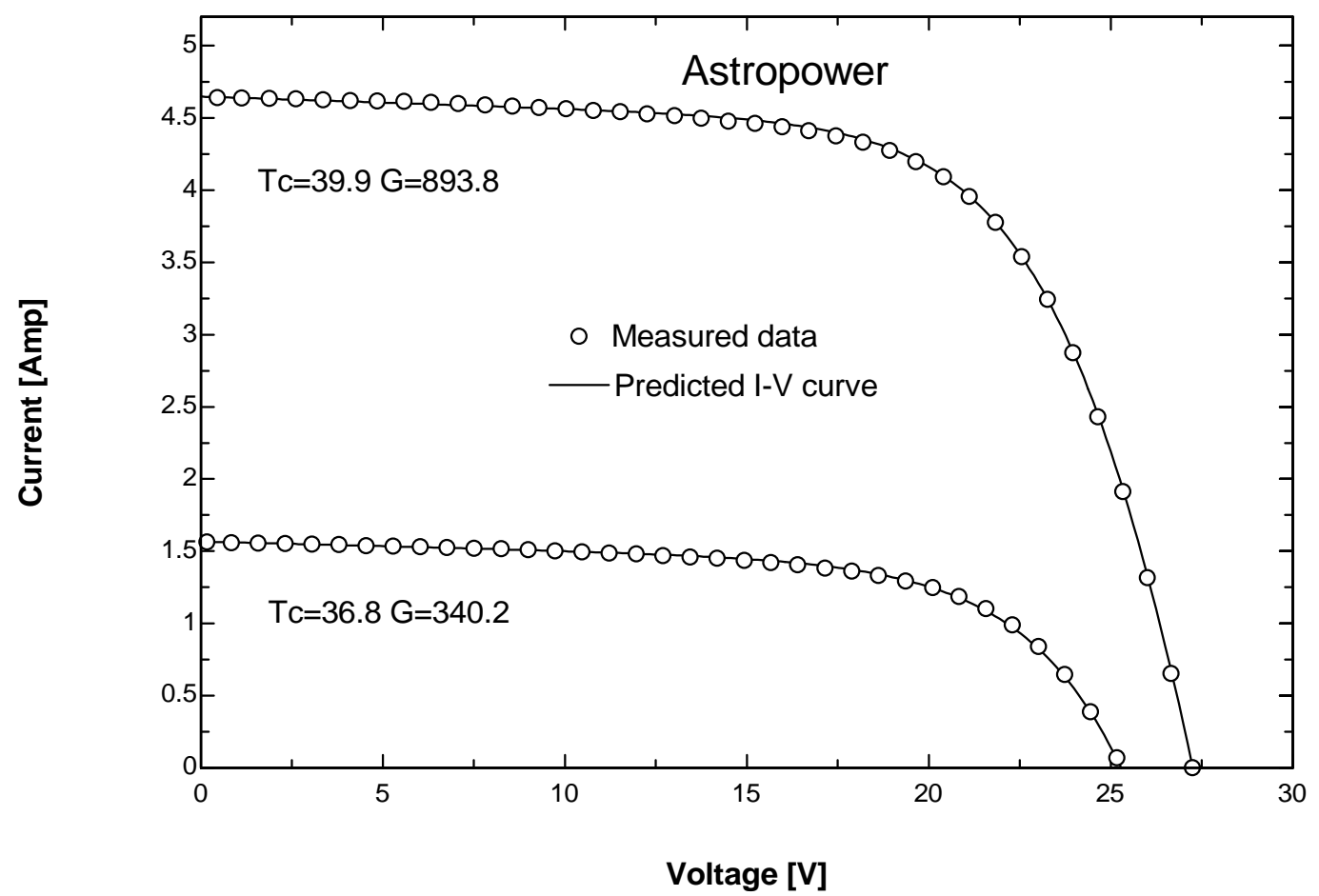

Figure 3.5: Measured vs. Predicted I-V curves for Astropower, summer and winter conditions

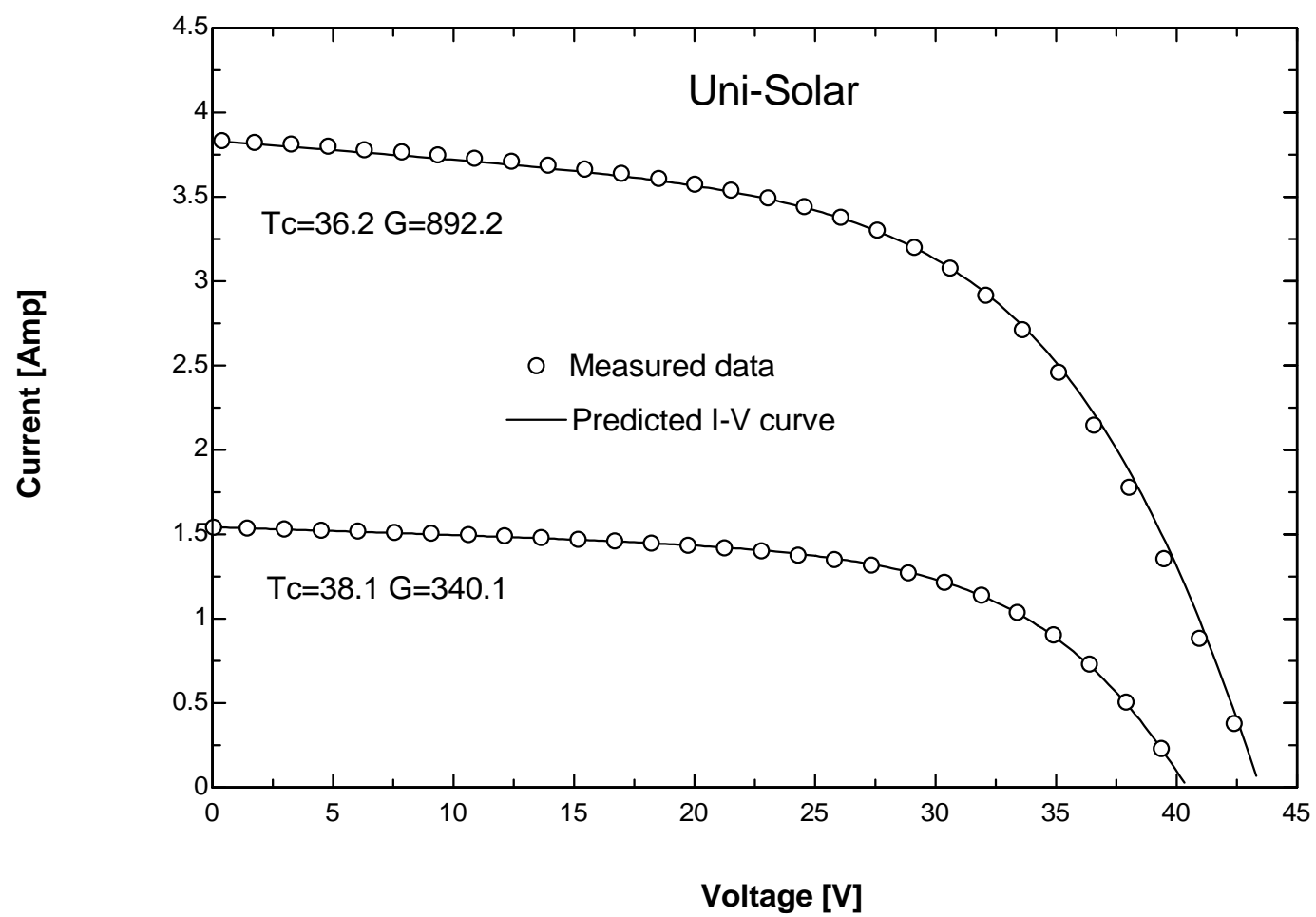

Figure 3.6: Measured vs. Predicted I-V curves for Uni-Solar, summer and winter conditions 


\subsection{Calculating the reference parameters at SRC}

To calculate the five reference parameters $\left(a_{r e f}, I_{o, r e f}, I_{L, r e f}, R_{s, r e f}\right.$, and $\left.R_{s h, r e f}\right)$, five pieces of information are needed at reference conditions (usually Standard Rated Conditions, SRC, where $T_{c}=25^{\circ} \mathrm{C}$ and $G_{e f f}=1000 \mathrm{~W} / \mathrm{m}^{2}$ ). The pieces of information are the short circuit current $\left(I_{s c 0}\right)$, open circuit voltage $\left(V_{o c 0}\right)$, current and voltage at the maximum power point ( $I_{m p 0}$ and $V_{m p 0}$, respectively), and the slope of the I-V curve at the short circuit point. The subscript " 0 " indicates at reference conditions. This information is usually provided by the manufacturer (values provided by NIST were used for this study). In the case that the slope of the I-V curve at the short circuit point is not directly provided, it can be calculated if the manufacturer provides an I-V curve at the reference conditions. If this is not provided, either the 4-Parameter model can be used (not recommended for amorphous cell types), or the slope can be approximated by plotting the points provided by the manufacturer $\left(V_{o c}, V_{m p}, I_{m p}, I_{s c}\right)$ and calculating the slope between the short circuit point and the maximum power point. This value should be divided by two in order to obtain a reasonable slope value. It will be shown in Chapter 4 that the shunt resistance does not affect too much the shape of the predicted I-V curve, therefore an approximation of this value should be sufficient. Knowing that the slope of the power at the maximum power point $\left(d P / d V_{m p}\right)$ is equal to zero constitutes the fifth piece of information required for the calculation of the five parameters. Figure 3.7 shows the location of the points of interest. 


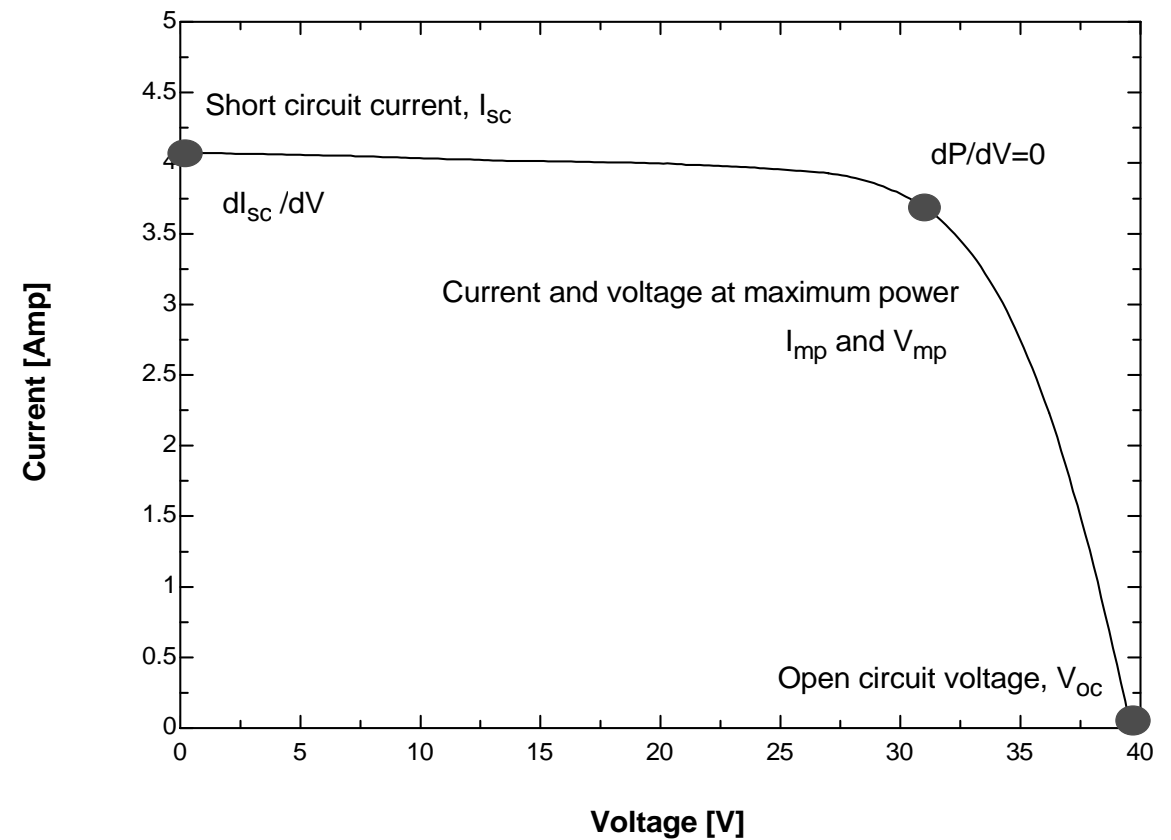

Figure 3.7: Location of the points of interest for calculating the reference parameters

To find the reference parameters it is important to know the meaning of each piece of information:

At short circuit current: $I=I_{s c 0}, V=0$

At open circuit voltage: $I=0, V=V_{o c 0}$

At the maximum power point: $I=I_{m p 0}, V=V_{m p 0}$

At the maximum power point: $d P / d V_{m p}=0$

At short circuit: $d I_{s d} / d V=-1 / R_{\text {sh, ref }}$

Having these five pieces of information, Equation (3.2) can be rewritten as Equation (3.4). Susbstituting the known information results in Equations (3.5) through (3.9) .

$$
I=I_{L, \text { ref }}-I_{o, r e f}\left[e^{\frac{V+I R_{s, r e f}}{a_{\text {ref }}}}-1\right]-\frac{V+I R_{s, \text { ref }}}{R_{s h, r e f}}
$$




$$
\begin{gathered}
I_{s c 0}=I_{L, r e f}-I_{o, r e f}\left[e^{\frac{I_{s c 0} R_{s, r e f}}{a_{r e f}}}-1\right]-\frac{I_{s c 0} R_{s, r e f}}{R_{s h, r e f}} \\
0=I_{L, r e f}-I_{o, r e f}\left[e^{\left.\frac{V_{o c 0}}{a_{r e f}}-1\right]-\frac{V_{o c 0}}{R_{s h, r e f}}}\right. \\
I_{m p 00}=I_{L, r e f}-I_{o, r e f}\left[e^{\left.\frac{V_{m p 0}+I_{m p 0} R_{s, r e f}}{a_{r e f}}-1\right]-\frac{V_{m p 0}+I_{m p 0} R_{s, r e f}}{R_{s h, r e f}}}\right. \\
\frac{d(I V)}{d V}=0 \\
\frac{d I p}{d V}=-\frac{1}{R_{s h, r e f}}
\end{gathered}
$$

The five reference parameters $\left(a_{r e f}, I_{o, r e f}, I_{L, r e f}, R_{s, r e f}\right.$, and $\left.R_{s h, r e f}\right)$ can be obtained by simultaneously solving Equations (3.5) through (3.9).

\subsubsection{The 5-Parameter model for Solarex, Uni-Solar, and Astropower}

All of the PV cells, with the exception of Siemens (single-crystalline) exhibit a pronounced slope at the short circuit point (therefore a finite shunt resistance exists). For the Solarex (poly-crystalline) I-V curves, although the slope does not seem too pronounced at high irradiances $(G)$, it is much obvious at lower irradiances and should be taken in consideration. If the slope is non-zero, Equation (3.9) yields a finite number for the shunt resistance.

3.3.2 The 4-Parameter model for Siemens $\left(R_{s h} \rightarrow \infty\right)$ 
Contrary to the other cell types, Siemens (single-crystalline) cell type tends to have an I-V curve in which the slope at short circuit is almost zero, yielding an infinite value for the shunt resistance from Equation (3.9). Since the shunt resistance $\left(R_{s h}\right)$ is infinite, the 5-Parameter model is reduced to a 4-Parameter model. In this case, the last term in Equation (3.4) equals zero and Equation (3.10) is obtained.

$$
I=I_{L, \text { ref }}-I_{o, r e f}\left[e^{\frac{V+I R_{s, \text { ref }}}{a_{\text {ref }}}}-1\right]
$$

Equations (3.5) through (3.7) become:

$$
\begin{aligned}
& I_{s c 0}=I_{L, r e f}-I_{o, r e f}\left[e^{\frac{I_{s c 0} R_{s, r e f}}{a_{r e f}}}-1\right] \\
& 0=I_{L, r e f}-I_{o, r e f}\left[e^{\frac{V_{o c 0}}{a_{r e f}}}-1\right] \\
& I_{m p 0}=I_{L, r e f}-I_{o, r e f}\left[e^{\frac{V_{m p 0}+I_{m p 0} R_{s, r e f}}{a_{r e f}}}-1\right]
\end{aligned}
$$

Assuming that the shunt resistance is infinite, the four reference parameters $\left(a_{r e f}\right.$, $I_{o, \text { ref, }}, I_{L, \text { ref, }}$ and $\left.R_{s, \text { ref }}\right)$ can be obtained using Equations (3.8) and (3.11)-(3.13).

An alternate equation for calculating $a_{r e f}$ is presented by Duffie and Beckman (1991) using the results of an analysis by Townsend [5]:

$$
a_{r e f}=\frac{\beta_{V o c} T_{c, r e f}-V_{o c, r e f}+\varepsilon N_{s}}{\frac{\alpha_{I s c} T_{c, r e f}}{I_{L, r e f}}-3}
$$


Using Equation (3.14) along with Equations (3.11)-(3.13) has the advantage that the four reference parameters $\left(a_{r e f}, I_{o, r e f}, I_{L, r e f}\right.$, and $\left.R_{S, r e f}\right)$ can be more easily obtained. Equation (3.14), is to be used only for the case where the shunt resistance is assumed to be infinite. Four additional pieces of information are needed for the calculation of the parameters when using the Equation (3.14): the band gap energy $(\varepsilon)$, the number of cells in series $\left(N_{s}\right)$, and the coefficients of temperature at open cicrcuit voltage and at short circuit current $\left(\beta_{V o c}\right.$ and $\alpha_{I s c}$, respectively). All of these values are either provided by the manufacturer or known for the different materials. Of the four cell types investigated in this reseach, only the Siemens (crystalline) cell type was well-represented by the 4 Parameter model. For an example program on how to calculate the reference parameters, view Appendix B, Part V.

\subsection{Calculating the reference parameters for winter and summer conditions}

In the case where weather conditions other than $\mathrm{SRC}$ are to be used as reference conditions, the same procedure explained in Section 3.3.1 applies. The only changes will be in the cell temperature, $T_{c}$, the irradiance, $G$, and the air mass modifier, $M_{a m}$ (which will probably be different from $25^{\circ} \mathrm{C}, 1000 \mathrm{~W} / \mathrm{m}^{2}$, and 1.0 , respectively). An I-V curve at these new operating conditions will also be needed in order to calculate the slope at the short circuit point (and therefore the shunt resistance). Since a finite value will be used for the shunt resistance, the 5-parameter model should be used rather than the 4parameter model. 


\section{Chapter 4}

\section{Variation of PV model parameters with operating conditions}

There are 5 unique parameter values which describe each I-V curve. The dependence on the operating conditions is different for each parameter value and is described in this chapter.

\subsection{Ideality factor, $a$}

The ideality factor parameter $(a)$ depends only on cell temperature, but not on irradiance level. Tests with the available data were done where the cell temperature was kept constant while the irradiance changed. The results obtained showed that the difference in irradiance did not affect the value of the ideality factor parameter.

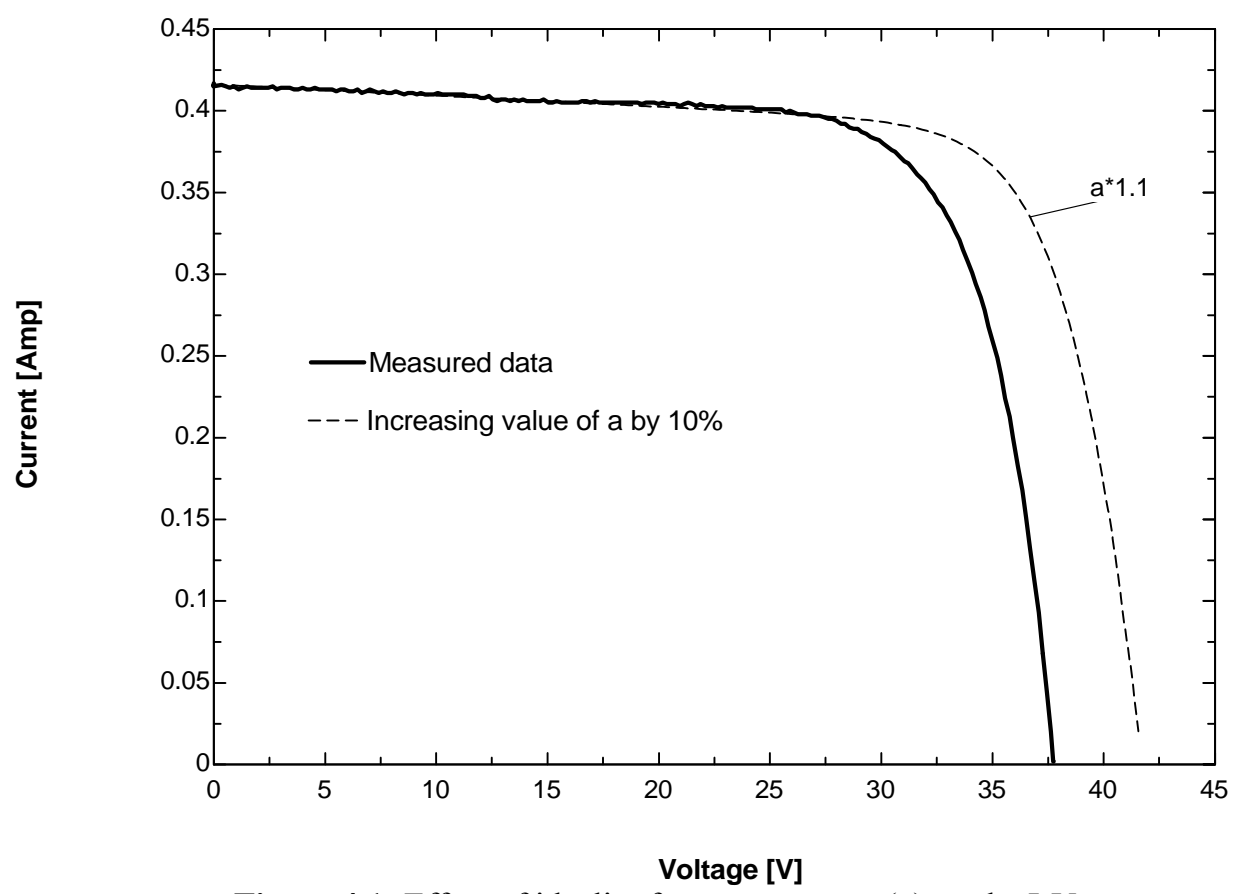

Figure 4.1: Effect of ideality factor parameter $(a)$ on the I-V curve 
Figure 4.1 shows the part of the I-V curve that is controlled by the ideality factor parameter. If the value of the ideality factor parameter is increased, the curve shifts toward the right, increasing the value of the open circuit voltage and the voltage at the maximum power point, while the value of the short circuit current remains unchanged.

From theory, the ideality factor is a linear function of cell temperature (in Kelvin).

$$
\frac{a}{a_{r e f}}=\frac{T_{c}}{T_{c, r e f}}
$$

$T_{c, r e f}$ and $a_{r e f}$ are the cell temperature and ideality factor parameter, respectively, obtained for reference conditions (usually SRC). The value of $a_{r e f}$ is obtained by simultaneously solving Equations (3.5) through (3.9) (if $R_{s h}$ is assumed to be finite) or from Equation (3.14) (if $R_{s h}$ is assumed to be infinite); $a$ is the ideality factor parameter for the new operating conditions.

\subsection{Diode reverse saturation current, $I_{o}$}

The diode reverse saturation current $\left(I_{o}\right)$ depends on temperature, as well as on the material band gap energy $(\varepsilon)$ and the number of cells in series $\left(N_{s}\right)$. Figure 4.2 shows the part of the I-V curve that it controls. Contrary to the ideality factor parameter $(a)$, if its value increases, the curve shifts toward the left, decreasing the value of the open circuit voltage and the voltage at the maximum power point. Note that just like the ideality factor, the diode reverse saturation current does not depend on radiation level as it has no effect on the short circuit current. 


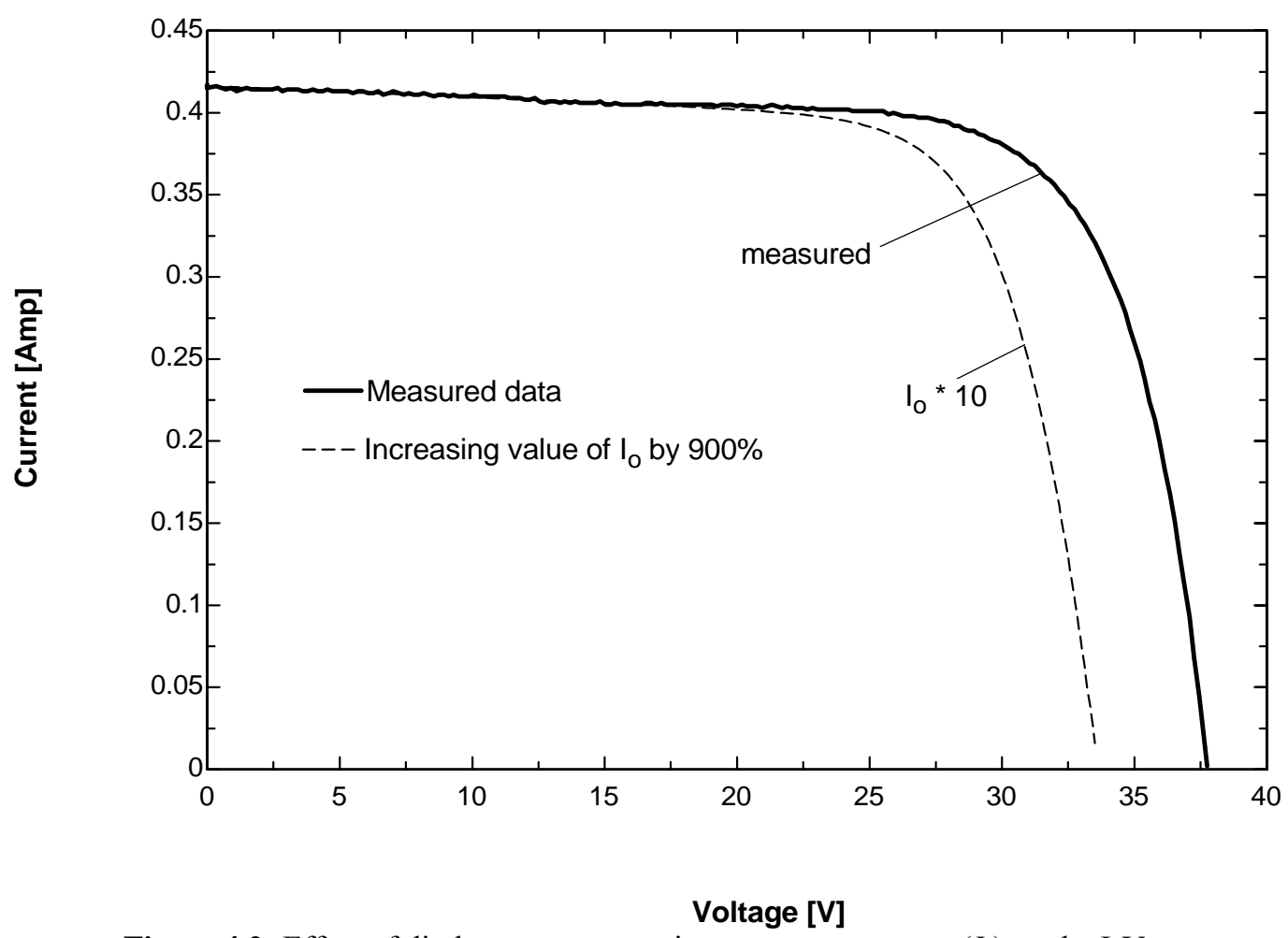

Figure 4.2: Effect of diode reverse saturation current parameter $\left(I_{o}\right)$ on the I-V curve

Equation (4.2), developed by Townsend (1989), presents an equation relating $I_{o}$ to the cell temperature (in Kelvin). This equation describes the effect that the diode in the equivalent circuit, seen in Figure 3.1, has on the final I-V curve.

$$
\frac{I_{o}}{I_{o, \text { ref }}}=\left[\frac{T_{c}}{T_{c, \text { ref }}}\right]^{3} e^{\frac{\varepsilon N_{s}}{a_{\text {ref }}}\left(1-\frac{T_{c, \text { ref }}}{T_{c}}\right)}
$$

$I_{o, r e f}$ and $a_{r e f}$ are the reference parameters obtained by simultaneously solving Equations (3.5) through (3.9) (if $R_{s h}$ is assumed to be finite) or by simultaneously solving Equations (3.11) through (3.14) (if $R_{s h}$ is assumed to be infinite). The material band gap energy $(\varepsilon)$ and the number of cells in series $\left(N_{s}\right)$ are different for each cell type and panel. The values used for this study can be found in Appendix A, Table A.1. $I_{o}$ is the diode reverse saturation current for the new operating conditions. 


\subsection{Light current, $I_{L}$}

The light current $\left(I_{L}\right)$ parameter was observed to depend on the effective solar irradiance $\left(G_{\text {eff }}\right)$, the cell temperature $\left(T_{c}\right)$, the short circuit current temperature coefficient $\left(\alpha_{I s c}\right)$, and the air mass modifier $\left(M_{a m}\right)$, among other parameters. Figure 4.3 shows that as the light current increases, so does the short circuit current. The I-V curve shifts upward.

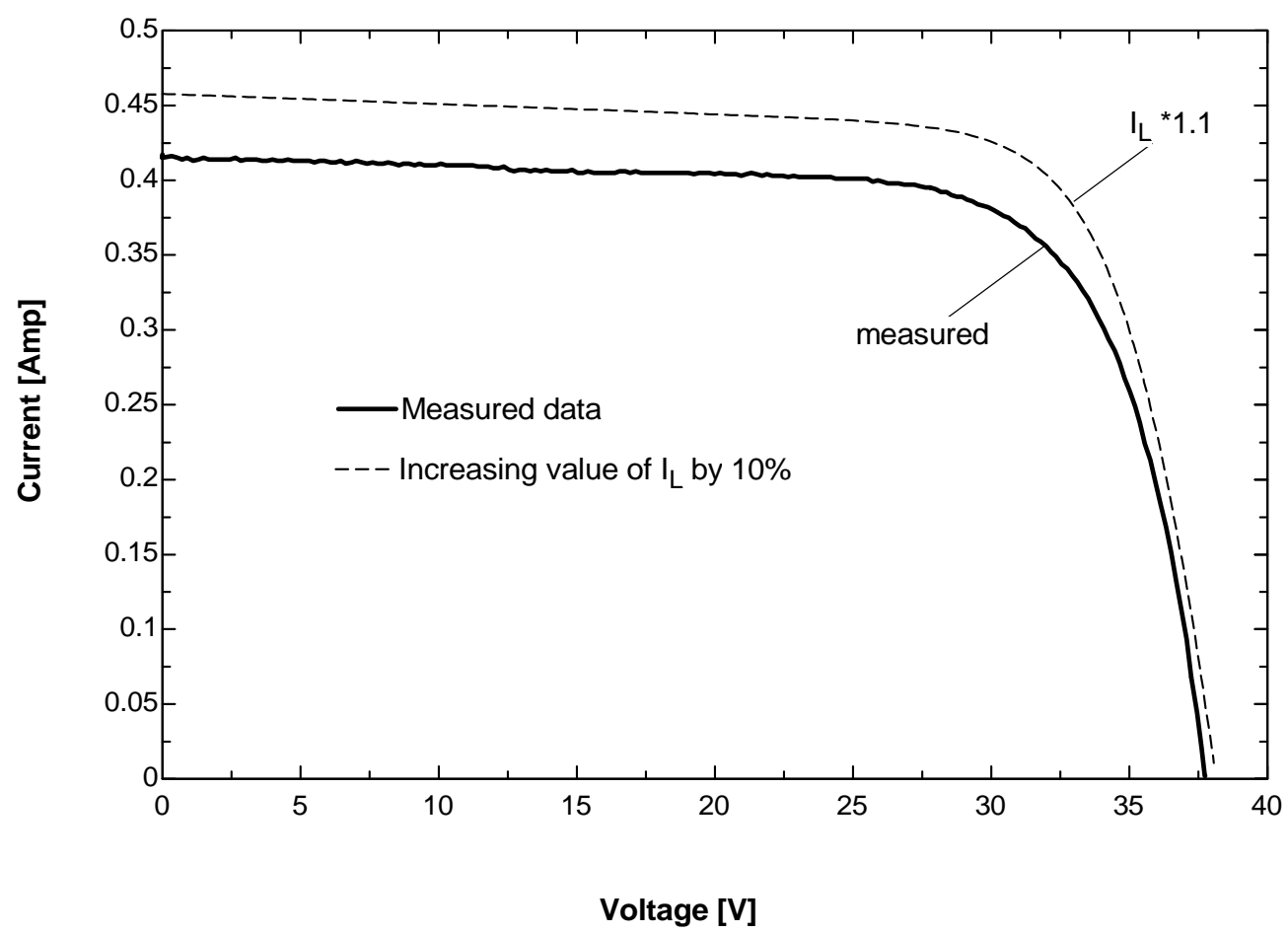

Figure 4.3: Effect of light current $\left(I_{L}\right)$ on the I-V curve

Townsend (1989) proposed Equation (4.3) to calculate the light current parameter at any operating condition, but it uses the irradiances on a tilted surface $\left(G_{T}\right.$ and $\left.G_{T, r e f}\right)$, which does not account for air mass or solar angle of incidence effects. Equation (4.4) is a modification of Equation (4.3) to include the effects of the effective irradiances $\left(G_{\text {eff }}\right.$ and $\left.G_{\text {eff,ref }}\right)$ and the air mass modifiers $\left(M_{a m}\right.$ and $\left.M_{a m, r e f}\right)$. From Equation (2.4) (repeated 
for ease of reading in Equation (4.5)), it can be seen that the incidence angle effects are built-in the effective irradiance $\left(G_{e f f}\right)$.

$$
\begin{gathered}
I_{L}=\frac{G_{T}}{G_{T, r e f}}\left[I_{L, r e f}+\alpha_{I s c}\left(T_{c}-T_{c, r e f}\right)\right] \\
I_{L}=\frac{G_{e f f} M_{a m}}{G_{e f f, r e f} M_{a m, r e f}}\left[I_{L, r e f}+\alpha_{I s c}\left(T_{c}-T_{c, r e f}\right)\right]
\end{gathered}
$$

$G_{\text {eff,ref, }}, M_{a m, r e f}, I_{L, r e f}, T_{c, \text { ref }}$ are the parameters at the reference condition (SRC), while $G_{e f f}, M_{a m}$, and $T_{c}$ are the values for the predicted operating conditions.

\subsubsection{Using effective radiation $\left(G_{\text {eff }}\right)$ vs. radiation on a tilted surface $\left(G_{T}\right)$}

The difference between the effective radiation $\left(G_{e f f}\right)$ and the radiation on a tilted surface (as derived by Liu and Jordan, 1963), seen in Equations (4.5) and (4.6) is that the first one accounts for the effects of the incidence angle, while the latter neglects them.

$$
\begin{gathered}
\mathrm{G}_{\text {eff }}=\mathrm{G}_{\mathrm{b}} \mathrm{R}_{\text {beam }} \mathrm{K}_{\tau \alpha}+\mathrm{G}_{\mathrm{d}} \mathrm{K}_{\tau \alpha, \mathrm{d}} \frac{1+\operatorname{Cos}(\beta)}{2}+\rho_{\mathrm{g}} \mathrm{GK}_{\tau \alpha, \mathrm{d}} \frac{1-\operatorname{Cos}(\beta)}{2} \\
\mathrm{G}_{\mathrm{T}}=\mathrm{G}_{\mathrm{b}} \mathrm{R}_{\text {beam }}+\mathrm{G}_{\mathrm{d}} \frac{1+\operatorname{Cos}(\beta)}{2}+\rho_{\mathrm{g}} \mathrm{G} \frac{1-\operatorname{Cos}(\beta)}{2}
\end{gathered}
$$

Figures 4.4 through 4.7 show the different I-V curve predictions resulting from using the different irradiances available, $G_{e f f}$ and $G_{T}$. 


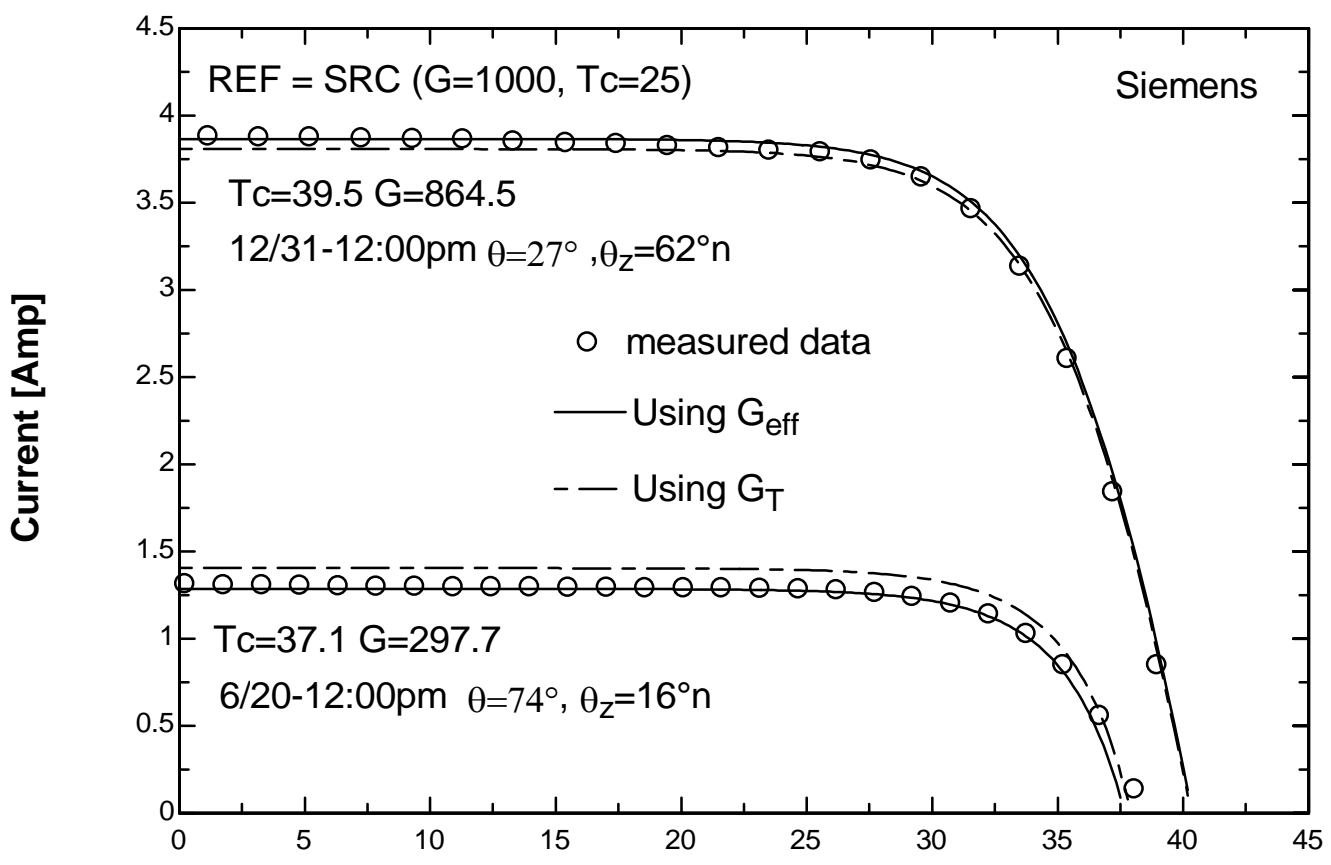

\section{Voltage [V]}

Figure 4.4: Using $G_{e f f}$ Vs. $G_{T}$ for Siemens, using SRC as reference conditions to predict summer and winter operating conditions

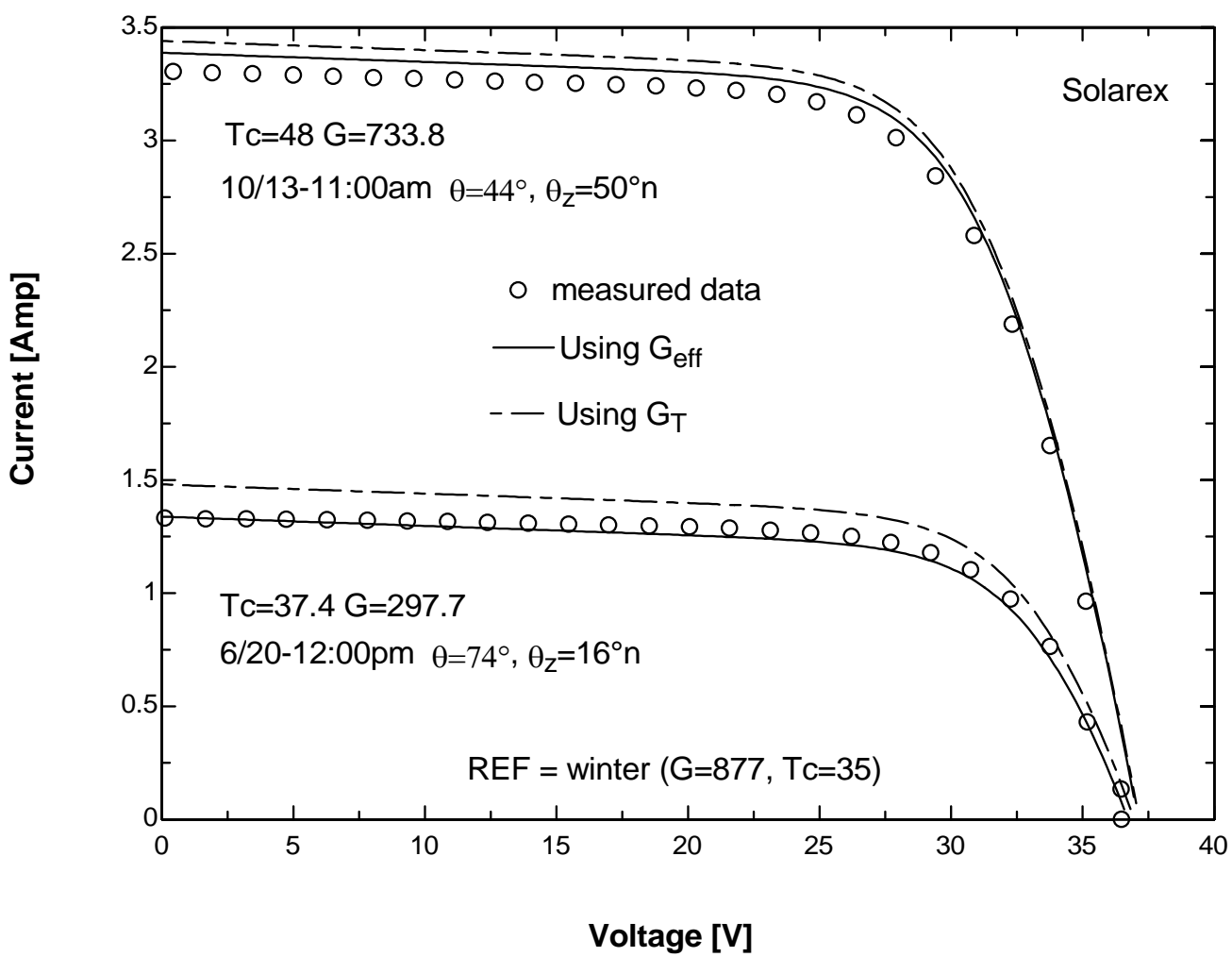

Figure 4.5: Using $G_{\text {eff }}$ vs. $G_{T}$ for Solarex, using winter as reference conditions to predict summer and winter operating conditions 


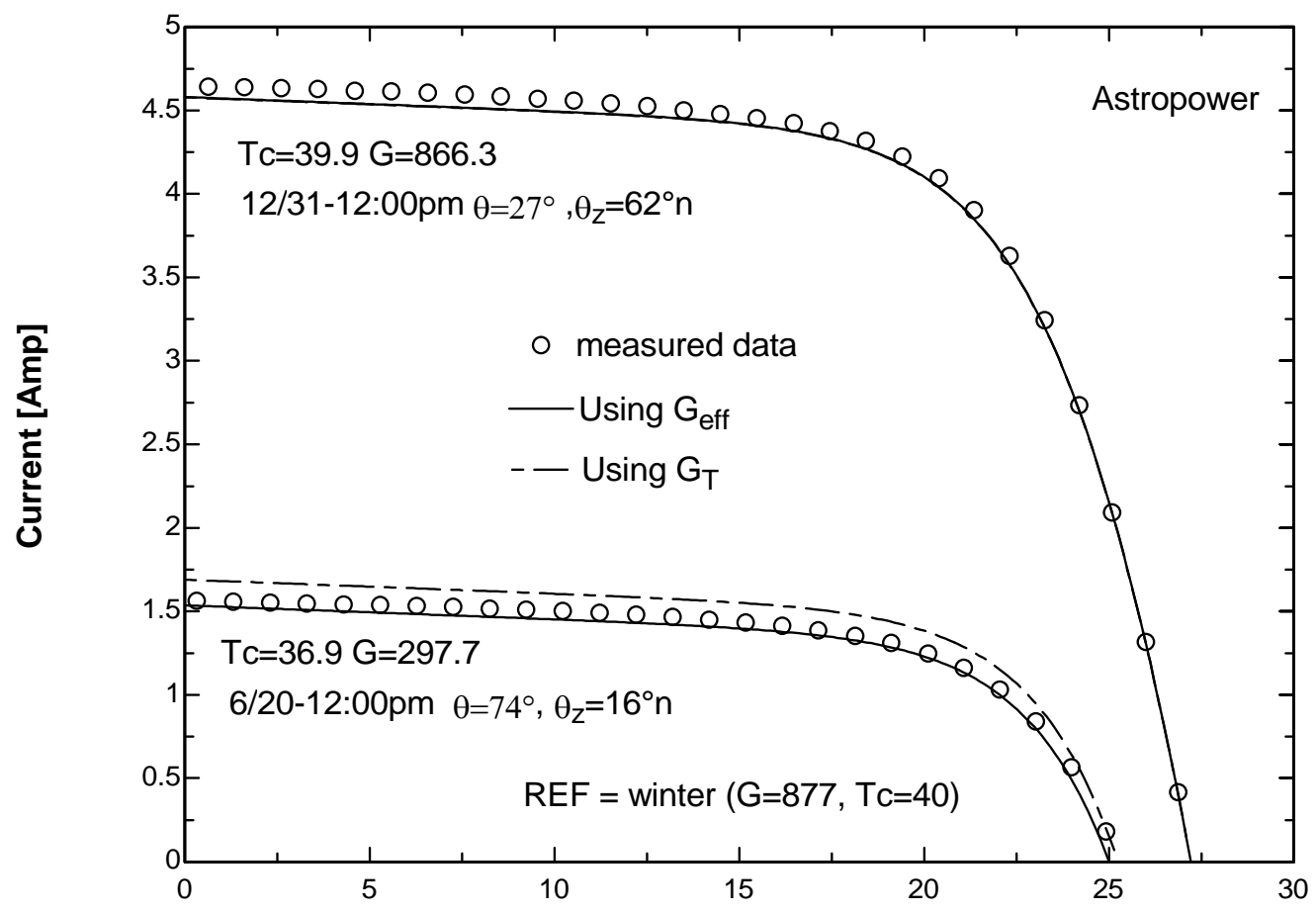

\section{Voltage [V]}

Figure 4.6: Using $G_{e f f}$ vs. $G_{T}$ for Astropower, using winter as reference conditions to predict summer and winter operating conditions

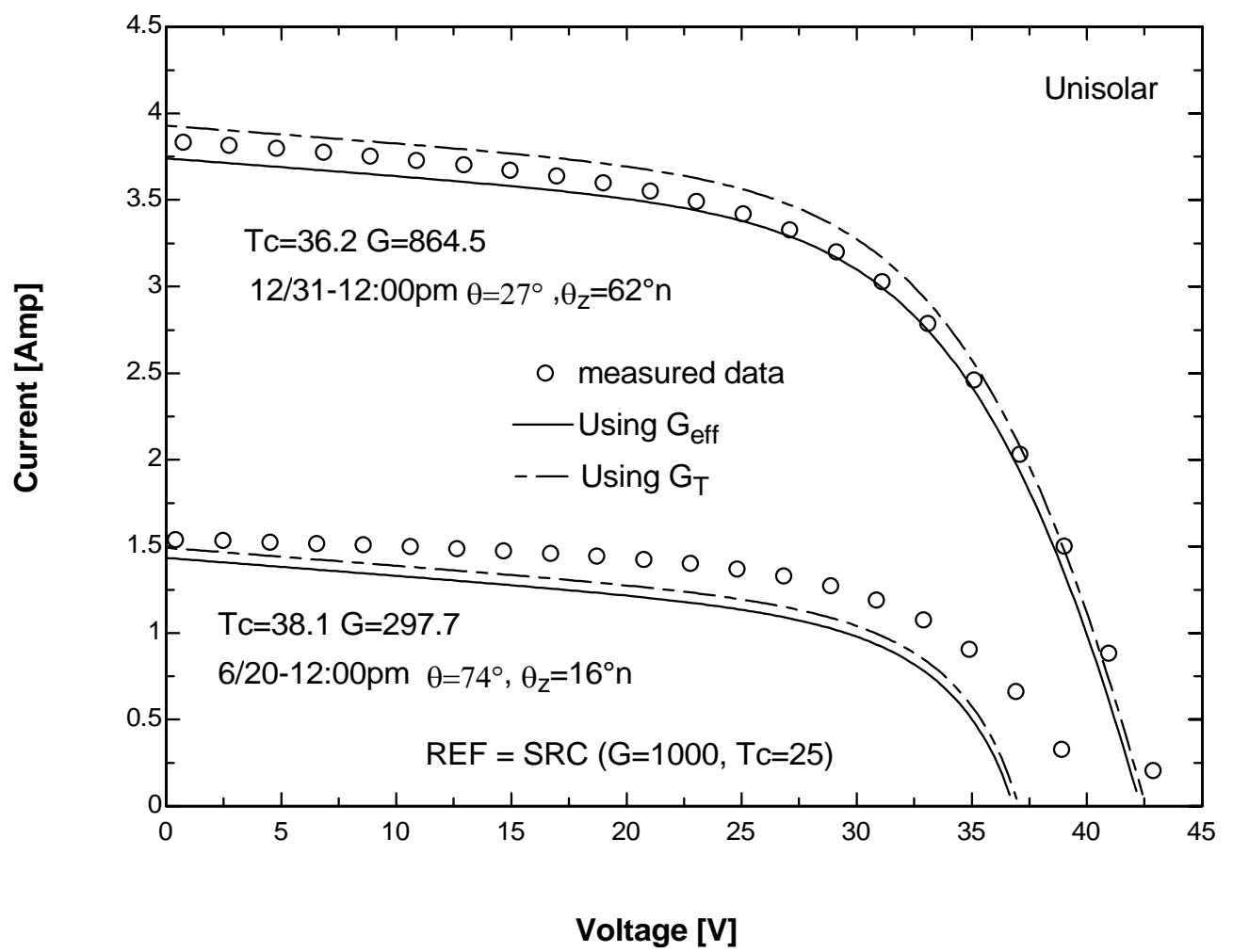

Figure 4.7: Using $G_{\text {eff }}$ vs. $G_{T}$ for Uni-Solar, using SRC as reference conditions to predict summer and winter operating conditions 
In general, at high irradiances, as seen in winter weather conditions, the incidence angle $(\theta)$ is small, which yields a value for the incidence angle modifier of nearly 1.0 ; in this case, the incidence angle has little effect on the beam component absorbed by the panel. Although the incidence angle modifier affects the other two components of the effective irradiance (diffuse and ground reflected), for high irradiances, the beam component dominates and tends to control the resulting effective irradiance. At high incidence angles (such as those seen during the summer), the effect of this modifier is much greater, without which (as in the case where $G_{T}$ is used instead of $G_{\text {eff }}$ ) there would be an over-prediction of the I-V curve. The Uni-Solar cell type, as will be shown in more detail later, does not behave as the other cell types do. In this case, the different behavior is caused by the value of its air mass modifier $\left(M_{a m}\right)$, presented in Equation (4.4). This value is smaller than the $M_{a m}$ values for other cell types, making the Uni-Solar I-V curve shift down a bigger distance than the other cell types do.

\subsubsection{Effect of air mass modifier $\left(M_{a m}\right)$}

As the air mass increases, the spectral content of irradiance changes, in many cases affecting the efficiency of the PV panel. Figures 4.8 through 4.11 show that at low zenith angles $\left(\theta_{z}\right)$ the air mass modifier's $\left(M_{a m}\right)$ value is almost 1.0, therefore its effect will hardly affect the behavior of the I-V curve, while at higher zenith angles (approximately over $60^{\circ}$ ), this value will tend to shift the I-V curve, altering the results of the prediction. 


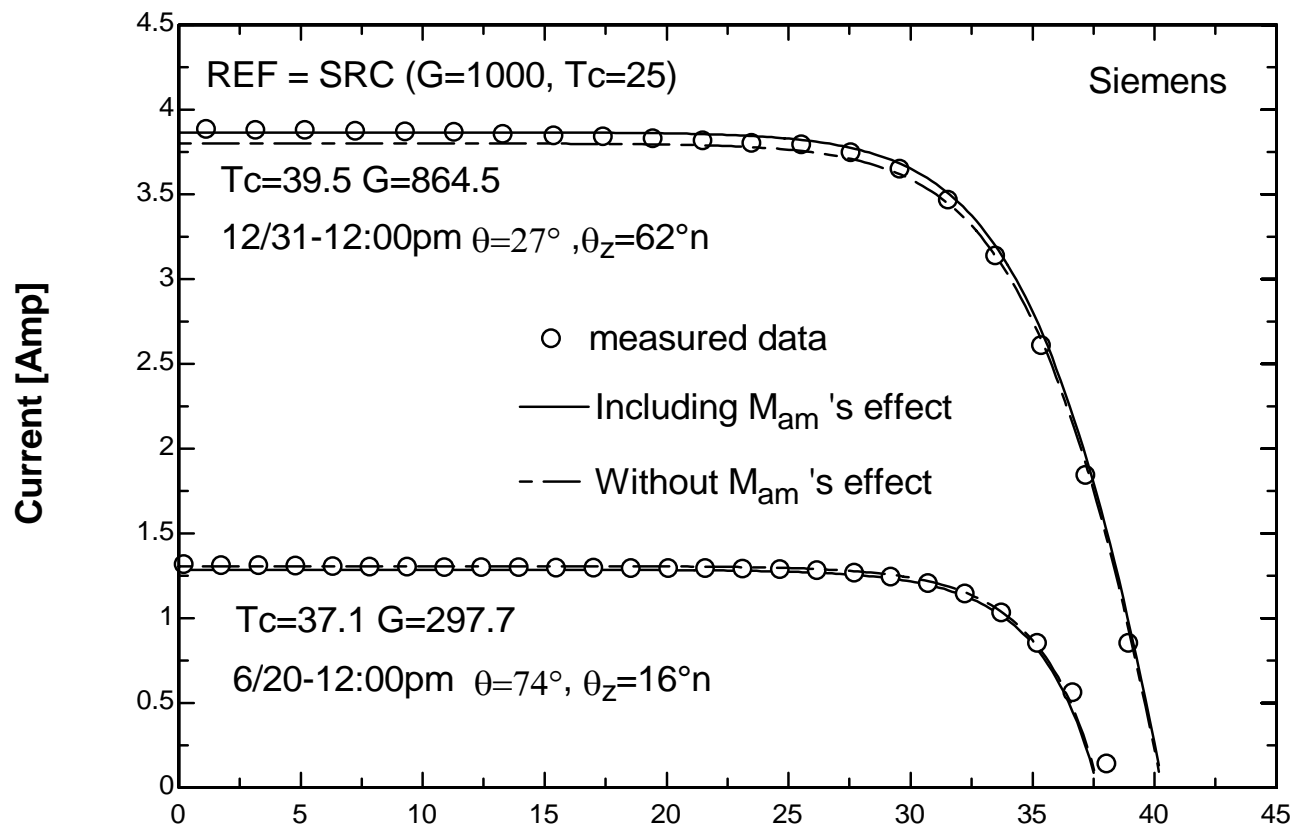

\section{Voltage [V]}

Figure 4.8: With and without taking in consideration $M_{a m}$ 's effect for Siemens cell type, using $\mathrm{SRC}$ as reference conditions to predict summer and winter operating conditions

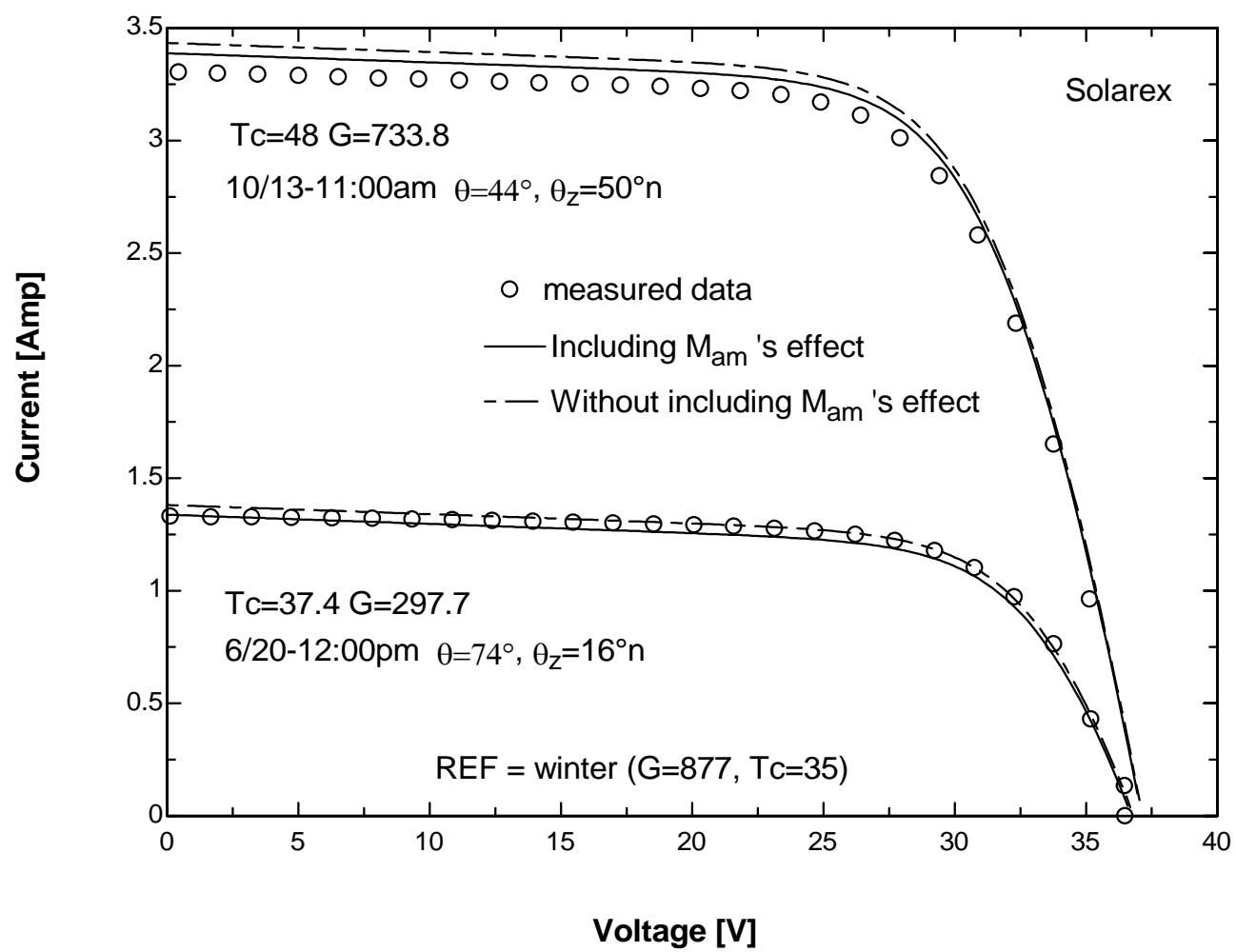

Figure 4.9: With and without taking in consideration $M_{a m}$ 's effect for Solarex cell type, using winter as reference conditions to predict summer and winter operating conditions 


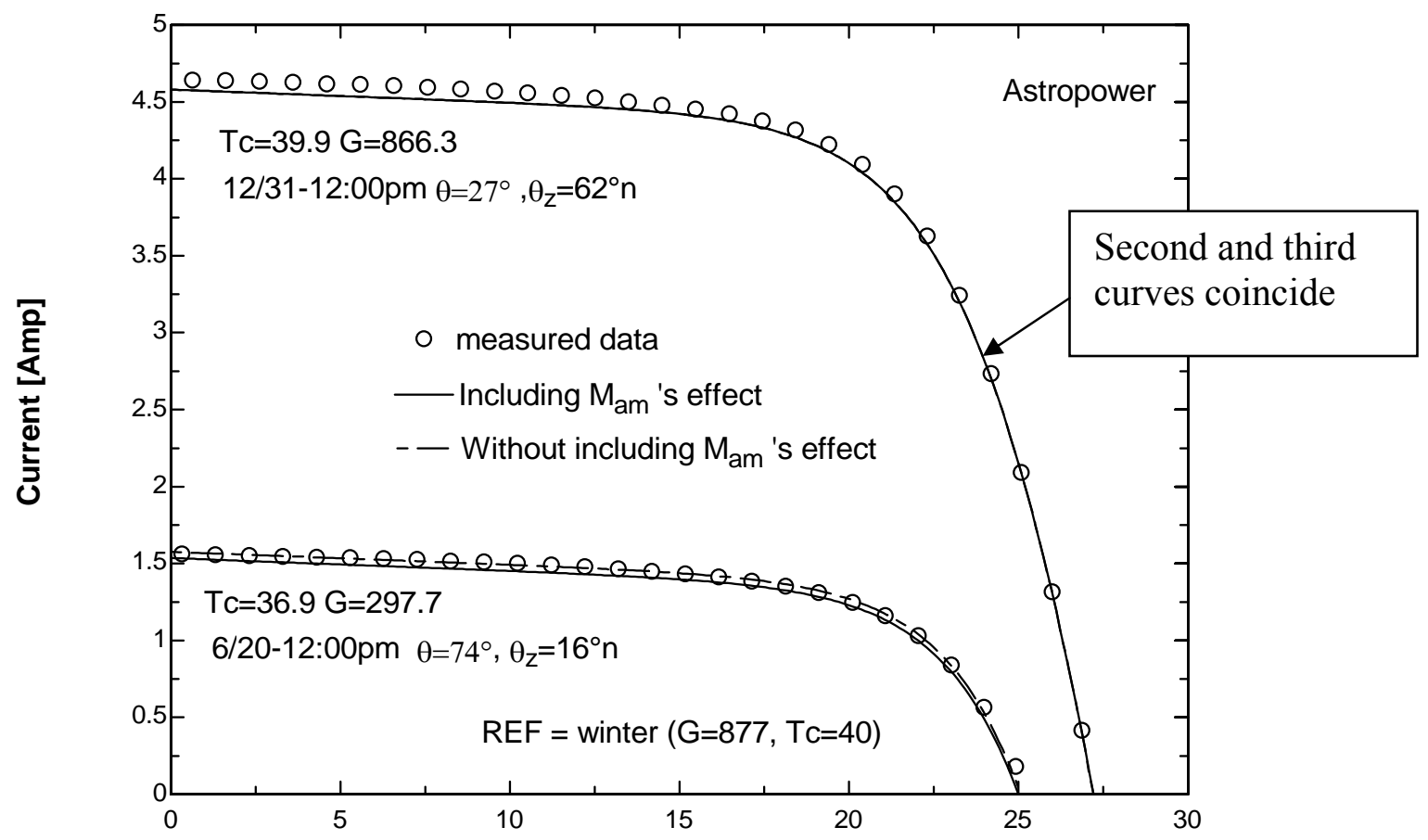

Voltage [V]

Figure 4.10: With and without taking in consideration $M_{a m}$ 's effect for Astropower cell type, using winter as ref conditions to predict summer and winter operating conditions

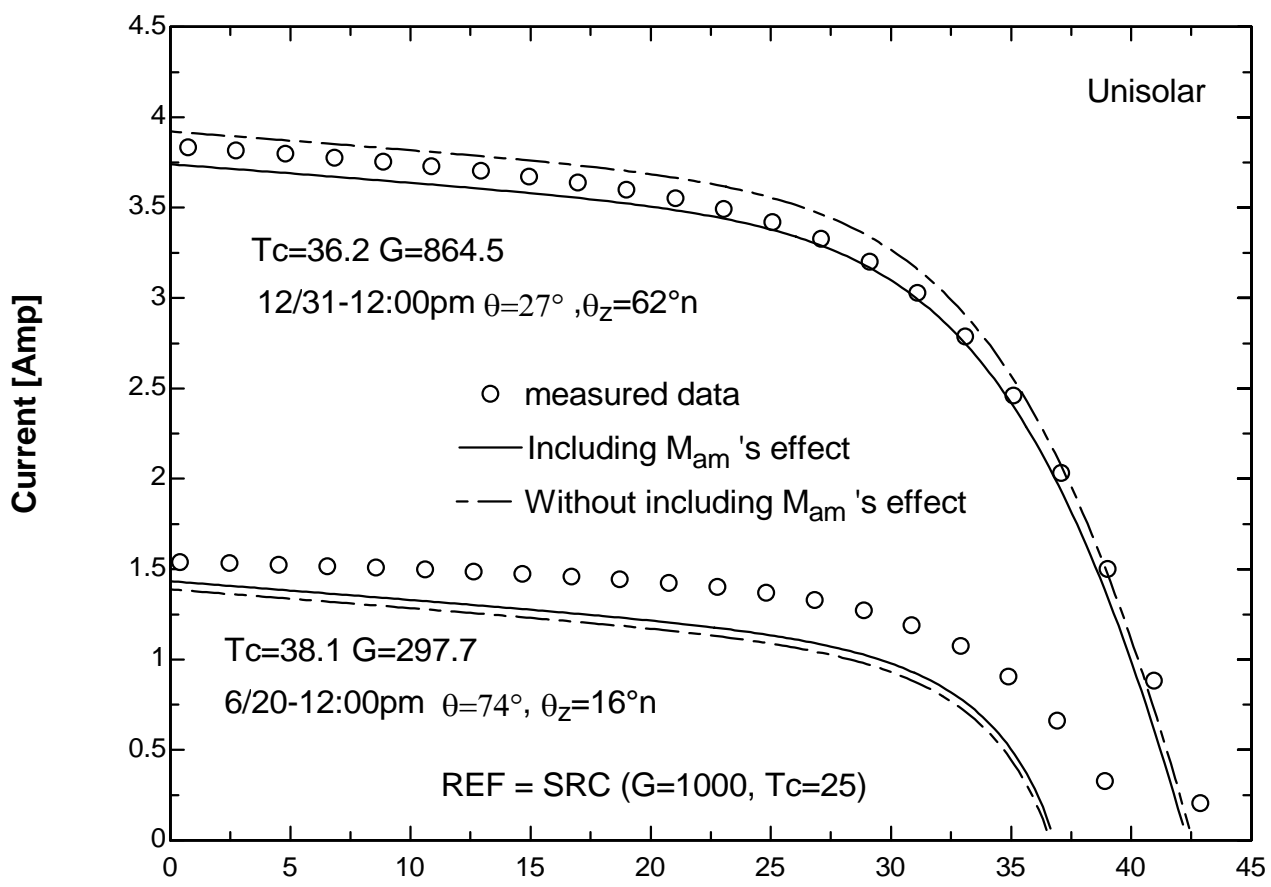

Voltage [V]

Figure 4.11: With and without taking in consideration $M_{a m}$ 's effect for Uni-Solar cell type, using SRC as ref conditions to predict summer and winter operating conditions 
The incidence angle and air mass effects greatly affect the performance of a PV cell, therefore Equation (4.4) should be the one used to correct the light current parameter $\left(I_{L}\right)$ when operating conditions different than SRC are present.

\subsection{Series resistance, $R_{s}$}

The series resistance $\left(R_{S}\right)$ parameter was observed to depend on the effective solar irradiance $\left(G_{e f f}\right)$ and the cell temperature $\left(T_{c}\right)$. It controls the location of the maximum power point, therefore controls the current and voltage at the maximum power point. Figure 4.12 shows that as the series resistance increases, the maximum power point moves down and to the left, decreasing the value of the current and voltage at the maximum power point. Note that the series resistance parameter does not affect the values of the short circuit current or the open circuit voltage.

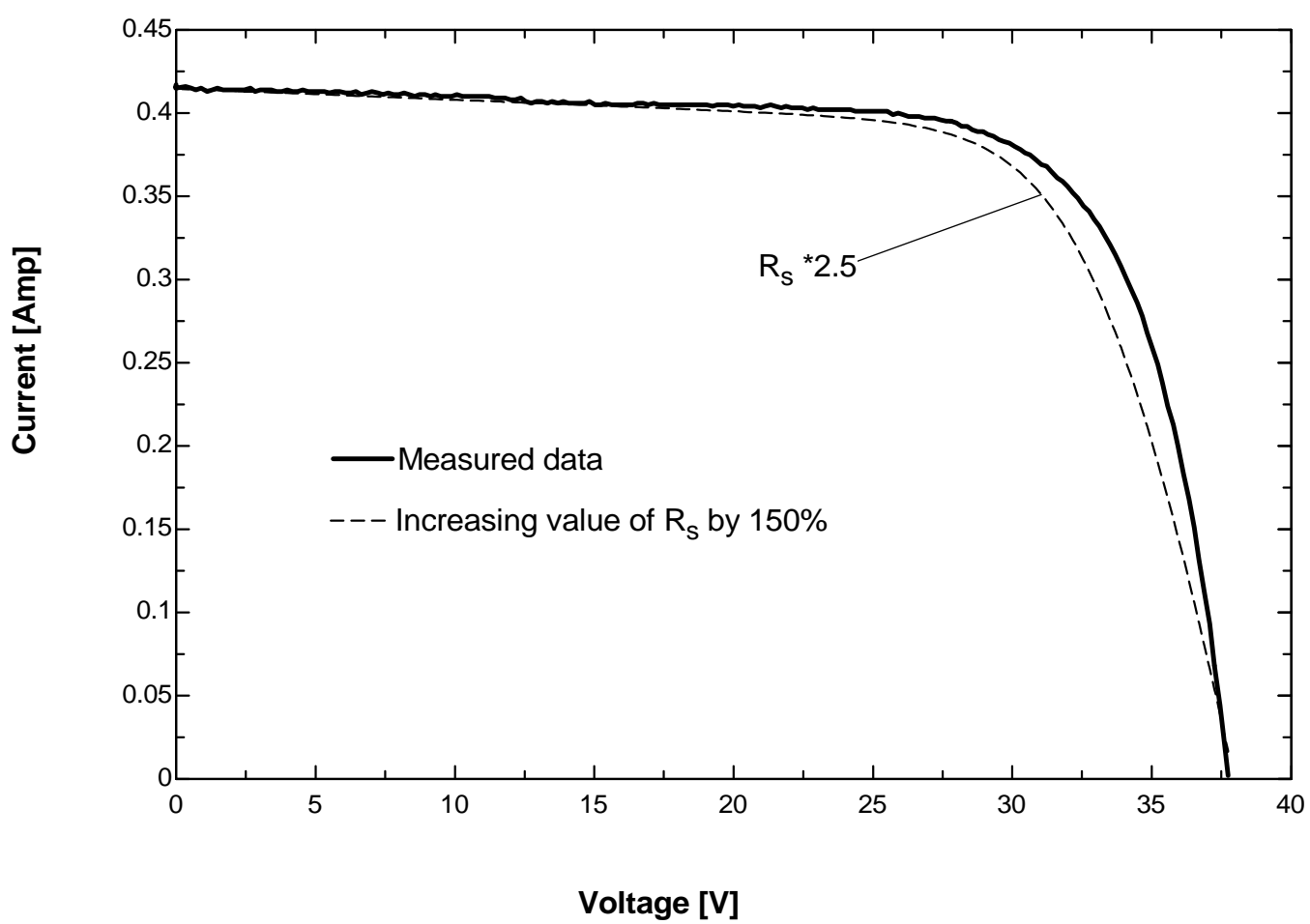

Figure 4.12: Effect of series resistance $\left(R_{s}\right)$ on the I-V curve 
In order to find an equation to correct for operating conditions other than SRC, some derivations are needed.

\subsubsection{Derivation of equation to correct $R_{S}$}

The five parameter model equation, Equation (4.7), was derived with respect to voltage, for the two possible cases (when $R_{s h}$ is assumed finite and when $R_{s h}$ is assumed infinite) and later evaluated at the maximum power point.

The five parameter model equation is:

$$
I=I_{L}-I_{o}\left(e^{\frac{V+I R_{s}}{a}}-1\right)-\frac{V+I R_{s}}{R_{s h}}
$$

The derivative of current with respect to voltage is:

$$
\frac{d I}{d V}=-I_{o} \frac{d}{d V}\left(e^{\frac{V+I R_{s}}{a}}-1\right)-\left[\frac{1}{R_{s h}}+\frac{d}{d V}\left(\frac{I R_{s}}{R_{s h}}\right)\right]
$$

For clarity, the derivative in the first term of Equation (4.8) is simplified separately:

$$
\frac{d}{d V}\left(e^{\frac{V+I R_{s}}{a}}-1\right)=\frac{d}{d V}\left(e^{\frac{V}{a}} e^{\frac{I R_{s}}{a}}-1\right)=e^{\frac{V}{a}} e^{\frac{I R_{s}}{a}} \frac{R_{s}}{a} \frac{d I}{d V}+e^{\frac{I R_{s}}{a}} e^{\frac{V}{a}} \frac{1}{a}
$$

After some algebraic rearrangement,

$$
\frac{d}{d V}\left(e^{\frac{V+I R_{s}}{a}}-1\right)=\frac{e^{\frac{V+I R_{s}}{a}}}{a}\left[R_{s} \frac{d I}{d V}+1\right]
$$

Substituting Equation (4.10) into Equation (4.8): 


$$
\frac{d I}{d V}=-\frac{I_{o} e^{\frac{V+I R_{s}}{a}}}{a}\left[R_{s} \frac{d I}{d V}+1\right]-\frac{1}{R_{s h}}-\frac{R_{s}}{R_{s h}} \frac{d I}{d V}
$$

Factoring common terms:

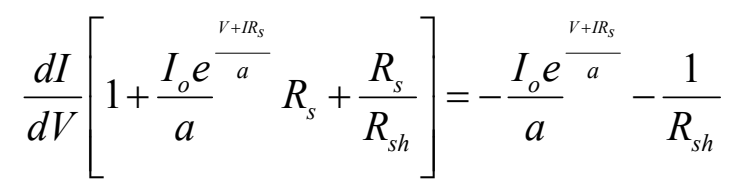

Solving for $d I / d V$ :

$$
\frac{d I}{d V}=\frac{\frac{-I_{o} e^{\frac{V+I R_{s}}{a}}}{a}-\frac{1}{R_{s h}}}{1+\frac{I_{o} e^{\frac{V+I R_{s}}{a}}}{a} R_{s}+\frac{R_{s}}{R_{s h}}}
$$

Assuming that $R_{s h} \rightarrow \infty$ and rearranging yields Equation (4.14)

$$
\left.\frac{d I}{d V}\right|_{\inf }=\frac{-1}{\frac{a}{I_{o}} e^{\frac{-\left(V+I R_{s}\right)}{a}}+R_{s}}
$$

Evaluating Equation (4.13) at the maximum power point results in:

$$
\left.\frac{d I}{d V}\right|_{m p}=\frac{\frac{-I_{o} e^{\frac{V_{m p}+I_{m p} R_{s}}{a}}}{a}-\frac{1}{R_{s h}}}{1+\frac{I_{o} e^{\frac{V_{m p}+I_{m p} R_{s}}{a}}}{a}} R_{s}+\frac{R_{s}}{R_{s h}}
$$

Evaluating Equation (4.14) at the maximum power point: 


$$
\left.\frac{d I}{d V}\right|_{\text {inf }, m p}=\frac{-1}{\frac{a}{I_{o}} e^{\frac{-\left({ }^{V_{m p}+I_{m p} R_{s}}\right)}{a}}+R_{s}}
$$

Equations (4.15) and (4.16) were solved numerically for $d I / d V_{m p}$ using data for the different cell types (poly-crystalline, mono-crystalline, etc.). Figure 4.13 shows the relationship between the derivative of current with respect to the voltage at the maximum power point $\left(d I / d V_{m p}\right)$ versus cell temperature for the case where the shunt resistance approaches infinity $\left(R_{s h} \rightarrow \infty\right)$, as well as for the case where it is considered finite. The graph shows that there is no obvious relationship between the cell temperature and $d I / d V_{m p}$. Figures 4.13 and 4.14 are representative of all cell types.

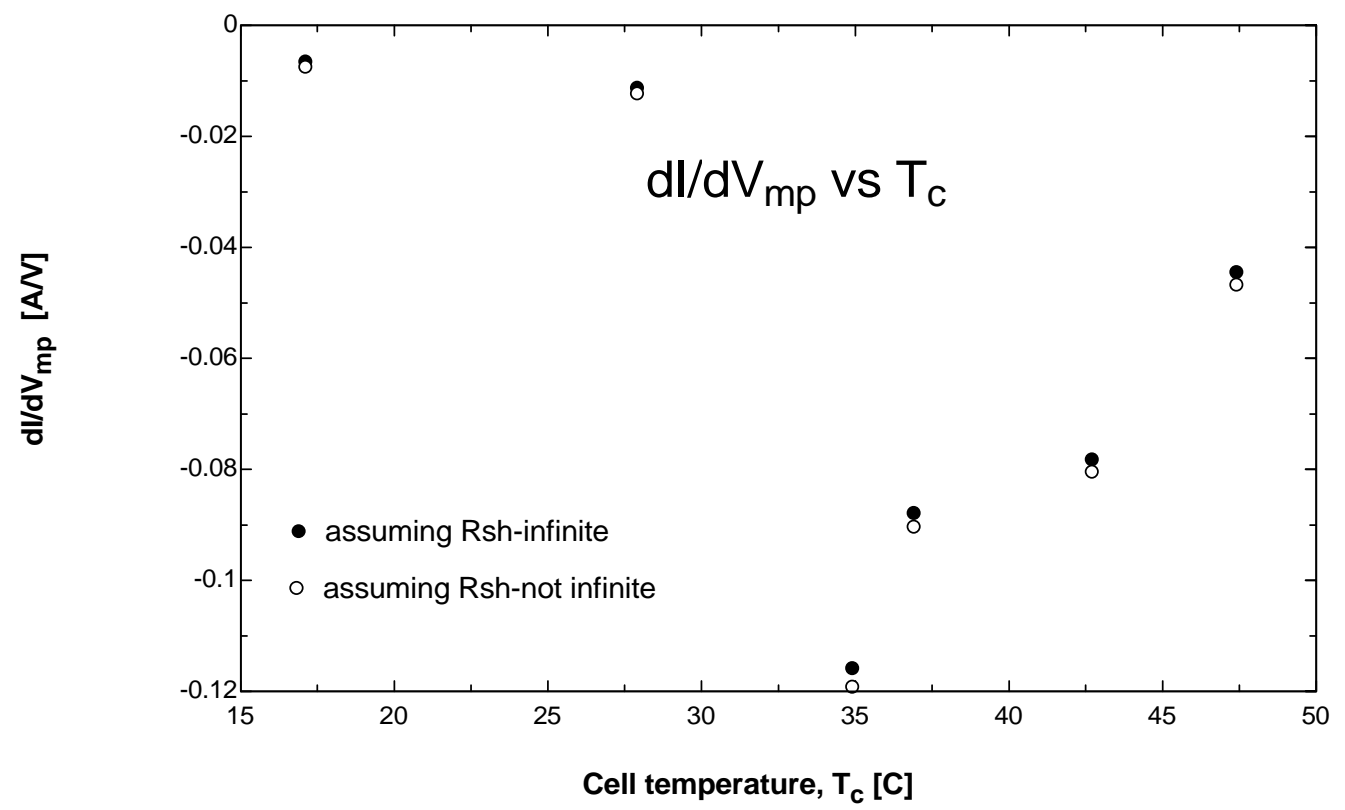

Figure 4.13: Derivative of current with respect to voltage at the maximum power point versus cell temperature, representative of all cell types

Figure 4.14 shows the relationship obtained for all cell types between the derivative of current with respect to the voltage at the maximum power point $\left(d I / d V_{m p}\right)$ 
and the effective irradiance for both cases $\left(R_{s h} \rightarrow \infty, R_{s h} \rightarrow\right.$ finite). The graph shows that there is a nearly linear relationship between the effective irradiance and $d I / d V_{m p}$. Figure 4.14 was plotted using data for the different cell types. Figure 4.15 shows the results obtained for Siemens, but representative of all cell types. It shows that the results obtained assuming $R_{s h}$ is infinite are very similar to the results obtained using the calculated value for $R_{s h}$.

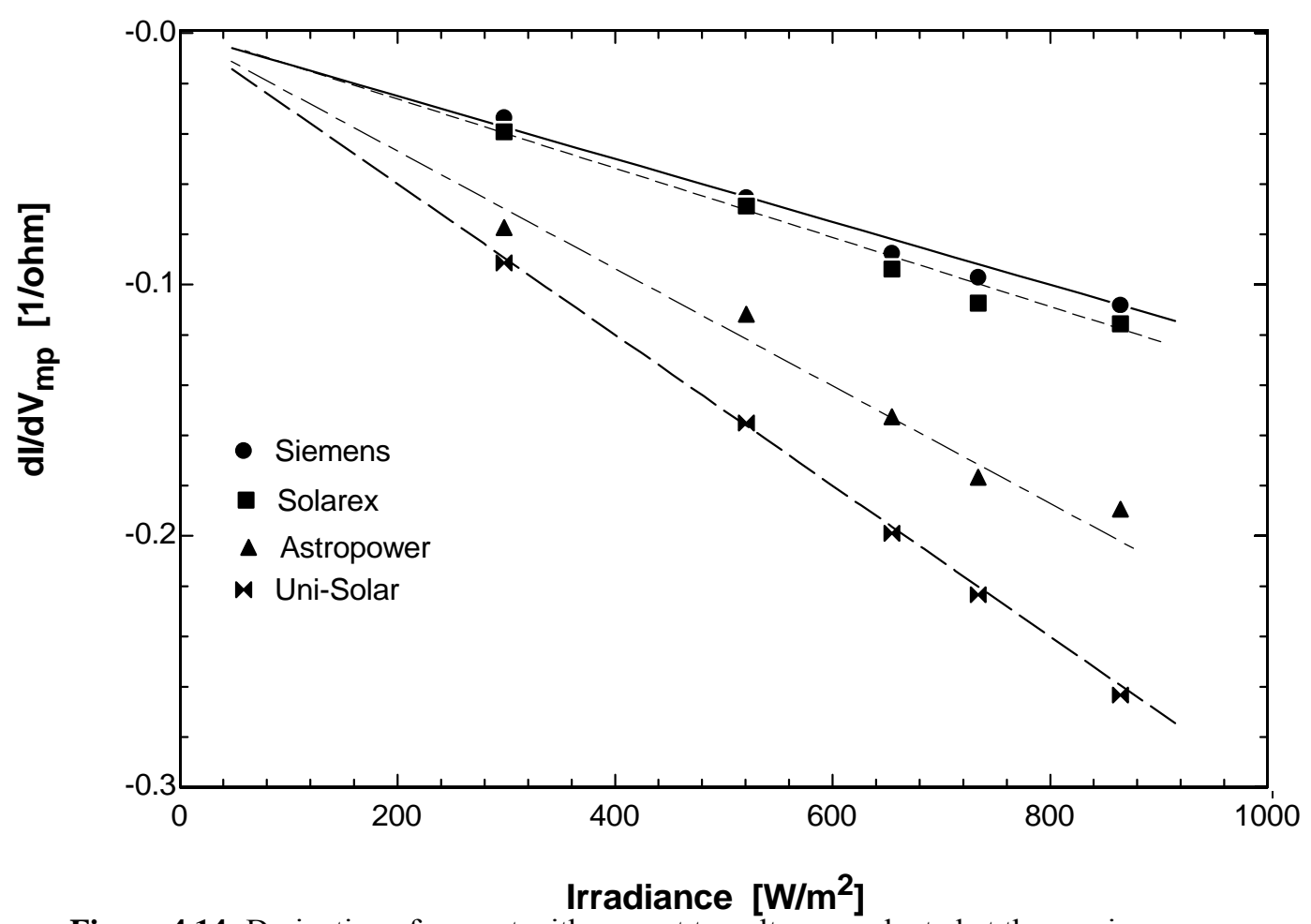

Figure 4.14: Derivative of current with respect to voltage, evaluated at the maximum power point versus irradiance for the different cell types. 


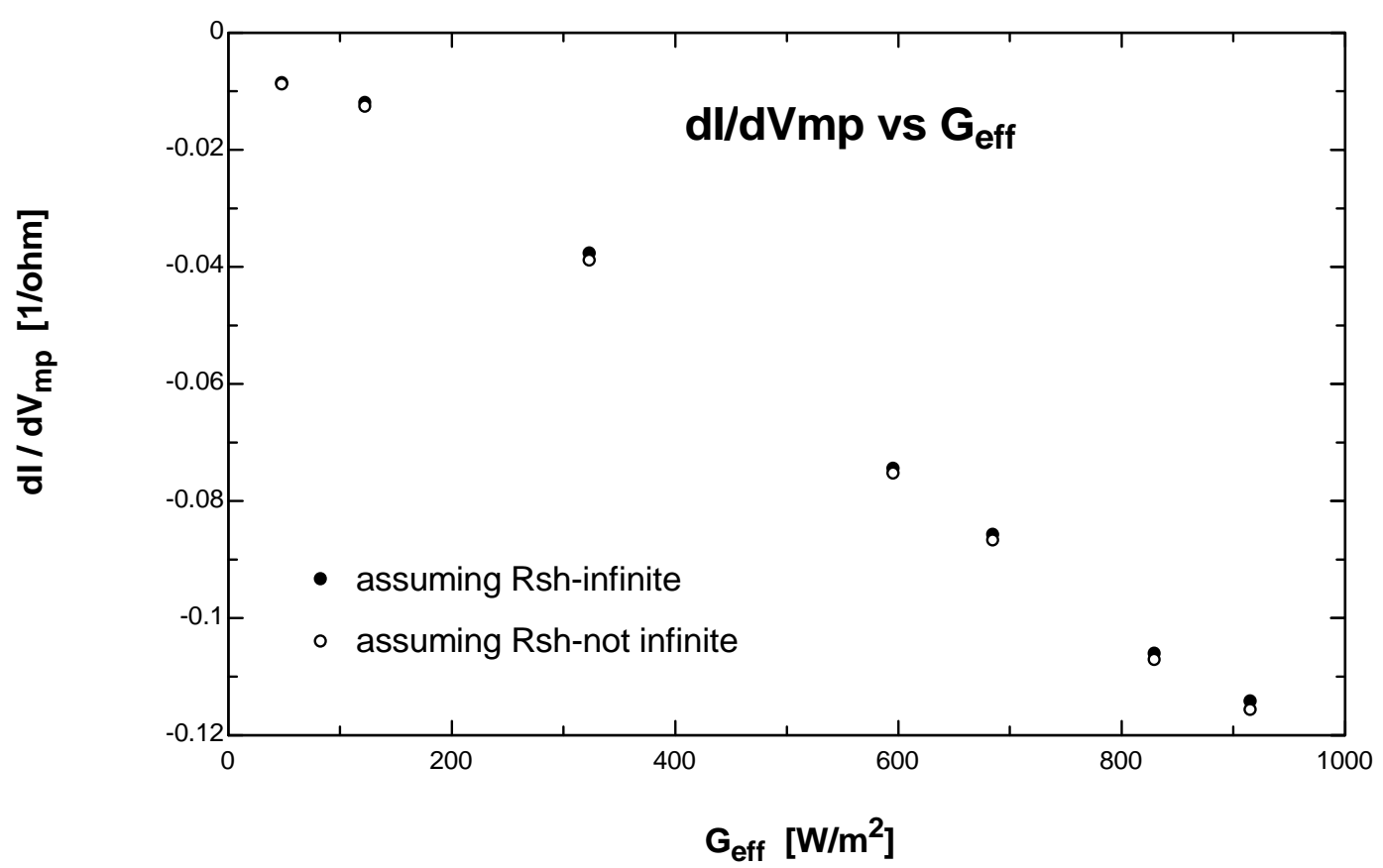

Figure 4.15: Derivative of current with respect to voltage at the maximum power point versus effective irradiance, representative of all cell types

Figure 4.15 was curve fitted with Equation (4.17):

$$
\frac{d I}{d V_{m p}}=0.00256286-0.000135351 \mathrm{G}_{\text {eff }}
$$

It is proposed that $d I / d V_{m p}$ is linearly dependent on solar radiation and that the slope is a constant, $C$, dependent only on cell type. The values obtained for the different cell technologies can be seen in Table 4.1. In this case, it can be established that for any operating conditions:

$$
\frac{d I}{d V_{\mathrm{inf}, m p}}=C G_{\text {eff }}=\frac{-1}{\frac{a}{I_{o}} e^{\left.\frac{-\left(V_{\text {mp }}+I_{m p} R_{s}\right.}{a}\right)}+R_{s}}
$$

and evaluating at the reference conditions: 


$$
\frac{d I}{d V_{\text {inf }, \text { } m p, r e f}}=C G_{e f f, r e f}=\frac{-1}{\frac{a_{r e f}}{I_{o, r e f}} e^{\frac{-\left(V_{m p, r e f+}+I_{m p, r e f} R_{s, r e f}\right)}{a_{r e f}}}+R_{s, r e f}}
$$

Table 4.1: Values of constant $C$ for different cell technologies

\begin{tabular}{|c|c|}
\hline Cell technology & Value of constant C \\
\hline Siemens & -0.000125209 \\
\hline Solarex & -0.000126515 \\
\hline Astropower & -0.000201387 \\
\hline Uni-Solar & -0.000300081 \\
\hline
\end{tabular}

For a specific type of cell, $C$ is a constant and its value does not change regardless of the weather or operating conditions used. We can therefore solve for $C$ in Equations (4.18) and (4.19) and set them equal to each other.

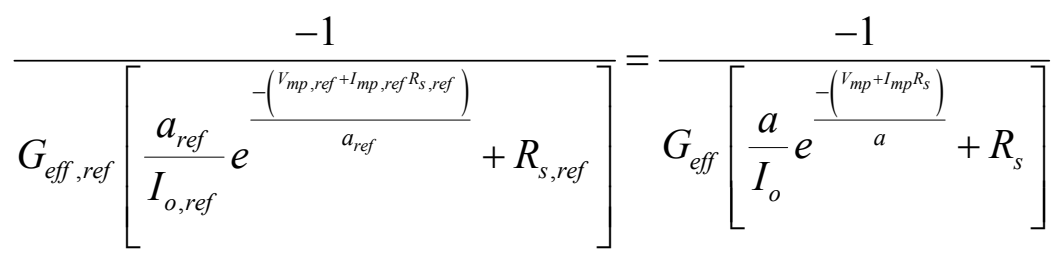

Rearranging Equation (4.20),

$$
\frac{G_{e f f}}{G_{e f f, r e f}}=\frac{\frac{a_{r e f}}{I_{o, r e f}} e^{\frac{-\left(V_{m p, r e f}+I_{m p, r e f} R_{s, r e f}\right.}{a_{r e f}}}+R_{s, r e f}}{\frac{a}{I_{o}} e^{\left.\frac{-\left(V_{m p}+I_{m p} R_{s}\right.}{a}\right)}+R_{s}}
$$

If the shunt resistance is assumed to be a finite number, Equation (4.22) can be used. 


$$
\frac{G_{e f f}}{G_{e f f, r e f}}=\frac{\left[\frac{-I_{o} / a \exp \left[\left(V_{m p}+I_{m p} R_{s}\right) / a\right]-1 / R_{s h}}{1+I_{o} R_{s} / a \exp \left[\left(V_{m p}+I_{m p} R_{s}\right) / a\right]+R_{s} / R_{s h}}\right]}{\left[\frac{-I_{o, r e f} / a_{r e f} \exp \left[\left(V_{m p, r e f}+I_{m p, r e f} R_{s, r e f}\right) / a_{r e f}\right]-1 / R_{s h, r e f}}{1+I_{o, r e f} R_{s, \text { ref }} / a_{r e f} \exp \left[\left(V_{m p, r e f}+I_{m p, r e f} R_{s, r e f}\right) / a_{r e f}\right]+R_{s, r e f} / R_{s h, r e f}}\right]}
$$

The results obtained using either Equation (4.21) or Equation (4.22) are very close, therefore for simplicity, Equation (4.21) will be used for this study.

Equation (4.21) will be referred to as the correcting equation for $R_{s}$. Figures 4.16 and 4.17 show the difference obtained in the maximum power point prediction when using $R_{s}=R_{s, r e f}$ (Figure 4.16) versus $R_{s}$ calculated from Equation (4.21) (Figure 4.17) for the Siemens cell type. Very similar results are obtained for the other cell types, and therefore are not presented.

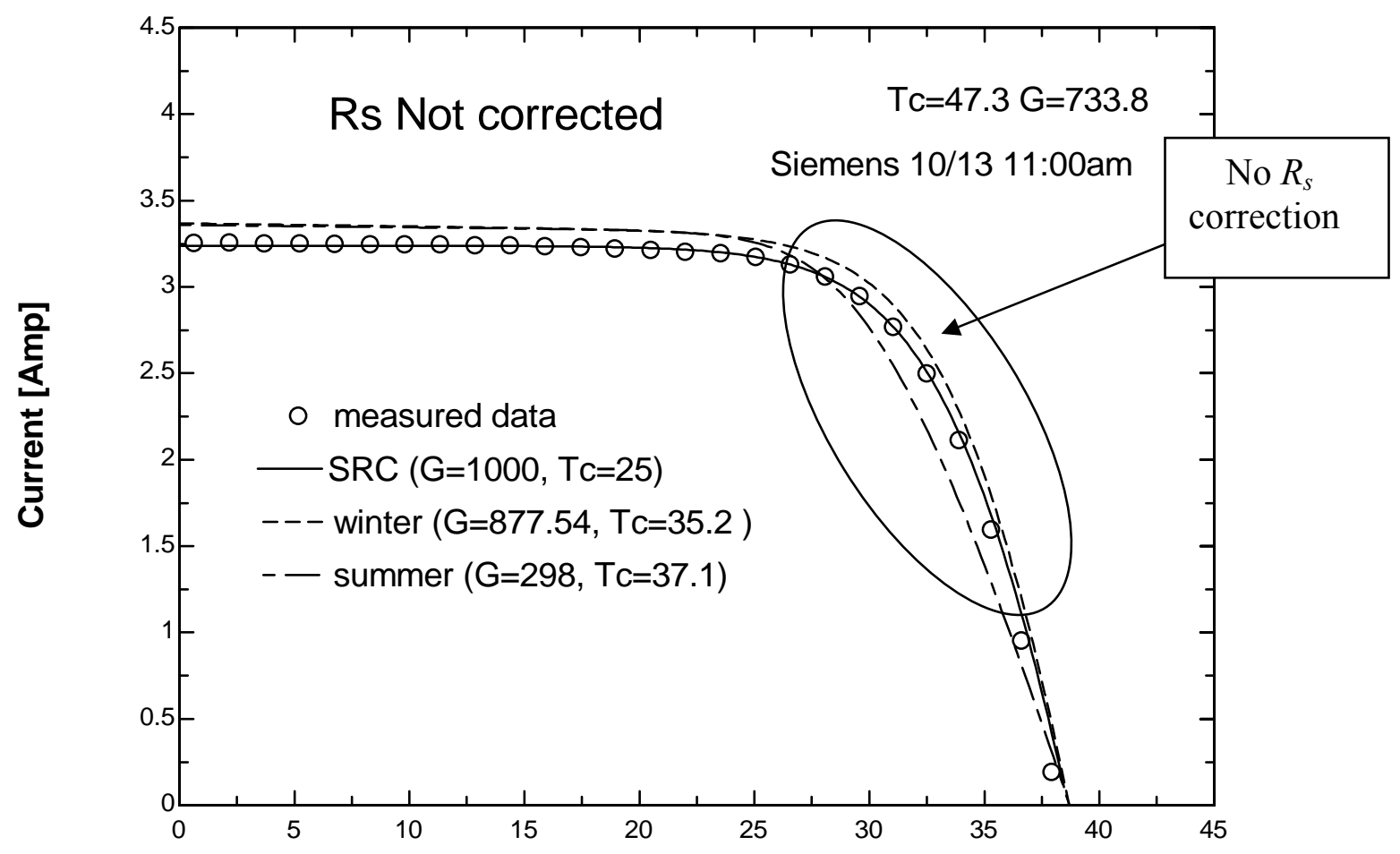

\section{Voltage [V]}

Figure 4.16: I-V curve for Siemens, October 13 at 11:00am, using different references (SRC, winter, and summer), without correcting series resistance, $R_{s}$ 


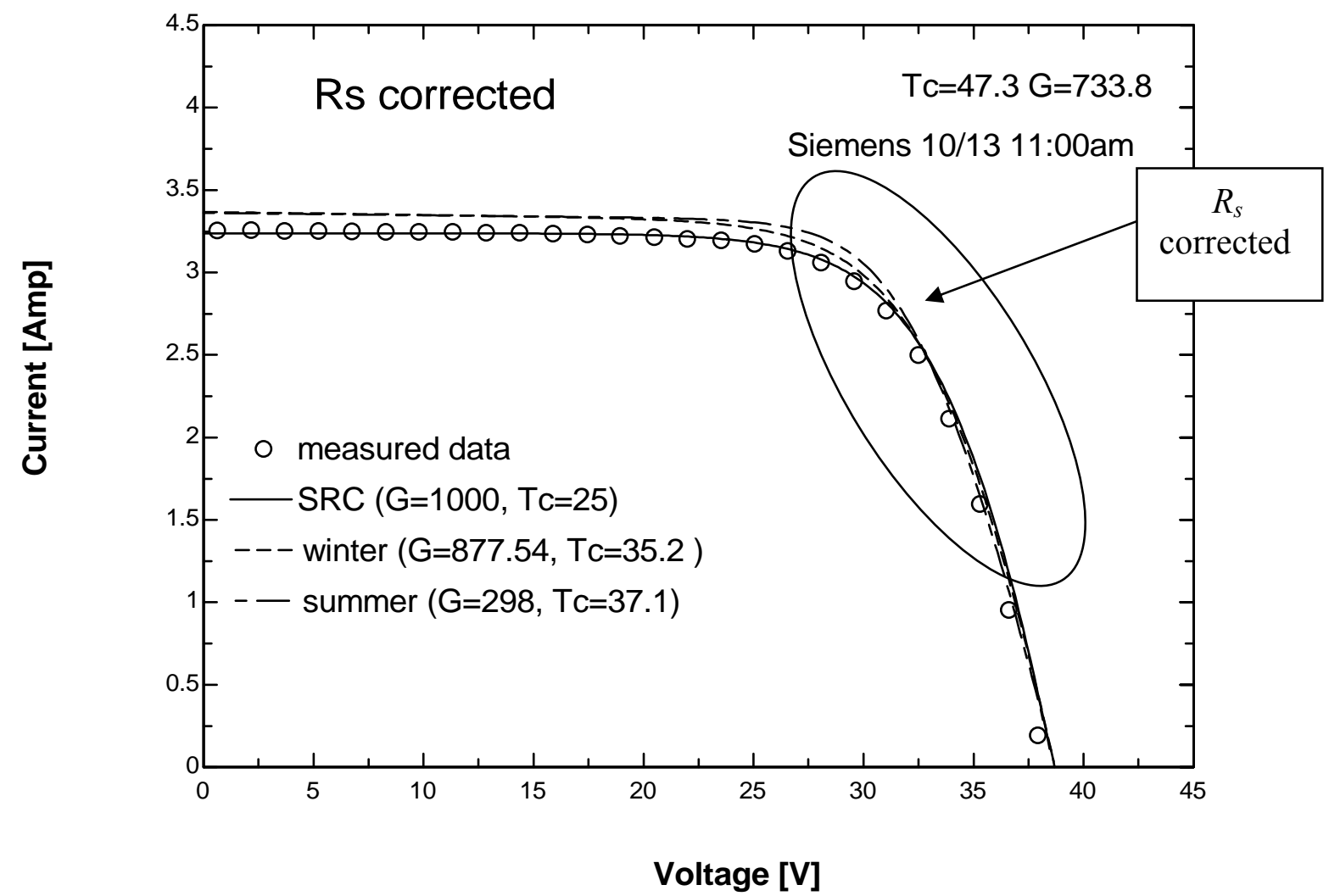

Figure 4.17: I-V curve for Siemens, October 13 at 11:00am, using different references (SRC, winter, and summer), correcting series resistance parameter, $R_{s}$

Figures 4.18 and 4.19 show different series resistance $\left(R_{S}\right)$ values obtained with the 5-Parameter model, (using the series resistance correcting equation, Equation (4.21)), and using SRC as reference conditions. The graphs show how the series resistance values vary with the irradiance and temperature. The irradiance dependence can easily be seen in Equation (4.21) and the temperature dependence is incorporated in the $V_{m p}$ and $I_{m p}$ values used, present in Equation (4.21). The $V_{m p}$ and $I_{m p}$ values are temperature dependent because they are calculated using the 5-Parameter model, which takes in consideration the temperature difference between the reference temperature of $25{ }^{\circ} \mathrm{C}$ and the measured temperature, present in the $I_{o}, I_{L}$, and $a$ parameters. Figures 4.18 and 4.19, although pertaining to the Siemens cell type, are typical for all the other cell types. 


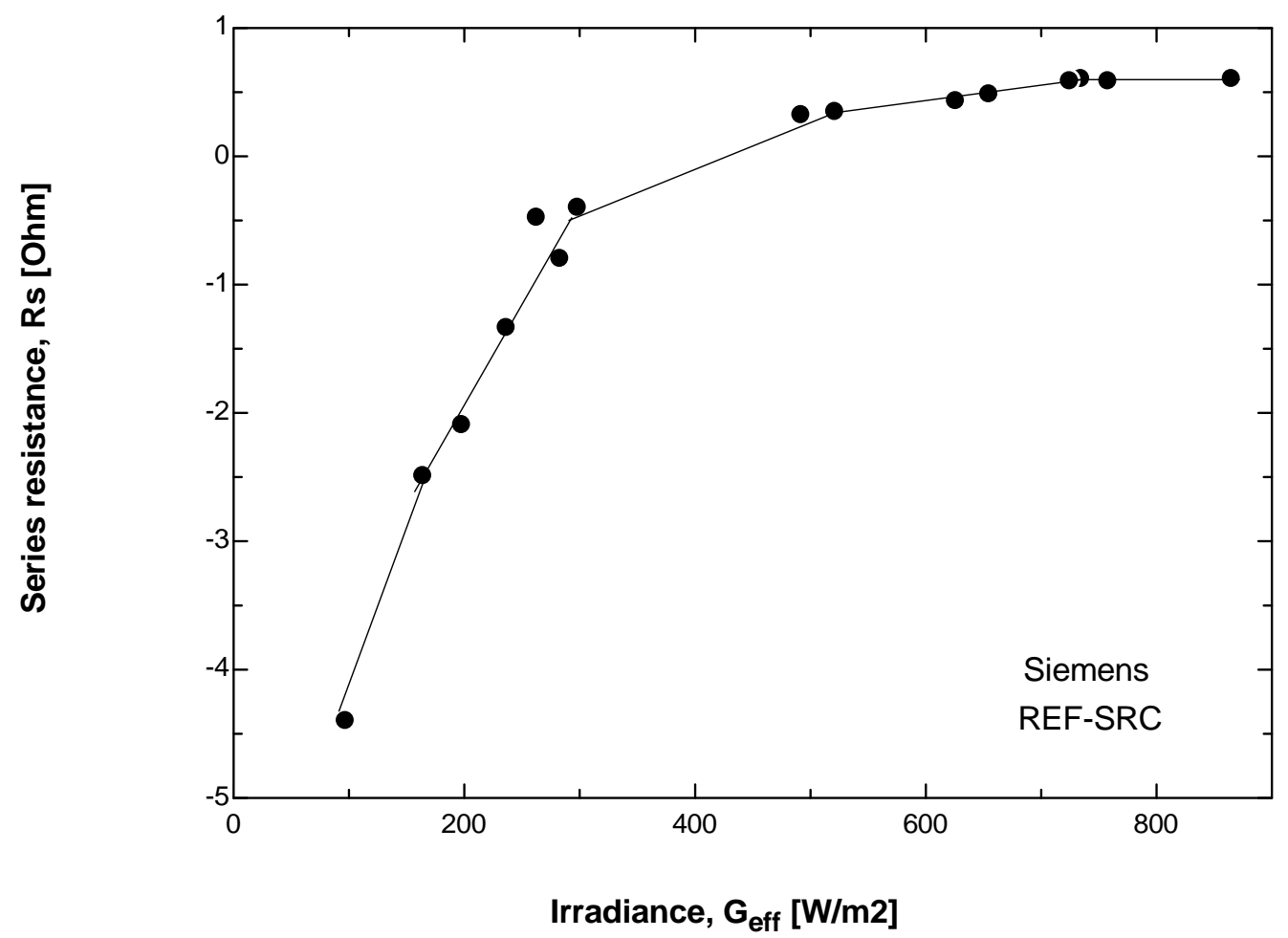

Figure 4.18: Series resistance, $R_{s}$, versus irradiance, $G$, for Siemens cell type, using SRC as reference

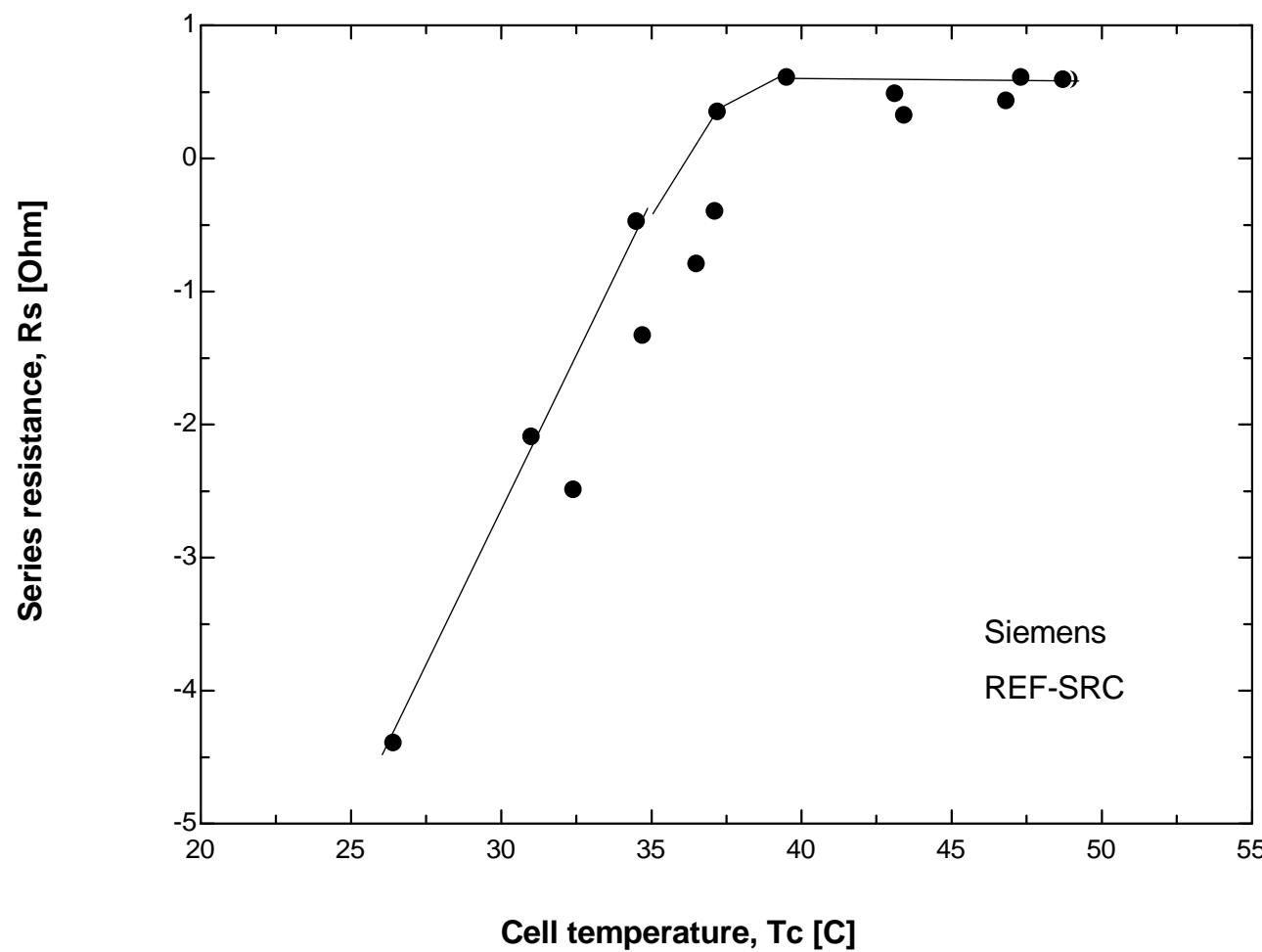

Figure 4.19: Series resistance, $R_{s}$, versus cell temperature, $T_{c}$, for Siemens cell type, using SRC as reference 
The measured $I_{m p}$ and $V_{m p}$ values provided by NIST were plotted versus

irradiance and cell temperature to determine the possibility of a correlation between these variables. Figures 4.20-4.23 show the results obtained.

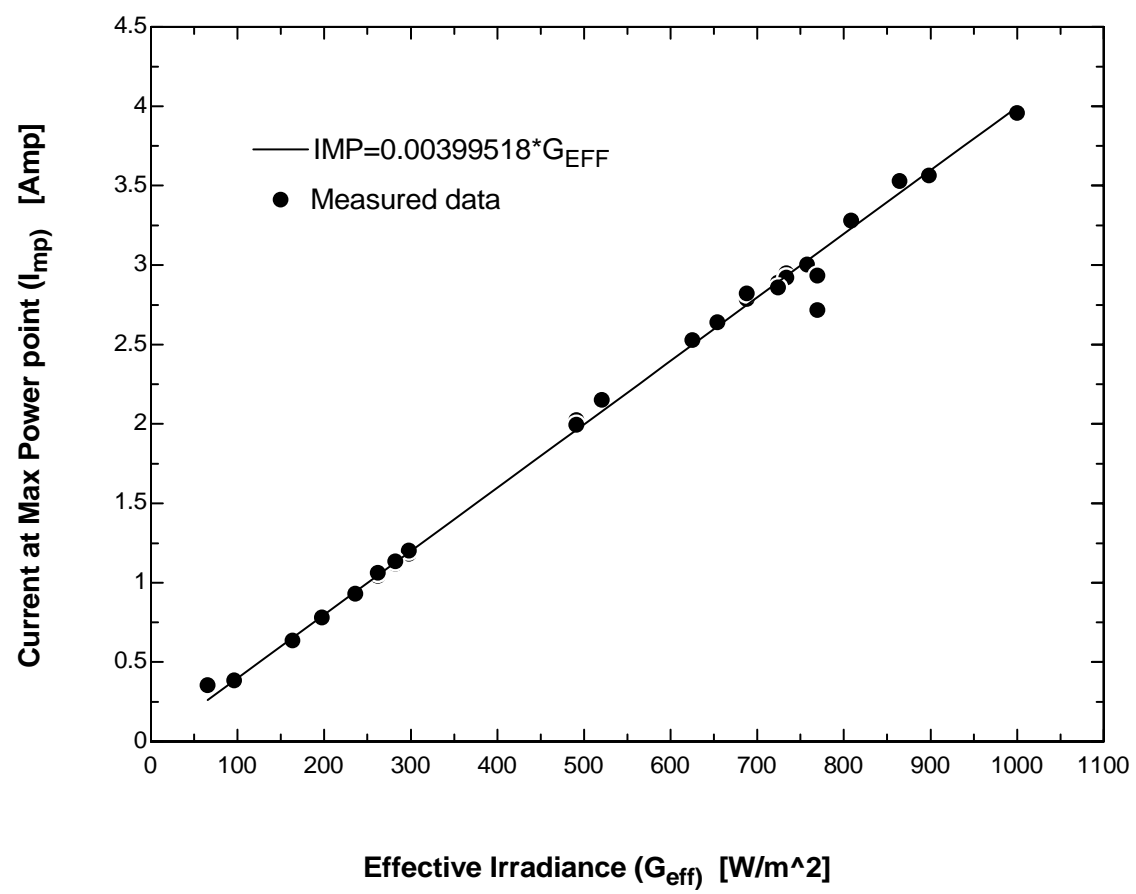

Figure 4.20: Current at maximum power point $\left(I_{m p}\right)$ versus effective irradiance $\left(G_{\text {eff }}\right)$

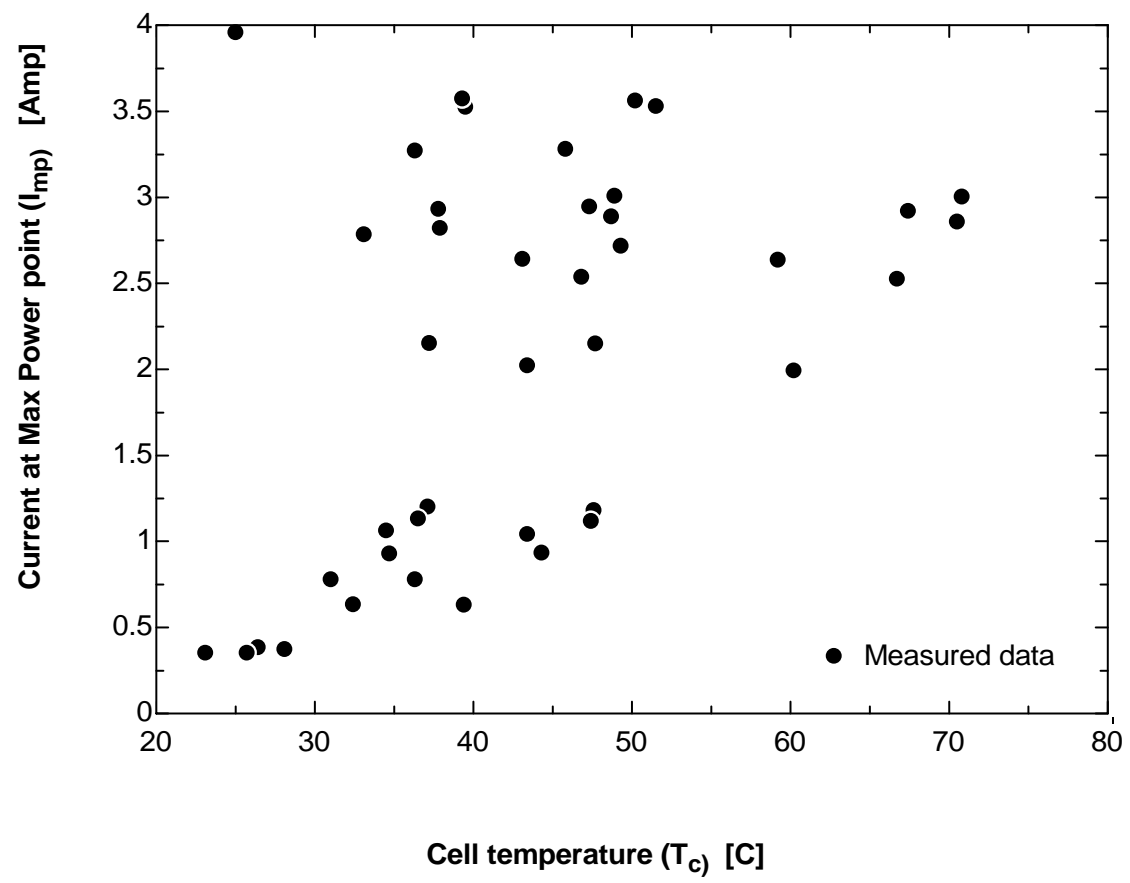

Figure 4.21: Current at maximum power point $\left(I_{m p}\right)$ versus cell temperature $\left(T_{c}\right)$ 


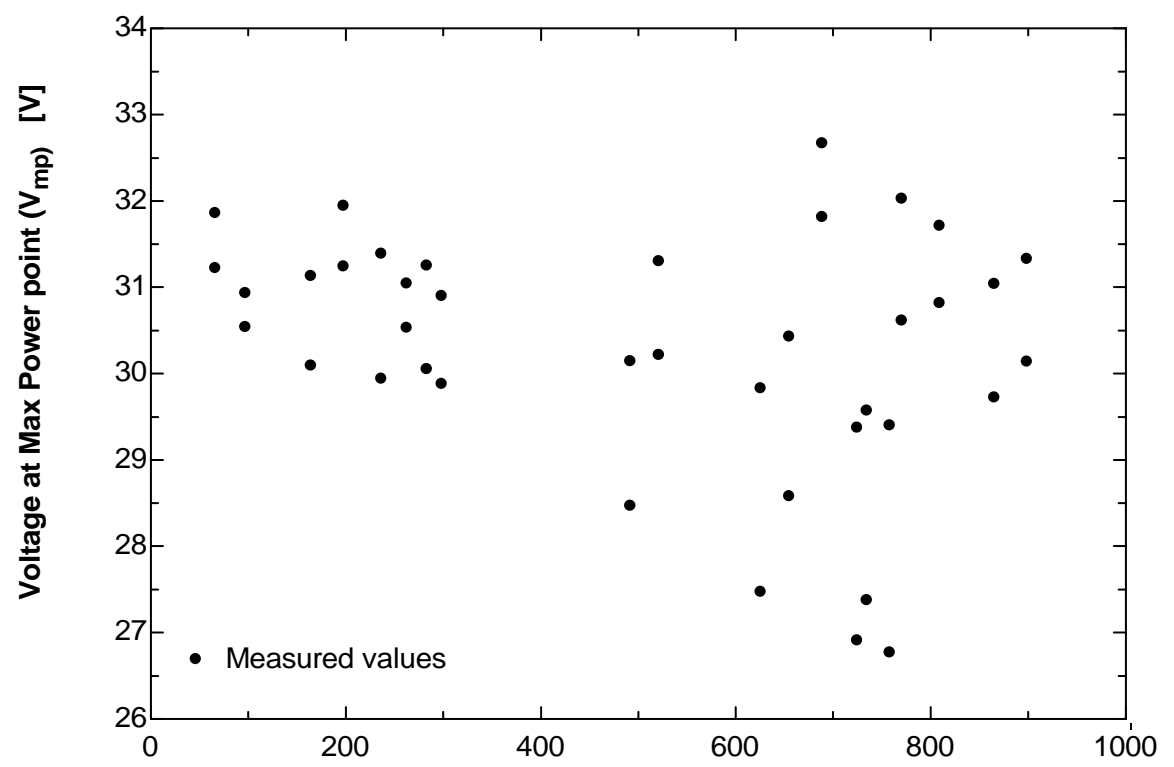

Effective Irradiance $\left(\mathbf{G}_{\text {eff }}\left[\mathbf{W} / \mathbf{m}^{\wedge} \mathbf{2}\right]\right.$

Figure 4.22: Voltage at maximum power point $\left(V_{m p}\right)$ versus effective irradiance $\left(G_{\text {eff }}\right)$

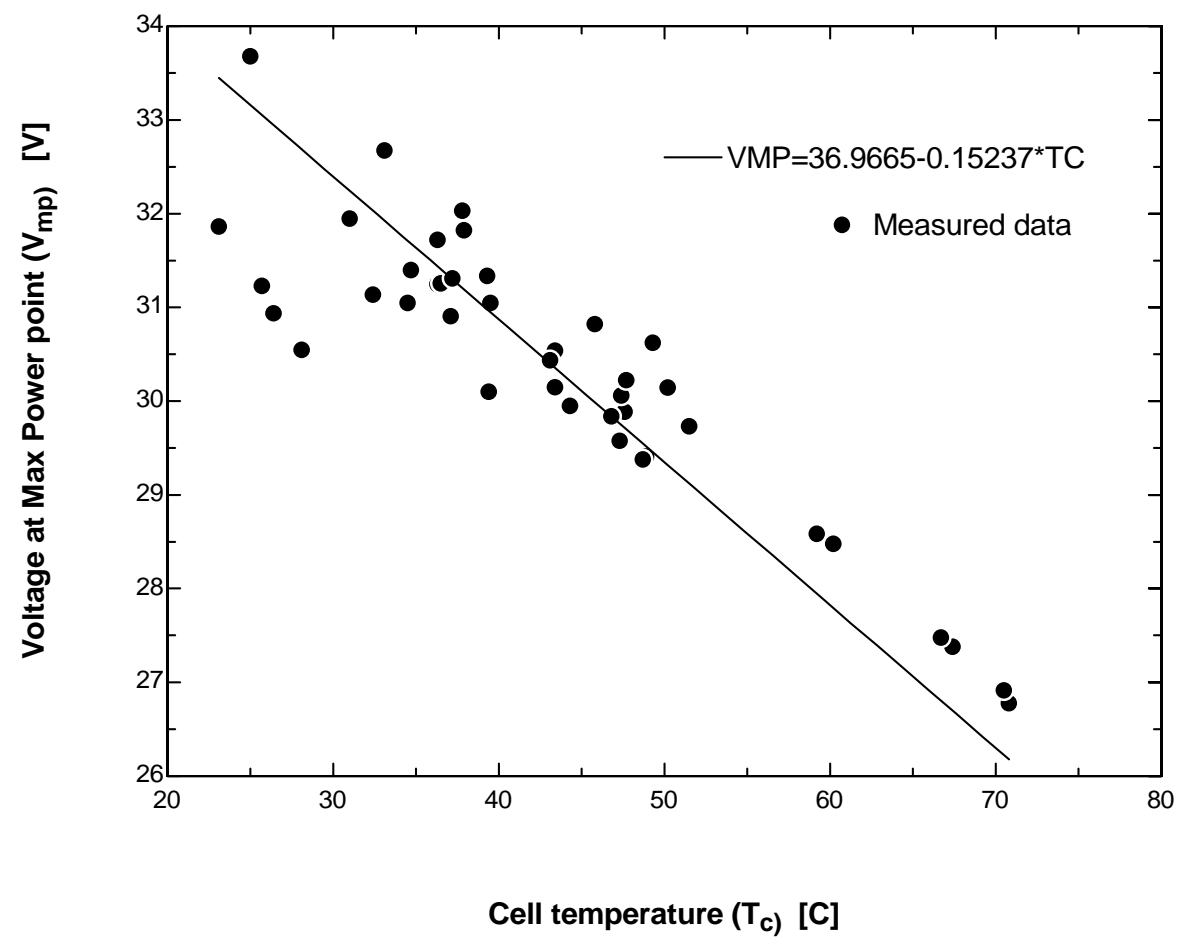

Figure 4.23: Voltage at maximum power point $\left(V_{m p}\right)$ versus cell temperature $\left(T_{c}\right)$

Although Figures 4.20-4.23 were obtained for the Siemens cell type, they are representative of all cell types. Figures 4.21 and 4.22 show that there is no visible 
relationship between the variables being compared, while Figures 4.20 and 4.23

demonstrate the existence of a nearly linear relationship between the current at maximum power point and the effective irradiance (also shown by King, 1996) and the voltage at the maximum power point and the cell temperature. The data were curve fitted for these two cases, obtaining linear equations which were then used to find correlations for the current and voltage at the maximum power point. Equation (4.23) shows the form of the equation that relates the current at maximum power with the effective irradiance.

$$
\mathrm{I}_{m p}=e G_{e f f}
$$

where $I_{m p}$ is the current at maximum power, $G_{\text {eff }}$ is the effective irradiance, and $e$ is a constant. To determine the current at the maximum power point, $G_{\text {eff }}$ is substituted with $G_{\text {eff,ref }}$ and $I_{m p}$ with $I_{m p, r e f}$, obtaining Equation (4.24).

$$
\mathrm{I}_{m p, r e f}=e G_{e f f, r e f}
$$

We can therefore solve for $e$ in Equations (4.23) and (4.24) and set them equal to each other. After rearranging, Equation (4.25) is obtained.

$$
I_{m p}=I_{m p, r e f} \frac{G_{e f f}}{G_{e f f, r e f}}
$$

Figure 4.23 shows that the relationship between the voltage at the maximum power point and the cell temperature can be assumed to be linear, yielding Equation (4.26).

$$
V_{m p}=a+b T_{c}
$$


where $V_{m p}$ is the voltage at maximum power, $T_{c}$ is the cell temperature $a$ and $b$ are constants. To find the voltage at the maximum power point for the reference condition, $T_{c}$ is substituted with $T_{c, \text { ref }}$ and $V_{m p}$ with $V_{m p, r e f}$, obtaining Equation (4.27).

$$
V_{m p, r e f}=a+b T_{c, \text { ref }}
$$

If Equations (4.26) and (4.27) are subtracted and rearranged, Equation (4.28) is obtained.

$$
V_{m p}=V_{m p, r e f}+b\left(T_{c}-T_{c, \text { ref }}\right)
$$

The value of the constant $b$ was observed to be very close to the value of the coefficient of temperature of the open circuit voltage $\left(\beta_{V o c}\right)$, therefore if substituted, Equation (4.28) becomes:

$$
V_{m p}=V_{m p, r e f}+\beta_{V o c}\left(T_{c}-T_{c, r e f}\right)
$$

Usually $V_{m p}$ and $I_{m p}$ at some specified operating conditions (needed for Equation (4.21)) will not be known but they can be determined from Equations (4.25) and (4.29).

Figures 4.24-4.31 show the results obtained with the previously described method for each cell type (Solarex, Siemens, Astropower, and Uni-Solar). The data provided by NIST for SRC conditions were used as reference in Figures 4.24-4.27, while Figures 4.28-4.31 were obtained using winter reference conditions. 


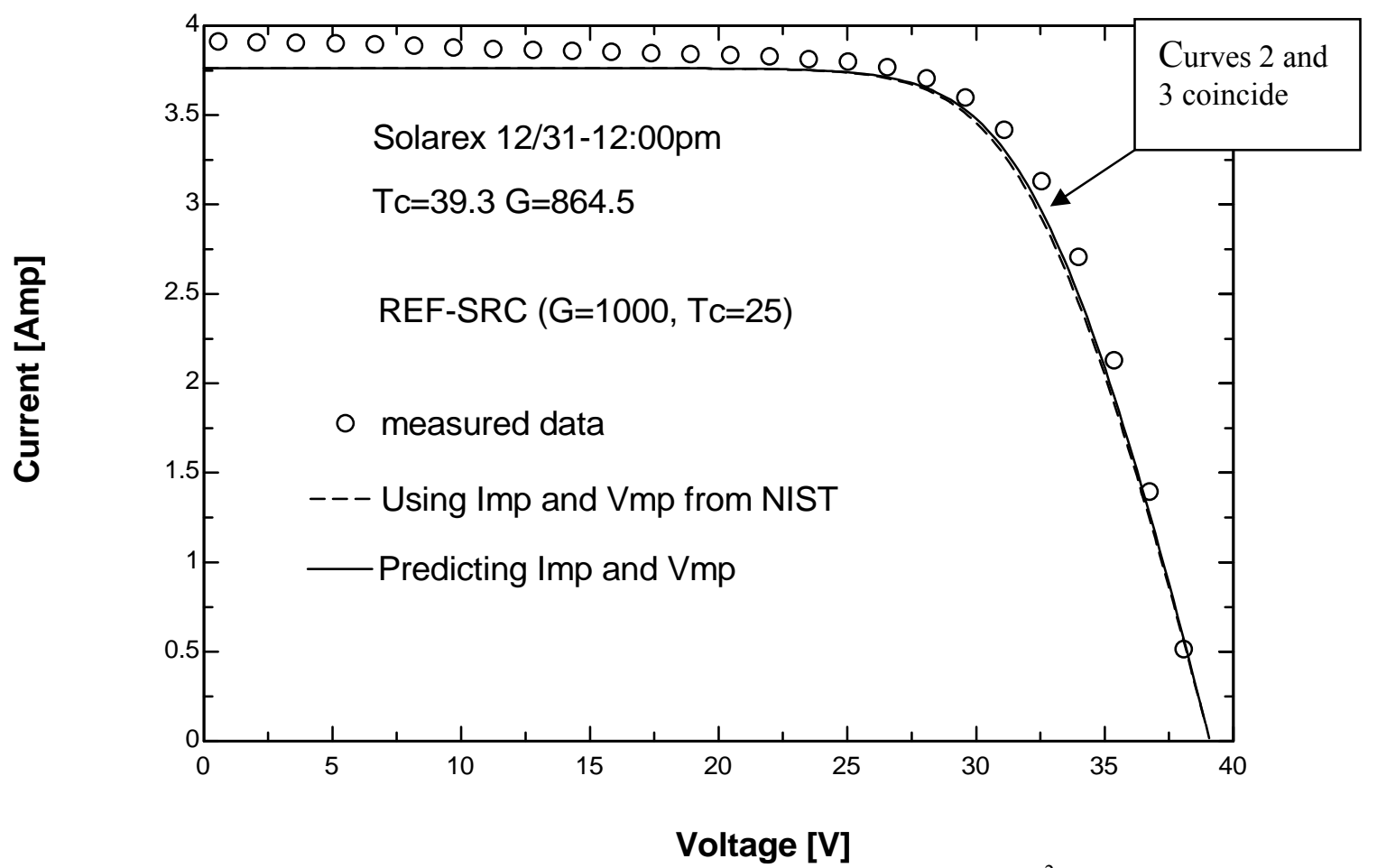

Figure 4.24: Solarex cell type, December 31 at noon, $T_{c}=39.3^{\circ} \mathrm{C}, G_{\text {eff }}=864.5 \mathrm{~W} / \mathrm{m}^{2}$, using SRC as reference

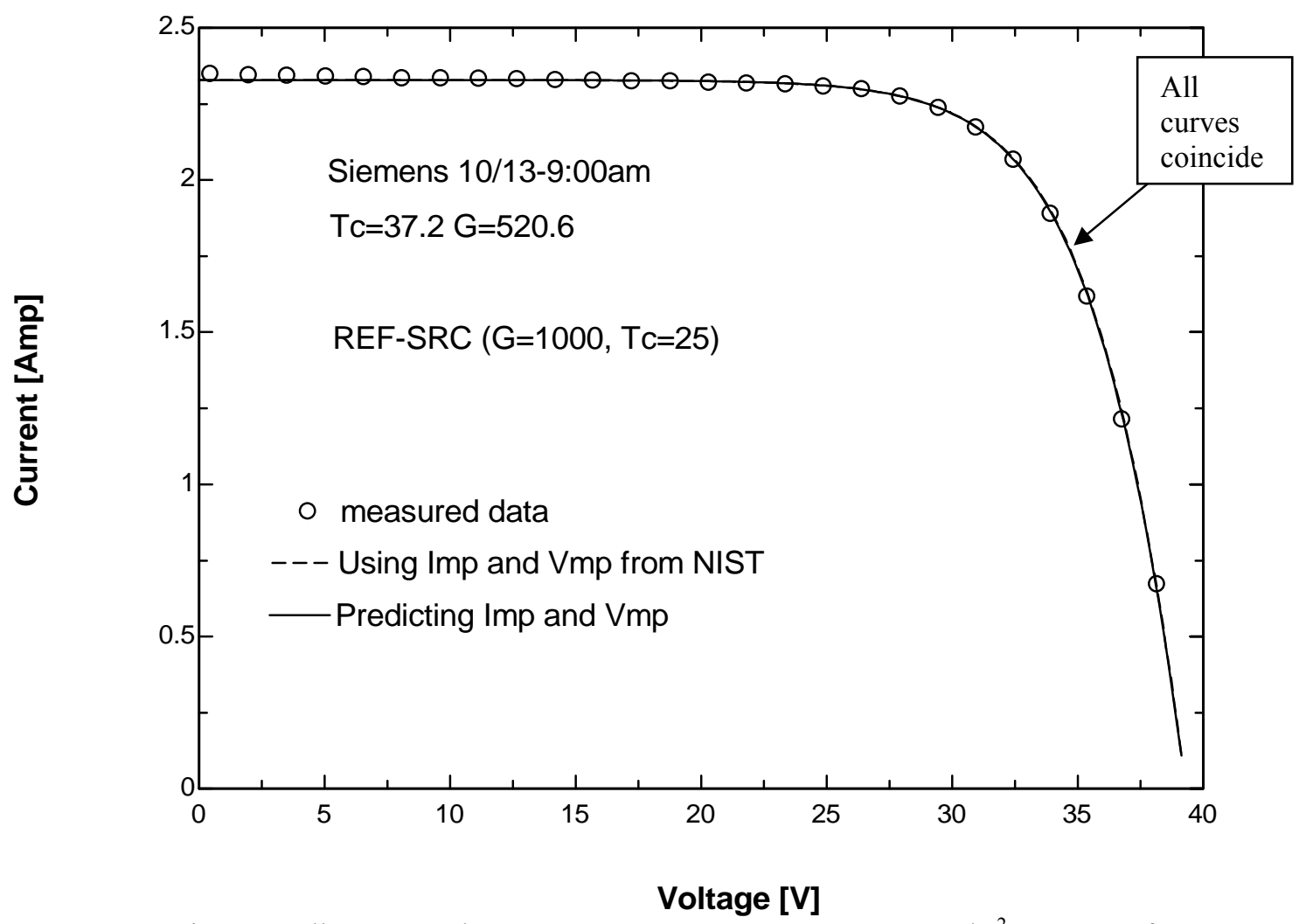

Figure 4.25: Siemens cell type, October 13 at noon, $T_{c}=37.2^{\circ} \mathrm{C}, G_{e f f}=520.6 \mathrm{~W} / \mathrm{m}^{2}$, SRC as reference 


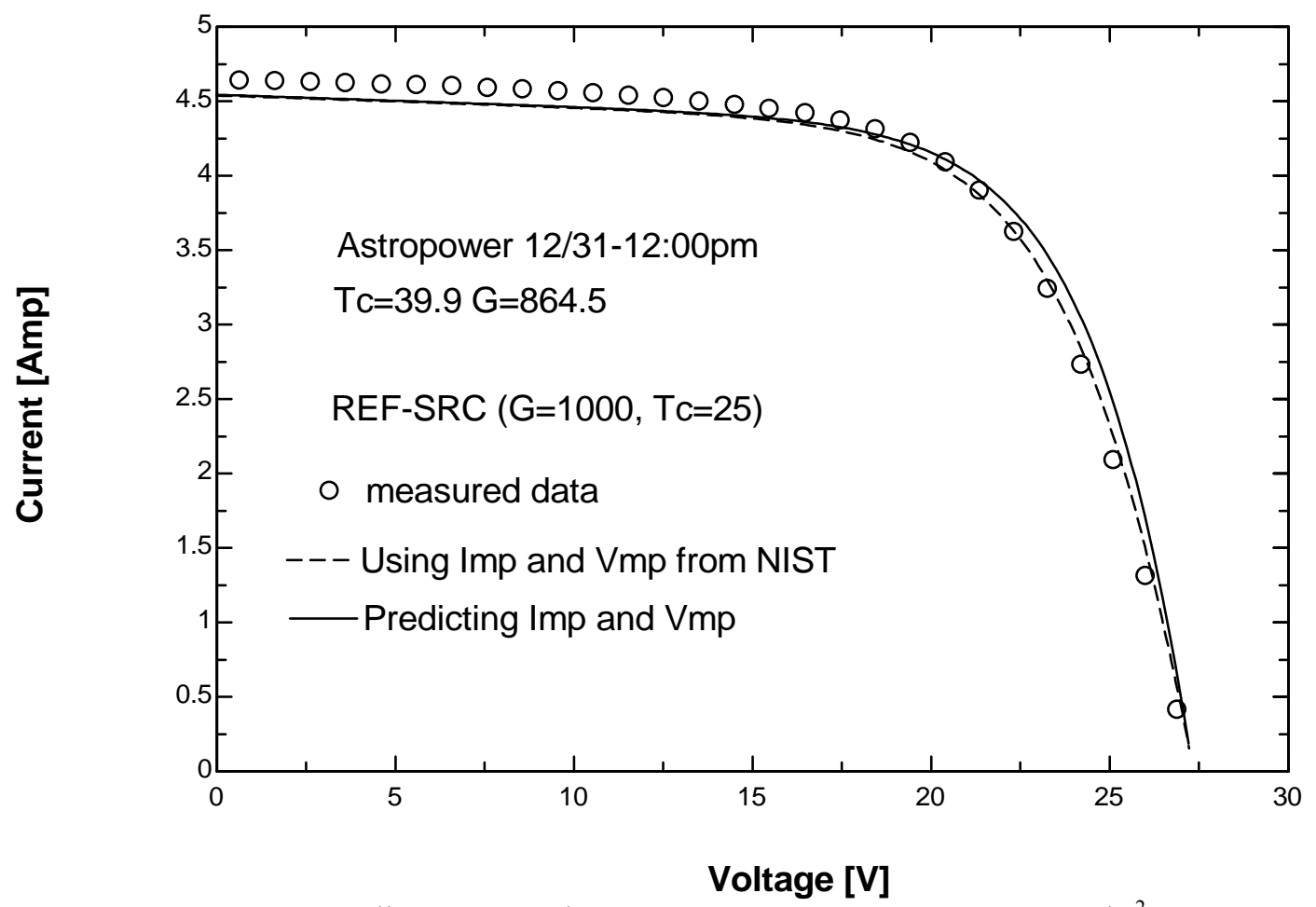

Figure 4.26: Astropower cell type, December 31 at noon, $T_{c}=39.9^{\circ} \mathrm{C}, G_{e f f}=864.5 \mathrm{~W} / \mathrm{m}^{2}$, SRC as reference

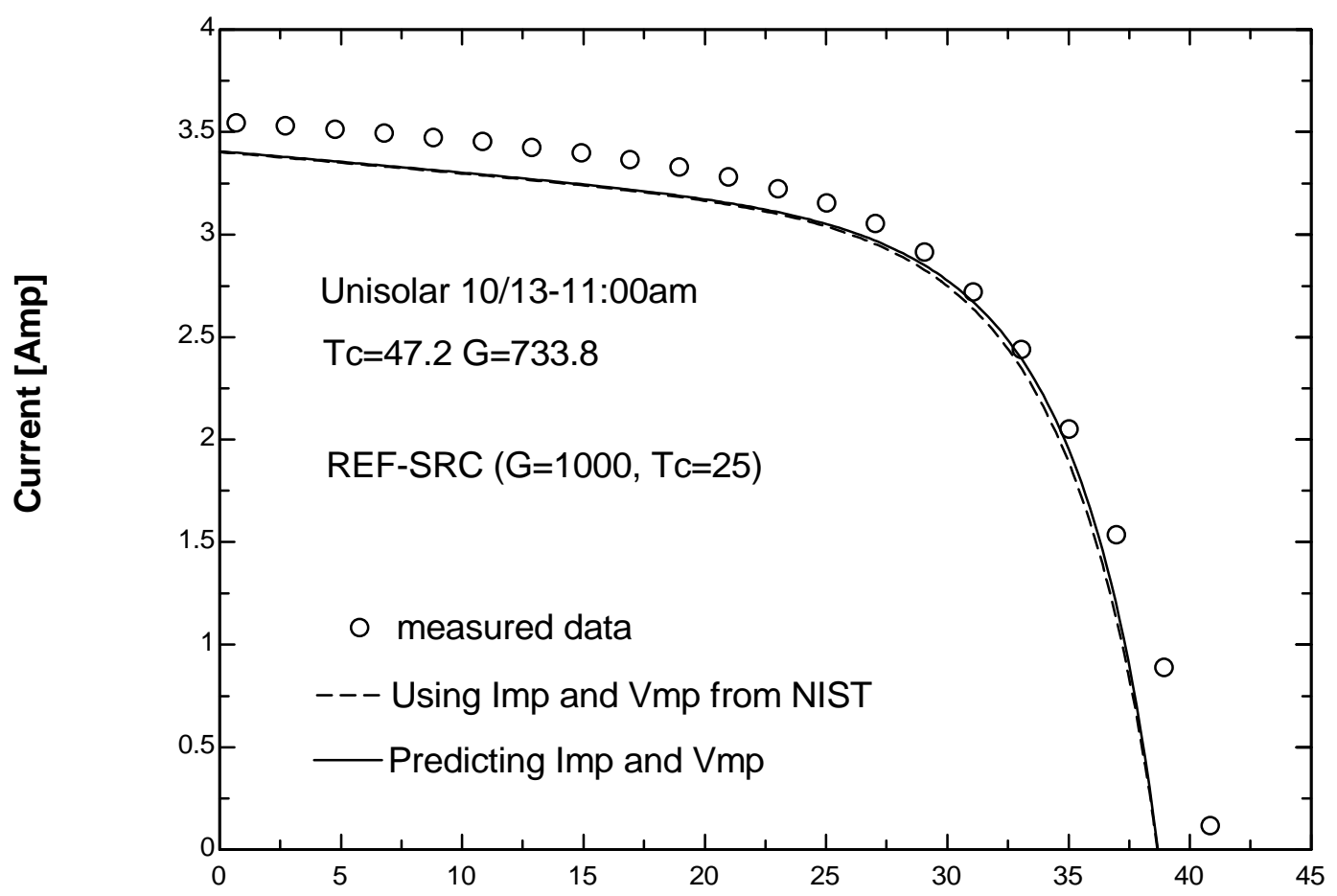

Voltage [V]

Figure 4.27: Uni-Solar cell type, October 13 at 11:00am, $T_{c}=47.2^{\circ} \mathrm{C}, G_{e f f}=733.8 \mathrm{~W} / \mathrm{m}^{2}$, SRC as reference 


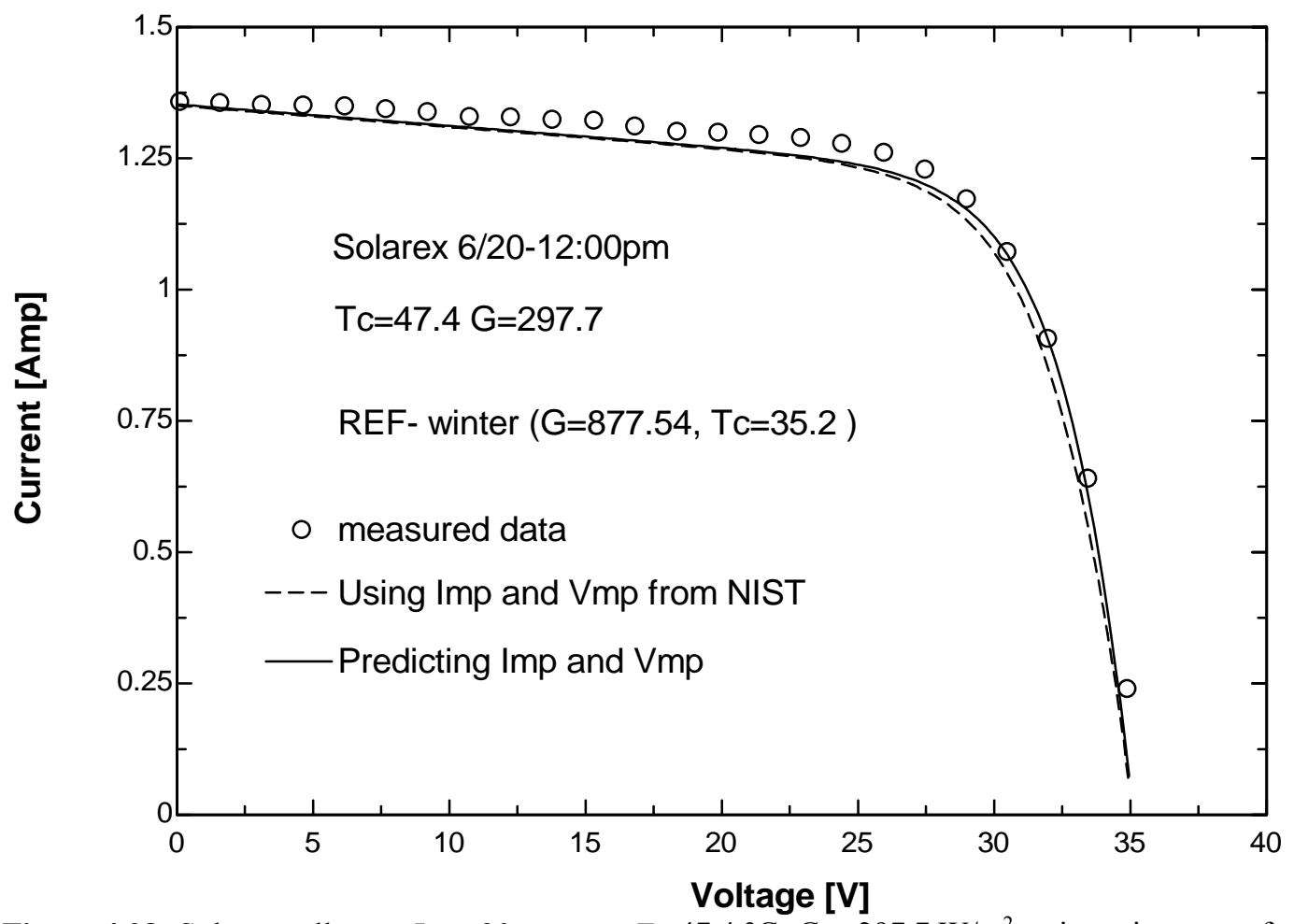

Figure 4.28: Solarex cell type, June 20 at noon, $T_{c}=47.4^{\circ} \mathrm{C}, G_{e f f}=297.7 \mathrm{~W} / \mathrm{m}^{2}$, using winter as reference

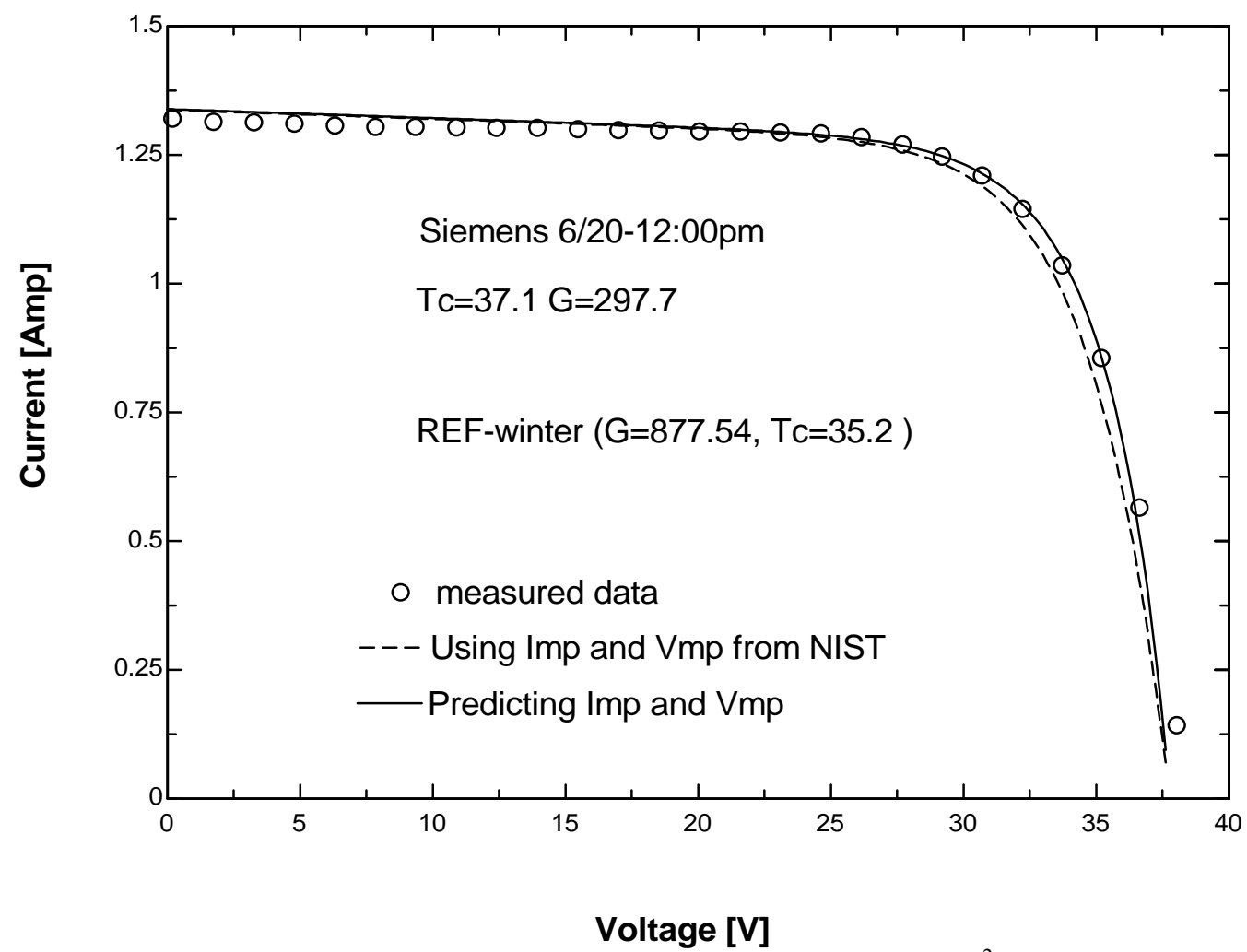

Figure 4.29: Siemens cell type, June 20 at noon, $T_{c}=37.1^{\circ} \mathrm{C}, G_{\text {eff }}=297.7 \mathrm{~W} / \mathrm{m}^{2}$, winter as reference 


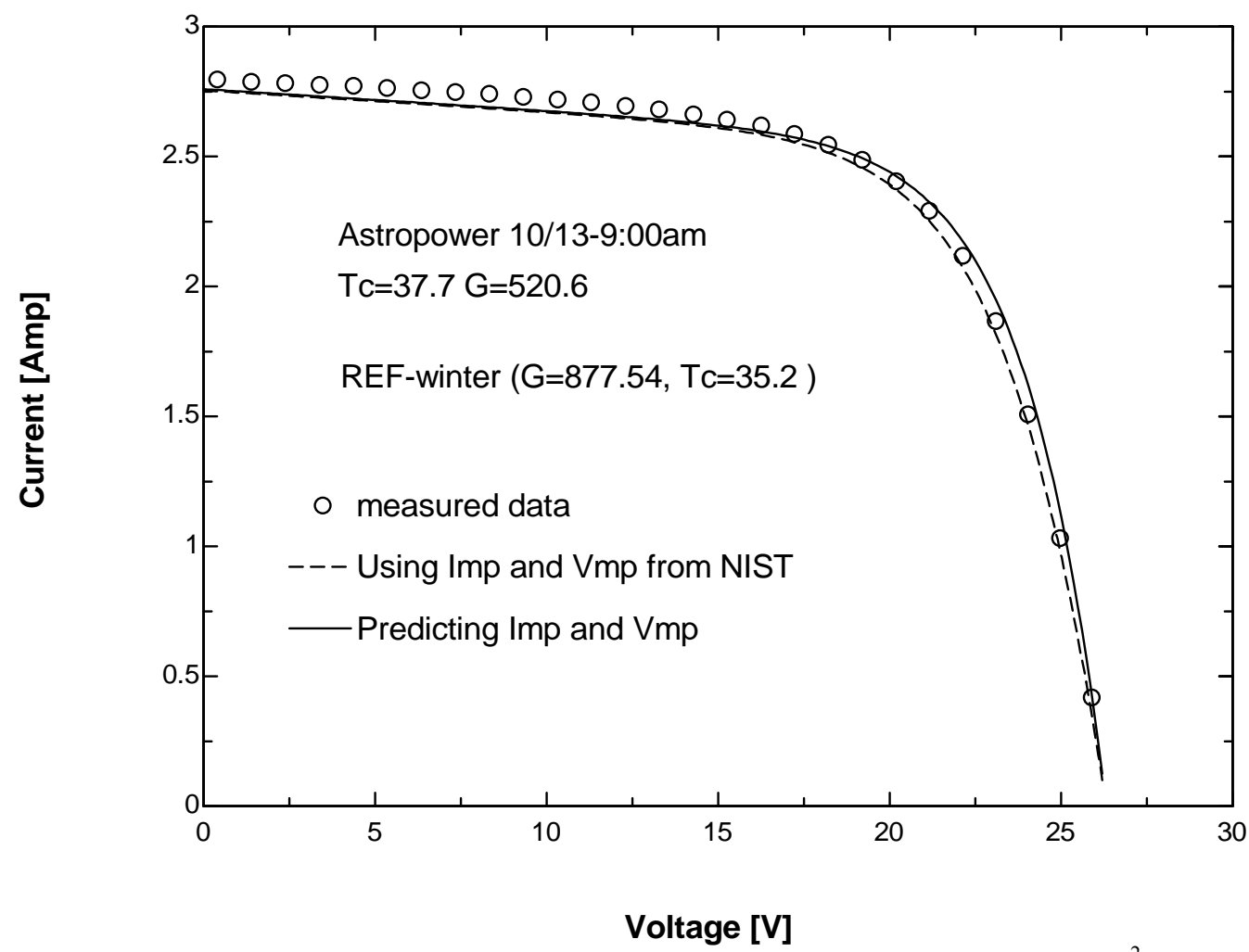

Figure 4.30: Astropower cell type, October 13 at 9:00am, $T_{c}=37.7^{\circ} \mathrm{C}, G_{e f f}=520.6 \mathrm{~W} / \mathrm{m}^{2}$, winter as

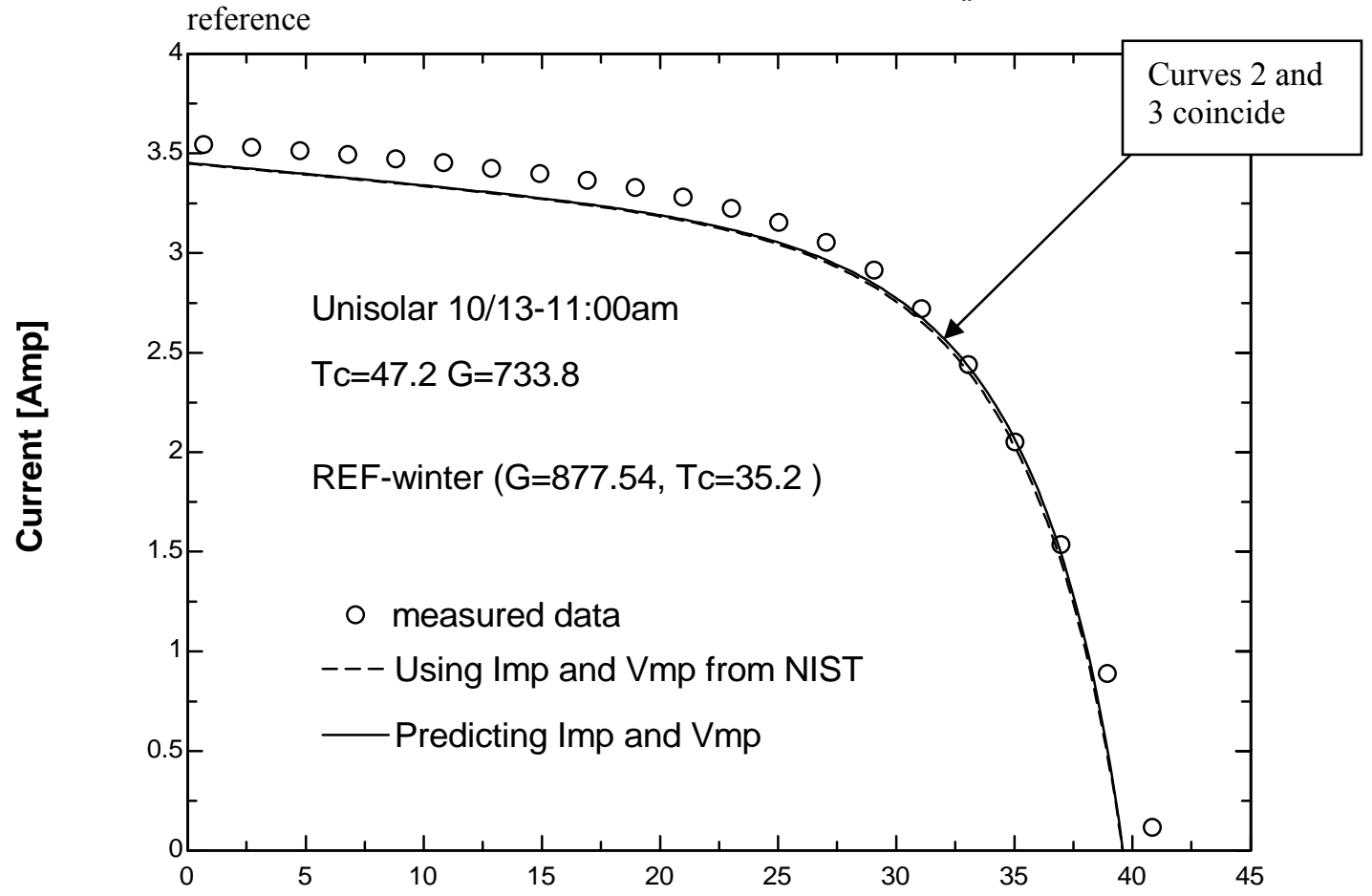

Voltage [V]

Figure 4.31: Uni-Solar cell type, October 13 at $11: 00 \mathrm{am}, T_{c}=47.2{ }^{\circ} \mathrm{C}, G_{\text {eff }}=733.8 \mathrm{~W} / \mathrm{m}^{2}$, winter as reference 
The value of the error calculated will depend on the number of points used and the type of error calculated. This study was conducted using the root mean square (RMS) error and a percentage error based on the RMS error. The errors were calculated using 15 equidistant voltage points (on the x-axis), 5 important points, and the maximum power point.

The root mean square (RMS) error compares the data provided by NIST with the values predicted using the 5-Parameter model. The error can be found by calculating the difference between the values of the current provided by NIST $\left(I_{\text {Data }}\right)$ and that predicted by the 5-Parameter model $\left(I_{\text {Model }}\right)$ for a specific number of points. The resulting difference of each set of points is squared and these values are then summed. The resulting value is divided by the number of set of points used $(N)$ and finally the square root of this value is calculated. This procedure is summarized in Equation (4.30).

$$
R M S=\sqrt{\frac{\sum_{i=1}^{N}\left(I_{\text {Data }}-I_{\text {Model }}\right)^{2}}{N}}
$$

To find the percentage RMS error, the same procedure described above is followed to calculate the RMS error. The value obtained is then divided by the short circuit current provided by NIST ( $\left.I_{\text {Data,sc }}\right)$ and multiplied by $100 \%$.

$$
\% R M S=\frac{\sqrt{\frac{\sum_{i=1}^{N}\left(I_{\text {Data }}-I_{\text {Model }}\right)^{2}}{N}}}{I_{\text {Data }, \text { sc }}} 100 \%
$$

Usually the value of the error obtained will depend on the number of points used and this number will vary according to the area of interest. 
Fifteen (15) or even a larger number of points may be used if it is of interest analyzing many points in a curve. The most logical way of choosing the points is by selecting equidistant points in the voltage or $\mathrm{x}$-axis. This is because it is the only axis whose values are always defined (each value of voltage corresponds with one value of current, contrary to the y-axis where each value of current might have more than one value of voltage). If fifteen points are to be considered, the value of $N$ in Equations (4.30) and (4.31) should be set equal to 15. An example of this calculation can be found in Appendix C, Part I, a.

The problem with selecting equidistant points is that the maximum power point (which is usually of interest) might not necessarily be included, plus many points (like those corresponding to the first part of the curve) might be redundant. To avoid this and use points of greater interest, the use of 5 important points is suggested.

Five well selected points are more than enough to determine whether a curve is a good approximation of measured data or not. This is useful when the PV cell will not be constantly operating at its maximum power point, but at some other point that matches the I-V characteristic of the load. The five points suggested can be seen in Figure 4.32 and correspond to the following voltages:

$V=0$ : voltage equals zero

$V=0.5 V_{o c}:$ voltage equals half of the open circuit voltage $V=V_{m p}$ : voltage equals the voltage at the maximum power point $V=0.5\left(V_{o c}+V_{m p}\right)$ : voltage equals half of the sum of the open circuit voltage and the voltage at the maximum power point $V=V_{o c}$ : voltage equals the open circuit voltage 


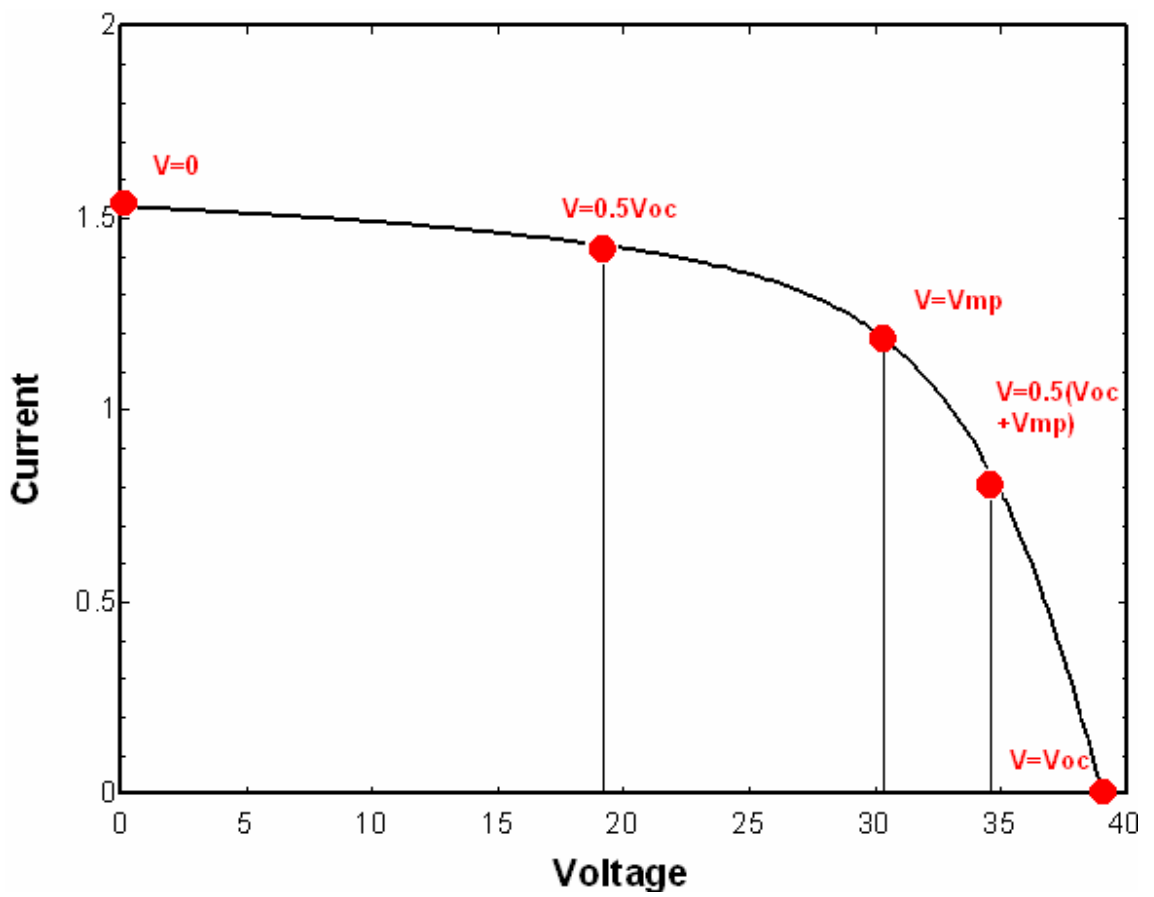

Figure 4.32: Location of the five important points on the I-V curve used to calculate the RMS error

If the five important points are used to calculate the error, the value of $N$ in Equations (4.30) and (4.31) should be set equal to 5. An example of this calculation can be found in Appendix C, Part I, b.

The error that makes use of only the maximum power point is very useful in applications where the PV cell is expected to operate at this point, as happens when a maximum power point tracker is used. If this is the only point used, the value of $N$ in Equations (4.30) and (4.31) should be set equal to 1 and the denominator in Equation (4.31) should read $I_{\text {data,mp }}$, instead of $I_{\text {data,sc }}$, obtaining Equation (4.32). An example of a program used to calculate this type of error can be found in Appendix C, Part I, c.

$$
\% R M S_{m p}=\frac{\sqrt{\left(I_{\text {Data }}-I_{\text {Model }}\right)^{2}}}{I_{\text {Data,mp }}} 100 \%
$$


In order to obtain useful results, consistency in the number of points analyzed is absolutely necessary. For this study, the "five important points" and the "maximum power points" were the points selection methods used for error calculation.

Tables 4.2 and 4.3 show the values of the errors obtained for the different curves, where "Using NIST data" implies that the $I_{m p}$ and $V_{m p}$ values provided by NIST were used, while "Not Using NIST data" implies that these values were predicted using Equations (4.25) and (4.29), respectively. The error using the 5 important points was calculated using Equation (4.31) (with an $N$ value of 5) and the error that uses only the maximum power point was calculated using Equation (4.32).

Table 4.2: Errors obtained for the different curves, using SRC as reference

\begin{tabular}{|c|c|c|c|c|c|}
\hline \multirow{2}{*}{$\begin{array}{c}\text { Type of Error } \\
\text { calculated }\end{array}$} & Curve Type & \multicolumn{4}{|c|}{ Cell Type } \\
\cline { 3 - 6 } & Solarex & Siemens & Astropower & Uni-Solar \\
\hline \multirow{2}{*}{$\begin{array}{c}\text { Using NIST } \\
\text { data }\end{array}$} & 2.931 & 2.881 & 2.025 & 3.776 \\
\cline { 2 - 6 } & $\begin{array}{c}\text { Not Using } \\
\text { NIST data }\end{array}$ & 3.059 & 2.718 & 3.366 & 3.088 \\
\hline $\begin{array}{c}\text { Max. Power } \\
\text { Point } \\
\% \text { Error }\end{array}$ & $\begin{array}{c}\text { Using NIST } \\
\text { data }\end{array}$ & 4.152 & 0.422 & 1.257 & 3.102 \\
\cline { 2 - 6 } & $\begin{array}{c}\text { Not Using } \\
\text { NIST data }\end{array}$ & 3.173 & 0.085 & 0.710 & 2.152 \\
\hline
\end{tabular}

If winter conditions are used as reference (instead of SRC), the following results, summarized in Table 4.3 are obtained. 
Table 4.3: Errors obtained for the different curves, using winter conditions as reference

\begin{tabular}{|c|c|c|c|c|c|}
\hline \multirow{2}{*}{$\begin{array}{l}\text { Type of Error } \\
\text { calculated }\end{array}$} & \multirow{2}{*}{ Curve Type } & \multicolumn{4}{|c|}{ Cell Type } \\
\hline & & Solarex & Siemens & Astropower & Uni-Solar \\
\hline \multirow{2}{*}{$\begin{array}{l}5 \text { points } \\
\% \text { Error }\end{array}$} & $\begin{array}{l}\text { Using NIST } \\
\text { data }\end{array}$ & 2.534 & 2.664 & 1.418 & 2.262 \\
\hline & $\begin{array}{l}\text { Not Using } \\
\text { NIST data }\end{array}$ & 1.174 & 0.720 & 1.752 & 2.067 \\
\hline \multirow{2}{*}{$\begin{array}{c}\text { Max. Power } \\
\text { Point } \\
\% \text { Error }\end{array}$} & $\begin{array}{l}\text { Using NIST } \\
\text { data }\end{array}$ & 3.482 & 1.905 & 1.433 & 2.899 \\
\hline & $\begin{array}{l}\text { Not Using } \\
\text { NIST data }\end{array}$ & 1.959 & 0.273 & 0.881 & 2.283 \\
\hline
\end{tabular}

From Tables 4.2 and 4.3 it can be concluded that the errors obtained when the values of $V_{m p}$ and $I_{m p}$ are predicted do not differ too much from those obtained when the data provided by NIST are used, therefore Equations (4.25) and (4.29) are effective at predicting the $I_{m p}$ and $V_{m p}$ values.

The errors obtained for the first three cell types (Solarex, Siemens, and Astropower) when using Equations (4.25) and (4.29) to predict the $I_{m p}$ and $V_{m p}$ values are small, averaging less than 5.5\%, while the Uni-Solar cell type yields an average error of up to $7.6 \%$.

4.4.2 Allowing negative values of $R_{S}$ versus forcing it to be zero

For some weather conditions $\left(T_{c}, G\right)$ the predicted value for the series resistance was found to be negative, which is not physically possible. It was of interest knowing if forcing $R_{S}$ to be positive would have any effect in the predictions. Analyses were conducted to compare the prediction with the negative $R_{s}$ versus setting $R_{s}$ equal to zero for these cases. The results show that forcing $R_{s}$ to be positive (or zero) increases the 
observed error. Figures 4.33-4.36 show the results obtained for a specific cell temperature and irradiance where $R_{s}$ was forced to be zero in comparison to the results for which $R_{s}$ was allowed to be a negative value. It is clear here that the equivalent circuit, presented in Figure 3.1, although a very good approximation, is not perfectly representative of the cells' physics, thus negative values can occur under some situations.

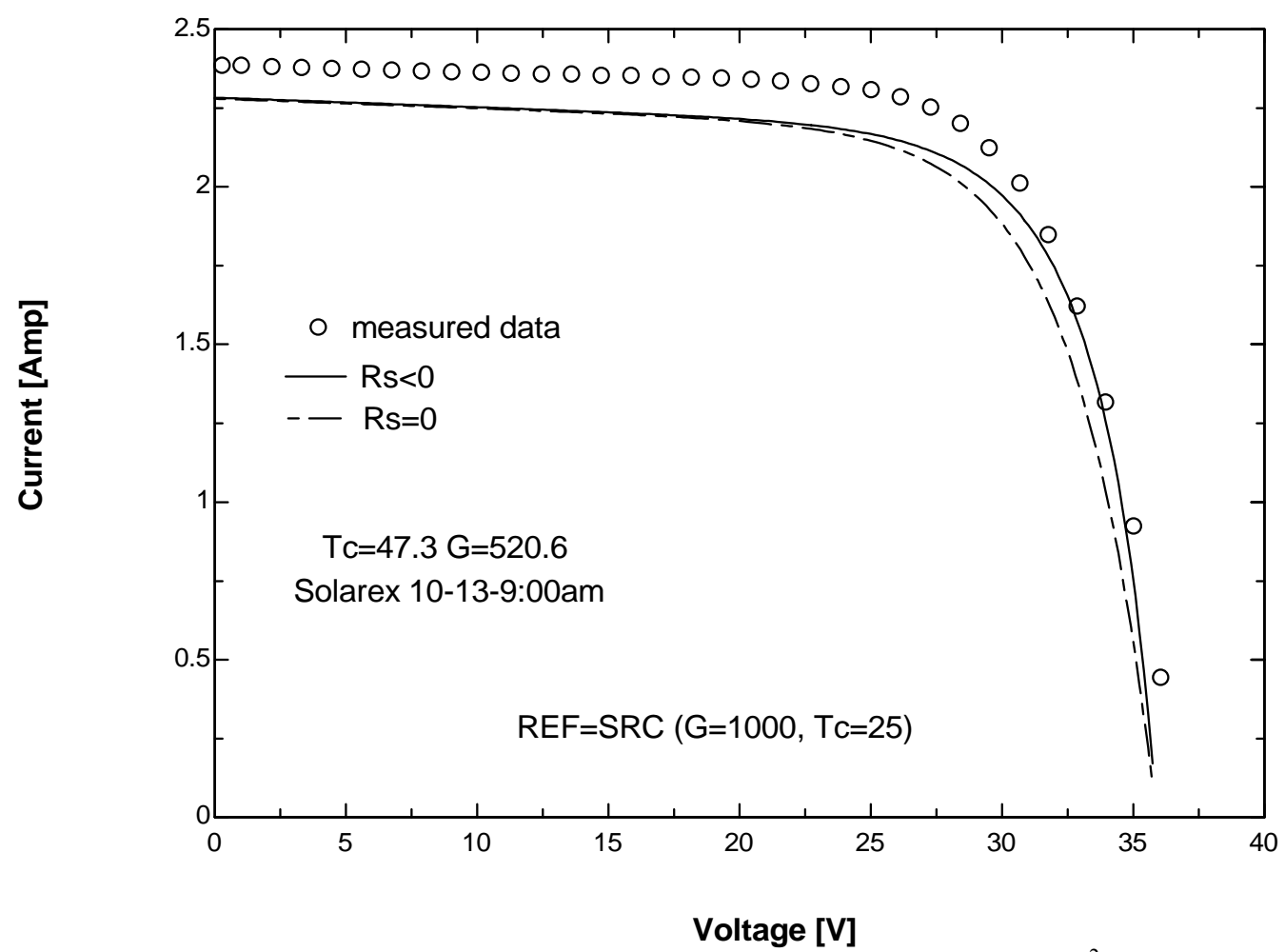

Figure 4.33: Solarex cell type, October 13 at 9:00am, $T_{c}=47.3^{\circ} \mathrm{C}, G_{e f f}=520.6 \mathrm{~W} / \mathrm{m}^{2}, \mathrm{SRC}$ as reference conditions 


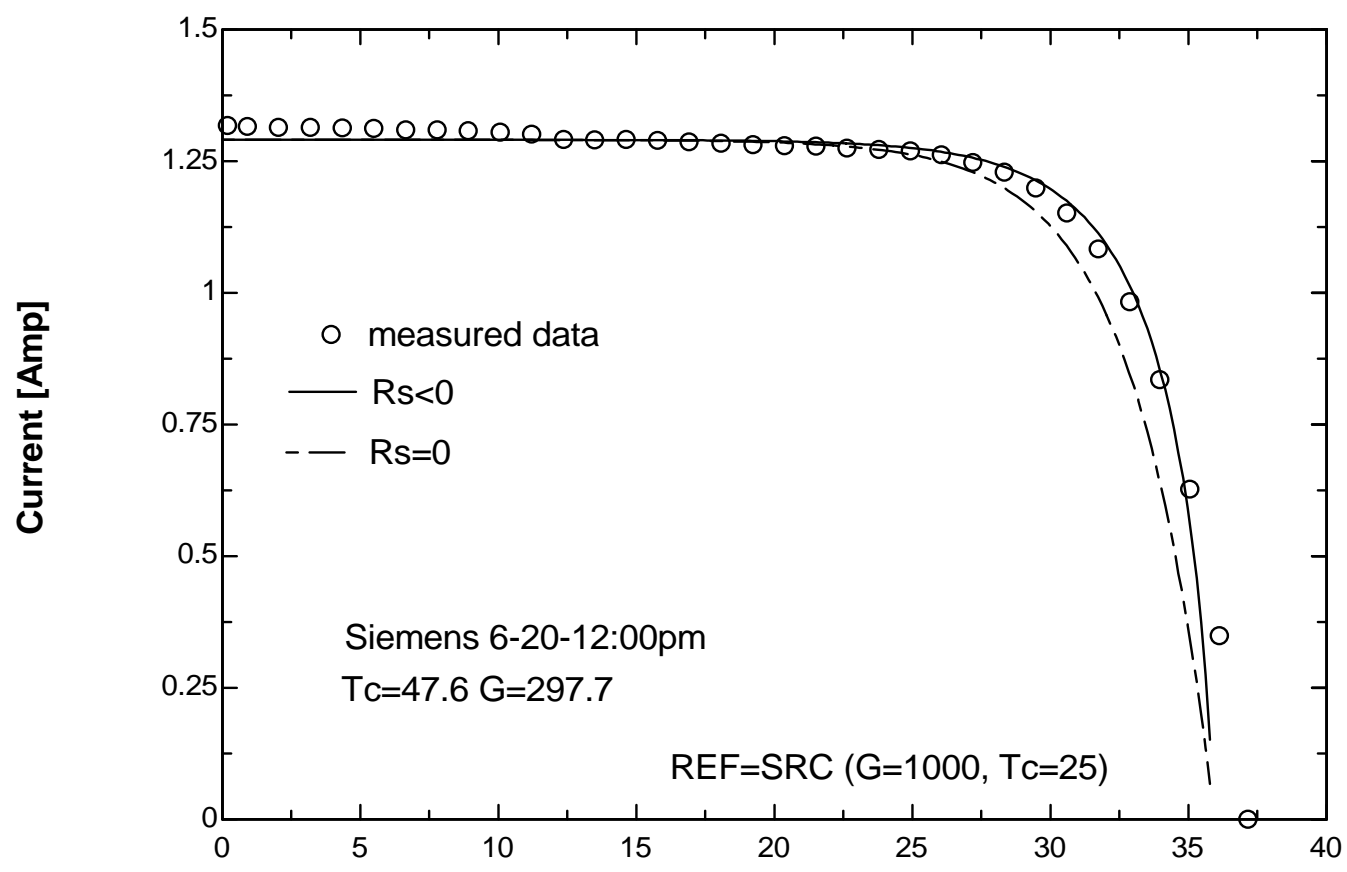

Voltage [V]

Figure 4.34: Siemens cell type, June 20 at noon, $T_{c}=47.6^{\circ} \mathrm{C}, G_{\text {eff }}=297.7 \mathrm{~W} / \mathrm{m}^{2}$, SRC as reference

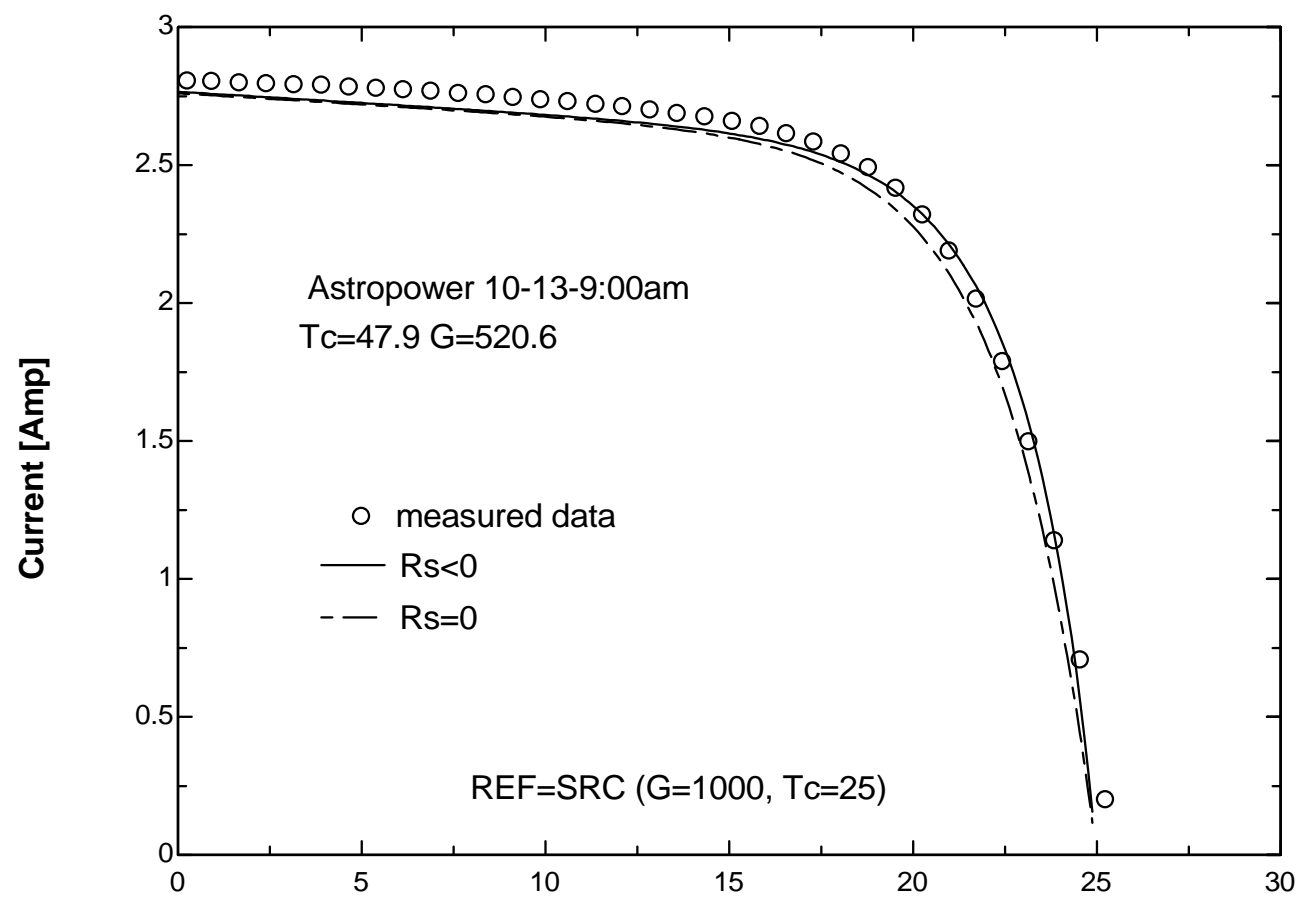

Voltage [V]

Figure 4.35: Astropower cell type, October 13 at 9:00am, $T_{c}=47.9^{\circ} \mathrm{C}, G_{\text {eff }}=520.6 \mathrm{~W} / \mathrm{m}^{2}$, using SRC as reference conditions 


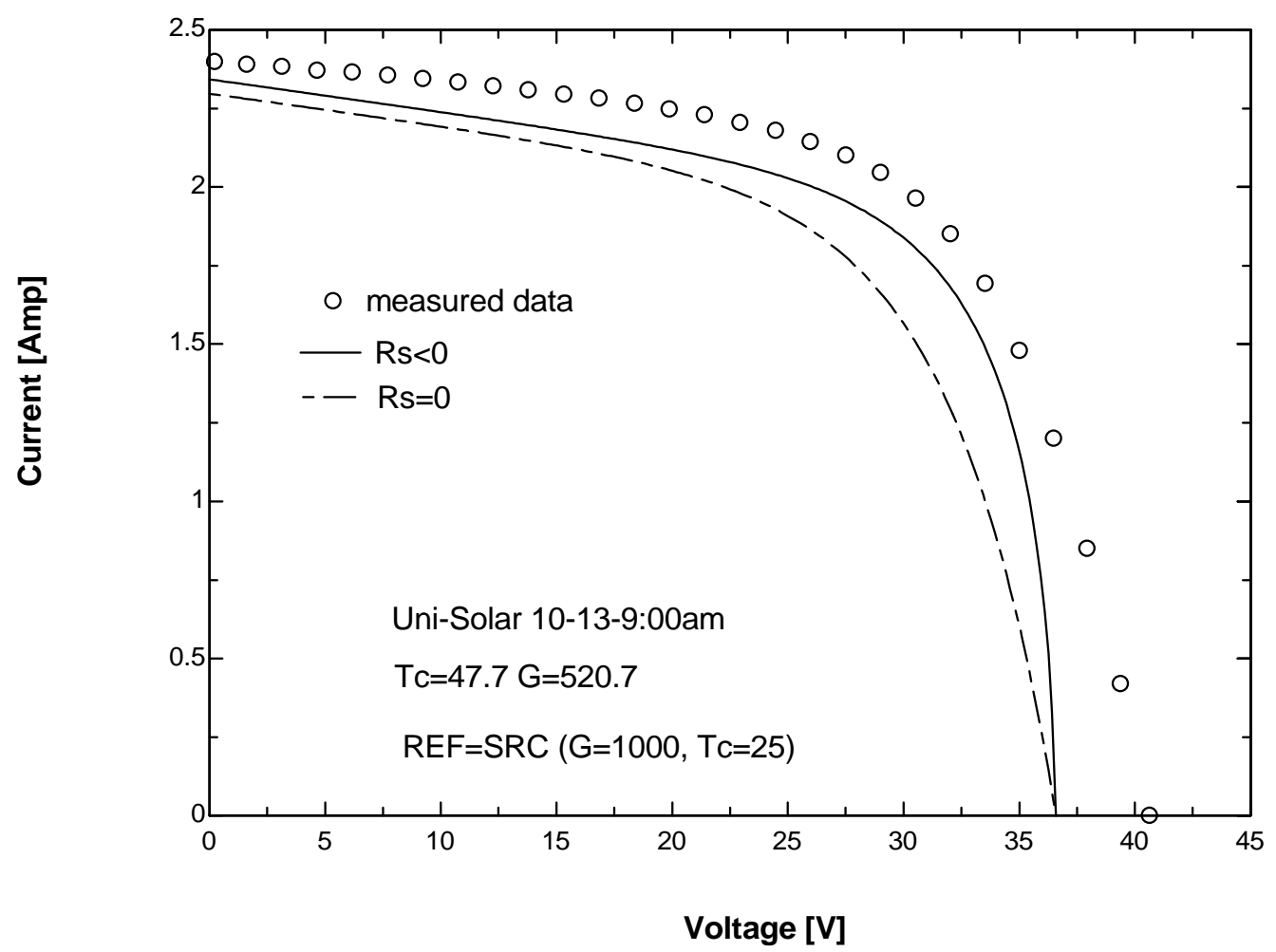

Figure 4.36: Uni-Solar cell type, October 13 at 9:00am, $T_{c}=47.7^{\circ} \mathrm{C}, G_{e f f}=520.7 \mathrm{~W} / \mathrm{m}^{2}$, SRC as reference conditions

\subsection{Shunt resistance, $R_{\text {sh }}$}

The shunt resistance $\left(R_{s h}\right)$ parameter controls the slope of the I-V curve at short circuit conditions. Figure 4.37 shows that as the shunt resistance increases, the slope of the I-V curve at short circuit conditions decreases. 


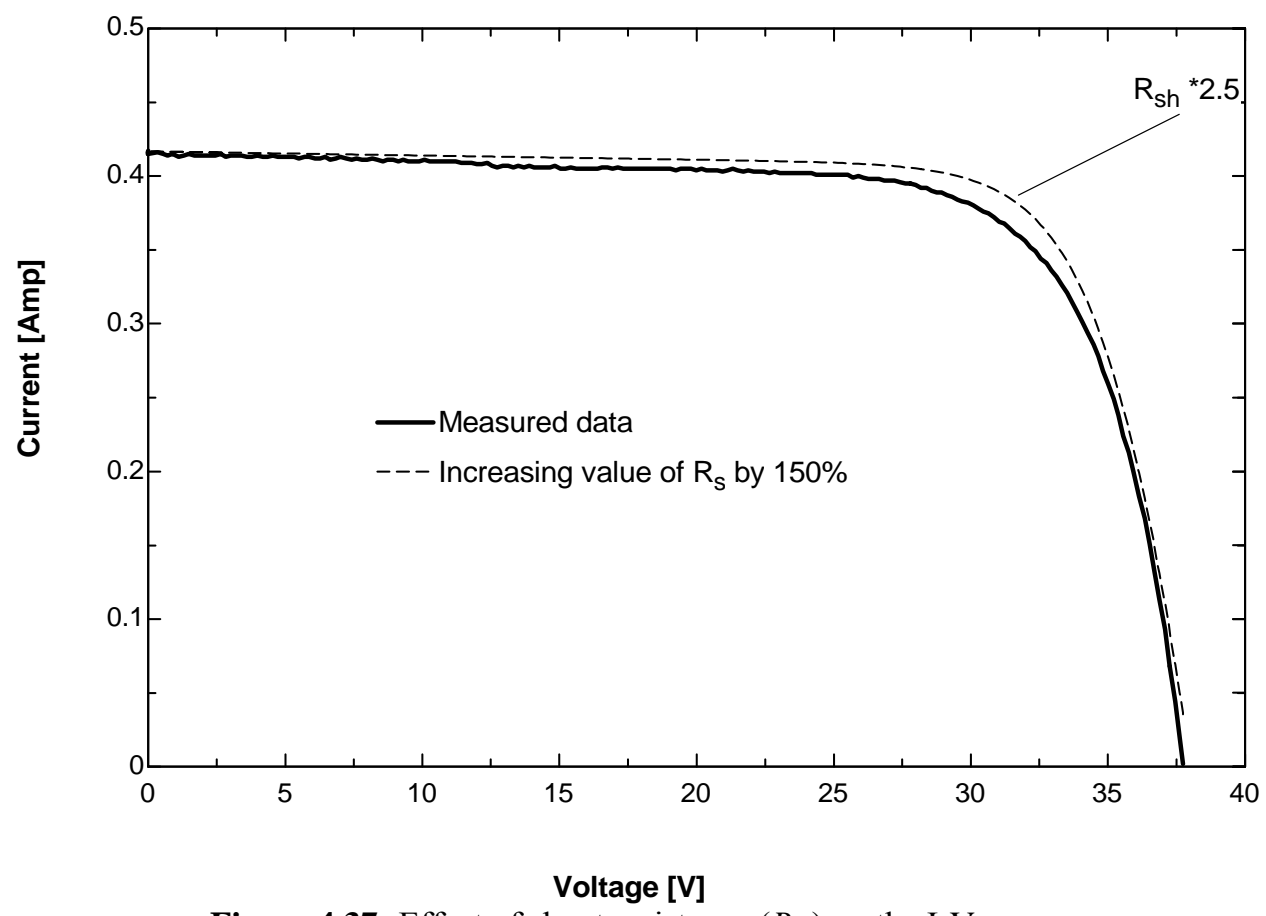

Figure 4.37: Effect of shunt resistance $\left(R_{s h}\right)$ on the I-V curve

\subsubsection{Derivation of equation to correct $R_{s h}$}

The effect of the shunt resistance $\left(R_{s h}\right)$ was studied for the Siemens (singlecrystalline), Solarex (poly-crystalline), Astropower (silicon thin film), and Uni-Solar (3Junction amorphous) cell types, by varying its value over a large range (Siemens: from $R_{s h}=500$ to $R_{s h} \rightarrow \infty$, Solarex: $R_{s h}=500$ to $R_{s h} \rightarrow \infty$, Astropower: $R_{s h}=125$ to $R_{s h}=1500$, UniSolar: $R_{s h}=100$ to $R_{s h}=1500$ ). The effects of these changes on the predicted currentvoltage (I-V) curve were analyzed. Figures 4.38-4.43 show that the value of $R_{s h}$ had essentially no effect on the predicted I-V curve for the Solarex, Siemens, and Astropower cell types. Figures 4.44-4.45 show that on the contrary, for the Uni-Solar cell type the $R_{s h}$ parameter has a direct impact on the I-V curve obtained. 


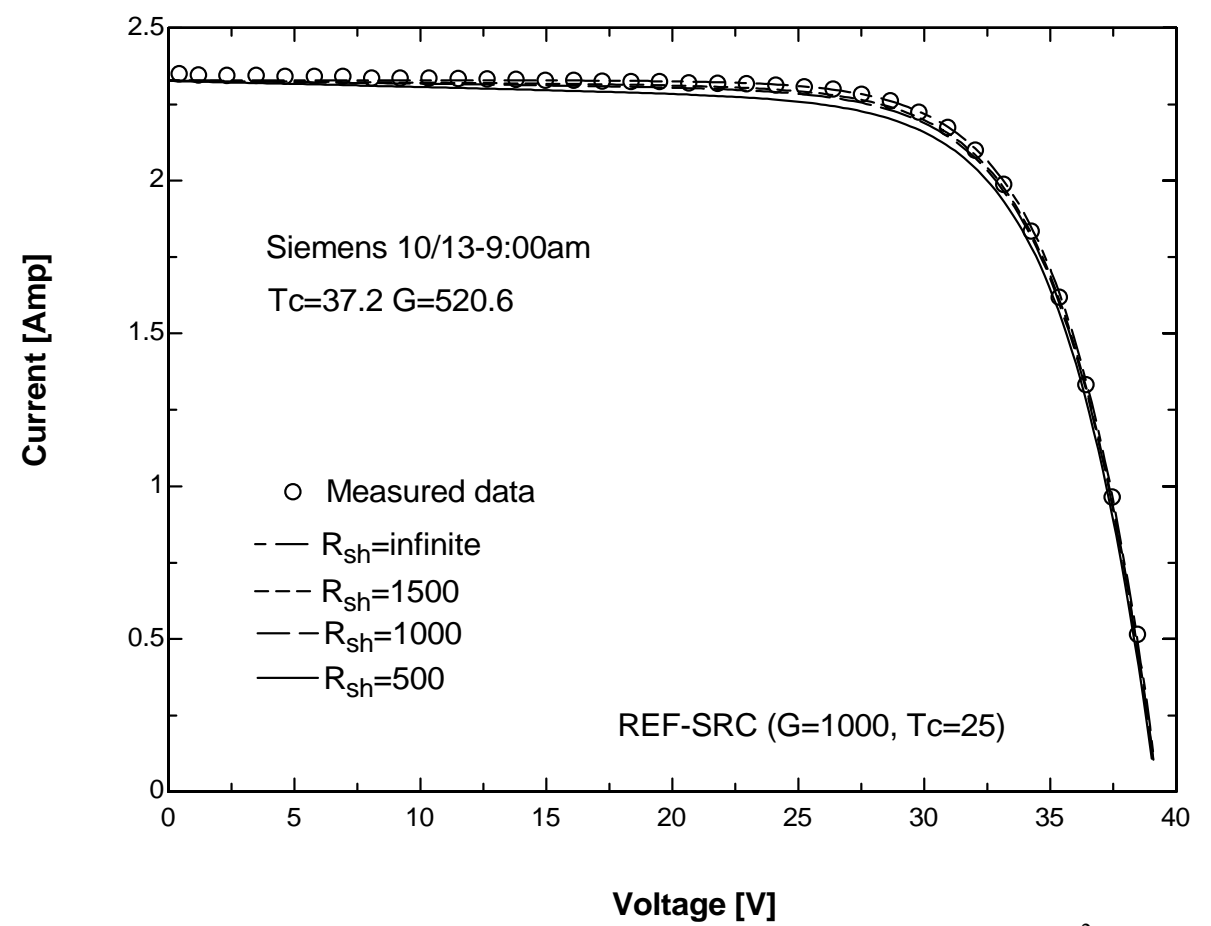

Figure 4.38: Siemens cell type, October 13 at $9: 00 \mathrm{am}, T_{c}=37.2^{\circ} \mathrm{C}, G_{\text {eff }}=520.6 \mathrm{~W} / \mathrm{m}^{2}$, SRC as reference conditions

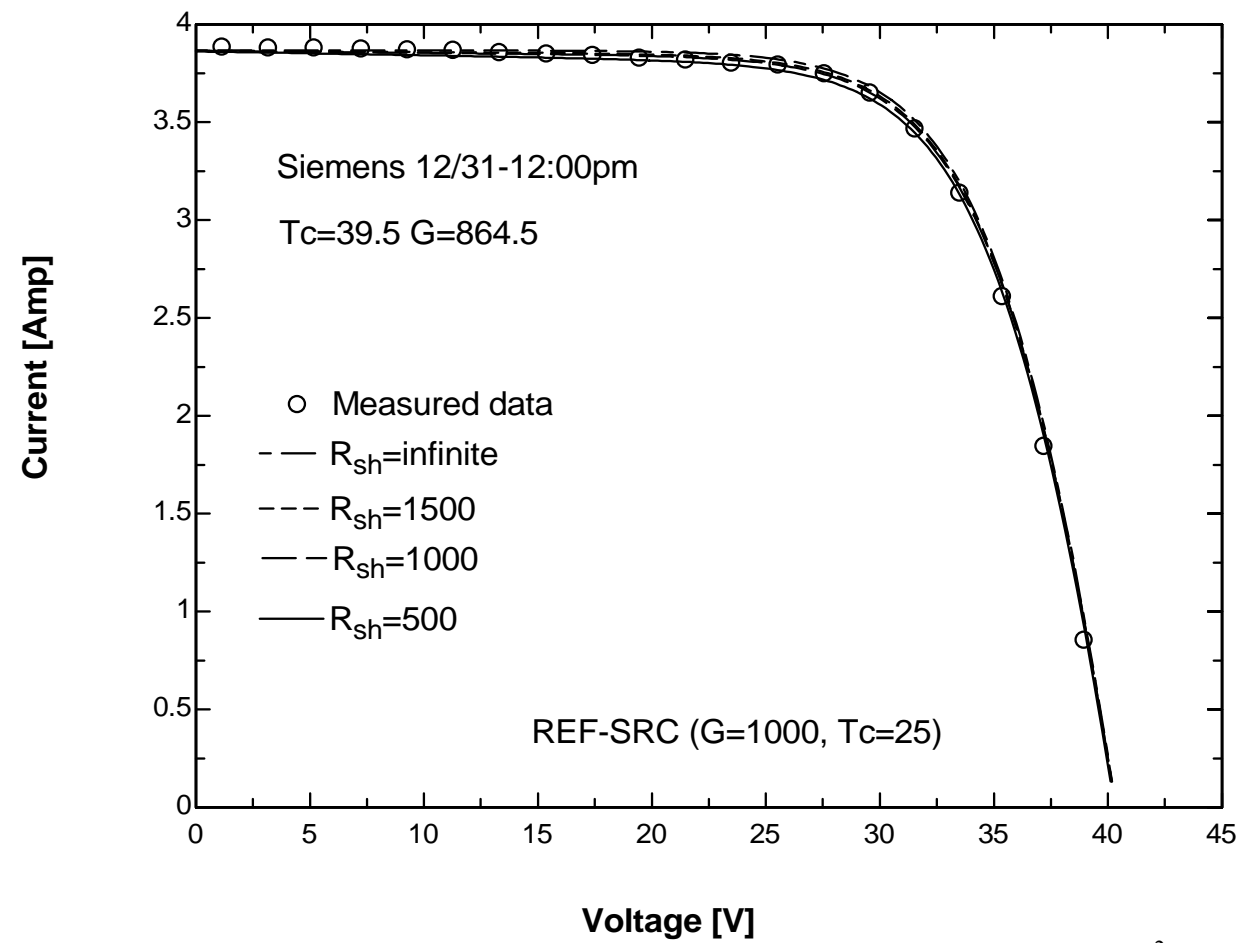

Figure 4.39: Siemens cell type, December 31 at $12: 00 \mathrm{pm}, T_{c}=39.5^{\circ} \mathrm{C}, G_{e f f}=864.5 \mathrm{~W} / \mathrm{m}^{2}$, $\mathrm{SRC}$ as reference conditions 


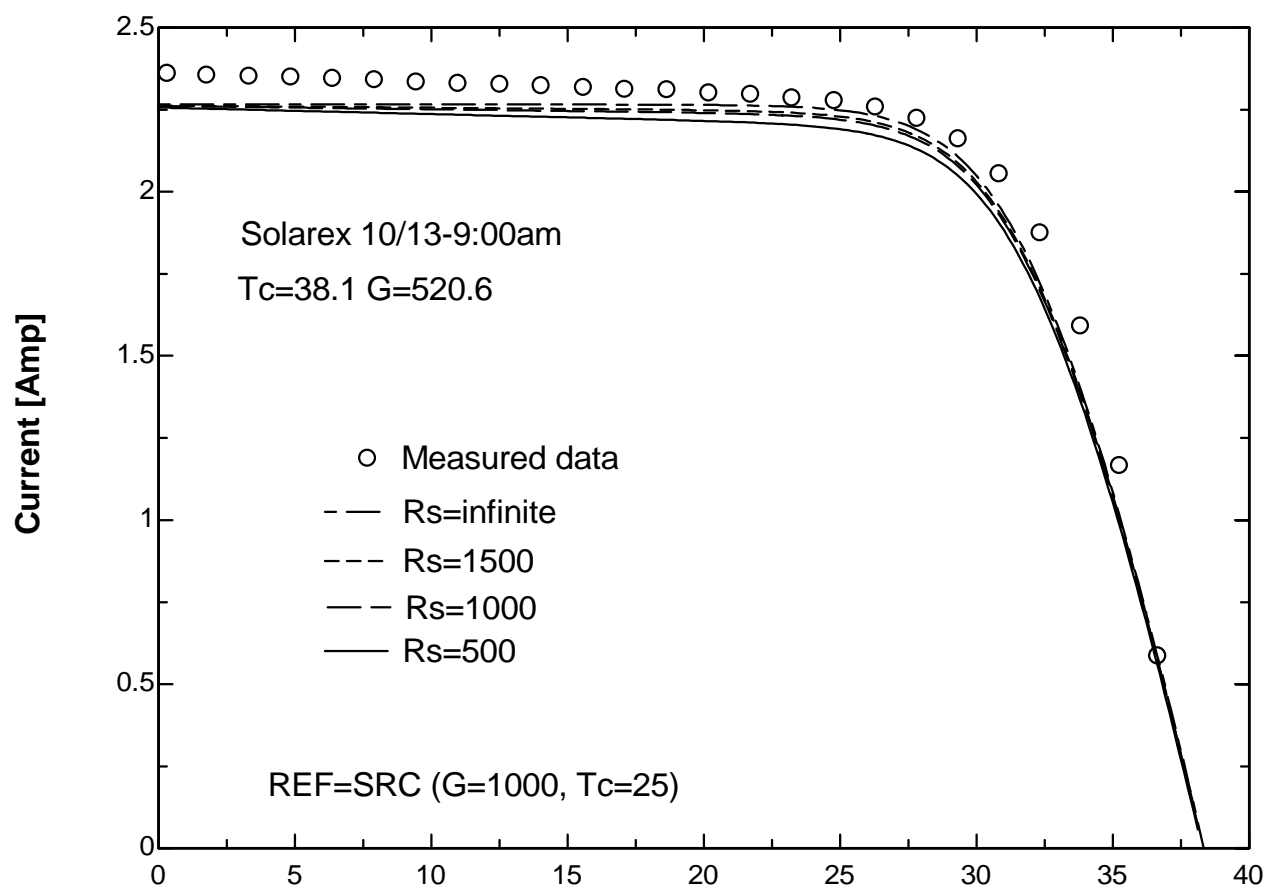

Voltage [V]

Figure 4.40: Solarex cell type, October 13 at 9:00am, $T_{c}=38.1^{\circ} \mathrm{C}, G_{\text {eff }}=520.6 \mathrm{~W} / \mathrm{m}^{2}$, SRC as reference conditions

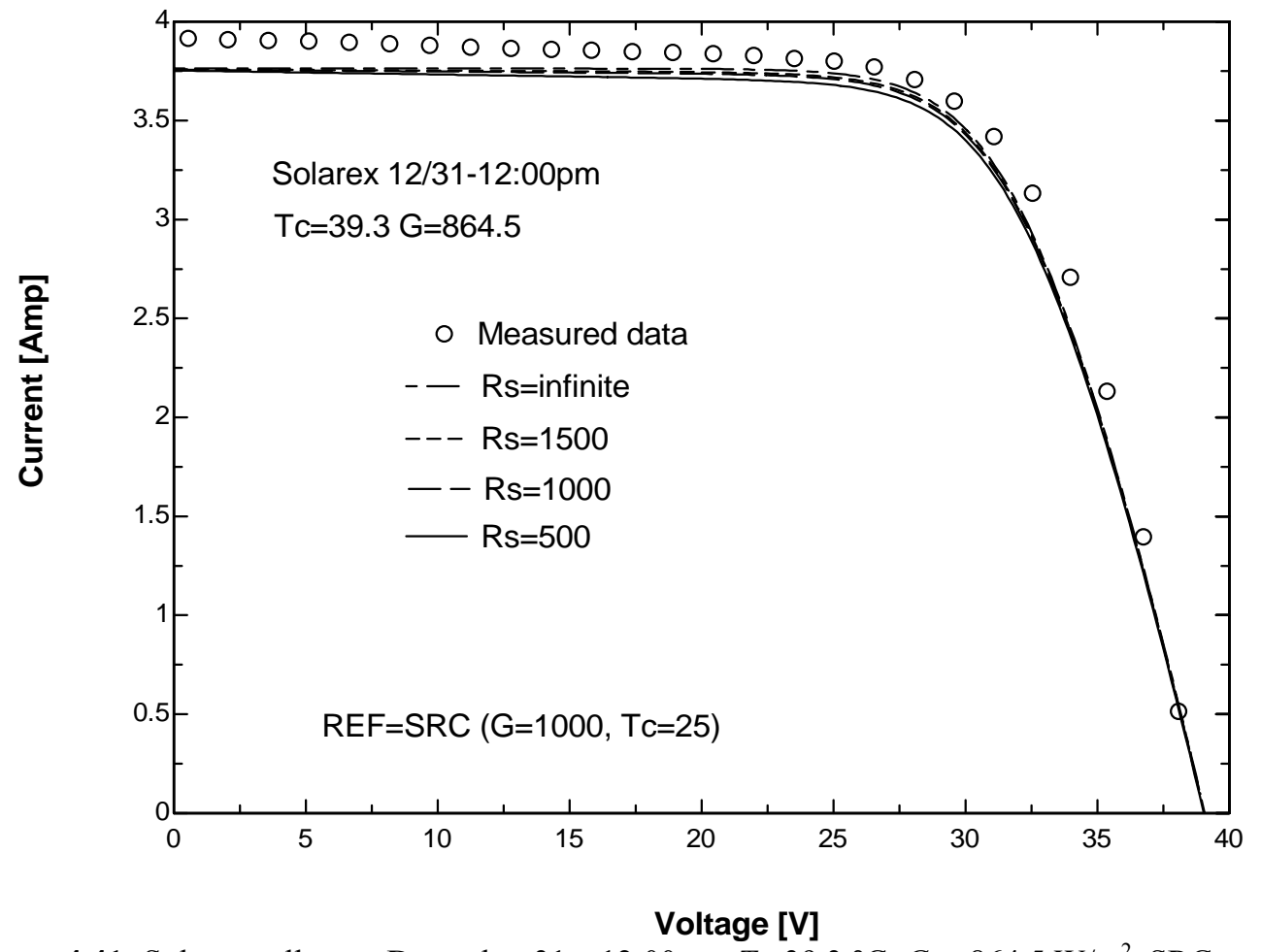

Figure 4.41: Solarex cell type, December 31at 12:00pm, $T_{c}=39.3^{\circ} \mathrm{C}, G_{e f f}=864.5 \mathrm{~W} / \mathrm{m}^{2}$, SRC as reference conditions 


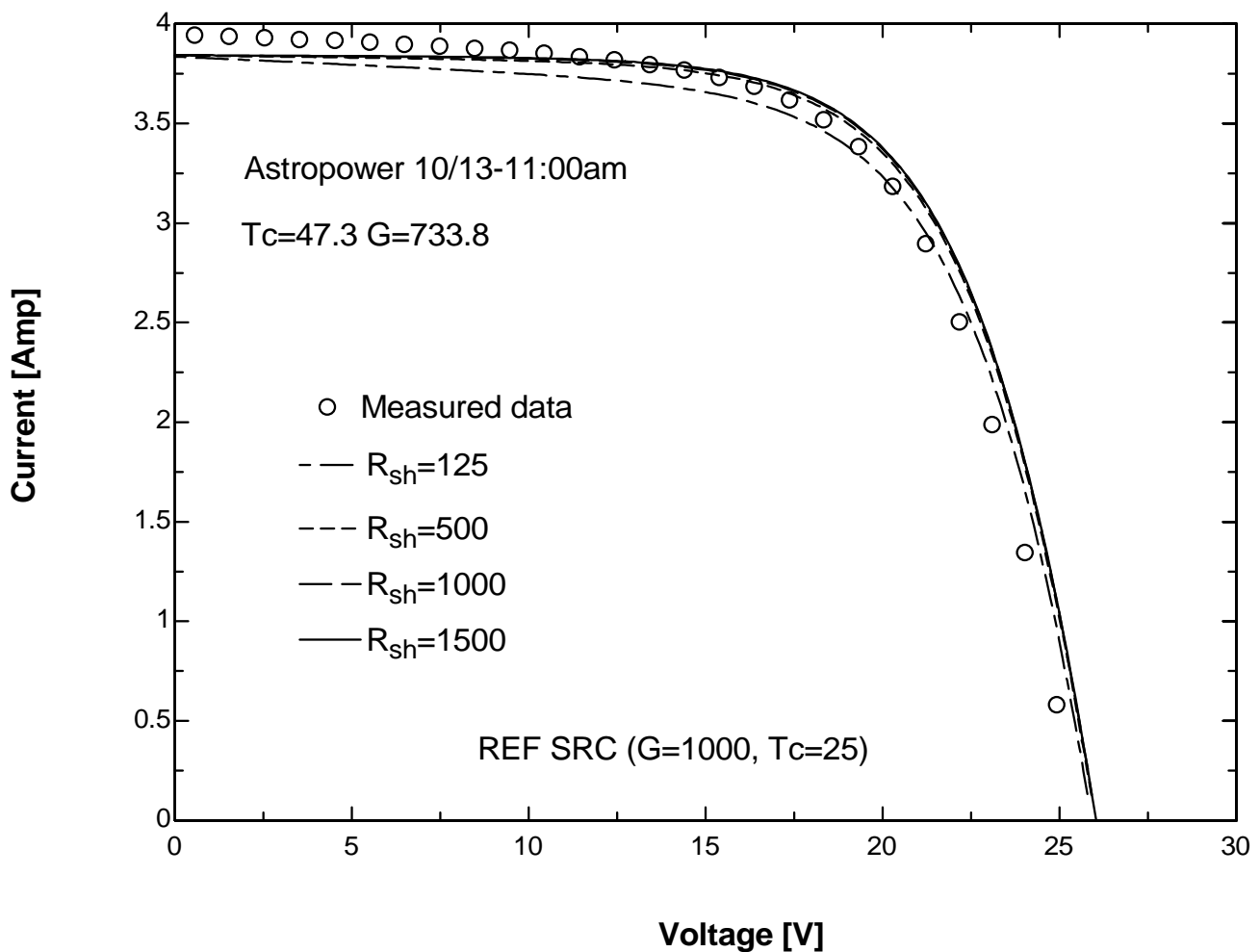

Figure 4.42: Astropower cell type, October 13 at $11: 00 \mathrm{am}, T_{c}=47.3^{\circ} \mathrm{C}, G_{e f f}=733.8 \mathrm{~W} / \mathrm{m}^{2}$, SRC as reference conditions

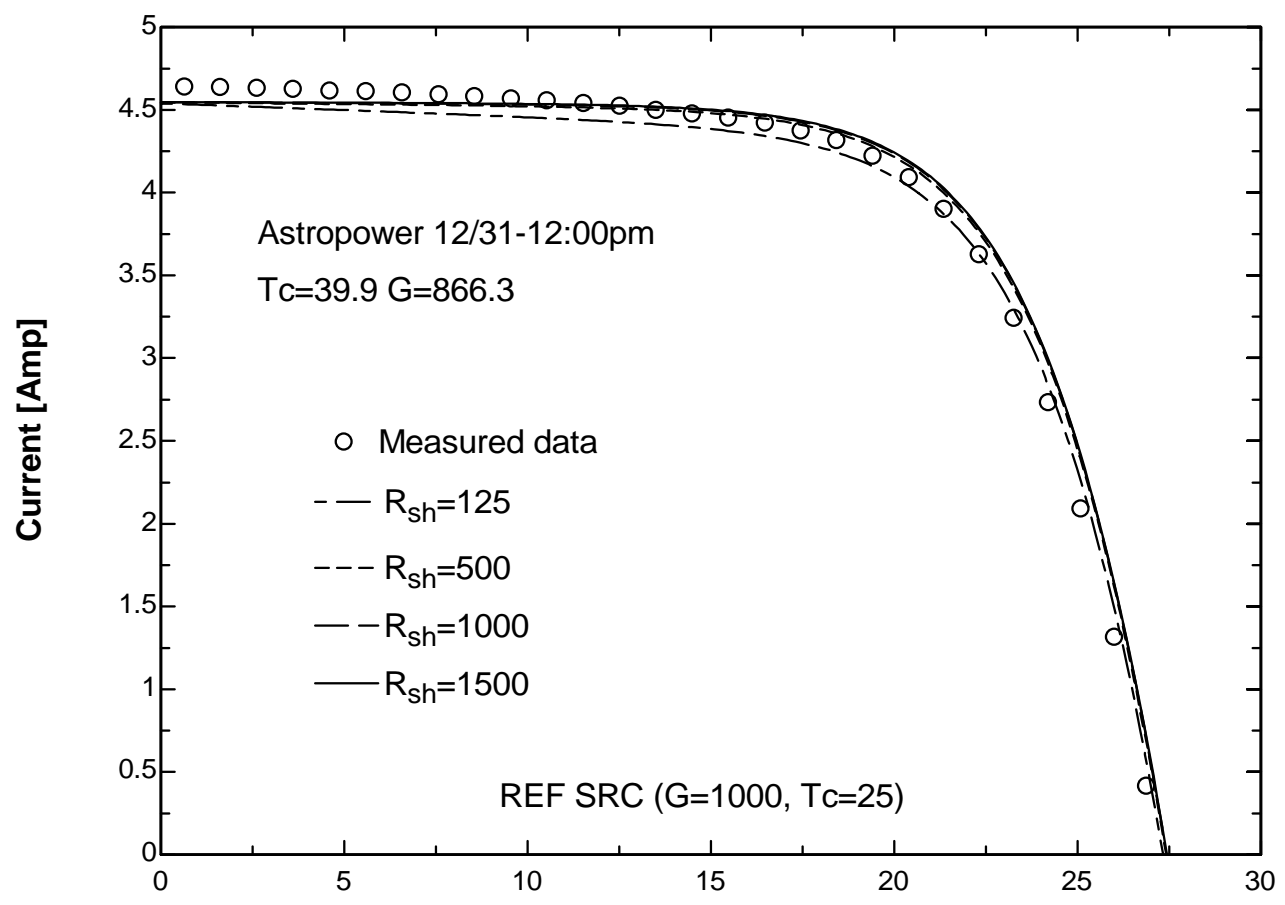

Voltage [V]

Figure 4.43: Astropower cell type, Dec. 31 at 12:00pm, $T_{c}=39.9^{\circ} \mathrm{C}, G_{\text {eff }}=866.3 \mathrm{~W} / \mathrm{m}^{2}$, SRC as reference conditions 


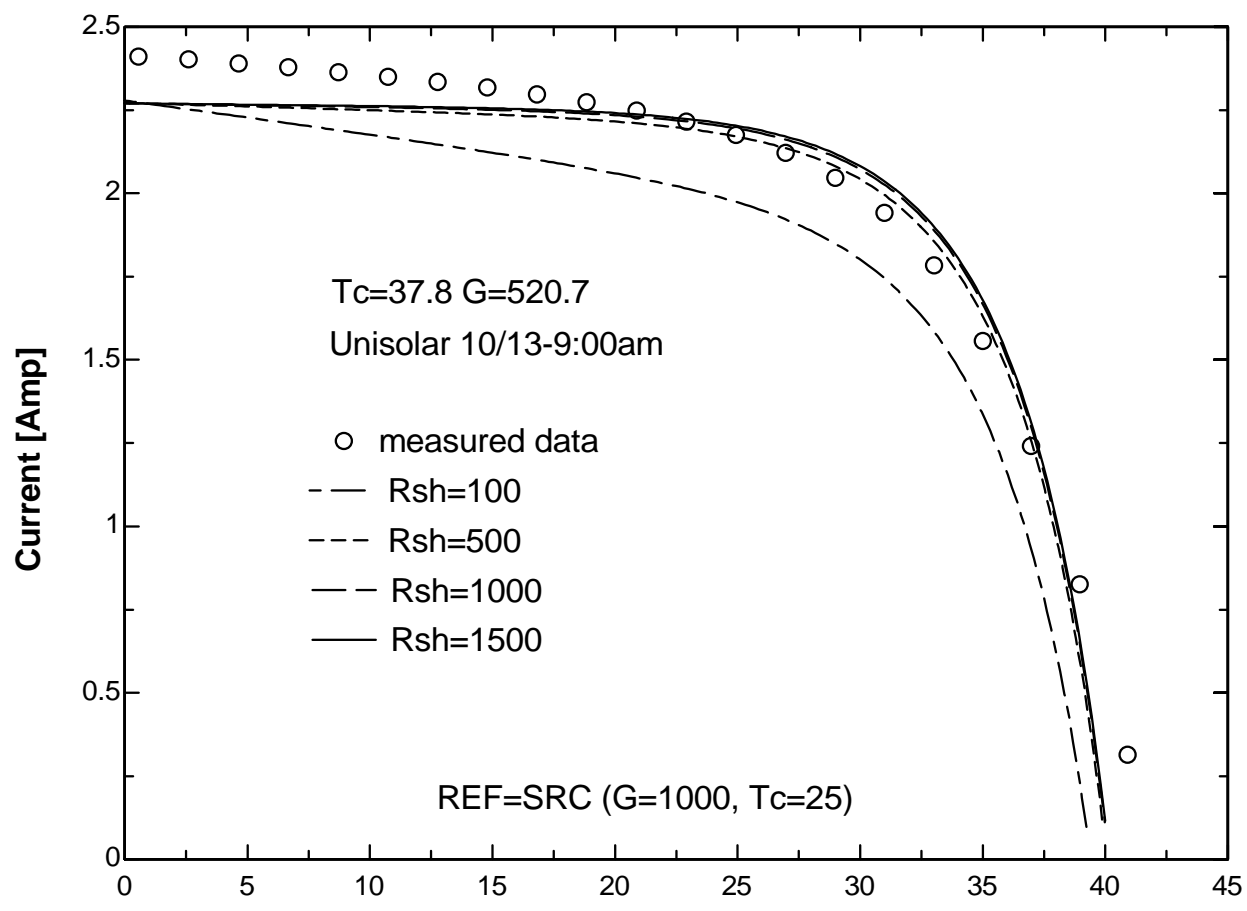

Voltage [V]

Figure 4.44: Uni-Solar cell type, October 13 at 9:00am, $T_{c}=37.8^{\circ} \mathrm{C}, G_{e f f}=520.7 \mathrm{~W} / \mathrm{m}^{2}$, SRC as reference conditions

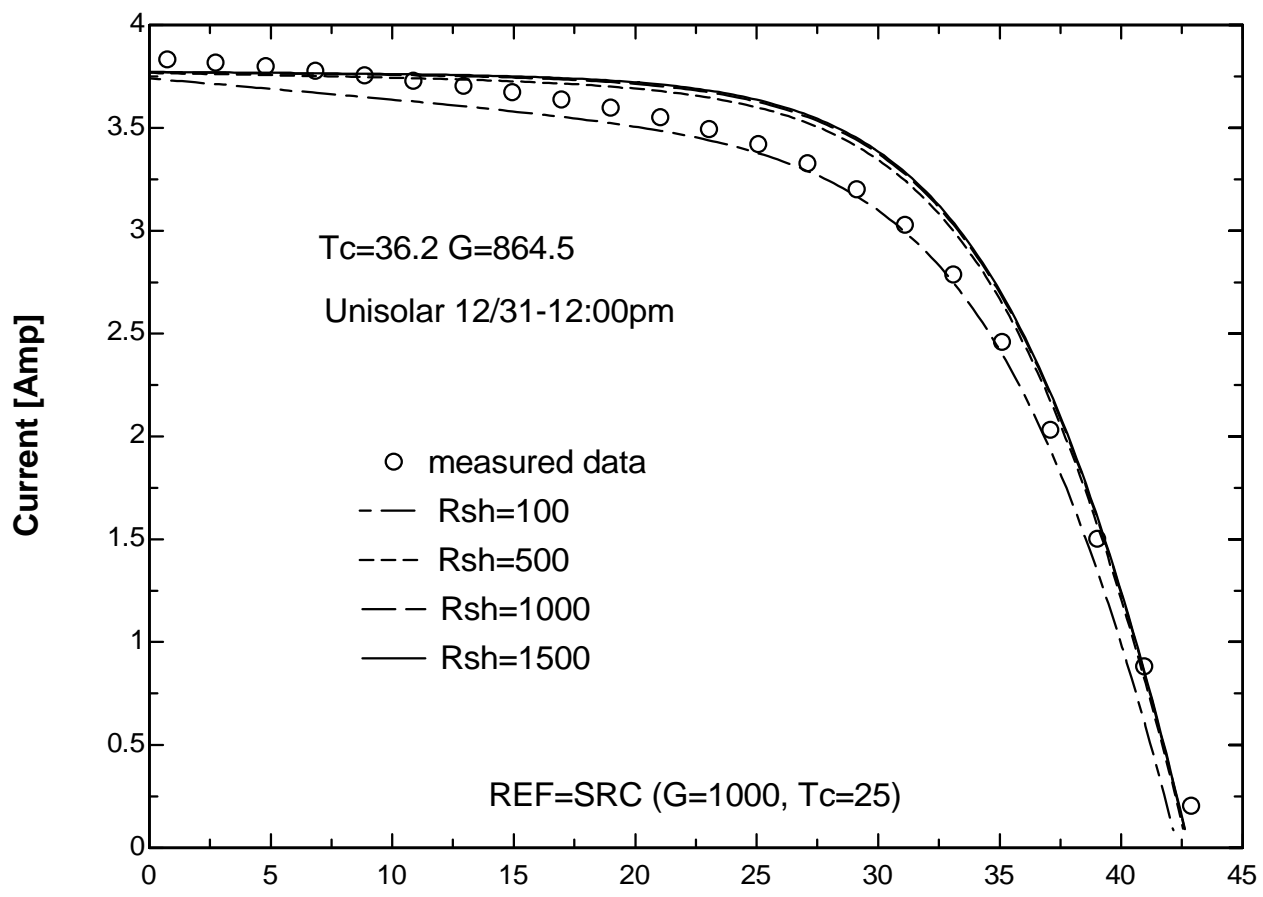

\section{Voltage [V]}

Figure 4.45: Uni-Solar cell type, December 31 at $12: 00 \mathrm{pm}, T_{c}=36.2^{\circ} \mathrm{C}, G_{e f f}=864.5 \mathrm{~W} / \mathrm{m}^{2}$, SRC as reference conditions 
Tables 4.4-4.11 show the percentage root mean square (RMS) error between the calculated current-voltage (I-V) curve and the data provided by NIST as a function of the value of the shunt resistance $\left(R_{s h}\right)$.

Tables 4.4-4.7 show the values of the errors obtained when using different shunt resistance $\left(R_{s h}\right)$ values. The error using the 5 important points which correspond to the following voltages: $V=0, V=0.5 V_{o c}, V=V_{m p}, V=0.5\left(V_{o c}+V_{m p}\right), V=V_{o c}$ was calculated using Equation (4.31) and the error that uses only the maximum power point was calculated using Equation (4.32). The results of Equation (4.32) are shown in Tables 4.8-4.11. The maximum difference between the obtained RMS errors is shown in the last row of each table.

Table 4.4: Siemens RMS Percentage Error using 5 points

\begin{tabular}{|c|c|c|}
\hline $\mathbf{R}_{\text {sh }}$ & RMS Error [\%] Fig.1 & RMS Error [\%] Fig.2 \\
\hline Infinity & 0.412 & 1.877 \\
\hline 1500 & 0.5989 & 1.574 \\
\hline 1000 & 0.8698 & 1.443 \\
\hline 500 & 1.778 & 1.178 \\
\hline Max. Difference & 1.366 & 0.699 \\
\hline
\end{tabular}

Table 4.5: Solarex RMS Percentage Error using 5 points

\begin{tabular}{|c|c|c|}
\hline $\mathbf{R}_{\text {sh }}$ & RMS Error [\%] Fig.3 & RMS Error [\%] Fig.4 \\
\hline Infinity & 5.913 & 4.311 \\
\hline 1500 & 6.118 & 4.493 \\
\hline 1000 & 6.235 & 4.59 \\
\hline 500 & 6.642 & 4.903 \\
\hline Max. Difference & 0.729 & 0.592 \\
\hline
\end{tabular}

Table 4.6: Astropower RMS Percentage Error using 5 points

\begin{tabular}{|c|c|c|}
\hline $\mathbf{R}_{\text {sh }}$ & RMS Error [\%] Fig.5 & RMS Error [\%] Fig.6 \\
\hline 125 & 5.188 & 1.999 \\
\hline 500 & 6.772 & 3.283 \\
\hline 1000 & 7.086 & 3.588 \\
\hline 1500 & 7.193 & 3.692 \\
\hline Max. Difference & 2.005 & 1.693 \\
\hline
\end{tabular}


Table 4.7: Uni-Solar RMS Percentage Error using 5 points

\begin{tabular}{|c|c|c|}
\hline $\mathbf{R}_{\text {sh }}$ & RMS Error [\%] Fig.7 & RMS Error [\%] Fig.8 \\
\hline 100 & 7.909 & 1.805 \\
\hline 500 & 2.981 & 3.426 \\
\hline 1000 & 3.379 & 3.975 \\
\hline 1500 & 3.565 & 4.16 \\
\hline Max. Difference & 4.928 & 2.355 \\
\hline
\end{tabular}

Table 4.8: Siemens RMS Percentage Error using Maximum Power point

\begin{tabular}{|c|c|c|}
\hline $\mathbf{R}_{\text {sh }}$ & RMS Error [\%] Fig.1 & RMS Error [\%] Fig.2 \\
\hline Infinity & 0.02452 & 0.9248 \\
\hline 1500 & 0.9482 & 0.3352 \\
\hline 1000 & 1.434 & 0.0405 \\
\hline 500 & 2.891 & 0.8426 \\
\hline Max. Difference & 2.866 & 0.8843 \\
\hline
\end{tabular}

Table 4.9: Solarex RMS Percentage Error using Maximum Power point

\begin{tabular}{|c|c|c|}
\hline $\mathbf{R}_{\text {sh }}$ & RMS Error [\%] Fig.3 & RMS Error [\%] Fig.4 \\
\hline Infinity & 3.337 & 2.83 \\
\hline 1500 & 4.206 & 3.362 \\
\hline 1000 & 4.642 & 3.628 \\
\hline 500 & 5.948 & 4.427 \\
\hline Max. Difference & 2.611 & 1.597 \\
\hline
\end{tabular}

Table 4.10: Astropower RMS Percentage Error using Maximum Power point

\begin{tabular}{|c|c|c|}
\hline $\mathbf{R}_{\mathbf{s h}}$ & RMS Error [\%] Fig.5 & RMS Error [\%] Fig.6 \\
\hline 125 & 1.252 & 1.254 \\
\hline 500 & 2.203 & 1.851 \\
\hline 1000 & 2.779 & 2.37 \\
\hline 1500 & 2.972 & 2.542 \\
\hline Max. Difference & 1.72 & 1.288 \\
\hline
\end{tabular}

Table 4.11: Uni-Solar RMS Percentage Error using Maximum Power point

\begin{tabular}{|c|c|c|}
\hline $\mathbf{R}_{\text {sh }}$ & RMS Error [\%] Fig.7 & RMS Error [\%] Fig.8 \\
\hline 100 & 10.37 & 1.224 \\
\hline 500 & 2.755 & 7.006 \\
\hline 1000 & 4.371 & 8.026 \\
\hline 1500 & 4.908 & 8.366 \\
\hline Max. Difference & 7.615 & 7.142 \\
\hline
\end{tabular}


The RMS errors (calculated using 5 points to represent the I-V curve) calculated for all of the cell technologies with the exception of Uni-Solar differ by $2 \%$ or less, while for the Uni-Solar differences of up to near 5\% were observed. When only the maximum power point is considered, the percentage error varies by approximately less than $3 \%$ for all the cell technologies with the exception of Uni-Solar, which varies by up to near $8 \%$.

From the graphs and the tables it can be concluded that for every cell technology with the exception of Uni-Solar (3-Junction Amorphous) the shunt resistance parameter $\left(R_{\text {sh }}\right)$ has only a small effect on the behavior of the current-voltage (I-V) curve and therefore an equation to vary the shunt resistance with operating conditions is not necessary, hence Equation (4.33):

$$
R_{s h}=R_{s h, r e f}
$$

For the Uni-Solar case this is not always true and an equation that corrects for the differences in cell temperature and irradiance would improve predictive capability. Because the 3-Junction amorphous cell technology (Uni-Solar) is composed of three different materials, it was expected that it will not behave like the other cell technologies and might not be reasonable to model it with the 5-Parameter model.

If conditions other than SRC (or any other conditions being used as reference) are present, Equations (4.1), (4.2), (4.4), (4.21), and (4.33) can be used to calculate the parameters $a, I_{o}, I_{L}, R_{s}$, and $R_{s h}$, respectively. If this parameters are substituted in Equation (4.7) the performance of the PV cell can be predicted. 


\section{Chapter 5 \\ Comparing Predicted I-V curves with NIST data}

The availability of high accuracy data for four types of PV modules at 5 minute intervals made possible the validation of the equations presented in Chapter 4. These data were used to prove that the 5-Parameter model constitutes a valuable tool for PV performance prediction.

Weather and operating conditions will usually be very different from those of SRC (or any other reference condition being used). Equations (4.1), (4.2), (4.4), (4.21), and (4.33) have been developed to account for these differences, where $G_{e f f}, I_{m p}$, and $V_{m p}$ can be calculated from Equations (4.5), (4.25), and (4.29), respectively. The reference conditions can be calculated following the instructions in Chapter 3, Sections 3.3 and 3.4. An example program on how to predict the I-V curve can be found in Appendix C, Part II.

Figures 5.1-5.12 show some resulting predictions for the different cell technologies (Siemens: single-crystalline, Solarex: poly-crystalline, Astropower: silicon thin film, Uni-Solar: 3-Junction amorphous) at different operating conditions, and using different reference conditions (SRC, winter, summer). Figures 5.1-5.3 correspond to the Siemens cell type, Figures 5.4-5.6 to the Solarex cell type, Figures 5.7-5.9 correspond to the Astropower cell type, and Figures 5.10-5.12 to the Uni-Solar cell type. 


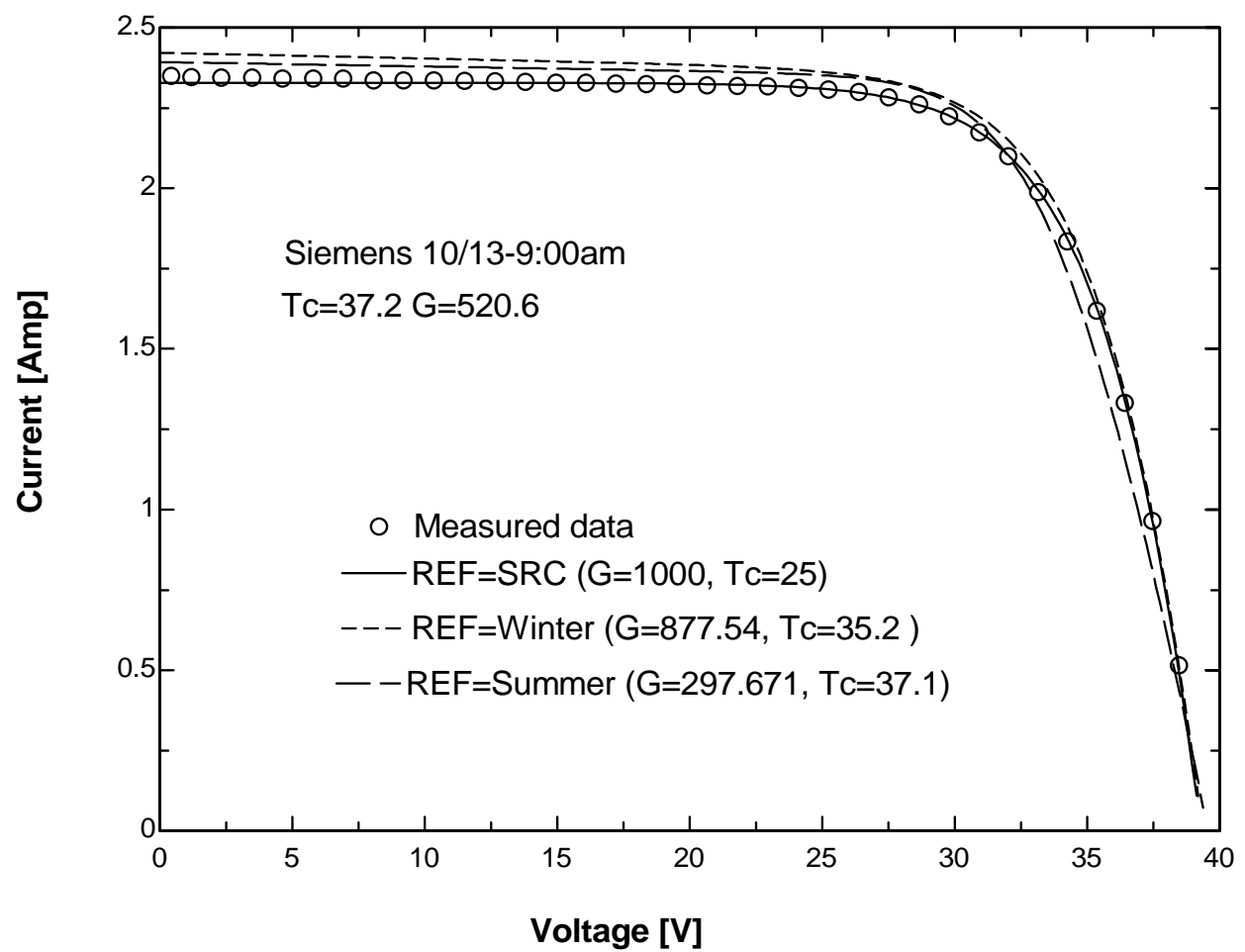

Figure 5.1: I-V curve predictions for Siemens, October 13 at 9:00am, using as reference conditions SRC, winter, and summer conditions

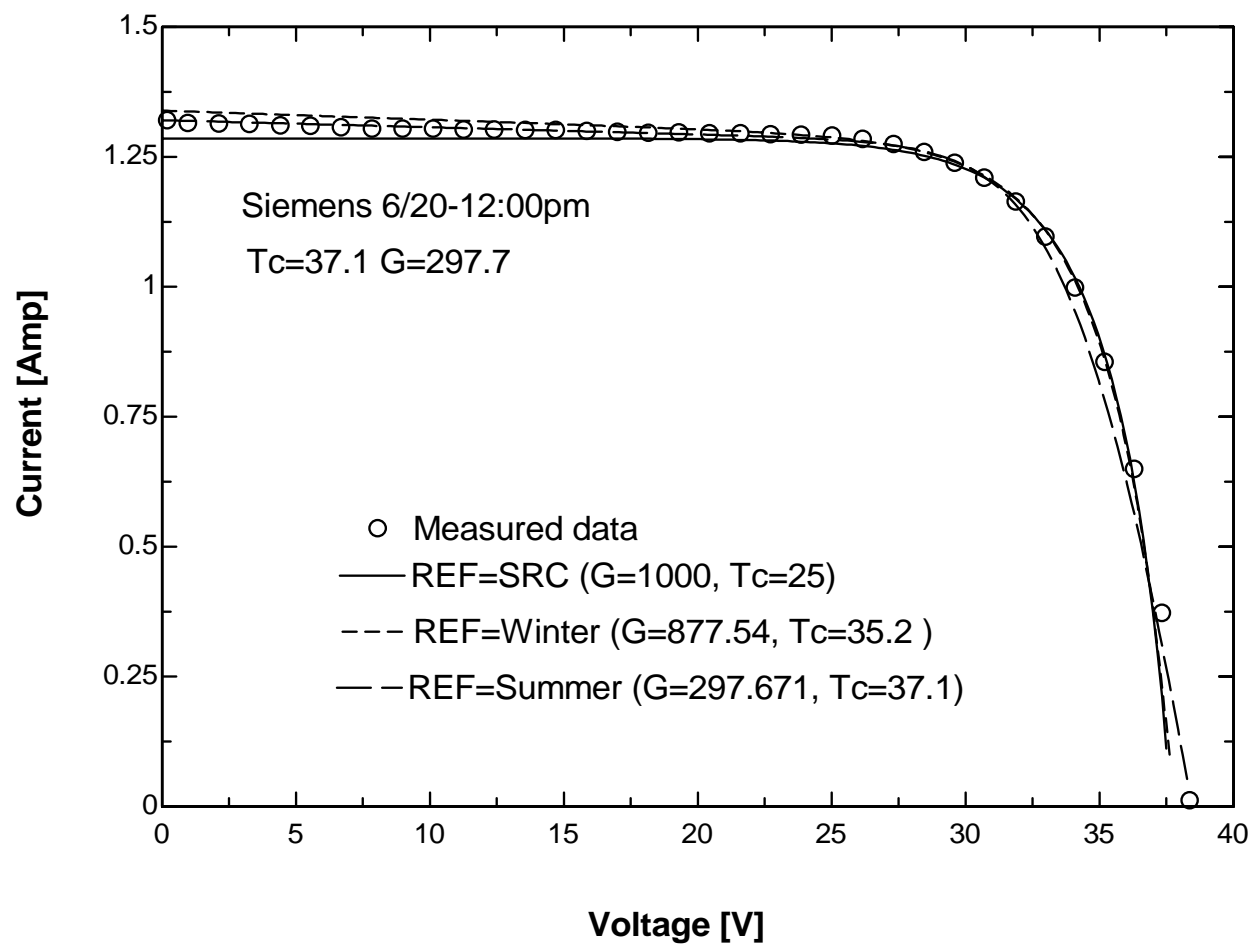

Figure 5.2: $\mathrm{I}-\mathrm{V}$ curve predictions for Siemens, June 20 at 12:00pm, using as reference conditions SRC, winter, and summer conditions 


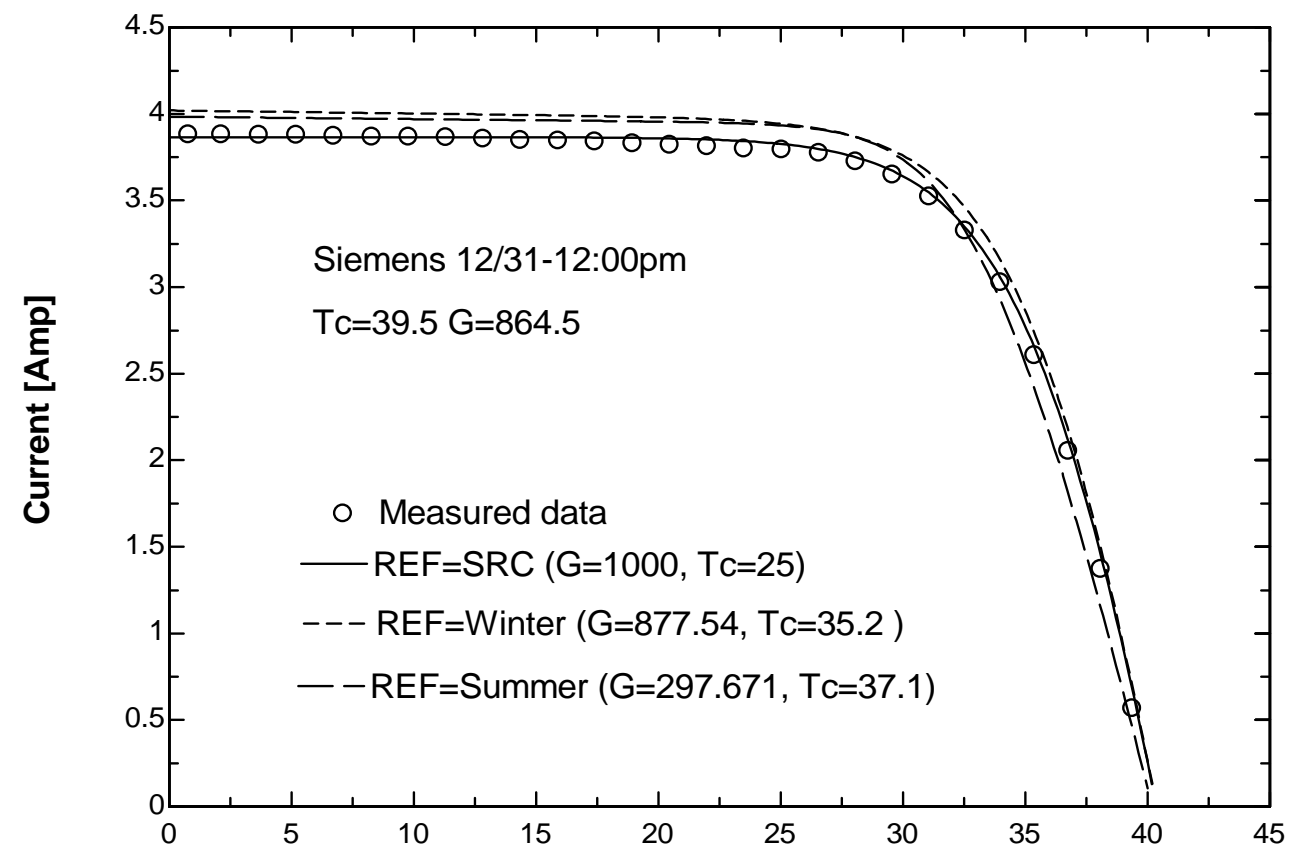

Voltage [V]

Figure 5.3: I-V curve predictions for Siemens, December 31at 12:00pm, using as reference conditions SRC, winter, and summer conditions

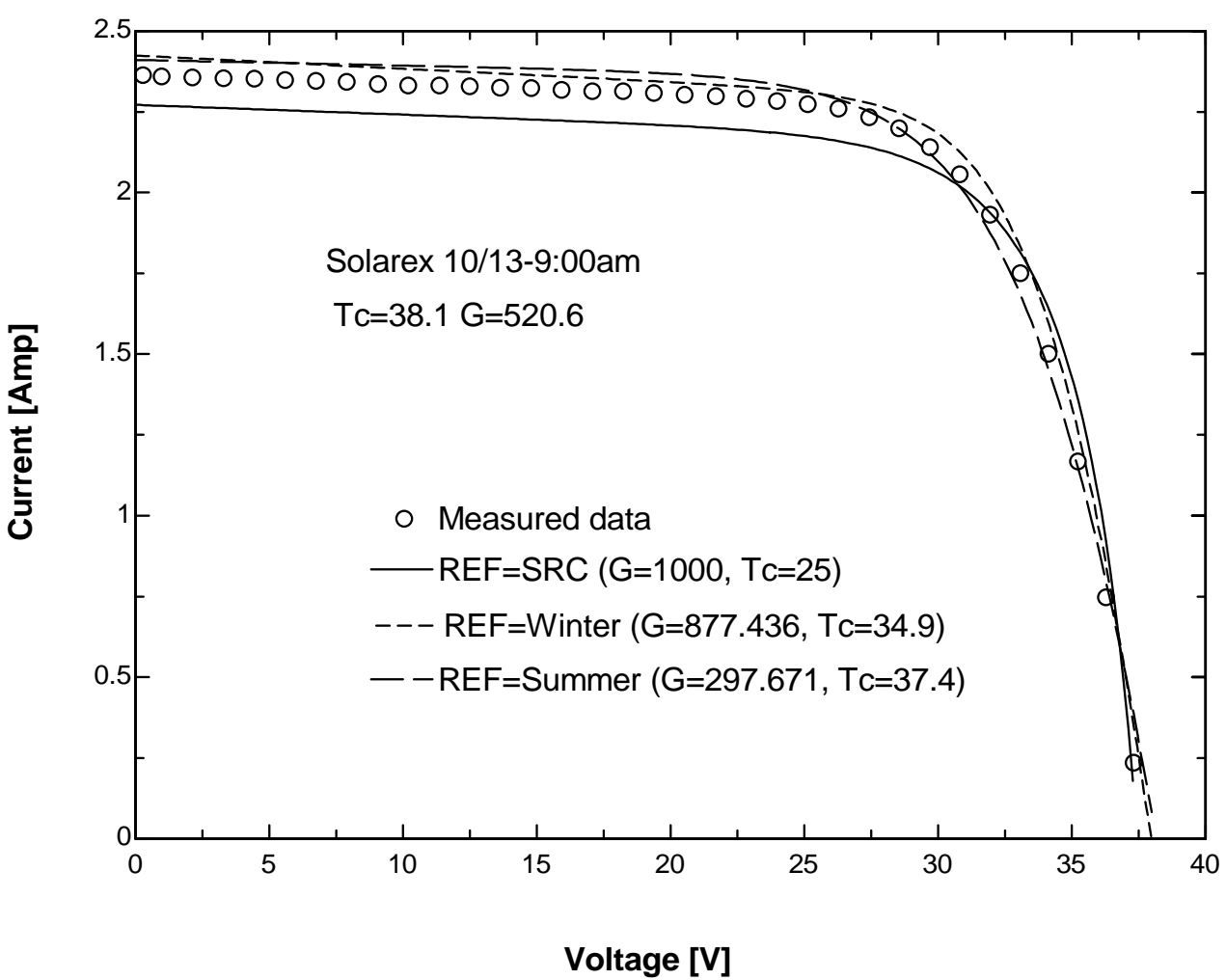

Figure 5.4: I-V curve predictions for Solarex, October 13 at 9:00am, using as reference conditions SRC, winter, and summer conditions 


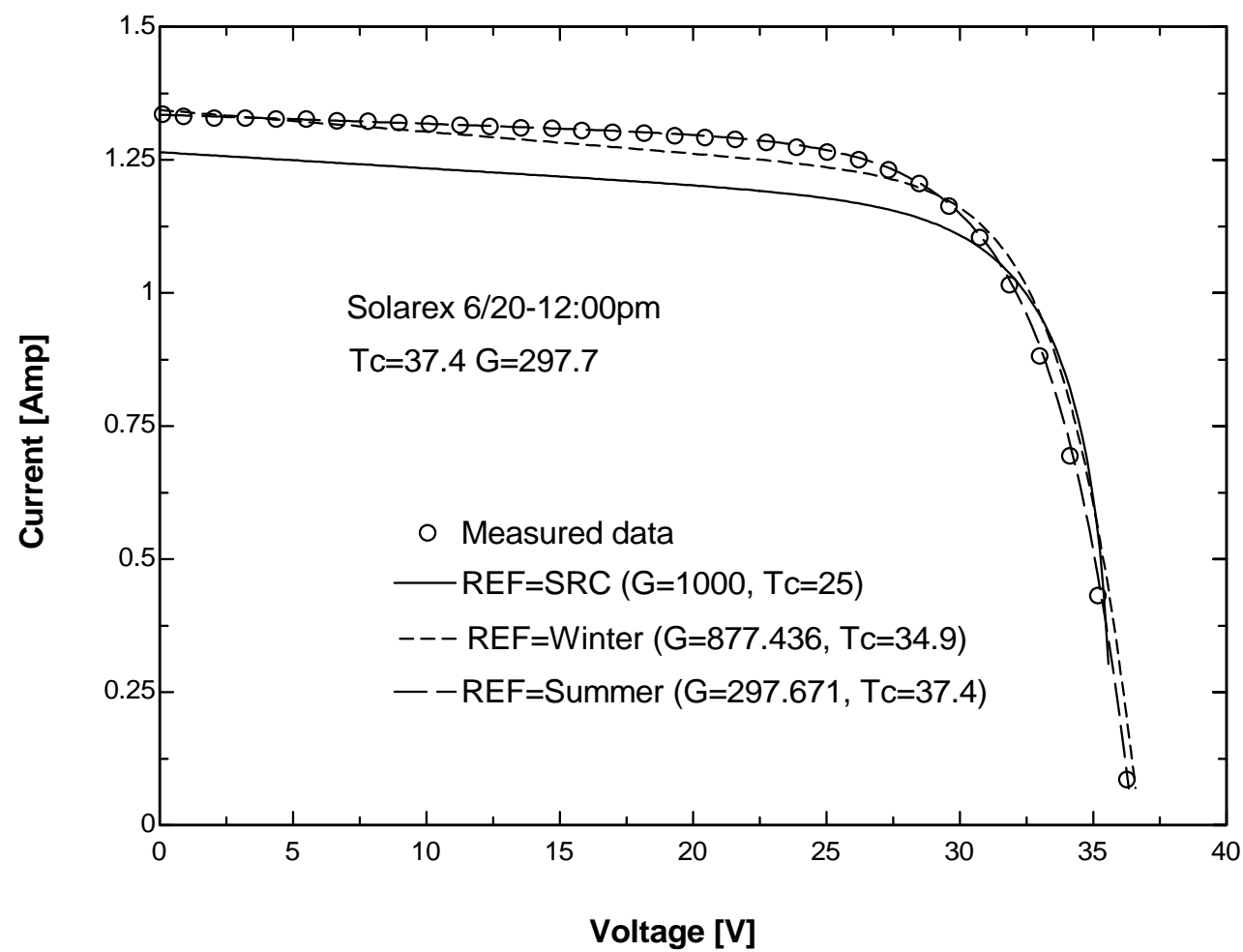

Figure 5.5: I-V curve predictions for Solarex, June 20 at 12:00pm, using as reference conditions SRC, winter, and summer conditions

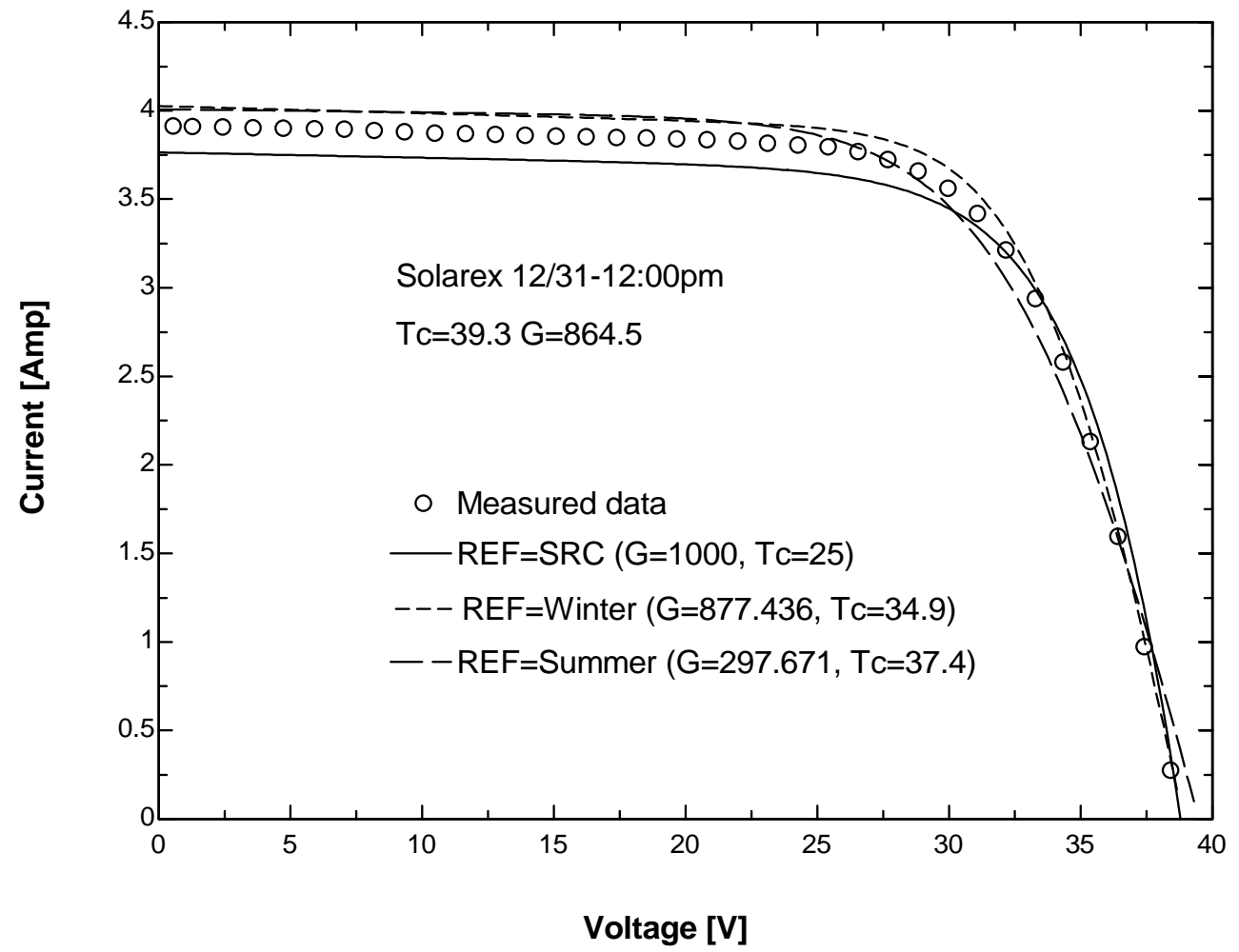

Figure 5.6: $\mathrm{I}-\mathrm{V}$ curve predictions for Solarex, December 31 at 12:00pm, using as reference conditions SRC, winter, and summer conditions 


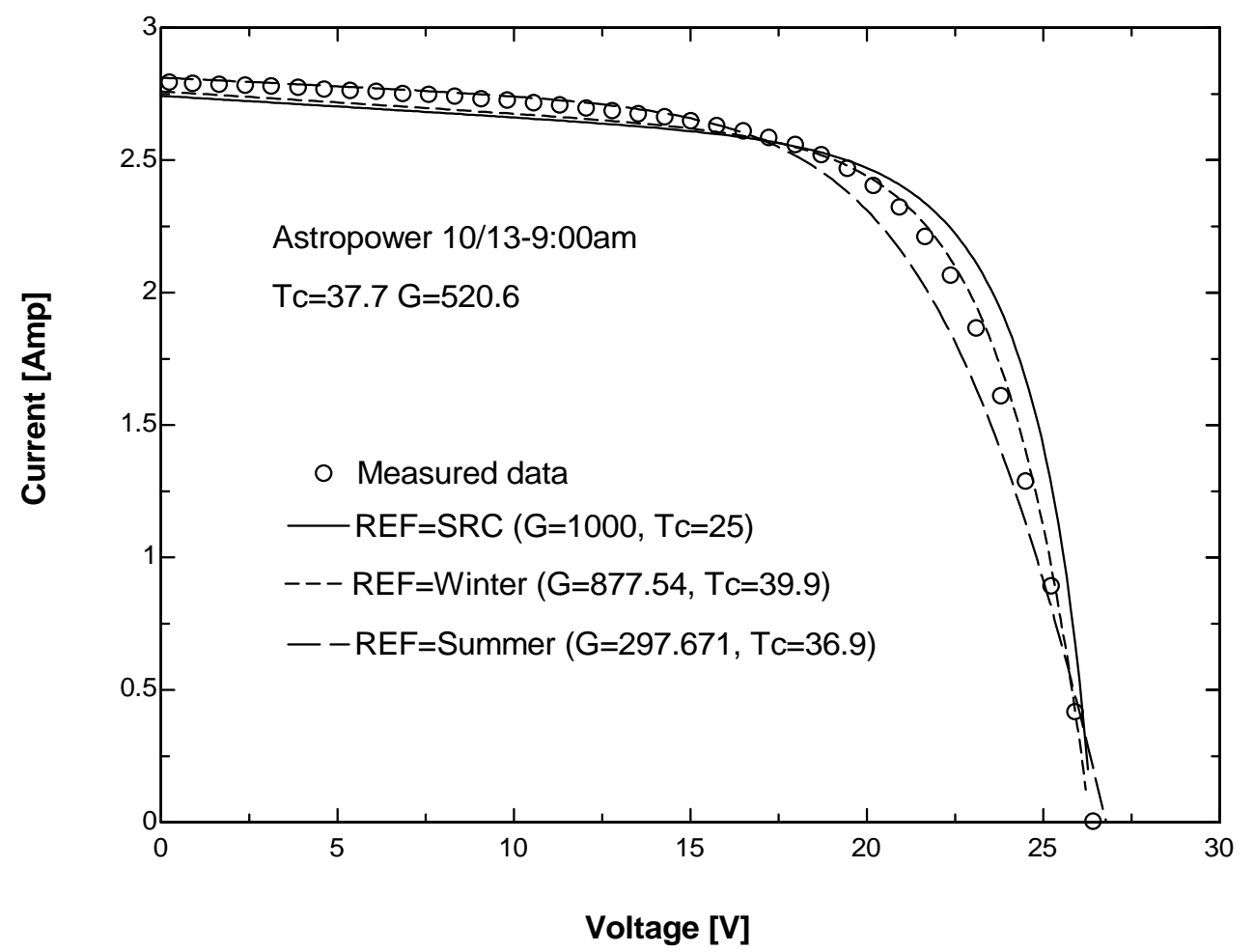

Figure 5.7: I-V curve predictions for Astropower, October 13 at 9:00am, using as reference conditions SRC, winter, and summer conditions

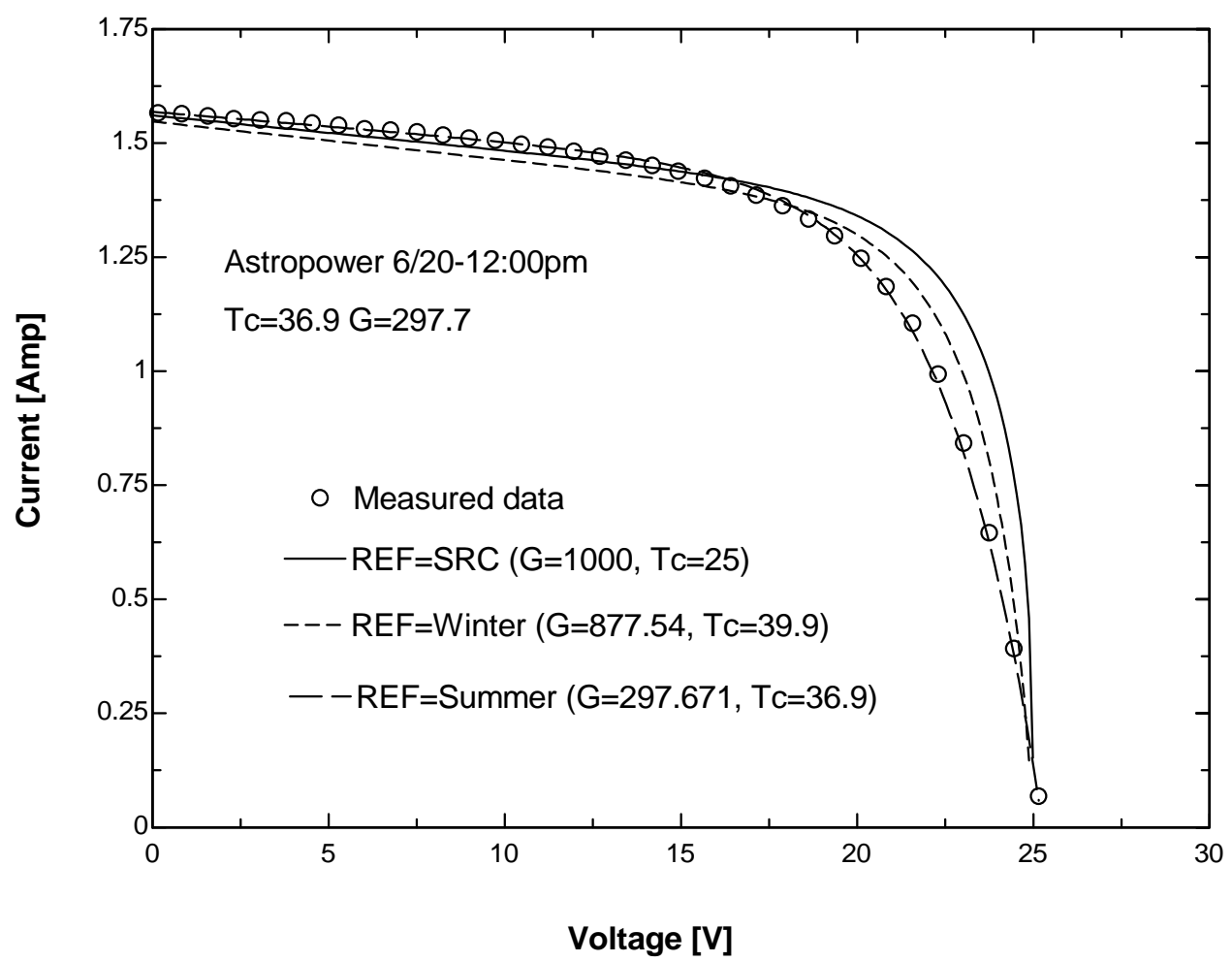

Figure 5.8: I-V curve predictions for Astropower, June 20 at 12:00pm, using as reference conditions SRC, winter, and summer conditions 


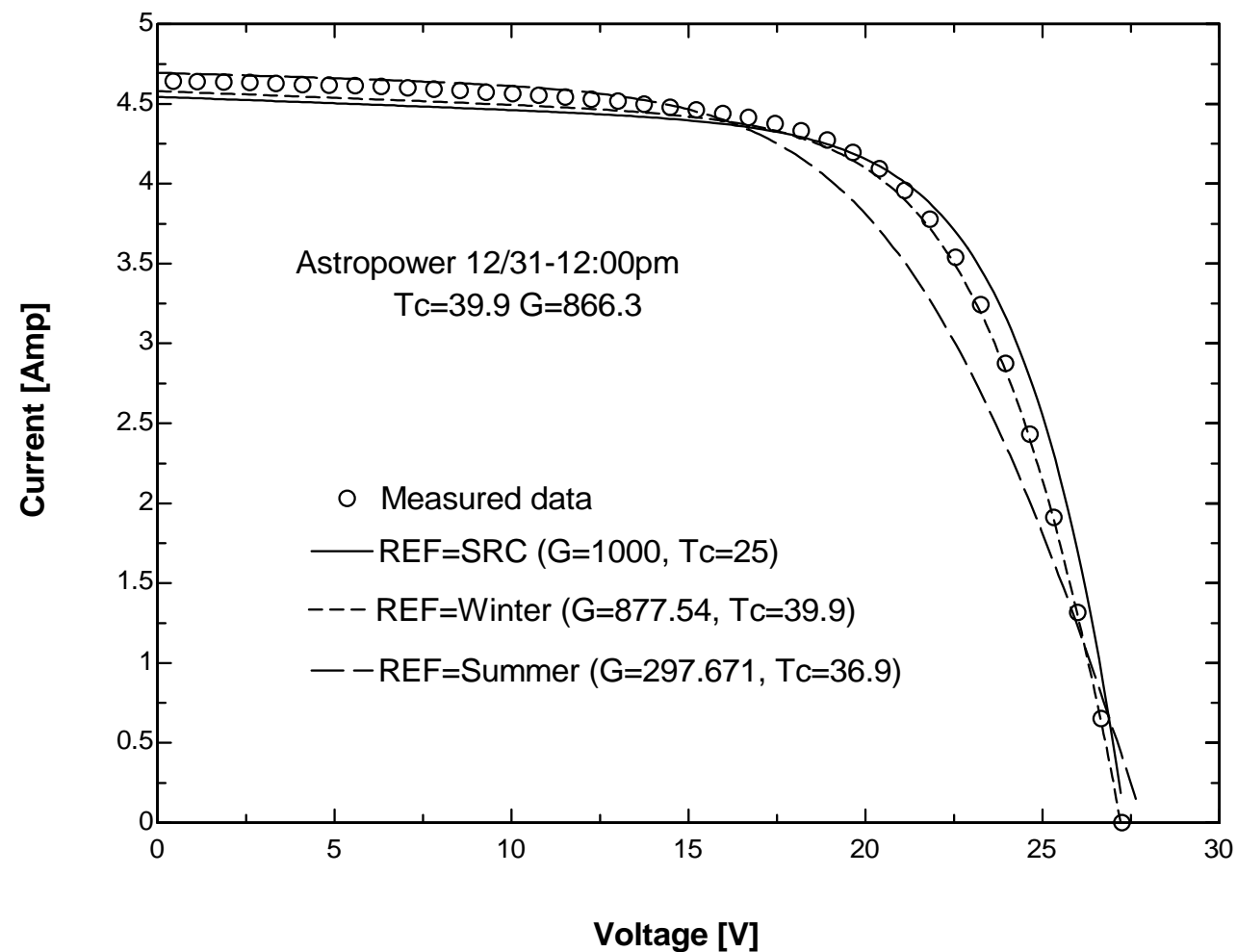

Figure 5.9: I-V curve predictions for Astropower, December 31 at 12:00pm, using as reference conditions SRC, winter, and summer conditions

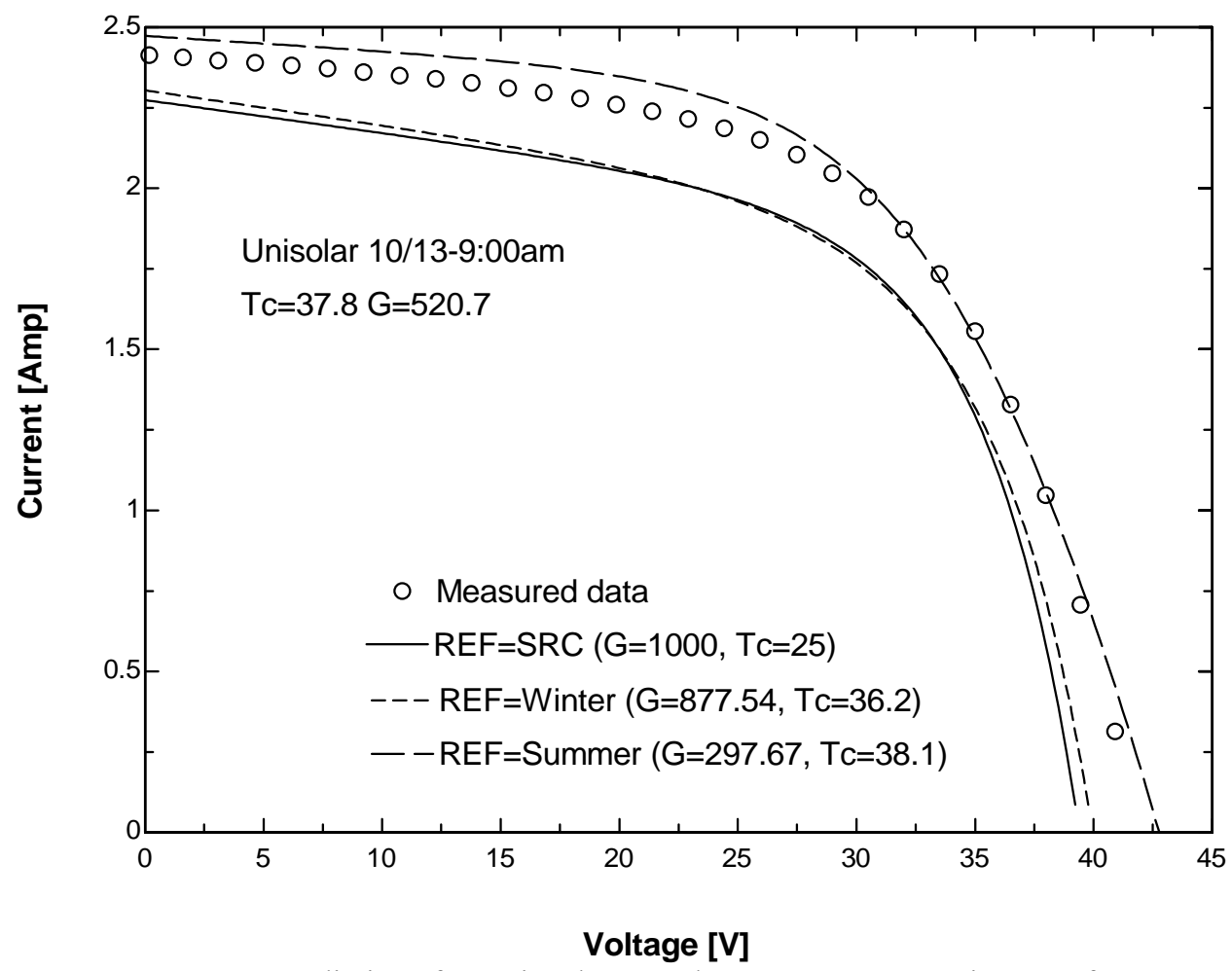

Figure 5.10: $\mathrm{I}-\mathrm{V}$ curve predictions for Uni-Solar, October 13 at 9:00am, using as reference conditions SRC, winter, and summer conditions 


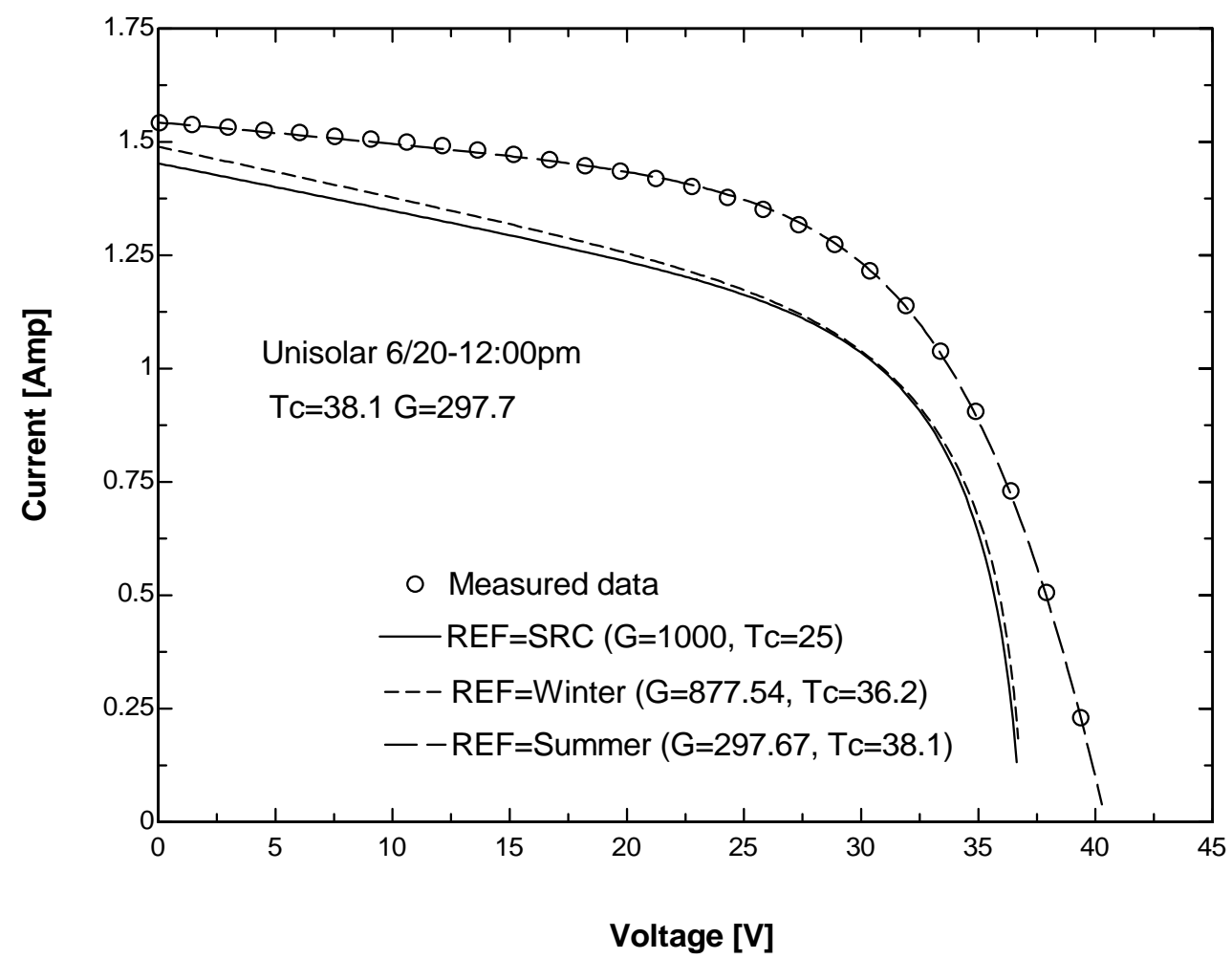

Figure 5.11: I-V curve predictions for Uni-Solar, June 20 at 12:00pm, using as reference conditions SRC, winter, and summer conditions

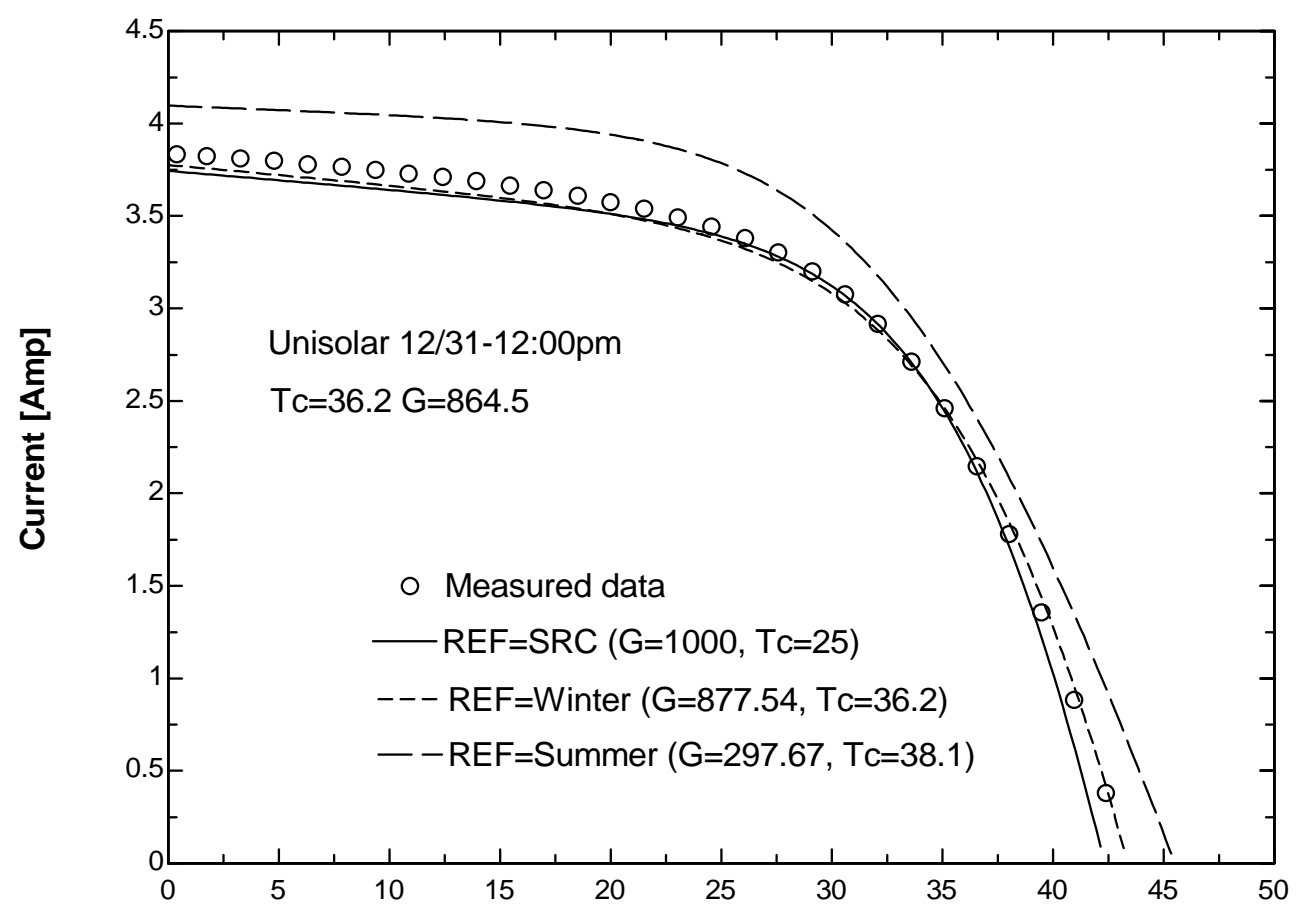

Voltage [V]

Figure 5.12: I-V curve predictions for Uni-Solar, December 31 at 12:00pm, using as reference conditions SRC, winter, and summer conditions 
Figures 5.1-5.6 show that sometimes there is an under-prediction or an overprediction in the short circuit current. This error in predicted short circuit current is probably due to uncertainties in the irradiance measurements, as will be discussed in details in Chapter 6. Figures 5.7-5.9, the predicted I-V curves for the Astropower cell type, over-predict the maximum power point voltages and currents for the case where Standard Rated Conditions (SRC) are taken as reference, while under-predicting these values for the case where summer conditions are taken as reference. This behavior can be caused by inaccurate determination of the reference parameters. Inaccurate predictions of the $V_{m p}$ and $I_{m p}$ values, used in Equation (4.21), might be another cause. In the case where SRC are taken as reference conditions, the differences can be attributed to the fact that the SRC values were measured using different equipment (such as pyranometers) than the rest of the values. By using different pyranometers, the bias error in the instruments is increased, increasing the uncertainties. Figures 5.10-5.12 show that the predictions for the Uni-Solar cell type do not seem to fit the data as well as those for the other cell types do.

Tables 5.1 and 5.2 show the errors calculated using the five points selected for error calculation (as discussed in Chapter 4) and using only the maximum power point, respectively. Details on uncertainty calculation can be found in Chapter 6 . 
Table 5.1: Errors (in percentage) calculated using five important points

\begin{tabular}{|c|c|c|c|c|c|c|c|c|c|}
\hline Plot & \multicolumn{2}{|c|}{ October 13 at 9:00am } & \multicolumn{2}{|c|}{ June 20 at 12:00pm } & \multicolumn{2}{|c|}{ Dec. 31 at 12:00pm } \\
\hline $\begin{array}{c}\text { REF } \\
\text { conditions }\end{array}$ & SRC & Win & Sum & SRC & Win & Sum & SRC & Win & Sum \\
\hline $\begin{array}{c}\text { Siemens } \\
\text { (single-crystalline) }\end{array}$ & 0.362 & 2.177 & 3.28 & 1.401 & 0.720 & 2.127 & 1.653 & 3.538 & 3.237 \\
\hline $\begin{array}{c}\text { Solarex } \\
\text { (poly-crystalline) }\end{array}$ & 3.507 & 3.313 & 4.133 & 4.922 & 4.416 & 0.552 & 3.059 & 2.531 & 5.395 \\
\hline $\begin{array}{c}\text { Astropower } \\
\text { (silicon thin film) }\end{array}$ & 4.819 & 1.752 & 5.328 & 6.583 & 4.082 & 0.739 & 3.365 & 1.101 & 7.52 \\
\hline $\begin{array}{c}\text { Uni-Solar } \\
\text { (3-Junction } \\
\text { amorphous) }\end{array}$ & 8.810 & 7.807 & 4.132 & 11.60 & 10.35 & 0.321 & 1.384 & 1.228 & 10.13 \\
\hline
\end{tabular}

Table 5.2: Errors (in percentage) calculated using the maximum power point

\begin{tabular}{|c|c|c|c|c|c|c|c|c|c|}
\hline Plot & \multicolumn{2}{|c|}{ October 13 at 9:00am } & \multicolumn{2}{|c|}{ June 20 at 12:00pm } & \multicolumn{2}{|c|}{ Dec. 31 at 12:00pm } \\
\hline $\begin{array}{c}\text { REF } \\
\text { conditions }\end{array}$ & SRC & Win & Sum & SRC & Win & Sum & SRC & Win & Sum \\
\hline $\begin{array}{c}\text { Siemens } \\
\text { (single-crystalline) }\end{array}$ & 0.070 & 2.174 & 0.741 & 0.020 & 0.273 & 0.038 & 0.501 & 3.836 & 2.254 \\
\hline $\begin{array}{c}\text { Solarex } \\
\text { (poly-crystalline) }\end{array}$ & 2.973 & 2.747 & 1.144 & 4.408 & 0.231 & 0.002 & 3.173 & 3.181 & 2.737 \\
\hline $\begin{array}{c}\text { Astropower } \\
\text { (silicon thin film) }\end{array}$ & 2.674 & 0.834 & 6.074 & 4.719 & 3.056 & 0.483 & 0.710 & 1.528 & 10.44 \\
\hline $\begin{array}{c}\text { Uni-Solar } \\
\text { (3-Junction } \\
\text { amorphous) }\end{array}$ & 11.6 & 12.24 & 0.527 & 16.11 & 15.77 & 0.016 & 0.340 & 1.575 & 8.900 \\
\hline
\end{tabular}

From Table 5.1 it can be seen that in general, the errors calculated using the five important points for the first three cell types are under 7\%, while under $12 \%$ for the UniSolar cell type. If only the maximum power point is used to calculate the errors, the values obtained are generally under $5 \%$ for the first three cell types and up to $16 \%$ for the Uni-Solar cell type. 


\section{Chapter 6 \\ Uncertainty Analysis}

The predicted I-V curves are based on experimental measurements such as temperature and irradiance. These experimental measurements have associated uncertainties that can affect the predicted results. For this reason, an uncertainty analysis is necessary to ensure that the predicted I-V results agree with the measured I-V values within a reasonable error margin. The uncertainty analysis studies the effects of random errors on the measurements of cell temperature and irradiance and analyzes how they propagate to errors in the calculated current and voltage. Thermocouples were used to measure the cell temperature with an uncertainty of $\pm 1^{\circ} \mathrm{C}$ (absolute value), while an uncertainty of $\pm 3 \%$ (relative value) was assigned to the irradiance measurements, made with PSP Eppley pyranometers. The current and voltage data measured at NIST are assumed to have negligible uncertainty, just like the measurements of time and any other input parameter, such as $\alpha_{I s c}$ and $\beta_{V o c}$.

For this study, uncertainty calculations were made by adding an uncertainty to the measurements of cell temperature and irradiance components prior to calculating the effective irradiance and the five parameters $\left(a, I_{o}, I_{L}, R_{s}, R_{s h}\right)$. The parameters carrying the uncertainty were then substituted in Equation (3.2), carrying this way the uncertainties into the predicted I-V curve. Equation (6.1) shows that for this study, the uncertainty in the current is composed of the partial derivatives of the current with respect to the cell temperature and the effective irradiance times their respective uncertainties. 


$$
\Delta I=\sqrt{\left(\frac{\partial I}{\partial T_{c}} \Delta T_{c}\right)^{2}+\left(\frac{\partial I}{\partial G_{e f f}} \Delta G_{e f f}\right)^{2}}
$$

Figures 6.1-6.4 show the predicted current-voltage (I-V) curves for different photovoltaic cell technologies, using SRC as reference operating conditions, where the cell temperature $\left(T_{c}\right)$ equals $25^{\circ} \mathrm{C}$ and the effective irradiance $\left(G_{\text {eff }}\right)$ equals $1000 \mathrm{~W} / \mathrm{m}^{2}$. The figures show the measured data and the uncertainty region within where the measured data should be located if the prediction is to be realiable.

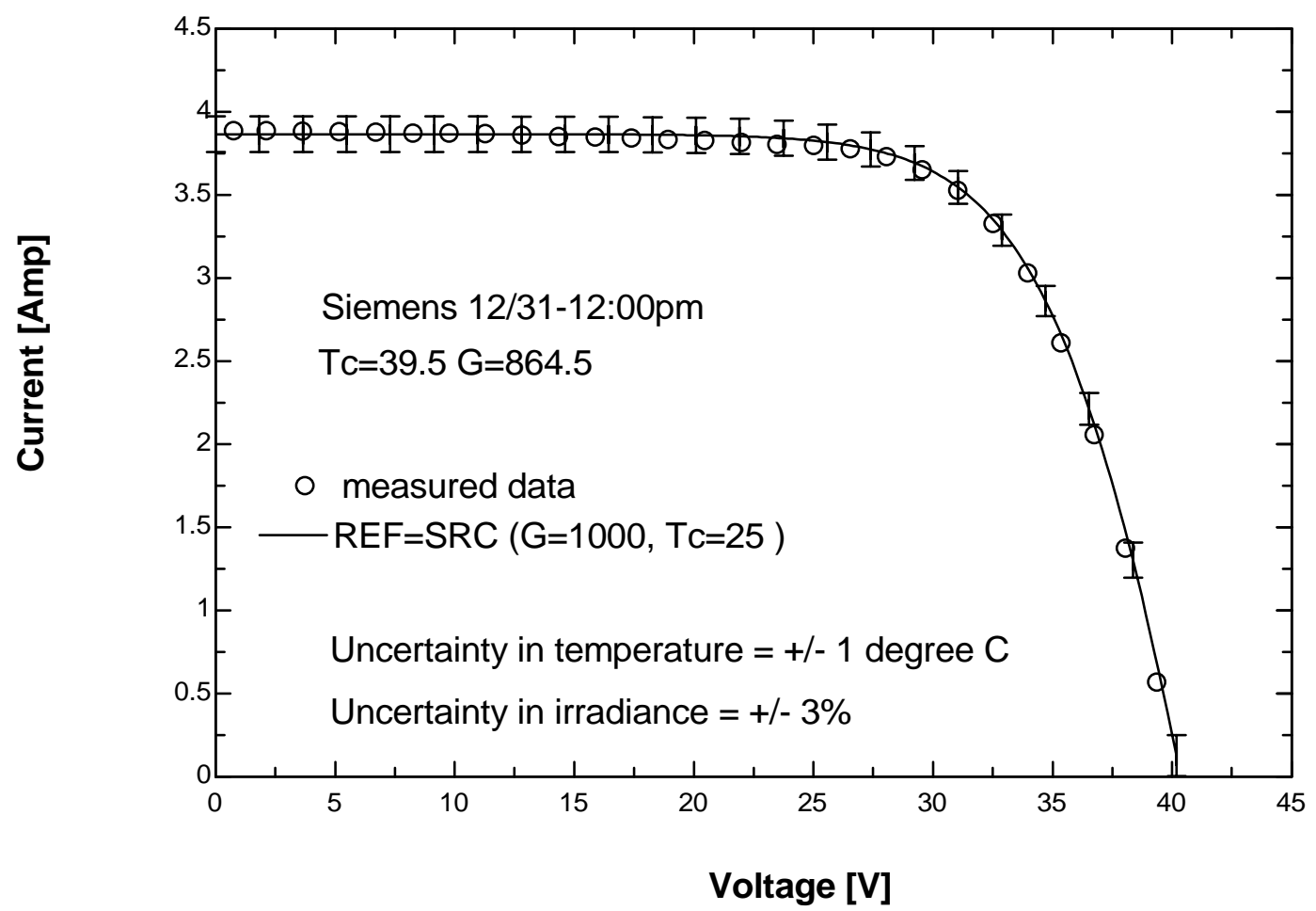

Figure 6.1: I-V curve predicted for Siemens cell type, December 31 at noon with $G_{\text {eff }}=864.5 \mathrm{~W} / \mathrm{m}^{2}$ and $T_{c}=39.5^{\circ} \mathrm{C}$, using $\mathrm{SRC}$ as reference conditions 


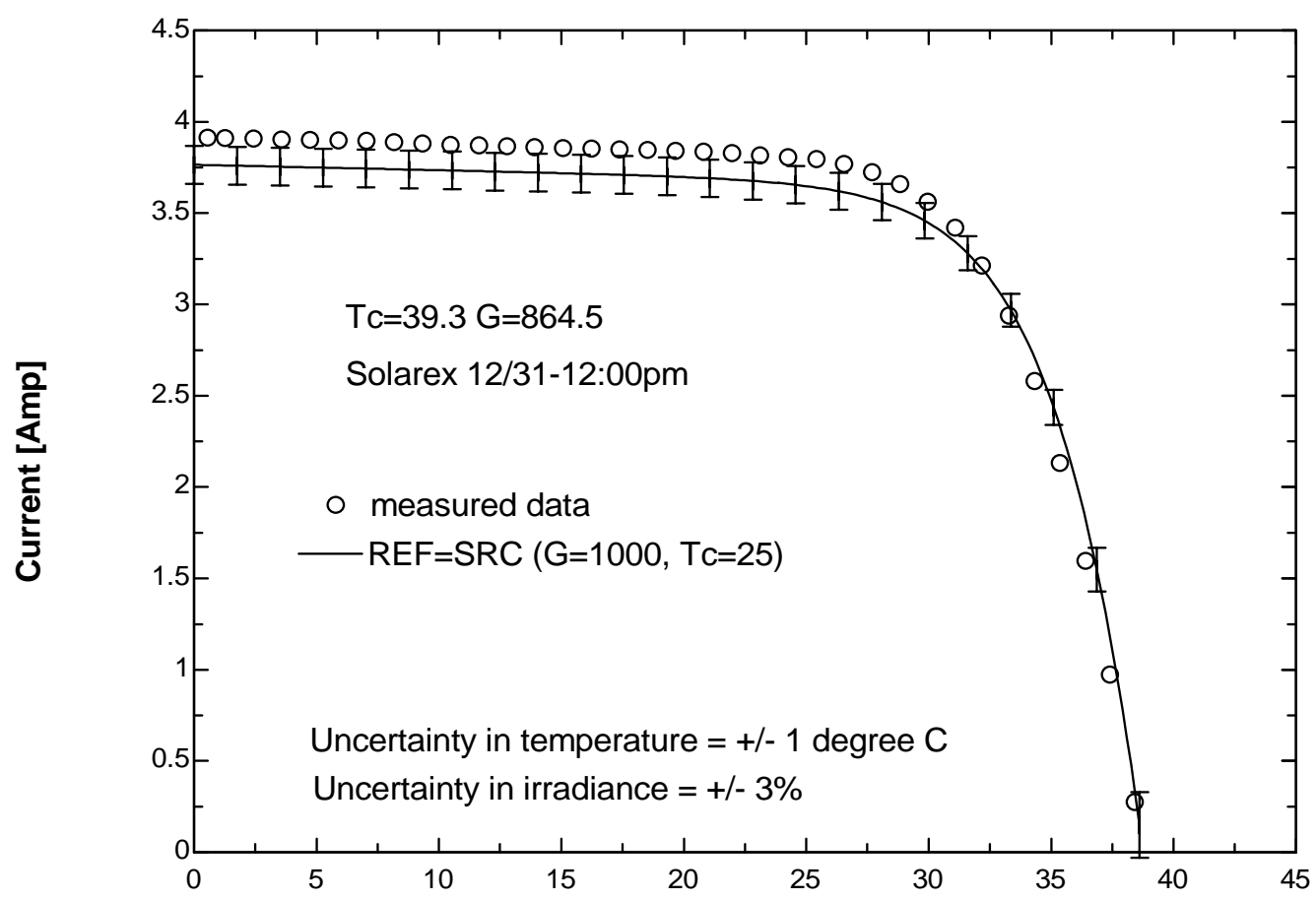

\section{Voltage [V]}

Figure 6.2: I-V curve predicted for Solarex cell type, December 31 at noon with $G_{\text {eff }}=864.5 \mathrm{~W} / \mathrm{m}^{2}$ and $T_{c}=39.3^{\circ} \mathrm{C}$, using $\mathrm{SRC}$ as reference conditions

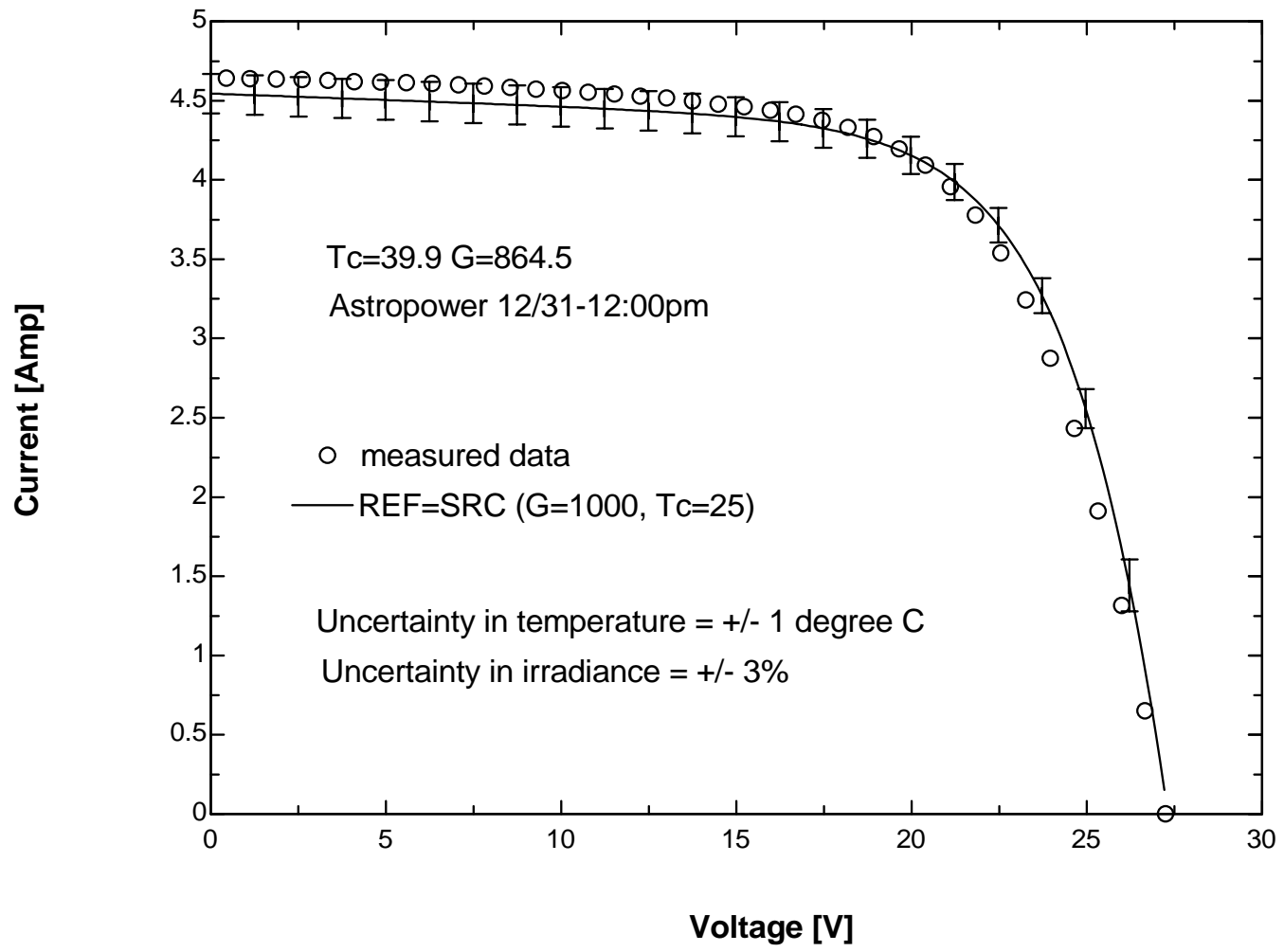

Figure 6.3: I-V curve predicted for Astropower cell type, December 31 at noon with $G_{\text {eff }}=864.5$ $\mathrm{W} / \mathrm{m}^{2}$ and $T_{c}=39.9^{\circ} \mathrm{C}$, using SRC as reference conditions 


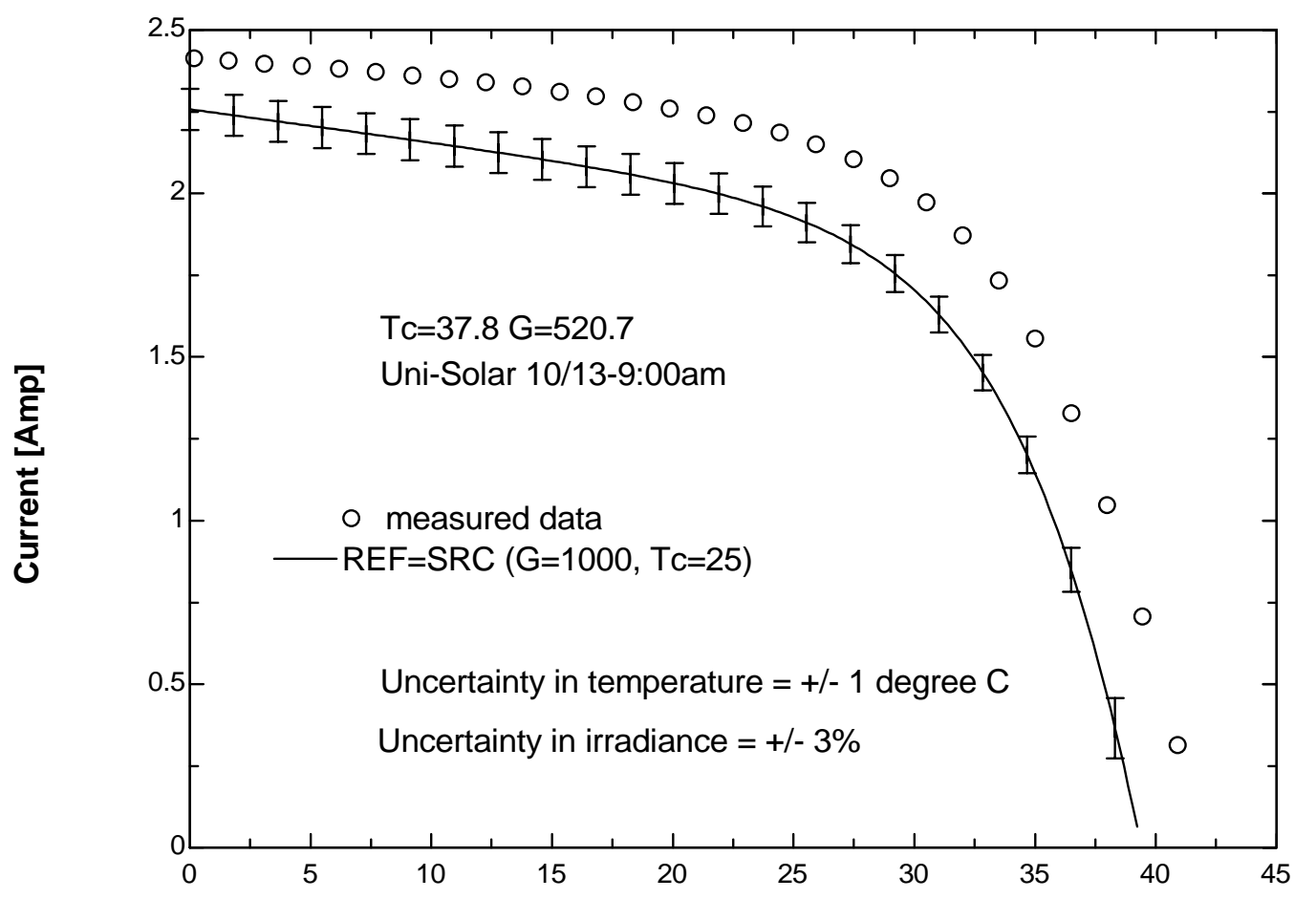

\section{Voltage [V]}

Figure 6.4: I-V curve predicted for Uni-Solar cell type, October 13 at 9:00am with $G_{\text {eff }}=520.7$ $\mathrm{W} / \mathrm{m}^{2}$ and $T_{c}=37.8^{\circ} \mathrm{C}$, using SRC as reference conditions

Figures 6.1-6.4 show that the measured data are located within the uncertainty region for all cell types, with the exception of the Uni-Solar cell type, whose data are located outside the uncertainty region. This proves that (with the exception of the 3junction amorphous cell type) reasonable results within the existing limitations (uncertainty in measurering instruments) can be obtained by using the 5-Parameter model.

If the predictions for the PV cells are made using reference curves obtained for the same panel and using the irradiance and temperature values obtained with the same instrumentation (as done in the case where winter conditions were used as reference), the uncertainty values should be smaller than if different instrumentation is used because the bias error in the instruments is eliminated. In general, if the same instrumentation is used 
to calculate the I-V curve at reference conditions and at any other operating conditions, the predictions should be closer to the measured data, decreasing the value of the uncertainties present. If different instrumentation is used (as happens in the case where SRC conditions are used as reference conditions), larger uncertainties need to be taken in consideration. This is the case when manufacturers provide a set of data to be used as reference conditions and the purchaser uses a different set of measuring instruments to evaluate the system's performance.

From the graphs it is clear that the measured I-V curves data and the predicted I-V curves coincide in the uncertainty range for all of the cell technologies, with the exception of the 3-Junction Amorphous (Uni-Solar). Due to the existing uncertainty in the instrumentation, it is not possible to predict the I-V curve any better than this. For the Uni-Solar case, once more this serves as proof that this cell technology cannot be accurately represented with the 5-Parameter model. 


\section{Chapter 7}

Advantage of manufacturers providing two sets of data instead of one (Two-curve optimization method)

It has been shown in Chapters 5-6 that the 5-Parameter model with parameters that vary as a function of operating conditions provides a very useful tool in accurately predicting the current-voltage (I-V) curve of a PV panel. The average error, previously discussed in Chapter 5, was found to be under $7 \%$ for cell technologies such as singlecrystalline, poly-crystalline, and silicon thin film. The conditions used as reference will slightly affect the results obtained (usually from 1-3\%) if the references used are very different among themselves (one for summer and one for winter conditions). It was of great interest knowing how much better the performance predictions would be if the manufacturer were to provide two different I-V curves (one for low irradiance and one for high irradiance, such as SRC) instead of just one. These two curves would be used to generate a set of reference conditions and parameters $\left(a_{r e f}, I_{L, r e f}, I_{o, r e f}, R_{s, r e f}, R_{s h, r e f}\right)$ which would minimize the error in the predictions.

The following steps explain the procedure that was used to determine the benefit of using two I-V curves:

1. Two data curves provided by NIST at different conditions (one summer, one winter) for each cell type were chosen (one of them was the SRC curve, where $G=1000 \mathrm{~W} / \mathrm{m}^{2}$ and $T_{c}=25^{\circ} \mathrm{C}$. 
2. Equations (7.1)-(7.14) were applied for both I-V curves (selected in step 1), where the subscripts 1 and 2 refer to each of the two different data curves, each at completely different operating conditions $\left(T_{c 1}\right.$ and $G_{e f f l}$ vs $T_{c 2}$ and $\left.G_{e f f 2}\right)$. The subscript " $r e f$ " indicates at reference conditions and is used as reference for both operating conditions (1 and 2).

Equations (7.1) and (7.2) are used to calculate the ideality factor parameters $\left(a_{1}\right.$, $a_{2}$ ) for each I-V curve, selected in step 1:

$$
\begin{aligned}
& \frac{a_{1}}{a_{\text {ref }}}=\frac{T_{c 1}}{T_{c, \text { ref }}} \\
& \frac{a_{2}}{a_{\text {ref }}}=\frac{T_{c 2}}{T_{c, \text { ref }}}
\end{aligned}
$$

where $T_{c}$ and $a$ are the cell temperature and ideality factor parameters, respectively.

Equations (7.3) and (7.4) are used to calculate the diode reverse saturation currents $\left(I_{o l}, I_{o 2}\right)$ :

$$
\begin{aligned}
& \frac{I_{o 1}}{I_{o, r e f}}=\left[\frac{T_{c 1}}{T_{c, r e f}}\right]^{3} e^{\left[\frac{\varepsilon N_{s}\left(1-\frac{T_{c r e f}}{a_{r e f}}\right)}{T_{c 1}}\right)} \\
& \frac{I_{o 2}}{I_{o, \text { ref }}}=\left[\frac{T_{c 2}}{T_{c, \text { ref }}}\right]^{3} e^{\left.\left[\frac{\varepsilon N_{s}\left(1-\frac{T_{c, e f}}{a_{r e f}}\right.}{T_{c 2}}\right)\right]}
\end{aligned}
$$

where $I_{o}, \varepsilon$, and $N_{s}$ are the diode reverse saturation current, bandgap energy, and number of cells in series, respectively.

Equations (7.5) and (7.6) are used to calculate the light currents $\left(I_{L 1}, I_{L 2}\right)$ : 


$$
\begin{aligned}
& I_{L 1}=\frac{G_{e f f 1} M_{a m 1}}{G_{e f f, r e f} M_{a m, r e f}}\left[I_{L, r e f}+\alpha_{I s c}\left(T_{c 1}-T_{c, r e f)}\right]\right. \\
& I_{L 2}=\frac{G_{e f f 2} M_{a m 2}}{G_{e f f, r e f} M_{a m, r e f}}\left[I_{L, r e f}+\alpha_{I s c}\left(T_{c 2}-T_{c, r e f)}\right]\right.
\end{aligned}
$$

where $G_{e f f}, M_{a m}, I_{L}$, and $\alpha_{I s c}$ are the effective irradiance, air mass modifier, light current, and coefficient of temperature at short circuit current, respectively.

Equations (7.7) and (7.8) are used to calculate the series resistances $\left(R_{s l}, R_{s 2}\right)$ :

$$
\begin{gathered}
\frac{G_{e f f 1}}{G_{e f f, r e f}}=\frac{\frac{a_{r e f}}{I_{o, r e f}} e^{-\left[\frac{V_{m p, r e f}+I_{m p, r e f} R_{s, r e f}}{a_{r e f}}\right]}+R_{s, r e f}}{\frac{a_{1}}{I_{o 1}} e^{-\left[\frac{V_{m p 1}+I_{m p 1} R_{s 1}}{a_{1}}\right]}+R_{s 1}} \\
\frac{G_{e f f 2}}{G_{e f f, r e f}}=\frac{\frac{a_{r e f}}{I_{o, r e f}} e^{-\left[\frac{V_{m p, e f}+I_{m p, r e f} R_{s, r e f}}{a_{r e f}}\right]}+R_{s, r e f}}{\frac{a_{2}}{I_{o 2}} e^{-\left[\frac{V_{m p 2}+I_{m p 2} R_{s 2}}{a_{2}}\right]}+R_{s 2}}
\end{gathered}
$$

where $V_{m p}, I_{m p}$, and $R_{s}$ are the voltage and current at the maximum power point and the series resistance, respectively. The values for $V_{m p 1}, V_{m p 2}, I_{m p 1}$, and $I_{m p 2}$ are calculated from Equations (7.9) through (7.12).

$$
\begin{gathered}
I_{m p 1}=I_{m p, r e f} \frac{G_{e f f 1}}{G_{e f f, r e f}} \\
I_{m p 2}=I_{m p, r e f} \frac{G_{e f f 2}}{G_{e f f, r e f}} \\
V_{m p 1}=V_{m p, r e f}+\beta_{V o c}\left(T_{c 1}-T_{c, r e f}\right)
\end{gathered}
$$




$$
V_{m p 2}=V_{m p, r e f}+\beta_{V o c}\left(T_{c 2}-T_{c, r e f}\right)
$$

$\beta_{V o c}$ is the coefficient of temperature at open circuit voltage.

Equations (7.13) and (7.14) are used to calculate the shunt resistances $\left(R_{s h l}, R_{s h 2}\right)$ :

$$
\begin{aligned}
& R_{s h 1}=R_{s h, r e f} \\
& R_{s h 2}=R_{s h, r e f}
\end{aligned}
$$

where $R_{s h}$ is the shunt resistance.

Equations (7.1), (7.3), (7.5), (7.7), (7.9), (7.11) and (7.13) are then substituted in Equation (7.15), while Equations (7.2), (7.4), (7.6), (7.8), (7.10), (7.12), and (7.14) are substituted in Equation (7.16). Equations (7.15) and (7.16) are used to calculate the currents predicted by the model $\left(I_{\text {Modell }}, I_{\text {Model } 2}\right)$.

$$
\begin{gathered}
I_{\text {Model } 1}=I_{L 1}-I_{o 1}\left(e^{\frac{\left(V_{1}+I_{\text {Model }} R_{s i s}\right)}{a_{1}}}-1\right)-\frac{V_{1}+I_{\text {Model } 1} R_{s 1}}{R_{s h 1}} \\
I_{\text {Model } 2}=I_{L 2}-I_{o 2}\left(e^{\frac{\left(V_{2}+I_{\text {Model }} R_{s 2}\right)}{a_{2}}}-1\right)-\frac{V_{2}+I_{\text {Model } 2} R_{s 2}}{R_{s h 2}}
\end{gathered}
$$

The root mean square error is calculated using five points of interest indicated below (therefore, $\mathrm{N}=5$ ). NIST measurements were used to provide the data points used to determine the accuracy of this method.

$$
\begin{aligned}
& I_{1} @ V=0 \\
& I_{2} @ V=0.5 V_{o c} \\
& I_{3} @ V=V_{m p} \\
& I_{4} @ V=0.5\left(V_{o c}+V_{m p}\right)
\end{aligned}
$$




$$
I_{5} @ V=V_{o c}
$$

where $V_{o c}$ and $V_{m p}$ are the open circuit voltage and the voltage at the maximum power point, respectively.

The Percentage RMS errors are calculated using Equations (7.17) and (7.18), while its sum is calculated in Equation (7.19):

$$
\begin{aligned}
& \% R M S_{1}=\frac{\sqrt{\frac{\sum_{i=1}^{N}\left(I_{\text {Data }, i}-I_{\text {Model }, i}\right)^{2}}{N}}}{I_{\text {Data }, \text { sc } 1}} * 100 \% \\
& \% R M S_{2}=\frac{\sqrt{\frac{\sum_{i=1}^{N}\left(I_{\text {Data }, i}-I_{\text {Model } 2, i}\right)^{2}}{N}}}{I_{\text {Data }, s c 2}} * 100 \% \\
& \text { Total }_{\% \text { Error }}=\% R M S_{1}+\% R M S_{2}
\end{aligned}
$$

where $\% \mathrm{RMS}$ is the percentage root mean square error, $N$ is the number of points used for error calculation (5), $I_{\text {Data }}$ is the current value recorded by NIST at a specified voltage, $I_{\text {Model }}$ is the predicted value obtained using Equations (7.15) and (7.16) (at the same voltage that the $I_{\text {Data }}$ values were recorded), $I_{\text {Data,sc }}$ is the value of the short circuit current provided by NIST, and Total $\%$ Error is the sum of the results of Equations (7.17) and (7.18).

To obtain the reference parameters $\left(a_{r e f}, I_{L, r e f}, I_{o, r e f}, R_{s, r e f}, R_{s h, r e f}\right)$ an optimization is applied, where the sum of the \%RMS values for two curves measured at completely different weather conditions (winter and summer) (Equation (7.19)) is minimized, while the reference parameters are set as independent variables. The reference parameters for the SRC curve can be used as guess values. The resulting reference parameters are then 
used in Equations (7.1) through (7.14) to compute the parameters $\left(a_{1}, a_{2}, I_{L 1}, I_{L 2}, I_{o 1}, I_{o 2}\right.$, $\left.R_{s 1}, R_{s 2}, R_{s h 1}, R_{s h 2}\right)$ which are then used in Equations (7.15) and (7.16) to predict the current-voltage (I-V) curves. The percentage RMS errors are then computed with Equations (7.17) and (7.18). Equations (7.1) through (7.19) are run simultaneously. The obtained reference parameters can then be used to predict the I-V curve for other operating conditions. An example of a program that applies this method can be found in Appendix C, Part III under the name "Two-curve optimization method".

The following is a summary of the previously explained:

\section{Initially known variables:}

$T_{c, r e f}=25^{\circ} \mathrm{C}, T_{c 1}, T_{c 2}, G_{e f f, r e f}=1000 \mathrm{~W} / \mathrm{m}^{2}, G_{e f f l}, G_{e f f 2}, N_{s}, \varepsilon, M_{a m, r e f}=1, M_{a m 1}, M_{a m 2}, \alpha_{I s c}$,

$V_{m p, r e f}, I_{m p, r e f}, V_{1}, V_{2}, I_{\text {Datal }}, I_{\text {Data2 } 2}, N=5, I_{\text {Data,scl }}, I_{\text {Data, }, s c 2}, I_{m p 1}, I_{m p 2}, V_{m p 1}, V_{m p 2}$

If the SRC curve is used as one of the data curves (as was done in this study for the winter case), $G_{e f f l}=1000 \mathrm{~W} / \mathrm{m}^{2}, T_{c l}=25^{\circ} \mathrm{C}, M_{a m l}=1, V_{m p l}=V_{m p, r e f}, I_{m p l}=I_{m p, r e f}$

Initially unknown variables (found by simultaneously solving Equations (7.1)-(7.19)):

$I_{\text {Modell }}, I_{\text {Model } 2}, a_{r e f}, a_{1}, a_{2}, I_{L, r e f}, I_{L 1}, I_{L 2}, I_{o, r e f}, I_{o 1}, I_{o 2}, R_{s, r e f}, R_{s 1}, R_{s 2}, R_{s h, r e f}, R_{s h 1}, R_{s h 2}$, $\% R M S_{1}, \% R M S_{2}$, Total $_{\% \text { Error }}$.

Figures 7.1-7.4 show the differences in results obtained when using the reference parameters for only one weather condition (SRC) versus using the Two-Curve Optimization Method. 


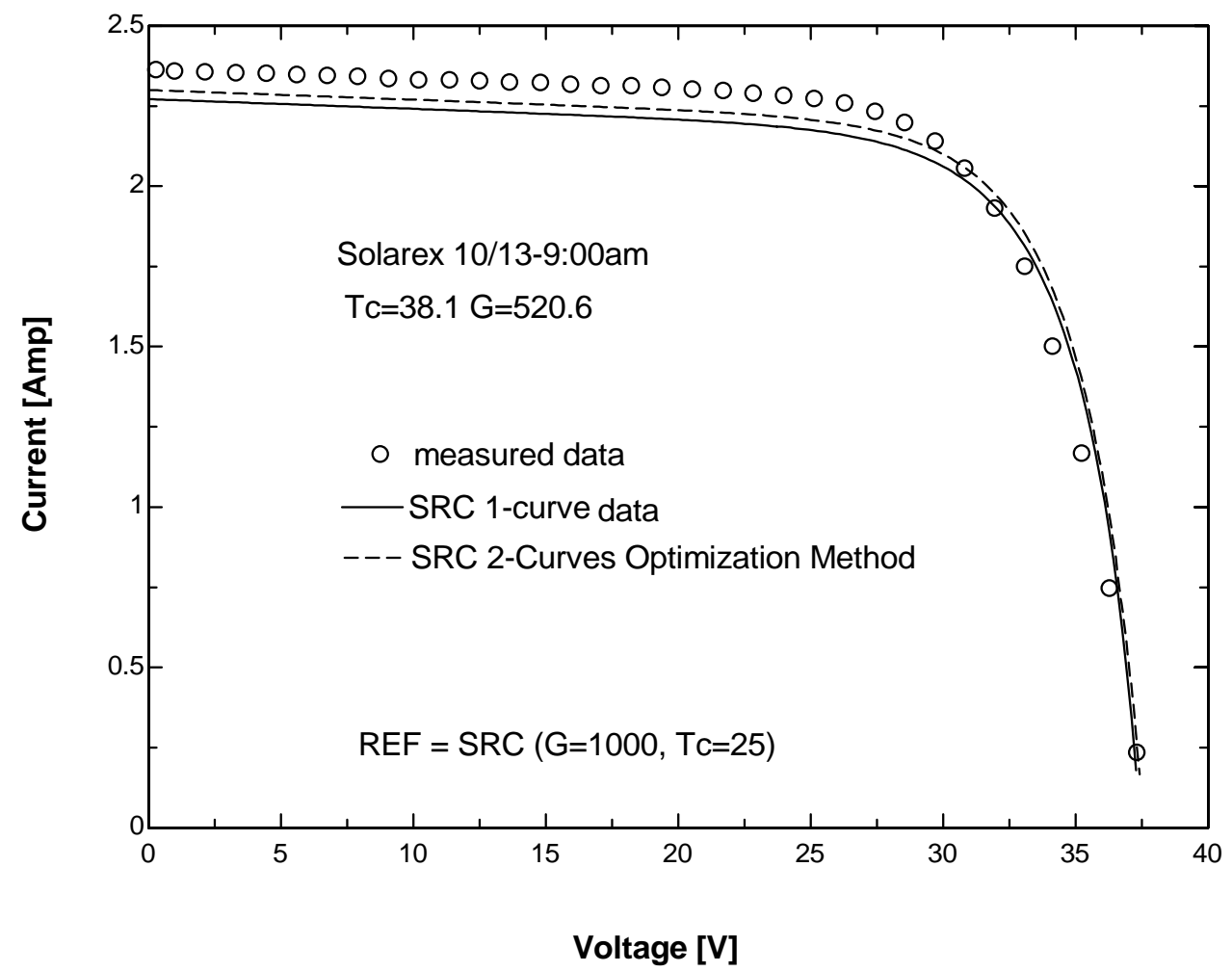

Figure 7.1: I-V curve predicted for Solarex cell type, October 13 at 9:00am with $G_{e f f}=520.6 \mathrm{~W} / \mathrm{m}^{2}$ and $T_{c}=38.1^{\circ} \mathrm{C}$, using SRC as reference conditions

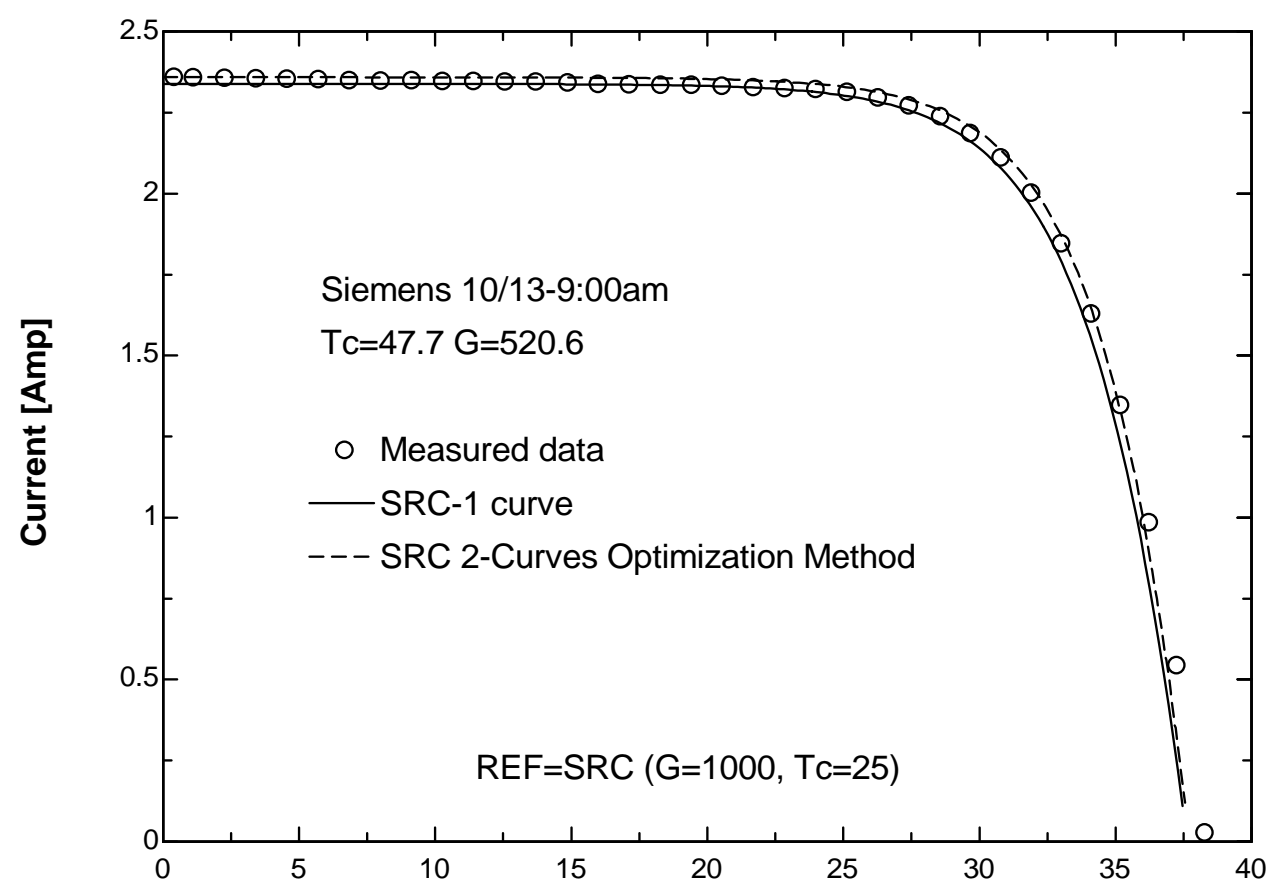

Voltage [V]

Figure 7.2: I-V curve predicted for Siemens cell type, October 13 at 9:00am with $G_{\text {eff }}=520.6$ $\mathrm{W} / \mathrm{m}^{2}$ and $T_{c}=47.7^{\circ} \mathrm{C}$, using SRC as reference conditions 


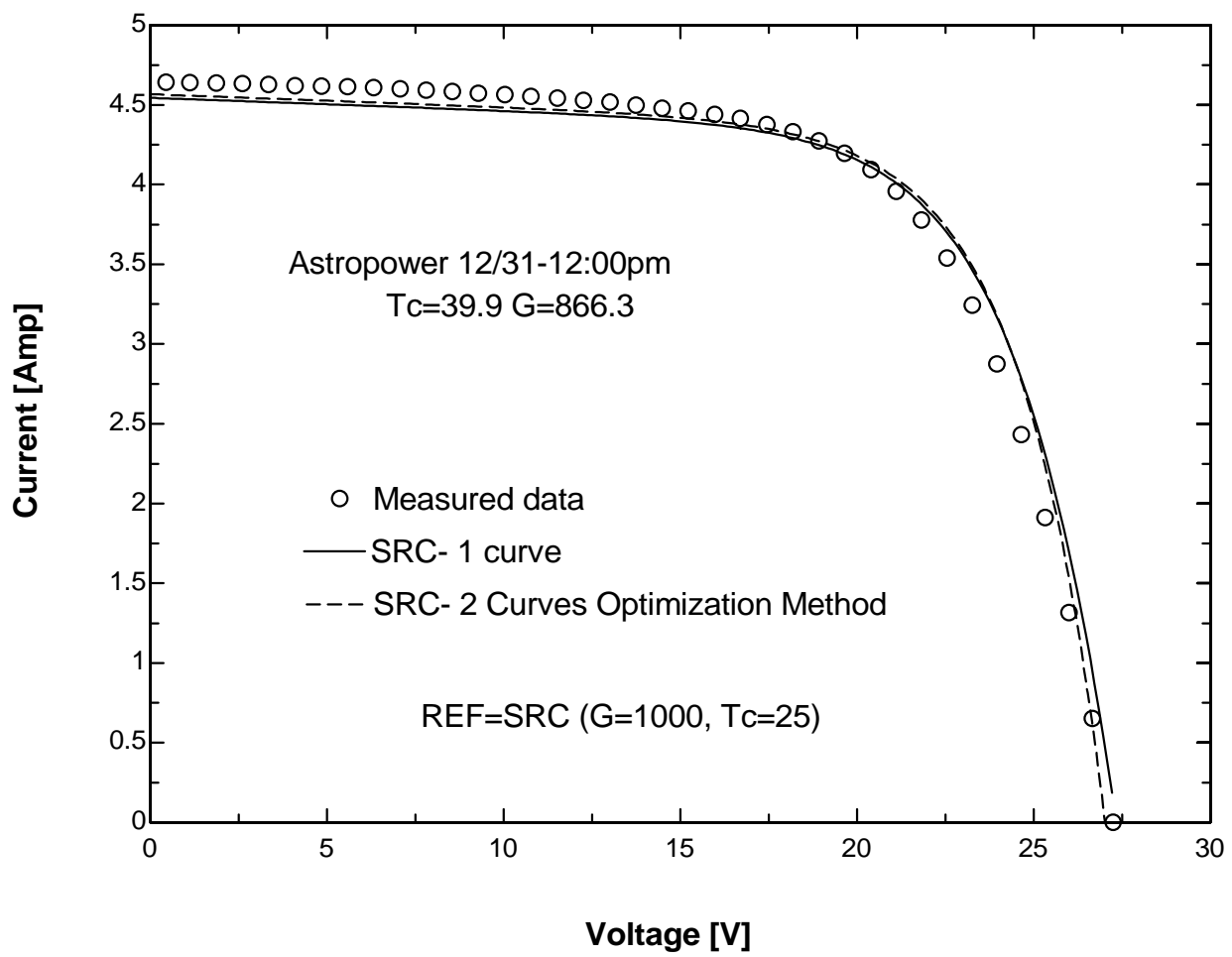

Figure 7.3: I-V curve predicted for Astropower cell type, December 31 at 12:00pm with $G_{\text {eff }}=866$ $\mathrm{W} / \mathrm{m}^{2}$ and $T_{c}=39.9^{\circ} \mathrm{C}$, using SRC as reference conditions

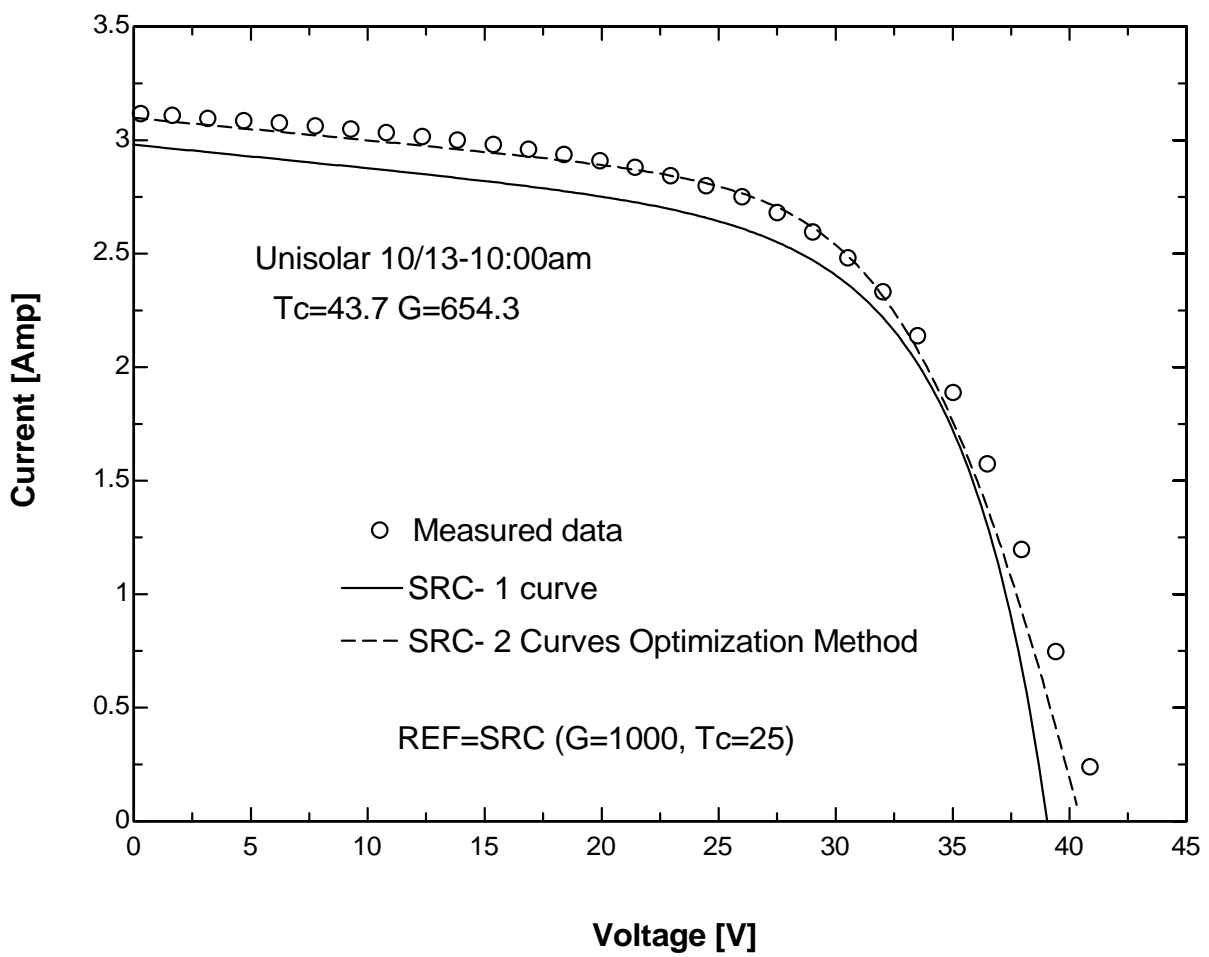

Figure 7.4: I-V curve predicted for Uni-Solar cell type, October 13 at 10:00am with $G_{\text {eff }}=654.3$ $\mathrm{W} / \mathrm{m}^{2}$ and $T_{c}=43.7^{\circ} \mathrm{C}$, using SRC as reference conditions 
The $\%$ RMS error was calculated for each I-V curve with respect to the data provided by NIST using Equation (7.20) :

$$
\% R M S=\frac{\sqrt{\frac{\sum_{i=1}^{N}\left(I_{\text {Data }, i}-I_{\text {Model }, i}\right)^{2}}{N}}}{I_{\text {Data }, s c}} * 100 \%
$$

where $\% \mathrm{RMS}$ is the percentage root mean square error, $N$ is the number of points used, $I_{\text {Data }}$ is the recorded value by NIST at a specified voltage, $I_{\text {Model }}$ is the predicted value from the model, and $I_{\text {Data,sc }}$ is the value of the short circuit current provided by NIST.

The \%RMS errors, shown in Table 7.1, were determined using the five strategic points, previously presented (at $V=0, V=0.5 V_{o c}$, etc.), hence $N=5$.

Table 7.1: RMS Percentage Errors using 5 Points

\begin{tabular}{|c|c|c|c|c|}
\hline Cell Technology & Solarex & Siemens & AstroPower & Unisolar \\
\hline $\begin{array}{c}\text { \% RMS error w/o } \\
\text { 2 curve } \\
\text { optimization }\end{array}$ & 3.507 & 1.808 & 3.365 & 4.592 \\
\hline $\begin{array}{c}\text { \% RMS error } \\
\text { with 2 curve } \\
\text { optimization }\end{array}$ & 3.391 & 0.555 & 3.137 & 2.356 \\
\hline
\end{tabular}

In the case that the PV-array will be used with a tracking device at the maximum power point, it is of interest to know the error that exists in the prediction of this point. Equation (7.20) was then used with $N=1$ where only the maximum power point was considered. The results are shown in Table 7.2. 
Table 7.2: RMS Percentage Errors at Maximum Power Point

\begin{tabular}{|c|c|c|c|c|}
\hline Cell Technology & Solarex & Siemens & AstroPower & Unisolar \\
\hline $\begin{array}{c}\text { \% RMS error w/o } \\
\text { 2 curve } \\
\text { optimization }\end{array}$ & 2.973 & 1.421 & 0.7097 & 4.808 \\
\hline $\begin{array}{c}\text { \% RMS error } \\
\text { with } 2 \text { curve } \\
\text { optimization }\end{array}$ & 1.185 & 1.019 & 1.396 & 0.4594 \\
\hline
\end{tabular}

The tables show that for all cell types the results obtained for the case where the reference parameters were obtained with optimization (minimizing the error, using two different curves as reference conditions) yield smaller errors than for the case in which the reference parameters were taken directly for only one reference curve at a time. Even if the method were to be used for the first three cell types (mono crystalline, polycrystalline, and silicon thin film), it would not signficantly affect the results because they were already in the desired range (less than 5-7\%). For the 3-Junction Amorphous UniSolar panels the observed error decrease is significantly higher than for the other cell technologies. When the complete I-V curve is plotted for the Uni-Solar cell type it is apparent that the 5-Parameter model is still not appropriate for predicting the behavior of this type of technology if small errors are desired. For 3-Junction Amorphous cell technology this model can still be used as a tool for predicting what the behavior might be like, but it should be discarded if very accurate results are expected.

In conclusion, the two-curve optimization method is highly suggested for the 3 junction amorphous technology because it significantly decreases the error obtained. For the other cell types (mono crystalline, poly-crystalline, and silicon thin film) it is also suggested because it decreases the errors obtained, but a significant decrease in these errors should not be expected. 


\section{Chapter 8 \\ Comparing the 5-Parameter Model with other models}

King (2000) has developed a model to predict the energy production from a PV array. A disadvantage with his model is that it requires a large amount of input data that are normally not available during the design phase. Manufacturers provide limited characteristic data for different photovoltaic cell technologies that have been developed over the years. The 5-Parameter model investigated in this research attempts to use these available data to accurately predict energy production. Luft et al. (1967), in work done for TRW Inc., proposed an equation to calculate the current through a PV array at known conditions. A. Hadj Arab et al. (2004) suggested the use of the 5-Parameter model as well, but developed very different equations for calculating the five parameters, therefore obtaining different results from those obtained using the equations suggested in this study. In this chapter, the 5-Parameter model is compared with King's model, Luft et al.'s equation, A. Hadj Arab et al.'s equations, and with experimental measurements for four different photovoltaic cell technologies (single-crystalline $\rightarrow$ Siemens, polycrystalline $\rightarrow$ Solarex, silicon film $\rightarrow$ Astropower, and 3-Junction amorphous $\rightarrow$ Uni-Solar).

\subsection{Available Models}

\subsubsection{The 5-Parameter model}

Equation (8.1) shows the 5-Parameter model equation, Equation (8.2) shows the equation used to calculate the power produced, and Equations (8.3)-(8.9) show the equations used to calculate the parameters $\left(a, I_{o}, I_{L}, R_{s}, R_{s h}\right.$, respectively), seen in 
Equation (8.1). These equations were presented in Chapter 4, but are reproduced here for ease of reading.

$$
\begin{aligned}
& I=I_{L}-I_{o}\left(e^{\frac{V+I R_{s}}{a}}-1\right)-\frac{V+I R_{s}}{R_{s h}} \\
& P=I V \\
& \frac{a}{a_{\text {ref }}}=\frac{T_{c}}{T_{c, \text { ref }}} \\
& \frac{I_{o}}{I_{o, \text { ref }}}=\left[\frac{T_{c}}{T_{c, \text { ref }}}\right]^{3} e^{\left[\frac{\varepsilon N_{s}\left(1-\frac{T_{c, r e f}}{a_{\text {ref }}}\right)}{T_{c}}\right]} \\
& I_{L}=\frac{G_{e f f} M_{a m}}{G_{e f f, r e f} M_{a m, r e f}}\left[I_{L, r e f}+\alpha_{I s c}\left(T_{c}-T_{c, r e f)}\right]\right. \\
& \frac{G_{e f f}}{G_{e f f, r e f}}=\frac{\frac{a_{r e f}}{I_{o, r e f}} e^{-\left[\frac{V_{m p, e f}+I_{m p, r e f} R_{s, e f}}{a_{r e f}}\right]}+R_{s, r e f}}{\frac{a}{I_{o}} e^{-\left[\frac{V_{m p}+I_{m p} R_{s}}{a}\right]}+R_{s}} \\
& I_{m p}=I_{m p, r e f} \frac{G_{e f f}}{G_{e f f, r e f}} \\
& V_{m p}=V_{m p, r e f}+\beta_{V o c}\left(T_{c}-T_{c, \text { ref }}\right) \\
& R_{s h}=R_{s h, r e f}
\end{aligned}
$$


If the effective irradiance $\left(G_{e f f}\right)$ and the air mass modifier $\left(M_{a m}\right)$ are unknown, they can be obtained with the previously discussed, Equations (8.10) and (8.11), respectively. These are Equations (4.5) and (2.5), previously presented, but repeated her for ease of reading.

$$
\begin{gathered}
G e f f=G_{b} R_{b e a m} K_{\tau \alpha, b}+G_{d} \frac{1+\operatorname{Cos} \beta}{2} K_{\tau \alpha, d}+G \rho \frac{1-\operatorname{Cos} \beta}{2} K_{\tau \alpha, g} \\
M_{a m}=a_{0}+a_{1} A M_{a}+a_{2} A M_{a}{ }^{2}+a_{3} A M_{a}{ }^{3}+a_{4} A M_{a}{ }^{4}
\end{gathered}
$$

Varying the voltage $(V)$ and solving all equations simultaneously yields the predicted current $(I)$ and power $(P)$, from where the maximum power can be deduced $\left(P_{m p}\right)$. In summary,

\section{Inputs:}

$V, I_{L, r e f}, a_{r e f}, I_{o, r e f}, R_{s, r e f}, R_{s h, r e f}, V_{m p, r e f}, I_{m p, r e f}, G_{e f f, r e f}, M_{a m, r e f}, \alpha_{I s c}, T_{c, r e f}, \varepsilon, N_{s}, G_{e f f}, T_{c}$, and $M_{a m}$

Known or provided by Manufacturer:

$$
V, V_{m p, r e f}, I_{m p, r e f}, G_{e f f, r e f}, M_{a m, r e f}, \alpha_{I s c}, T_{c, r e f}, \varepsilon, N_{s}, G_{e f f}, T_{c}
$$

\section{Outputs:}

$I, P, I_{L}, I_{o}, a, R_{s}, R_{s h}$

If $G_{\text {eff }}$ and $M_{a m}$ are to be calculated, the following parameters are needed:

For $G_{\text {eff: }} G_{b}, R_{\text {beam }}, K_{\tau \alpha, b}, G_{d}, K_{\tau \alpha, d}, K_{\tau \alpha, g}, \beta, \rho, G$ 
For $M_{a m}: a_{0}, a_{1}, a_{2}, a_{3}, a_{4}, A M_{a}$

\subsubsection{King's model}

King's model, presented in Equations (8.12)-(8.22), calculates the short circuit current $\left(I_{s c}\right)$, current and voltage at the maximum power point ( $I_{m p}$ and $V_{m p}$, respectively), the currents at two intermediate points $\left(I_{x}\right.$ and $\left.I_{x x}\right)$, and the open circuit voltage $\left(V_{o c}\right)$.

$$
\begin{aligned}
& I_{s c}=I_{s c o} f_{1}\left(A M_{a}\right)\left[1+\alpha_{I s c}\left(T_{c}-T_{o}\right)\right]\left[\frac{E_{b} f_{2}(A O I)+f_{d} E_{d i f f}}{E_{o}}\right] \\
& \mathrm{I}_{m p}=\mathrm{I}_{m p o}\left[C_{0} E_{e}+C_{1} E_{e}^{2}\right]\left[1+\alpha_{I m p}\left(T_{c}-T_{o}\right)\right] \\
& I_{x}=I_{x o}\left[C_{4} E_{e}+C_{5} E_{e}^{2}\right]\left[1+\frac{\alpha_{I s c}+\alpha_{I m p}}{2}\left(T_{c}-T_{o}\right)\right] \\
& I_{x x}=I_{x x o}\left[C_{6} E_{e}+C_{7} E_{e}^{2}\right]\left[1+\alpha_{I p m}\left(T_{c}-T_{o}\right)\right] \\
& V_{m p}=V_{m p o}+C_{2} N_{s} \delta\left(T_{c}\right) \ln \left(E_{e}\right)+C_{3} N_{s}\left[\delta\left(T_{c}\right) \ln \left(E_{e}\right)\right]^{2}+\beta_{V m p}\left(E_{e}\right)\left(T_{c}-T_{o}\right) \\
& V_{o c}=V_{o c o}+N_{s} \delta\left(T_{c}\right) \ln \left(E_{e}\right)+\beta_{V o c}\left(E_{e}\right)\left(T_{c}-T_{o}\right) \\
& P_{m p}=I_{m p} V_{m p} \\
& E_{e}=\frac{I_{s c}}{I_{s c o}\left[1+\alpha_{I s c}\left(T_{c}-T_{o}\right)\right]} \\
& \delta\left(T_{c}\right)=n k \frac{\left(T_{c}+273.15\right)}{q} \\
& f_{1}\left(A M_{a}\right)=a_{0}+a_{1} A M_{a}+a_{2} A M_{a}^{2}+a_{3} A M_{a}^{3}+a_{4} A M_{a}^{4} \\
& f_{2}(A O I)=b_{0}+b_{1} A O I+b_{2} A O I^{2}+b_{3} A O I^{3}+b_{4} A O I^{4}+b_{5} A O I^{5}
\end{aligned}
$$


The maximum power can be calculated directly, substituting the resulting $I_{m p}$ and $V_{m p}$ values from Equations (8.13) and (8.16) into Equation (8.18). In summary,

\section{Inputs:}

$$
\begin{aligned}
& I_{s c 0}, I_{m p 0}, I_{x 0}, I_{x x 0}, V_{m p 0}, V_{o c 0}, E_{b}, E_{d i f f}, E_{0}, f_{d}, T_{c}, T_{0}, \alpha_{I s c}, \alpha_{I m p}, \beta_{V o c}, \beta_{V m p}, N_{s}, n, k, q, \mathrm{C}_{0}, \\
& C_{1}, C_{2}, C_{3}, C_{4}, C_{5}, C_{6}, C_{7}, f_{1}\left(A M_{a}\right), f_{2}(A O I)
\end{aligned}
$$

Known or provided by Manufacturer:

$$
I_{s c 0}, I_{m p 0}, V_{m p 0}, V_{o c 0}, E_{b}, E_{\text {diff }}, E_{0}, f_{d}, T_{c}, T_{0}, \alpha_{I s c}, \beta_{V o c}, N_{s}, n, k, q
$$

\section{Outputs:}

$$
I_{s c}, I_{m p}, I_{x}, I_{x x}, V_{m p}, V_{o c}, P_{m p}, E_{e}, \delta\left(T_{c}\right)
$$

If $f_{1}(A M a)$ and $f_{2}(A O I)$ are to be calculated, Equations (8.21) and (8.22) are used and the following parameters are needed:

For $f_{1}\left(A M_{a}\right): a_{0}, a_{1}, a_{2}, a_{3}, a_{4}, A M_{a}$

For $f_{2}(A O I): b_{0}, b_{1}, b_{2}, b_{3}, b_{4}, b_{5}, A O I$

The coefficients $\left(C_{0^{-}} C_{7}, a_{0}-a_{4}, b_{0}-b_{5}\right.$, etc. $)$ are determined from previous tests performed on the panels.

Equations (8.12)-(8.18) give information on only 5 points, corresponding to:

$$
\begin{aligned}
& V=0 \\
& V=0.5 V_{o c}=V_{x} \\
& V=V_{m p}
\end{aligned}
$$




$$
\begin{aligned}
& V=0.5\left(V_{m p}+V_{o c}\right)=V_{x x} \\
& V=V_{o c}
\end{aligned}
$$

\subsubsection{Luft et. al's equation}

Luft et al. (1967), in work done for TRW Inc., proposed an equation to calculate the current produced, shown in Equation (8.23). Equations (8.24) and (8.25) are substituted in Equation (8.23).

$$
\begin{gathered}
I_{T R W}=I_{s c}\left[1-k_{2}\left(e^{\frac{V}{k_{1} V_{o c}}}-1\right)\right] \\
k_{1}=\frac{\frac{V_{m p}}{V_{o c}}-1}{\ln \left(1-\frac{I_{m p}}{I_{s c}}\right)} \\
k_{2}=\left(1-\frac{I_{m p}}{I_{s c}}\right) \mathrm{e}^{-\frac{V_{m p}}{k_{1} V_{o c}}}
\end{gathered}
$$

Photovoltaic panels will generally not operate at the maximum power point and it is important to know the current and power produced at operating points other than those predicted with King's model. Equation (8.26) yields the current produced at any voltage, which serves to generate a current - voltage (I-V) curve. This equation substitutes the current on the right side of the 5-Parameter model equation (Equation (8.1)) with Luft et al.'s equation in order to avoid having an implicit equation. Equations (8.27) through (8.29) are manipulations of the 5-Parameter model equation, explained in detail by Barker, G. and Norton, P., (2003). Equations (8.23) through (8.29) are then substituted in Equation (8.26) to obtain the complete I-V curve. 


$$
\begin{gathered}
I=I_{L}-I_{o}\left(e^{\frac{V+I_{T R W} R_{s}}{a}}-1\right)-\frac{V+I_{T R W} R_{s}}{R_{s h}} \\
I_{L}=\frac{V_{o c}}{R_{s h}}+I_{0}\left(e^{\frac{V_{o c}}{a}}-1\right) \\
I_{o}=\frac{I_{s c} R_{s h}+I_{s c} R_{s}-V_{o c}}{R_{s h}\left(e^{\frac{V_{o c}}{a}}-e^{\frac{I_{s c} R_{s}}{a}}\right)} \\
R_{s h}=\frac{\left(I_{s c} R_{s}-V_{o c}\right)\left(e^{\frac{V_{o c}}{a}}-e^{\frac{V_{m p}+I_{m p} R_{s}}{a}}\right)+\left(V_{o c}-V_{m p}-I_{m p} R_{s}\right)\left(e^{\frac{V_{o c}}{a}}-e^{\frac{I_{s c} R_{s}}{a}}\right)}{I_{m p}\left(e^{\frac{V_{o c}}{a}}-e^{\frac{I_{s c} R_{s}}{a}}\right)+I_{s c}\left(e^{\frac{V_{m p}+I_{m p} R_{s}}{a}}-e^{\frac{V_{o c}}{a}}\right)}
\end{gathered}
$$

Equations (8.27)-(8.29) force the I-V curve generated with Equation (8.26) to pass through the points calculated with King's model in Equations (8.12)-(8.17). The parameters, $R_{s}$ and $a$, are unknown but can be adjusted to obtain the best fit through the two remaining points $\left(I_{x}, V_{x}\right.$ and $\left.I_{x x}, V_{x x}\right)$ by minimizing the RMS error between the predicted values of $I_{x}$ and $I_{x x}$ with Equations (8.14) and (8.15) and current values calculated with Equation (8.26). The RMS error is calculated using Equation (8.30).

$$
E_{r m s}=\sqrt{\frac{\left(I_{x, p r e d}-I_{x, \text { calc }}\right)^{2}+\left(I_{x x, p r e d}-I_{x x, c a l c}\right)^{2}}{2}}
$$

\subsubsection{A. Hadj Arab et al.'s equations}

A. Hadj Arab et al. (2004) developed a model to predict the preformance of photovoltaic cells based on the 5-Parameter model characteristic equation, 


$$
I=I_{L}-I_{0}\left(e^{\frac{V+I R_{s}}{m V_{t}}}-1\right)-\left(\frac{V+I R_{s}}{R_{s h}}\right)
$$

where $I_{L}, I_{o}, m, R_{s}$, and $R_{s h}$ are the five parameters that once found, can be substituted in Equation (8.31) to create the I-V curve.

They defined $-R_{s 0}$ as the slope of the I-V curve at open circuit voltage

$$
\left(\frac{d V}{d I}\right)_{V=V_{O C}}=-R_{s 0}
$$

and $-R_{s h 0}$ as the slope of the I-V curve at the short circuit current.

$$
\left(\frac{d V}{d I}\right)_{I=I_{s c}}=-R_{s h 0}
$$

The values for $-R_{s 0}$ and $-R_{s h 0}$ are calculated directly from the reference curve provided by NIST.

The parameters in Equation (8.31) are calculated using Equations (8.34)-(8.39), where Equation (8.34) yields the diode quality factor, $m$

$$
m=\frac{V_{m p}+I_{m p} R_{s 0}-V_{o c}}{V_{t}\left[\ln \left(I_{s c}-\frac{V_{m p}}{R_{s h}}-I_{m p}\right)-\ln \left(I_{s c}-\frac{V_{o c}}{R_{s h}}\right)+\left(\frac{I_{m p}}{\left.I_{s c}-\frac{V_{o c}}{R_{s h}}\right)}\right]\right.}
$$

where $V_{m p}$ and $I_{m p}$ are the voltage and current at the maximum power point, $I_{s c}$ is the short circuit current, and $V_{o c}$ is the open circuit voltage. $V_{t}$ is defined as 


$$
V_{t}=\frac{k T_{c}}{e}
$$

where $k$ is Boltzmann's constant, $T_{c}$ is the cell temperature, and $e$ is the charge of the electron.

Equation (8.36) yields the diode reverse saturation current, $I_{o}$.

$$
I_{0}=\left(I_{s c}-\frac{V_{o c}}{R_{s h}}\right) e^{-\frac{V_{o c}}{m V_{t}}}
$$

The series resistance, $R_{s}$, can be obtained from Equation (8.37).

$$
R_{s}=R_{s 0}-\frac{m V_{t}}{I_{0}} \mathrm{e}^{-\frac{V_{o c}}{m V_{t}}}
$$

Equation (8.38) yields the light current, $I_{L}$.

$$
I_{L}=I_{s c}\left(1+\frac{R_{s}}{R_{s h}}\right)+I_{0}\left(\mathrm{e}^{\frac{I_{s c} R_{s}}{m V_{t}}}-1\right)
$$

The shunt resistance, $R_{s h}$, can be assumed to be equal to the previously calculated value of $R_{s h}$.

$$
R_{s h}=R_{s h 0}
$$

A. Hadj Arab et al.'s model calculates the five parameters $\left(I_{L}, I_{o}, m, R_{s}\right.$, and $\left.R_{s h}\right)$ for a set of specific operating conditions $\left(T_{c l}, G_{\text {effl }}\right)$ (SRC conditions are generally used, where $T_{c}=25^{\circ} \mathrm{C}$ and $G_{e f f}=1000 \mathrm{~W} / \mathrm{m}^{2}$ ). Once these parameters are known, they use Equations (8.40)-(8.45) to translate the I-V curve calculated from Equation (8.31) as a template and fit it for different operating conditions $\left(T_{c 2}, G_{e f f 2}\right)$. 
Equation (8.40) yields the new value for the short circuit current, $I_{s c 2}$.

$$
I_{s c 2}=I_{s c 1} \frac{G_{e f f 2}}{G_{e f f 1}}+\alpha\left(T_{c 2}-T_{c 1}\right)
$$

where every parameter with subscript 1 refers to the reference conditions $\left(T_{c l}, G_{e f f l}\right)$ and those with subscript 2 refer to the new operating conditions $\left(T_{c 2}, G_{\text {eff } 2}\right)$. The constant $\alpha$ is the coefficient of temperature for short circuit current.

The new value for the open circuit voltage, $V_{o c 2}$, can be obtained from Equation (8.41).

$$
V_{o c 2}=V_{o c 1}+m V_{t} \ln \frac{G_{e f f 2}}{G_{e f f 1}}+\beta\left(T_{c 2}-T_{c 1}\right)
$$

The constant $\beta$ is the coefficient of temperature for open circuit voltage.

The new values for the current and voltage for the new operating conditions can be obtained from Equations (8.42) and (8.43).

$$
\begin{gathered}
I_{2}=I_{1}+\Delta I_{s c} \\
V_{2}=V_{1}+\Delta V_{o c}
\end{gathered}
$$

where

$$
\Delta I_{s c}=I_{s c 2}-I_{s c 1}
$$

and

$$
\Delta V_{o c}=V_{o c 2}-V_{o c 1}
$$




\subsection{Comparing the Models}

I-V curves were predicted for four cell types for different operating conditions.

Results are shown for three (3) of the different operating conditions (summer, winter, and intermediate), using the 5-Parameter model, as well as King's model and A. Hadj Arab et al.'s equations. Equation (8.23), the equation proposed by Luft et al. while working for TRW Inc. (1967) to calculate current was also used to compare with King's and the 5Parameter models. The following results were determined using the current yielding Equations (8.1), (8.23), and (8.26). Standard Rated Conditions (SRC) were used as reference conditions for all cases. For the Siemens cell type the 5-Parameter model was used, assuming that the shunt resistance $\left(R_{s h}\right)$ was infinite, therefore only four parameters were taken in consideration $\left(a, I_{o}, I_{L}, R_{s}\right)$. Figures 8.1-8.3 show the results obtained for the Solarex cell type (multi-crystalline), Figures 8.4-8.6 Siemens (single-crystalline), Figures 8.7-8.9 Astropower (silicon thin film), and Figures 8.10-8.12 Uni-Solar (3Junction Amorphous). For clarity, the results obtained comparing the 5-Parameter model with A. Hadj Arab et al.'s model are shown in Figures 8.13-8.16 as part of section 8.2.2. An example of the steps followed to obtain these results can be seen in Appendix D, Parts I and II.

8.2.1 5-Parameter model vs. King's model and Luft et al.'s equation 


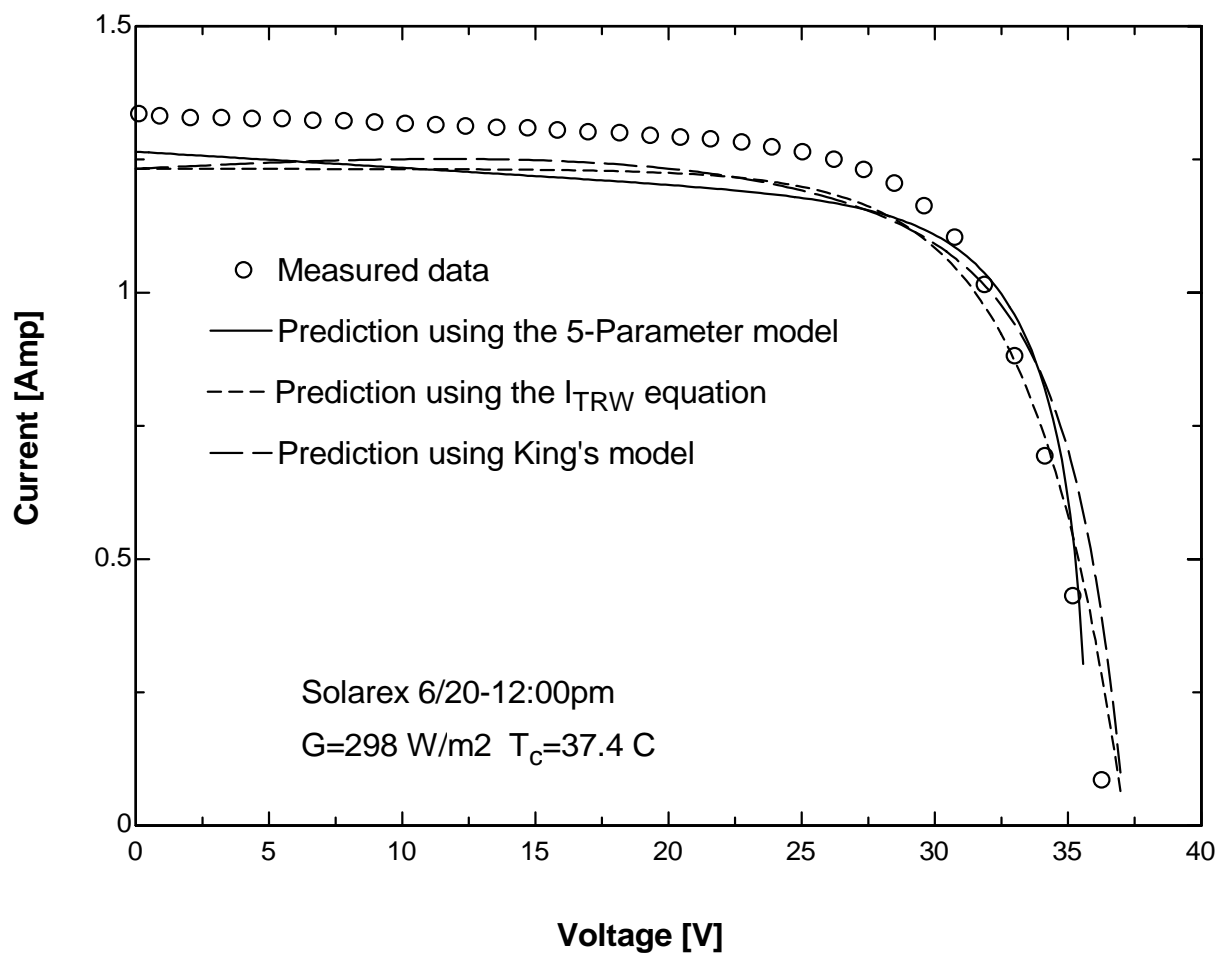

Figure 8.1: I-V curve predicted for Solarex cell type, June 20 at noon with $G_{\text {eff }}=298 \mathrm{~W} / \mathrm{m}^{2}$ and $T_{c}=37.4^{\circ} \mathrm{C}$, using $\mathrm{SRC}$ as reference conditions

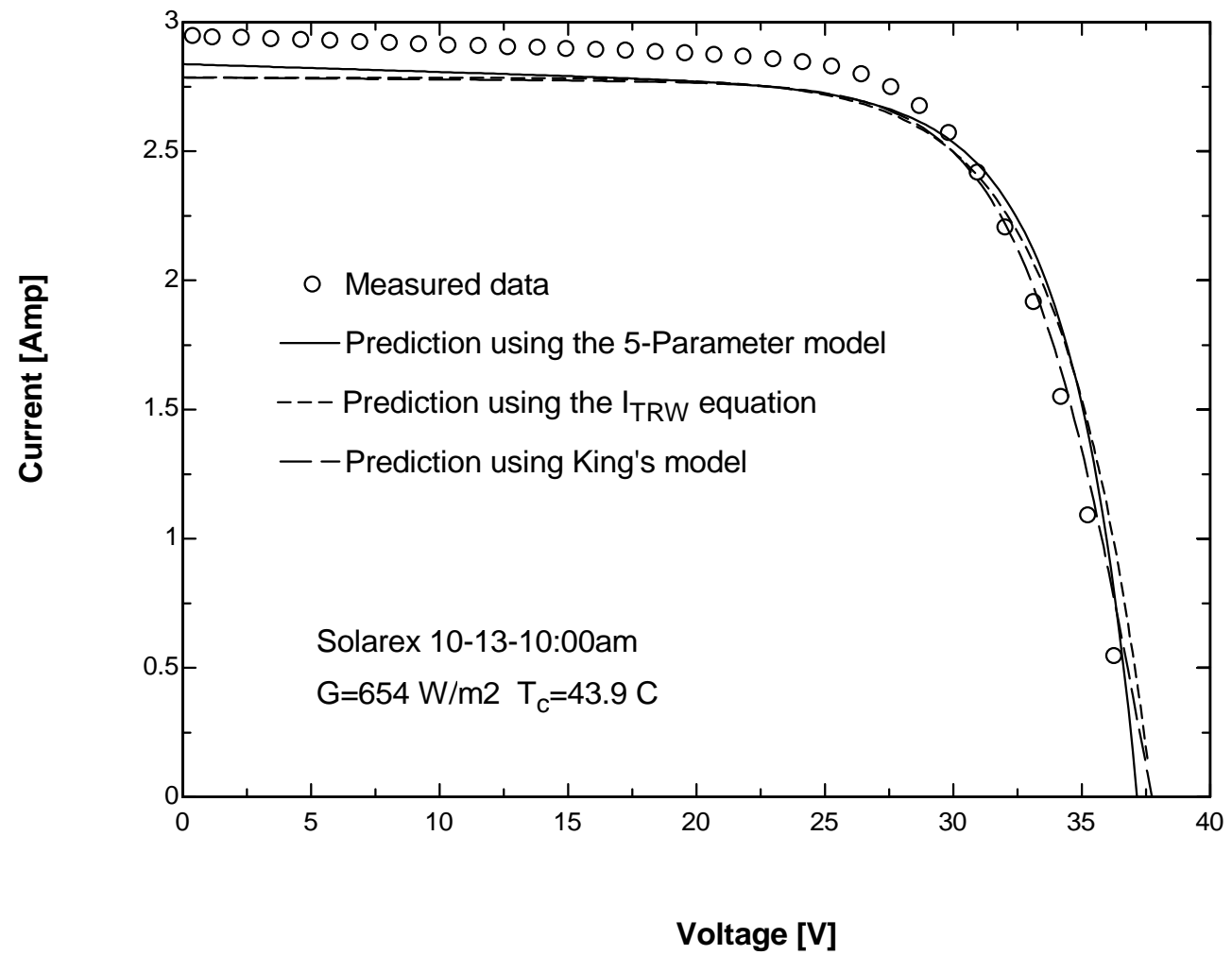

Figure 8.2: $\mathrm{I}-\mathrm{V}$ curve predicted for Solarex cell type, October 13 at 10:00am with $G_{\text {eff }}=654 \mathrm{~W} / \mathrm{m}^{2}$ and $T_{c}=43.9^{\circ} \mathrm{C}$, using SRC as reference conditions 


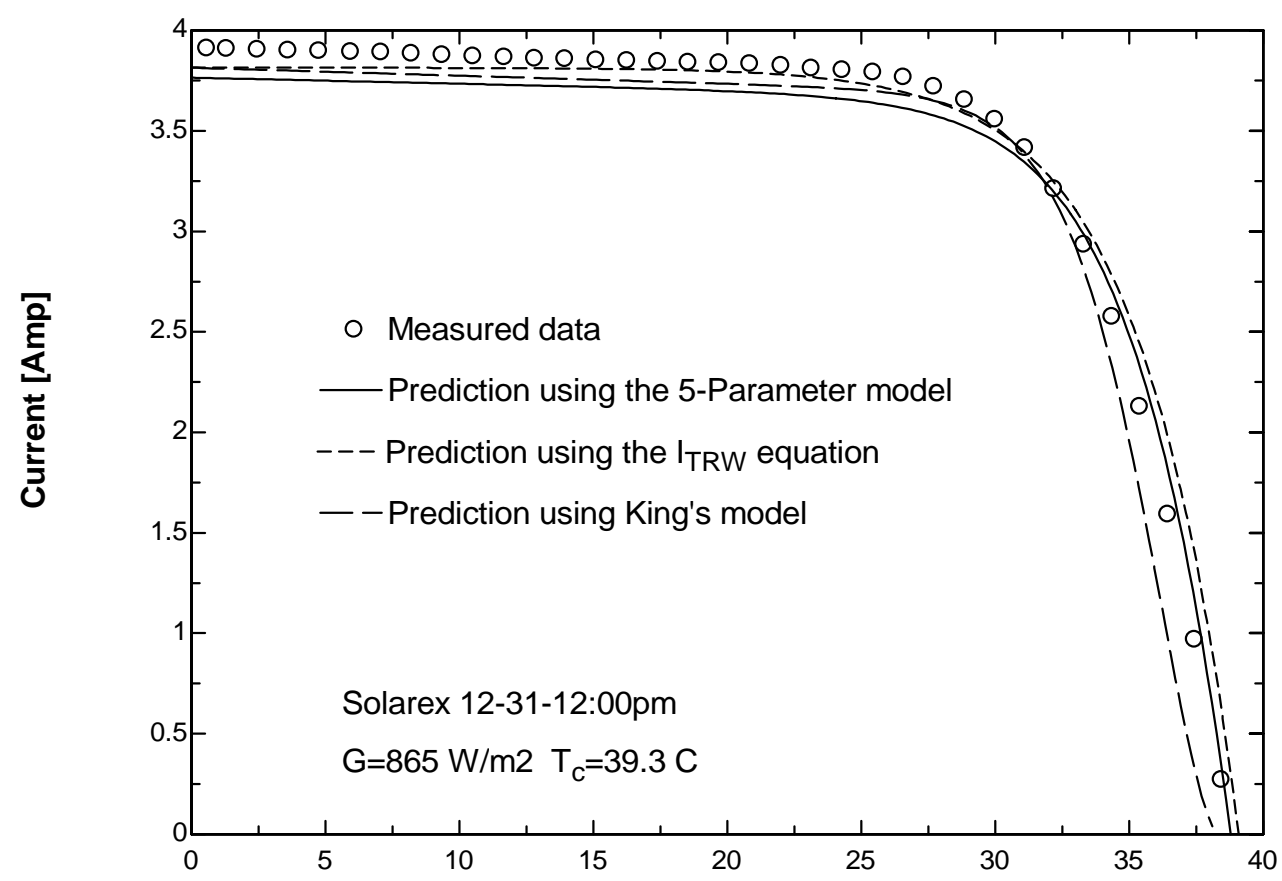

Voltage [V]

Figure 8.3: $\mathrm{I}-\mathrm{V}$ curve predicted for Solarex cell type, December 31 at noon with $G_{\text {eff }}=865 \mathrm{~W} / \mathrm{m}^{2}$ and $T_{c}=39.3^{\circ} \mathrm{C}$, using $\mathrm{SRC}$ as reference conditions

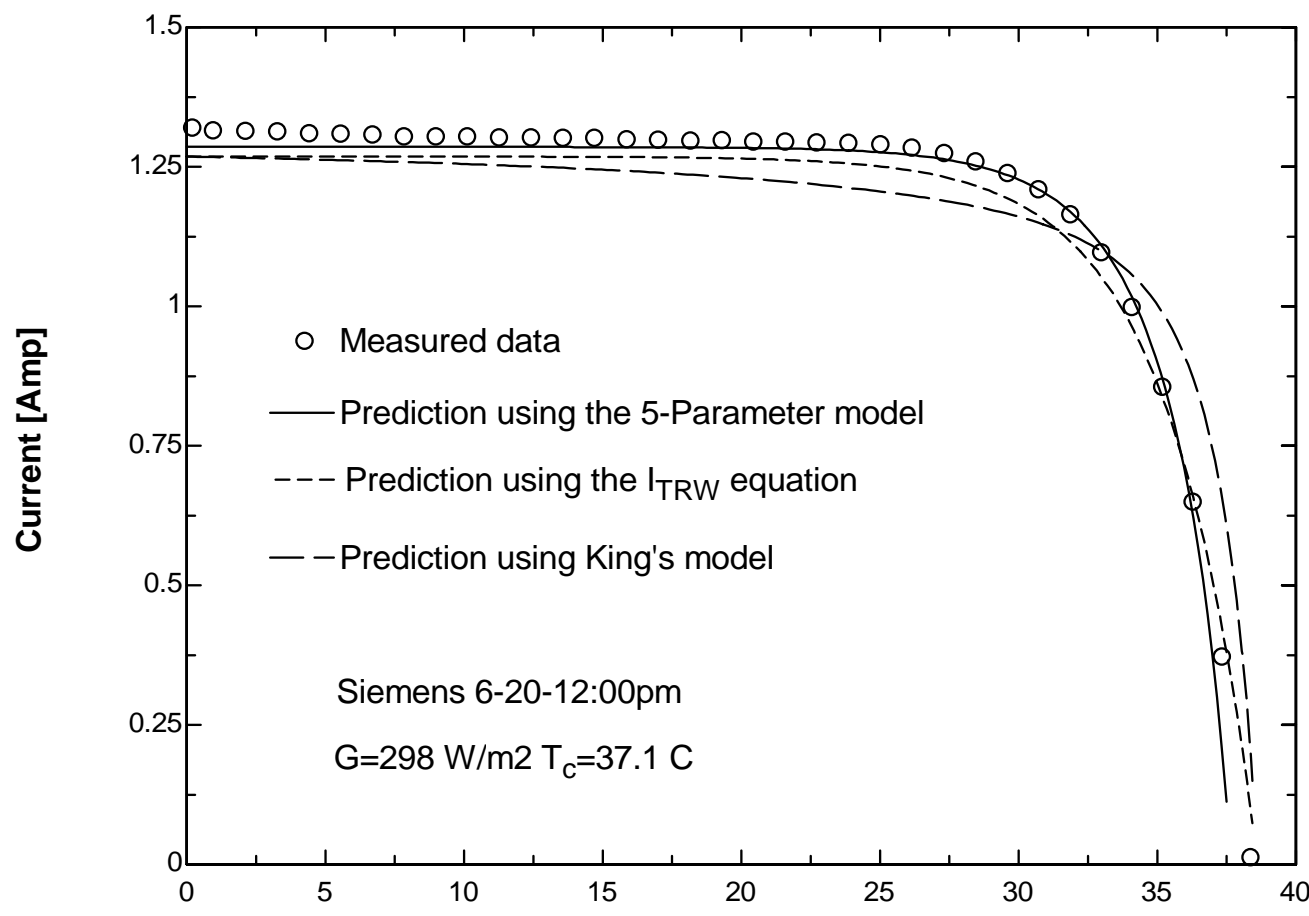

Voltage [V]

Figure 8.4: $\mathrm{I}-\mathrm{V}$ curve predicted for Siemens cell type, June 20 at noon with $G_{\text {eff }}=298 \mathrm{~W} / \mathrm{m}^{2}$ and $T_{c}=37.1^{\circ} \mathrm{C}$, using SRC as reference conditions 


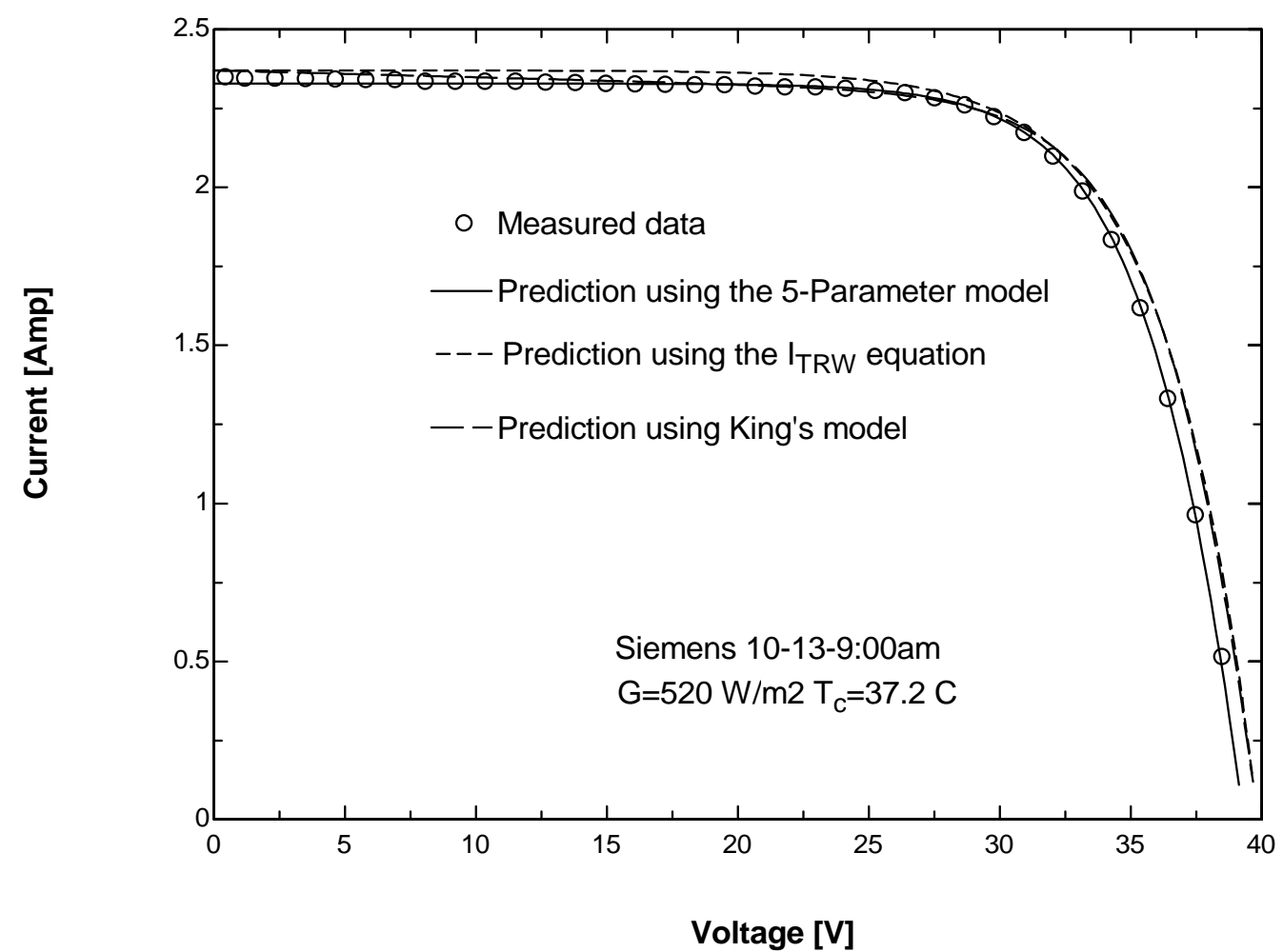

Figure 8.5: I-V curve predicted for Siemens cell type, October 13 at $9: 00 \mathrm{am}$ with $G_{\text {eff }}=520 \mathrm{~W} / \mathrm{m}^{2}$ and $T_{c}=37.2^{\circ} \mathrm{C}$, using SRC as reference conditions

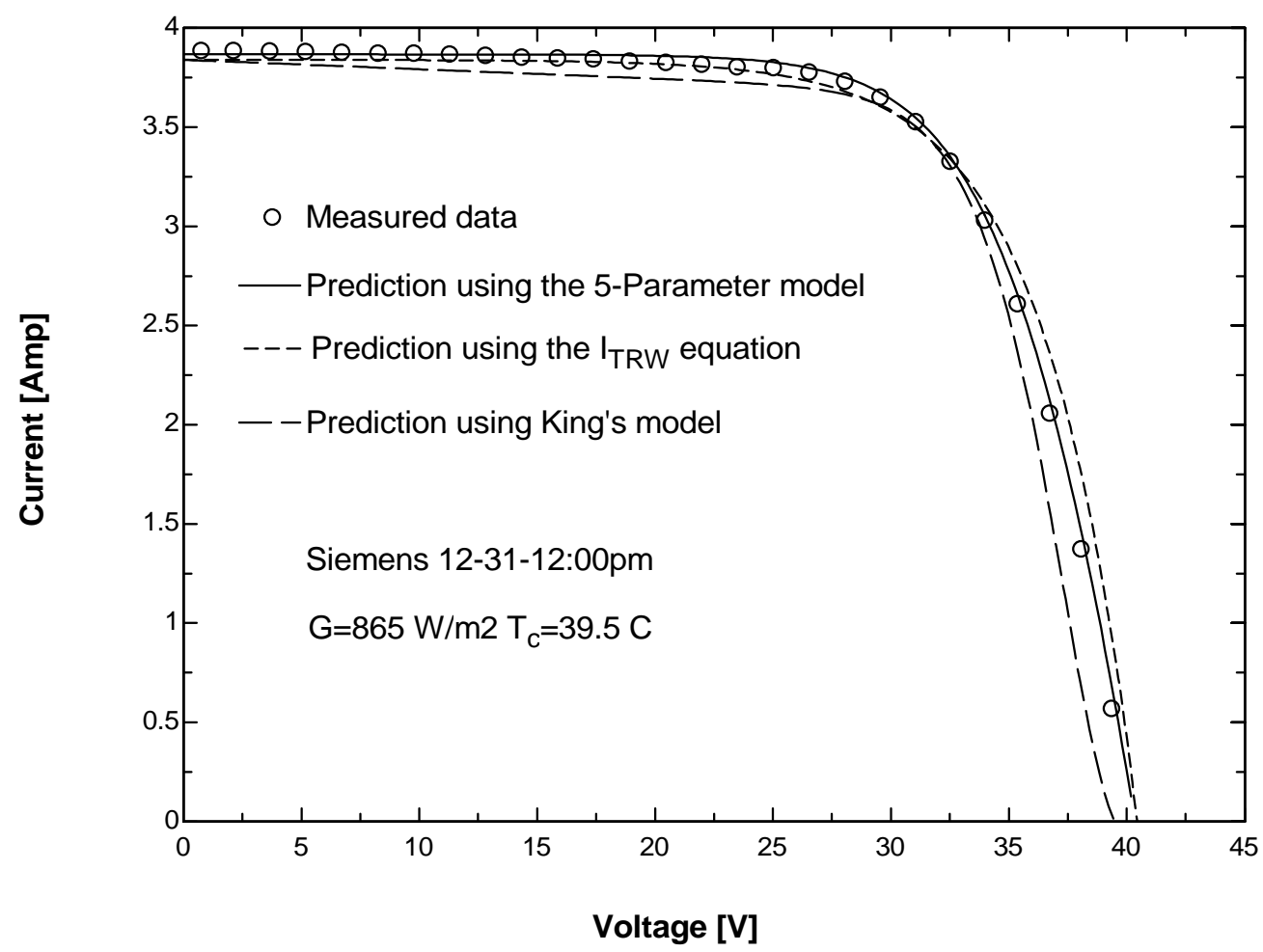

Figure 8.6: $\mathrm{I}-\mathrm{V}$ curve predicted for Siemens cell type, December 31 at noon with $G_{\text {eff }}=865 \mathrm{~W} / \mathrm{m}^{2}$ and $T_{c}=39.5^{\circ} \mathrm{C}$, using $\mathrm{SRC}$ as reference conditions 


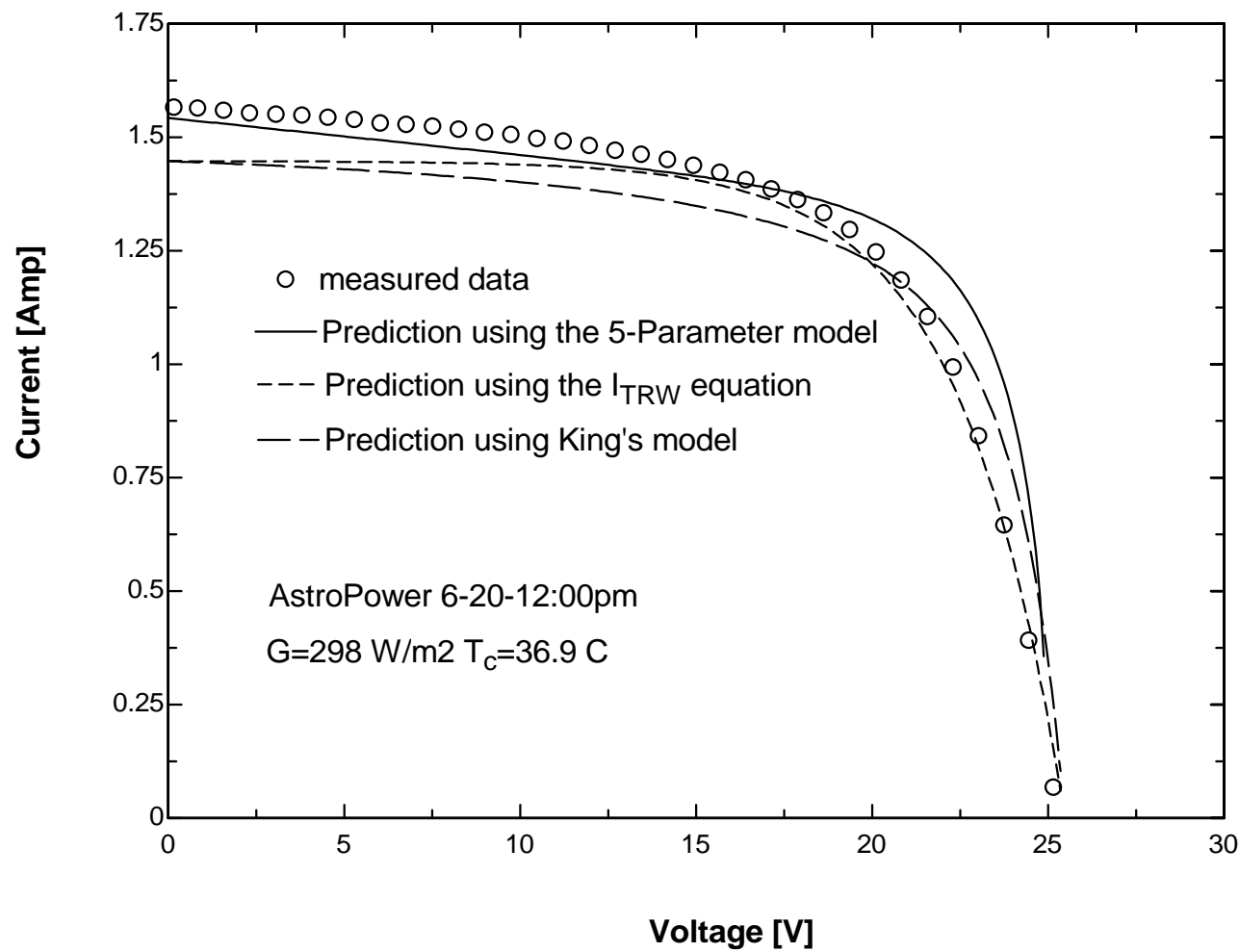

Figure 8.7: I-V curve predicted for Astropower cell type, June 20 at noon with $G_{\text {eff }}=298 \mathrm{~W} / \mathrm{m}^{2}$ and $T_{c}=36.9^{\circ} \mathrm{C}$, using $\mathrm{SRC}$ as reference conditions

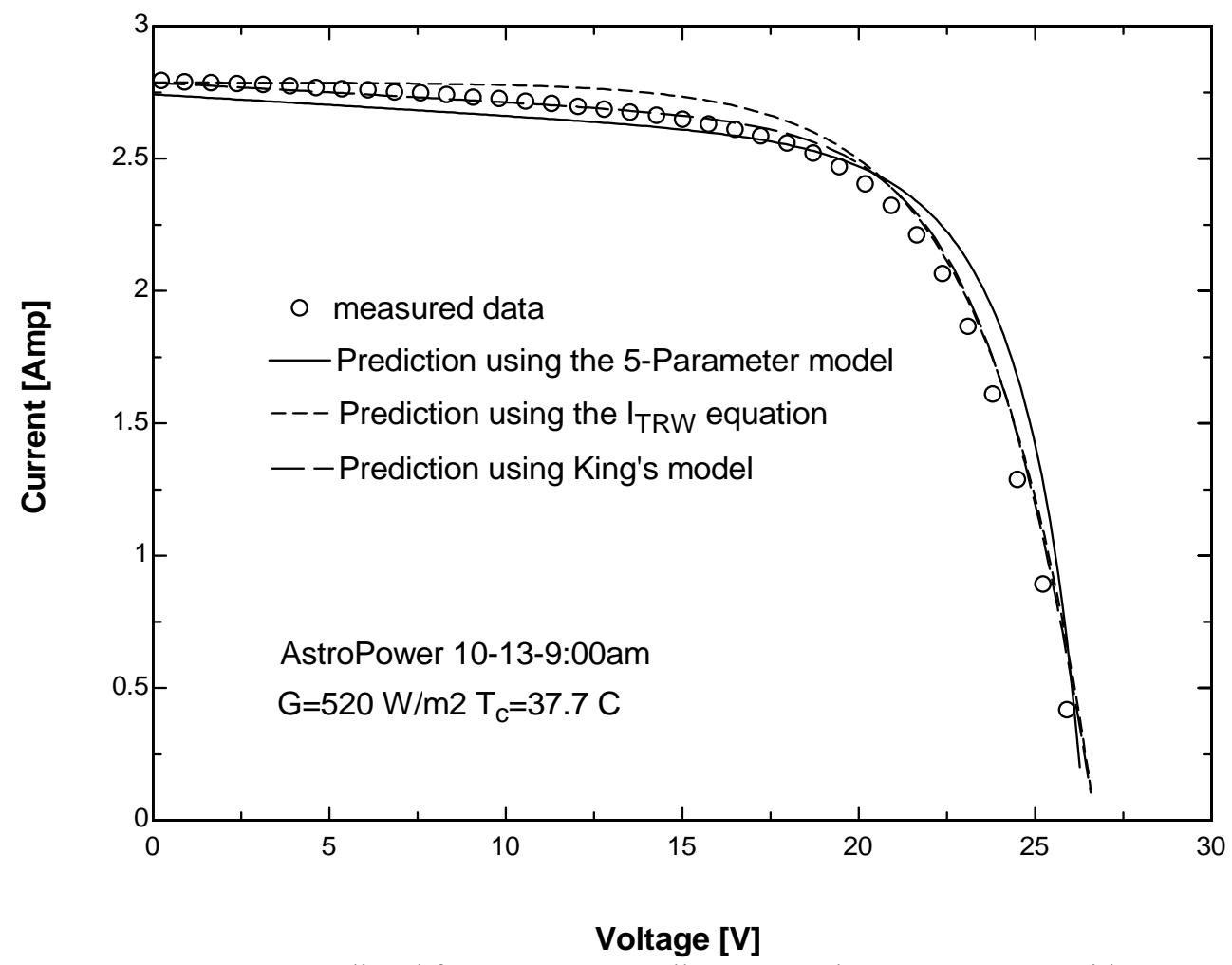

Figure 8.8: $\mathrm{I}-\mathrm{V}$ curve predicted for Astropower cell type, October 13 at 9:00am with $G_{\text {eff }}=520$ $\mathrm{W} / \mathrm{m}^{2}$ and $T_{c}=37.7^{\circ} \mathrm{C}$, using SRC as reference conditions 


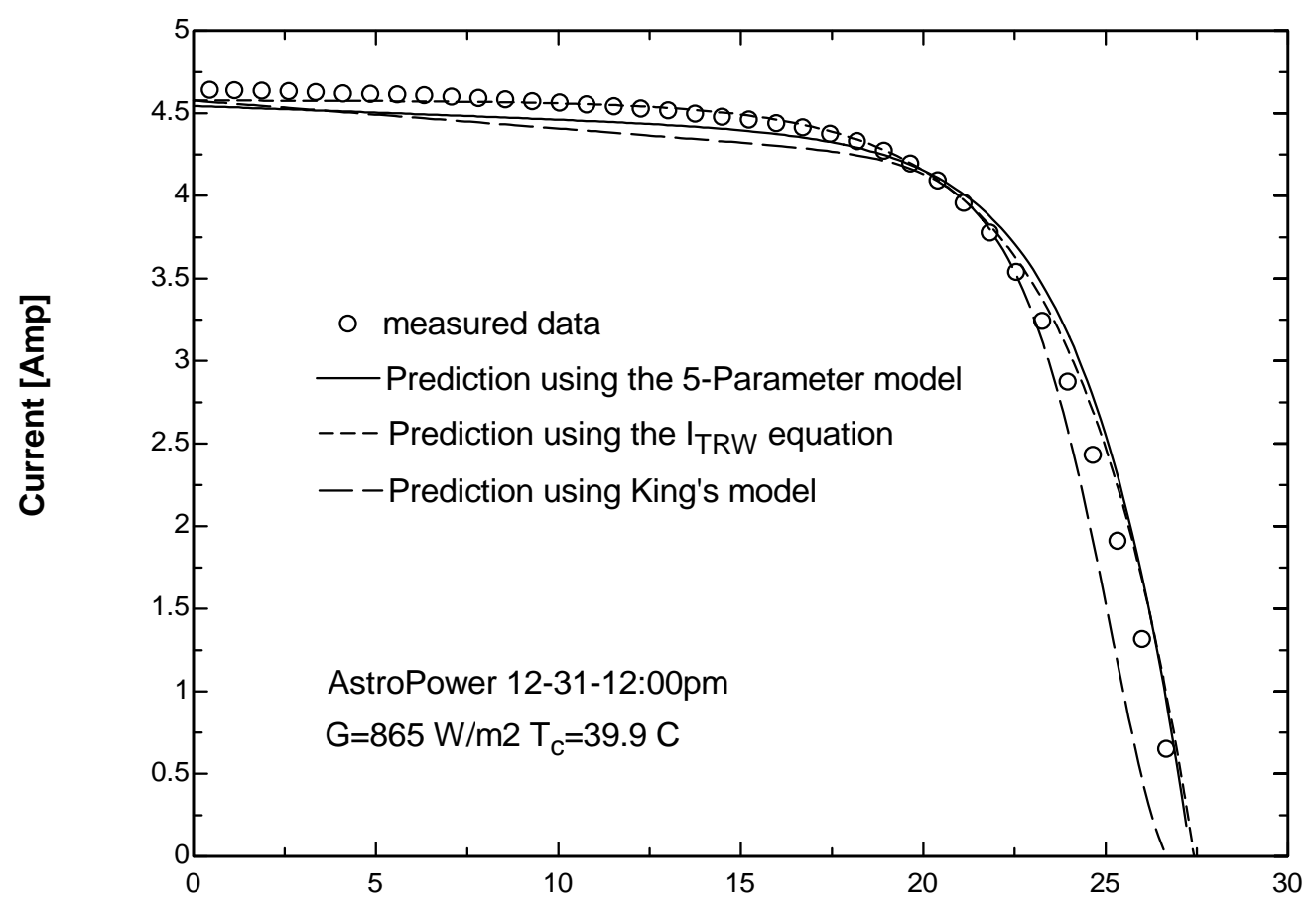

Voltage [V]

Figure 8.9: $\mathrm{I}-\mathrm{V}$ curve predicted for Astropower cell type, December 31 at noon with $G_{\text {eff }}=865$ $\mathrm{W} / \mathrm{m}^{2}$ and $T_{c}=39.9^{\circ} \mathrm{C}$, using SRC as reference conditions

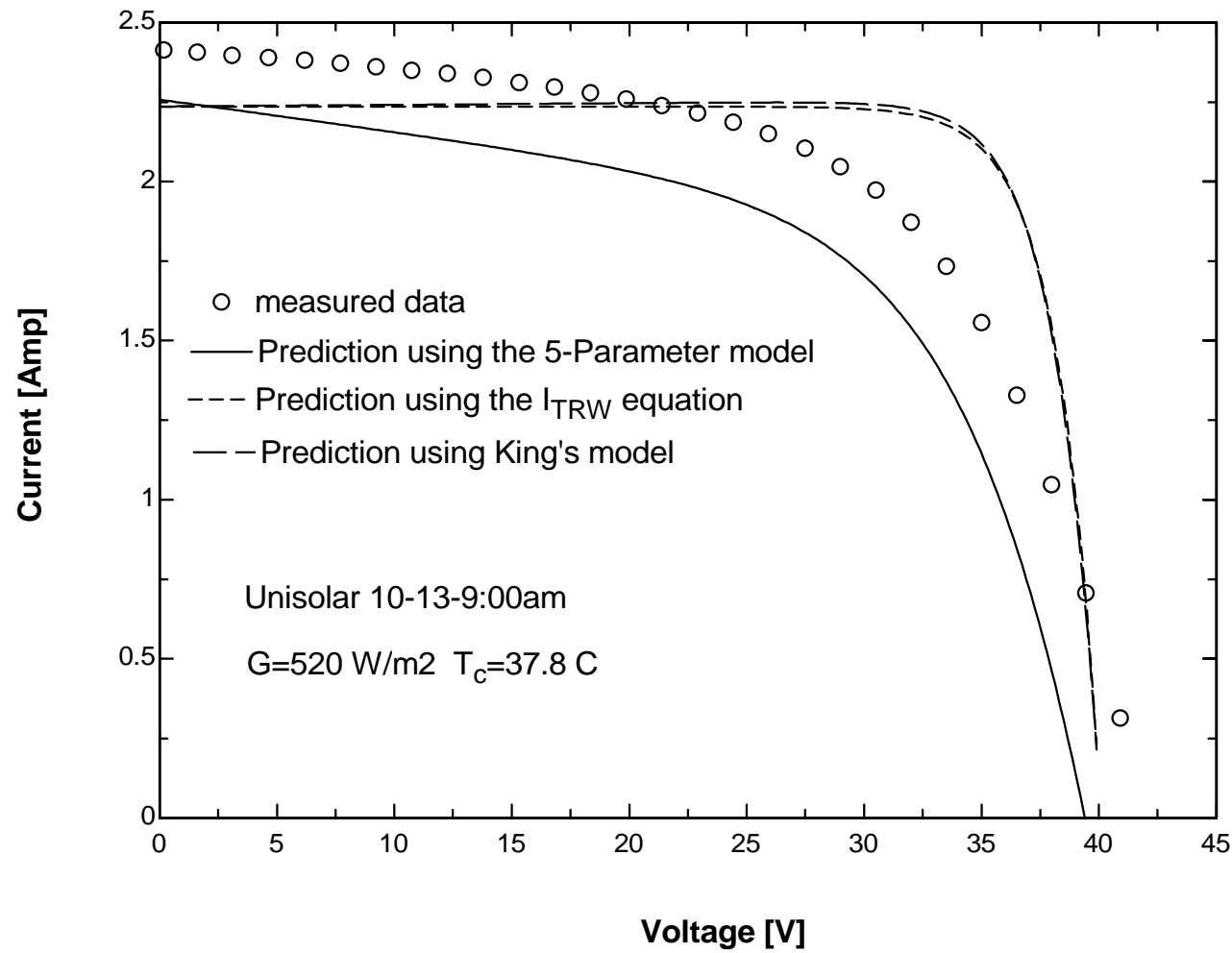

Figure 8.10: $\mathrm{I}-\mathrm{V}$ curve predicted for Uni-Solar cell type, October 13 at 9:00am with $G_{\text {eff }}=520$ $\mathrm{W} / \mathrm{m}^{2}$ and $T_{c}=37.8^{\circ} \mathrm{C}$, using SRC as reference conditions 


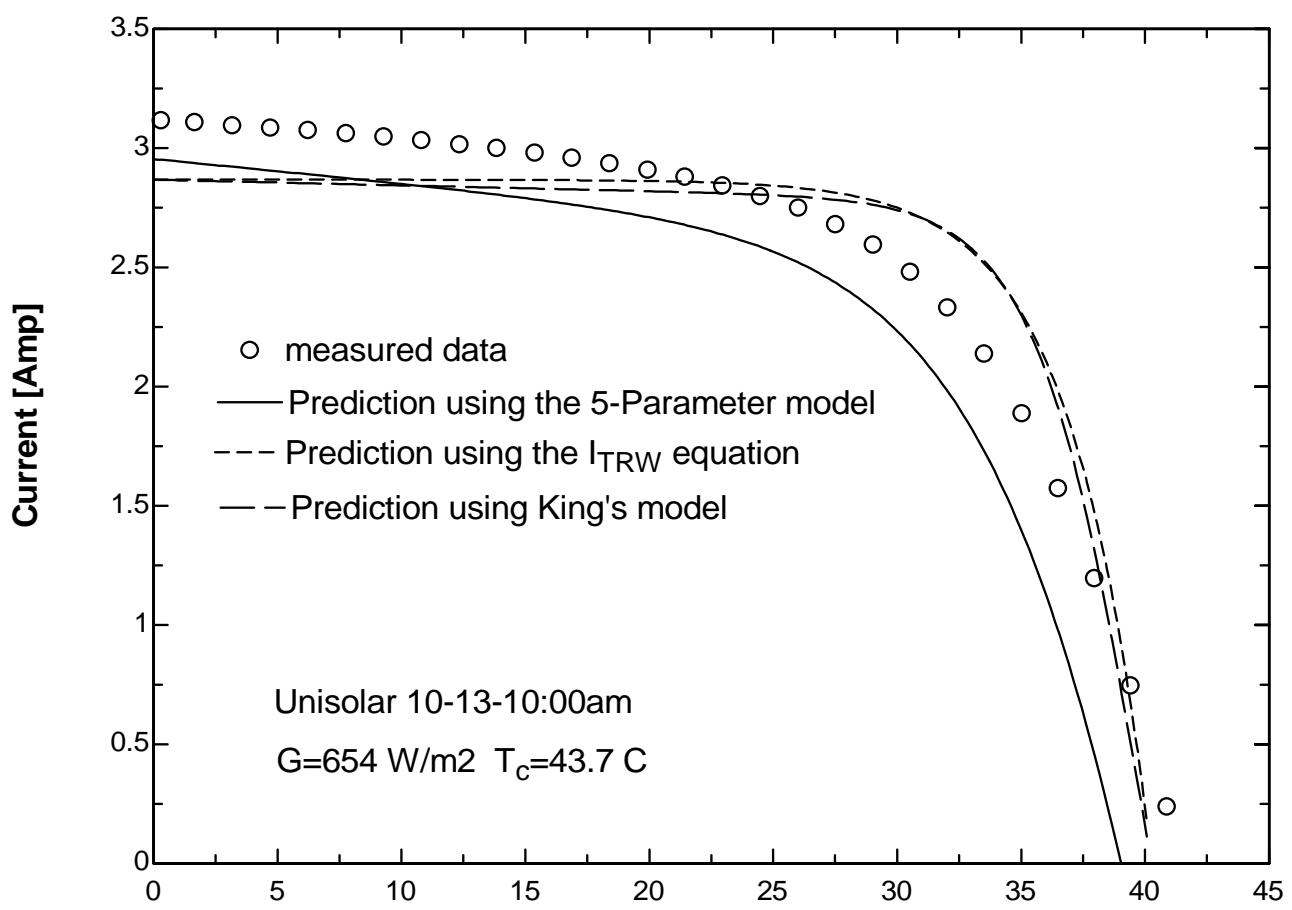

Voltage [V]

Figure 8.11: I-V curve predicted for Uni-Solar cell type, October 13 at 10:00am with $G_{\text {eff }}=654$ $\mathrm{W} / \mathrm{m}^{2}$ and $T_{c}=43.7^{\circ} \mathrm{C}$, using SRC as reference conditions

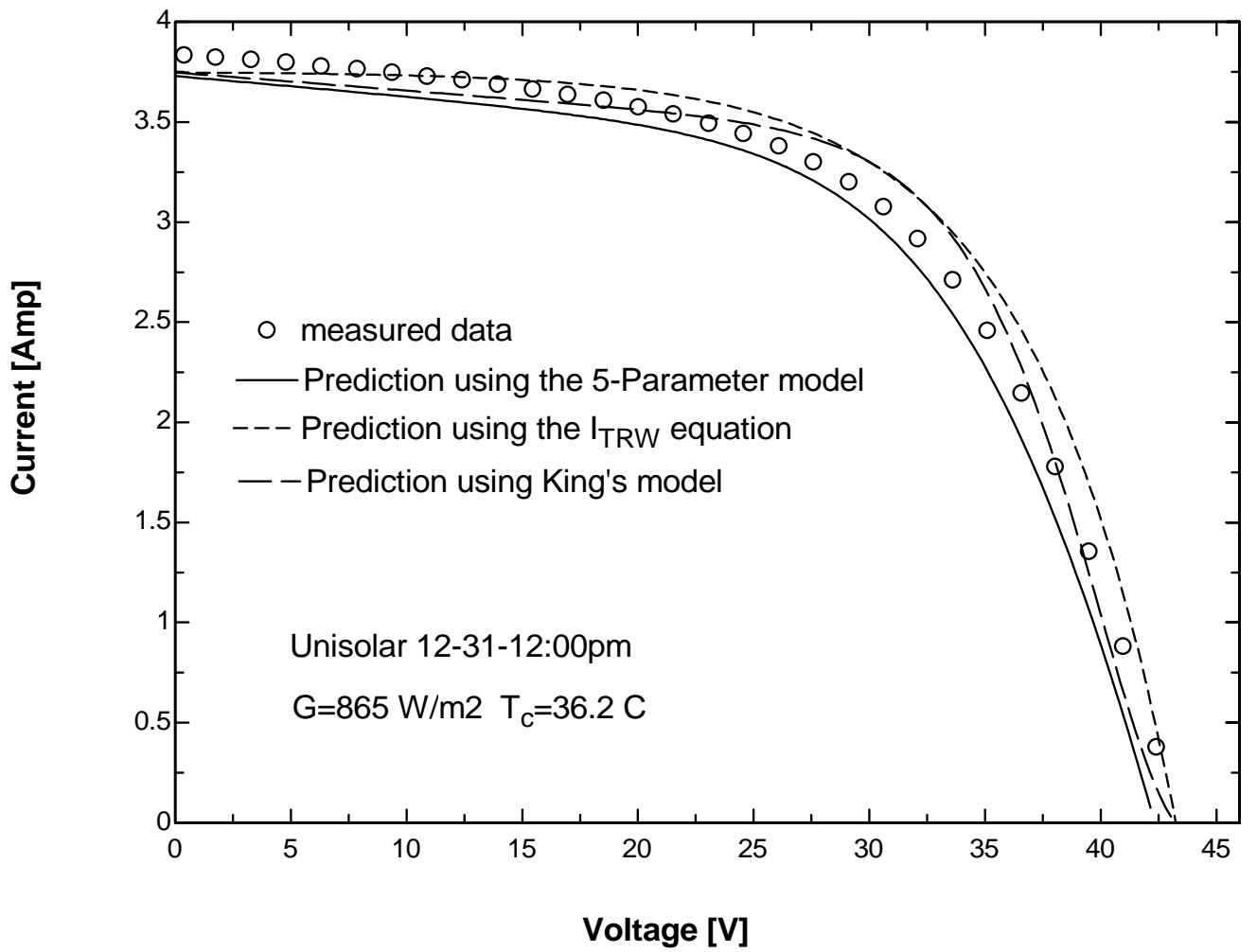

Figure 8.12: I-V curve predicted for Uni-Solar cell type, December 31 at noon with $G_{e f f}=865$ $\mathrm{W} / \mathrm{m}^{2}$ and $T_{c}=36.2^{\circ} \mathrm{C}$, using SRC as reference conditions 
The percentage RMS errors were calculated using Equation (8.46) for each

prediction and are shown in Tables 8.1-8.3, where the best results are marked in bold.

$$
\% R M S=\frac{\sqrt{\frac{\sum_{i=1}^{N}\left(I_{\text {Data }, i}-I_{\text {Model }, i}\right)^{2}}{N}}}{I_{\text {Data }, s c}} 100 \%
$$

RMS is the root mean square error, $I_{\text {Data }}$ is the current value measured by NIST which corresponds to the voltages of interest $\left(V=0, V=0.5 V_{o c}, V=V_{m p}, V=0.5\left(V_{o c}+V_{m p}\right), V=V_{o c}\right)$, $I_{\text {Model }}$ is the current predicted by the different models, $I_{\text {Data,sc }}$ is the short circuit current measured by NIST (corresponds to $V=0$ ), and $N$ is the number of points used.

Table 8.1 shows the results obtained when the five important points, previously mentioned, are used, therefore $N=5$. For clarity, the results obtained using Had Arab's model will be discussed in the next section, Section 8.2.2.

Table 8.1: RMS errors for different cell technologies, using 5 important points

\begin{tabular}{|c|c|c|c|c|c|c|c|c|c|c|c|c|}
\hline $\begin{array}{c}\text { Cell } \\
\text { Technology }\end{array}$ & \multicolumn{3}{|c|}{ Solarex } & \multicolumn{3}{c|}{ Siemens } & \multicolumn{3}{c|}{ AstroPower } & \multicolumn{3}{c|}{ Unisolar } \\
\hline Figure \# & 1 & 2 & 3 & 4 & 5 & 6 & 7 & 8 & 9 & 10 & 11 & 12 \\
\hline $\begin{array}{c}\text { \% RMS } \\
\text { error } \\
\text { using 5-Par. } \\
\text { Model }\end{array}$ & $\mathbf{4 . 9 2 2}$ & $\mathbf{3 . 9 3 6}$ & $\mathbf{3 . 0 5 9}$ & $\mathbf{1 . 4 0 1}$ & $\mathbf{0 . 3 6 2}$ & $\mathbf{1 . 6 5 2}$ & 6.583 & 4.819 & 3.365 & $\mathbf{1 1 . 9 9}$ & 9.573 & 3.659 \\
\hline $\begin{array}{c}\text { \% RMS } \\
\text { error } \\
\text { using King's } \\
\text { Model }\end{array}$ & 11.38 & 5.826 & 3.315 & 6.917 & 5.376 & 3.525 & 6.516 & $\mathbf{4 . 2 5 7}$ & 3.345 & 12.98 & $\mathbf{7 . 3 8 8}$ & $\mathbf{2 . 5 6 2}$ \\
\hline $\begin{array}{c}\text { \% RMS } \\
\text { error } \\
\text { using TRW } \\
\text { Eqn. }\end{array}$ & 8.638 & 7.964 & 4.617 & 3.796 & 5.733 & 3.878 & $\mathbf{4 . 5 8 6}$ & 4.705 & $\mathbf{3 . 1 1 4}$ & 12.8 & 7.779 & 4.588 \\
\hline
\end{tabular}


Solar panels may operate with a maximum power point tracker; it is of interest knowing how well the model works in calculating the maximum power point. Table 8.2 shows the results obtained when only the maximum power point is used, hence $N=1$ and $I_{\text {Data,mp }}$, the current at the maximum power point measured by NIST substitutes $I_{\text {Data,sc, }}$ therefore Equation (8.46) becomes:

$$
\% R M S=\frac{\sqrt{\left(I_{\text {Data }, m p}-I_{\text {Model }, m p}\right)^{2}}}{I_{\text {Data }, m p}} 100 \%
$$

Table 8.2: RMS errors for different cell technologies, using maximum power point

\begin{tabular}{|c|c|c|c|c|c|c|c|c|c|c|c|c|}
\hline $\begin{array}{c}\text { Cell } \\
\text { Technology }\end{array}$ & \multicolumn{3}{|c|}{ Solarex } & \multicolumn{3}{c|}{ Siemens } & \multicolumn{3}{c|}{ AstroPower } & \multicolumn{3}{c|}{ Unisolar } \\
\hline Figure \# & 1 & 2 & 3 & 4 & 5 & 6 & 7 & 8 & 9 & 10 & 11 & 12 \\
\hline $\begin{array}{c}\text { \% RMS } \\
\text { error } \\
\text { using 5-Par. } \\
\text { Model }\end{array}$ & $\mathbf{4 . 4 0 8}$ & $\mathbf{1 . 8 5 7}$ & 3.173 & $\mathbf{0 . 0 2 0}$ & $\mathbf{0 . 0 7 0}$ & $\mathbf{0 . 5 0 1}$ & 4.719 & 2.674 & 0.710 & 16.46 & 11.66 & $\mathbf{4 . 4 3 1}$ \\
\hline $\begin{array}{c}\text { \% RMS } \\
\text { error } \\
\text { using King's } \\
\text { Model }\end{array}$ & 5.548 & 2.771 & $\mathbf{1 . 2 0 9}$ & 4.772 & 0.701 & 0.710 & $\mathbf{2 . 9 7 1}$ & $\mathbf{2 . 4 8 9}$ & $\mathbf{0 . 0 7 4}$ & 16 & $\mathbf{8 . 4 8 2}$ & 6.213 \\
\hline $\begin{array}{c}\text { \% RMS } \\
\text { error } \\
\text { using TRW } \\
\text { Eqn. }\end{array}$ & 5.696 & 2.993 & 1.581 & 4.036 & 0.932 & 0.940 & 3.193 & 2.773 & 0.128 & $\mathbf{1 5 . 1 1}$ & 8.861 & 5.986 \\
\hline
\end{tabular}

It is of interest knowing how well each model predicts the following parameters: $I_{s c}, I_{m p}, V_{o c}, V_{m p}, P_{m p}$. The results were obtained with Equations (8.48) through (8.52) and are shown in Table 8.3.

$$
\begin{gathered}
\% R M S=\frac{\sqrt{\left(I_{\text {Data }, s c}-I_{\text {Model }, s c}\right)^{2}}}{I_{\text {Data }, s c}} 100 \% \\
\% R M S=\frac{\sqrt{\left(I_{\text {Data } m p}-I_{\text {Model }, m p}\right)^{2}}}{I_{\text {Data }, m p}} 100 \%
\end{gathered}
$$




$$
\begin{gathered}
\% R M S=\frac{\sqrt{\left(V_{\text {Data }, o c}-V_{\text {Model }, o c}\right)^{2}}}{V_{\text {Data }, o c}} 100 \% \\
\% R M S=\frac{\sqrt{\left(V_{\text {Data }, m p}-V_{\text {Model }, m p}\right)^{2}}}{V_{\text {Data }, m p}} 100 \% \\
\% R M S=\frac{\sqrt{\left(P_{\text {Data }, m p}-P_{\text {Model }, m p}\right)^{2}}}{P_{\text {Data }, m p}} 100 \%
\end{gathered}
$$

where the parameters with the subscript "Data" were measured by NIST and the ones with the subscript "Model" were predicted with the different available models (5-

\begin{tabular}{|c|c|c|c|c|c|c|c|c|c|c|c|c|c|}
\hline \multirow{2}{*}{\multicolumn{2}{|c|}{$\begin{array}{c}\begin{array}{c}\text { Cell } \\
\text { Technology }\end{array} \\
\text { Figure \# }\end{array}$}} & \multicolumn{3}{|c|}{ Solarex } & \multicolumn{3}{|c|}{ Siemens } & \multicolumn{3}{|c|}{ AstroPower } & \multicolumn{3}{|c|}{ Unisolar } \\
\hline & & 1 & 2 & 3 & 4 & 5 & 6 & 7 & 8 & 9 & 10 & 11 & 12 \\
\hline \multirow{3}{*}{$I_{s c}$} & 5-Pars & 5.285 & 3.739 & 3.725 & 2.689 & 0.753 & 0.461 & 1.560 & 1.947 & 2.246 & 6.53 & 5.252 & 2.668 \\
\hline & King & 7.696 & 5.5 & 2.463 & 3.992 & 1.024 & 1.164 & 7.643 & 0.362 & 1.558 & 7.415 & 8.033 & 2.195 \\
\hline & TRW & 7.696 & 5.5 & 2.463 & 3.992 & 1.024 & 1.164 & 7.643 & 0.362 & 1.558 & 7.415 & 8.034 & 2.195 \\
\hline \multirow{3}{*}{$I_{m p}$} & 5-Pars & 7.465 & 4.502 & 5.525 & 1.757 & 1.126 & 2.910 & 0.137 & 1.235 & 1.853 & 9.659 & 7.205 & 0.747 \\
\hline & King & 8.268 & 3.75 & 2.589 & 9.307 & 1.249 & 1.449 & 6.008 & 1.342 & 1.374 & 11.07 & 3.533 & 4.35 \\
\hline & TRW & 5.903 & 5.01 & 3.901 & 4.494 & 0.617 & 3.353 & 0.267 & 2.845 & 1.366 & 10.24 & 3.125 & 3.459 \\
\hline \multirow{2}{*}{$V_{o c}$} & 5-Pars & 2.111 & 0.040 & 0.065 & 2.016 & 0.317 & 0.473 & 1.292 & 0.167 & 0.316 & 6.146 & 5.952 & 2.578 \\
\hline & King & 1.781 & 1.643 & 0.826 & 0.507 & 1.109 & 0.697 & 0.684 & 1.098 & 0.624 & 4.471 & 2.94 & 0.483 \\
\hline \multirow{2}{*}{$V_{m p}$} & 5-Pars & 4.375 & 3.397 & 3.062 & 2.004 & 1.11 & 2.963 & 6.315 & 5.120 & 3.127 & 5.838 & 4.097 & 3.343 \\
\hline & King & 3.396 & 1.111 & 1.566 & 7.405 & 2.363 & 0.815 & 3.777 & 1.237 & 1.599 & 10.95 & 8.555 & 1.973 \\
\hline \multirow{3}{*}{$\boldsymbol{P}_{m p}$} & 5-Pars & 3.416 & 1.258 & 2.633 & 0.212 & 0.029 & 0.140 & 6.461 & 3.822 & 1.215 & 14.93 & 11.01 & 4.065 \\
\hline & King & 5.152 & 2.681 & 1.064 & 2.591 & 1.085 & 0.646 & 2.458 & 2.596 & 0.202 & 23.24 & 12.39 & 6.409 \\
\hline & TRW & 2.707 & 3.954 & 2.397 & 2.578 & 1.732 & 2.566 & 3.499 & 4.117 & 0.211 & 22.32 & 11.95 & 5.5 \\
\hline
\end{tabular}
Parameter, King, TRW).

Table 8.3: RMS errors for different cell technologies, using different parameters 
Analyzing the calculated error values we can conclude that in general, using the 5-Parameter model for the Siemens (mono-crystalline), Solarex (poly-crystalline), and Astropower (silicon thin film) cell types the RMS errors calculated using the five important points previously discussed, are under $6.5 \%$ and for the Uni-Solar (3-Junction amorphous) cell type under 12\%. King's model yields slightly larger errors of under 7\% for the first three cell types mentioned and up to $13 \%$ for the Uni-Solar cell type. The errors obtained using the TRW equation (Equation (8.23)) are up to $8.6 \%$ for the first three cell types and up to near $13 \%$ for the Uni-Solar cell type.

When only the maximum power point is used to calculate the RMS error, the obtained results are consistent with those obtained using the five important points. The 5-Parameter model yields RMS errors in general of less than $4.7 \%$ for the first three cell types discussed and up to $16.5 \%$ for the Uni-Solar cell type, while King's model yields errors of up to $5.5 \%$ for the first three cell types and up to $16 \%$ for the Uni-Solar cell type. The TRW equation yields errors of near $5.7 \%$ for the Solarex cell type and over $15 \%$ for the Uni-Solar cell type.

When the RMS error is calculated for each of the important parameters $\left(I_{s c}, I_{m p}\right.$, $\left.V_{o c}, V_{m p}, P_{m p}\right)$ the following conclusions can be made:

$I_{s c}: \quad 5$-Parameter model in general yields the best results, under $6.5 \%$ for all cell types King's model and TRW equation yield identical results, in general all under $8 \%$ for all cell types

$I_{m p}: \quad 5$-Parameter model in general under 7.5\% for all cell types (except Uni-Solar, which is under 9.7\%) 
King's model up to $9.3 \%$ for the first three cell types and up to $11 \%$ for Uni-Solar TRW equation under $6 \%$ for the first three cell types and under $10.5 \%$ for UniSolar cell type

$V_{o c}: \quad$ Up to $2.1 \%$ for the 5-Parameter model (except Uni-Solar, which is under 6.2\%) King's model under $2 \%$ for all cell types (except Uni-Solar, which is up to $4.5 \%$ ) $V_{m p}: \quad 5$-Parameter model under $6.3 \%$ for all cell types Up to near 7.5\% for King's model for all cell types (except Uni-Solar, which is up to $11 \%)$

$P_{m p}: \quad$ Using the 5-Parameter model, under 6.5\% for all cell types, with the exception of Uni-Solar, which has errors of up to near $15 \%$ King's model yields errors of up to $5.2 \%$ for the first three cell types and up to $23 \%$ for Uni-Solar

The TRW equation yields errors of up to $4.2 \%$ for the first three cell types and up to $23 \%$ for the Uni-Solar cell type.

The 5-Parameter model can be considered just as good at yielding results as King's model because at some conditions the 5-Parameter works better, yet at other conditions King's model is better. The main explanation for this would be that King's model uses many coefficients $\left(C_{0^{-}} C_{7}\right)$ which are determined from curve fittings after running the panel for about three consecutive days (therefore they are not representative of ALL weather conditions, summer, winter, etc.). The 5-Parameter model is based on a semi-empirical model and does not use as many empirical coefficients. Because it 
requires less input data, it is not surprising that, in some cases, results are less accurate than those from the King model.

In general, it can be said that the 5-Parameter model yields near, if not better results than King's model and the TRW current equation when compared with the NIST data. The main advantage of using the 5-Parameter model over King's model is that it requires less input data which is not provided by the manufacturer. The only input data which needs to be calculated is the five parameters $\left(I_{L, r e f}, a_{r e f}, I_{o, r e f}, R_{s, r e f}, R_{s h, r e f}\right)$ for each cell type at reference conditions (SRC) and this is done once from the data provided by the manufacturer. The only disadvantage in using the 5-Parameter model is that it requires the values of the voltage and current at the maximum power point ( $V_{m p}$ and $I_{m p}$, respectively) to calculate the series resistance $\left(R_{s}\right)$ and although they can be predicted using the equations previously mentioned in Section 4.4.1, this method tends to slightly increase the error. Even with this disadvantage, the errors obtained are within an accepted tolerance. King's model requires more data in order to calculate all the coefficients $C_{0^{-}} C_{7}, \alpha_{I m p}, \beta_{V m p}, I_{x o}, I_{x x o}$, among other parameters and these values usually come from regressions, increasing the uncertainty and errors. In addition, King's model makes use of the $f_{2}(A O I)$ angle of incidence modifier, which is an empirically determined polynomial and yields values of over 1.0, which physically is impossible without the use of a concentrator. None of the models provide an accurate model for predicting the performance of the 3-Junction amorphous cell types, but can be used to get an idea of the possible output values. The 5-Parameter model yields the best results for this case. 


\subsubsection{5-Parameter Model vs. A. Hadj Arab's equations}

Figures 8.13-8.16 compare some of the results obtained using Hadj Arab's model versus those obtained using the 5-Parameter model proposed in this research. Only the Siemens cell type was used for this comparison, because this is usually the cell type that yields the best results; if the model does not do a good job at predicting mono-crystalline cell types, it will not yield good results for the other cell types.

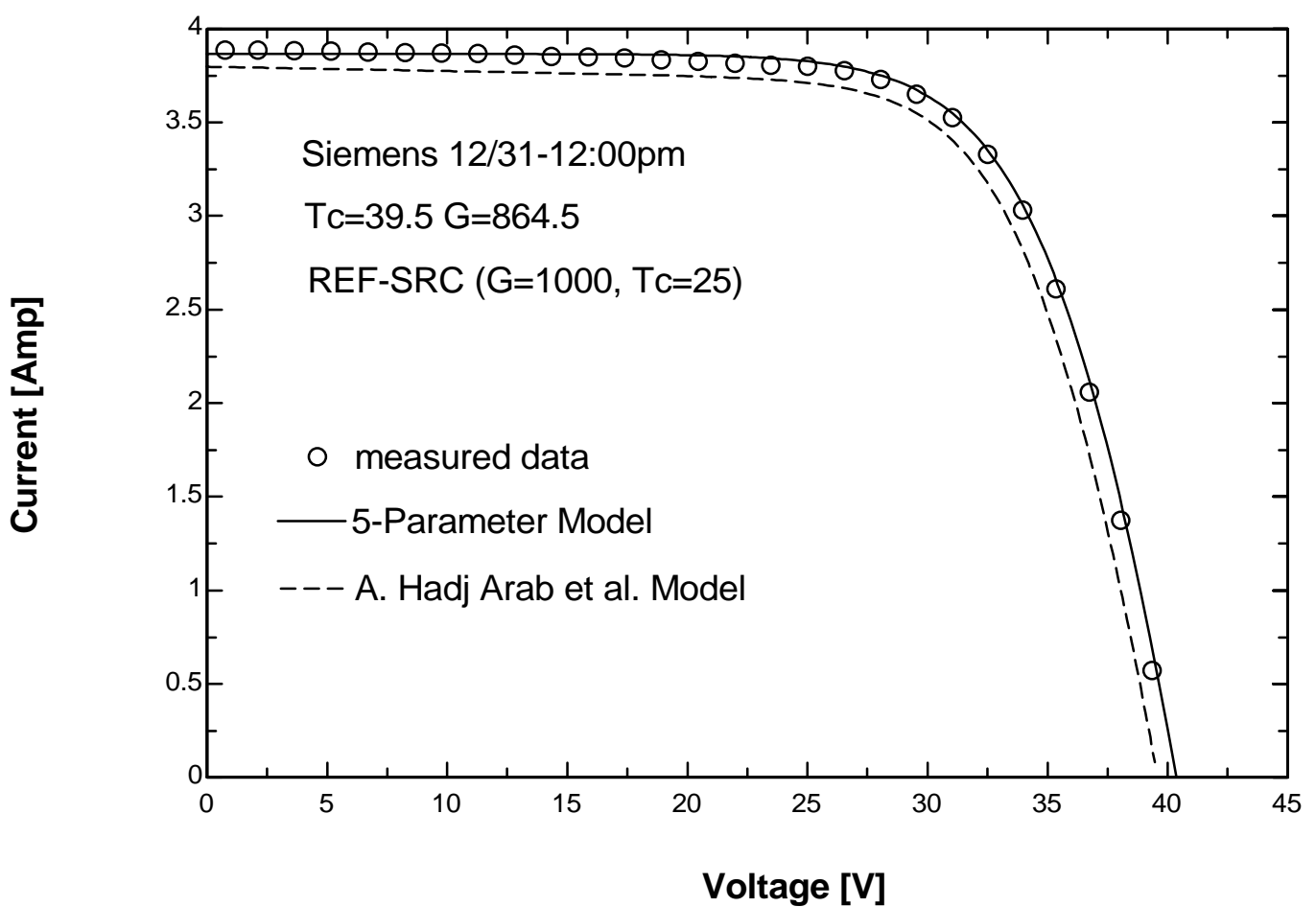

Figure 8.13: Siemens cell type, December 31 at noon with $G_{\text {eff }}=864.5 \mathrm{~W} / \mathrm{m}^{2}$ and $T_{c}=39.5^{\circ} \mathrm{C}$, using SRC reference conditions 


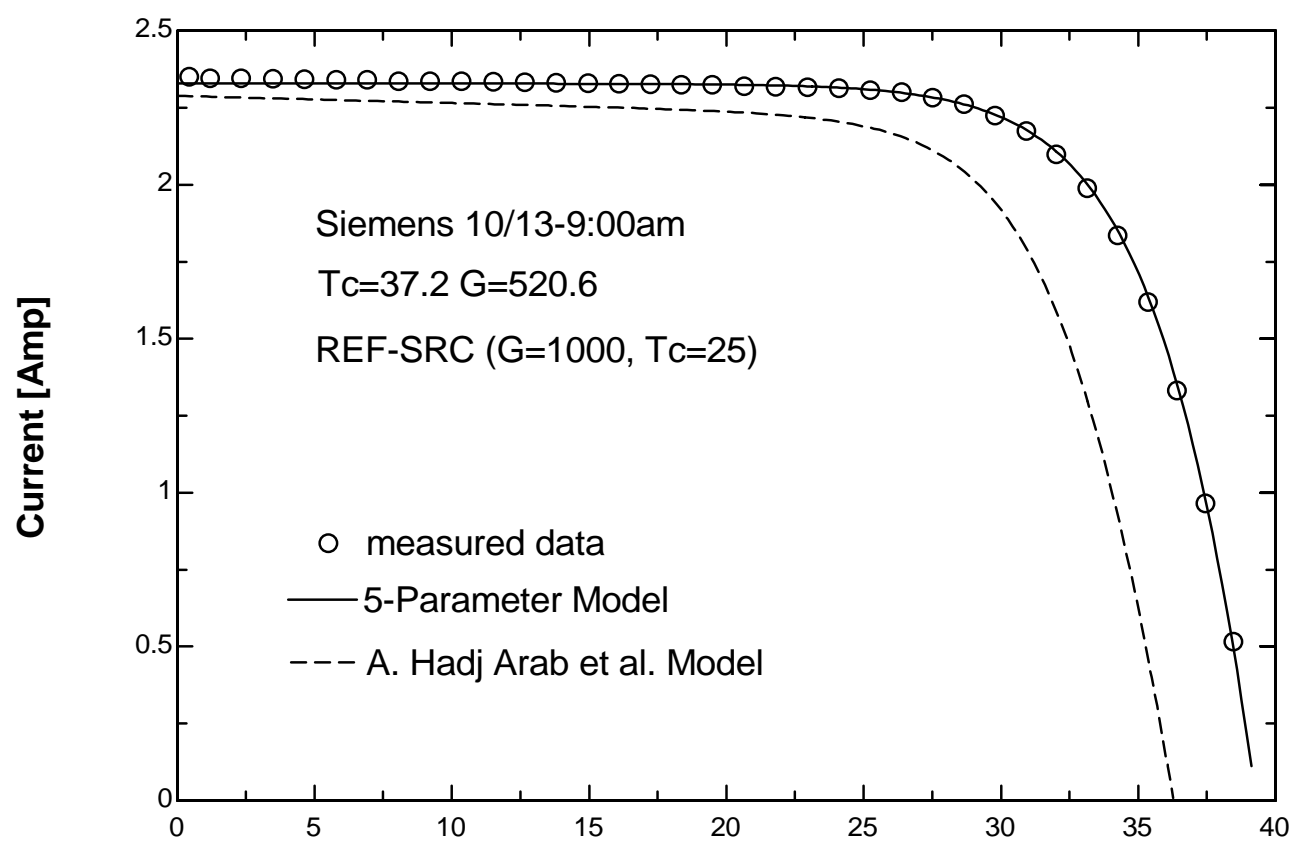

Voltage [V]

Figure 8.14: Siemens cell type, October 13 at 9:00am with $G_{\text {eff }}=520.6 \mathrm{~W} / \mathrm{m}^{2}$ and $T_{c}=37.2^{\circ} \mathrm{C}$, using $\mathrm{SRC}$ as reference conditions

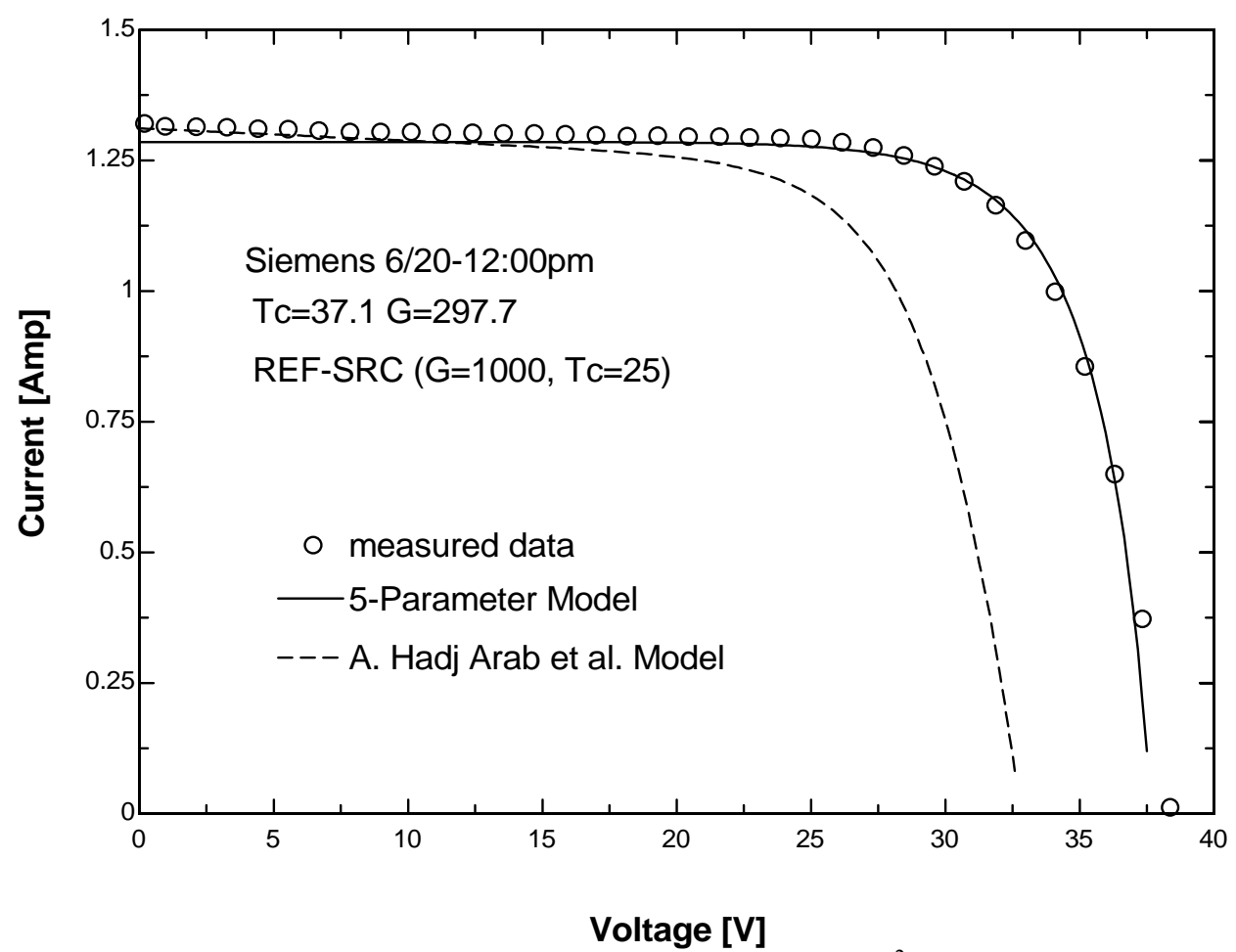

Figure 8.15: Siemens cell type, June 20 at noon with $G_{\text {eff }}=297.7 \mathrm{~W} / \mathrm{m}^{2}$ and $T_{c}=37.1^{\circ} \mathrm{C}$, using SRC as reference conditions 


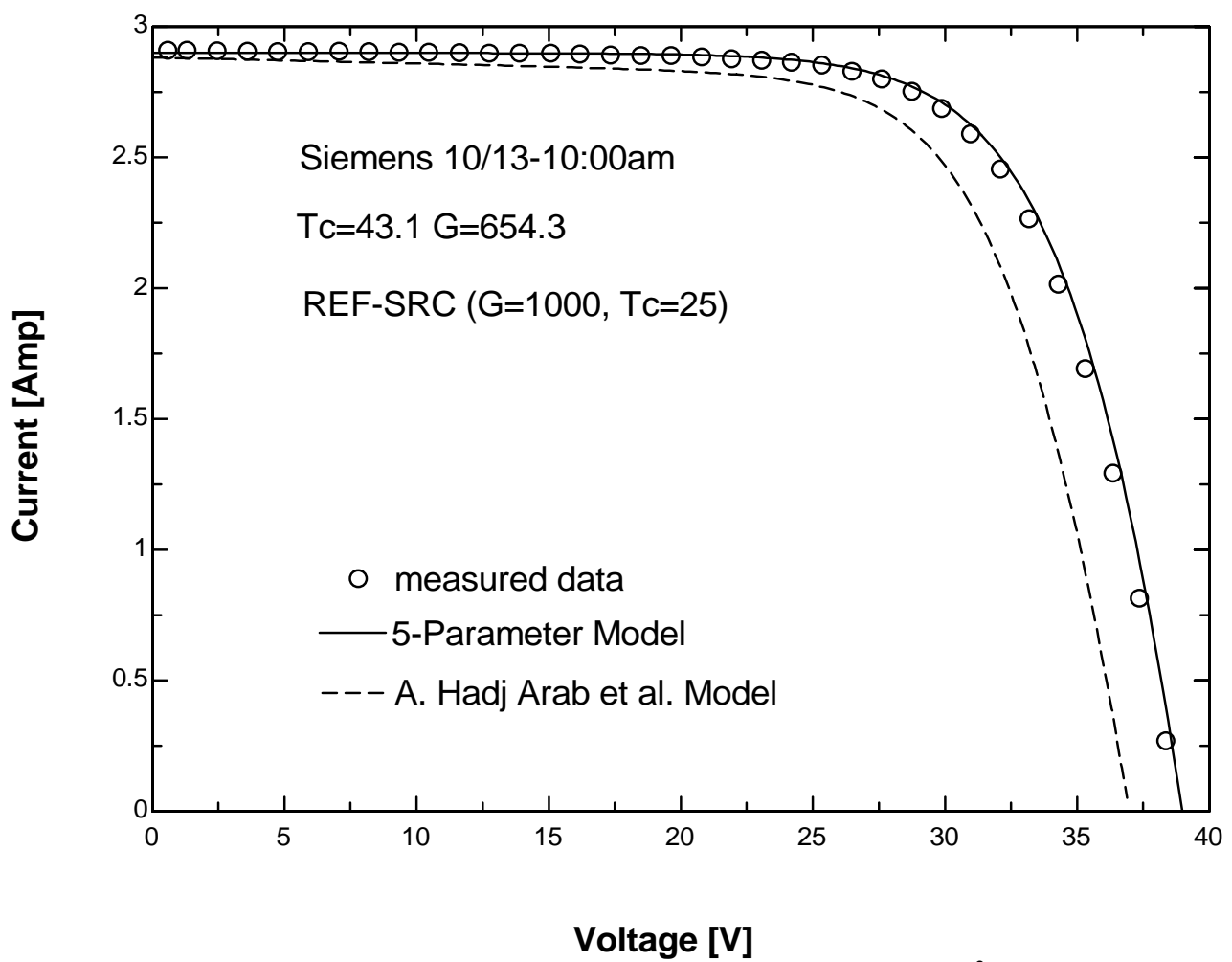

Figure 8.16: Siemens cell type, October 13 at $10: 00 \mathrm{am}$ with $G_{\text {eff }}=654.3 \mathrm{~W} / \mathrm{m}^{2}$ and $T_{c}=43.1^{\circ} \mathrm{C}$, using SRC as reference conditions

Tables 8.4 and 8.5 show the errors obtained using the two different models (5Parameter and Hadj Arab's). The values in Table 8.4 were calculated using the 5 important points, using Equation (8.46).

Table 8.5 uses only the maximum power point to calculate the error and the values were obtained from Equation (8.47).

Table 8.4: Errors using five important points

\begin{tabular}{|c|c|c|c|c|}
\hline Figure \# & Figure 1 & Figure 2 & Figure 3 & Figure 4 \\
\hline 5-Parameter Model & 1.653 & 0.4702 & 1.613 & 2.344 \\
\hline Hadj Arab's Model & 3.910 & 23.62 & 38.21 & 11.21 \\
\hline
\end{tabular}

Table 8.5: Errors using maximum power point only

\begin{tabular}{|c|c|c|c|c|}
\hline Figure \# & Figure 1 & Figure 2 & Figure 3 & Figure 4 \\
\hline 5-Parameter Model & 0.5006 & 0.0995 & 0.2638 & 0.9946 \\
\hline Hadj Arab's Model & 3.542 & 19.78 & 53.04 & 8.949 \\
\hline
\end{tabular}


Hadj Arab et al.'s model seems to agree with the behavior of the photovoltaic cells' performance because it acknowledges that the values of the short circuit current and open circuit voltage (calculated in Equations (8.40) and (8.41)) depend on both, irradiance and temperature, yet from the results previously shown (plots and RMS errors) it can be easily concluded that the model proposed by Hadj Arab et al. does not do a good job at fitting data for operating conditions too different from SRC. While the 5Parameter shows errors under 3\% for both analysis (using 5 important points, as well as using only the maximum power point), Hadj Arab et al.'s model yields errors of over $50 \%$ for some operating conditions. The results show that this model is good at predicting data obtained under high irradiance (such as that seen in Figure 8.13), but not good at lower irradiances (Figure 8.15). The 5-Parameter model yields excellent results, no matter the operating conditions. 


\section{Chapter 9 \\ Implementation in TRNSYS}

When evaluating a photovoltaic system, it is necessary to calculate its performance over all possible types of operating conditions - rather than for just a few selected conditions. The results obtained in Chapter 8 could perhaps not be representative of long-term performance. To investigate this possibility, a simulation using a large amount of data was used. This simulation used data at 5 minute intervals from four days with completely different operating conditions (March 18, June 20, October 13, and December 31) in Gaithersburg, MD. Experimental data from NIST were available for these days. The data between hours 9:00 am and 4:00 pm, being the hours where the incidence of light on the panels is at its highest, were selected for this study. Increments of five minutes were used in the simulations, yielding a total of over three hundred points for the number of points analyzed. The PV models used as input the measured solar radiation on the PV array, incidence angle for beam radiation, and cell temperature. Figure 9.1 shows the values of the irradiance measured on the tilted surface for the corresponding times. 


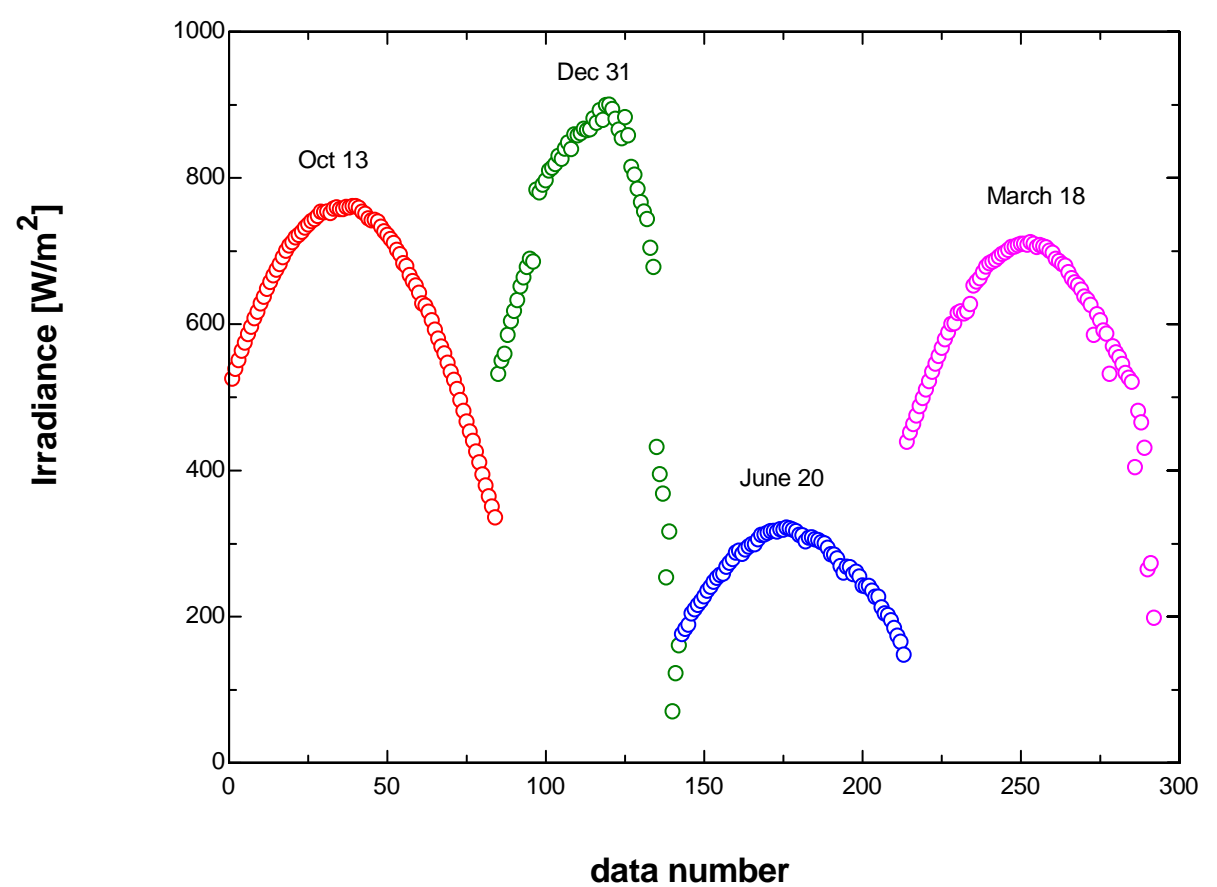

Figure 9.1: Measured irradiance on tilted surface for the different days selected for the simulation in TRNSYS

Figure 9.1 shows that the days selected were clear days through out the entire day, with the exception of December 31, which had some periods of cloudiness during the afternoon, decreasing the amount of irradiance incident on the solar panels and pyranometer. The power at the maximum power point was selected as the point for comparison.

\subsection{Simulation using the 5-Parameter model}

The existing code in FORTRAN "Type 94" was modified to account for the changes made to the five parameter model. Figures 9.2 and 9.3 show that the same results are obtained using either the EES program or the TRNSYS code. 


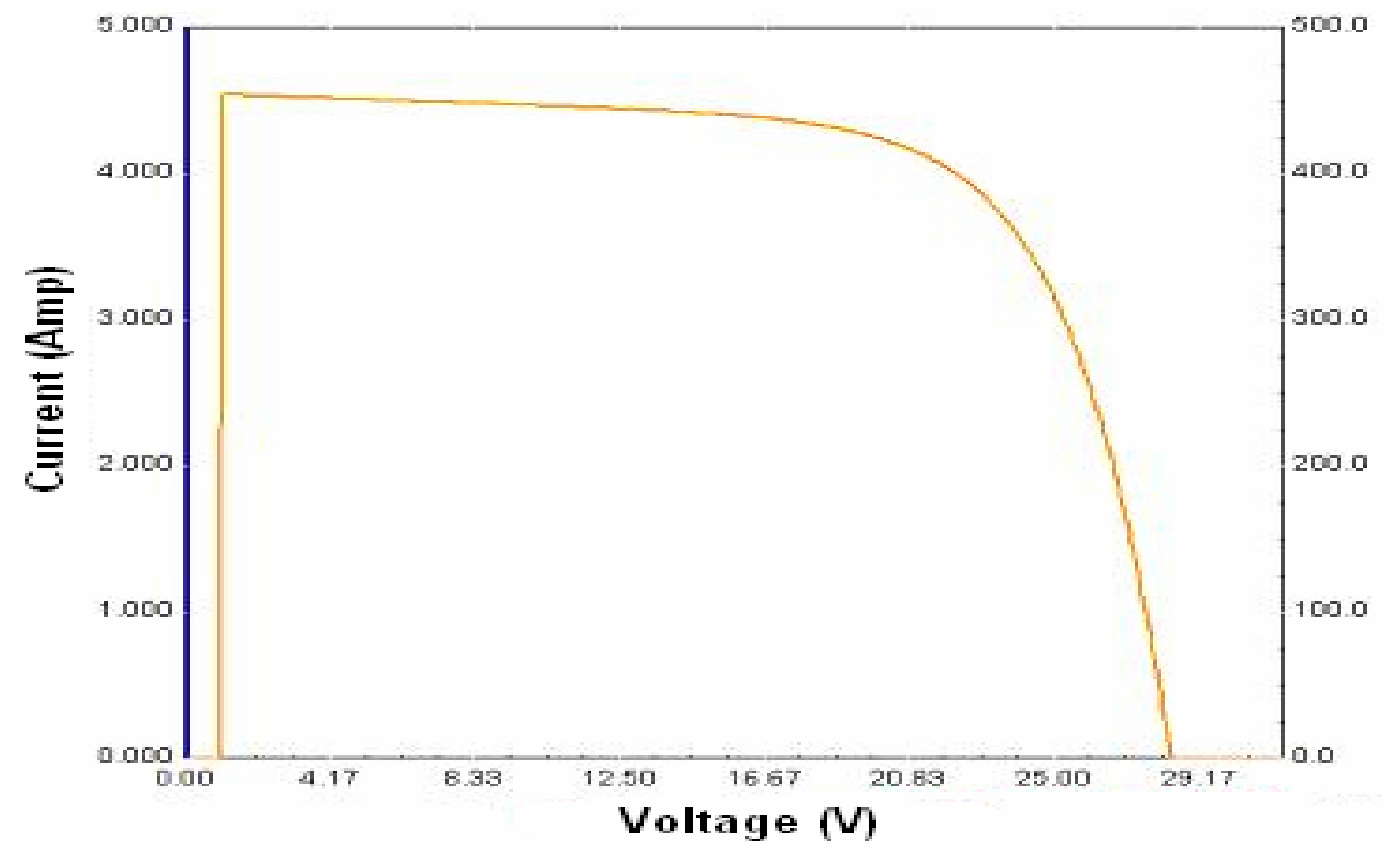

Figure 9.2: I-V curve for Astropower cell type, December 31 at noon, using SRC as reference conditions, calculated using TRNSYS. Obtained values: $I_{s c}=4.544 \mathrm{Amp}, V_{o c}=27.33 \mathrm{~V}, I_{m p}=3.951 \mathrm{Amp}$, $V_{m p}=21.44 \mathrm{~V}, P_{m p}=84.71 \mathrm{~W}$.

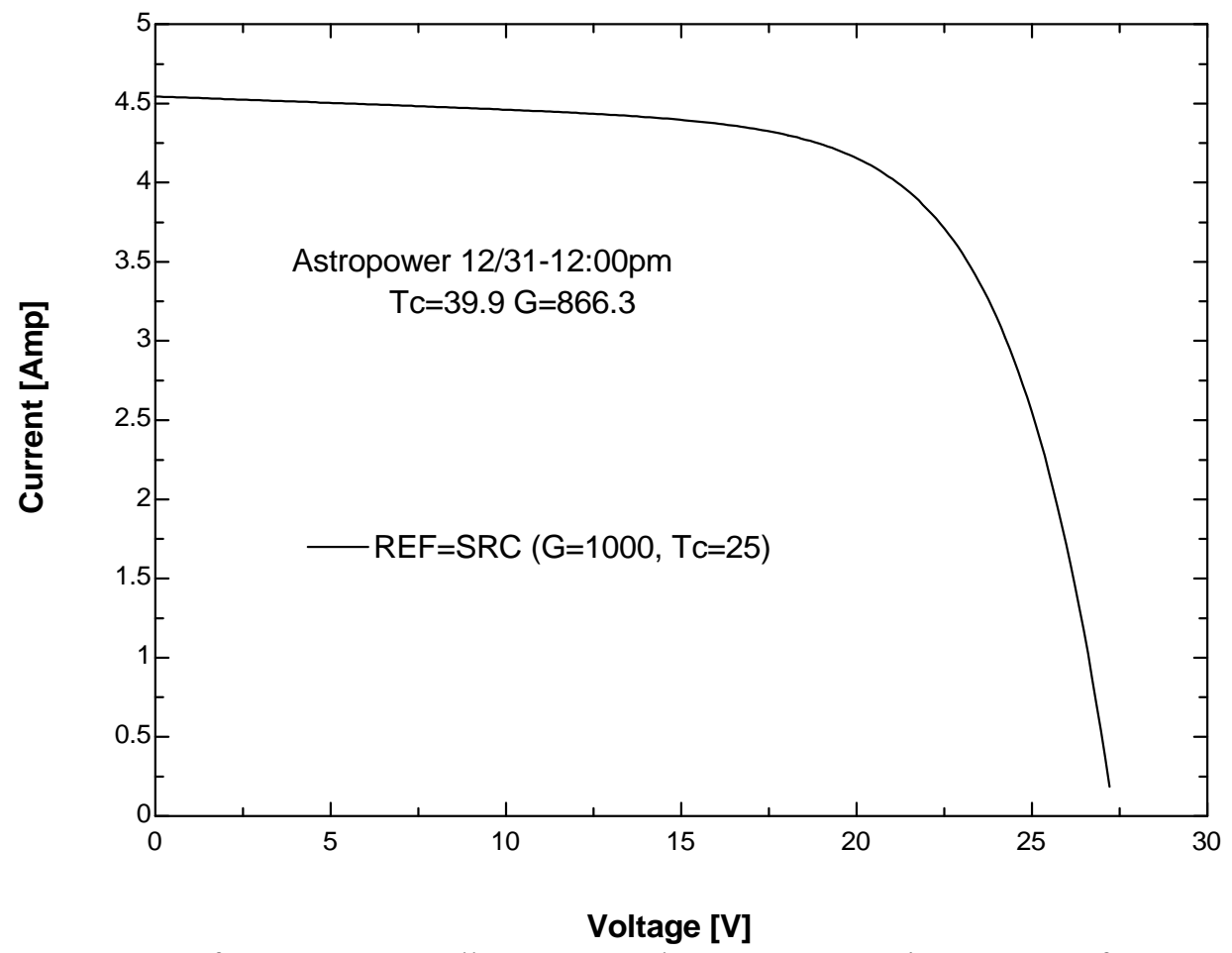

Figure 9.3: I-V curve for Astropower cell type, December 31 at noon, using SRC as reference conditions, calculated using EES. Obtained values: $I_{s c}=4.544 \mathrm{Amp}, V_{o c}=27.34 \mathrm{~V}, I_{m p}=3.959 \mathrm{Amp}$, $V_{m p}=21.4 \mathrm{~V}, P_{m p}=84.72 \mathrm{~W}$. 
Figure 9.4 shows the TRNYS model in schematic form using the TRNSYS Studio graphical input program. Figures 9.5-9.8 show the values used for the simulation of the Siemens cell type. The values used for the other cell types can be found in Appendix A, Table A1.

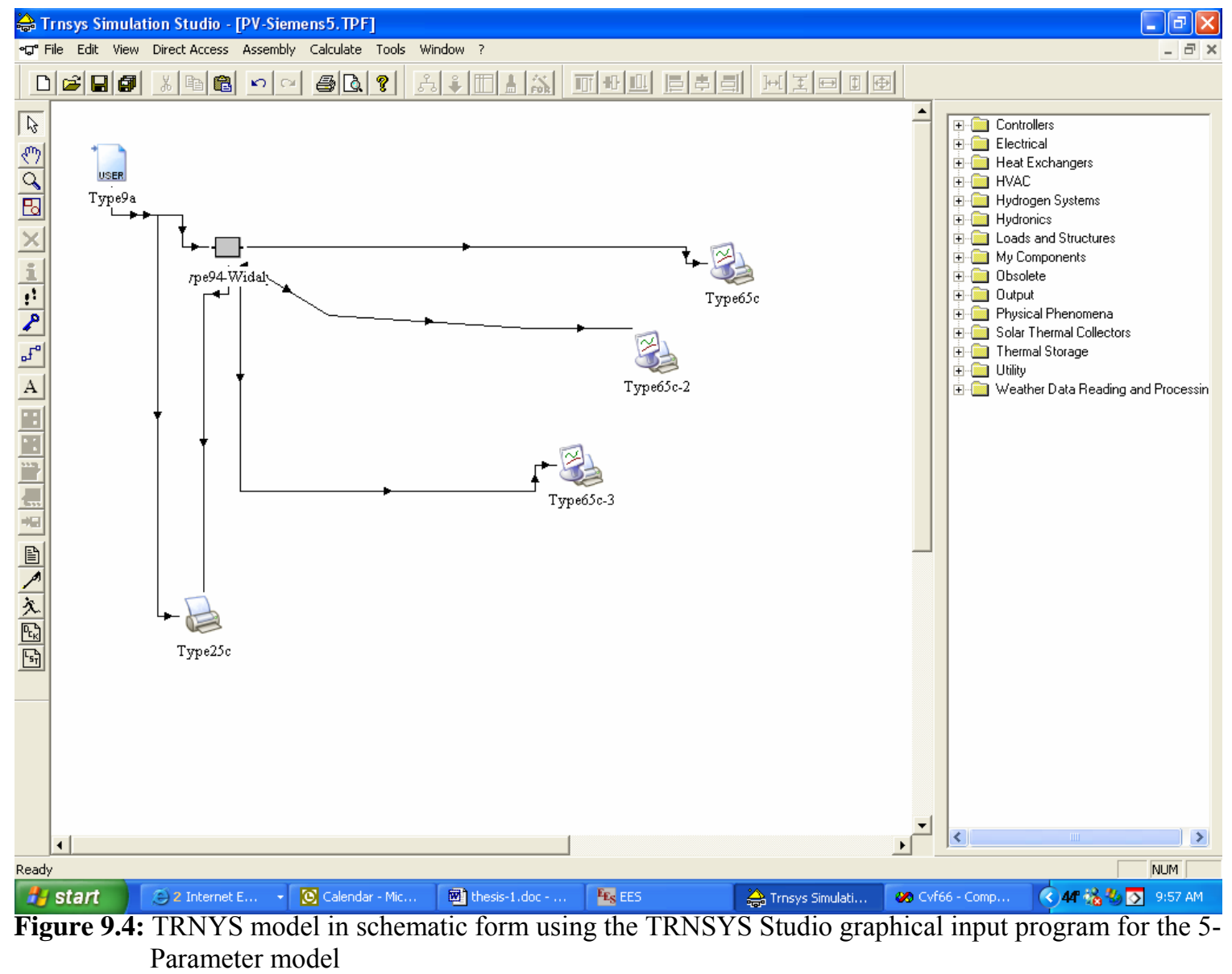




\section{(PV-Siemens5.TPF) Type94-Widalys}

\section{Parameter Input | Output $\mid$ Derivative $\mid$ Special Cards $\mid$ External Files $\mid$ Comment}

\begin{tabular}{|c|c|c|c|c|c|c|}
\hline 1 & 田 & $\begin{array}{l}\text { Module short-circuit current at } \\
\text { reference conditions }\end{array}$ & 4.37 & amperes & More... & $\wedge$ \\
\hline 2 & 田 & $\begin{array}{l}\text { Module open-circuit voltage at } \\
\text { reference conditions }\end{array}$ & 42.93 & $\mathrm{~V}$ & More... & E \\
\hline 3 & 田 & Reference temperature & 298 & K & More... & \\
\hline 4 & 田 & Reference insolation & 1000 & $\operatorname{Wim}^{\wedge} 2$ & More... & \\
\hline 5 & 田 & $\begin{array}{l}\text { Module voltage at max power point and } \\
\text { reference conditions }\end{array}$ & 33.68 & $\mathrm{~V}$ & More... & \\
\hline 6 & 囫 & $\begin{array}{l}\text { Module current at max power point and } \\
\text { reference conditions }\end{array}$ & 3.96 & amperes & More... & \\
\hline 7 & ๑ீ & $\begin{array}{l}\text { Temperature coeficient of lsc at (ref. } \\
\text { cond) }\end{array}$ & 0.00175 & any & More... & \\
\hline 8 & al & Temperature coeficient of Voc iref. & -0.1524 & Tan & . & $\underline{v}$ \\
\hline
\end{tabular}

Figure 9.5: Values used in the "Parameter" tab, parameters number 1-7, using the 5-Parameter model

\section{(PV-Siemens5.TPF) Type94-Widalys}

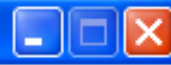

Parameter | Input | Output | Derivative | Special Cards | External Files | Comment |

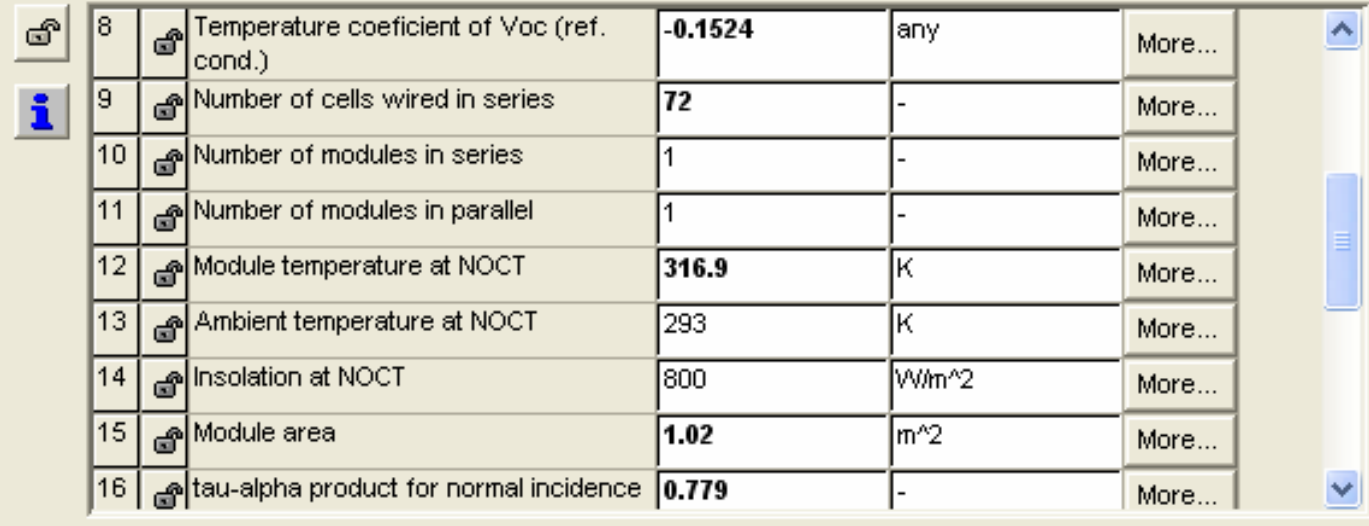

Figure 9.6: Values used in the "Parameter" tab, parameters number 8-16, using the 5-Parameter model 


\section{(PV-Siemens5.TPF) Type94-Widalys}

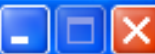

Parameter $\mid$ Input | Output | Derivative |Special Cards | External Files | Comment |

\begin{tabular}{|c|c|c|c|c|c|}
\hline 四 17 & 田 & Serniconductor bandgap & 1.12 & any & More... \\
\hline 18 & 田 & Slope of IV curve at Isc & 0 & any & More... \\
\hline 19 & 田 & Module series resistance & .7375 & any & More... \\
\hline 20 & 田 & Air mass coeff, a0 & 0.935823 & - & More... \\
\hline 21 & 田 & Air mass coeff, a1 & 0.054289 & - & More... \\
\hline 22 & 田 & Air mass coeff, a2 & -0.008677 & - & More... \\
\hline 23 & 田 & Air mass coeff, a3 & 0.000527 & - & More... \\
\hline 24 & 田 & Air mass coeff, a4 & -0.000011 & - & More... \\
\hline
\end{tabular}

Figure 9.7: Values used in the "Parameter" tab, parameters number 17-24, using the 5-Parameter model

\section{PV-Siemens5.TPF) Type94-Widalys}

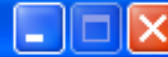

Parameter Input |Output|Derivative |Special Cards| External Files | Comment|

\begin{tabular}{|c|c|c|c|c|c|c|}
\hline 1 & 田 & Total incident radiation & 445.000000 & W/m² & More... & ^ \\
\hline 2 & 田 & Cell temperature & 310.2 & K & More... & \\
\hline 3 & 田 & Load voltage & 100 & 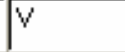 & More... & \\
\hline 4 & 田 & Flag for convergence promotion & 0 & - & More... & \\
\hline 5 & 田 & Array slope & 90 & degrees & More... & \\
\hline 6 & 田 & Bearn normal radiation & 869.900000 & W/m² & More... & \\
\hline 7 & 田 & Radiation on titted surface & 525.900000 & $W / m^{\wedge} 2$ & More... & \\
\hline 8 & 田 & Incidence angle of bearn radiation & 55.27 & degrees & More... & \\
\hline 9 & 田 & Zenith angle & 62.96 & degrees & More... & $v$ \\
\hline
\end{tabular}

Figure 9.8: Values used in the "Input" tab for the 5-Parameter model 
Figures 9.9-9.12 show the predicted maximum power using the 5-Parameter model versus the values measured by NIST for the different cell types, using SRC as reference conditions.

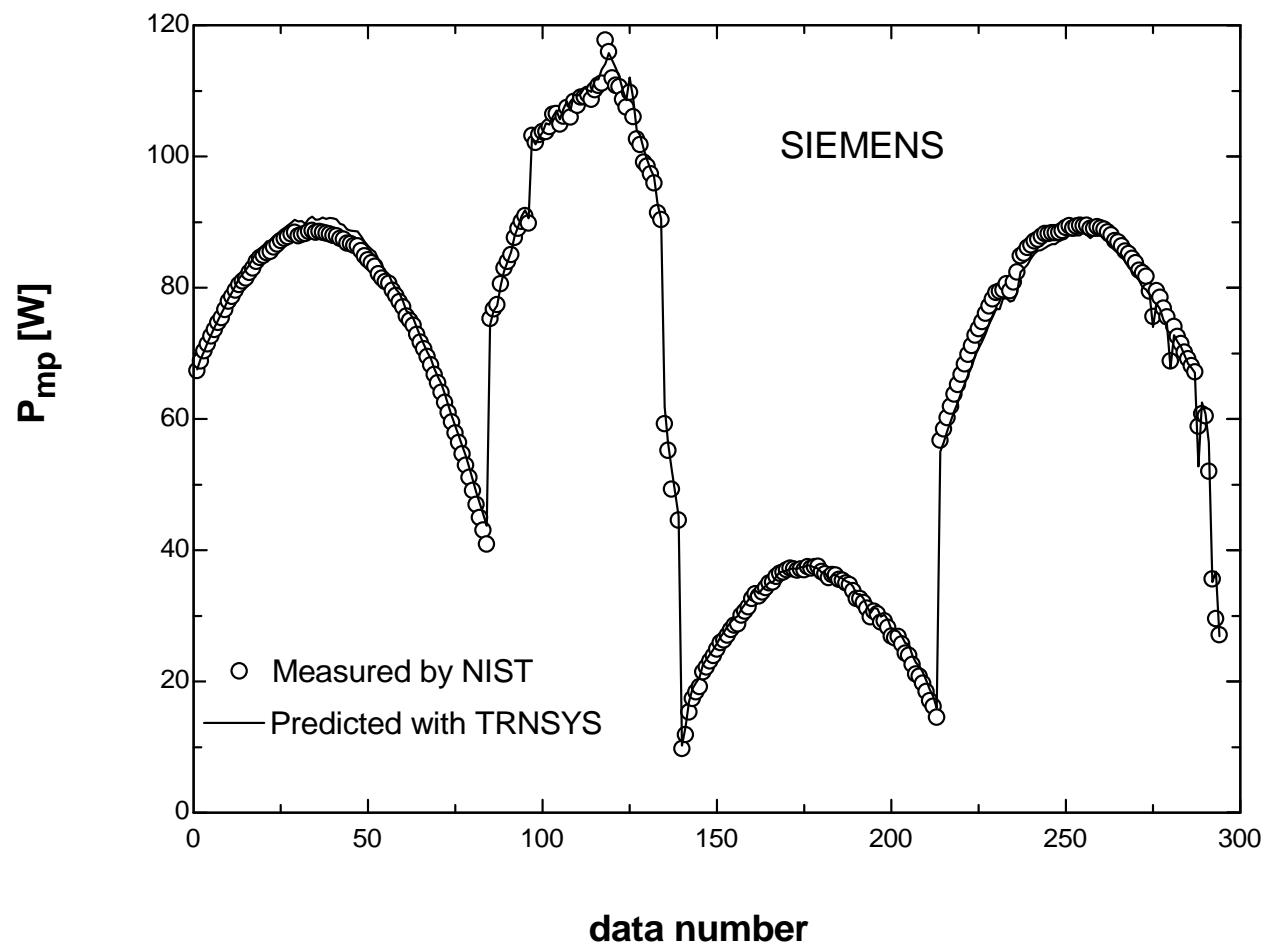

Figure 9.9: Maximum power points measured by NIST versus predicted with the 5-Parameter model using TRNSYS for the Siemens cell type 


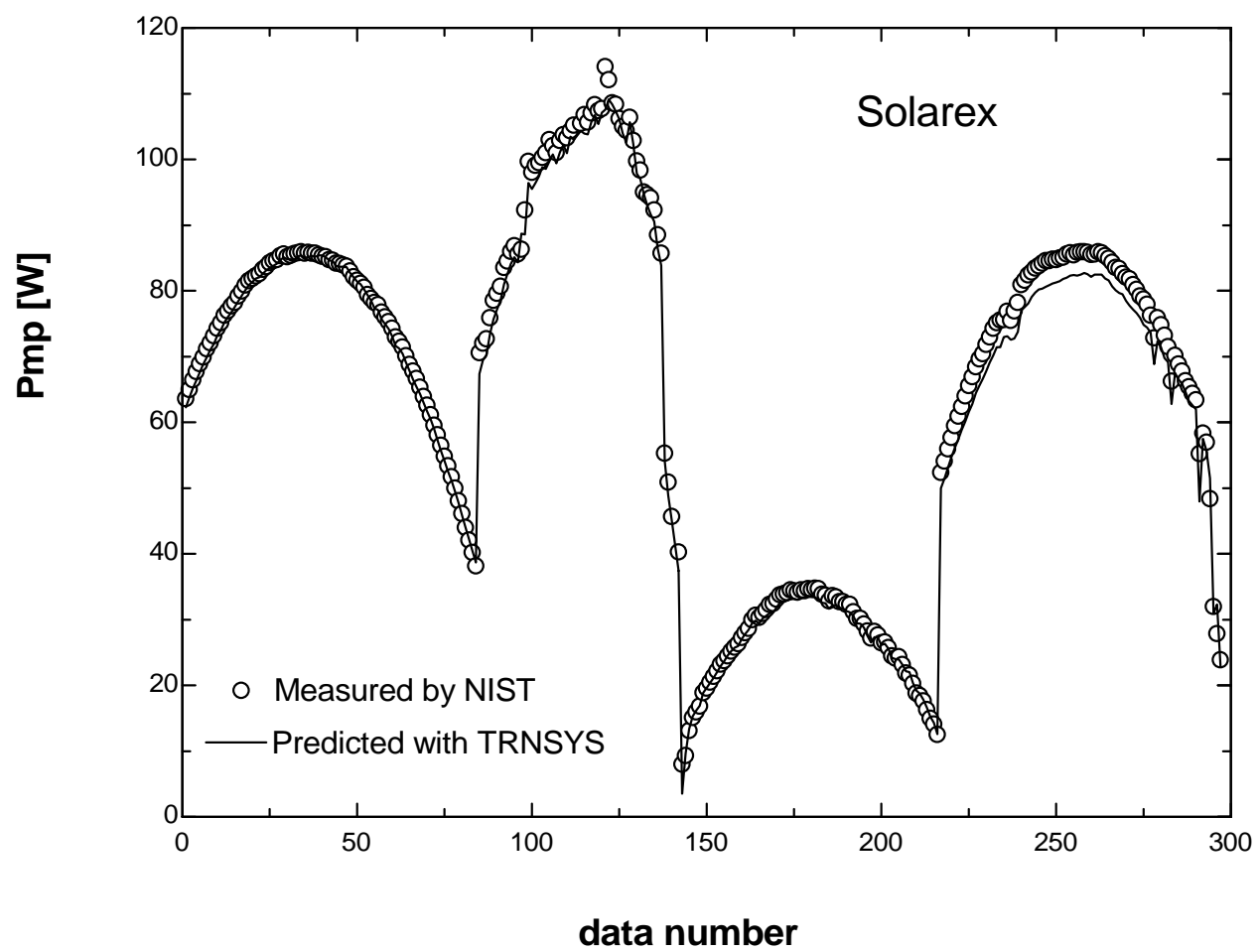

Figure 9.10: Maximum power points measured by NIST versus predicted with the 5-Parameter model using TRNSYS for the Solarex cell type

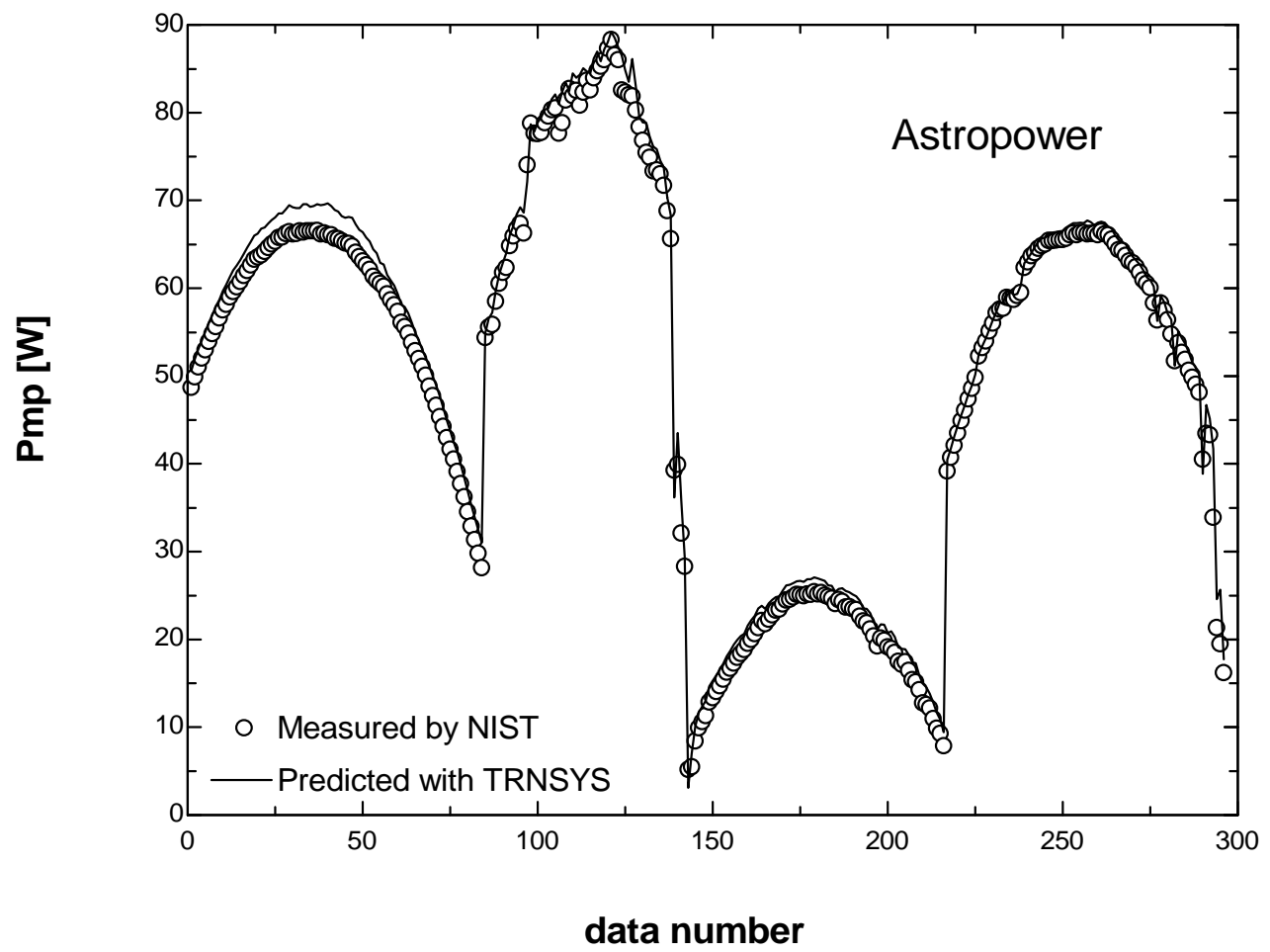

Figure 9.11: Maximum power points measured by NIST versus predicted with the 5-Parameter model using TRNSYS for the Astropower cell type 


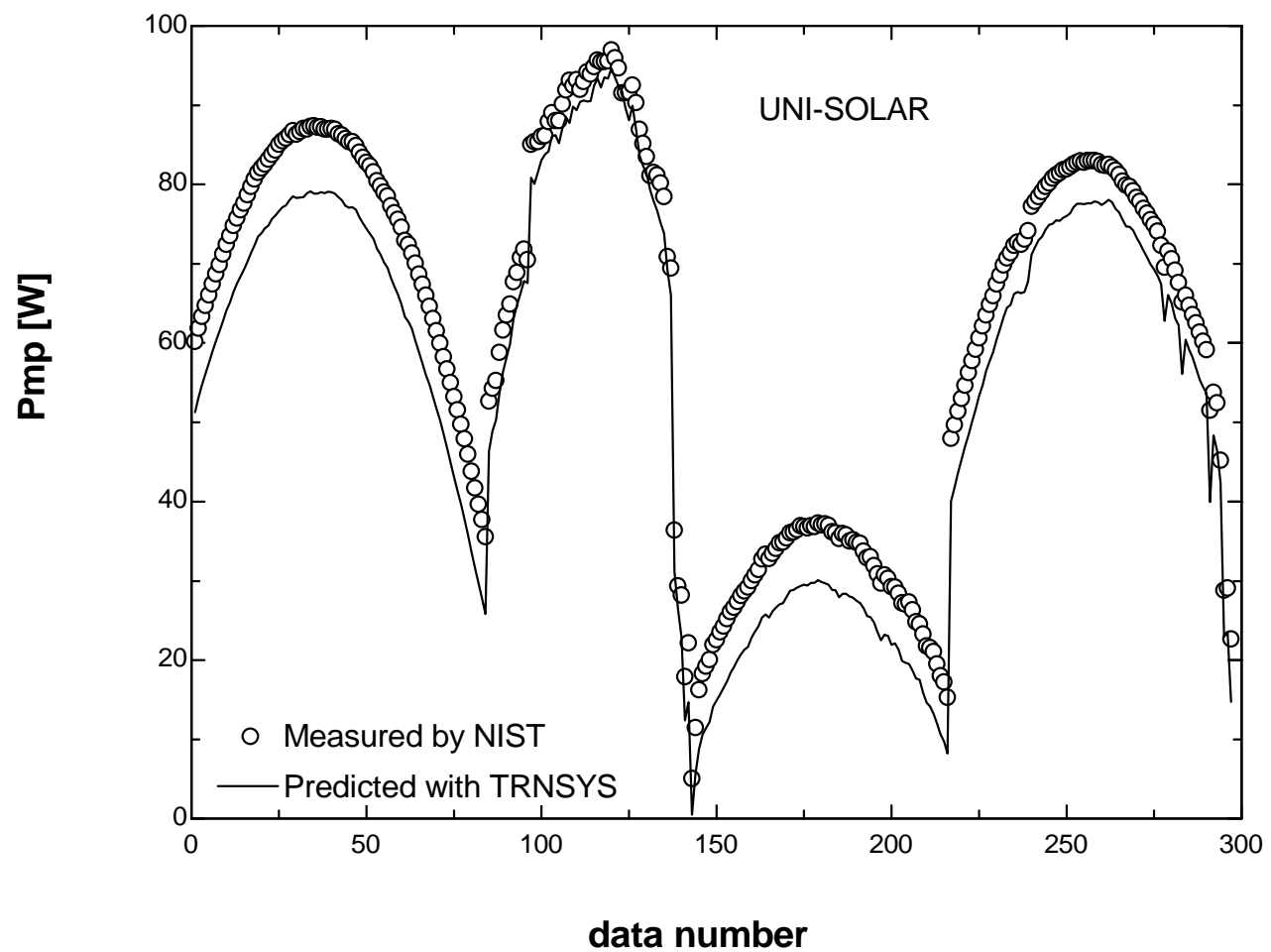

Figure 9.12: Maximum power points measured by NIST versus predicted with the 5-Parameter model using TRNSYS for the Uni-Solar cell type

Figure 9.9 shows that for the Siemens cell type, the fit between the prediction using the 5-Parameter model with TRNSYS and the measured data is almost perfect. Figure 9.10 shows that for the Solarex cell type, the predictions for the first three days (October 13, December 31, and June 20) fall on top of the measured data, while for the last day (March 18), the 5-Parameter model, using TRNSYS underpredicts the power produced at times near noon. On the contrary, Figure 9.11 shows that for the Astropower cell type, the 5-Parameter model overpredicts the power produced on October 13, yet the predictions for the other three days fall on top of the measured data. Figure 9.12 shows that the 5-Parameter model underpredicts the power produced for every single day with the exception of December 31, where the predictions are closer to the measured value than those for the other days. 
Figures 9.13-9.16 show the maximum power predicted using TRNSYS in comparison to the values measured and provided by NIST. The diagonal line has a slope of 1.0 and shows the area where the points should be located to minimize the error. As can be seen from Figures 9.13-9.15, most of the predicted values lie on the diagonal, yielding a very small error.

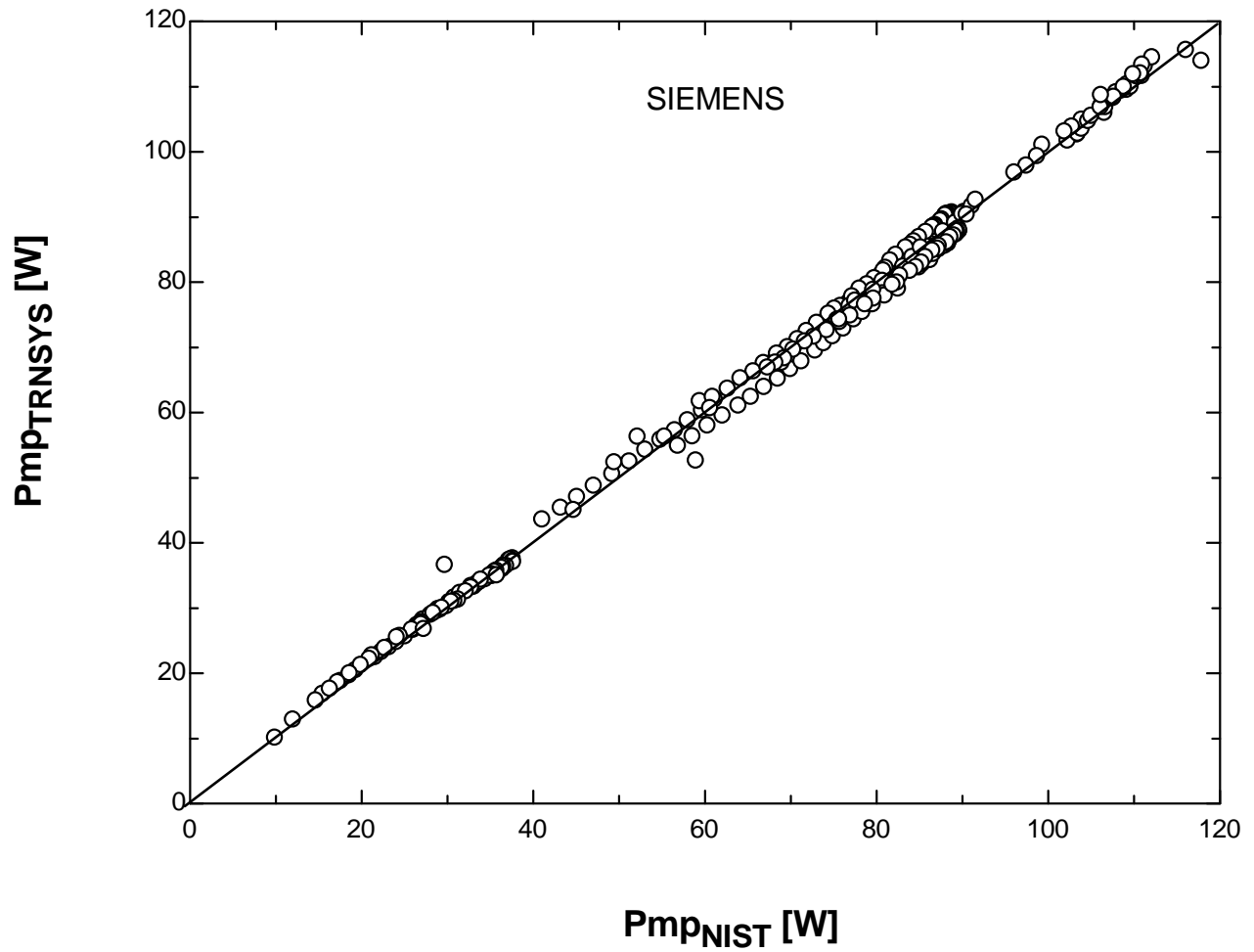

Figure 9.13: Maximum power points predicted with the 5-Parameter model using TRNSYS versus measured by NIST for the Siemens cell type 


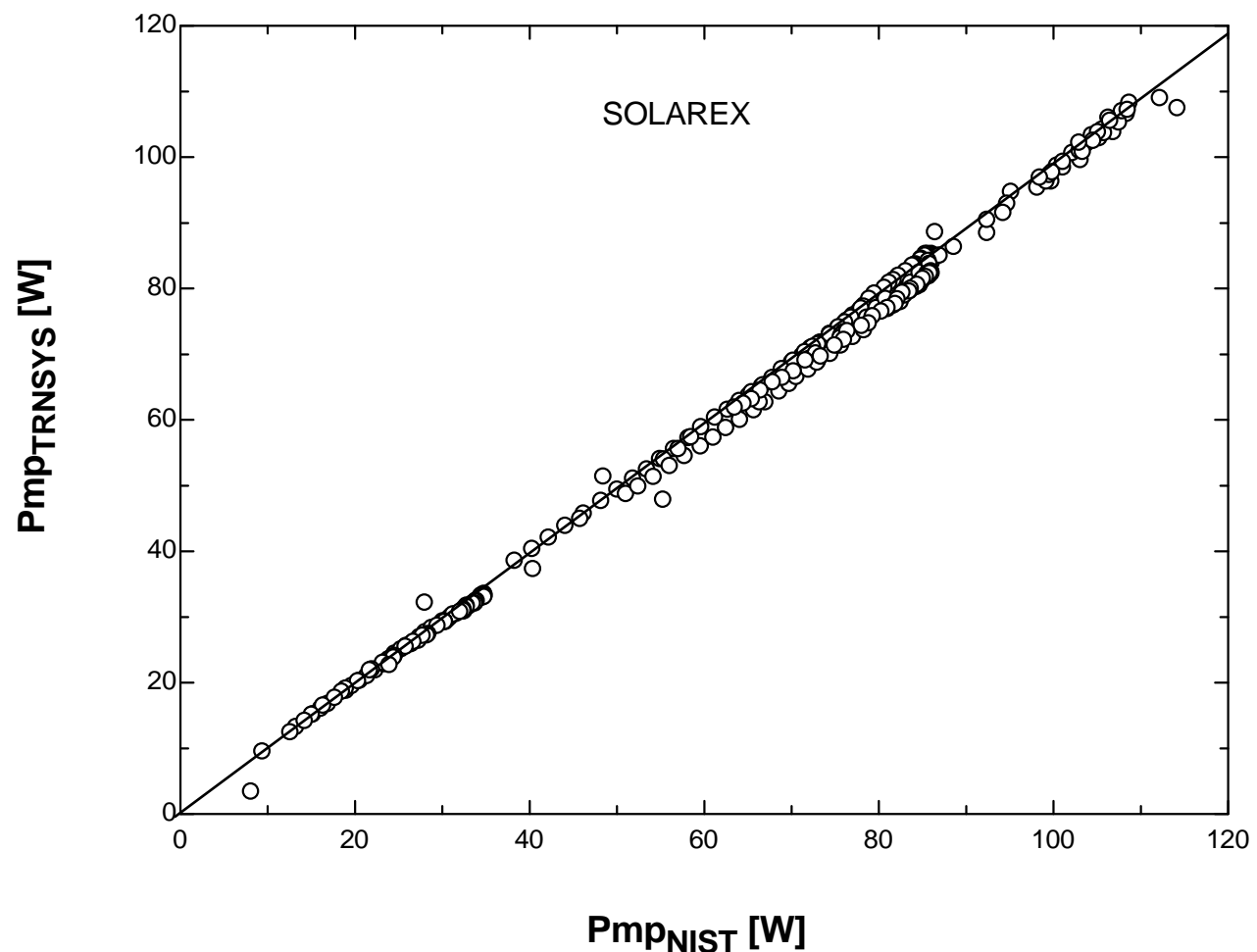

Figure 9.14: Maximum power points predicted with the 5-Parameter model using TRNSYS versus measured by NIST for the Solarex cell type

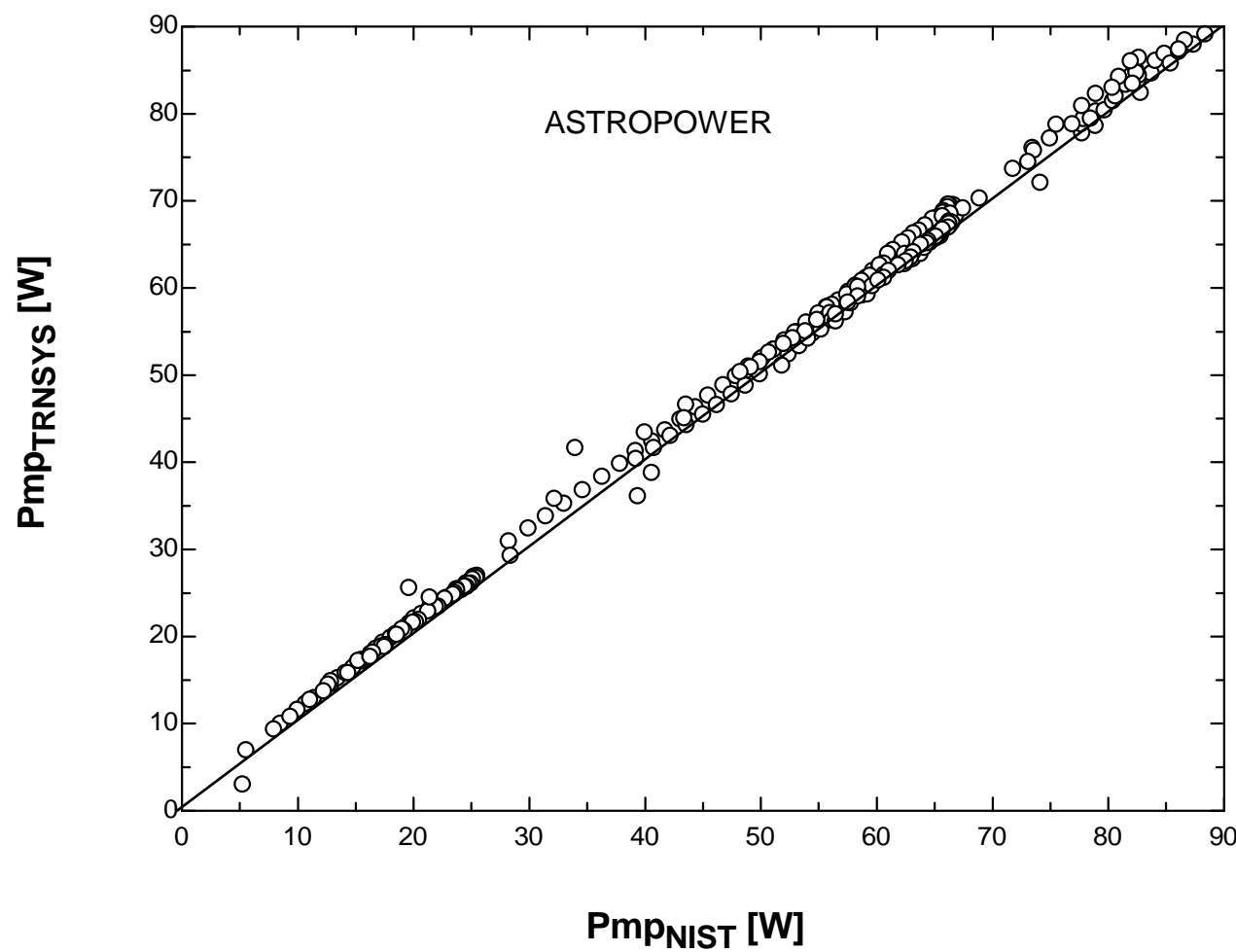

Figure 9.15: Maximum power points predicted with the 5-Parameter model using TRNSYS versus measured by NIST for the Astropower cell type 


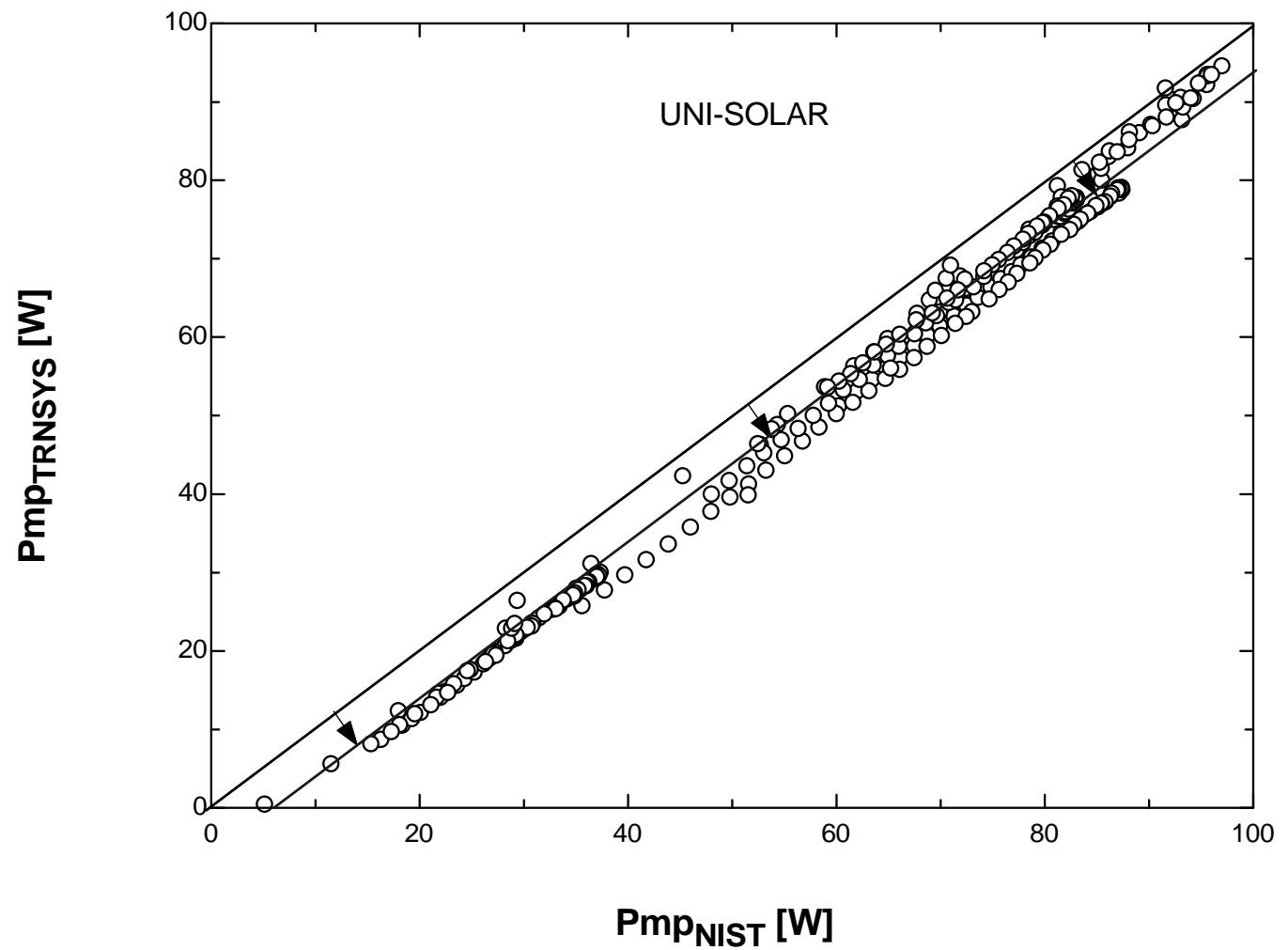

Figure 9.16: Maximum power points predicted with the 5-Parameter model using TRNSYS versus measured by NIST for the Uni-Solar cell type

Figure 9.16 shows that the data maintains the same slope as that of the diagonal line, but there is a shift downward. This occurs because the values obtained with the 5Parameter model are being underpredicted.

The pyranometers and panels were located near, but not in the exact same place. Some of them were located in the roof to measure the beam normal and diffuse components, while others were located in the same wall, somewhere between the four panels. The repercussion that this had is that in the instants where clouds were partially or completely covering either the panels or the pyranometers, the pyranometers would register values that do not necessarily reflect the values perceived by the panels. This explains the few points that are farther away from the diagonal line in Figures 9.13-9.15. In addition, the data recorded during the afternoon of December 31 included some points 
that when analyzed were located completely out of the bounds of where they should be located. This occurred because the afternoon of December 31 seemed to be very cloudy, increasing the severity of the problem previously explained. To avoid confusion, these data were removed from the simulations and therefore are not shown in any of the plots.

Table 9.1 shows the total energy measured by NIST, the total energy predicted with TRNSYS, the percentage difference between these values, and the RMS value calculated for the different cell types. The total energy, the percentage difference and the RMS values were calculated using Equations (8.53) through (8.55).

$$
\begin{gathered}
\text { Total }_{\text {Energy }}=\int_{t=0}^{t_{\text {Num }}^{\text {hours }}} P_{m p} d t \\
\% \text { Diff }=\frac{a b s\left(\text { Total }_{\text {Energy }, \text { IST }}-\text { Total }_{\text {Energy }, T R N S Y S}\right)}{\text { Total }_{\text {Energy }, N I S T}} 100 \% \\
\% R M S=\frac{\sqrt{\frac{\sum_{i=1}^{N}\left(P_{m p, N I S T, i}-P_{m p, T R N S Y S, i}\right)^{2}}{N}}}{P_{m p, a v e, N I S T}} 100 \%
\end{gathered}
$$

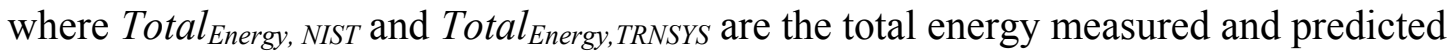
over the range of 9:00am to 4:00pm, respectively, $P_{m p, a v e, N I S T}$ is the average maximum power measured by NIST, $P_{m p, N I S T}$ and $P_{m p, T R N S Y S}$ are the values for the maximum power point measured and predicted every five minutes, and $N$ is the number of points used. 
Table 9.1: Total energy and RMS values obtained for measured and predicted $P_{m p}$ for different cell types

\begin{tabular}{|c|c|c|c|c|}
\hline Cell type & $\begin{array}{c}\text { Measured } \\
\text { Energy } \\
\text { (KW-hr) }\end{array}$ & $\begin{array}{c}\text { Predicted } \\
\text { Energy } \\
\text { (KW-hr) }\end{array}$ & $\begin{array}{c}\text { \% Difference in } \\
\text { energy values }\end{array}$ & $\begin{array}{c}\text { \% RMS in } \\
\mathbf{P}_{\text {mp values }}\end{array}$ \\
\hline Siemens & 122.52 & 122.952 & 0.35 & 2.365 \\
\hline Solarex & 118.646 & 115.713 & 2.472 & 3.36 \\
\hline Astropower & 91.904 & 95.050 & 3.423 & 4.011 \\
\hline Uni-Solar & 114.435 & 102.066 & 10.81 & 11.326 \\
\hline
\end{tabular}

\subsection{Simulation using King's model}

For the simulation using King's model, "Type 101" was used instead of "Type 94”. Figure 9.17 shows the TRNYS model in schematic form using the TRNSYS Studio graphical input program for King's model. Figures 9.18-9.23 show the values used for the simulation of the Siemens cell type. The values used for the other cell types can be found in Appendix A, Table A1. 


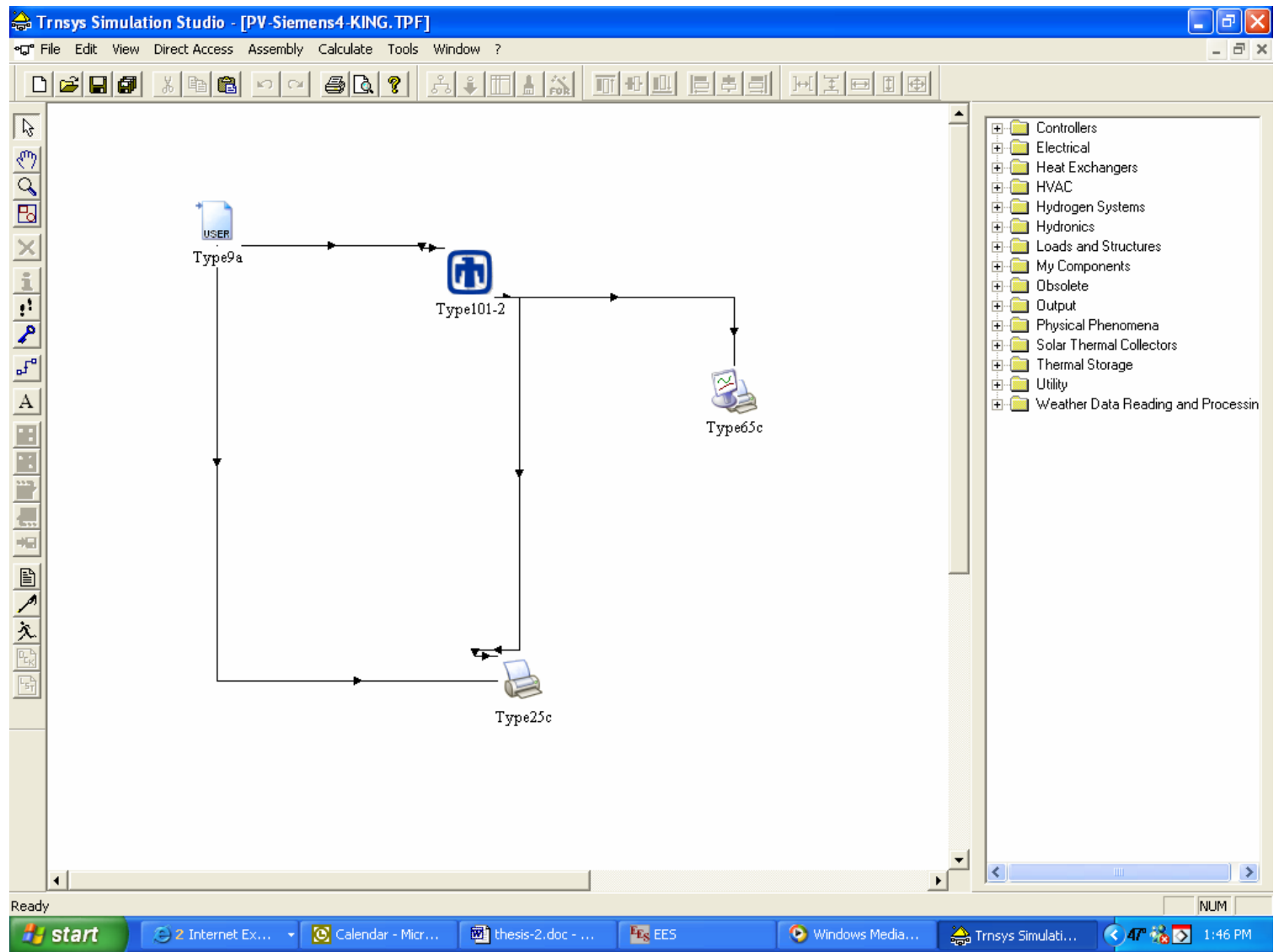

Figure 9.17: TRNYS model in schematic form using the TRNSYS Studio graphical input program for King's model

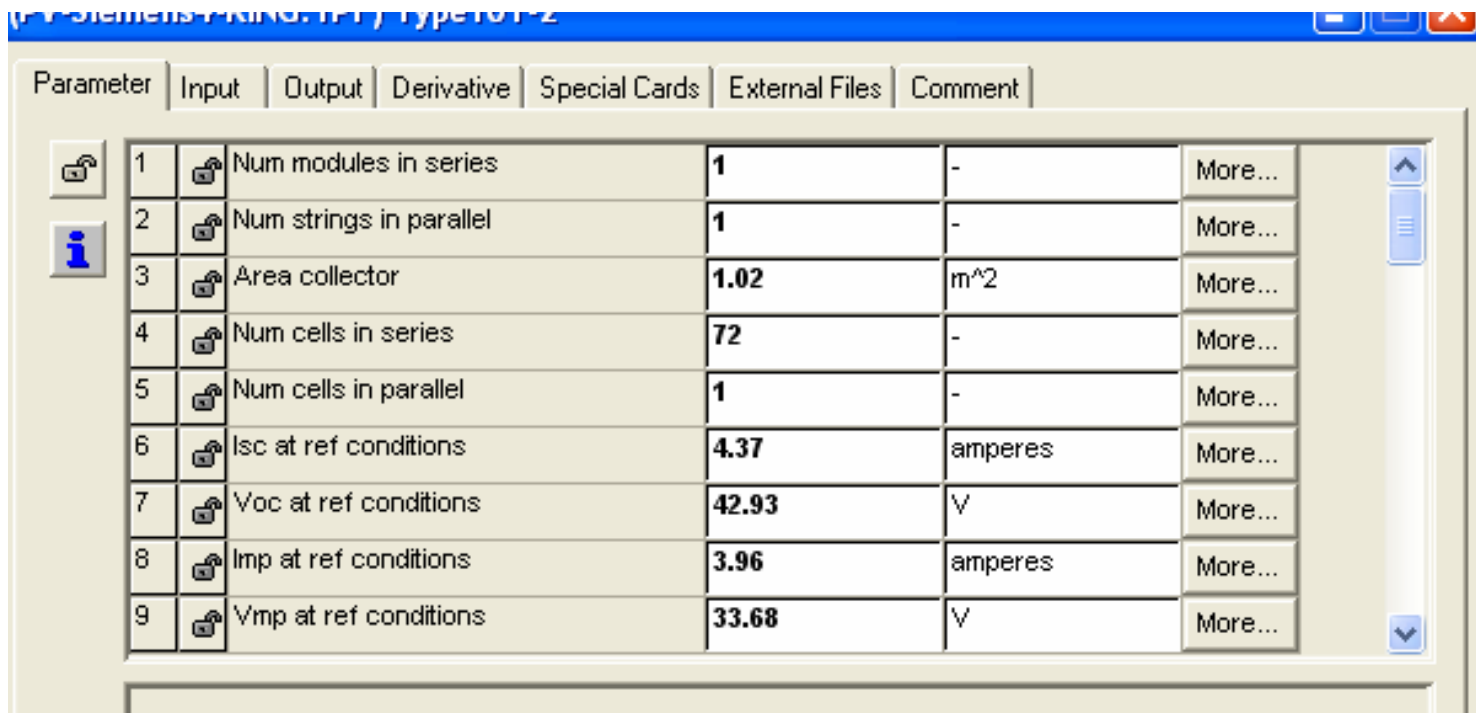

Figure 9.18: Values used in the "Parameter" tab, parameters number 1-9, using King's model 


\section{(PV-Siemens4-KING. TPF) Type101-2}

Parameter |Input | Output | Derivative | Special Cards | External Files | Comment |

\begin{tabular}{|c|c|c|c|c|c|}
\hline 10 & 田 & alpha Isc & 0.000401 & - & More... \\
\hline 11 & 田 & alpha Imp & -0.000390 & - & More... \\
\hline 12 & 田 & $\mathrm{CO}$ & 0.9995 & - & More... \\
\hline 13 & (90) & C1 & 0.0026 & - & More... \\
\hline 14 & 田 & Beta Voc at ref cond & -.15237 & - & More... \\
\hline 15 & (9) & mEetavoc & 0 & - & More... \\
\hline 16 & 固 & Beta $V m p$ at ref cond & -0.15358 & - & More... \\
\hline 17 & 田 & mBetaVmp & 0 & - & More... \\
\hline 18 & 田 & Diode factor & 1.026 & - & More... \\
\hline
\end{tabular}

Figure 9.19: Values used in the "Parameter" tab, parameters number 10-18, using King's model

\section{[(PV-stemens4-KING. IPF) Гуре।U1-2}

Parameter | Input | Dutput | Derivative | Special Cards | External Files | Comment |

\begin{tabular}{|c|c|c|c|c|c|}
\hline 19 & 㘣 & $\mathrm{C} 2$ & -0.5385 & - & More... \\
\hline 20 & 圆 & $\mathrm{C3}$ & -21.4078 & - & More... \\
\hline 21 & 固 & $a 0$ & 0.935823 & - & Mlore... \\
\hline 22 & 回 & a1 & 0.054289 & - & More... \\
\hline 23 & 圆 & $a 2$ & -0.008677 & - & More... \\
\hline 24 & 田 & a3 & 0.000527 & - & More... \\
\hline 25 & 田 & a4 & -0.000011 & - & More... \\
\hline 26 & 田 & $\mathrm{b0}$ & 1.000341 & - & More... \\
\hline 27 & 田 & b1 & -0.005557 & - & More... \\
\hline
\end{tabular}

Figure 9.20: Values used in the "Parameter" tab, parameters number 19-27, using King's model 


\section{(PV-Siemens4-KING. TPF) Type101-2}

Parameter Input | Output | Derivative | Special Cards | External Files | Comment|

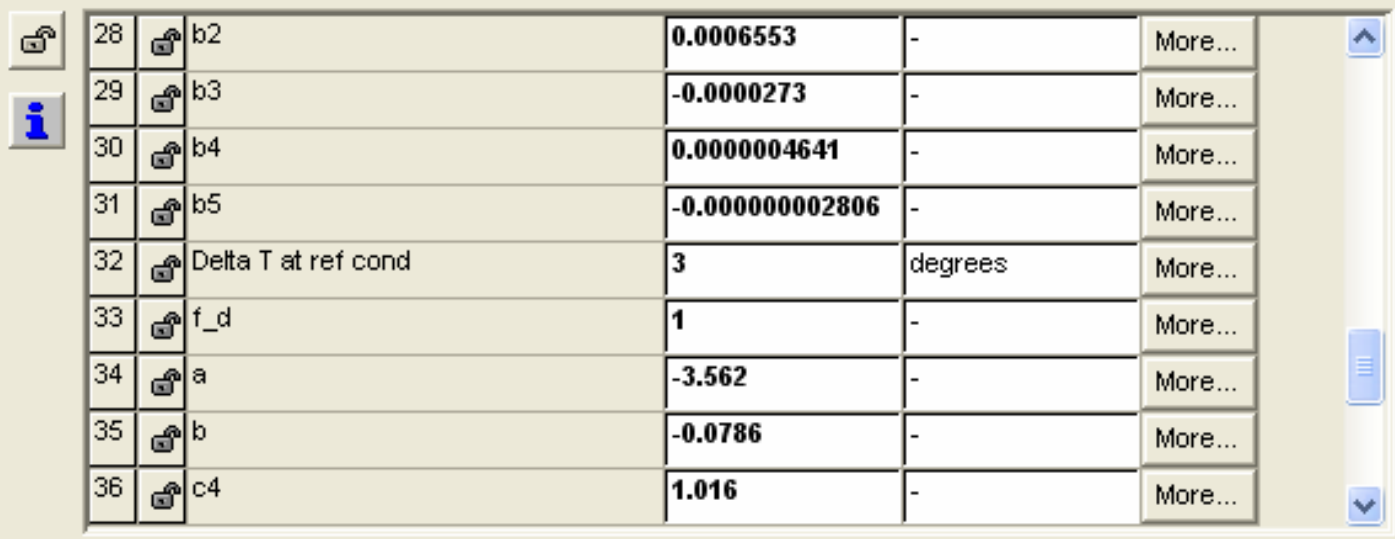

Figure 9.21: Values used in the "Parameter" tab, parameters number 28-36, using King's model

\section{(PV-Siemens4-KING. TPF) Type101-2}

Parameter Input | Output | Derivative | Special Cards | External Files | Comment |

\begin{tabular}{|c|c|c|c|c|c|}
\hline 36 & ๑ึ & c4 & 1.016 & - & More... \\
\hline 37 & 田 & c5 & -0.01568 & - & More... \\
\hline 38 & 田 & I $x$ at ref conditions & 4.275 & amperes & More... \\
\hline 39 & 田 & Ixx at ref conditions & 2.063 & amperes & More... \\
\hline 40 & 田 & C6 & 1.998 & - & More... \\
\hline 41 & 田 & C7 & -0.9983 & - & More... \\
\hline 42 & 田 & Irradiance Threshold & 0 & $\mathrm{~kJ} / \mathrm{h} \cdot \mathrm{m}^{\wedge} 2$ & More... \\
\hline 43 & 田 & InverterCapacityFactor & 1.2 & - & More... \\
\hline
\end{tabular}

Figure 9.22: Values used in the "Parameter" tab, parameters number 36-43, using King's model 


\section{(PV-Siemens-KING. TPF) Type101-2}

$\square \square$

Parameter Input |Output | Derivative | Special Cards | External Files | Comment |

\begin{tabular}{|c|c|c|c|c|c|}
\hline 1 & (9 & IcBeam & 1462 & kJ/hr .m $m^{\wedge} 2$ & More... \\
\hline 2 & 田 & IcDiffuse & 125 & kJ.hr. $m^{\wedge} 2$ & More... \\
\hline 3 & (9 & IncidenceAngle & 76 & degrees & More... \\
\hline 4 & 田 & ZenithAngle & 36 & degrees & More... \\
\hline 5 & 田 & Tamb & 25 & $\mathrm{C}$ & More... \\
\hline 6 & 四 & WindSpeed & 1 & $\mathrm{~m} / \mathrm{s}$ & More... \\
\hline 7 & 田 & Altitude & 0 & $\mathrm{~m}$ & More... \\
\hline 8 & 田 & OperatingVoltage & $\mathbf{1 0 0}$ & $\mathrm{V}$ & More... \\
\hline
\end{tabular}

Figure 9.23: Values used in the "Input" tab for King's model

Figures 9.24-9.27 show the predicted maximum power using King's model versus the values measured by NIST for the different cell types.

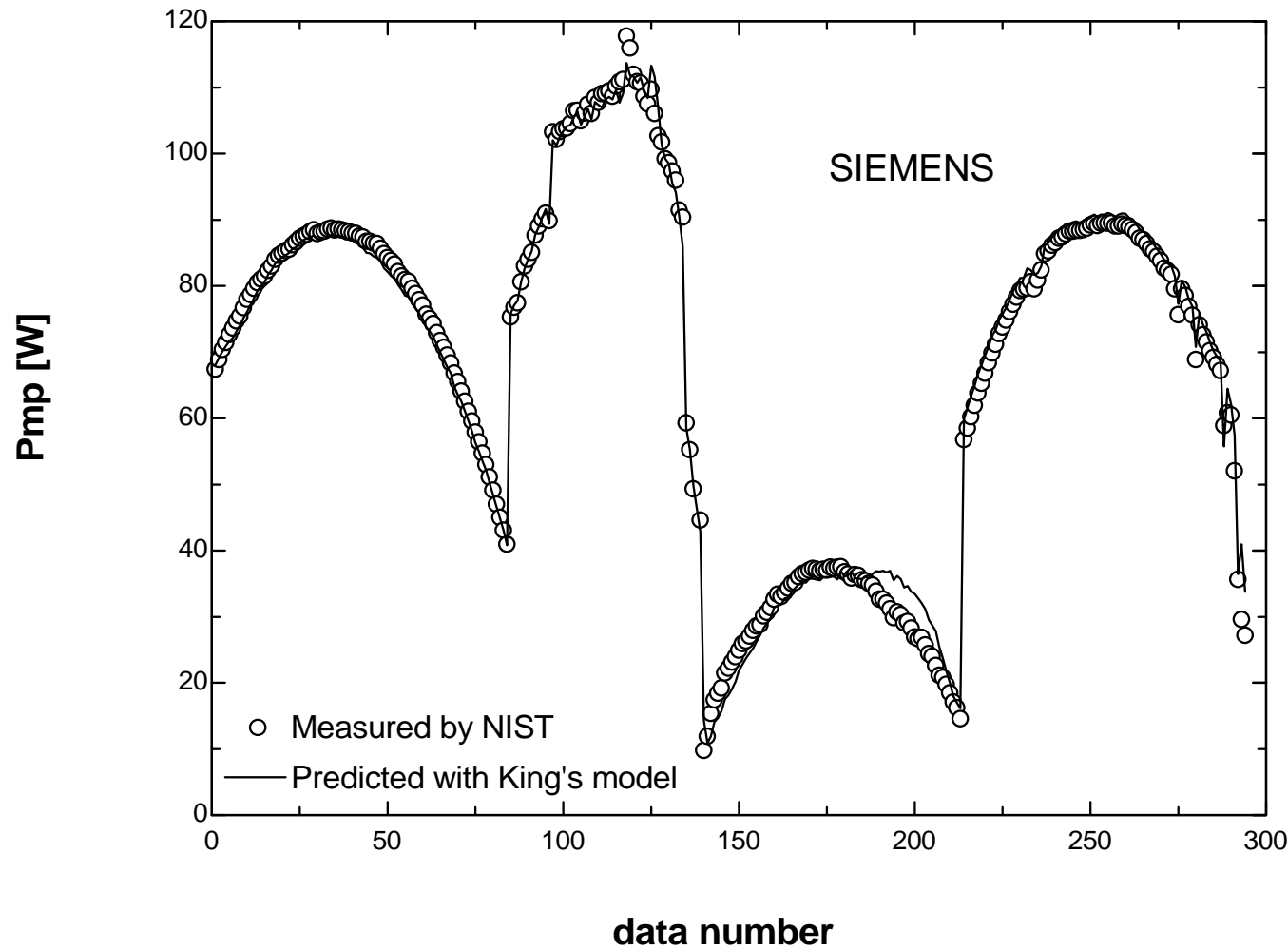

Figure 9.24: Maximum power points measured by NIST versus predicted with King's model using TRNSYS for the Siemens cell type 


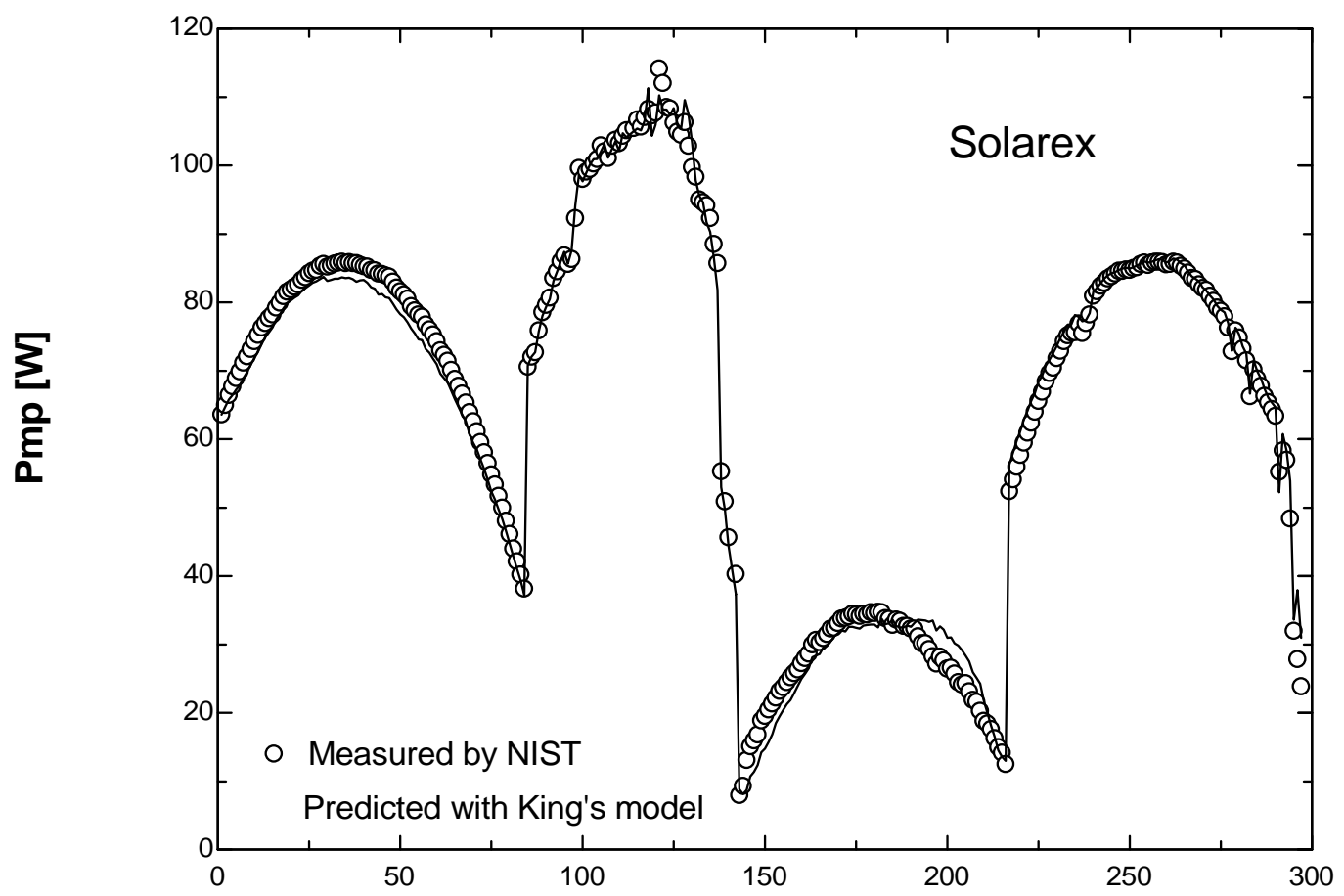

data number

Figure 9.25: Maximum power points measured by NIST versus predicted with King's model using TRNSYS for the Solarex cell type

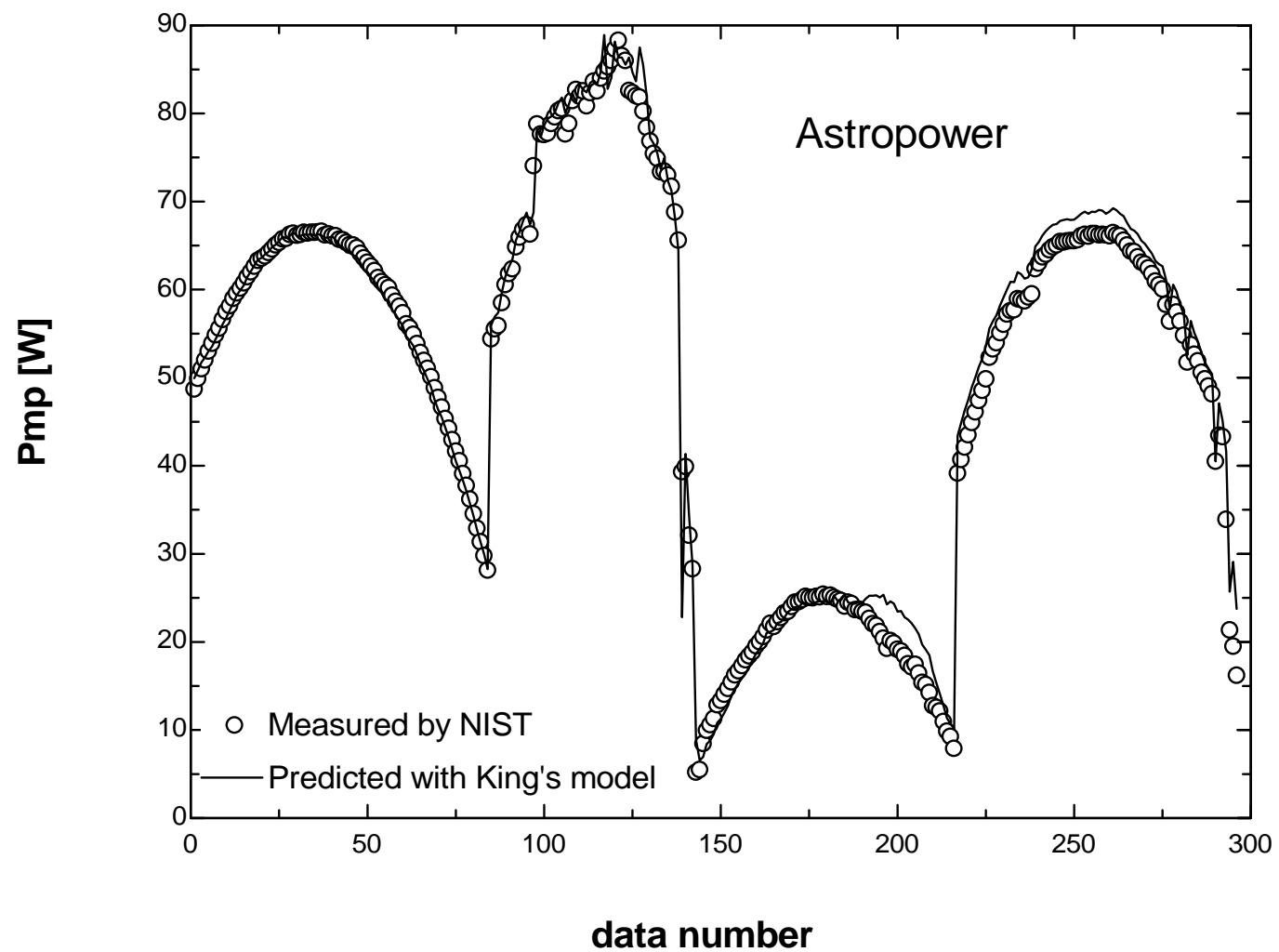

Figure 9.26: Maximum power points measured by NIST versus predicted with King's model using TRNSYS for the Astropower cell type 


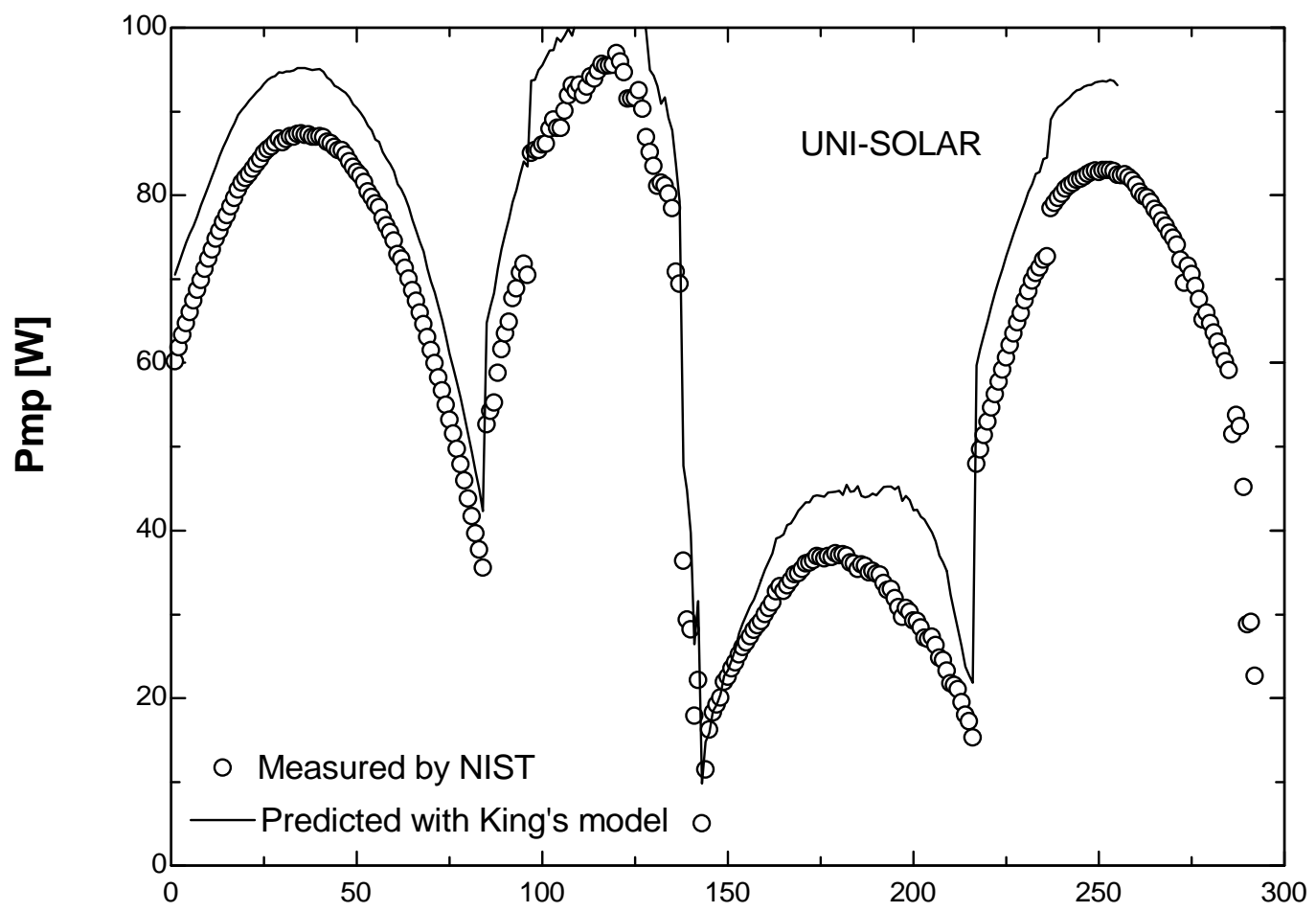

data number

Figure 9.27: Maximum power points measured by NIST versus predicted with King's model using TRNSYS for the Uni-Solar cell type

Figure 9.24 shows that for the Siemens cell type, the fit between the prediction using King's model with TRNSYS and the measured data is almost perfect, with the exception of the afternoon of June 20, where the power is slightly overpredicted. The exact same behavior is shown in Figure 9.25 and Figure 9.26 for the Solarex and Astropower cell types, respectively, where King's model over predicts the power produced for the afternoon hours of June 20. For the Solarex cell type the power is underpredicted for the peak hours of October 13, while for the Astropower cell type, it is overpredicted for the peak hours of March 18. Figure 9.27 shows that King's model overpredicts the power produced for every single day. This figure also shows that for the afternoon hours of March 18, King's model did not converge, therefore no results are shown. King's model uses Equations (8.12)-(8.18) to calculate values corresponding 
only to five points $\left(I_{s c}, I_{x}, I_{m p}, I_{x x}, V_{o c}\right)$. King recognizes that sometimes the PV cell will operate at a point other than one of these five points, therefore his model uses the singlediode equation (Equation (3.2)) to try to fit a curve through these points, so the current at any voltage between 0 and $V_{o c}$ can be predicted. This is achieved by using an optimization method to find the values of the parameters that minimize the errors between the values obtained using the single-diode equation and those initially predicted with Equations (8.12)-(8.18). If the values of the parameters used do not yield an error smaller than the specified tolerance, the model will not converge, which explains what happened during the afternoon hours of March 18. This method is employed and explained in detail by Barker and Norton (2003). Section 8.1.3 also shows more details on this process.

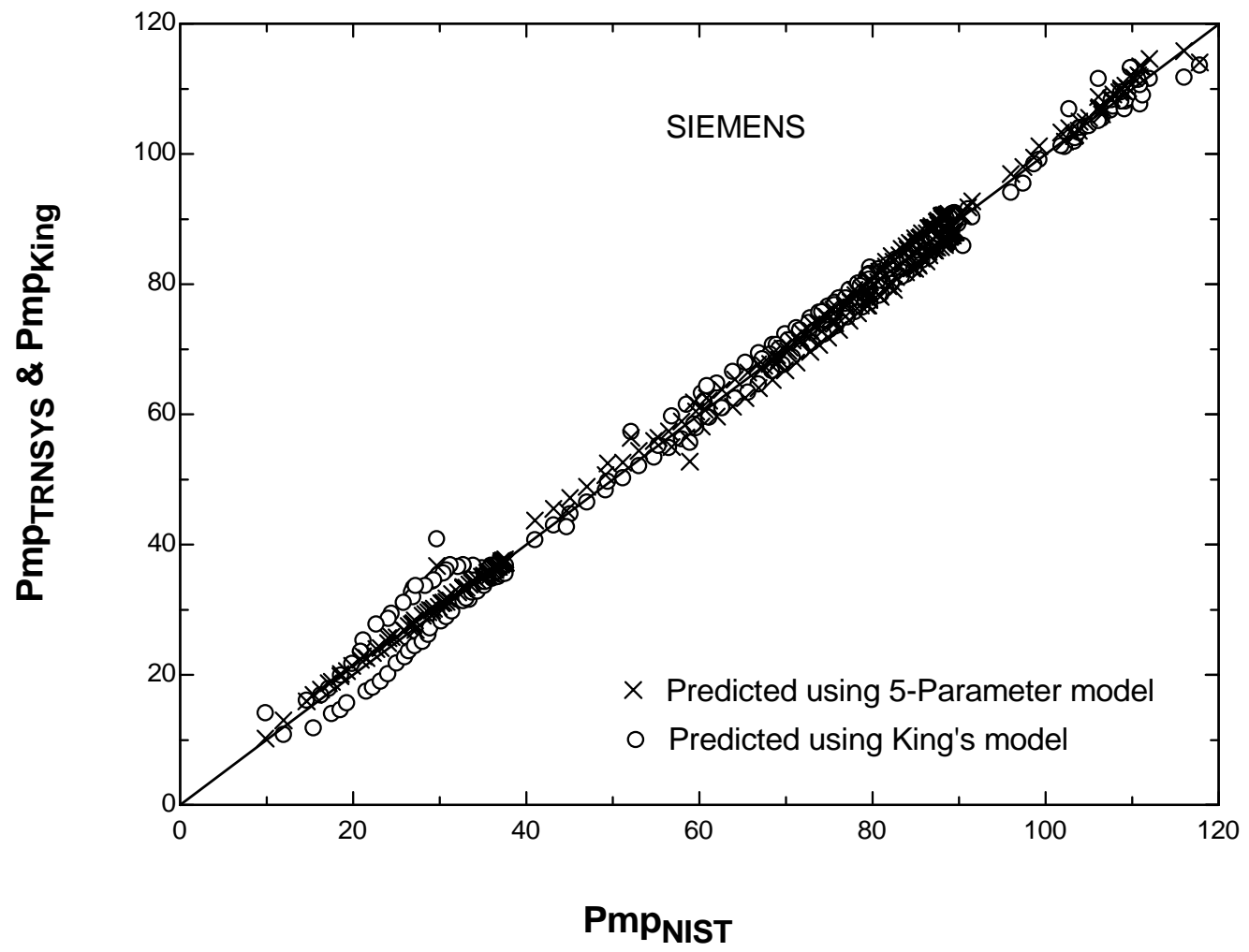

Figure 9.28: Maximum power points predicted with King's model using TRNSYS versus measured by NIST for the Siemens cell type 


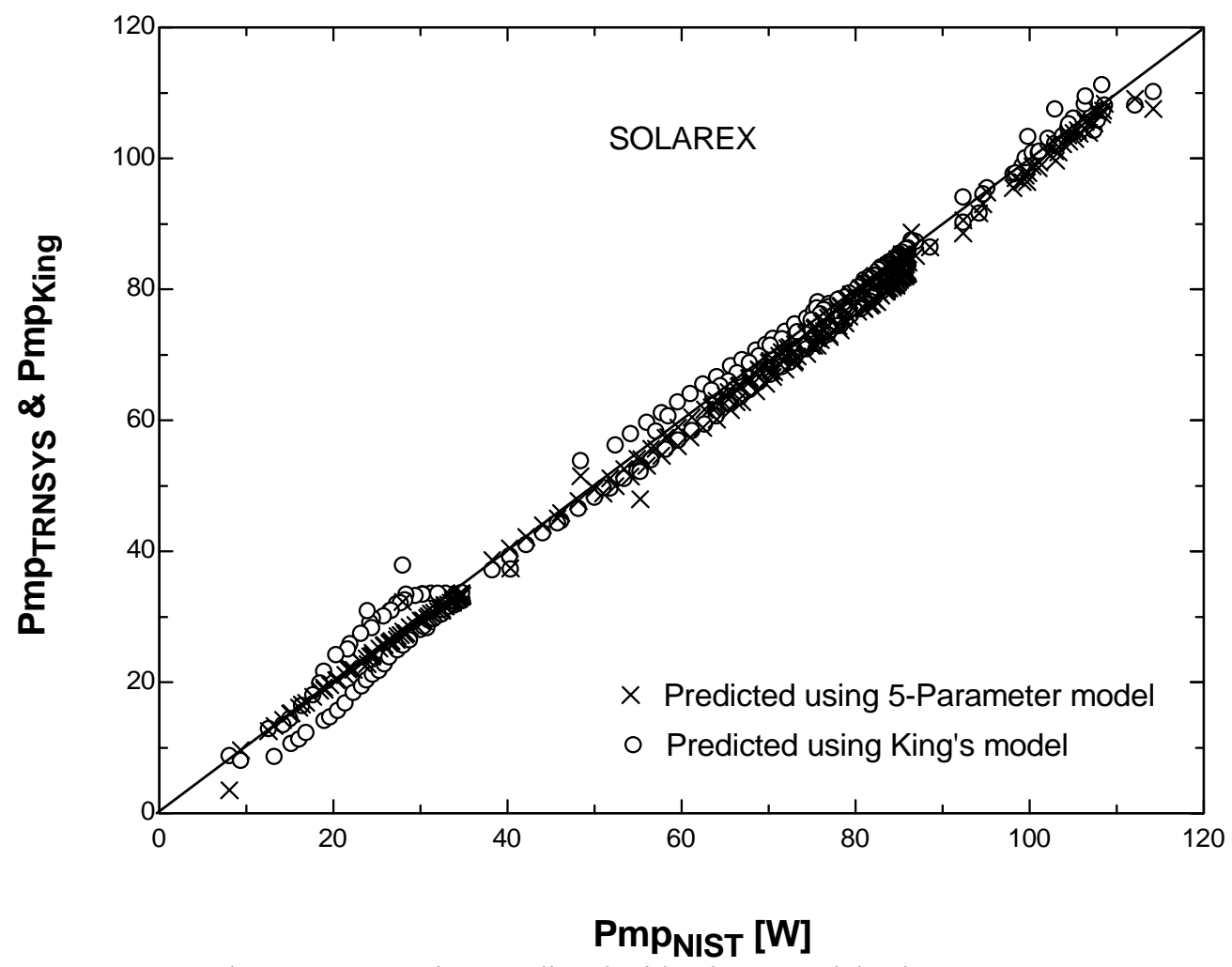

Figure 9.29: Maximum power points predicted with King's model using TRNSYS versus measured by NIST for the Solarex cell type

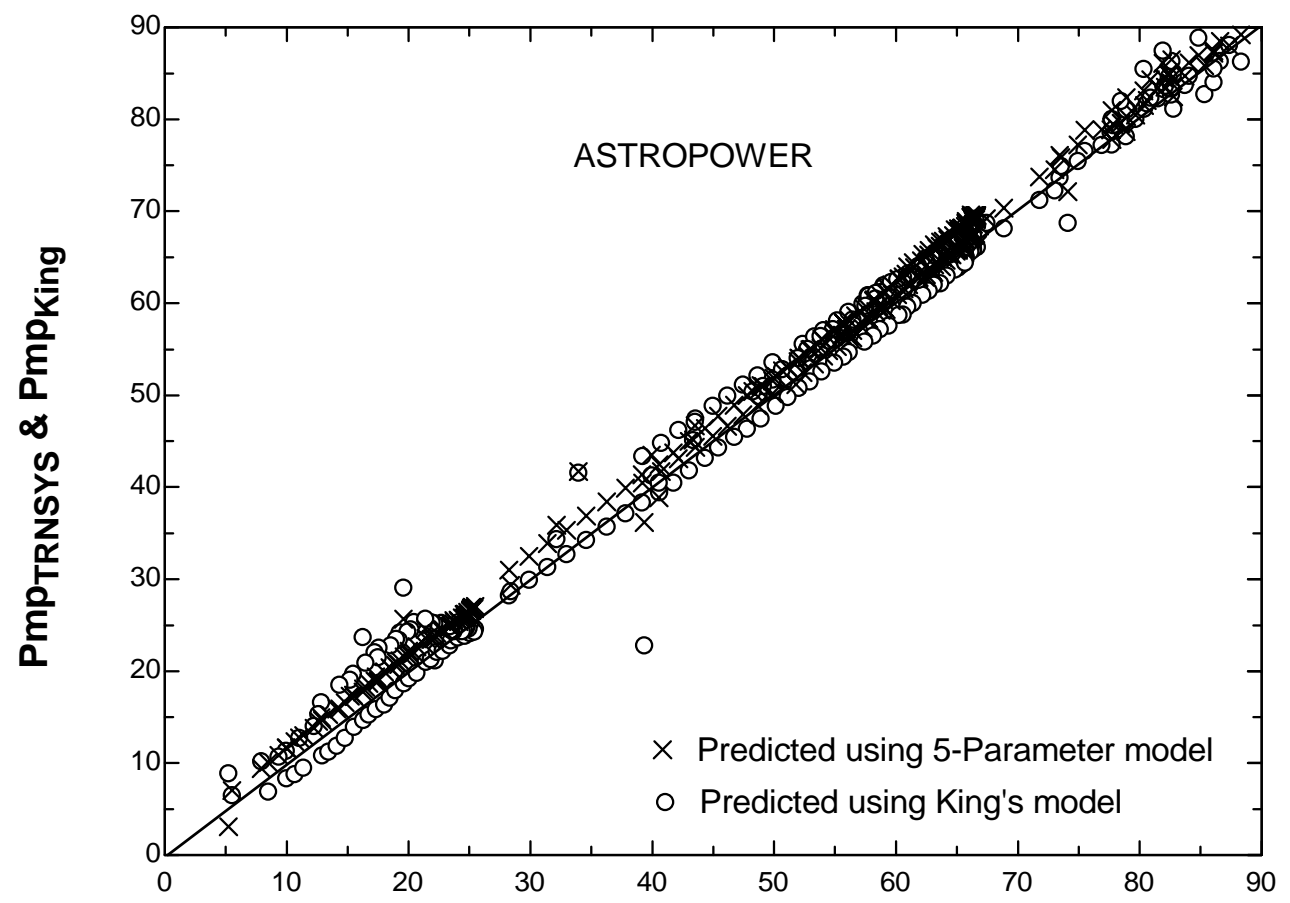

Pmp $_{\text {NIST }}$ [W]

Figure 9.30: Maximum power points predicted with King's model using TRNSYS versus measured by NIST for the Astropower cell type 


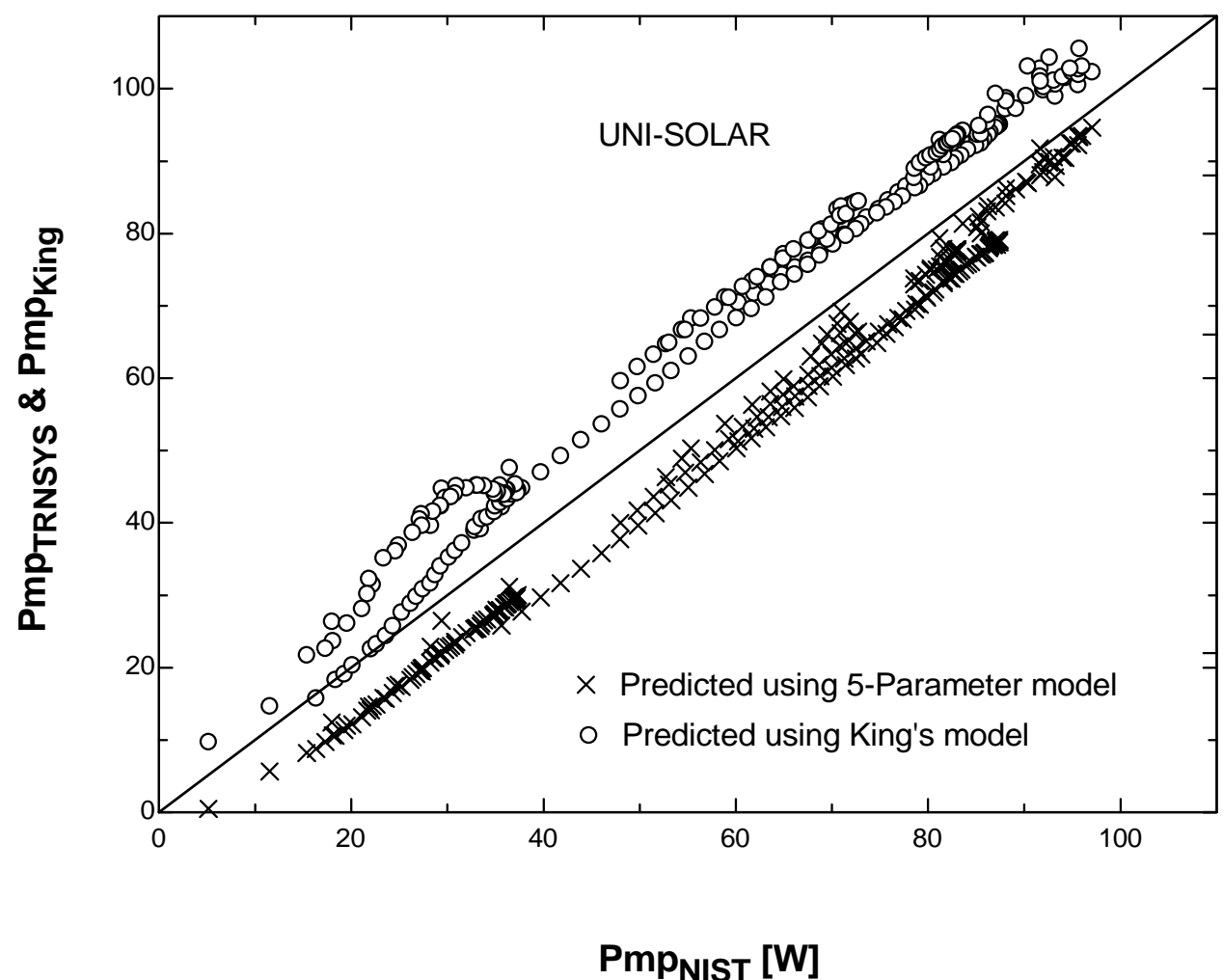

Figure 9.31: Maximum power points predicted with King's model using TRNSYS versus measured by NIST for the Uni-Solar cell type

Figures 9.28-9.30 show that in general, King's model and the 5-Parameter model predict similar results for the Siemens, Solarex, and Astropower cell types. The opposite is shown in Figure 9.31 for the Uni-Solar cell type, where the figure makes it clear that very different results are obtained depending on the prediction model used. The values obtained with King's model are located above the diagonal line, meaning that this model overpredicts the power produced, while the values obtained with the 5-Parameter model are located below the diagonal line, which implies that these values are underpredictions of the measured values. The values predicted with the 5-Parameter model are closer to the diagonal line, implying that these values will have a smaller RMS error than those obtained with King's model. Table 9.2 shows numerically the differences obtained between the two models. 
Table 9.2 : Values measured and predicted for different cell types using 5-Parameter and King's models

\begin{tabular}{|c|c|c|c|c|c|c|c|}
\hline Cell type & $\begin{array}{c}\text { Measured } \\
\text { Energy }_{\text {NIST }} \\
\text { (KW-hr) }\end{array}$ & $\begin{array}{r}\text { Prec } \\
\text { Energ } \\
\text { (KV }\end{array}$ & $\begin{array}{l}\text { cted } \\
\text { TRNSYS } \\
\text { hr) }\end{array}$ & $\begin{array}{c}\text { \% Diff } \\
\text { energ }\end{array}$ & $\begin{array}{l}\text { ence in } \\
\text { values }\end{array}$ & $\begin{array}{r}\% \text { RM } \\
\text { va }\end{array}$ & in $P_{m p}$ \\
\hline Model & NIST & 5-Par & King & 5-Par & King & 5-Par & King \\
\hline Siemens & 122.52 & 122.95 & 122.74 & 0.35 & 0.18 & 2.365 & 3.342 \\
\hline Solarex & 118.646 & 115.71 & 117.72 & 2.472 & 0.78 & 3.36 & 3.689 \\
\hline Astropower & 91.904 & 95.050 & 93.546 & 3.423 & 1.786 & 4.011 & 4.849 \\
\hline Uni-Solar & 83.126 & 73.797 & 95.117 & 11.223 & 14.43 & 11.768 & 15.094 \\
\hline
\end{tabular}

Notice that the values of Uni-Solar presented for the Total Energy measured by NIST and the Total Energy predicted with the 5-Parameter model are different from those presented in Table 9.1. This is because because King's model did not converge for the last hours of March 18, therefore for a fair comparison between the models, the last values of March 18 were not used, obtaining the new values presented in Table 9.2.

Table 9.2 shows that King's model did better at predicting the total energy produced for the first three cell types (Siemens, Solarex, and Astropower), while did not do as well for the Uni-Solar cell type. The \%RMS error column shows that the 5Parameter model did better at minimizing this error. This means that the results of King's model tend to fluctuate more from the measured values, sometimes overpredicting them, sometimes underpreciting them. Overall, when the total energy is calculated, the 
result is closer to the measured one, but when individually analyzed, the 5-Parameter model always yields smaller differences for the sum of the individual errors than King's model. Since the values of the \%RMS errors obtained using either model for the first three cell types is very small, it can be concluded that either method is good for predicting the maximum power output for these types of cells. On the contrary, the values of the \%RMS errors obtained for the Uni-Solar cell type are much higher than for the first three cell types, no matter the model used. Contrary to King's model, the 5Parameter model always converges, no matter the operating conditions. This proves that neither model is great at predicting accurately maximum power production for the 3Junction amorphous cell type, yet the models can be used to get an idea of what the results might be like, taking in consideration that there will be a higher error involved.

\subsection{Conclusion and Suggestions}

The 5-Parameter model presented in this research uses the data provided by the manufacturers and semi-empirical correlation equations to predict the energy production for specified cell parameters and operating conditions. The model requires an easy one time calculation of the five parameters $\left(a_{r e f}, I_{o, r e f}, I_{L, r e f}, R_{s, r e f}\right.$, and $\left.R_{s h, r e f}\right)$ at reference conditions (usually Standard Rated Conditions, SRC). These values are then used with semi-empirical equations to calculate the parameters at other operating conditions, making it possible to predict the power output at other operating conditions.

This research has shown that the 5-Parameter model constitutes a great tool for the prediction of energy production. The 5-Parameter model uses only data provided by the manufacturer, and in contrast to King's model, always converges and does not require 
the use of 43 parameters, parameters which need to be predetermined by performing long and costly tests. Not needing to depend on previous tests, the customer can have an idea of how the panel will work prior to purchasing it, saving time and money. Similar results were obtained for all cell types, making the RMS error results for the first three cell types (single crystalline, poly-crystalline, and silicon thin film) lower than 5\%, an acceptable value. For the triple-junction amorphous cell type the results are higher (around 10\% using the 5-Parameter model and around 15\% using King's model). Additional research needs to be done to identify a better model for this type of PV array.

To further increase the accuracy of the predictions it is suggested that the manufacturers provide two sets of data at two different reference conditions (for example, at $1000 \mathrm{~W} / \mathrm{m}^{2}$ with a cell temperature of $25^{\circ} \mathrm{C}$ and at $500 \mathrm{~W} / \mathrm{m}^{2}$ with a cell temperature of $40^{\circ} \mathrm{C}$ ). Finally, it is also suggested that the manufacturers provide either a complete current-voltage curve or the value of the slope at the short circuit current $\mathrm{I}_{\mathrm{sc}}$, at the reference condition so that the parameters of the panels $\left(V_{m p, r e f}, I_{m p, r e f}, I_{s c, r e f}\right.$, slope at $I_{s c}$, etc.) needed for modeling the panel performance can be determined. 


\section{$\underline{\text { References }}$}

Barker, Greg and Norton, Paul, (2001), "Predicting Long-Term Performance of Photovoltaic Arrays Using Short-Term Test Data and an Annual simulation Tool", Colorado.

Barker, G. and Norton, P., (2003) "Building America System Performance Test Practices: Part 1 - Photovoltaic Systems”, National Renewable Energy Laboratory, Golden, Colorado.

Duffie, J. and Beckman, W., (1991), Solar Engineering of Thermal Processes, $2^{\text {nd }}$ Edition, John Wiley \& Sons, Inc., New York.

Fanney, A. H., Dougherty, B.P., and Davis, M.W., (2002), "Evaluating Building Integrated Photovoltaic Performance Models", Reprinted from the Proceedings of the $29^{\text {th }}$ IEEE Photovoltaic Specialists Conference (PVSC), May 20-24 ${ }^{\text {th }}$, New Orleans, Louisiana.

Fanney, A. H., Dougherty, B.P., and Davis, M.W., (2002), "Short-Term Characterization of Building Integrated Photovoltaic Panels", Proceedings of Solar Forum, June 15-19, Reno, Nevada.

Fry, Bryan, (1998), M.S. Thesis, Mechanical Engineering, U. of Wisconsin-Madison, "Simulation of Grid-Tied Building Integrated Photovoltaic Systems"

Hadj Arab, A., Chenlo, F., Benghanem, M., (2004), "Loss-of-load probability of photovoltaic water pumping systems", Solar Energy, 76, p.713-723.

King, D.L., (1996) "Photovoltaic Module and Array Performance Characterization Methods for All System Operating Conditions", Proceeding of NREL/SNL Photovoltaics Program Review Meeting, Lakewood, CO, November 18-22, AIP Press, New York, 1997.

King, D.L., Boyson, W.E., and Bower, W.I., (1998) "Field Experience with a New Performance Characterization Procedure for Photovoltaic Arrays", presented at the $2^{\text {nd }}$ World Conference and Exhibition on Photovoltaic Solar energy Conversion, Vienna, Austria, July 6-10.

King, D.L., (2000), “Sandia’s PV Module Electrical Performance Model” (Version, 2000), Sandia National Laboratories, Albuquerque, New Mexico, September 5.

King, D.L., Boyson, W.E., Kratochvil, J.A., (2003), "Photovoltaic Array Performance Model" (Draft), Albuquerque, New Mexico. 
Liu, B. Y. H. and R. C. Jordan, (1963), "The Long-Term Average Performance of FlatPlate Solar Energy Collectors", Solar Energy, 7, p. 53.

Luft, W., Barton, J.R., and Conn, A.A., (1967), "Multifaceted Solar Array Performance Determination", TRW Systems Group, Redondo Beach, California, February.

Townsend, T. U., (1989), M.S. Thesis, Mechanical Engineering, U. of WisconsinMadison, "A Method for Estimating the Long-Term Performance of Direct-Coupled Photovoltaic Systems".

http://www.eppleylab.com/PrdPrecSpectralPyrmtr.htm 


\section{Appendix A}

Table A.1: Values provided by NIST

\begin{tabular}{|c|c|c|c|c|}
\hline $\begin{array}{l}\text { Type of } \\
\text { Cell }\end{array}$ & $\begin{array}{l}\text { Astropower } \\
\text { Apex Bin } \\
\text { G/APX-90 }\end{array}$ & $\begin{array}{c}\text { Siemens } \\
\text { Bin1/SP75 } \\
\text { (average of 2) } \\
\end{array}$ & $\begin{array}{c}\text { Solarex } \\
\text { MegaCell/MSX- } \\
64(1997)\end{array}$ & $\begin{array}{l}\text { Uni-Solar } \\
\text { US-64 Module } \\
\text { (average of 3) }\end{array}$ \\
\hline \multicolumn{5}{|c|}{ At Reference Conditions } \\
\hline $\mathrm{P}_{\mathrm{mp} 0}(\mathrm{~W})$ & 103.96 & 133.40 & 125.78 & 57.04 \\
\hline $\mathrm{I}_{\mathrm{sc} 0}(\mathrm{~A})$ & 5.11 & 4.37 & 4.25 & 4.44 \\
\hline $\mathrm{V}_{\mathrm{oc} 0}(\mathrm{~V})$ & 29.61 & 42.93 & 41.50 & 23.16 \\
\hline $\mathrm{I}_{\mathrm{mp} 0}(\mathrm{~A})$ & 4.49 & 3.96 & 3.82 & 3.61 \\
\hline $\mathrm{V}_{\mathrm{mp} 0}(\mathrm{~V})$ & 23.17 & 33.68 & 32.94 & 16.04 \\
\hline $\operatorname{NOCT}(\mathrm{K})$ & 316.15 & 316.85 & 316.45 & 311.05 \\
\hline NOCT (Ins) (K) & 337.85 & 340.05 & 338.55 & 328.45 \\
\hline \multicolumn{5}{|c|}{ Temp. Coefficients } \\
\hline$\alpha_{\mathrm{Isc}}\left(\mathrm{A} /{ }^{\circ} \mathrm{C}\right)$ & 0.00468 & 0.00175 & 0.00238 & 0.00561 \\
\hline$\alpha_{\text {Isc }}\left(1 /{ }^{\circ} \mathrm{C}\right)$ & 0.000916 & 0.000401 & 0.000560 & 0.001263 \\
\hline$\alpha_{\operatorname{Imp}}\left(\mathrm{A} /{ }^{\circ} \mathrm{C}\right)$ & 0.00160 & -0.00154 & 0.00018 & 0.00735 \\
\hline$\alpha_{\operatorname{Imp}}\left(1 /{ }^{\circ} \mathrm{C}\right)$ & 0.000358 & -0.000390 & 0.000047 & 0.002034 \\
\hline$\beta_{\mathrm{Voc}}\left(\mathrm{V} /{ }^{\circ} \mathrm{C}\right)$ & -0.12995 & -0.15237 & -0.15280 & -0.09310 \\
\hline$\beta_{\mathrm{Voc}}\left(1 /{ }^{\circ} \mathrm{C}\right)$ & -0.004388 & -0.003549 & -0.003682 & -0.004021 \\
\hline$\beta_{\mathrm{Vmp}}\left(\mathrm{V} /{ }^{\circ} \mathrm{C}\right)$ & -0.13039 & -0.15358 & -0.15912 & -0.04773 \\
\hline$\beta_{\mathrm{Vmp}}\left(1 /{ }^{\circ} \mathrm{C}\right)$ & -0.005629 & -0.004560 & -0.004830 & -0.002976 \\
\hline \multicolumn{5}{|c|}{ Sandia National Lab Parameters } \\
\hline $\mathrm{a}_{0}$ & 0.938110 & 0.935823 & 0.918093 & 1.10044085 \\
\hline$a_{1}$ & 0.062191 & 0.054289 & 0.086257 & -0.06142323 \\
\hline$a_{2}$ & -0.015021 & -0.008677 & -0.024459 & -0.00442732 \\
\hline$a_{3}$ & 0.001217 & 0.000527 & 0.002816 & 0.000631504 \\
\hline $\mathrm{a}_{4}$ & -0.000034 & -0.000011 & -0.000126 & $-1.9184 \mathrm{E}-05$ \\
\hline $\mathrm{b}_{0}$ & 0.998980 & 1.000341 & 0.998515 & 1.001845 \\
\hline $\mathrm{b}_{1}$ & -0.006098 & -0.005557 & -0.012122 & -0.005648 \\
\hline $\mathrm{b}_{2}$ & $8.117 \mathrm{E}-04$ & $6.553 \mathrm{E}-04$ & $1.440 \mathrm{E}-03$ & $7.25 \mathrm{E}-04$ \\
\hline $\mathrm{b}_{3}$ & $-3.376 \mathrm{E}-05$ & $-2.730 \mathrm{E}-05$ & $-5.576 \mathrm{E}-05$ & $-2.916 \mathrm{E}-05$ \\
\hline $\mathrm{b}_{4}$ & $5.647 \mathrm{E}-07$ & $4.641 \mathrm{E}-07$ & 8.779E-07 & 4.696E-07 \\
\hline $\mathrm{b}_{5}$ & $-3.371 \mathrm{E}-09$ & $-2.806 \mathrm{E}-09$ & $-4.919 \mathrm{E}-09$ & $-2.739 \mathrm{E}-09$ \\
\hline $\mathrm{C}_{0}$ & 0.9615 & 0.9995 & 1.0144 & 1.072 \\
\hline $\mathrm{C}_{1}$ & 0.0368 & 0.0026 & -0.0055 & -0.098 \\
\hline $\mathrm{C}_{2}$ & 0.2322 & -0.5385 & -0.3211 & -1.8457 \\
\hline $\mathrm{C}_{3}$ & -9.4295 & -21.4078 & -30.2010 & -5.1762 \\
\hline $\mathrm{n}$ & 1.357 & 1.026 & 1.025 & 3.09 \\
\hline \multicolumn{5}{|c|}{ OTHER Parameters } \\
\hline $\mathrm{N}_{\mathrm{s}}$ & 56 & 72 & 72 & 66 \\
\hline Slope at $\mathrm{I}_{\mathrm{sc}}(\mathrm{A} / \mathrm{V})$ & -0.008 & -0.004 & -0.003 & -0.020 \\
\hline$\varepsilon(\mathrm{eV})$ & 1.12 & 1.12 & 1.14 & 1.6 \\
\hline
\end{tabular}


Table A.2: Values used to calculate incidence angle modifier, using King's correlation

\begin{tabular}{|c|c|}
\hline Coefficient & 1.0 \\
\hline $\mathrm{b}_{0}$ & $-4.6445 \mathrm{E}-03$ \\
\hline $\mathrm{b}_{1}$ & $5.8607 \mathrm{E}-04$ \\
\hline $\mathrm{b}_{2}$ & $-2.3108 \mathrm{E}-05$ \\
\hline $\mathrm{b}_{3}$ & $3.7843 \mathrm{E}-07$ \\
\hline $\mathrm{b}_{4}$ & $-2.2515 \mathrm{E}-09$ \\
\hline $\mathrm{b}_{5}$ & \\
\hline
\end{tabular}

Table A.3: Incidence angle modifier $\left(K_{\tau \alpha}\right)$ values

\begin{tabular}{|c|c|}
\hline $\begin{array}{c}\text { Incidence angle, } \\
\theta \text { [degree] }\end{array}$ & $\begin{array}{c}\text { Incidence angle } \\
\text { modifier, } \mathrm{K}_{\tau \alpha}\end{array}$ \\
\hline 0 & 1 \\
\hline 1 & 1 \\
\hline 2 & 1 \\
\hline 3 & 1 \\
\hline 4 & 1 \\
\hline 5 & 1 \\
\hline 6 & 1 \\
\hline 7 & 1 \\
\hline 8 & 0.9999 \\
\hline 9 & 0.9999 \\
\hline 10 & 0.9999 \\
\hline 11 & 0.9999 \\
\hline 12 & 0.9999 \\
\hline 13 & 0.9998 \\
\hline 14 & 0.9998 \\
\hline 15 & 0.9998 \\
\hline 16 & 0.9997 \\
\hline 17 & 0.9997 \\
\hline 18 & 0.9996 \\
\hline 19 & 0.9996 \\
\hline 20 & 0.9996 \\
\hline 21 & 0.9995 \\
\hline 22 & 0.9994 \\
\hline 23 & 0.9994 \\
\hline 24 & 0.9993 \\
\hline 25 & 0.9993 \\
\hline 26 & 0.9992 \\
\hline 27 & 0.9991 \\
\hline 28 & 0.999 \\
\hline 29 & 0.9989 \\
\hline 30 & 0.9988 \\
\hline 31 & 0.9987 \\
\hline
\end{tabular}

\begin{tabular}{|c|c|}
\hline 32 & 0.9986 \\
\hline 33 & 0.9985 \\
\hline 34 & 0.9984 \\
\hline 35 & 0.9982 \\
\hline 36 & 0.9981 \\
\hline 37 & 0.9979 \\
\hline 38 & 0.9977 \\
\hline 39 & 0.9975 \\
\hline 40 & 0.9973 \\
\hline 41 & 0.9971 \\
\hline 42 & 0.9969 \\
\hline 43 & 0.9966 \\
\hline 44 & 0.9963 \\
\hline 45 & 0.996 \\
\hline 46 & 0.9956 \\
\hline 47 & 0.9952 \\
\hline 48 & 0.9948 \\
\hline 49 & 0.9944 \\
\hline 50 & 0.9939 \\
\hline 51 & 0.9933 \\
\hline 52 & 0.9927 \\
\hline 53 & 0.992 \\
\hline 54 & 0.9912 \\
\hline 55 & 0.9904 \\
\hline 56 & 0.9894 \\
\hline 57 & 0.9883 \\
\hline 58 & 0.9871 \\
\hline 59 & 0.9858 \\
\hline 60 & 0.9843 \\
\hline 61 & 0.9825 \\
\hline 62 & 0.9806 \\
\hline 63 & 0.9784 \\
\hline 64 & 0.9758 \\
\hline 65 & 0.973 \\
\hline
\end{tabular}




\begin{tabular}{|c|c|}
\hline 66 & 0.9697 \\
\hline 67 & 0.9659 \\
\hline 68 & 0.9615 \\
\hline 69 & 0.9565 \\
\hline 70 & 0.9507 \\
\hline 71 & 0.9439 \\
\hline 72 & 0.9361 \\
\hline 73 & 0.927 \\
\hline 74 & 0.9163 \\
\hline 75 & 0.9039 \\
\hline 76 & 0.8893 \\
\hline 77 & 0.8722 \\
\hline 78 & 0.852 \\
\hline 79 & 0.8283 \\
\hline 80 & 0.8003 \\
\hline 81 & 0.7671 \\
\hline 82 & 0.7279 \\
\hline 83 & 0.6815 \\
\hline 84 & 0.6265 \\
\hline 85 & 0.5612 \\
\hline 86 & 0.4838 \\
\hline 87 & 0.3919 \\
\hline 88 & 0.2828 \\
\hline 89 & 0.1534 \\
\hline 90 & 0.01654 \\
\hline
\end{tabular}




\section{Appendix B}

Part I: Calculating the effective absorbed irradiance $\left(\mathrm{G}_{\text {eff }}\right)$

The following program needs as an input the total irradiance on the tilted surface $\left(\mathrm{G}_{\mathrm{T}}\right)$, the total irradiance on a horizontal surface $(\mathrm{G})$, and the beam component of the irradiance on a surface normal to the beam $\left(\mathrm{G}_{\mathrm{bn}}\right)$. It also needs as input the latitude (Lat), longitude $\left(\mathrm{L}_{\mathrm{loc}}\right)$, the standard meridian for the local time zone $\left(\mathrm{L}_{\mathrm{st}}\right)$, the slope of the panel, the surface azimuth angle, the clock time, month, and the day number (0-31). A lookup table named "K_taualpha" with columns named "K_ta" and "theta" are also needed for the program to calculate the incidence angle modifier (table can be seen in Appendix A, Table A.3).

\begin{tabular}{|c|c|c|}
\hline \multicolumn{3}{|c|}{ Start of Code in EES } \\
\hline Lat $=39+13 / 60$ & [degree] & "Latitude" \\
\hline $\mathrm{L}_{1} \mathrm{loc}=77+21 / 60$ & [degree] & "Longitude" \\
\hline L_st $=75$ & [degree] & "Standard meridian for the local time zone" \\
\hline slope $=90$ & [degree] & "Slope of panel" \\
\hline SurfAzAng $=0$ & [degree] & "Surface azimuth angle" \\
\hline Time $=12$ & & "Clock time" \\
\hline Month $=12$ & & "Month number" \\
\hline Day $=31$ & & "Day number" \\
\hline $\mathrm{G} \mathrm{T}=866.3$ & {$[\mathrm{~W} / \mathrm{m} 2]$} & "Total irradiance on tilted surface" \\
\hline $\mathrm{G}=484.9$ & {$[\mathrm{~W} / \mathrm{m} 2]$} & "Total irradiance on horizontal surface" \\
\hline G_b_n $=894.5$ & {$[\mathrm{~W} / \mathrm{m} 2]$} & $\begin{array}{l}\text { "Beam component of irradiance on surface } \\
\text { normal to the beam" }\end{array}$ \\
\hline
\end{tabular}

"Calculation of parameters, using SETP functions"

n_day=nDay_(month, day)

DELTAtime=EqnTime_(n_day)

Time_solar-Time $=\left(4[\mathrm{~min} / \mathrm{deg}] *\left(\mathrm{~L} \_\mathrm{st}-\mathrm{L} \_\right.\right.$loc $)+$DELTAtime $) *$ Convert $(\mathrm{min}, \mathrm{hr})$

HrAng $=15[\mathrm{deg} / \mathrm{hr}] *$ (Time_solar-12 $[\mathrm{hr}])$

R_beam=R_beam_(Lat,n_day,HrAng, Slope, SurfAzAng)

CosTheta $=$ cosIncAng_(Lat, n_day, HrAng, Slope, SurfAzAng)

Theta $1=\operatorname{ArcCos}(\operatorname{Cos}$ Theta $)$

CosZenith=CosZenAng_(Lat, n_day, HrAng)

"Incidence angle modifiers calculated from lookup Table"

K_TauAlpha=Interpolate1('K_taualpha','K_ta','Theta',Theta=Theta1)

K_Ta_d=Interpolate1('K_taualpha','K_ta','Theta',Theta=58)

G_T $=\mathrm{G} \_b * \mathrm{R} \_$beam $+\mathrm{G} \_\mathrm{d} *(1+\cos ($ slope $)) / 2+$ rho $* \mathrm{G} *(1-\cos ($ slope $)) / 2$

G_b $=\mathrm{G} \_\mathrm{b} \_\mathrm{n} * \mathrm{CosZ}$ enith

$\mathrm{G}+\mathrm{b}=\mathrm{G}-\mathrm{G}_{-} \mathrm{d}$ 
G_eff $=\left(\mathrm{G} \_\mathrm{b} * \mathrm{R} \_\right.$beam $* \mathrm{~K} \_$taualpha $+\mathrm{G} \_\mathrm{d} * \mathrm{~K}$ ta_d $*(1+\cos ($ slope $)) / 2+$ rho $* \mathrm{G} * \mathrm{~K} \_$ta $\_$d $*(1-$ $\cos ($ slope $) \overline{)} / 2$ )

Part II: Calculating the $\mathrm{K}_{\tau \alpha}$ values: Using index of refraction (n) equal to 1.526

$\mathrm{n}_{1}=1.0$

$\mathrm{n}_{2}=1.526$

$\mathrm{L}=0.002 \mathrm{~m}$

$\mathrm{K}=4$

$\theta_{1}=$ varies

$\theta_{2}=0^{\circ}$

$\tau=$ TransHalfCov_ $\left(\theta_{1}, \mathrm{~K}^{*} \mathrm{~L}, \mathrm{n}_{2}\right)$

$\tau_{\mathrm{n}}=$ TransHalfCov_ $\left(\theta_{2}, \mathrm{~K}^{*} \mathrm{~L}, \mathrm{n}_{2}\right)$

$\mathrm{K}_{\tau \alpha}=\tau / \tau_{\mathrm{n}}$
"Index of refraction of air "

"Index of refraction of glass"

"Thickness of glass"

"Proportionality constant of glass"

"Angle of incidence"

"Angle of incidence normal to surface"

"SETP function at any angle of incidence"

"SETP function at angle of incidence normal to surface"

"Incidence Angle modifier"

Part III: Calculating the $\mathrm{K}_{\tau \alpha}$ values: Finding index of refraction (n) that minimizes difference between King et al.'s and SEL's incidence angle modifiers

1) Ten incidence angle points were selected on the range of $0^{\circ}$ to $90^{\circ}$.
$\theta_{1}[1]=1^{\mathrm{o}}$
$\theta_{1}[6]=65^{\circ}$
$\theta_{1}[2]=40^{\circ}$
$\theta_{1}[7]=70^{\circ}$
$\theta_{1}[3]=50^{\circ}$
$\theta_{1}[8]=75^{\circ}$
$\theta_{1}[4]=55^{\circ}$
$\theta_{1}[9]=80^{\circ}$
$\theta_{1}[5]=60^{\circ}$
$\theta_{1}[10]=85^{\circ}$

2) The respective incidence angle modifiers $\left(\mathrm{M}_{\theta}\right.$ and $\left.\mathrm{K}_{\tau \alpha}\right)$ were calculated using

King et al.'s Equation (2.6) and the SETP function, respectively, while leaving the index of refraction (n) as an unknown.

Duplicate $\mathrm{i}=1,10$

$\mathrm{K} \tau \alpha \_\operatorname{King}[\mathrm{i}]=\mathrm{b}_{0}+\mathrm{b}_{1} \theta_{1}[\mathrm{i}]+\mathrm{b}_{2} \theta_{1}[\mathrm{i}]^{2}+\mathrm{b}_{3} \theta_{1}[\mathrm{i}]^{3}+\mathrm{b}_{4} \theta_{1}[\mathrm{i}]^{4}+\mathrm{b}_{5} \theta_{1}[\mathrm{i}]^{5}$

$\tau[\mathrm{i}]=$ TransHalfCov_$\left(\theta_{1}[\mathrm{i}], \mathrm{K} * \mathrm{~L}, \mathrm{n}_{2}\right)$

$\mathrm{K} \tau \alpha_{-} \mathrm{SETP}[\mathrm{i}]=\tau[\mathrm{i}] / \tau_{\mathrm{n}}$

Difference[i] $=\left(\text { K } \tau \alpha \_ \text {King[i]-K } \tau \text { __SETP[i] }\right)^{2}$ 
end

3) The value of the index of refraction (n) was found by minimizing the sum of the square of the differences between the incidence angle modifiers $\left(\mathrm{M}_{\theta}\right.$ and $\left.\mathrm{K}_{\tau \alpha}\right)$ and setting the index of refraction as the independent variable (under the Calculate $\operatorname{Min} / \operatorname{Max}$ tab).

Suma $=$ sum(Difference[i], $\mathrm{i}=1,10)$

Tab: Calculate, Min/Max, Minimize: Suma, Independent Variable: $\mathrm{n}_{2}$

Result: $\mathrm{n}_{2}=1.256$; Suma $=0.005002$

\section{Part IV: Calculating the $\mathrm{K}_{\tau \alpha}$ values: Finding index of refraction (n) that minimizes the error between the measured data and the predictions}

This program is run together with a parametric table where the value of $n \_2$ varies from 1 to 1.5 and the value of "Percentage1" is calculated. The goal of the program is to calculate the value of $n \_2$ that yields the smaller value for "Percentage1" (the percentage error between the measured data and the predicted values).

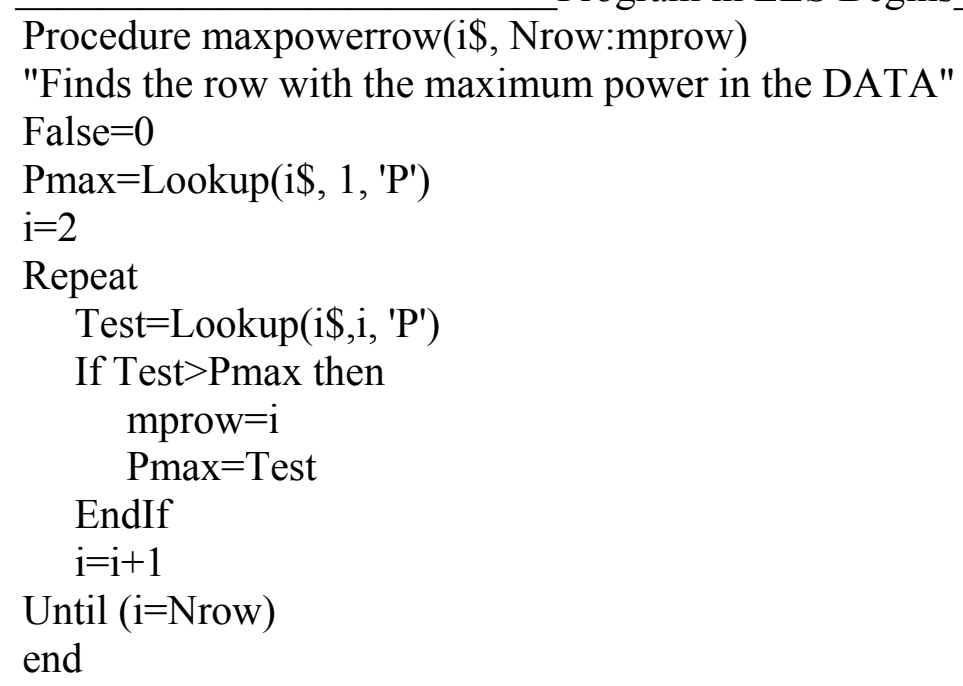




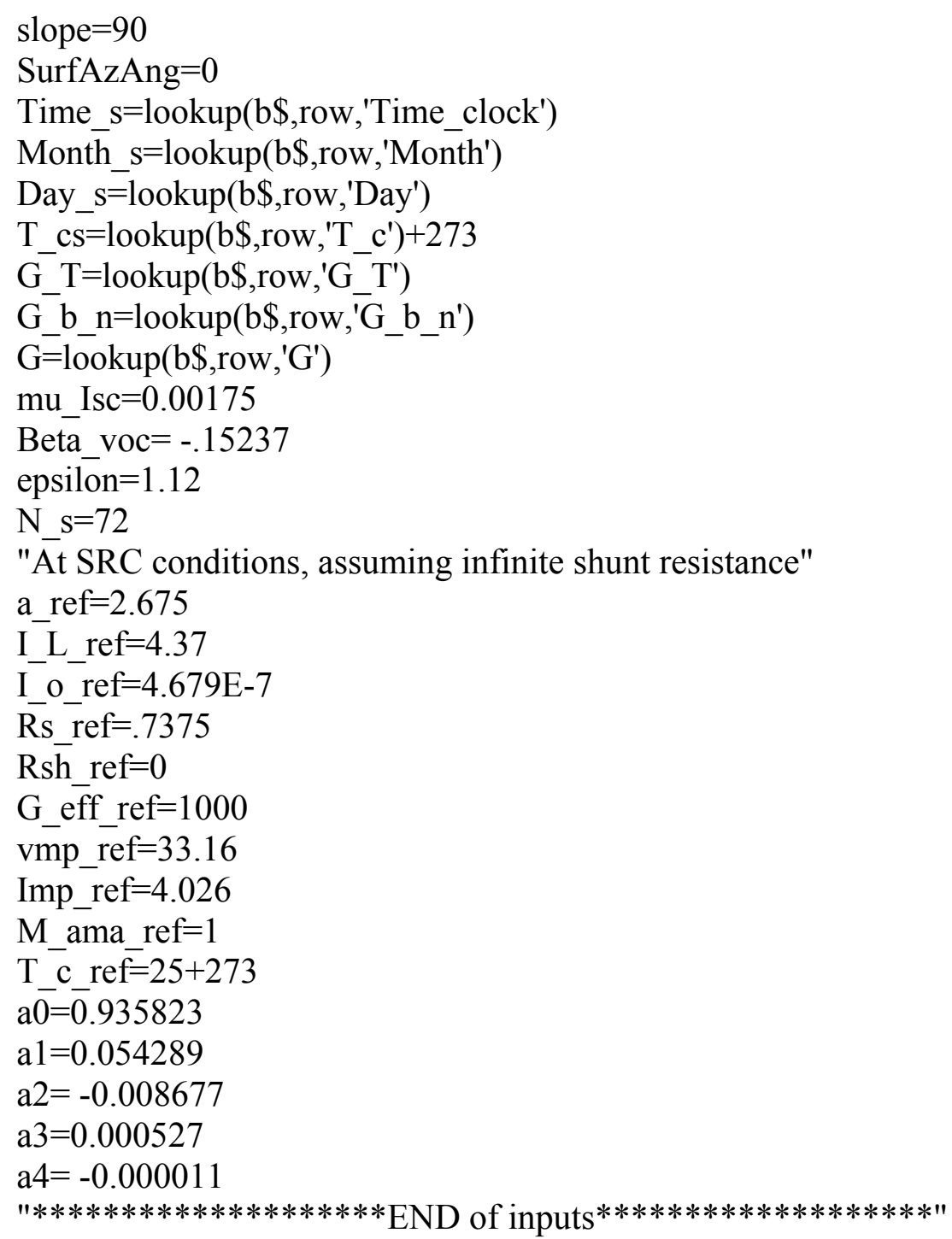

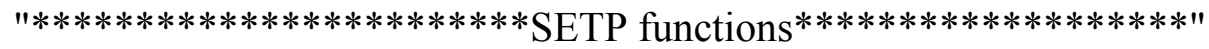

n_day_s=nDay_(month_s, day_s)

DELTAtime_s=EqnTime_(n_day_s)

Time solar_s-Time $s=(4[\mathrm{~min} / \mathrm{deg}] *(\mathrm{~L}$ st-L loc $)+$ DELTAtime $s) *$ Convert $(\min , \mathrm{hr})$

HrAng_s $=15[\mathrm{deg} / \mathrm{hr}] *(12[\mathrm{hr}]$-Time_solar_s $)$

CosTheta_s=cosIncAng_(Lat, n_day_s, HrAng_s, Slope, SurfAzAng)

Theta_s $=\bar{A} \operatorname{ArcCos}\left(\operatorname{Cos} T h e t a \_s\right)$

R_beam=R_beam_(Lat,n_day_s,HrAng_s, Slope, SurfAzAng)

CosZenith s $=$ CosZenAng (Lat, $n$ day s, HrAng s)

Zenith_s $=$ ArcCos(CosZenith_s)

$\mathrm{AM} \_\mathrm{s}=1 /\left(\cos Z e n i t h \_s+0.5057 *\left(96.080-Z e n i t h \_s\right)^{\wedge}(-1.634)\right)$

M_ama_s $=a 0+a 1 * A \bar{M} \_s+a 2 * A M \_s \wedge 2+a 3 * A M \_s \wedge 3+a 4 * A M \_s \wedge 4$

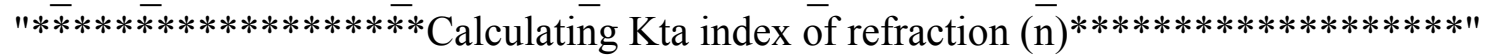

theta_1=theta_s

$\mathrm{L}=0.002$

"assumed value for glass thickness" 
$\mathrm{K}=4$

tau $1=$ TransHalfCov_(theta $1, \mathrm{~K} * \mathrm{~L}, \mathrm{n} 2$ )

tau_2=TransHalfCov_( $\left(0, \mathrm{~K}^{*} \mathrm{~L}, \mathrm{n} \_2\right)$

tau_d=TransHalfCov_(58, K*L, $\left.{ }_{-} 2\right)$

$\mathrm{K} \_$TauAlpha_s=tau_1/tau_2

$\mathrm{K}^{-} \mathrm{Ta} \mathrm{d}=$ tau_d/tau 2

n $1=\overline{1} .0$

$\{$ n_ $2=1.1\} \quad$ "blocked so it can be varied in parametric table"

"!calculating errors, using 15 pts"

$\mathrm{N}=15$

Duplicate $\mathrm{t}=0, \mathrm{~N}$ "water white glass"

"for any incidence angle"

"for zero incidence angle (normal)"

"for equivalent angle of 58(diffuse)"

\section{Volt1 $[\mathrm{t}]=$ Totalvoltage $1 / \mathrm{N} * \mathrm{t}$}

Data1[t] $=$ Interpolate $1\left(\mathrm{i} 1 \$,{ }^{\prime} \mathrm{I},{ }^{\prime} \mathrm{V}, \mathrm{V}, \mathrm{V}=\mathrm{Volt} 1[\mathrm{t}]\right)$

I1 $[\mathrm{t}]=\mathrm{I}\left[\mathrm{L} \_\mathrm{s}-\mathrm{I} \_\right.$os $*(\exp ((\operatorname{Volt} 1[\mathrm{t}]+\mathrm{I} 1[\mathrm{t}] *$ Rs_s $) / \mathrm{as})-1)\{-$

$(\operatorname{Volt} 1[\mathrm{t}]+\mathrm{I} 1[\mathrm{t}] *$ Rs_s $) /$ Rsh_s $\mathrm{s}\}$

"blocked for 4-Parameter model"

Model1[t] $=\max (0, \mathrm{I} 1[\mathrm{t}])$

END

$\operatorname{Diff1}[\mathrm{t}]=(\operatorname{Data} 1[\mathrm{t}]-\operatorname{Model} 1[\mathrm{t}])^{\wedge} 2$

Totaldiffs $1=\operatorname{sum}(\operatorname{Diff} 1[\mathrm{t}], \mathrm{t}=1, \mathrm{~N})$

RMS1 $=(\text { Totaldiffs } 1 /(\mathrm{N}+1))^{\wedge} .5$

Percentage $1=$ RMS1/Data1 $[0]^{*} 100$

G_T $=$ G_b ${ }^{*}$ R_beam $+\mathrm{G} \_\mathrm{d} *(1+\cos ($ slope $)) / 2+\mathrm{rho}^{*} \mathrm{G} *(1-\cos ($ slope $)) / 2$

$\mathrm{G} b=\mathrm{G}$ b $\_$n* CosZenith $\mathrm{s}$

$\mathrm{G} b=\mathrm{G}-\mathrm{G} \mathrm{d}$

G_eff $=\left(G \_b * R \_b e a m * K \_\right.$taualpha_s $+G \_d * K \_t a \_d *(1+\cos ($ slope $)) / 2+$ rho $* G * K \_t a \_d *(1$ $-\cos ($ slope $) / 2$ )

"Calculating new parameters"

as/a_ref $=$ T_cs/T_c_ref

I_os/I_o_ref=(T_cs/T_c ref) $)^{\wedge} * \exp \left(\left(\operatorname{epsilon} * \mathrm{~N} \_\mathrm{s} / \mathrm{a} \_\right.\right.$ref $) *(1-\mathrm{T}$ c c ref $/ \mathrm{T}$ cs $\left.)\right)$

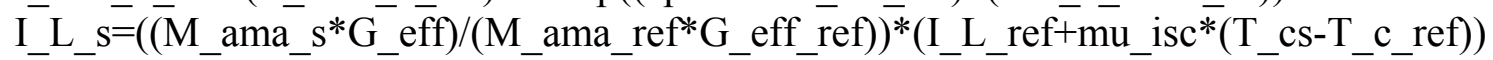

Rsh_s=Rsh_ref

Imp=Imp_ref*G_eff/G_eff_ref

Vmp $=$ Vmp_ref+Beta_voc*(T_cs-T_c_ref)

G_eff/G_eff_ref=(a_ref/I_o_ref*exp(-

(Vmp_ref+Imp_ref*Rs_ref)/a_ref)+Rs_ref)/(as/I_os*exp(-(Vmp+Imp*Rs_s)/as)+Rs_s)

Part V: Calculating the reference parameters $\left(\mathrm{a}_{\mathrm{ref}}, \mathrm{I}_{\mathrm{o}, \mathrm{ref}}, \mathrm{I}_{\mathrm{L}, \text { ref }}, \mathrm{R}_{\mathrm{s}, \mathrm{ref}}\right.$, and $\mathrm{R}_{\text {sh,ref }}$ )

The following codes are in EES

1) Using the 5-Parameters model $\left(R_{\text {sh }}\right.$ is a finite number) 
Start of Code in EES

$\begin{array}{ll}\text { G_ref }=1000\left[\mathrm{~W} / \mathrm{m}^{\wedge} 2\right] & \text { "if values were recorded at } \mathrm{SRC} \text { " } \\ \text { T_c_ref }=298[\mathrm{~K}] & \text { "if values were recorded at } \mathrm{SRC} \text { " }\end{array}$

"Start of input information from manufacturer, different for each cell type"

V_oc_ref $=41.5[\mathrm{~V}]$

I_sc_ref $=4.25[\mathrm{Amp}]$

I_mp $=3.82[\mathrm{Amp}]$

$\overline{\mathrm{V}}_{-} \mathrm{mp}=32.94[\mathrm{~V}]$

P_mp $=125.78[\mathrm{~W}]$

epsilon $=1.14[\mathrm{eV}]$

$\mathrm{mu} \_\mathrm{Voc}=-0.1528 \quad[\mathrm{Volt} / \mathrm{K}]$

mu_Isc $=0.00238 \quad[\mathrm{Amp} / \mathrm{K}]$

$\mathrm{N} \_\mathrm{s}=72$

$\mathrm{dI} \backslash \mathrm{dV} \_\mathrm{Isc}=-0.003$

"End of input information"

"!Short circuit conditions, $\mathrm{V}=0$ "

I_sc_ref=I_L_ref-I_o_ref*(exp(I_sc_ref*R_s/a_ref)-1)-I_sc_ref*R_s/R_sh

"!Open Voltage conditions, I $=0 "$

I_L_ref=I_o_ref*(exp(V_oc_ref/a_ref $)-1)+V$ oc _ref $/ R \_s h$

"!Maximum Power Point"

I_mp=I_L_ref-I_o_ref*X-(V_mp+I_mp*R_s)/R_sh

$\bar{X}=\left(\exp \left(\left(\bar{V} \_m p+I-I_{-} m * R_{-} s\right) / \bar{a} \_r e f\right)-\overline{1}\right)$

"!dP/dV=0 at Max Power"

$\mathrm{dI} \backslash \mathrm{dV} \_\mathrm{mp}=$ -

(I_o_ref/a_ref*exp $\left.\left(\left(\mathrm{V} \_m p+I \_m p * R \_s\right) / a \_r e f\right)+1 / R \_s h\right) /\left(1+R \_s / R \_s h+\left(I \_o \_r e f * R \_s\right) / a \_r e\right.$

$\mathrm{f}^{*} \exp \left(\left(\mathrm{V} \_\mathrm{mp}+\mathrm{I} \_\mathrm{mp} * \mathrm{R}_{-} \mathrm{s}\right) / \mathrm{a} \_\right.$ref $\left.)\right)$

$0=I \_m p+V \_m p * d I \backslash d V \_m p+E R R O R$

"!Slope of I-V curve at short circuit - uses V_mp/2 to get slope."

$\mathrm{dI} \backslash \mathrm{dv} \mathrm{Isc}_{-}=$-

(I_o_ref/a_ref*exp((I_sc_ref*R_s)/a_ref)+1/R_sh)/(1+R_s/R_sh+(I_o_ref*R_s)/a_ref*ex

$\mathrm{p}\left(\left(\mathrm{I} \_\mathrm{sc} \_\right.\right.$ref*R_s $) / \mathrm{a} \_$ref $\left.)\right)$

"!TRW Inc. model for guess values"

k_1=(V_mp/V_oc_ref-1)//n(1-I_mp/I_sc_ref)

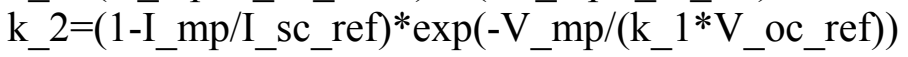

R_s_guess $=1$

I_L_guess=I_sc_ref

I_o_guess $=$ I_sc_ref*k_2 
R_sh_guess $=-1 / \mathrm{dI} \backslash \mathrm{dV}$ _Isc

a_guess $=\mathrm{N} \_\mathrm{s}^{*} \mathrm{k} \# *$ ConvertTemp $(\mathrm{C}, \mathrm{K}, \mathrm{T}$ _c_ref $) / \mathrm{e} \#$

End of Code in EES

To find the values a parametric table must be used with two variables: $a_{\text {ref }}$ and error. The value of $a_{\text {ref }}$ must be varied until the value of error equals zero. Once the value of $\mathrm{a}_{\text {ref }}$ has been determined, the other four parameters will be automatically calculated and can be seen in the results window.

This is the same procedure for all of the cell technologies as long as the shunt resistance parameter $\left(R_{\text {sh }}\right)$ is assumed to be a finite number. The only values that might change are the input variables at the top of the program.

2) Using the 4-Parameters model ( $R_{\text {sh }}$ is infinite)

Start of Code in EES
G_ref $=1000\left[\mathrm{~W} / \mathrm{m}^{\wedge} 2\right]$
"if values were recorded at SRC"
T_c_ref=298[K]
"if values were recorded at SRC"

"Start of input information from manufacturer, different for each cell type"

$$
\begin{aligned}
& \text { V_oc_ref }=41.5[\mathrm{~V}] \\
& \text { I_sc_ref }=4.25[\mathrm{Amp}] \\
& \text { I_mp_ref }=3.82[\mathrm{Amp}] \\
& \text { V_mp_ref }=32.94[\mathrm{~V}] \\
& \text { P_mp_ref }=125.78[\mathrm{~W}] \\
& \text { N_s }=72 \\
& \text { mu_Voc }=-0.1528 \quad[\mathrm{Volt} / \mathrm{K}] \\
& \text { mu_Isc }=0.00238 \quad[\mathrm{Amp} / \mathrm{K}] \\
& \text { epsilon }=1.14 \quad[\mathrm{Amp} / \mathrm{K}]
\end{aligned}
$$

"End of input information"

"! Short circuit conditions, $\mathrm{V}=0 "$

I_sc_ref=I_L_ref-I_o_ref*(exp(I_sc_ref*R_s_ref/a_ref)-1)

"! Open Voltage conditions, $\overline{\mathrm{I}}=0$ "

I_L_ref=I_o_ref*(exp(V_oc_ref/a_ref)-1)

"! Maximum Power Point"

$$
\text { I_mp_ref=I_L_ref-I_o_ref* }\left(\exp \left(\left(\mathrm{V} \_\mathrm{mp} \_r e f+I \_m p \_r e f^{*} \mathrm{R} \_s \_r e f\right) / \mathrm{a} \_r e f\right)-1\right)
$$

"! Equation for a ref using the four parameter method"

a_ref $=\left(\mathrm{mu} \_\right.$voc*T_c_ref-V_oc_ref + epsilon*N_s $) /((\mathrm{mu}$ _isc $* T$ c_ref $/$ I_L_ref $)-3)$

End of Code in EES 
There are four equations and four unknowns, therefore the parameters can be found by solving the equations simultaneously.

This is the procedure in the case where the shunt resistance $\left(\mathrm{R}_{\mathrm{sh}}\right)$ parameter is assumed to be infinite (usually only for mono-crystalline cell type). 


\section{Appendix C}

\section{Part I: Error calculation}

This section shows an example of a program in EES used to calculate the RMS and percentage RMS error analyzing 15 points, 5 well selected important points, and the maximum power point. The code for all three of them is the same, with the exception of the block marked "CHANGES FOR DIFFERENT NUMBER OF POINTS”, which varies, depending on the type of calculation ( $\mathrm{N}$ number of points equally distributed in the x-axis, 5 important points, or the maximum power point). The different codes are shown in the three following sections $(a, b, c)$. This program runs as long as there are two lookup tables, one called "Data-NIST" and one called "Model I-V". Both lookup tables should have three columns labeled "I", "V", and "P" (the power column is optional for the "Model I-V" lookup table. Parts b and c show the code that must be substituted in the designated part of the code shown in part a if the 5 important points or the maximum power point are to be used to calculate the error in the prediction made.

a) Using fifteen (15) points

Beginning of Code in EES

Procedure Difference(h\$:RMS)

"Name of lookup table with values of Data provided by NIST"

i\$='Data-NIST'

"Calculates the number of rows in the lookup table with NIST's data"

Nrow=Nlookuprows(i\$)

"! $* * * * * * * * * * * * * * 11$

"Finds the row with the maximum power in NIST's data"

False $=0$

Pmax $=$ Lookup(i\$, 1, 'P') 


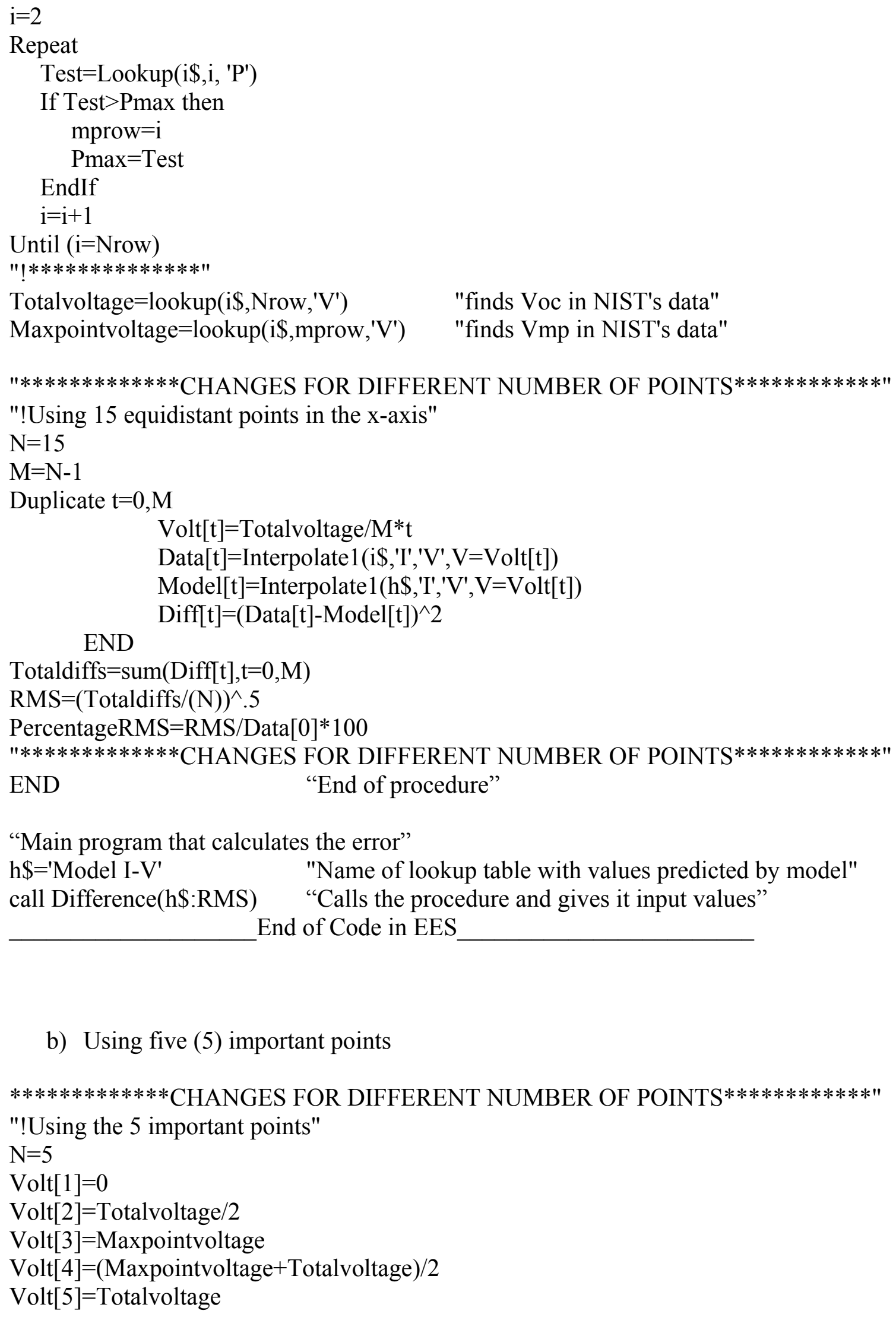

"Main program that calculates the error" $\mathrm{h} \$=$ 'Model I-V' "Name of lookup table with values predicted by model" call Difference(h\$:RMS) "Calls the procedure and gives it input values" End of Code in EES

b) Using five (5) important points 


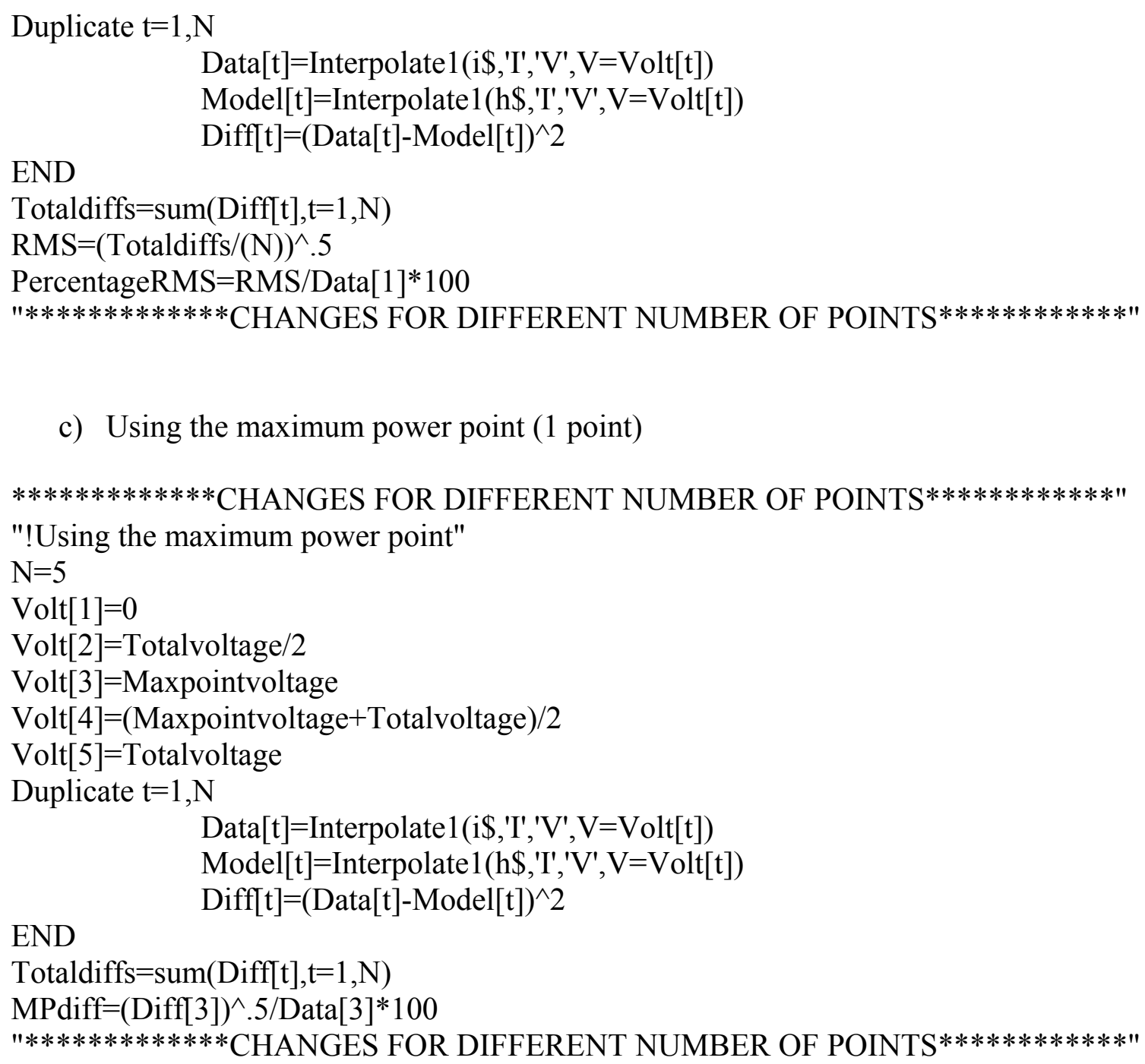

Also, the first and last lines of the code, which read "Procedure Difference (h\$:RMS)" and "call Difference(h\$:RMS)" should be changed to "Procedure Difference(h\$:MPdiff)” and “call Difference(h\$:MPdiff)", respectively.

\section{Part II: Predicting the I-V curve}

The following EES program uses SETP functions, together with the lookup table 'Ktaualpha' to predict the I-V curve for a set of specific operating conditions (date, time, location, cell temperature, irradiance, etc.). A parametric table was used to vary the value of the voltage $(\mathrm{V})$. 
Beginning of Code in EES

"Program to predict the I-V curve for Astropower cell type"

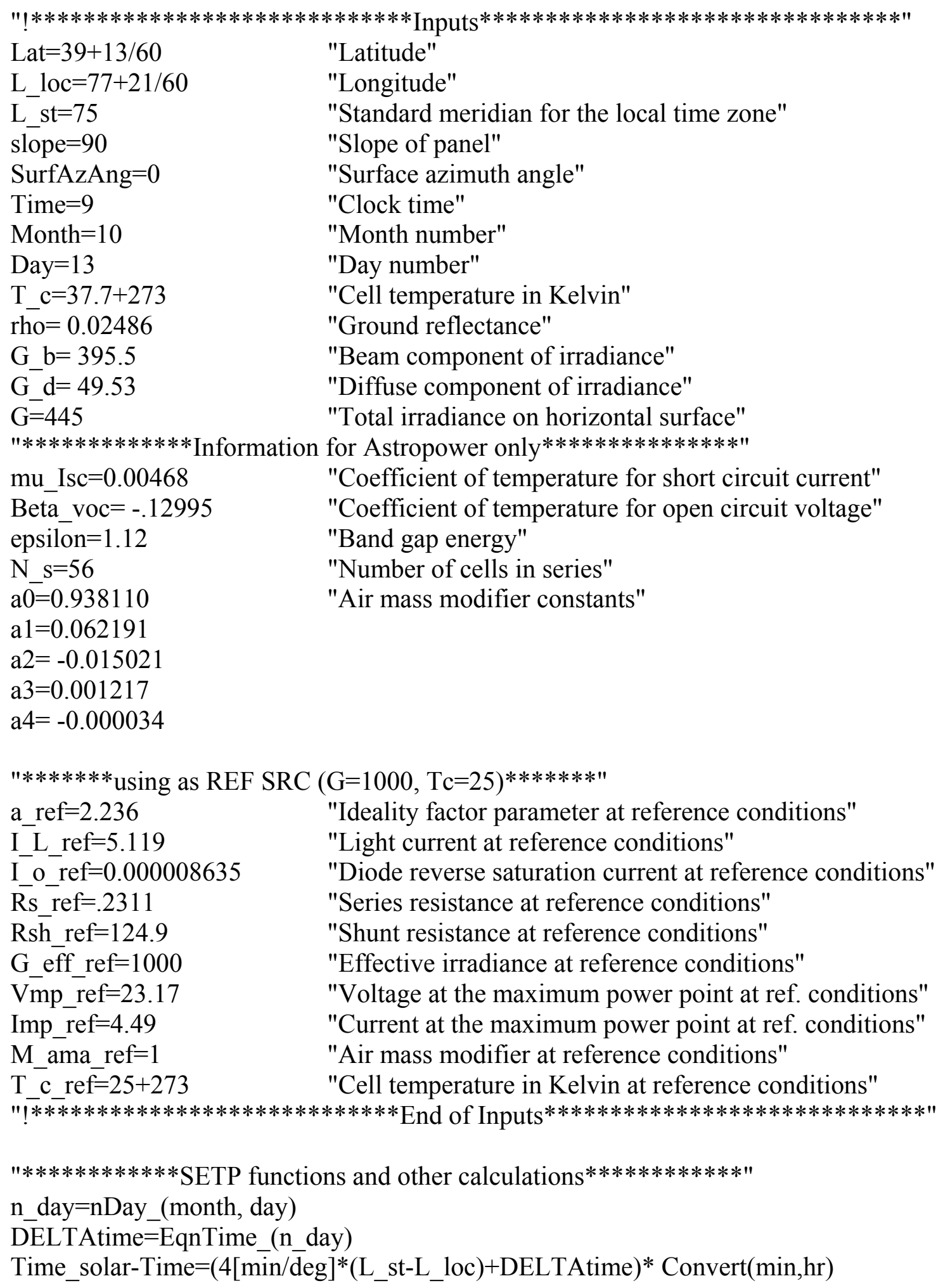


HrAng=15[deg/hr]*(12[hr]-Time_solar)

CosTheta $=$ cosIncAng_(Lat, n_day, HrAng, Slope, SurfAzAng)

Theta $=$ ArcCos(CosTheta)

R_beam=R_beam_(Lat,n_day,HrAng, Slope, SurfAzAng)

CosZenith $=\overline{\text { CosZenAng_(Lat, n_day, HrAng) }}$

Zenith $=$ Arc Cos(CosZenith)

$\mathrm{AM}=1 /\left(\cos Z\right.$ enith $\left.+0.5057 *(96.080-\text { Zenith })^{\wedge}(-1.634)\right)$

M ama $=a 0+a 1 * A M+a 2 * A M^{\wedge} 2+a 3 * A M^{\wedge} 3+a 4 * A^{\wedge} 4$

K_TauAlpha=Interpolate1('K_taualpha','K_ta_n1.1','Theta',Theta=Theta) "Ktaualpha calculation at Theta degrees"

K_Ta_d=Interpolate1('K_taualpha','K_ta_n1.1','Theta',Theta=58) "Ktaualpha

calculation at 58 degrees"

a/a_ref $=$ T_c/T_c_ref

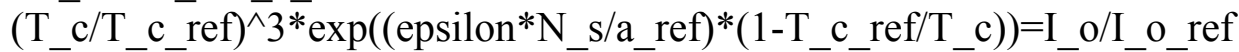

G_eff $=\left(G \_b * R \_b e a m * K \_t a u a l p h a+G \_d * K \_t a-d *(1+\cos (\operatorname{slope})) / 2+r h o * G * K \_t a \_d *(1-\right.$

$\cos ($ slope $)) / 2$ )

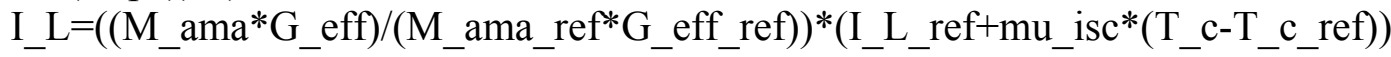

Imp $=$ Imp_ref* $\mathrm{G}_{-}$eff/G_eff_ref

Vmp $=$ Vmp_ref + Beta_voc* $\left(T \_c-T \_c \_r e f\right)$

G_eff/G_eff_ref=(a_ref/I_o_ref* $\exp (-$

$(\overline{V m p}$ ref + Imp_ref*Rs_ref $) / \bar{a} \_$ref $)+$Rs_ref $) /\left(\mathrm{a} / \mathrm{I} \_\mathrm{o}^{*} \exp (-(\mathrm{Vmp}+\mathrm{Imp} * \mathrm{Rs}) / \mathrm{a})+\mathrm{Rs}\right)$

Rsh=Rsh_ref

$\mathrm{I}=\mathrm{I} \_\mathrm{L}-\mathrm{I} \_\mathrm{o}^{*}(\exp ((\mathrm{V}+\mathrm{I} * \mathrm{Rs}) / \mathrm{a})-1)-(\mathrm{V}+\mathrm{I} * \mathrm{Rs}) / \mathrm{Rsh}$

End of Code in EES

\section{Part III: Two-curve optimization method (if manufacturers provided two sets of data)}

The following EES program can be used to determine the five reference

parameters ( $\mathrm{a}_{\mathrm{ref}}, \mathrm{I}_{\mathrm{L}, \mathrm{ref}}, \mathrm{I}_{\mathrm{o}, \mathrm{ref}}, \mathrm{R}_{\mathrm{s}, \mathrm{ref}}$, and $\left.\mathrm{R}_{\mathrm{sh}, \mathrm{ref}}\right)$ that minimize the errors in the predictions.

This program must be run together with two lookup tables "curve1" and "curve2", where the measured values by NIST (V, I, P) for the two curves being used can be found. To find the reference parameters, press the tab "Calculate", "Min/Max", select the button "Minimize" and from the table on the left, select "Sumpercentages". From the table on 
the right, select the 5 independent variables "a_ref, I_L_ref, I_o_ref, Rs_ref, Rsh_ref".

Press the button "Bounds" and set the guess values equal to the reference parameters obtained for SRC (these are shown in the following program as comments). Press "OK" and the results should appear in the results window.

Beginning of Code in EES

Procedure maxpowerrow(i\$, Nrow:mprow)

"Finds the row with the maximum power in the DATA provided by NIST"

False $=0$

Pmax=Lookup(i\$, 1, 'P')

$\mathrm{i}=2$

Repeat

Test=Lookup(i\$,i, 'P')

If Test $>$ Pmax then mprow $=\mathrm{i}$

Pmax $=$ Test

EndIf

$\mathrm{i}=\mathrm{i}+1$

Until ( $\mathrm{i}=$ Nrow)

end

Lat $=39+13 / 60$

"Latitude"

L_loc $=77+21 / 60$

"Longitude"

L_st $=75$

"Standard meridian for the local time zone"

slope $=90$

"Slope of PV module"

SurfAzAng $=0$

"Surface azimuth angle"

T_c1 $=25+273.15$

G_eff $1=1000$

M_ama_1=1

"Cell temperature for curve \#1"

"Effective irradiance for curve \#1"

"Air mass modifier for curve \#1"

Time $2=12$

Month_2=6

Day_2 $=20$

"Clock time for curve \#2"

"Month for curve \#2"

"Day number for curve \#2"

T_c2 $=37.1+273.15$

"Cell temperature for curve \#2"

G_eff2=297.7

"Effective irradiance for curve \#2"

"SETP functions for curve \#2, since curve \#1 is the same as SRC, these functions are not needed for the first curve"

n_day_2=nDay_(month_2, day_2) 
DELTAtime_2=EqnTime_(n_day_2)

Time_solar_2-Time_2 $=\left(4[\overline{\mathrm{min}} / \mathrm{deg}] *\left(\mathrm{~L} \_ \text {st-L_loc }\right)+\text { DELTAtime_2 }\right)^{*}$ Convert $(\min , \mathrm{hr})$

HrAng_2 $=\overline{15}[\mathrm{deg} / \mathrm{hr}]^{*}(12[\mathrm{hr}]$-Time_solar_2 $)$

CosTheta_2=cosIncAng_(Lat, n_day_2, HrAng_2, Slope, SurfAzAng)

Theta_2=ArcCos(CosTheta_2)

R_beam2=R_beam_(Lat,n_day_2,HrAng_2, Slope, SurfAzAng)

CosZenith_2=CosZenAng_(Lat, n_day_2, HrAng_2)

Zenith_2=ÄArcCos(CosZenith_2)

AM_ $2=1 /\left(\cos Z e n i t h \_2+0.5057 *\left(96.080-Z e n i t h \_2\right)^{\wedge}(-1.634)\right)$

M_ama_2=a_0+a_1*AM_2+a_2*AM_2^2+a_3*AM_2^3+a_4*AM_2^4

"For Siemens cell type"

$\mathrm{mu}$ Isc $=0.00175$

epsilon $=1.12$

N_s $=72$

"Values for calculation of air mass modifier"

a $0=0.935823$

a $1=0.054289$

a_2 $=-0.008677$

a_3 $=0.000527$

a_ $4=-0.000011$

$" ! * * * * * * "$

"Reference parameters for SRC to be used as guess values"

a_ref $=2.675$

I $\bar{L}$ ref $=4.37$

I_o_ref $=4.679 \mathrm{E}-7$

Rs_ref $=.7375$

Rsh_ref=10000 "infinite"

G_eff_ref $=1000$

"Effective irradiance at SRC"

Vmp_ref $=33.68$

"Vmp at SRC"

Imp_ref $=3.96$

"Imp at SRC"

M_ama_ref $=1$

T_c_ref= $25+273.15$

"Air mass modifier at SRC"

"Cell temperature at SRC"

"Calculation of parameters for both curves"

al/a_ref $=$ T_c1/T_c_ref

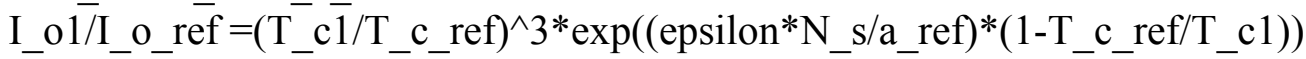

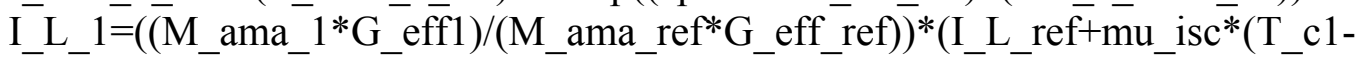

T_c_ref))

Vmp $1=33.68$

"Vmp measured for curve \#1"

Imp $1=3.96$

"Imp measured for curve \#1"

G_effl/G_eff_ref=(a_ref/I_o_ref*exp(-(Vmp_ref + Imp_ref*Rs_ref $\left.) / a \_r e f\right)$

$\left.+\bar{R} s \_r e f\right) /\left(a 1 / \bar{I} \_1 * \exp \left(-\left(\overline{V m p} 1+\operatorname{Imp} 1 * \mathrm{Rs} \_1\right) / \mathrm{a} 1\right)+\mathrm{Rs} \_1\right)$

Rsh_1=Rsh_ref 


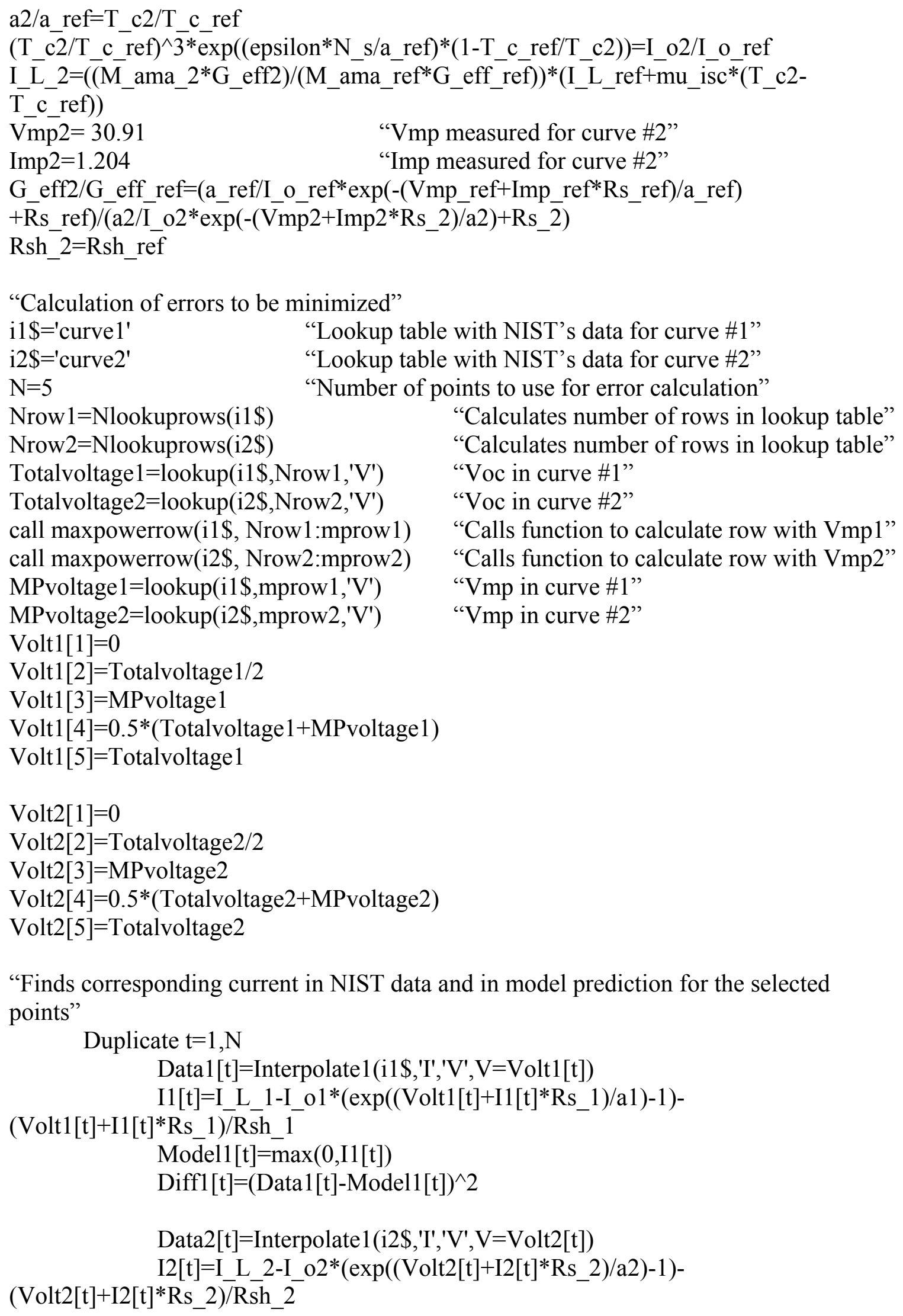

"Finds corresponding current in NIST data and in model prediction for the selected points"

Duplicate $\mathrm{t}=1, \mathrm{~N}$

Data1 $[\mathrm{t}]=$ Interpolate1 $\left(\mathrm{i} 1 \$, \mathrm{I}^{\prime}, \mathrm{I}^{\prime}, \mathrm{V}=\operatorname{Volt} 1[\mathrm{t}]\right)$

I1[t] $=$ I_L_1-I_o1* $(\exp ((\operatorname{Volt} 1[\mathrm{t}]+\mathrm{I} 1[\mathrm{t}] *$ Rs_1)/a1 $)-1)-$

$(\operatorname{Volt1}[\mathrm{t}]+\mathrm{I} 1[\mathrm{t}] *$ Rs_1)/Rsh_1

Model1 $[\mathrm{t}]=\overline{\max }(0, \mathrm{I} 1[\mathrm{t}])$

$\operatorname{Diff} 1[\mathrm{t}]=(\operatorname{Data} 1[\mathrm{t}]-\operatorname{Model} 1[\mathrm{t}])^{\wedge} 2$

Data2[t] $=$ Interpolate1 $\left(\mathrm{i} 2 \$, \mathrm{I}^{\prime}, \mathrm{V}^{\prime}, \mathrm{V}=\right.$ Volt2 $\left.[\mathrm{t}]\right)$

$\mathrm{I} 2[\mathrm{t}]=\mathrm{I}$ L_2-I_o $2 *(\exp ((\operatorname{Volt} 2[\mathrm{t}]+\mathrm{I} 2[\mathrm{t}] *$ Rs_2 $) / \mathrm{a} 2)-1)-$

$(\operatorname{Volt} 2[\mathrm{t}]+\mathrm{I} 2[\mathrm{t}] *$ Rs_2)/Rsh_2 


\section{Model2[t] $=\max (0, I 2[t])$ \\ END \\ $\operatorname{Diff} 2[\mathrm{t}]=(\text { Data2 }[\mathrm{t}]-\operatorname{Model} 2[\mathrm{t}])^{\wedge} 2$}

Totaldiffs $1=\operatorname{sum}(\operatorname{Diff} 1[\mathrm{t}], \mathrm{t}=1, \mathrm{~N})$

RMS1 $=(\text { Totaldiffs } 1 /(\mathrm{N}))^{\wedge} .5$

Percentage $1=$ RMS1/Data1 $[1]^{*} 100$

Totaldiffs2 $=\operatorname{sum}(\operatorname{Diff} 2[\mathrm{t}], \mathrm{t}=1, \mathrm{~N})$

RMS2 $=(\text { Totaldiffs } 2 /(\mathrm{N}))^{\wedge} .5$

Percentage2=RMS2/Data2[1]*100

Sumpercentages=Percentage $1+$ Percentage 2 "Variable to be minimized"

End of Code in EES 


\section{Part I: Comparing the 5-Parameter Model with King's model and the TRW equation}

The following program compares the predictions between King's model, the TRW equation, and the 5-Parameter Model. Many comments have been inserted through out the program help clarify it. The program runs with different parametric and lookup tables (the names of the tables are written in the comments in the "Legend" section).

Program in EES begins

"!****************HOW TO USE THIS PROGRAM***

"The first section is composed of the Functions and Procedures needed to run the program."

"The second section is composed of the models (5-Parameters and King's), divided in BLOCKS for easy recognition."

"For details on how to run the program scroll down to where the second section (models) starts."

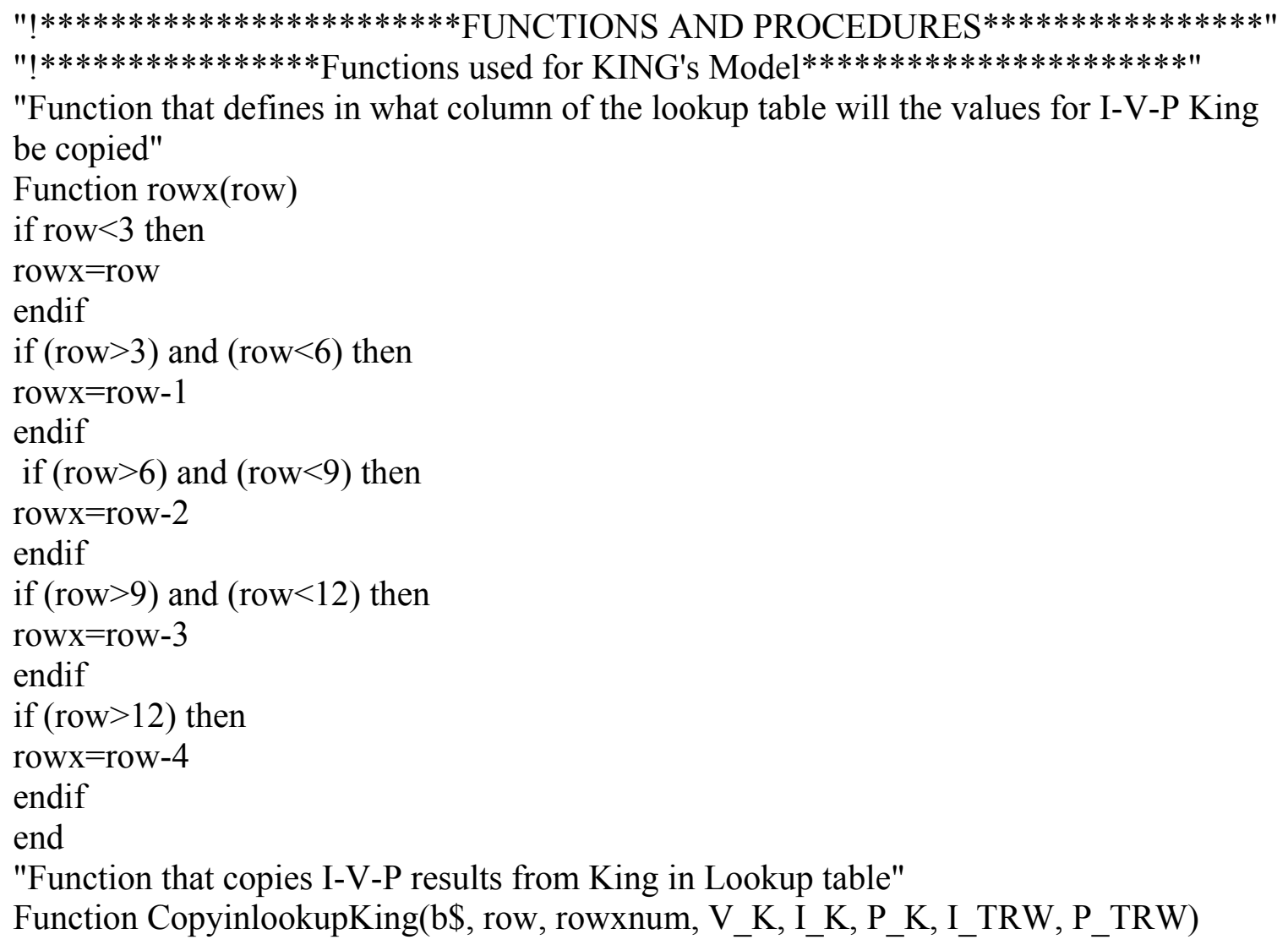




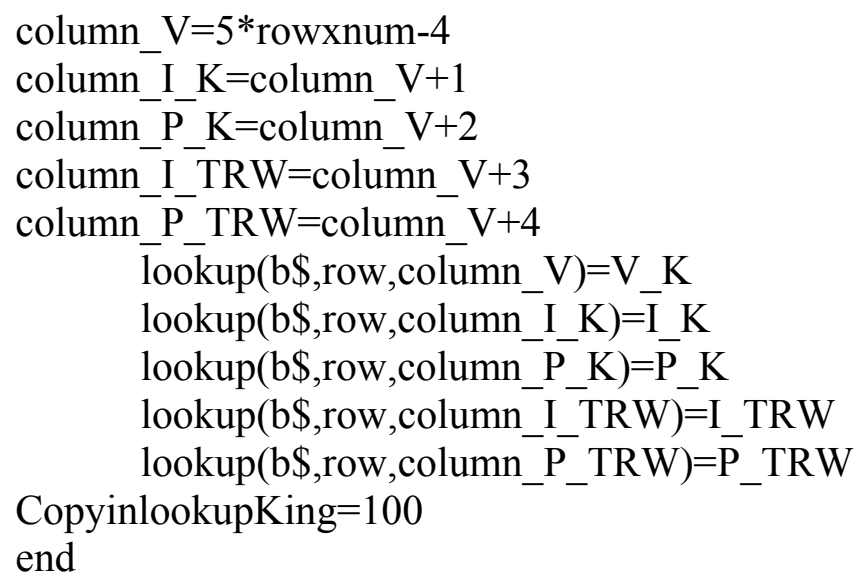




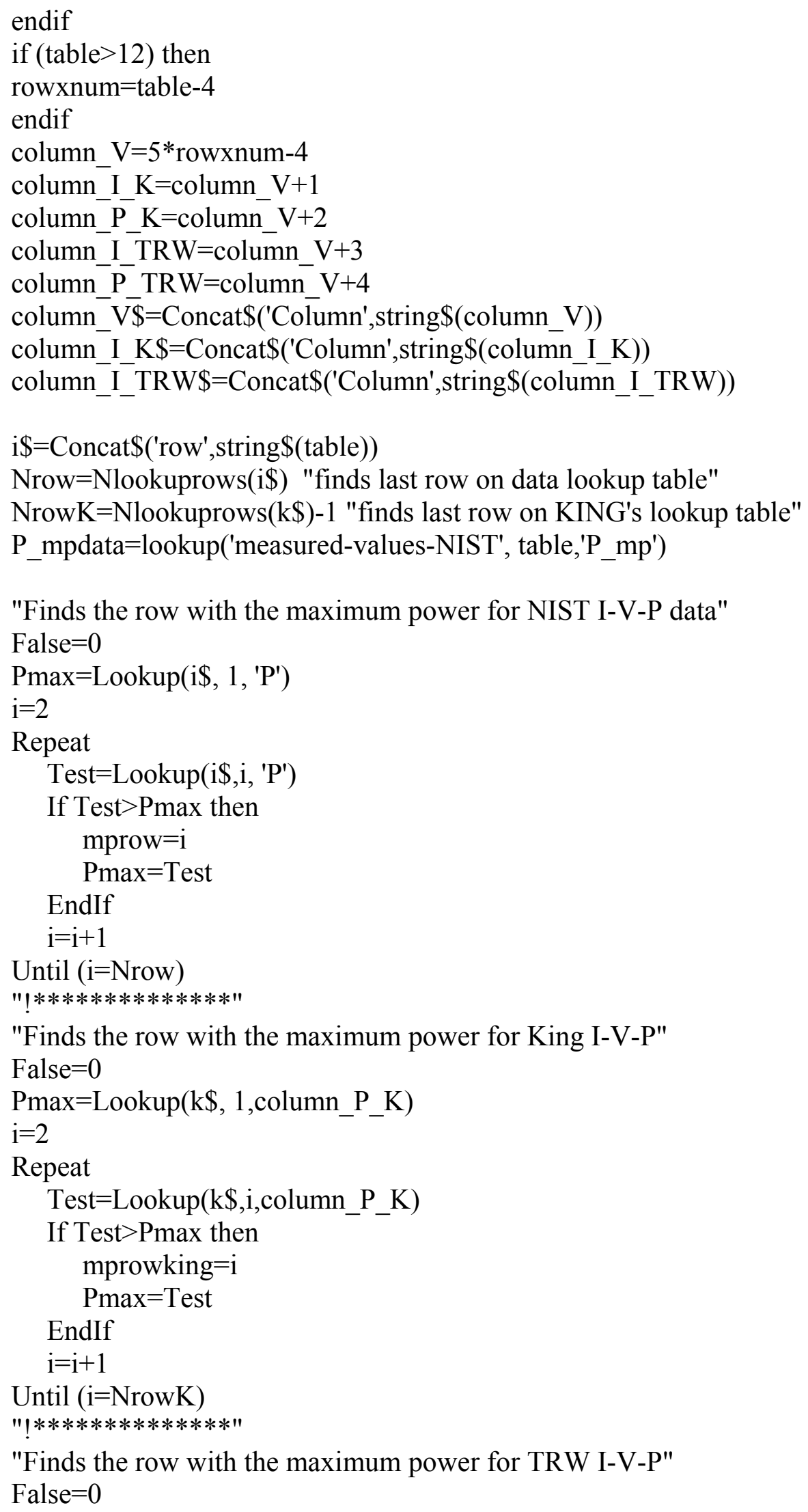

"Finds the row with the maximum power for King I-V-P"

False $=0$

Pmax $=$ Lookup $(\mathrm{k} \$, 1$,column_P_K)

$\mathrm{i}=2$

Repeat

Test $=$ Lookup $(\mathrm{k} \$, \mathrm{i}$, column_P_K $)$

If Test>Pmax then

mprowking $=\mathrm{i}$

$P \max =$ Test

EndIf

$\mathrm{i}=\mathrm{i}+1$

Until ( $\mathrm{i}=$ NrowK)

"!**************"

"Finds the row with the maximum power for TRW I-V-P"

False $=0$ 


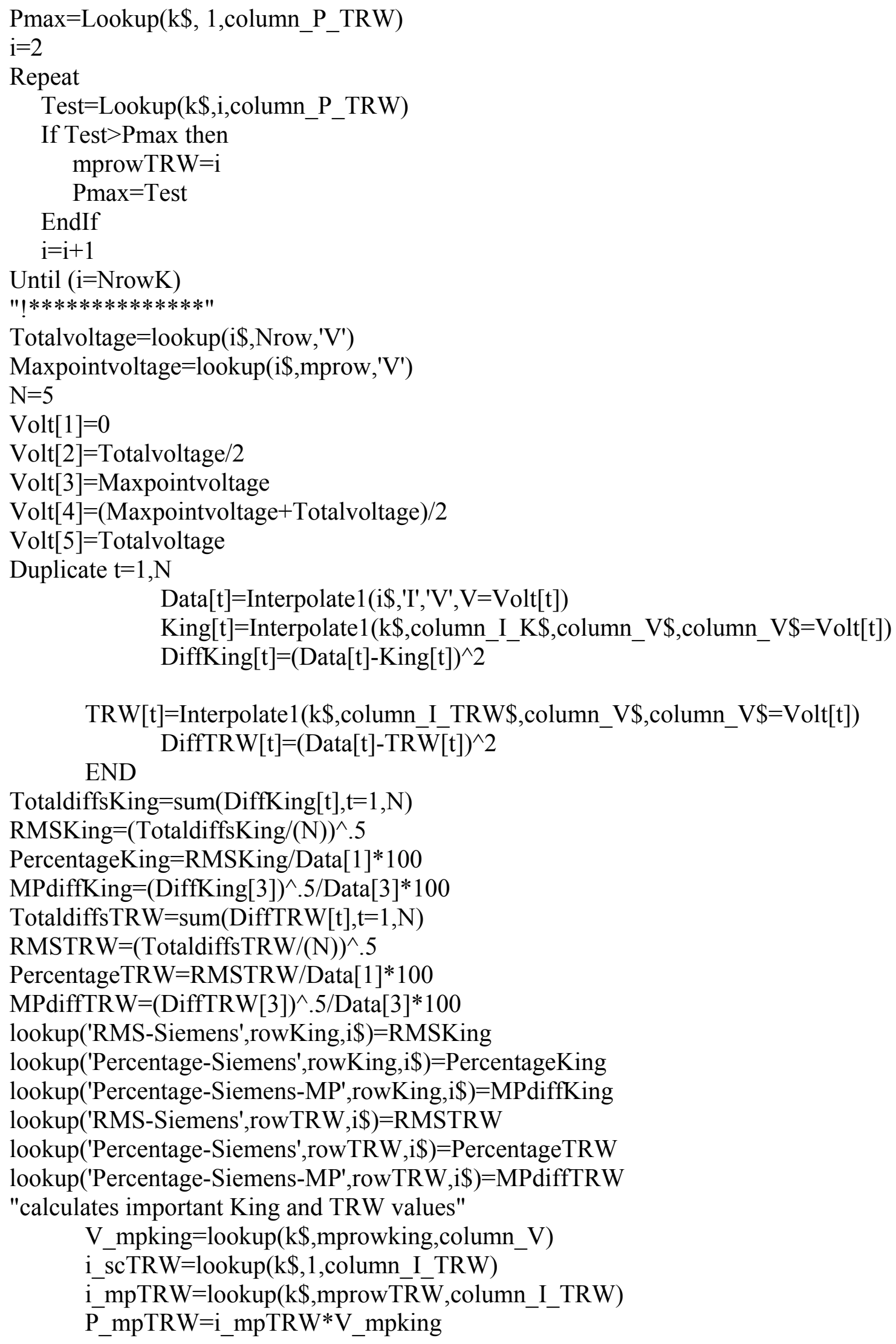


i_scking=lookup(k\$,1,column_I_K)

i_mpking $=$ lookup(k\$,mprowking,column_I_K)

$\overline{\mathrm{V}}$ _ocking=lookup $(\mathrm{k} \$$,Nrowk,column_V)

P_mpking $=$ __mpking*V_mpking

"calculates percentage rms difference in important predicted TRW values"

isc_trwdiff $=\left((\text { Data[1] }- \text { i_sctrw })^{\wedge} 2\right)^{\wedge} .5 /$ Data[1] $]^{*} 100$

imp_trwdiff $=\left((\text { Data[3]-i_mptrw })^{\wedge} 2\right)^{\wedge} .5 /$ Data[3]*100

Pmp_trwdiff $=\left(\left(\mathrm{P} \_ \text {mpdata-P_mptrw }\right)^{\wedge} 2\right)^{\wedge} .5 / \mathrm{P} \_$mpdata* 100

"calculates percentage rms difference in important predicted King values"

isc_kingdiff $=\left((\text { Data[1]-i_scking })^{\wedge} 2\right)^{\wedge} .5 /$ Data[1] $]^{*} 100$

imp_kingdiff $=\left((\text { Data[3]-i_mpking })^{\wedge} 2\right)^{\wedge} .5 /$ Data[3]*100

Voc_kingdiff $=\left(\left(\text { Volt }[5]-\bar{V} \_ \text {ocking }\right)^{\wedge}\right)^{\wedge} .5 / \operatorname{Volt}[5]^{*} 100$

Vmp_kingdiff $=\left(\left(\text { Volt }[3]-\bar{V}_{-} \text {mpking }\right)^{\wedge} 2\right)^{\wedge} .5 /$ Volt $[3]^{*} 100$

Pmp_kingdiff $=\left(\left(P_{-} \text {mpdata-P_mpking }\right)^{\wedge} 2\right)^{\wedge} .5 / \mathrm{P}_{-}$mpdata* 100

"copies RMS results for important values in lookup table"

duplicate $\mathrm{a}=1,27$

$\operatorname{rowh}[\mathrm{a}]=\mathrm{a}$

end

lookup('Percentage-main variables-Siemens',rowh[4],i\$)=isc_trwdiff lookup('Percentage-main variables-Siemens',rowh[5],i\$)=isc_kingdiff lookup('Percentage-main variables-Siemens',rowh[10],i\$)=imp_trwdiff lookup('Percentage-main variables-Siemens',rowh[11],\$\$)=imp_kingdiff lookup('Percentage-main variables-Siemens',rowh[16],\$\$)=Voc_kingdiff lookup('Percentage-main variables-Siemens',rowh[21],i\$)=Vmp_kingdiff lookup('Percentage-main variables-Siemens',rowh[26],i\$)=Pmp_trwdiff lookup('Percentage-main variables-Siemens',rowh[27],i\$)=Pmp_kingdiff END

!!****************FOR BOTH (KING and 5-Parameter Models) $)^{* * * * * * * * * * * "}$

"Procedure that finds the value for I_x, I_xx, measured, Nrow, mprow"

Procedure i_x_xx_values(i\$:I_x_meas, I_xx_meas, Nrow, mprow)

"Finds the row with the maximum power for NIST data"

False $=0$

Nrow=Nlookuprows $(\mathrm{i} \$$ )

Pmax=Lookup(i\$, 1, 'P')

$\mathrm{i}=2$

Repeat

Test=Lookup(i\$,i, 'P')

If Test $>$ Pmax then

mprow $=\mathrm{i}$

Pmax $=$ Test

EndIf

$\mathrm{i}=\mathrm{i}+1$

Until ( $\mathrm{i}=\mathrm{Nrow})$

"Finds the value of measured i_x and i_xx for NIST data" 
Totalvoltage=lookup $\left(\$ \$, N r o w,{ }^{\prime}{ }^{\prime}\right)$

Maxpointvoltage=lookup(i\$,mprow, 'V')

$\mathrm{N}=5$

Volt $[1]=0$

Volt[2] $=$ Totalvoltage/2

Volt[3]=Maxpointvoltage

Volt[4] $=($ Maxpointvoltage + Totalvoltage $) / 2$

Volt[5] $=$ Totalvoltage

Duplicate $\mathrm{t}=1, \mathrm{~N}$

END

Data[t] $=$ Interpolate1 $\left(i \$, I^{\prime},{ }^{\prime} V^{\prime}, \mathrm{V}=\right.$ Volt $\left.[\mathrm{t}]\right)$

i_x_meas $=$ Data[2]

i_xx_meas $=$ Data[4]

end

!!**************"

"!**********************Functions for 5-Parameter Model

"!*******Copies results of parameters in lookup table for 5-Parameter Model********"

Procedure SetLookups(P\$, row, Par[1..12]:done)

\{SetLookups(a\$, row,Time_solar_s, Theta_s,K_TauAlpha_s, as, I_os, I_L_s, Rs_s,

Rsh_s,I_L_AMA,I_L_2,I_L_2mama: Done)\}

LookUp(P\$, row, 'Time_solar') $=$ Par[1]

LookUp(P\$, row, 'Theta') $=$ Par[2]

LookUp(P\$, row, 'Zenith')=Par[3]

LookUp(P\$, row, 'K_ta')=Par[4]

LookUp(P\$, row, 'a')=Par[5]

LookUp(P\$, row, 'I_o')=Par[6]

LookUp(P\$, row, 'I_L')=Par[7]

LookUp(P\$, row, 'R_- s') $=\operatorname{Par}[8]$

LookUp(P\$, row, 'R_sh')=Par[9]

LookUp(P\$, row, 'G_eff') $=\operatorname{Par}[10]$

LookUp(P\$, row, 'Imp')=Par[11]

LookUp(P\$, row, 'Vmp')=Par[12]

Done $=1$

end

"!**************************************************"

"Functions that copies I-V-P results from 5-Parameters Model in Lookup Table"

Function Copyinlookup $(\mathrm{b} \$$, row, I1\$, V1\$, I1, V1, I2\$, V2\$, I2, V2, I4\$, V4\$, I4, V4, $\mathrm{I} 5 \$, \mathrm{~V} 5 \$, \mathrm{I} 5, \mathrm{~V} 5, \mathrm{I} 7 \$, \mathrm{~V} 7 \$, \mathrm{I} 7, \mathrm{~V} 7, \mathrm{I} 8$, V8\$, I8, V8, I10\$, V10\$, I10, V10, I11\$, V11\$, I11, V11, I13\$, V13\$, I13, V13, I14\$, V14\$, I14, V14)

lookup $(\mathrm{b} \$$, row, $\mathrm{I} 1 \$)=\mathrm{I} 1$

lookup $(\mathrm{b} \$$, row, $\mathrm{I} 2 \$)=\mathrm{I} 2$

lookup $(\mathrm{b} \$$, row, $\mathrm{I} 4 \$)=\mathrm{I} 4$

lookup $(\mathrm{b} \$$, row, I5\$) $=\mathrm{I} 5$

lookup $(\mathrm{b} \$$, row, I7\$) $=\mathrm{I} 7$

lookup $(b \$$, row, I8\$) $=\mathrm{I} 8$

lookup $(\mathrm{b} \$$, row, $\mathrm{I} 10 \$)=\mathrm{I} 10$ 
lookup(b\$, row, I11\$)=I11

lookup(b\$, row, I13\$)=I13

lookup $(\mathrm{b} \$$, row, $\mathrm{I} 14 \$)=\mathrm{I} 14$

$\operatorname{lookup}(\mathrm{b} \$$, row, $\mathrm{V} 1 \$)=\mathrm{V} 1$

lookup $(\mathrm{b} \$$, row, $\mathrm{V} 2 \$)=\mathrm{V} 2$

lookup(b\$, row, V4\$) $=\mathrm{V} 4$

lookup(b\$, row, V5\$)=V5

lookup $(\mathrm{b} \$$, row, V7 $\$)=\mathrm{V7}$

lookup(b\$, row, V8\$) =V8

lookup $(\mathrm{b} \$$, row, V10 $\$)=\mathrm{V} 10$

lookup (b\$, row, V11\$) $=\mathrm{V} 11$

lookup $(\mathrm{b} \$$, row, V13\$) $=\mathrm{V} 13$

lookup (b\$, row, V14\$)=V14

copyinlookup $=10$

end

Function Copyinlookuppower(b\$, row, P1\$, P2\$, P4\$, P5\$, P7\$, P8\$, P10\$, P11\$, P13\$,

P14\$, P1, P2, P4, P5, P7, P8, P10, P11, P13, P14)

lookup $(\mathrm{b} \$$, row, $\mathrm{P} 1 \$)=\mathrm{P} 1$

lookup $(\mathrm{b} \$$, row, $\mathrm{P} 2 \$)=\mathrm{P} 2$

lookup $(\mathrm{b} \$$, row, $\mathrm{P} 4 \$)=\mathrm{P} 4$

lookup $(\mathrm{b} \$$, row, $\mathrm{P} 5 \$)=\mathrm{P} 5$

lookup $(\mathrm{b} \$$, row, $\mathrm{P} 7 \$)=\mathrm{P} 7$

lookup $(\mathrm{b} \$$, row, $\mathrm{P} 8 \$)=\mathrm{P} 8$

lookup $(\mathrm{b} \$$, row, $\mathrm{P} 10 \$)=\mathrm{P} 10$

lookup $(\mathrm{b} \$$, row, $\mathrm{P} 11 \$)=\mathrm{P} 11$

lookup $(\mathrm{b} \$$, row, $\mathrm{P} 13 \$)=\mathrm{P} 13$

lookup $(\mathrm{b} \$$, row, $\mathrm{P} 14 \$)=\mathrm{P} 14$

Copyinlookuppower $=100$

end

!!**************Calculates error for 5-Parameter Model $* * * * * * * * * * * * * * * * * * * * * "$

Procedure Difference(h\$,row,table,n\$:RMS)

if table $=1$ then

$i \$=$ 'row1'; $b \$==^{\prime} I 1 ' ; c \$=' \mathrm{~V} 1$ '; $d \$={ }^{\prime} \mathrm{P} 1^{\prime}$

endif

if table $=2$ then

$\mathrm{i} \$=$ 'row2'; $\mathrm{b} \$=^{\prime} \mathrm{I} 2$ '; $\mathrm{c} \$=^{\prime} \mathrm{V} 2^{\prime} ; \mathrm{d} \$={ }^{\prime} \mathrm{P} 2$ '

endif

if table $=4$ then

i $\$=$ 'row4'; b\$='I4'; c\$='V4'; $\$==^{\prime} \mathrm{P} 4$ '

endif

if table $=5$ then

$\mathrm{i} \$==^{\prime}$ row5'; $\mathrm{b} \$==^{\prime} \mathrm{I} 5^{\prime} ; \mathrm{c} \$==^{\prime} \mathrm{V} 5^{\prime} ; \mathrm{d} \$==^{\prime} \mathrm{P} 5^{\prime}$

endif

if table $=7$ then

i $\$=$ 'row7'; b\$='I7'; c $\$=' V 7$ '; $d \$=' P 7^{\prime}$

endif 


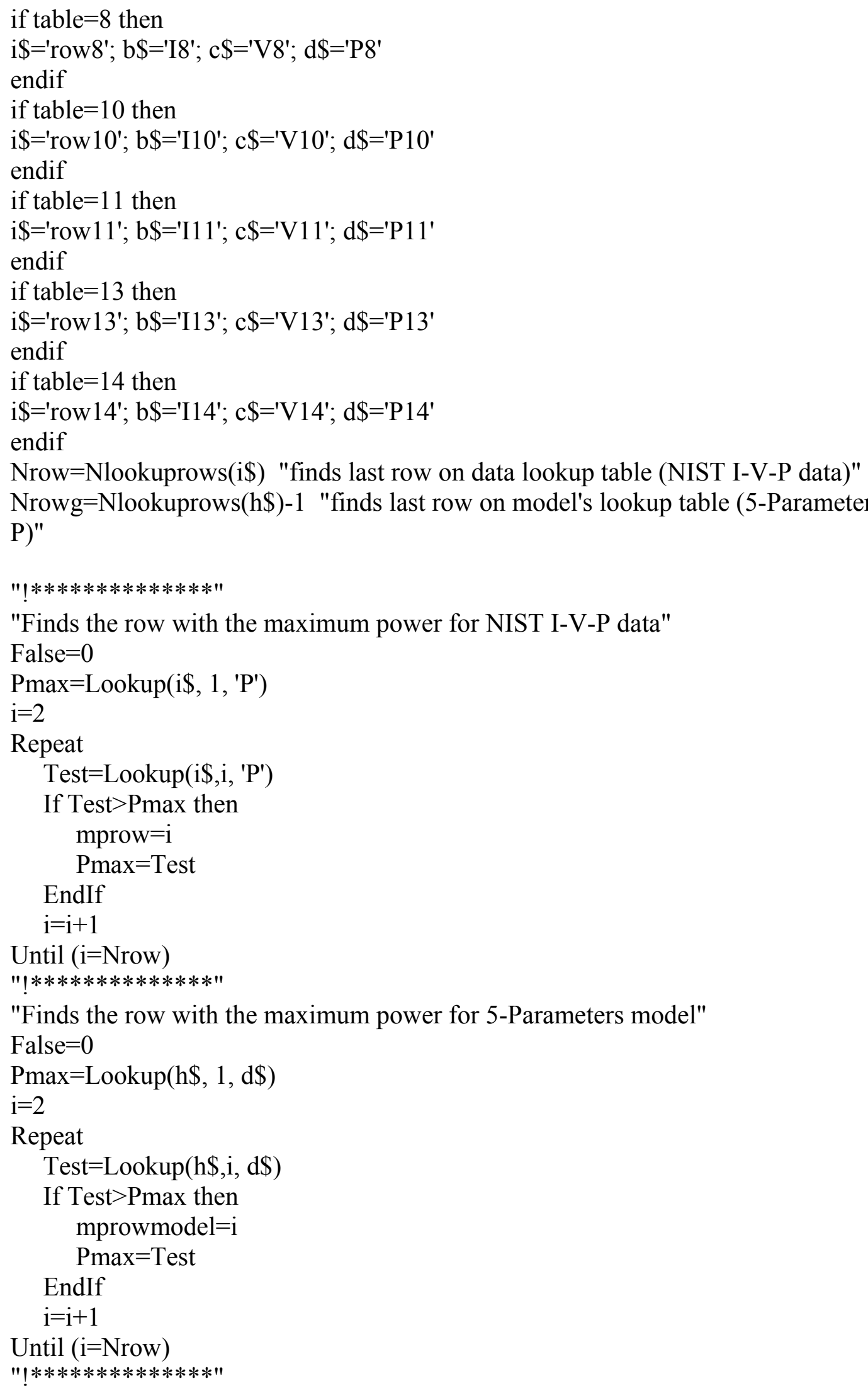

"Finds the row with the maximum power for NIST I-V-P data"

False $=0$

Pmax $=$ Lookup(i\$, 1, 'P')

$\mathrm{i}=2$

Repeat

Test=Lookup(i\$,i, 'P')

If Test $>$ Pmax then mprow $=\mathrm{i}$ Pmax $=$ Test

EndIf

$\mathrm{i}=\mathrm{i}+1$

Until ( $\mathrm{i}=$ Nrow)

"!**************"

"Finds the row with the maximum power for 5-Parameters model"

False $=0$

Pmax $=$ Lookup $(\mathrm{h} \$, 1, \mathrm{~d} \$)$

$\mathrm{i}=2$

Repeat

Test=Lookup $(\mathrm{h} \$, \mathrm{i}, \mathrm{d} \$)$

If Test>Pmax then mprowmodel $=\mathrm{i}$ $P \max =$ Test

\section{EndIf}

$\mathrm{i}=\mathrm{i}+1$

Until ( $\mathrm{i}=$ Nrow)

"! $* * * * * * * * * * * * * *$ " 
Totalvoltage $=$ lookup $(\mathrm{i} \$$, Nrow, 'V')

Maxpointvoltage $=$ lookup(i\$, mprow, 'V')

$\mathrm{N}=5$

Volt $[1]=0$

Volt[2] $=$ Totalvoltage/2

Volt[3] =Maxpointvoltage

Volt[4] $=($ Maxpointvoltage + Totalvoltage $) / 2$

Volt [5] $=$ Totalvoltage

Duplicate $\mathrm{t}=1, \mathrm{~N}$

Data[t] $=$ Interpolate $1\left(\mathrm{i} \$\right.$, $^{\prime}$ ', 'V', V $=$ Volt $\left.[\mathrm{t}]\right)$

Model $[\mathrm{t}]=$ Interpolate $1(\mathrm{~h} \$, \mathrm{~b} \$, \mathrm{c} \$, \mathrm{c} \$=\operatorname{Volt}[\mathrm{t}])$

END

$\operatorname{Diff}[\mathrm{t}]=(\text { Data[}[\mathrm{t}]-\text { Model }[\mathrm{t}])^{\wedge} 2$

Totaldiffs $=\operatorname{sum}($ Diff $[\mathrm{t}], \mathrm{t}=1, \mathrm{~N})$

RMS $=(\text { Totaldiffs } /(\mathrm{N}))^{\wedge} .5$

Percentage $=$ RMS/Data[1] $* 100$

MPdiff $=(\text { Diff }[3])^{\wedge} .5 /$ Data[3] $* 100$

lookup('RMS-Siemens',row, i\$)=RMS

lookup('Percentage-Siemens',row, $\mathbf{i}$ )=Percentage

lookup('Percentage-Siemens-MP',row, i $\$$ )=MPdiff

"copies important predicted (5-Parameters model) values to main lookup table"

V_ocmodel=lookup(h\$,nrowg,c\$)

V_mpmodel=lookup(h\$,mprowmodel,c\$)

i_mpmodel=lookup $(\mathrm{h} \$$, mprowmodel,b\$)

P_mpmodel=lookup $(\mathrm{h} \$$, mprowmodel, $\mathrm{d} \$$ )

lookup(n\$, table, 'i_sc')=Model[1]

lookup(n\$, table, 'i_mp')=i_mpmodel

lookup(n\$, table, ' $\overline{\mathrm{V}} \_\mathrm{mp}$ ') $=\overline{\mathrm{V}} \_$mpmodel

lookup(n\$, table, 'V_oc') $=$ V_ocmodel

lookup(n\$, table, 'P_mp')=P_mpmodel

"copies important measured values (NIST) to main lookup table"

Pmp_data=Data[3]*Volt[3]

lookup('measured-values-NIST', table, 'i_sc')=Data[1]

lookup('measured-values-NIST', table, 'i_mp')=Data[3]

lookup('measured-values-NIST', table, 'V_mp')=Volt[3]

lookup('measured-values-NIST', table, 'V_oc')=Volt[5]

lookup('measured-values-NIST', table, 'P_mp')=Pmp_data

"calculates percentage rms difference in important predicted 5-Parameters model values" isc_modeldiff $=(\operatorname{Diff}[1])^{\wedge} .5 / \operatorname{Data}[1]^{*} 100$

imp_modeldiff $=\left((\text { Data[3]-i_mpmodel })^{\wedge} 2\right)^{\wedge} .5 /$ Data[3]*100

Voc_modeldiff $=\left(\left(\text { Volt }[5]-V_{-} \text {ocmodel }\right)^{\wedge} 2\right)^{\wedge} .5 /$ Volt $[5]^{*} 100$

Vmp_modeldiff $=\left(\left(\operatorname{Volt}[3]-\bar{V}_{-} \text {mpmodel }\right)^{\wedge} 2\right)^{\wedge} .5 / \operatorname{Volt}[3]^{*} 100$

Pmp_modeldiff $=\left((\text { Pmp_data-P_mpmodel })^{\wedge} 2\right)^{\wedge} .5 /$ Pmp_data*100

"copies RMS results for important values in lookup table"

duplicate $\mathrm{a}=1,23$ 
$\operatorname{rowh}[\mathrm{a}]=\mathrm{a}+\mathrm{row}-1$

end

lookup('Percentage-main variables-Siemens',rowh[1],i\$)=isc_modeldiff

lookup('Percentage-main variables-Siemens',rowh[7],i\$)=imp_modeldiff

lookup('Percentage-main variables-Siemens',rowh[13],i\$)=Voc_modeldiff

lookup('Percentage-main variables-Siemens',rowh[18],i\$)=Vmp_modeldiff

lookup('Percentage-main variables-Siemens',rowh[23],\$ $)=$ Pmp_modeldiff

END

$" ! * * * * * * * * * * * * * * * * * *$ FUNCTIONS AND PROCEDURES END $* * * * * * * * * * * * * * * * * "$

"!*******************************MODDLS START***************************

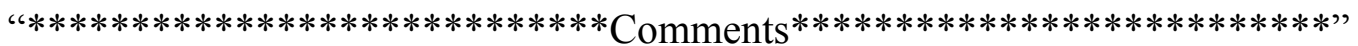

"How to use this program:"

"!To run the 5-Parameters Model:"

"1. To calculate all the Parameters (a, I_L, I_o, R_s, R_sh) for the different weather conditions (T_c, G_eff), the following"

"Blocks are needed: A, B (Block B has to be manually removed from the 'comment mode'). Make sure that $b \$$ is set "

"to the lookup table where the weather data is recorded and choose the line with the name of the lookup table where to record the"

"parameters (a\$, c\$, errorow). Select the line with: runprog $\$=' P a r a m e t e r s-S E L '$. Run the program by pressing F2 and"

"varying the number of the ROW. After finishing, comment out Block B or the rest of the program won't work."

"2. To calculate the I-V-P curves the following Blocks are needed: A, C. Select the line with the name of the lookup"

"table to use (a\$). If the lookup table 'parameters-SEL-4pars' is selected the last term in the equations in Block $\mathrm{C}$ "

"((V1+I1*R_s1)/R_sh1) needs to be blocked for each line because R_sh is assumed to be infinite. Select the line with runprog $\$=' \mathrm{I}-\mathrm{V}-\mathrm{P}-\mathrm{SEL} "$

"To run the program go to the parametric table whose name is equal to that selected in c\$ and run it, varying the "

"voltage column (V) until the current (I) measured is equal or as close to zero as possible. The program will automatically"

"copy these results in a lookup table with the same name (c\$). Remember to remove the comments from the last term of"

"the equations if they were commented to avoid errors in following predictions."

"3. To calculate the errors in the predictions vs. the measured data by NIST, the

following Blocks are needed: A, D. Seclect"

"the line with the respective reference being used (a\$, c\$, errorow), select the line with: runprog $\$=$ 'Error-calculation-SEL', vary the number"

"of the row and run the program by pressing F2. The results are recorded in the lookup tables: Percentage-Siemens," 
"Percentage-Siemens-MP, RMS-Siemens, Percentage-main variables-Siemens, measured-values-NIST."

"!To run King's Model:"

"1. If not provided by manufacturer, calculate Ixo and Ixxo by plotting the reference values provided by the manufacturer"

"(Voc, Vmp, Imp, Isc) and interpolating in the plot to find the currents corresponding to $\mathrm{V}=0.5 \mathrm{Voc}$ and $\mathrm{V}=0.5(\mathrm{Voc}+\mathrm{Vmp})$. This can"

"be done by using the lookup table 'SRC-ref' and plotting these values. Manually, go to the plot and determine the current values."

"2. Calculate $\mathrm{C} 0, \mathrm{C} 1, \mathrm{C} 2, \mathrm{C} 3, \mathrm{C} 4, \mathrm{C} 5, \mathrm{C} 6, \mathrm{C} 7$ if not provided. For this case, $\mathrm{C} 4-\mathrm{C} 7$ were not provided, so they were calculated"

"using this program. To get the values the data in the first row was used. The following Blocks are needed: A, E, F, G."

"Select a $\$=$ 'parameters-King', set row=1, select the line with: runprog $\$=$ 'Parameters-

King'; run\$='Find Parameters'; runx\$='Find coefficients-King'"

"make sure that i\$ is on and C4, C5, C6, and C7 in Block E are set as 'comments'. Run the program by pressing F2. Copy the results in Block E"

"and remove the 'comment mode'."

"3. To calculate the parameters, together with the Rs and $z$ values that minimize the error in the prediction, the following Blocks"

"are used: A, E, F, H. Select a $\$=$ 'parameters-King', the line with: runprog $\$=$ 'ParametersKing'; run $\$=$ 'Find Parameters'; runx $\$=$ 'Find-parameters-King'"

"Run the program by varying the row number and using the MIN/MAX function (under the 'Calculate' tab). Select 'minimize: E_rms"

"and set as independent variables Rs and $\mathrm{z}$. The program will automatically copy the results in the lookup table 'parameters-King'."

"4. To calculate the I-V-P curve select a $\$=$ parameters-King', the line with: runprog $\$=$ 'Calculate I-V-P curves'; run $\$=$ 'I-V-P curves'; runx $\$='$ King Model'"

"The following Blocks are needed: A, I. Use together with the parametric table 'King-IV-\#' whose ending number corresponds"

"to the row number being used. Vary the voltage until the currents obtained are as close to zero as possible. The program automatically copies the"

"results to the lookup table 'I-V-King'."

"5. To calculate the error in the predictions the following Blocks are used: A, J. Select a $\$=$ 'parameters-King', the line with:"

"runprog $\$=$ 'Error-calculation-KING'; run $\$=$ 'Error'; runx $\$='$ King'. To run the program vary the number of the row and press F2."

"The results are recorded in the lookup tables: Percentage-Siemens, Percentage-SiemensMP, RMS-Siemens,"

"Percentage-main variables-Siemens." 
“!*********************** Legend of tables $* * * * * * * * * * * * * * * * * * * * * * *$ "

"!Legend of Lookup Tables"

"K_taualpha_2: incidence angle modifier values for the 5-parameters model"

"Siemens-data: weather data"

"parameters-SEL-4pars: used for the 5-parameters model when Rsh is assumed infinite;

parameters are recorded here"

"parameters-SEL-5pars: used for the 5-parameters model when Rsh is assumed finite;

parameters are recorded here"

"parameters-SEL-2curves: used for the 5-parameters model when reference values are

obtained from 2 curves provided by manufacturer; parameters are recorded here"

"parameters-King: used for King's model; parameters are recorded here"

"row1, row2, row4, .... row14: NIST I-V-P data"

"SRC-SEL-4pars: I-V-P values predicted with 5-parameters model (using infinite Rsh) is recorded"

"SRC-SEL-5pars: I-V-P values predicted with 5-parameters model (using finite Rsh) is recorded"

"SRC-SEL-2curves: I-V-P values predicted with reference values obtained from 2 curves provided by manufacturer is recorded"

"SRC-ref: Reference values provided by manufacturer at SRC"

"I-V-King: I-V-P values predicted with King's model is recorded"

"Percentage-Siemens: errors obtained for different predictions using 5 points, which correspond to $\mathrm{V}=0, \mathrm{~V}=0.5 \mathrm{Voc}, \mathrm{V}=\mathrm{Vmp}, \mathrm{V}=0.5$ (Voc $+\mathrm{Vmp}$ ), $\mathrm{V}=\mathrm{Voc} "$

"Percentage-Siemens-MP: errors obtained for different predictions using only the maximum power point"

"RMS-Siemens: RMS error values obtained for the different predictions"

"Percentage-main variables-Siemens: errors obtained for the different predictions for specific information (rows 1-5: Isc, 7-11:Imp, 13-16:Voc, 18-21:Vmp, 23-27:Pmp)"

"measured-values-NIST: values measured by NIST for specific information (Isc, Imp, Voc, Vmp, Pmp)"

"!Legend of Parametric Tables"

"SRC-SEL-4pars: used to calculate I-V-P for 5-parameters model (using infinite Rsh)"

"SRC-SEL-5pars: used to calculate I-V-P for 5-parameters model (using finite Rsh)"

"SRC-SEL-2curves: used to calculate I-V-P for 5-parameters model (using reference values obtained from 2 curves provided by manufacturer)"

"King-I-V-1....King-I-V14: used to calculate I-V-P for King's model"

"!Legend of Plots"

"For all plots:"

"The data provided by NIST is shown in black under the title: measured data"

"The plots predicted using King's model is shown in blue"

"The plots predicted using the TRW equation is shown in green"

"1-1...14-1: plots predicted using the 5-parameters model, using infinite Rsh"

"1-2...14-2: plots predicted using the 5-parameters model, using finite Rsh"

"1-3...14-3: plots predicted using the 5-parameters model, using the reference values

obtained from the 2 curves provided by manufacturer" 
“**************************) Programs $* * * * * * * * * * * * * * * * * * * * * * * * * * * * * * \cdots$

"!*****BLOCK A******for both models (5-Parameters and King's)********"

$\mathrm{b} \$=$ 'Siemens-data' "always on, name of lookup table where weather data is recorded, always on"

$\mathrm{a} \$=$ 'parameters-SEL-4pars'; $\mathrm{c} \$=$ ='SRC-SEL-4pars'; errorow=1 "select complete line if using the 4-Parameters (R_sh is infinite)"

$\{\mathrm{a} \$=$ 'parameters-SEL-5pars'; $\mathrm{c} \$=$ 'SRC-SEL-5pars'; errorow=2\} "select complete line if using the 5-Parameters ( $\mathrm{R} \_$sh is finite)"

$\{\mathrm{a} \$=$ 'parameters-SEL-2curves'; $\mathrm{c} \$=$ 'SRC-SEL-2curves'; errorow=3 $\}$ "select complete line if using the reference values obtained for the 2-curve (5-Pars)"

$\{\mathrm{a} \$=$ 'parameters-King'\} "select for King's Model"

$\mathrm{i} \$=$ Concat $\$($ 'row',string $\$(\mathrm{row})$ ) "always on, used for copying data from parametric

to lookup table and error calculation"

row $=14$ "can be $1,2,4,5,7,8,10,11,13,14$, always on, number of row in lookup table being used"

"!Which sub-program to run"

"!5 Parameters Model"

\{runprog $\$=' P a r a m e t e r s-S E L ' ;$ run $\$=' F i n d$ Parameters'; runx $\$=$ '5ParametersModel'\} "Finds parameters for 5-Parameter Model"

\{runprog\$='I-V-P-SEL'; run\$='Find I-V-P curves'; runx\$='5ParametersModel'\} "Finds IV-P curve for 5-Parameter Model"

runprog $\$=$ Error-calculation-SEL'; run $\$=$ 'Calculate error'; runx $\$=$ '5ParametersModel'

"Finds error for 5-Parameter Model predictions"

"!King's Model"

\{runprog $\$=$ 'Parameters-King'; run $\$=$ Find Parameters'; runx $\$=' F i n d$ coefficients-King'\}

"Finds coefficients for King's Model"

\{runprog $\$='$ Parameters-King'; run $\$=$ 'Find Parameters'; runx $\$=$ 'Find-parameters-King'\}

"Finds parameters for King's Model and Rs and z values that minimize error for King's

Model, copies results in lookup table"

\{runprog $\$=' C a l c u l a t e ~ I-V-P$ curves'; run $\$=' I-V-P$ curves'; runx $\$=' K i n g$ Model'\}

"Calculates I-V-P curve for King's Model"

\{runprog $\$=$ 'Error-calculation-KING';run\$='Error'; runx\$='King' \} "Finds error for

King's Model predictions"

\$if run\$='Find Parameters'

"Calculating incidence angle and zenith angle for both models"

Lat $=39+13 / 60$

L_loc $=77+21 / 60$

L st $=75$

slope $=90$

SurfAzAng $=0$

n_day_s=nDay_(month_s, day_s)

Time_s=lookup(b\$,row,'Time_clock')

Month_s=lookup(b\$,row,'Month')

Day_s=lookup(b\$,row,'Day') 
DELTAtime_s=EqnTime_(n_day_s)

Time_solar_s-Time_s $=\left(4[\mathrm{~min} / \mathrm{deg}] *\left(\mathrm{~L} \_\mathrm{st}-\mathrm{L} \_\right.\right.$loc $)+$DELTAtime_s $) *$ Convert $(\mathrm{min}, \mathrm{hr})$

HrAng_s $=15[\mathrm{deg} / \mathrm{hr}]^{*}(12[\mathrm{hr}]-$ Time_solar_s $)$

CosTheta_s=cosIncAng_(Lat, n_day_s, HrAng_s, Slope, SurfAzAng)

Theta_ $\mathrm{s}=\overline{\mathrm{ArcC}} \mathrm{Cos}(\operatorname{Cos}$ Theta $\mathrm{s})$

R_beam=R_beam_(Lat,n_day_s,HrAng_s, Slope, SurfAzAng)

CosZenith_s=CosZenAng_(Lat, n_day_s, HrAng_s)

Zenith $\mathrm{s}=\mathrm{ArcCos}(\operatorname{Cos} Z$ enith $\mathrm{s})$

AM_s $=1 /\left(\operatorname{cosZenith\_ s} \mathrm{s}+0.5057^{*}(96.080-\text { Zenith_s })^{\wedge}(-1.634)\right)$

M_ama_s $=a 0+a 1 * A M \_s+a 2 * A M \_s \wedge 2+a 3 * A M \_s \wedge 3+a 4 * A M \_s \wedge 4$

Sendif

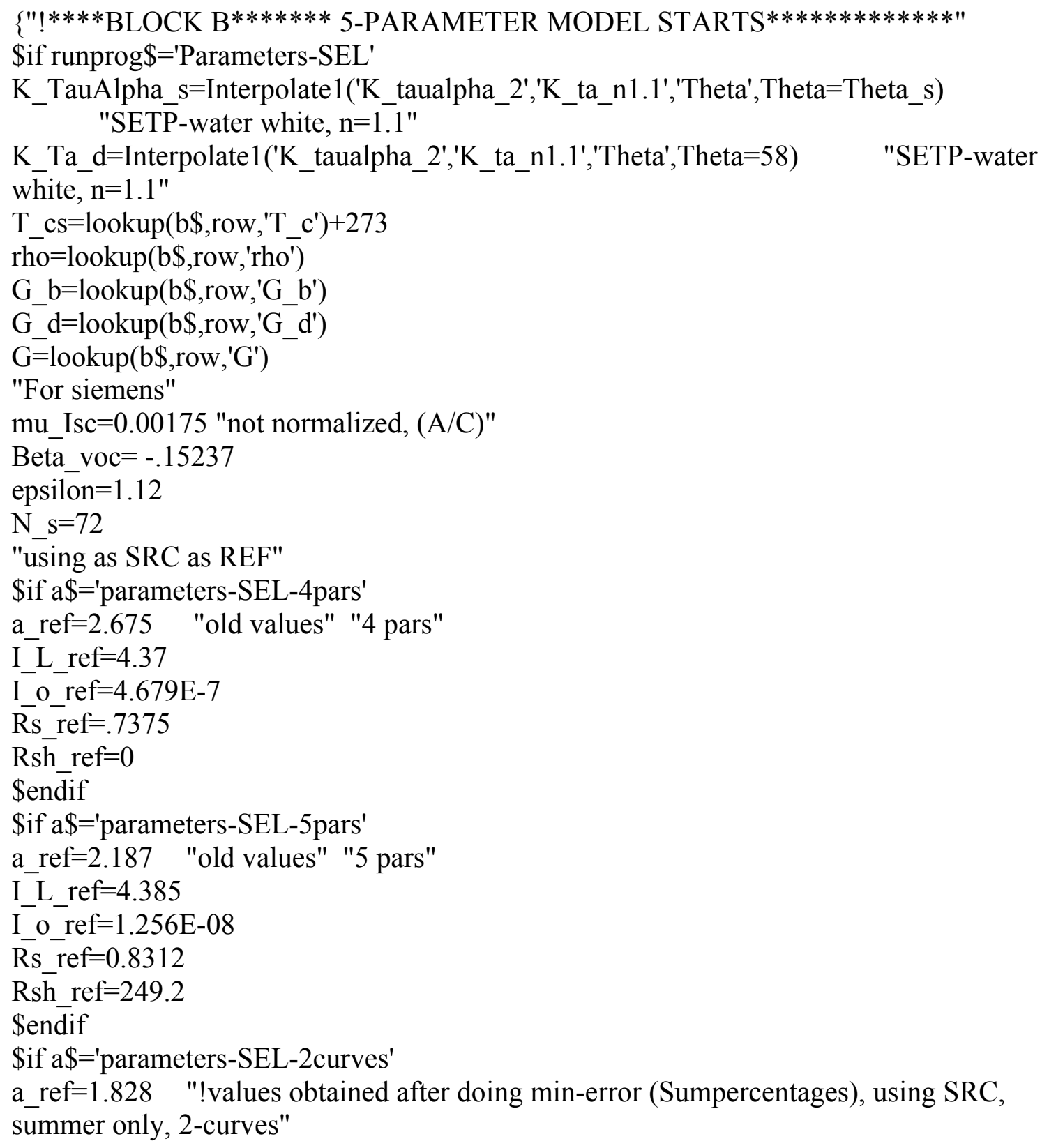




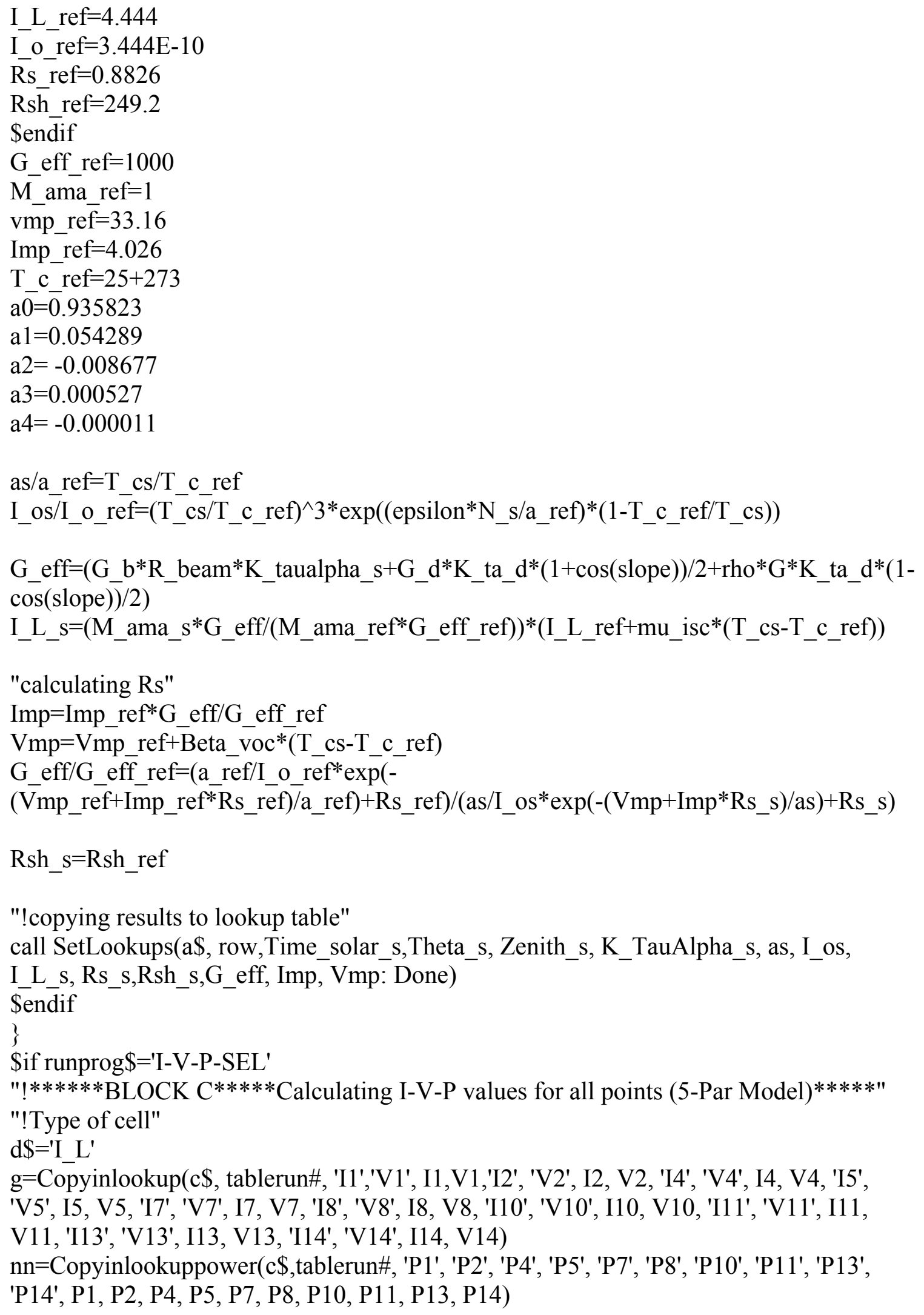




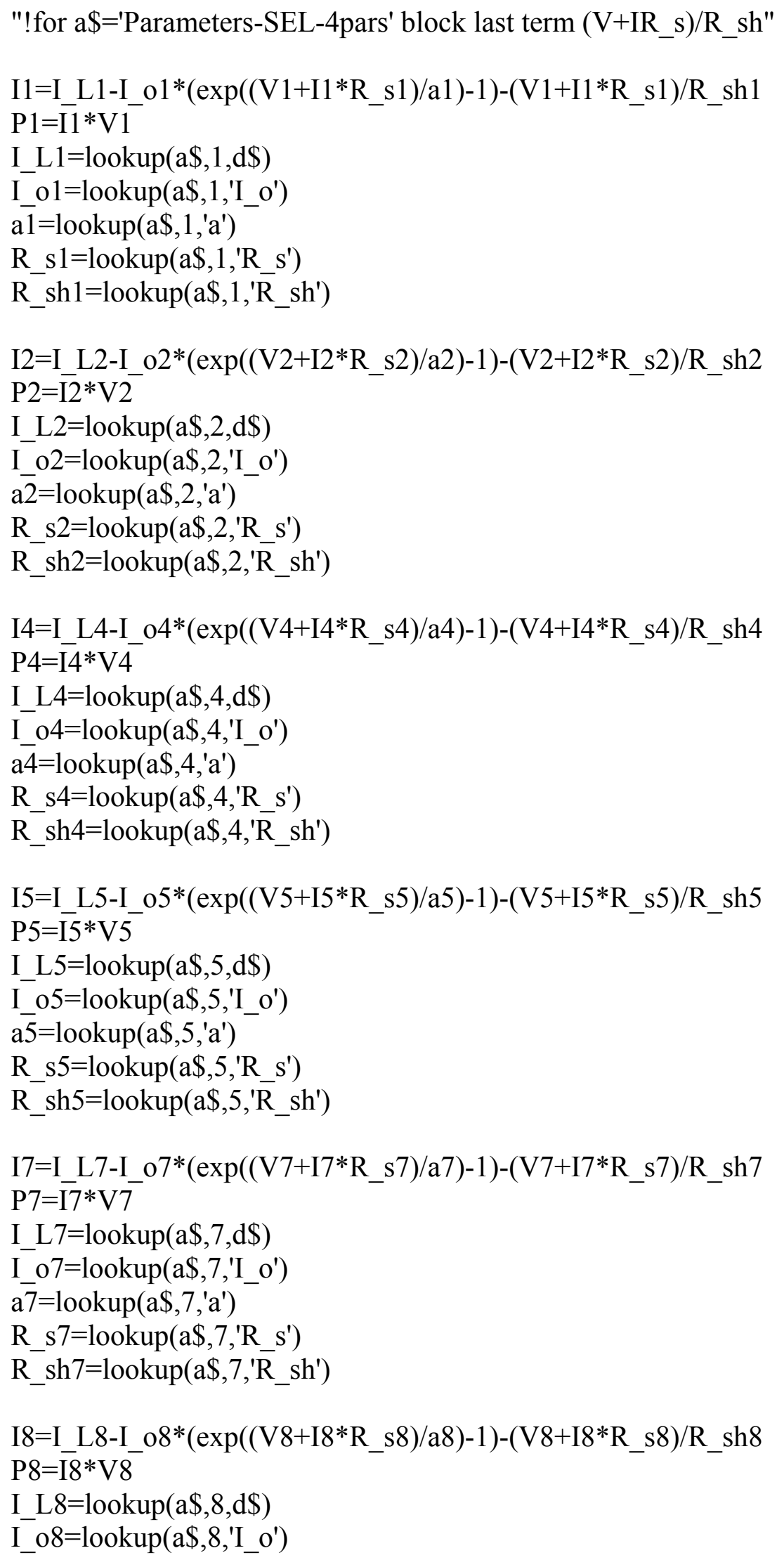




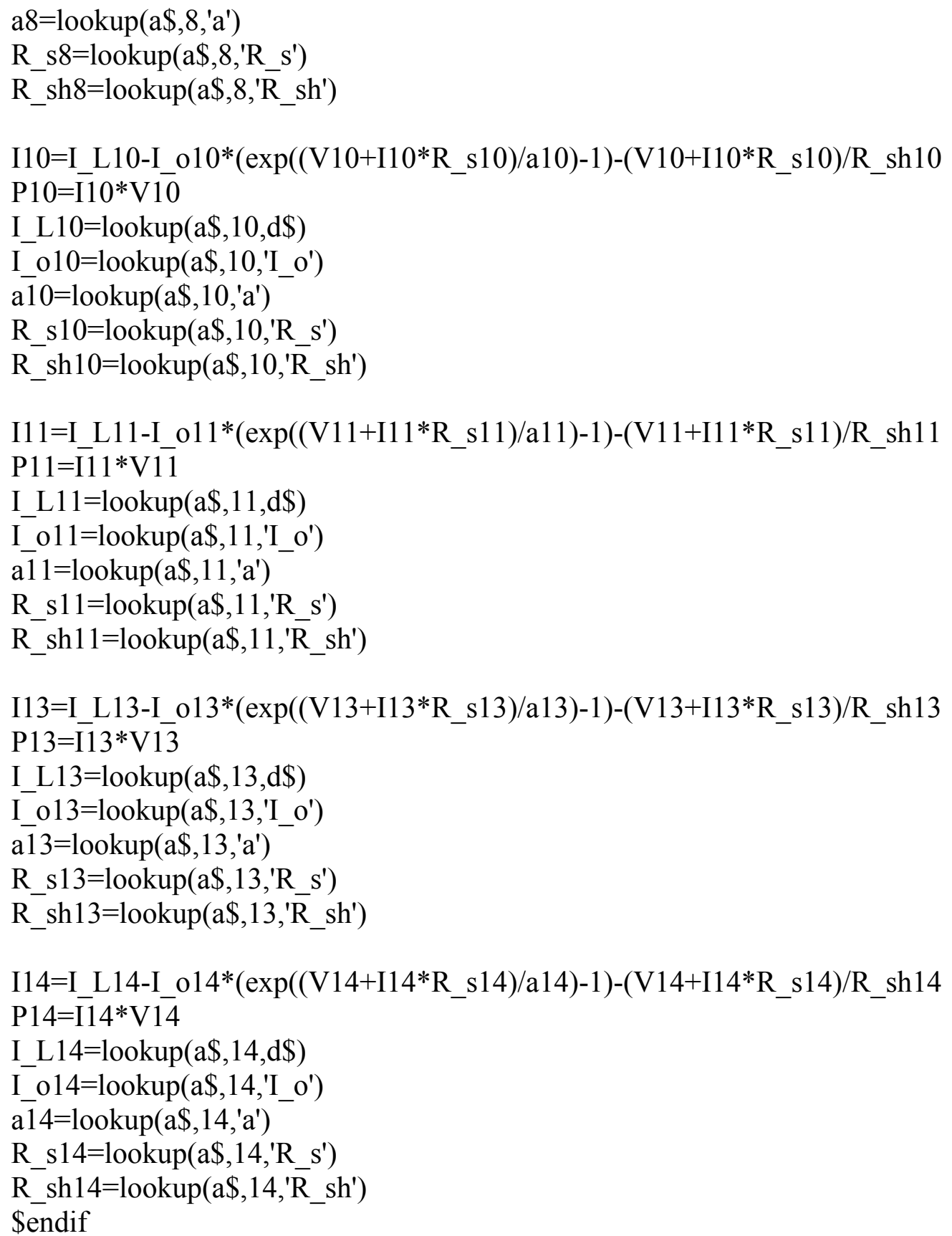


$\$$ if runprog $\$='$ Parameters-King'

!!******BLOCK E*******Values used from NIST data in KING's model $* * * * * * * * * * * "$

I $\mathrm{sc} 0=4.37$

i_ $\mathrm{mp} 0=3.96$

$\overline{\mathrm{V}}$ oc $0=42.93$

V-mp $0=33.68$

P_mp0 $=133.40$

I_x $0=4.275$ "approximated from curve"

I_xx $0=2.063$ "approximated from curve"

alpha_isc $=0.000401$ "normalized! (1/C)"

alpha_imp $=-0.000390$ "normalized! (1/C)"

Beta $\mathrm{Voc}=-0.15237$

Beta_Vmp $=-0.15358$

$\mathrm{a} 0=0.935823$

$\mathrm{a} 1=0.054289$

$\mathrm{a} 2=-0.008677$

a3 $=0.000527$

$\mathrm{a} 4=-0.000011$

$\mathrm{b} 0=1.000341$

$\mathrm{b} 1=-0.005557$

$\mathrm{b} 2=6.553 \mathrm{E}-4$

$\mathrm{b} 3=-2.73 \mathrm{E}-5$

$\mathrm{b} 4=4.641 \mathrm{E}-7$

$\mathrm{b} 5=-2.806 \mathrm{E}-9$

$\mathrm{C} 0=0.9995$

$\mathrm{C} 1=0.0026$

$\mathrm{C} 2=-0.5385$

$\mathrm{C} 3=-21.4078$

"**block when unknown and being calculated in step $1 * * "$

$\mathrm{C} 4=1.016$ "calculated from curve fitting in step 1"

$\mathrm{C} 5=-0.01568$ "calculated from curve fitting in step 1"

C6 $=1.998$ "calculated from curve fitting in step 1"

$\mathrm{C} 7=-.9983$ "calculated from curve fitting in step 1"

$" * * * * * * * * * * * * * * * * * * * * * * * * * * * * * * * * * * * * * * * * * * * * * * * * * * * * * * * * * * * * * * * * * "$

$\mathrm{n}=1.026$

$\mathrm{Ns}=72$

$\mathrm{SF}=1$

f_d $=1$

$\mathrm{k}=1.38066 \mathrm{E}-23[\mathrm{~J} / \mathrm{K}]$

$\mathrm{q}=1.60218 \mathrm{E}-19$ [Coulomb]

T_o $=25[\mathrm{C}]$

T_c=lookup $(\mathrm{b} \$$,row,'T_c' $)\{[\mathrm{C}]\}$

E_o $=1000\left[\mathrm{~W} / \mathrm{m}^{\wedge} 2\right]$

E_d $=\operatorname{lookup}\left(\mathrm{b} \$\right.$, row,'G_d') $\left\{\left[\mathrm{W} / \mathrm{m}^{\wedge} 2\right]\right\}$

E_bn=lookup(b\$,row, 'G_b_n') $\left\{\left[\mathrm{W} / \mathrm{m}^{\wedge} 2\right]\right\}$

AOI $=$ Theta_s 
AM_a $=A M \_s$

"! ********BLOCK F*********King's Model************"

"Air mass modifier"

f1AM_a $=a 0+a 1 * A M \_a+a 2 * A M \_a^{\wedge} 2+a 3 * A M \_a^{\wedge} 3+a 4 * A M \_a^{\wedge} 4$

"Incidence angle modifier"

$\mathrm{f} 2 \mathrm{AOI}=\mathrm{b} 0+\mathrm{b} 1 * \mathrm{AOI}+\mathrm{b} 2 * \mathrm{AOI}^{\wedge} 2+\mathrm{b} 3 * \mathrm{AOI}^{\wedge} 3+\mathrm{b} 4 * \mathrm{AOI}^{\wedge} 4+\mathrm{b} 5 * \mathrm{AOI}^{\wedge} 5$

"Dimensionless Effective Irradiance"

$E \_e=f 1 A M \_a *\left(\left(E \_b * f 2 A O I+f \_d * E \_d\right) / E \_o\right) * S F$

$\mathrm{E} \_\mathrm{b}=\mathrm{E} \_\mathrm{bn} * \cos (\mathrm{AOI})$

\{"Five Important Points being predicted on the I-V curve"

$\mathrm{i}=\mathrm{i} \_\mathrm{sc} @ \mathrm{~V}=0$

i=i_x@V=0.5V_oc

$\mathrm{i}=\mathrm{i} \mathrm{mp} @ \mathrm{~V}=\mathrm{V} \mathrm{mp}$

$\mathrm{i}=\mathrm{i} \_\mathrm{xx} @ \mathrm{~V}=0 . \overline{5}\left(\mathrm{~V} \_\mathrm{mp}+\mathrm{V} \_\mathrm{oc}\right)$

$\mathrm{i}=0 @ \mathrm{~V}=\mathrm{V} \_$oc $\}$

I $s c=I \_s c 0 * f 1 A M \_a *\left(\left(E \_b * f 2 A O I+f \_d * E \_d\right) / E \_o\right) *\left(1+a l p h a \_I s c *\left(T \_c-T \_o\right)\right)$

E_e $=I \_s c /\left(I \_s c o *\left(1+a l p h a \_I s c *\left(T \_c-T \_o\right)\right)\right)$

$\mathrm{I}$ mp $=\overline{\mathrm{I}} \_\mathrm{mp} 0 *\left(\mathrm{C} 0 * \mathrm{E} \_\mathrm{e}+\mathrm{C} \overline{1} * \mathrm{E} \_\mathrm{e}^{\wedge} \overline{2}\right) *\left(1+\mathrm{alpha}\right.$ imp* $\left.\left(\mathrm{T} \_\mathrm{c}-\mathrm{T} \_\mathrm{o}\right)\right)$

dT_c $=\mathrm{n}^{*} \mathrm{k} *\left(\mathrm{~T} \_\mathrm{c}+273.15\right) / \mathrm{q}$

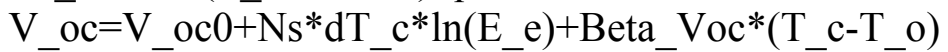

$\mathrm{V} \_\mathrm{mp}=\overline{\mathrm{V}} \mathrm{mp} 0+\mathrm{C} 2 * \overline{\mathrm{Ns}} * \mathrm{dT} \_\mathrm{c} * \ln \left(\mathrm{E} \_\mathrm{e}\right) \overline{+} \mathrm{C} 3 * \mathrm{Ns} *\left(\mathrm{dT} \_\mathrm{c}^{*} \ln \left(\mathrm{E} \_\mathrm{e}\right)\right)^{\wedge} 2+\mathrm{Beta} \mathrm{Vmp}^{*}\left(\mathrm{~T} \_\mathrm{c}-\right.$

T_o)

P_mp=I_mp*V_mp

I_x $=I \_x 0^{*}\left(C 4 * \bar{E} \_\mathrm{e}+\mathrm{C} 5 * \mathrm{E} \_\mathrm{e}^{\wedge} 2\right) *\left(1+((\right.$ alpha_Isc + alpha_Imp $\left.) / 2) *\left(T \_c-T \_o\right)\right)$

I_xx $=\bar{I} \_\mathrm{xx} 0 *\left(\mathrm{C} 6^{*} \mathrm{E} \_\mathrm{e}+\mathrm{C} 7 * \mathrm{E} \_\mathrm{e}^{\wedge} 2\right)^{*}\left(1+\mathrm{alpha} \mathrm{Imp} *\left(\mathrm{~T} \_\mathrm{c}-\mathrm{T} \_\mathrm{o}\right)\right)$

Sendif

\$if runx $\$=$ 'Find coefficients-King'

"****************BLOCK G** Finding C4-C7****************************"

"used only to calculate C4, C5, C6, C7 for each cell type (technology)"

"Ran with row $=1 "$

$\mathrm{C} 4+\mathrm{C} 5=1$

$\mathrm{C} 6+\mathrm{C} 7=1$

call i_x_xx_values(i\$:I_x_meas, I_xx_meas, Nrow, mprow) "sets the values for i_x_meas and i_xx_meas equal to the data obtained by NIST in order to calculate C4-C7"

i $\mathrm{x}=\mathrm{i} \mathrm{x}$ meas

i_ $\mathrm{xx}=\mathrm{i}$. Xx_meas

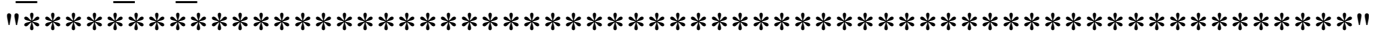

Sendif

\$if runx $\$=$ 'Find-parameters-King' 
"!********BLOCK $\mathrm{H}^{* * * *}$ used to calculate the ideal $\mathrm{Rs}, \mathrm{z}$ that minimizes the error between NIST and King's model and copy all results in lookup table****"

"Use with the MIN/MAX function, minimize E_rms and independent variables Rs, $\mathrm{z}$.

Vary the row \#, one at a time"

$\mathrm{k} 1=\left(\mathrm{V} \_\mathrm{mp} / \mathrm{V} \_\right.$oc-1 $) / \ln \left(1-\mathrm{I} \_\mathrm{mp} / \mathrm{I} \_\mathrm{sc}\right)$

$\mathrm{k} 2=\left(1-\overline{\mathrm{I}} \_\mathrm{mp} / \mathrm{I} \_\mathrm{sc}\right) * \exp \left(-\mathrm{V} \_\mathrm{mp} /\left(\overline{\mathrm{k}} 1 * \mathrm{~V} \_\right.\right.$oc $\left.)\right)$

I_L=V_oc/R_sh+I_o* $\left(\exp \left(\mathrm{V} \_\right.\right.$oc/z $\left.)-1\right)$

I_o $=\left(I \_s c * R \_s h+I \_s c * R \_s-V \_o c\right) / R \_s h /\left(\exp \left(V \_o c / z\right)-\exp \left(I \_s c * R \_s / z\right)\right)$

$\bar{R} \_s h=\left(\left(I \_s c^{*} R \_s-\bar{V} \_o c\right) *\left(\exp \left(V \_o c / z\right)-\exp \left(\left(V \_m p+I \_m p * \bar{R} \_s\right) / z\right)\right)+\left(V \_o c-V \_m p-\right.\right.$

I_mp*R_s $\left.)^{*}\left(\exp \left(\mathrm{V} \_\mathrm{oc} / \mathrm{z}\right)-\exp \left(\mathrm{I} \_\mathrm{sc} * \mathrm{R} \_\mathrm{s} / \mathrm{z}\right)\right)\right) /\left(\mathrm{I} \_\mathrm{mp} *\left(\exp \left(\mathrm{V} \_\mathrm{oc} / \mathrm{z}\right)-\right.\right.$

$\left.\left.\exp \left(I \_s c * R \_s / z\right)\right)+I \_s c *\left(\exp \left(\left(V \_m p+I \_m p * R \_s\right) / z\right)-\exp \left(V \_o c / z\right)\right)\right)$

I_TRW1 $=\mathrm{I} \_\mathrm{sc} *\left(1-\mathrm{k} 2 *\left(\exp \left(\mathrm{V} 1 /\left(\mathrm{k} 1 * \mathrm{~V} \_\mathrm{oc}\right)\right)-1\right)\right)$

$\mathrm{I} \overline{1}=\mathrm{I} \_\mathrm{L}-\mathrm{I} \_\mathrm{O}^{*}\left(\exp \left(\left(\mathrm{V} 1+\mathrm{I} \_\mathrm{TRW} 1 * \mathrm{R} \_\mathrm{s}\right) / \mathrm{z}\right)-1\right)-\left(\mathrm{V} 1+\mathrm{I} \_\mathrm{TRW} 1 * \mathrm{R} \_\mathrm{s}\right) / \mathrm{R} \_\mathrm{sh}$

$\mathrm{I} 1=\mathrm{I}+\mathrm{x} \_$calc

$\mathrm{V} 1=\overline{\mathrm{V}} \overline{\mathrm{x}}$

$\mathrm{V}_{-} \mathrm{x}=0.5^{*} \mathrm{~V}_{-}$oc

I_TRW2 $=$ I_sc $*\left(1-\mathrm{k} 2 *\left(\exp \left(\mathrm{V} 2 /\left(\mathrm{k} 1 * \mathrm{~V} \_\right.\right.\right.\right.$oc $\left.\left.\left.)\right)-1\right)\right)$

$\mathrm{I} \overline{2}=\mathrm{I} \_$L-I_o $\left(\exp \left(\left(\mathrm{V} 2+\mathrm{I} \_\mathrm{TRW} 2 * \mathrm{R} \_\mathrm{s}\right) / \mathrm{z}\right)-1\right)-\left(\mathrm{V} 2+\mathrm{I} \_\mathrm{TRW} 2 * \mathrm{R} \_\mathrm{s}\right) / \mathrm{R} \_\mathrm{sh}$

I2 $=$ I_xx_calc

$\mathrm{V} 2=\mathrm{V}_{-} \mathrm{xx}$

$\mathrm{V} \_\mathrm{xx}=0.5 *\left(\mathrm{~V} \_\mathrm{mp}+\mathrm{V} \_\mathrm{oc}\right)$

i_x_meas $=$ I_x

i_xx_meas $=$ I_xx

"Room mean square error"

E_rms $=\left(\left(\left(I \_x \_m e a s-I \_x \_c a l c\right) \wedge 2+\left(I \_x x \_m e a s-I \_x x \_c a l c\right)^{\wedge} 2\right) / 2\right)^{\wedge} .5$

call SetKing(a\$, row, Time_solar_s, Theta_s, Zenith_s, f2AOI, f1AM_a, I_sc, I_mp, V mp, V oc, E e, P mp, $\overline{\mathrm{dT}}$ c, I x, I xx, R s, z, E rms: Done)

"!

Sendif

Sif runprog $\$=$ 'Calculate I-V-P curves'

"!******BLOCK I********Calculating I-V-P for all points, KING***************"

"Run together with Parametric Table. Make sure that Parametric Table number coincides with row number set in Block A"

King\$='I-V-King' "name of lookup table where to copy I-V-P results"

rowxnum=rowx(row) "determines number of row where to copy the results"

$\mathrm{g}=$ CopyinlookupKing $(\mathrm{King} \$$, tablerun\#, rowxnum, V_K, I_K, P_K, I_TRW, P_TRW)

"copies results to I-V-P lookup table"

I_TRW $=\mathrm{I} \_\mathrm{sc} \_1 *\left(1-\mathrm{k} 2 \_1 *\left(\exp \left(\mathrm{V} \_\mathrm{K} /\left(\mathrm{k} 1 \_1 * \mathrm{~V} \_\mathrm{oc} \_1\right)\right)-1\right)\right)$

$\mathrm{k} 1 \_1=\left(\mathrm{V} \_\mathrm{mp} \_1 / \mathrm{V} \_\right.$oc $\left.\_1-1\right) / \ln \left(1-\mathrm{I} \_\mathrm{mp} \_1 / \mathrm{I} \_\mathrm{sc} \_1\right)$

$\mathrm{k} 2 \_1=\left(1-\overline{\mathrm{I}} \_\mathrm{mp} \_1 / \mathrm{I} \_\mathrm{sc} \_1\right)^{*} \exp \left(-\mathrm{V} \_\mathrm{mp} \_1 /\left(\overline{\mathrm{k}} 1 \_\overline{1} * \mathrm{~V} \_\right.\right.$oc_1 $\left.)\right)$ 
P_TRW=I_TRW*V_K

I_K=I_L_1-I_o_1*(exp $\left.\left(\left(\mathrm{V} \_\mathrm{K}+\mathrm{I} \_T R W^{*} \mathrm{R} \_\mathrm{s} \_1\right) / \mathrm{z} \_1\right)-1\right)-\left(\mathrm{V} \_\mathrm{K}+\mathrm{I}\right.$-TRW $\left.* \mathrm{R} \_\mathrm{s} \_1\right) / \mathrm{R} \_\mathrm{sh} 1$

I_L_1 $=\mathrm{V} \_$oc $1 / \mathrm{R} \_s h \_1+\mathrm{I} \_\mathrm{o} \_1 *\left(\exp \left(\mathrm{V} \_\mathrm{oc}-\overline{1} / \mathrm{z} \_1\right)-1\right)$

I_o_1 $(I$ _sc_1 $*$ R_sh_1+I_sc_1*R_s_1-V_oc_1 $) / R \_s h \_1 /\left(\exp \left(V_{-}\right.\right.$oc_1/z_1)-

$\exp \left(\right.$ I_sc_1*R_s_ $\left.\left.1 / z_{-} 1\right)\right)$

R_sh_1=((I_sc_1*R_s_1-V_oc_1 $) *\left(\exp \left(\mathrm{V} \_\right.\right.$oc_1/z_1 $)-$

$\left.\left.\exp \left(\overline{\mathrm{V}} \mathrm{mp} \_1+\overline{\mathrm{I}} \mathrm{mp} \_1 * \mathrm{R} \_\mathrm{s}-1\right) / \mathrm{z} 1\right)\right)+\left(\mathrm{V} \_\mathrm{oc} \_\overline{1}-\mathrm{V} \_\mathrm{mp} \_1-\right.$

I_mp_1*R_s_1 $)^{*}\left(\exp \left(V_{-}\right.\right.$oc $\left._{-} 1 / z_{-}-1\right)-$

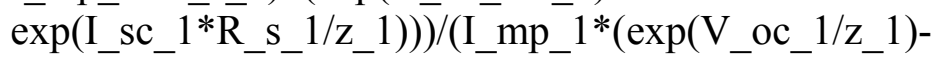

$\left.\exp \left(I \_s c \_1 * R \_s \_1 / z \_1\right)\right)+I \_s c \_1 *\left(\exp \left(\left(V_{-}\right.\right.\right.$mp_1+I_mp_1*R_s_1 $\left.) / z \_1\right)-$

$\exp \left(\mathrm{V}_{-}\right.$oc_1/z_1) $\left.)\right)$

$\mathrm{P} \mathrm{K}=\overline{\mathrm{I}} \mathrm{K} \overline{\mathrm{V}}^{\overline{\mathrm{K}}}$

I_sc $1=$ lookup(a\$,row,'I_sc')

$\overline{\mathrm{V}}$ _oc_1=lookup(a\$,row, 'V_oc')

I_mp_1=lookup(a\$,row,'I_mp')

$\overline{\mathrm{V}}$ mp_1=lookup(a\$,row,' $\overline{\mathrm{V}} \mathrm{mp}^{\prime}$ )

R_s_1=lookup(a\$,row,'R_s')

z_ $1=$ lookup(a\$,row, 'z')

"! $* * * * * * * * * * * * * * * * * * * * * * * * * * * * * * * * * * * * * * * * * * * * * * * * * * * * * * * * 1 "$

Sendif

Sif runprog $\$=$ 'Error-calculation-KING'

"! ***********BLOCK $\mathrm{J} * * * * * * *$ Error calculation for $\mathrm{KING}^{* * * * * * * * * "}$

$\mathrm{k} \$=$ 'I-V-King'; rowTRW=5; rowking=6

call DifferenceKing(k\$,rowTRW, rowking,row:RMSKing)

"! $* * * * * * * * * * * * * * * * * * * * * * * * * * * * * * * * * * * * * * * * * * * * * * * * * * * * * * * * * * * * * * * * * * * "$

Sendif

"! $* * * * * * * * * * * * * * * * * * * * * * * * * * \mathrm{END}$ of $\mathrm{King} \operatorname{s} \mathrm{Model} * * * * * * * * * * * * * * * * * * * * * * * * "$

END of Program in EES 


\section{Part II: Comparing the 5-Parameter Model with A. Hadj Arab et al.'s model}

The following program can be used to compare the I-V curve predictions using both, the 5-Parameter model and A. Hadj Arab et al.'s model. The lookup tables needed are "Siemens-SRC-4pars", "SRC-4pars", "Siemens-A.HadjArab", "A.HadjArab", "RMSSiemens-N=5mp", "Percentage-Siemens-N=5mp", "Percentage-siemens-MP", where the first two lookup tables are the tables where the values for the 5-Parameter model are recorded, the second two are the tables where the A. Hadj Arab et al.'s values are recorded and the last three are where the error results are recorded. Other two lookup tables needed are "K_taualpha_2", which has the $\mathrm{K}_{\tau \alpha}$ values and "Siemens-weatherdata", which has the weather data recorded. Various comments have been written through out the program to facilitate its comprehension.

START of Program in EES

\footnotetext{
" ***********************FUNCTIONS AND PROCEDURES $* * * * * * * * * * * * * * * * * *$ "********************Functions for both models $* * * * * * * * * * * * * * * * * * * * * * "$

Function Copyinlookup(b\$, row, I1\$, V1\$, I1, V1, I2\$, V2\$, I2, V2, I4\$, V4\$, I4, V4, I5\$, V5\$, I5, V5, I7\$, V7\$, I7, V7, I8\$, V8\$, I8, V8, I10\$, V10\$, I10, V10, I11\$, V11\$, I11, V11, I13\$, V13\$, I13, V13, I14\$, V14\$, I14, V14)

lookup(b\$, row, I1\$)=I1

$\operatorname{lookup}(\mathrm{b} \$$, row, $\mathrm{I} 2 \$)=\mathrm{I} 2$

lookup (b\$, row, I4\$) $=\mathrm{I} 4$

lookup (b\$, row, I5\$)=I5

lookup $(\mathrm{b} \$$, row, $\mathrm{I} 7 \$)=\mathrm{I7}$

lookup $(\mathrm{b} \$$, row, I8\$) $=\mathrm{I} 8$

lookup(b\$, row, I10\$) $=\mathrm{I} 10$

lookup(b\$, row, I11\$)=I11

lookup(b\$, row, I13\$)=I13

lookup(b\$, row, I14\$) $=\mathrm{I} 14$

lookup $(\mathrm{b} \$$, row, V1\$) $=\mathrm{V} 1$

lookup $(\mathrm{b} \$$, row, V2\$) $=\mathrm{V} 2$

lookup $(\mathrm{b} \$$, row, $\mathrm{V} 4 \$)=\mathrm{V} 4$

lookup $(\mathrm{b} \$$, row, V5\$) $=\mathrm{V} 5$

lookup $(\mathrm{b} \$$, row, V7\$) $=\mathrm{V} 7$

lookup $(\mathrm{b} \$$, row, $\mathrm{V} 8 \$)=\mathrm{V} 8$

lookup $(\mathrm{b} \$$, row, V10 $\$)=\mathrm{V} 10$

lookup (b\$, row, V11\$)=V11

lookup (b\$, row, V13\$) =V13

lookup $(\mathrm{b} \$$, row, V14\$) $=\mathrm{V} 14$

copyinlookup $=10$

end

Function Copyinlookuppower(b\$, row, P1\$, P2\$, P4\$, P5\$, P7\$, P8\$, P10\$, P11\$, P13\$, P14\$, P1, P2, P4, P5, P7, P8, P10, P11, P13, P14)

lookup $(\mathrm{b} \$$, row, $\mathrm{P} 1 \$)=\mathrm{P} 1$
} 
lookup $(\mathrm{b} \$$, row, $\mathrm{P} 2 \$)=\mathrm{P} 2$

lookup $(\mathrm{b} \$$, row, $\mathrm{P} 4 \$)=\mathrm{P} 4$

lookup $(\mathrm{b} \$$, row, $\mathrm{P} 5 \$)=\mathrm{P} 5$

lookup $(\mathrm{b} \$$, row, $\mathrm{P} 7 \$)=\mathrm{P} 7$

lookup $(\mathrm{b} \$$, row, $\mathrm{P} 8 \$)=\mathrm{P} 8$

lookup $(\mathrm{b} \$$, row, $\mathrm{P} 10 \$)=\mathrm{P} 10$

lookup $(\mathrm{b} \$$, row, $\mathrm{P} 11 \$)=\mathrm{P} 11$

lookup (b\$, row, $\mathrm{P} 13 \$)=\mathrm{P} 13$

lookup (b\$, row, $\mathrm{P} 14 \$)=\mathrm{P} 14$

Copyinlookuppower $=100$

end

Procedure Difference(h\$,row,table:RMS)

if table $=1$ then

i $\$=$ 'row1'; $b \$=' I 1$ '; $c \$=' V 1$ 1'; $\$==^{\prime} \mathrm{P} 1{ }^{\prime}$

endif

if table $=2$ then

$\mathrm{i} \$=$ 'row2'; $\mathrm{b} \$={ }^{\prime} \mathrm{I} 2 ' ; \mathrm{c} \$=^{\prime} \mathrm{V} 2^{\prime} ; \mathrm{d} \$={ }^{\prime} \mathrm{P} 2^{\prime}$

endif

if table $=4$ then

i $\$=$ 'row4'; b\$='I4'; c $\$={ }^{\prime} \mathrm{V} 4$ '; $\mathrm{d} \$==^{\prime} \mathrm{P} 4$ '

endif

if table $=5$ then

$\mathrm{i} \$=$ 'row5'; $\mathrm{b} \$={ }^{\prime} \mathrm{I} 55^{\prime} ; \mathrm{c} \$={ }^{\prime} \mathrm{V} 5^{\prime} ; \mathrm{d} \$={ }^{\prime} \mathrm{P} 5{ }^{\prime}$

endif

if table $=7$ then

i $\$=$ 'row7'; $b \$=' I 7$ '; $c \$=' V 7$ '; $d \$=' P 7 '$

endif

if table $=8$ then

i $\$=$ 'row8'; b\$='I8'; $c \$=' V 8^{\prime} ; d \$==^{\prime} P 8^{\prime}$

endif

if table $=10$ then

i $\$='$ row $10^{\prime} ; b \$=' I 10^{\prime} ; c \$=' V 10^{\prime} ; d \$=' P 10^{\prime}$

endif

if table $=11$ then

$\mathrm{i} \$=$ 'row11'; b\$='I1 1'; $\mathrm{c} \$={ }^{\prime} \mathrm{V} 11^{\prime} ; \mathrm{d} \$={ }^{\prime} \mathrm{P} 11^{\prime}$

endif

if table $=13$ then

$\mathrm{i} \$=$ 'row13'; $\mathrm{b} \$={ }^{\prime} \mathrm{I} 13^{\prime} ; \mathrm{c} \$==^{\prime} \mathrm{V} 13^{\prime} ; \mathrm{d} \$==^{\prime} \mathrm{P} 13^{\prime}$

endif

if table $=14$ then

i\$='row14'; b\$='I14'; c $\$=' \mathrm{~V} 14$ '; $d \$=' \mathrm{P} 14$ '

endif

Nrow=Nlookuprows $(\mathrm{i} \$)$

"!***************"

"Finds the row with the maximum power in the DATA"

False $=0$ 


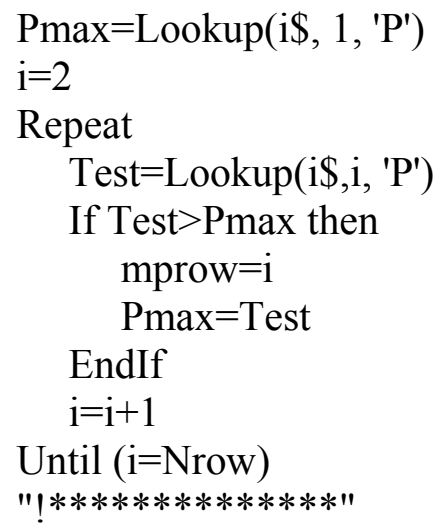

"Finds the row with the maximum power in the Model"

Nrowmodel=Nlookuprows(h\$)

False $=0$

$\operatorname{Pmax}=\operatorname{Lookup}(\mathrm{h} \$, 1, \mathrm{~d} \$)$

$\mathrm{i}=2$

Repeat

Test $=$ Lookup $(\mathrm{h} \$, \mathrm{i}, \mathrm{d} \$)$

If Test>Pmax then mprowmodel $=\mathrm{i}$ Pmax $=$ Test

EndIf

$\mathrm{i}=\mathrm{i}+1$

Until (i=Nrowmodel)

"!***************"

Totalvoltage $=$ lookup(i\$,Nrow, 'V')

Maxpointvoltage $=\operatorname{lookup}\left(\mathrm{i} \$\right.$, mprow, ${ }^{\prime} \mathrm{V}$ ')

$\mathrm{N}=5$

Volt $[1]=0$

Volt $[2]=$ Totalvoltage $/ 2$

Volt[3]=Maxpointvoltage

Volt[4] $=($ Maxpointvoltage + Totalvoltage $) / 2$

Volt [5]=Totalvoltage

Duplicate $\mathrm{t}=1, \mathrm{~N}$

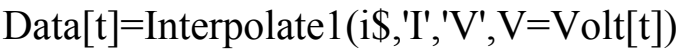

Model $[\mathrm{t}]=$ Interpolate $(\mathrm{h} \$, \mathrm{~b} \$, \mathrm{c} \$, \mathrm{c} \$=\operatorname{Volt}[\mathrm{t}])$

END

$\operatorname{Diff}[\mathrm{t}]=(\operatorname{Data}[\mathrm{t}]-\operatorname{Model}[\mathrm{t}])^{\wedge} 2$

Totaldiffs $=\operatorname{sum}(\operatorname{Diff}[\mathrm{t}], \mathrm{t}=1, \mathrm{~N})$

$\mathrm{RMS}=(\text { Totaldiffs } /(\mathrm{N}))^{\wedge} .5$

Percentage $=$ RMS/Data[1] $* 100$

MPdiff $=(\operatorname{Diff}[3])^{\wedge} .5 / \operatorname{Data}[3] * 100$

"Select in which lookup table to record the results, according to the reference used" lookup('RMS-Siemens-N=5mp-SRC-4pars',row,i\$)=RMS

lookup('Percentage-Siemens-N=5mp-SRC-4pars',row, $i \$$ )=Percentage

lookup('Percentage-siemens-MP-SRC-4pars',row,i\$)=MPdiff 
END

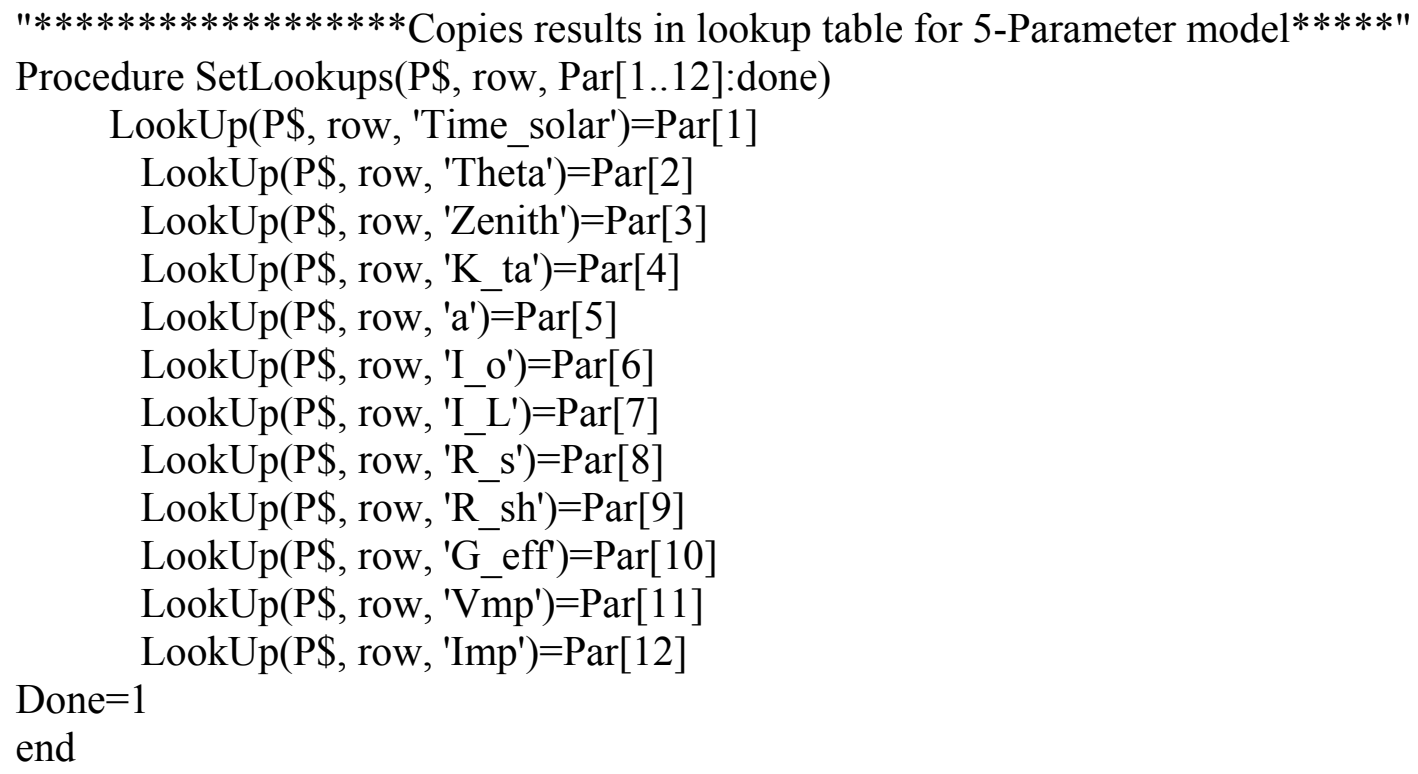

"!Choose which model to use" Model\$='5-Parameter Model' 
row $=$ table

Sif Model\$='5-Parameter Model'

"*****************************5-Parameter model $* * * * * * * * * * * * * * * * * * * * * * * * * * "$

a $\$=$ 'Siemens-SRC-4pars'

$\mathrm{REF} \$=$ 'SRC'

Lat $=39+13 / 60$

$\mathrm{L} 1 \mathrm{loc}=77+21 / 60$

L_st $=75$

slope $=90$

SurfAzAng $=0$

Time s=lookup(a\$,row,'Time clock')

Month_s=lookup(a\$,row,'Month')

Day_s=lookup(a\$,row,'Day')

n_day_s=nDay_(month_s, day_s)

T_cs=lookup(a\$,row,'T_c') +273

rho=lookup (b\$,row,'rho')

G_b=lookup(b\$,row,'G_b')

$\mathrm{G}_{-} \mathrm{d}=\operatorname{lookup}(\mathrm{b} \$$,row, 'G_- d')

$\mathrm{G}=\operatorname{lookup}(\mathrm{b} \$$,row,'G')

DELTAtime_s=EqnTime_(n_day_s)

Time_solar_s-Time_s $=\left(4[\mathrm{~min} / \mathrm{deg}] *\left(\mathrm{~L} \_s t-L \_l o c\right)+D E L T A t i m e \_s\right) * \operatorname{Convert}(\min , \mathrm{hr})$

HrAng_s $=\overline{15}[\mathrm{deg} / \mathrm{hr}] *(12[\mathrm{hr}]-$ Time_solar_s $)$

CosTheta_s=cosIncAng_(Lat, n_day_s, HrAng_s, Slope, SurfAzAng)

Theta_s=ArcCos(CosTheta_s)

R_beam=R_beam_(Lat,n_day_s,HrAng_s, Slope, SurfAzAng)

CosZenith $s=$ CosZenAng (Lat, $n$ day s, HrAng s)

Zenith_s $=\bar{A} \operatorname{rrc} C o s\left(\operatorname{Cos} Z e n i t h \_s\right)$

AM_s $=1 /\left(\right.$ cosZenith_s $\left.+0.5057^{*}\left(96.080-Z e n i t h \_s\right)^{\wedge}(-1.634)\right)$

M_ama_s $=a 0+a 1 * A M \_s+a 2 * A M \_s \wedge 2+a 3 * A M \_s \wedge 3+a 4 * A M \_s \wedge 4$

K_TauAlpha_s=Interpolate1('K_taualpha_2','K_ta_n1.1','Theta',Theta=Theta_s)

K_Ta_d=Interpolate $1\left(' K \_\right.$taualpha_2','K_ta_n1.1','Theta',Theta=58)

mu_Isc $=0.00175$

Beta $\mathrm{voc}=-0.15237$

epsilon $=1.12$

N_S=72

$"$ ! $* * * * * * *$

"using as reference SRC and assuming Rsh is infinite"

a_ref=2.675 "4 pars (Rsh assumed infinite)"

I $\mathrm{L}$ ref $=4.37$

I o ref $=4.679 \mathrm{E}-7$

Rs ref $=.7375$

Rsh ref $=0$

$G$ eff ref $=1000$

Vmp ref $=33.68$ 


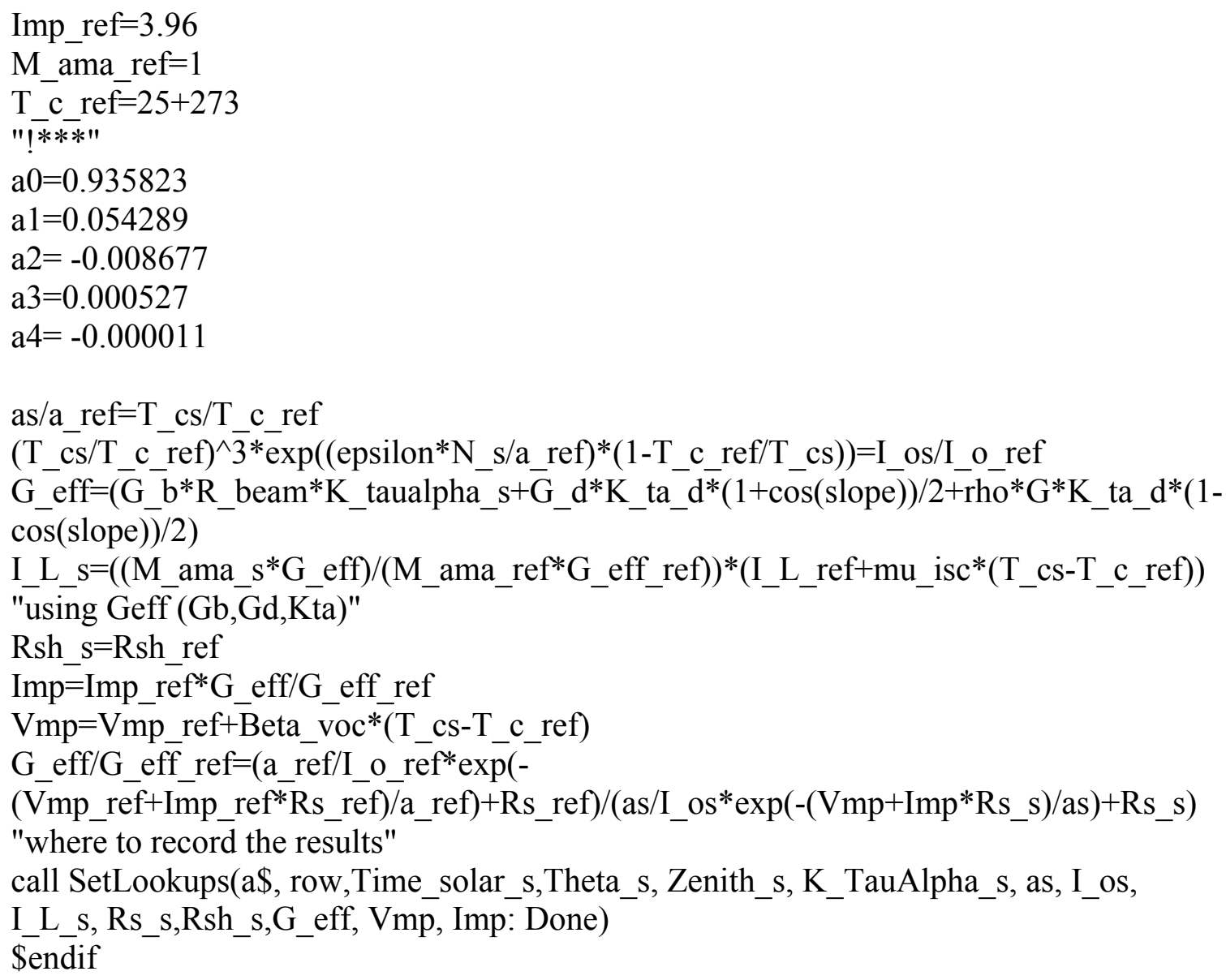




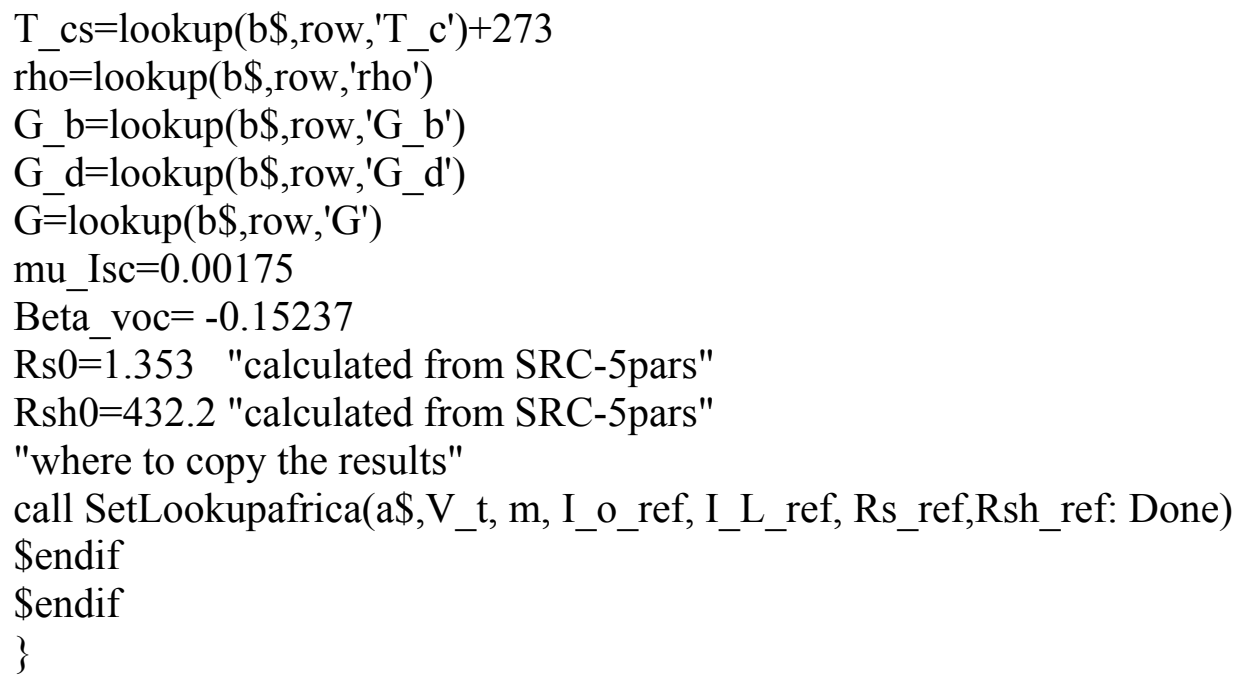

Sif calculate $\$=' \mathrm{I}-\mathrm{V}$ curves'

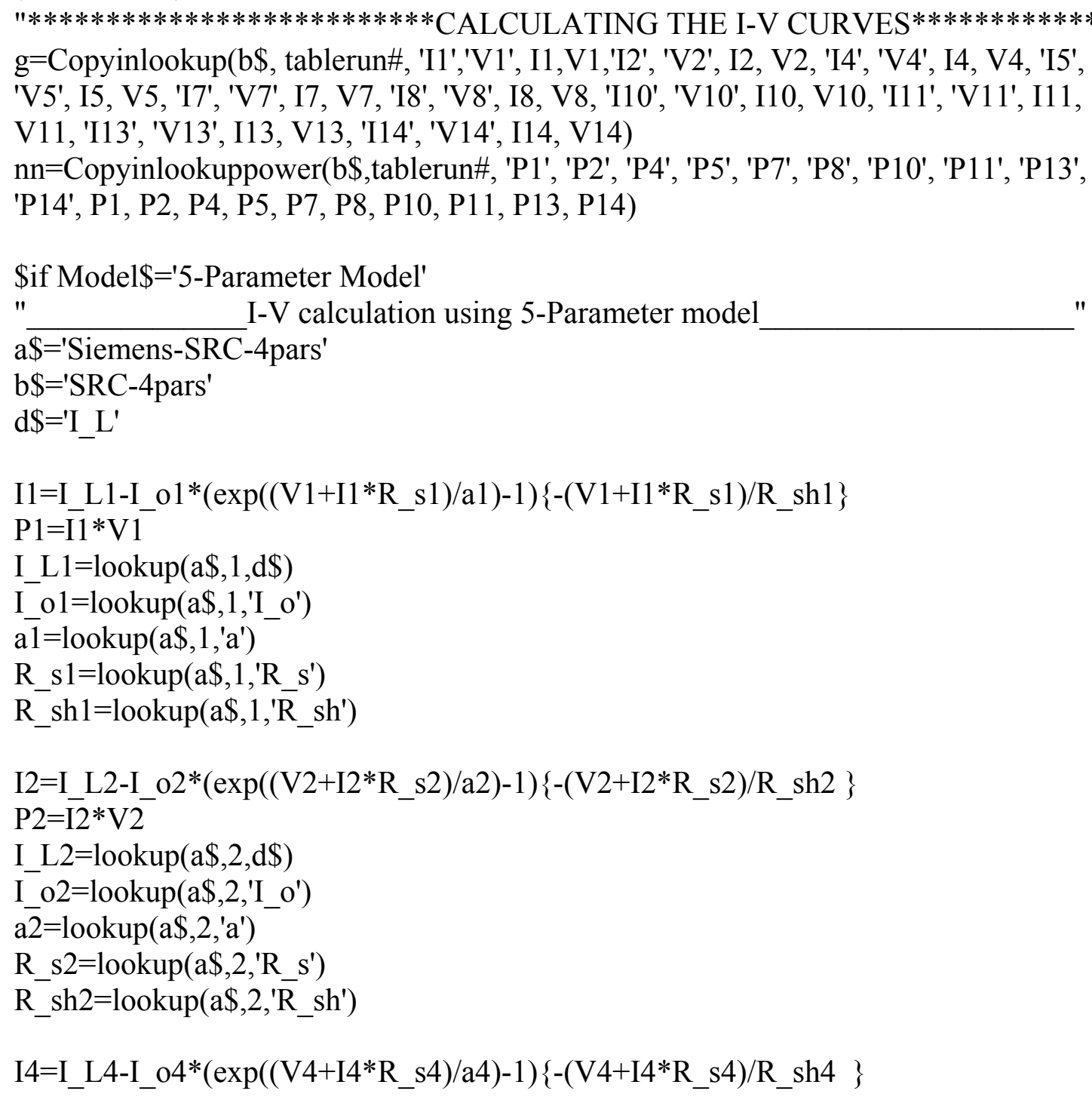




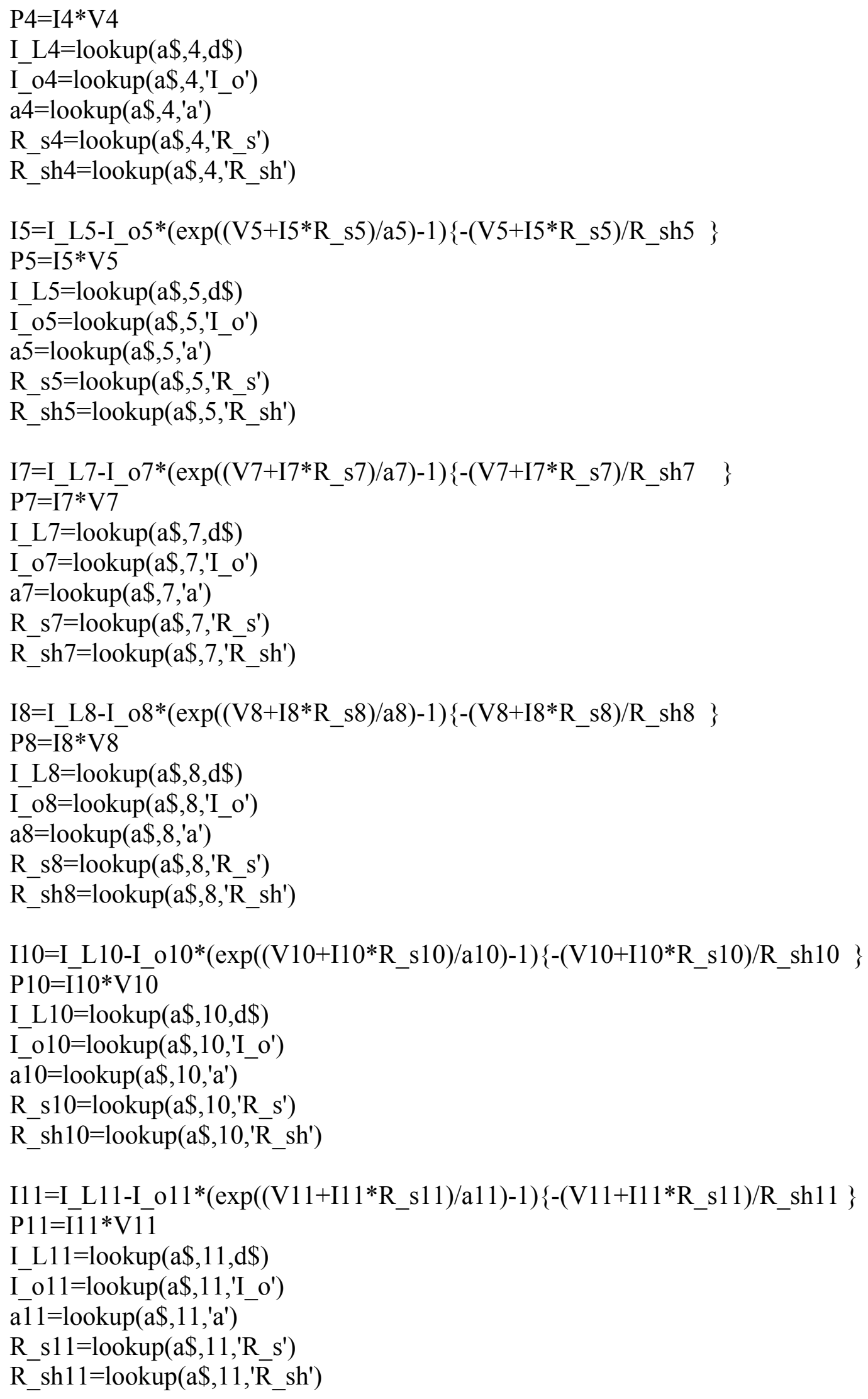




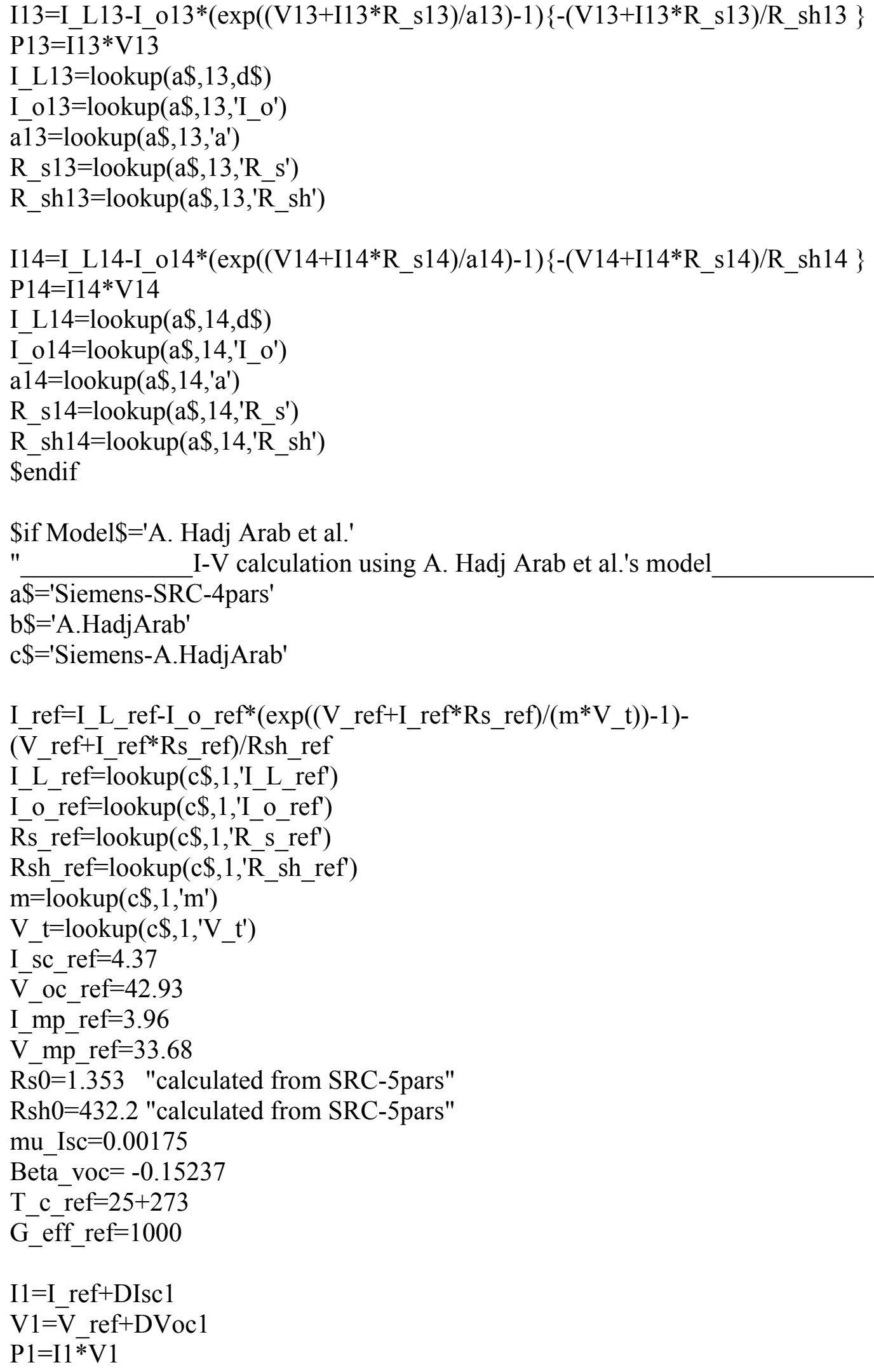


I_sc1=I_sc_ref*G_eff $1 / \mathrm{G}$ eff_ref $+\mathrm{mu}$ isc*(T_cs $1-T$-c_ref $)$

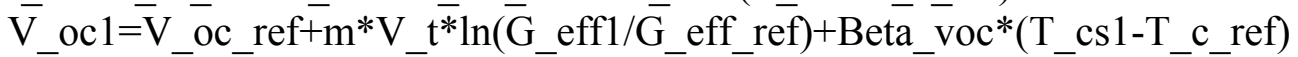

G_eff1=lookup(a\$,1,'G_eff')

T_cs1=lookup $\left(\mathrm{a} \$, 1,{ }^{\prime} \mathrm{T}_{-} \overline{\mathrm{c}}^{\prime}\right)+273$

DIsc1=I_sc1-I_sc_ref

DVoc1 $=\overline{\mathrm{V}}$ _oc $\overline{1-V}-\mathrm{V}$ oc_ref

$\mathrm{I} 2=\mathrm{I}$ ref $+\mathrm{DIsc} 2$

$\mathrm{V} 2=\overline{\mathrm{V}}$ ref $+\mathrm{DVoc} 2$

$\mathrm{P} 2=\mathrm{I} 2 * \mathrm{~V} 2$

I_sc2 $=I$ Isc_ref* $\mathrm{G} \_$eff $2 / \mathrm{G}$ eff_ref $+\mathrm{mu}$ isc $*\left(T \_c s 2-\mathrm{T}\right.$ c

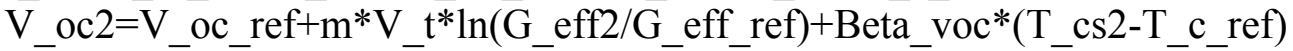

G_eff2=lookup $\left(\mathrm{a} \$, 2,{ }^{\prime} \mathrm{G} \_\right.$eff' $)$

T_cs2=lookup $\left(\mathrm{a} \$, 2,{ }_{-} \mathrm{T}_{-} \mathrm{c}^{\prime}\right)+273$

DIsc2=I_sc2-I_sc_ref

DVoc2 $=\bar{V}$ _oc $2-\mathrm{V}$ _oc_ref

I4 $=$ I_ref + DIsc4

$\mathrm{V} 4=\overline{\mathrm{V}}$ ref $+\mathrm{DVoc} 4$

$\mathrm{P} 4=\mathrm{I} 4^{*} \mathrm{~V} 4$

I sc4 $=I$ sc ref* $\mathrm{G}$ eff4/G eff ref + mu isc $*(T$ cs $4-T$ c ref $)$

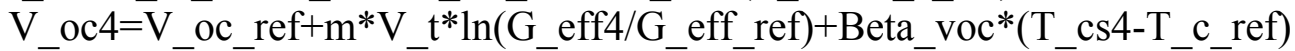

G_eff4=lookup $\left(a \$, 4,{ }^{\prime} G \_\right.$eff')

T_cs4=lookup $\left(\mathrm{a} \$, 4,{ }^{\prime} \mathrm{T} \_\mathrm{c}^{\prime}\right)+273$

DIsc4=I_sc4-I_sc_ref

DVoc4 $=$ V_oc4-V_oc_ref

$\mathrm{I} 5=\mathrm{I} \_$ref $+\mathrm{DIsc} 5$

$\mathrm{V} 5=\mathrm{V} \_$ref $+\mathrm{DVoc} 5$

$\mathrm{P} 5=\mathrm{I} 5 * \overline{\mathrm{V}} 5$

I_sc5 $=I$ sc_ref*G_eff5 $/ \mathrm{G}$ eff_ref $+\mathrm{mu}$ isc $*(T$ _cs5-T_c_ref $)$

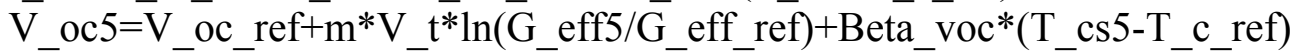

G_eff5=lookup $\left(\mathrm{a} \$, 5,{ }^{\prime} \mathrm{G} \_\right.$eff' $)$

T_cs5=lookup $\left(\mathrm{a} \$, 5,{ }^{\prime} \mathrm{T} \_-\mathrm{c}^{\prime}\right)+273$

DIsc5=I_sc5-I_sc_ref

DVoc5 $=$ V_oc5-V_oc_ref

I7 $=$ I ref + DIsc7

$\mathrm{V} 7=\overline{\mathrm{V}}$ ref $+\mathrm{DVoc} 7$

$\mathrm{P} 7=\mathrm{I} 7 * \overline{\mathrm{V}} 7$

I_sc7 $=I$ Isc_ref*G_eff7/G_eff_ref + mu_isc* $\left(T \_c s 7-T \_c \_r e f\right)$

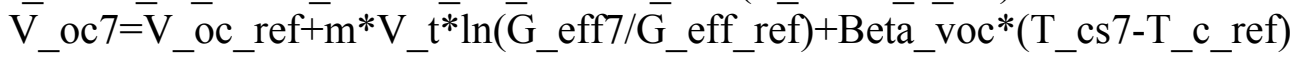

G_eff7=lookup(a\$,7,'G_eff')

T_cs7=lookup(a\$,7,'T_c')+273

DIsc7=I_sc7-I_sc_ref

DVoc7 $=\bar{V}$ _oc $7-V_{-}$oc_ref 


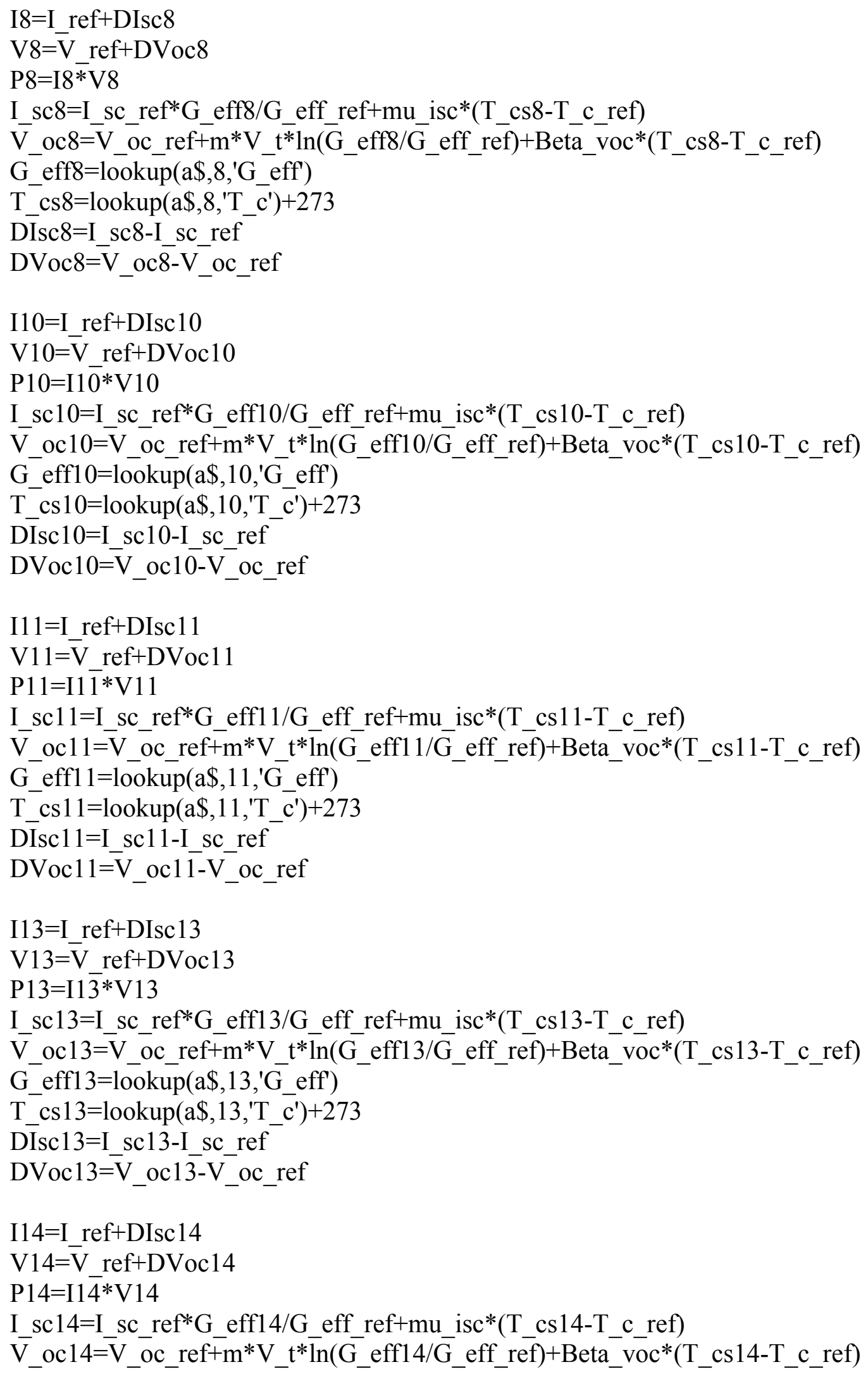


G_eff14=lookup(a\$,14,'G_eff')

T_cs14=lookup $\left(\mathrm{a} \$, 14\right.$, 'T_c' $\left.^{\prime}\right)+273$

DIsc14=I sc14-I sc ref

DVoc14 $=$ V_oc14-V_oc_ref

Sendif

\$endif

$" * * * * * * * * * * * * * * * * * * * * \mathrm{ERROR}$ CALCULATION************************"

\$if calculate $\$=$ 'error'

$\$$ if Model $\$=' 5$-Parameter Model'

\$endif $\mathrm{h} \$=$ 'SRC-4pars'; row $=1$

\$if Model $\$=' A$. Hadj Arab et al.'

Sendif $\mathrm{h} \$=$ 'A.HadjArab'; row=2

call Difference(h\$,row,table:RMS)

\$endif

END of Program in EES 
This appendix shows the changes made to "Type 94" in order to be able to run it in TRNSYS with the changes made to the 5-Parameter model. This document shows what was originally written in the code and to what it was changed or added. For convenience, it is stated in order of appearance in the code.

Was:

PARAMETER $(\mathrm{NP}=19, \mathrm{NI}=8, \mathrm{NO}=11, \mathrm{ND}=0, \mathrm{NSMAX}=16)$

Changed to:

PARAMETER $(\mathrm{NP}=24, \mathrm{NI}=9, \mathrm{NO}=22, \mathrm{ND}=0, \mathrm{NSMAX}=16)$

Was:

COMMON /ARRAY/ GAM,TC,Q_BZ,IL,IO,RS,IMP,RSH,ISC

Changed to:

COMMON /ARRAY/ GAM,TC,Q_BZ,IL,IO,RS,IMP,RSH,ISC,RSR

Added:

\& SUNEFF, \& SUNBN, $\&$ SUNTOT, $\&$ SUNTILT, $\&$ RHO, \& AMASS, $\&$ MAM, $\& \mathrm{a} 0$, $\&$ a1, $\& \mathrm{a} 2$, $\& \mathrm{a} 3$, $\& \mathrm{a} 4$ $\& \mathrm{n} 2$ $\& \mathrm{KL}$, \& RefrAng1, \& RefrAng2, \& RefrAng3, \& TransSurfl, \& TransSurf2, \& TransSurf3, \& TransCoverABS1, \& TransCoverABS2, \& TransCoverABS3, $\&$ taul, $\& \operatorname{tau} 2$, 
$\&$ tau3,

\& THETA2,

\& THETA3,

$\& \mathrm{AR}$,

Was:

$\mathrm{RS}=\mathrm{PAR}(19)$

Changed to and added:

$\mathrm{RSR}=\mathrm{PAR}(19)$

$\mathrm{a} 0=\operatorname{PAR}(20)$

$\mathrm{a} 1=\operatorname{PAR}(21)$

$\mathrm{a} 2=\operatorname{PAR}(22)$

a3 $=\operatorname{PAR}(23)$

$\mathrm{a} 4=\operatorname{PAR}(24)$

Was:

!IF RS WAS NOT PROVIDED IN THE PARAMETER LIST, EVALUATE IT IF (RS.LT.0) THEN

IF (JFIX(NPAM+0.1).EQ.4) THEN

CALL SERIES4PAM(RS,Q_BZ,INFO) !four parameter model

ELSE

CALL SERIES5PAM(RS,RSH,Q_BZ,INFO) !five parameter model ErrorStatus $=$ ErrorFound ()

Changed to:

!IF RSR WAS NOT PROVIDED IN THE PARAMETER LIST, EVALUATE IT IF (RSR.LT.0) THEN

IF (JFIX(NPAM+0.1).EQ.4) THEN

CALL SERIES4PAM(RSR,Q_BZ,INFO) !four parameter model ELSE

CALL SERIES5PAM(RSR,RSH,Q_BZ,INFO) !five parameter model ErrorStatus $=$ ErrorFound ()

Was:

!EVALUATE THE 3 UNKNOWNS AT REFERENCE CONDITIONS (IOR, ILR, AND GAM) AS FUNCTIONS OF RS

IF (NPAM.EQ.4) THEN !four parameter model

GAM=Q_BZ*(VMR-VOCR+IMR*RS)/(TCR*DLOG(1.-IMR/ISCR))

ILR $=$ ISCR

$\mathrm{IOR}=\mathrm{ILR} / \mathrm{DEXP}\left(\mathrm{Q} \_\mathrm{BZ} * \mathrm{VOCR} /(\mathrm{GAM} * \mathrm{TCR})\right)$

ELSE

!five parameter model

$\mathrm{ILR}=\mathrm{ISCR}+(\mathrm{ISCR} * \mathrm{RS} / \mathrm{RSH})$

$\mathrm{GAM}=\mathrm{Q} \_\mathrm{BZ} /(\mathrm{TCR}) *(\mathrm{VMR}-\mathrm{VOCR}+\mathrm{IMR} * \mathrm{RS}) / \mathrm{DLOG}((\mathrm{ILR}-\mathrm{IMR}-$ $(\mathrm{VMR}+\mathrm{IMR} * \mathrm{RS}) /$

$\& \quad \mathrm{RSH}) /(\mathrm{ILR}-\mathrm{VOCR} / \mathrm{RSH}))$

$\mathrm{IOR}=(\mathrm{ILR}-\mathrm{VOCR} / \mathrm{RSH}) / \mathrm{DEXP}(\mathrm{Q} B \mathrm{BZ} /(\mathrm{TCR} * \mathrm{GAM}) * \mathrm{VOCR})$

!COMPUTE PV PARAMETERS FOR ENTIRE ARRAY 


$$
\begin{aligned}
& \text { ILR }=\text { NPRL } * \text { ILR } \\
& \text { IOR }=\text { NPRL*IOR } \\
& \text { GAM = NSER } * \text { GAM } \\
& \text { RS = (NSER/NPRL)*RS } \\
& \text { RSH = (NSER/NPRL)*RSH } \\
& \text { A = GAM/(NSER } * \text { SERCELL) } \\
& \text { VOCR = VOCR NSER } \\
& \quad \text { !save computed PV parameters: RS,ILR,IOR,GAM,A,RSH }
\end{aligned}
$$$$
\operatorname{STORED}(7)=\mathrm{RS}
$$$$
\text { STORED }(8)=\text { ILR }
$$$$
\text { STORED }(9)=\text { IOR }
$$$$
\text { STORED }(10)=\text { GAM }
$$$$
\operatorname{STORED}(11)=\mathrm{A}
$$$$
\text { STORED }(12)=\text { RSH }
$$

Changed to:

!EVALUATE THE 3 UNKNOWNS AT REFERENCE CONDITIONS (IOR, ILR, AND GAM) AS FUNCTIONS OF RSR

IF (NPAM.EQ.4) THEN !four parameter model

GAM=Q_BZ*(VMR-VOCR+IMR*RSR $/($ TCR *DLOG(1.-IMR/ISCR $))$

$$
\mathrm{ILR}=\mathrm{ISCR}
$$$$
\mathrm{IOR}=\mathrm{ILR} / \mathrm{DEXP}\left(\mathrm{Q} \_\mathrm{BZ} * \mathrm{VOCR} /(\mathrm{GAM} * \mathrm{TCR})\right)
$$

!COMPUTE PV PARAMETERS FOR ENTIRE ARRAY

$\mathrm{ILR}=\mathrm{NPRL} * \mathrm{ILR}$

$\mathrm{IOR}=\mathrm{NPRL} * \mathrm{IOR}$

$\mathrm{GAM}=\mathrm{NSER} * \mathrm{GAM}$

$\mathrm{AR}=(\mathrm{MVOC} * \mathrm{TCR}-\mathrm{VOCR}+\mathrm{EG} * \mathrm{SERCELL} * \mathrm{NSER}) /(\mathrm{MISC} * \mathrm{TCR} / \mathrm{ILR}-3)$

$\mathrm{RSR}=(\mathrm{NSER} / \mathrm{NPRL}) * \mathrm{RSR}$

$\mathrm{RSH}=(\mathrm{NSER} / \mathrm{NPRL}) * \mathrm{RSH}$

$\mathrm{VOCR}=\mathrm{VOCR} * \mathrm{NSER}$

ELSE

$\mathrm{ILR}=\mathrm{ISCR}+(\mathrm{ISCR} * \mathrm{RSR} / \mathrm{RSH})$

GAM=Q_BZ/(TCR)*(VMR-VOCR+IMR*RSR)/DLOG((ILR-IMR$(\mathrm{VMR}+\mathrm{IMR} * \mathrm{RSR}) /$

\& $\mathrm{RSH}) /(\mathrm{ILR}-\mathrm{VOCR} / \mathrm{RSH}))$

$\mathrm{IOR}=(\mathrm{ILR}-\mathrm{VOCR} / \mathrm{RSH}) / \mathrm{DEXP}(\mathrm{Q}$ BZ/(TCR*GAM)*VOCR $)$

!COMPUTE PV PARAMETERS FOR ENTIRE ARRAY

ILR $=$ NPRL $*$ ILR

$\mathrm{IOR}=\mathrm{NPRL} * \mathrm{IOR}$

GAM $=$ NSER $*$ GAM

$\mathrm{RSR}=(\mathrm{NSER} / \mathrm{NPRL}) * \mathrm{RSR}$

$\mathrm{RSH}=(\mathrm{NSER} / \mathrm{NPRL}) * \mathrm{RSH}$

$\mathrm{VOCR}=\mathrm{VOCR} * \mathrm{NSER}$

$\mathrm{AR}=\mathrm{VOCR} / \mathrm{DLOG}((\mathrm{ILR}-\mathrm{VOCR} / \mathrm{RSH}) / \mathrm{IOR}+1)$

ENDIF

!save computed PV parameters: RS,ILR,IOR,GAM,AR,RSH

STORED $(7)=$ RSR 


$$
\begin{aligned}
& \text { STORED(8) }=\text { ILR } \\
& \text { STORED(9) }=\text { IOR } \\
& \text { STORED }(10)=\text { GAM } \\
& \text { STORED }(11)=\text { AR } \\
& \text { STORED }(12)=\text { RSH }
\end{aligned}
$$

Was:

$\mathrm{RS}=\mathrm{PAR}(19)$

Changed to and added:

$\mathrm{RSR}=\mathrm{PAR}(19)$

a0 $=\operatorname{PAR}(20)$

a1 $=\operatorname{PAR}(21)$

a2 $=\operatorname{PAR}(22)$

a3 $=\operatorname{PAR}(23)$

a4 $=\operatorname{PAR}(24)$

Was:

$\mathrm{SUN}=\mathrm{XIN}(1) / 3.6 \mathrm{~d} 0$

$\mathrm{TA}=\mathrm{XIN}(2)$

$\mathrm{V}=\mathrm{XIN}(3)$

$\mathrm{FLAG}=\mathrm{XIN}(4)$

$\mathrm{SLOPE}=\mathrm{XIN}(5)$

SUNDIR $=\mathrm{XIN}(6) \quad / 3.6 \mathrm{~d} 0$

SUNDIFF $=\operatorname{XIN}(7) / 3.6 \mathrm{~d} 0$

THETA $=\mathrm{XIN}(8)$

Changed to and added:

C RETRIEVE THE CURRENT VALUES OF THE INPUTS TO THIS MODEL FROM THE XIN ARRAY

$$
\begin{aligned}
& \text { SUN }=\text { XIN(1) } ! / 3.6 \mathrm{~d} 0 \\
& \text { TA }=\text { XIN(2) } \\
& V=\text { XIN(3) } \\
& \text { FLAG =XIN(4) } \\
& \text { SLOPE =XIN(5) } \\
& \text { SUNBN =XIN(6) } ! / 3.6 \mathrm{~d} 0 \\
& \text { SUNTILT }=\text { XIN(7) } ! / 3.6 \mathrm{~d} 0 \\
& \text { THETA }=\text { XIN(8) } \\
& \text { THETAZ = XIN(9) }
\end{aligned}
$$

Was:

$$
\begin{aligned}
& \text { RS = STORED }(7) \\
& \text { ILR = STORED }(8) \\
& \text { IOR = STORED }(9) \\
& \text { GAM = STORED }(10) \\
& \text { A = STORED }(11) \\
& \text { RSH = STORED }(12)
\end{aligned}
$$

Changed to and added: 
$\mathrm{RSR}=\mathrm{STORED}(7)$

$\mathrm{ILR}=\operatorname{STORED}(8)$

IOR $=$ STORED $(9)$

GAM $=$ STORED $(10)$

$\mathrm{AR}=\mathrm{STORED}(11)$

$\mathrm{RSH}=\mathrm{STORED}(12)$

$\mathrm{C}^{* * * *}$ Calculation of Incidence angle modifiers

IF (THETA.LE.0) THEN

THETA $=1$

ENDIF

$\mathrm{n} 2=1.1$

$\mathrm{KL}=0.002 * 4$

C Evaluating transmittance at angle THETA

RefrAng $1=\operatorname{asinD}(\sin \mathrm{D}(\mathrm{THETA}) / \mathrm{n} 2)$

TransSurf1 $=1-0.5 *((\sin D($ RefrAng $1-$ THETA $)) * * 2 /(\sin D($ RefrAng $1+$

\&THETA $\left.\left.))^{* * 2+(\tan D(\text { RefrAng1-THETA })}\right) * * 2 /(\operatorname{tanD}(\text { RefrAng } 1+\text { THETA }))^{* * 2}\right)$

TransCoverAbs $1=\operatorname{Dexp}(-\mathrm{KL} / \operatorname{cosD}($ RefrAng 1$))$

tau1=TransCoverAbs $1 *$ TransSurf1

C Evaluating transmittance at angle Normal to surface (0), use 1 to avoid probs.

THETA2 $=1$

RefrAng2 $=\operatorname{asinD}(\sin D($ THETA2 $) / \mathrm{n} 2)$

TransSurf2 $=1-0.5 *((\sin D(\operatorname{RefrAng} 2-1)) * * 2 /(\sin D(\operatorname{Refr} A n g 2+1)) * * 2+$

$\&(\tan D(\operatorname{RefrAng} 2-1)) * * 2 /(\tan D(\operatorname{RefrAng} 2+1)) * * 2)$

TransCoverAbs $2=\operatorname{Dexp}(-\mathrm{KL} / \operatorname{cosD}($ RefrAng 2$))$

tau2 $=$ TransCoverAbs $2 *$ TransSurf2

C Evaluating transmittance at equivalent angle for diffuse and ground components

THETA $3=58$

RefrAng3 $=$ AsinD $(\sin D($ THETA3 $) / \mathrm{n} 2)$

TransSurf3 $=1-.5 *((\sin D(\operatorname{RefrAng} 3-58)) * * 2 /(\sin \mathrm{D}(\operatorname{RefrAng} 3+58)) * * 2+$

$\&(\tan D($ RefrAng3-58) $) * * 2 /(\tan D(\operatorname{RefrAng} 3+58)) * * 2)$

TransCoverAbs $3=\operatorname{Dexp}(-\mathrm{KL} / \operatorname{cosD}($ RefrAng 3$))$

tau3 $=$ TransCoverAbs $3 *$ TransSurf3

TADIR $=\operatorname{tau} 1 / \operatorname{tau} 2$

TADIFF=tau $3 /$ tau 2

TAGND $=$ TADIFF

C**** Calculation of Effective irradiance

SUNDIR $=$ SUNBN $* \cos D($ THETAZ $)$

SUNDIFF $=$ SUN-SUNDIR 
SUNGND $=\mathrm{SUN} * 0.5 *(1-\cos \mathrm{D}(\mathrm{SLOPE}))$

RHO=SUNTILT/SUNGND-SUNBN* $\operatorname{cosD}($ THETA $) / S U N G N D$

RHO $=$ RHO-SUNDIFF $* 0.5 *(1+\cos$ (SLOPE) $) /$ SUNGND

SUNGND $=$ SUN $* 0.5 *(1-\cos$ (SLOPE) $) *$ RHO

$\mathrm{SUNEFF}=\mathrm{SUNBN} * \operatorname{cosD}(\mathrm{THETA}) * \mathrm{TADIR}+\mathrm{SUNDIFF} * .5 *(1+\operatorname{cosD}(\mathrm{SLOPE}))^{*} \mathrm{~T}$ ADIFF+

\& SUNGND*TAGND

IF (SUNEFF.LT.0) SUNEFF=0

$\mathrm{C}^{* * * * *}$ Calculation of Air Mass Modifier

IF (THETAZ.LE.0) THETAZ $=0$

AMASS $=1 /(\operatorname{cosD}($ THETAZ $)+0.5057 *(96.080-$ THETAZ $) * *(-1.634))$

MAM $=\mathrm{a} 0+\mathrm{a} 1 *$ AMASS $+\mathrm{a} 2 *$ AMASS $* * 2+\mathrm{a} 3 *$ AMASS $* * 3+\mathrm{a} 4 *$AMASS $^{* * 4}$

Was (2x, twice):

IF (SUN.LT.1) THEN

$\mathrm{TC}=\mathrm{TA}$

ELSE

$\mathrm{TC}=\mathrm{TA}+\left(\mathrm{SUN} *(\mathrm{TCNOCT}-\mathrm{TANOCT}) / \mathrm{SUNNOCT} *\left(1 .-\mathrm{EFFREF} / \mathrm{TAU} \_\mathrm{AL}\right)\right)$ ENDIF

Changed to:

IF (SUN.LT.1) THEN

$\mathrm{TC}=\mathrm{TA}$

ELSE

$\mathrm{TC}=\mathrm{TA}$

ENDIF

Was (2x, twice):

Evaluation of IL and IO at operating conditions

$\mathrm{IL}=(\mathrm{SUN} / \mathrm{SUNR}) *(\mathrm{ILR}+\mathrm{MISC} * \mathrm{NPRL} *(\mathrm{TC}-\mathrm{TCR}))$

IF(IL.LT.0.0) IL $=0.0$

$\mathrm{IO}=\mathrm{IOR} *((\mathrm{TC} / \mathrm{TCR}) * * 3) * \operatorname{DEXP}\left(\left(\mathrm{Q} \_\mathrm{BZ} * \mathrm{EG} /(\mathrm{A})\right) *((1 . / \mathrm{TCR})-(1 . / \mathrm{TC}))\right)$

Changed to and added:

Evaluation of IL and IO at operating conditions

$\mathrm{IL}=(\mathrm{SUNEFF} * \mathrm{MAM} / \mathrm{SUNR}) *(\mathrm{ILR}+\mathrm{MISC} * \mathrm{NPRL} *(\mathrm{TC}-\mathrm{TCR}))$

IF(IL.LT.0.0) IL $=0.0$

$\mathrm{IO}=\mathrm{IOR} *((\mathrm{TC} / \mathrm{TCR}) * * 3) * \mathrm{DEXP}((\mathrm{EG} * \mathrm{SERCELL} * \mathrm{NSER} /(\mathrm{AR})) *(1-\mathrm{TCR} / \mathrm{TC}))$ $\mathrm{A}=\mathrm{AR} * \mathrm{TC} / \mathrm{TCR}$

$\mathrm{IMP}=\mathrm{IMR} * \mathrm{SUNEFF} / \mathrm{SUNR}$

$\mathrm{VMP}=\mathrm{VMR}+\mathrm{MVOC} *(\mathrm{TC}-\mathrm{TCR})$

$\mathrm{RS} 1=\mathrm{RSR}$

WRS1=SUNEFF/SUNR-(AR/IOR*Dexp(-(VMR+IMR*

$\& \quad \mathrm{RSR}) / \mathrm{AR})+\mathrm{RSR}) /(\mathrm{A} / \mathrm{IO} * \operatorname{Dexp}(-(\mathrm{VMP}+\mathrm{IMP} * \mathrm{RS} 1) / \mathrm{A})+\mathrm{RS} 1)$

$\mathrm{RS} 2=\mathrm{RS} 1 * 1.01$ 


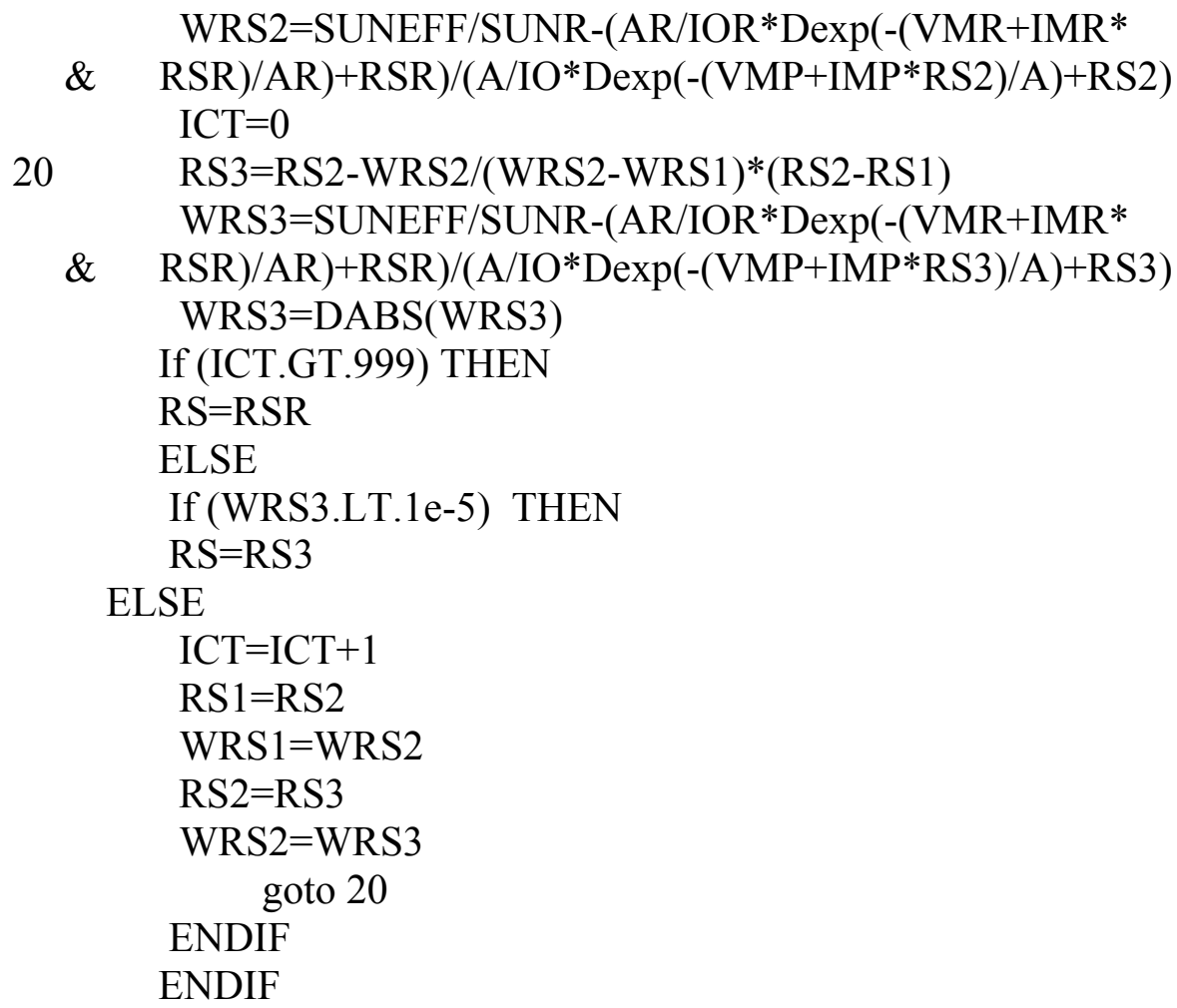

Was:

IF (IL.GT.0.0) THEN $\mathrm{IMXN}=\mathrm{SUN} / \mathrm{SUNR} * \mathrm{NPRL} *(\mathrm{IMR}+\mathrm{MISC} *(\mathrm{TC}-\mathrm{TCR}))$

Changed to:

IF (IL.GT.0.0) THEN

IMXN=SUNEFF/SUNR *NPRL*(IMR+MISC*(TC-TCR)

Added:

$$
\begin{aligned}
& \text { OUT(12) }=\text { AR } \\
& \text { OUT(13) }=\text { IOR } \\
& \text { OUT(14) }=\text { ILR } \\
& \text { OUT }(15)=\text { RSR } \\
& \text { OUT }(16)=\text { RSH } \\
& \text { OUT }(17)=\text { SUNEFF } \\
& \text { OUT }(18)=\text { A } \\
& \text { OUT }(19)=\text { IO } \\
& \text { OUT }(20)=\text { IL } \\
& \text { OUT }(21)=\text { RS } \\
& \text { OUT }(22)=\text { RSH }
\end{aligned}
$$

Was:

SUBROUTINE SERIES5PAM(RS,RSH,Q_BZ,INFO) DOUBLE PRECISION IONEW,IOLOW,IOUP,RS,RSNEW,RSLOW,RSUP $\mathrm{RS}=\mathrm{RSNEW}$ 
IF (RS.LT.0.001) THEN

Changed to:

SUBROUTINE SERIES5PAM(RSR,RSH,Q BZ,INFO)

DOUBLE PRECISION IONEW,IOLOW,IOUP,RSR,RSNEW,RSLOW,RSUP

RSR $=$ RSNEW

IF (RSR.LT.0.001) THEN

Was:

SUBROUTINE SERIES4PAM(RS,Q_BZ,INFO)

DOUBLE PRECISION IONEW,IOLOW,IOUP,RS,RSNEW,RSLOW,RSUP

$\mathrm{RS}=\mathrm{RSNEW}$

IF (RS.LT.0.001) THEN

Changed to:

SUBROUTINE SERIES4PAM(RSR,Q_BZ,INFO)

DOUBLE PRECISION IONEW,IOLOW,IOUP,RSR,RSNEW,RSLOW,RSUP

$\mathrm{RSR}=\mathrm{RSNEW}$

IF (RSR.LT.0.001) THEN 